Af.

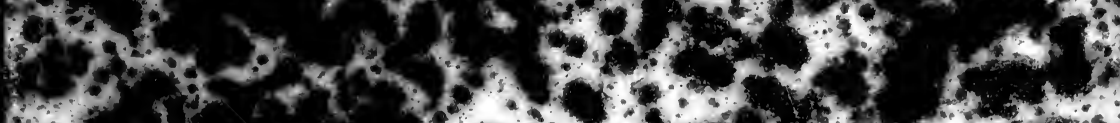

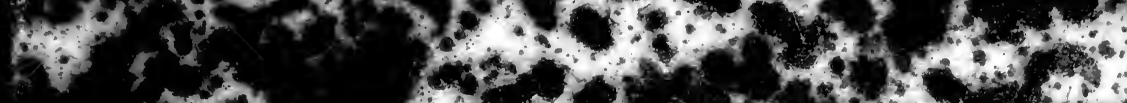

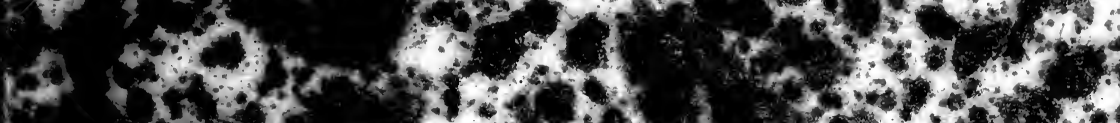

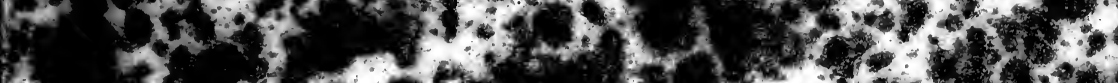

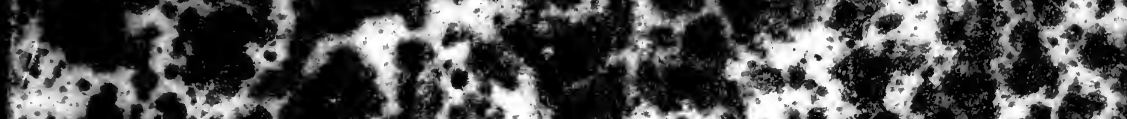

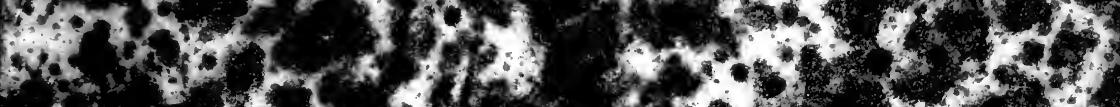

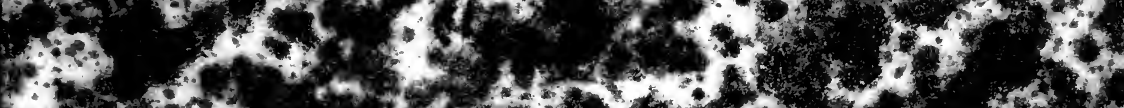

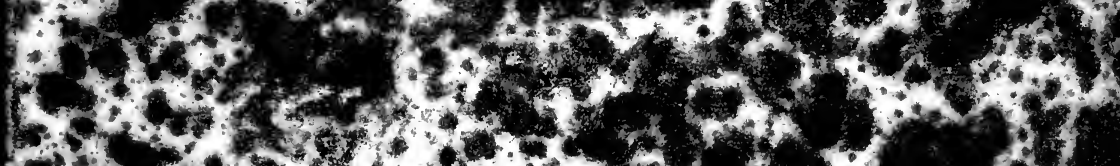

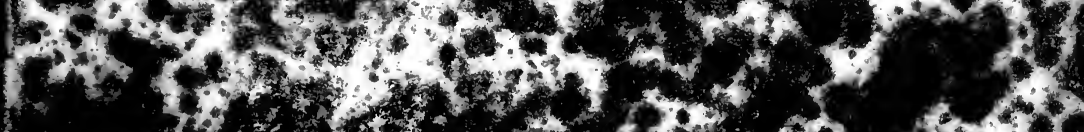
(2)

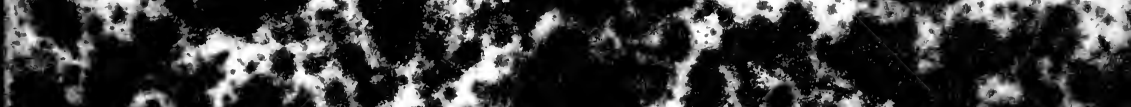

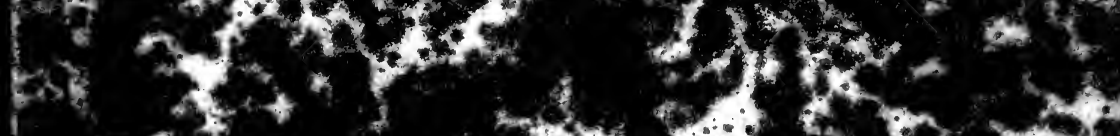

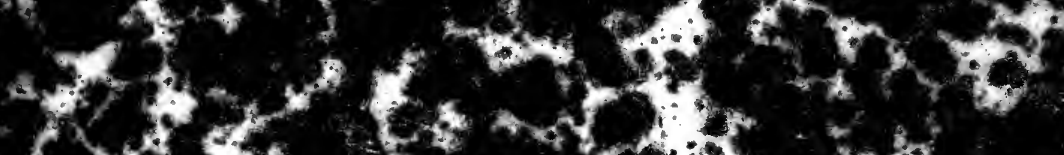

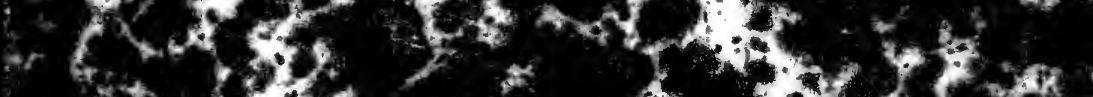

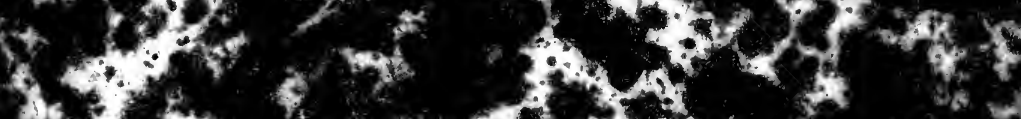

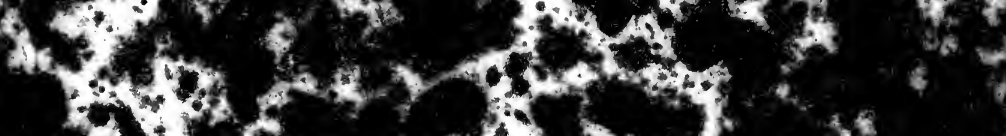

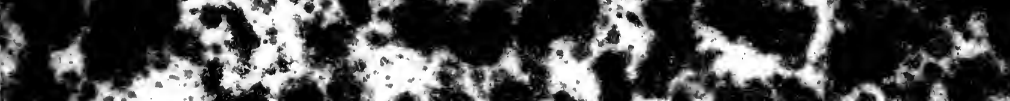

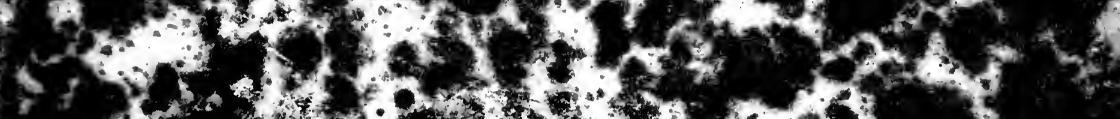

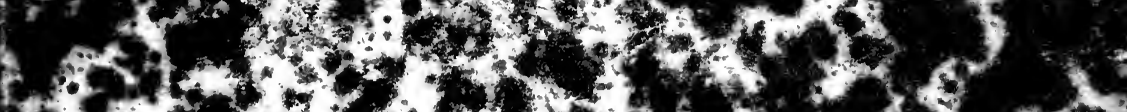

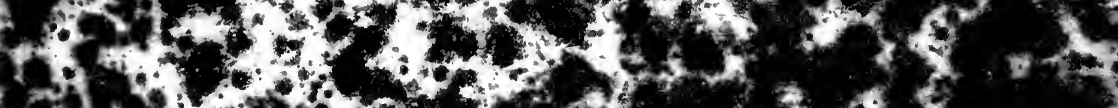

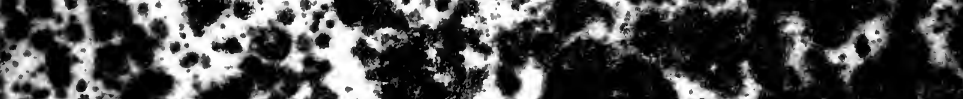

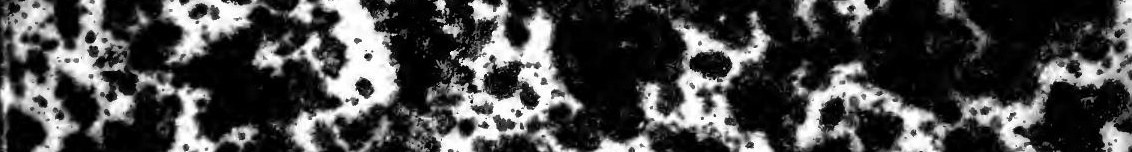

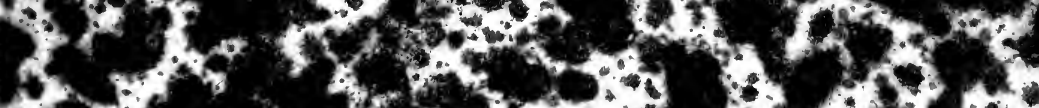

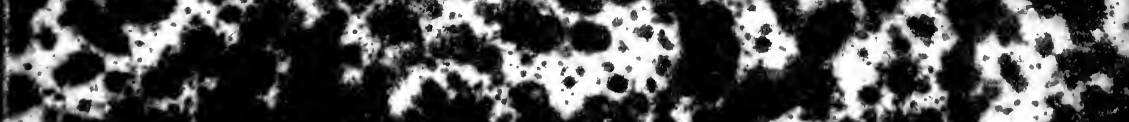

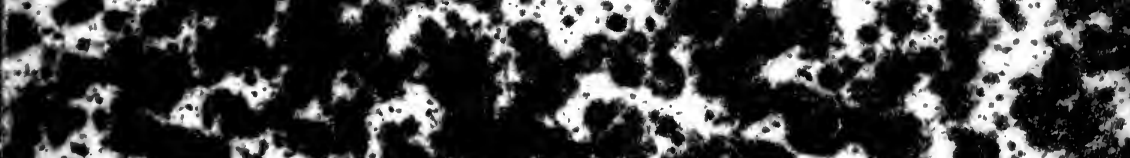
P.

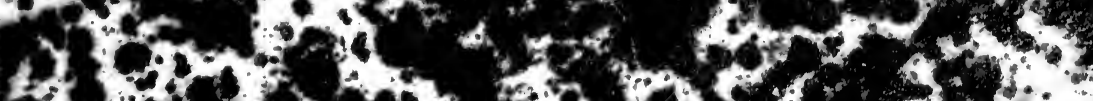

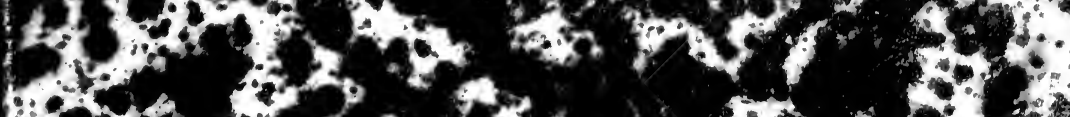

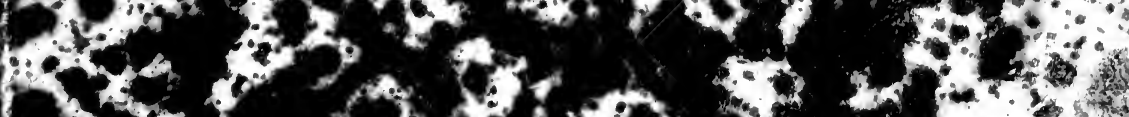

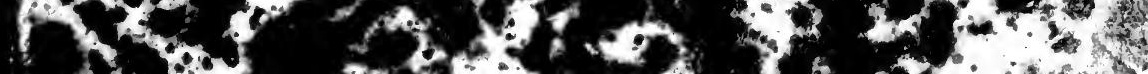




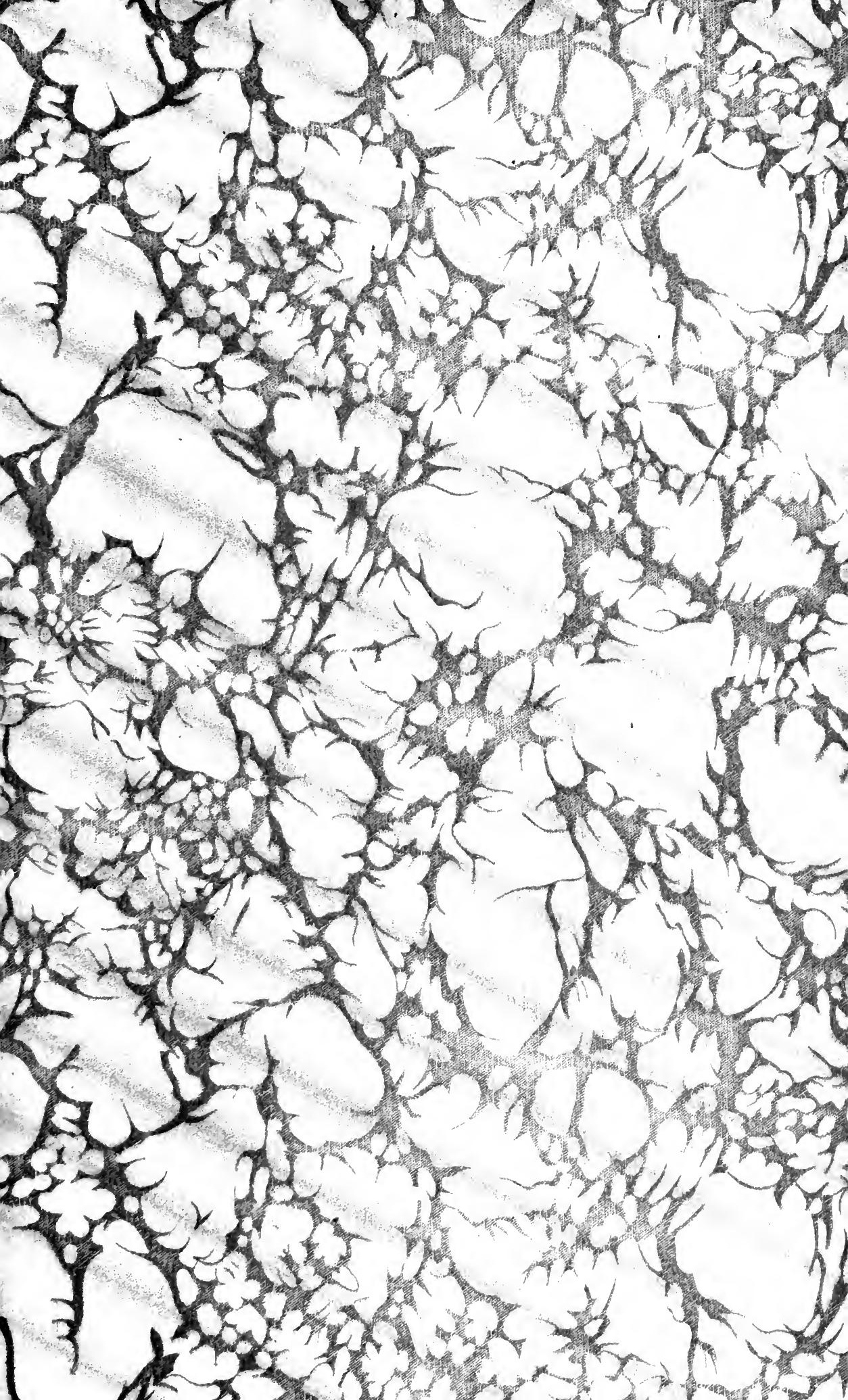





VERS LE SALAIRE MINIMUM 



\section{VERS LE SALAIRE MINIMUII}

ÉTUDE D’ÉCONONIE

ET DE LÉGISLATION INDUSTRIELLES

PAR

\section{BARTHÉLEMY RAYNAUD}

PROFESSEUR a LA FACULTÉ DE DROIT DE L'UNIVERSITÉ D'AIX-MARSEILLE

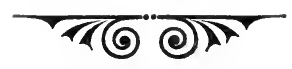

L I B R A I R I E

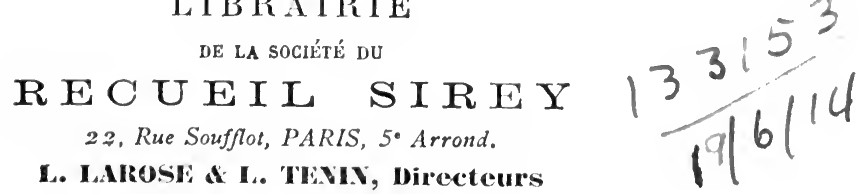





\section{VERS LE SALAIRE MINIMUM}

\section{PRÉFACE}

La vie des individus, comme celle des nations, est une marche vers l'idéal : celui-ci, pour variable qu'il soit, semble inaccessible. Les jours passent, les générations se succèdent pour essayer de l'atteindre.

La question du minimum de salaire révèle un aspect de cette marche de l'humanité. Un droit affirmé et reconnu au travailleur d'obtenir au nom de sa dignité d'homme ce qui lui esí nécessaire pour vivre, a living wage, comme disent énergiquement les Anglais; un salaire minimum avec tout ce que cette réforme comporte de mieuxi-être, d'abolition de souffrances et de tristesses - voilà le rêve, voilà le but.

Et d'autre part des difficultés très grandes de réalisation pratique, des objections scientifiques ou prétendues telles, l'égoïsme des possédants, les nécessités de la vie industrielle, la routine aussi et l'habitude de ce qui a été et semble devoir toujours être, voilì la réalité.

Comment, en présence de cette réalité, l'idéal sera-t-il possible à instituer dans les faits, c'est ce que nous voudrions rechercher ici.

Ce n'est donc pas un plaidoyer nouveau en faveur de la thèse du minimum de salaire - ce n'est pas une théorie de plus ajoutée à tant d'autres qu'il s'agit d'introduire. C'est seulement la marche et l'évolution contemporaine des faits vers le minimum de salaire que nous voudrions retracer.

Les meilleures réformes sociales sont celles que l'opinion publique a lentement préparées et mûries : c'est donc sur elle surtout qu'il faut compter pour hater le jour oì cette réforme sera généralisée.

Le minimum de salaire en voie de réalisation pratique, tel est l'objet propre de ce livre.

De nombreuses études de détail existent aujourd'hui sur 
cette importante question; l'heure est venue d'en tenter la synthèse.

Le lecteur pardonnera les imperfections fatales de ce travail, à raison même de la camplexité des faits. Ne vautil pas mieux cependant, en observateur réaliste, essayer de reconstituer cet admirable effort plutôt que de s'illusionner sur sa réalisation prochaine? Le minimum de salaire, comme le contrat collectif, saura trouver sa voie : marquer ses progrès à l'heure présente est encore la meilleure manière de hater son définitif triomphe.

Le problème ainsi posé, la méthode qu'il convient d'adopter pour en poursuivre l'étude s'impose d'elle-même.

Il nous faudra, dans une première partie intitulée " La Théorie ", exposer les différentes précisions doctrinales qui en ont été données.

Une seconde partie, que nous pourrons appeler "Les Faits ", nous permettra de chercher dans quelle mesure et comment cet idéal du minimum de salaire est aujourd'hui en voie de réalisation pratique, soit qu'il s'agisse de mesures le préparant indirectement et de loin, soit que par le contrat, la puissance publique ou la loi, le minimum de salaire soit dès aujourd'hui appliqué.

Puis, après avoir ainsi marqué et le but ci atteindre et le point actuel de l'évolution, nous aurons à nous demander dans une troisième partie, "l'Opinion publique ", si cet intervalle a des chances d'ètre comblé, si la route qui reste à parcourir sera quelque jour achevée, en faisant le tableau de l'opinion contemporaine par l'exposé des projets et des réformes.

Enfin, par manière de conclusion, il faudra discuter la très actuelle et très grosse question de l'intervention législative en matière de minimum de salaire. Celui-ci 'a-t-il chances d'aboutir par la liberté et sans la contrainte du législateur, ou, au contraire, n'est-il pas indispensable pour hâter sa prochaine réalisation d'admettre, tout au moins d'une manière supplétive et provisoire, à titre peut-être d'éducation, l'intervention nécessaire et bienfaisante de la loi? Le minimum légal de salaire apparaîtra sans doute comme une étape indispensable dans la marche entreprise et poursuivie.

(Paris, octobre Igro.) 


\section{INTRODUGTION}

\section{L'Histoire doctrinale du Minimum de salaire.}

L'idéal du minimum de salaire n'est pas absolument nouveau: il remonte, au contraire, à plusieurs siècles dans le passé.

Il importe donc de retracer brièvement l'histoire doctrinale du minimum de salaire.

Ce n'est guère qu'au moyen âge ( $\mathrm{I}$ ) avec les canonistes que l'on voit apparaître, comme une des exigences de la justice chrétienne, l'idée d'un juste salaire suffisant à faire vivre le travailleur.

Au début, (2) au xiII ${ }^{\theta}$ et au xive siècle, la doctrine sur le salaire n'est guère qu'une application de la théorie du juste prix dans les contrats (3).

L'iủée principale de la doctrine du juste prix (4) est que dans toute vente, et plus généralement dans tout contrat, la prestation et la contre-prestation doivent s'égaler (5). Une

(I) J. Brants. Les théories économiques au XIII et au XIVe siècle. Louvain, 1895 .

Polier. L'idée du juste salaire. Thèse, Toulouse. Paris. Giard, I9o3, p. 25 .

(2) En ce sens, Brants, op. cit., p. 125.

(3) S' Thomas, Summa theol. II. II. qu. 114. art. 1, dit d'ailleurs formellement que de même que la justice exige qu'un juste prix soit payé pour un objet matériel, ainsi elle réclame un juste salaire pour le travail humain. "Unde sicut reddere justum pretium pro re accepta ab aliquo est actus justitice; ita etiam recompensare mercedem operis vel laboris, est actus justitice. 》

(4) Sur les origines historiques de cette théorie si curieuse, cf. Polier, op. cit., 36. Sur son évolution: Ashley. Doctrines économiques de l'Angleterre, t. II, p. 437. Elle se rattache entièrement à la théorie de l'usure qui est le point central des doctrines canonistes de l'époque. "Une sorte d'usure intervient aisément dans les contrats par des perceptions injustes n, si l'une des parties abuse de sa situation pour extorquer des prix abusivement élevés. Brants, op. cit., p. 198.

(5) Endemann. Studien über Romanisch-Kanonistichen Wirthschrifs und Rechtlehre bis gegen Ende des Sielzehirten Jahrhunderts. Berlin, I883, t. II, p. $3 \mathrm{r}$. 
certaine équivalence (contrapassum) doit être observée pour réaliser ce que les canonistes appellent l'aqualitas, c'està-dire l'égalité des deux prestations. Malgré de nombreuses divergences d'opinions, c'est surtout l'estimation commune qui définit ce juste prix objectif; d'aucuns (I) admettaient même comme expression parfaite de cette estimation commune la taxation soit par réglementation professionnelle, soit par loi générale de l'Etat (2).

En somme, et à l'appliquer aux salaires, le juste prix demandait l'adéquation des salaires au travail fourni. “ C'est la coutume qui attribue à l'ouvrier une rémunération suffisante pour lui permettre de vivre selon sa condition (3). )

En dehors de cette application partielle de la théorie plus générale du juste prix, on retrouve en somme peu de chose (4), point de doctrines à proprement parler, sur le salaire au $\mathrm{XIII}^{\mathrm{e}}$ et au XIr ${ }^{\mathrm{e}}$ siècle.

On peut citer un passage curieux d'Henri de Langenstein (5): l'auteur, à propos de l'estimation des travaux à faire, se demande ce qu'en conscience peut bien réclamer un "laborator " (6) pour les choses qu'il fait ou se procure. Il répond que celui-ci pourrait bien se rendre compte de la valeur de ces choses sur le marché, mais que s'il veut faire un calcul spécial, “il doit considérer comment en vendant ses biens il peut maintenir son état et se nourrir suffisamment eu égard à cet état; c'est d'après cela, une fois ses

(I) Gerson. De contractibus. Cf. autres références, Brants, op. clt., p. 200. Repris plus tard par Scaccia. Trait. de comm. et camb. Cologne, 1738.

(2) Sur cette théorie brièvement résumée au texte, cf. Brants, op. cit., p. 193. Polier, op. cit., p. 40. H. Garnier. De l'idée du juste prix chez les théologiens et canonistes du moyen âge. Thèse, Paris, 1900. Rousseau.

(3) Polier, op. cit., p. 73 .

(4) Brants, op. cit., p. 118.

(5) Henri de Langenstein. Henricus de Hassia (1325-1397), né à Langenstein, de la famille seigneuriale de ce nom, dans la Hesse, professeur, vice-chancelier de l'Université de Paris, puis organisateur de l'Université de Vienne. Son principal ouvrage est: Tractatus de Contractibus et origine de censuum, publié dans l'édition des œuvres de Gerson, éd.,. Coloniæ, 1484, t. IV.

(6) Laborator a ici un sens un peu douteux, travailleur en général ou mème ouvrier. C.f. Brants, op. cit., p. 119, note 1 . 
dépenses et ses travaux raisonnablement estimés, qu'il doit fixer le prix de son ouvrage (I).

De même on peut encore indiquer quelques textes intéressants de $\mathrm{S}^{\mathrm{t}}$ Antonin (2) où l'idée de justice dans le contrat de salaire est formellement exprimée sous la forme de congrua merces operis. Dans un passage où il examine les artifices d'avarice frauduleuse pour réduire le salaire des ouvriers tisserands (textores), il en arrive à examiner le cas de paiement en nature où l'on n'a pas payé le salaire réputé convenable selon l'estimation commune : "Si l'ouvrier est pauvre et a dù accepter un salaire insuffisant pour se nourrir lui et sa famille, l'employeur est tenu de donner un supplément (3). "

C'est donc déjà l'idée du salaire suffisant (4) pour vivre qui est dès cette époque posée comme une des exigences de la justice.

Ce n'est que beaucoup plus tard, avec les théologiens plus modernes, à la fin du $\mathrm{xvi}^{\mathrm{e}}$ siècle et au $\mathrm{xvir}^{\mathrm{e}}$ (5) que se constitua une théorie originale et spéciale au salaire. Nous la retrouvons chez des canonistes plus récents, Molina, de Lugo et quelques autres.

On retrouve déjà la même doctrine dans l'œuvre de Molina (6), peut-être un peu atténuée au point de vue de la.

(I) De contractibus. $I^{a}$ pars, cap. XII. Voici le texte latin : "Consider et pro quanto res suas vendendo statum suum continuare possit et se in ipso competenter nutrire et secundum hoc impensis et laboribus rationabiliter estimatis, mesuret et precium operum."

(2) St Antonin de Florence (1389-1455), Antonin de Forciglioni, archevêque de Florence. Son principal ouvrage est une "Summa theologica » éd. Venise, 1480 .

(3) Summa theol., titre I, cap. XVII, \& 7. Voici le passage complet: "Nota tamen quia si ex hoc non accipit textor debitum lucrum de labore suo secundum communem estimationem, sed diminutum... sed qui a pauper est et debet eum accipere etiam mino minus ut se et familiam sustentet, tunc utique setariolus sibi tenetur clare supplementum usque... quia sicut dignus est operarius mercede sua ex debito justicie, ita et conveniente mercede alias esset contra equalitatem justitia : sicut in contractu emptionis et venditionis est injusticia et peccatum cum res emitur minus justo precio ex necessitate venditoris. ")

(4) Sur la question de fait et le point de savoir si ce salaire était effectivement fourni en tenant compte du paiement en nature et des prestations diverses, cf. Brants, op. cit., p. 122.

(5) W. Endemann, Studien uber Romanisch-Kanonistichen Wirtschrifs und Rechtlehre bis gegen Ende des Sielzehirten Jahrluanderts. Berlin, 1883.

(6) Molina (1535-r6or), jésuite espagnol, professeur de théologie à l'Université d'Evora en Portugal. 
conscience des pénitents (I). Elle est surtout développée chez ses disciples de Lugo et Bonacina, où nous la reprendrons avec quelques détails.

Le problème du minimum de salaire se pose alors comme une question d'école, un problème traditionnel qu'étudient les traités de théologie à propos des serviteurs.

Le Cardinal de Lugo (2) étudie longuement la question dans son traité de morale De justitia et jure, sous ce titre : De justa famulorum mercede, " Du juste salaire des serviteurs (3). "

Il commence par poser (4) la définition du juste salaire : " Il faut tenir pour juste le salaire du serviteur, qui égale au moins le dernier taux du salaire qui est attribué d'ordinaire en ce lieu, où de telles personnes rendent tels services. " G'est en somme le salaire couramment payé.

Toutefois, pour déterminer ce juste salaire, il ne faut ni tirer argument de ceux qui donnent plus par générosité, amour de la gloire ou tout autre motif, ni non plus décider que sera injuste fatalement tout salaire insuffisant pour vivre; "il ne faut pas non plus tenir toujours pour injuste le salaire qui ne suffit pas à l'alimentation, ni à acquérir un vêtement convenable, ni encore moins celui qui ne permet pas au serviteur de se nourrir lui et les siens. Il arrive en effet que le service n'est pas digne d'un salaire aussi élevé et que beaucoup se contentent d'un salaire inférieur, parce qu'ils peuvent en même temps se procurer d'autres ressources qui leur permettent de trouver par ailleurs le

(1) De contractibus. Disp. 506, nos 2, 3, 4, t. II, p. 654. Ed. 1733. Molina distingue deux hypothèses principales:

a) Ou bien un salaire fixe (certa merces) a été arrêté : le salaire juste est en ce cas le salaire convenu, conforme au salaire habituel.

b) Ou bien aucun salaire n'a été convenu. Ici encore le salaire habituel est dans la majorité des cas le salaire juste.

(2) Jean de Lugo (1583-r66o), jésuite espagnol, professeur de théologie et de philosophie, cardinal en 1643 .

(3) Cardinalis Lugo. De justitia et jure, t. I, Lyon, 1646, Bib. nationale, in fol., D. 2805, pp. 439-440. Disp. 29. " De locatione et conductione, emphyteusi fundo ", sect. III. " De locatione operarum personalium et de famulorum stipendio », $\mathrm{n}^{\circ}$ 62. " De justa famulorum mercede. "

(4) Loc. cit., p. 440. " Primum illam censeri justum famuli mercedem, quæ attingit saltem infimum gradum mercedis, quæ in eo loco talibuspersonis ad ea ministeria tribui solet. " 
supplément qui manque pour la nourriture et le vêtement (I). ")

Cette dernière hypothèse vise le cas des apprentis (scolastici) ou encore celui des personnes en service pour y apprendre la bonne éducation, les bonnes manières, etc...

Sauf ces cas exceptionnels, le juste salaire reste dû en justice, notamment lorsque rien n'a été convenu d'avance (2):

" On se demande d'ordinaire, pour le cas où le serviteur ne passe pas de contrat exprès, mais prend du service auprès du maître, s'en remettant à sa décision et à son gré, quel salaire le maître est tenu de payer.

On doit répondre qu'il est tenu de payer le juste salaire, celui qui est ordinairement payé aux autres pour des services de ce genre; celui qui comprendra parfois la seule nourriture et le vêtement, tantôt plus, tantôt moins.

Si d'ailleurs le maître, qui est tenu de nourrir le serviteur, ne donne pas la nourriture ordinairement octroyée à des serviteurs de ce genre, - et le cas est le même pour le vêtement, lorsqu'il est tenu de le fournir - il manquera au devoir de justice; on ne doit pas condamner les serviteurs placés dans cette situation et empêchés d'obtenir leur dû d'une autre manière sans une grande difficulté, s'ils prennent en cachette sur les biens du maître ce qui est nécessaire à leur existence (3). ")

(I) Ibid., p. 440. "Tertio, neque etiam injustam semper mercedem quæ non sufficit ad victum, et vestitum decentem famuli, et multo minus, qua non possit famulus se, suamque uxorem et liberos alere. Contingit enim obsequium non esse tanta mercede dignum et multos ea mercede contentos esse, quia possint simul rebus aliis attendere quibus id, quod ad victum et vestitum deficit, supplere et providere sibi possint. ")

(2) Quæstio 63. "Quæri solet, quando famulus nullum aliud pretium determinat, sed inservit domino, remittens se ejus judicio et arbitrio, ad quam mercedem dominus teneatur. Respondetur teneri ad dandam justam mercedem, qualis communiter dari solet, aliis pro ejusmodi ministeriis; quæ aliquando continebit solum victum, et vestitum, aliquando plus, aliquando minus. "

"Si autem dominus, qui alere tenetur famulum, non dat victum, qui communiter dari solet ejusmodi famulis, et idem est de vestibus, quando ad eas etiam dandas tenetur, non satisfecit debito justitiæ nec damnandi sint famuli, quibus de hoc constat et qui aliter sine magna difficultate jus suum obtinere nequeunt, si occulte de bonis domini accipiant necessaria ad suam sustentationem. ")

(3) Ce n'est là, toutefois, qu'un principe qui est posé. Par ailleurs (Ibid., disp. XVI, sect. IV : de furtis famulorum), de Lugo discute longuement les conditions du vol des serviteurs et remarque notam- 
Au total, l'œuvre de Lugo affirme une fois de plus le principe du salaire minimum, c'est-à-dire du salaire correspondant aux besoins de l'existence, à l'entretien convenable de l'ouvrier et même aux besoins des siens. Le problème est d'ailleurs posé comme question de théologie morale pratique : réserve est donc faite par l'auteur des cas concrets dans lesquels le principe peut être invoqué.

En ce qui concerne la portée des textes précités, on peut remarquer qu'ils visent le louage de services en général et ne visent pas le cas des seuls domestiques ( $\mathrm{I}$ ).

Le catholicisme social, à notre époque, ira reprendre chez cet auteur la doctrine traditionnelle et la remettre en honneur (2).

L'œuvre de Bonacina (3) s'inspire des mêmes principes. On trouve dans son "De contractibus » (4) et avec la mème portée (5) la proclamation du juste salaire :

" On doit payer aux serviteurs et aux autres gens de service un juste salaire, à condition qu'ils travaillent fidèlement et à moins de convention contraire " (6). "La raison en est que l'ouvrier ou le serviteur mérite son salaire :

ment que pour que les serviteurs aient le droit d'opposer en compensation quelque chose pris sur les biens des maitres, il faut de multiples conditions, notamment il ne faut pas que le maître les ait employés par charité, mais qu'il ait réellement besoin du service de ses domestiques. " Oportet tamen quod dominus revera famuli opera indigeat. » Ibid., p. 434. )

(1) Cela paraît ressortir nettement de la place de ces développements dans l'ensemble de l'ouvrage : après avoir parlé du louage en général, l'auteur examine les particularités de ce contrat, en tant qu'il porte sur des personnes. "Aliqua tamen in particulari examinare oportet de hoc contractu prout terminatur ad personas. "Ibid., loc. cit., p. 437.

(2) L'influence est directement visible, par Gury, Théologie morale. Disp. 29, sect. III. 62, citant Lugo et visé dans le volume de L'œuvre des cercles catholiques ouvriers, p. 274. Cf. infra, p. I 7 .

(3) Bonacina, théologien italien, né à Milan, mort en 1631 .

(4) Bonacina. De contractibus. Disp. III, questio VII, punct. IV. Dans Martini Bonacince Mediolanensis opera de morali theologia. Lyon, Landry, 1629, t. II, p. 818, à la Bib. nationale, in-fol., D. 1258 .

(5) Les textes ci-après rapportés sont dans le chapitre intitulé : « De conductione famulorum aliorumque officialium et justo ipsorum stipendio. " C'est également le louage des services qui est visé : "Validus et licitus est contractus, quo famulus aut alius mercede locat alteri operas suas ad rem licitam. ) T. II, p. 819 .

(6) « Famulis, aliisque officialibus solvendum est stipendium justum, modo fideliter laboraverint, nec aliter conventum sit. Ratio est quia operarius et mercenarius dignus est mercede sua, et sicut in aliis rebus servanda est œqualitas pretii ; ita etiam servanda est in stipendio famuJorum. " Loc. cit., t. II, p. 819 . 
comme dans les autres cas, il faut observer l'aqualitas en ce qui concerne le prix, de même ici il la faut sauvegarder dans le salaire des serviteurs. ")

L'idée de minimum passe ainsi au second plan ( $\mathrm{I}$ ). Le juste salaire est le plus souvent le salaire ordinaire (2) :

" On demandera tout d'abord le moyen de reconnaître quand un salaire est juste.

Je réponds qu'il peut être déterminé par la décision d'un sage, en tenant compte des services, des habitudes, du temps et des autres circonstances...

D'où il suit qu'il faut déclarer juste le salaire quand il atteint le salaire courant, ou quand beaucoup de serviteurs accepteraient librement du service pour un pareil salaire; une chose vaut, en effet, selon l'estimation commune ou selon la convention passée pour le prix, pourvu, toutefois, que le serviteur ait passé cette convention sur le taux de salaire spontanément et librement, non malgré lui et sous l'empire de la nécessité... "

Ces restrictions sur la liberté réelle des contractants étaient intéressantes à souligner et à rapprocher d'une doctrine qui voit le juste salaire dans le salaire courant; elles montrent jusqu'à l'évidence la persistance du principe du minimum de salaire en dépit des atténuations ou des affaiblissements de l'idée (3).

(1) On la retrouve cependant à propos du développement de la première condition : modo fideliter laboraverint. - A condition qu'ils travaillent fidélement, "le maitre est tenu de donner au serviteur qui travaille, selon la justice, de quoi vivre ": " et sicut dominus tenetur ex justitia lahoranti famulo stipendium, aut etiam sustentationem juxta conventionem tradere. " Ibid., t. Il, p. 819.

(2) Quœres primo, quomodo possimus judicare aliquod stipendium esse justum.

" Respondeo judicari posse arbitrio prudentis habita ratione obsequiorum, consuetudinis, temporis et aliarum circumstantiarum...

" Ex quo sequitur, stipendium judicandum esse justum quando tantum est, quantum alii recipiunt, seu quando non desunt multi alli, qui libenter inservirent pro eodem stipendio; res enim tanti valet, quanti communiter æstimatur, vel quando conventum fuit solum de tanto pretio, modo famulus sponte et libere, non vero invitus et ex necessitate convenerit solum de tanto pretio... ")

(3) Bonacina excuse par ailleurs les maîtres qui engagent à un prix. inférieur les serviteurs en état de nécessité et s'offrant d'eux-mêmes, sauf cependant au cas où le salaire ainsi convenu s'abaisse au-dessous de l'estimation commune, " dicendo non excusare quando conductores minus tradunt, quam alioquin famulorum opera juxta communem æstimationem valeat domino. "I Ibid, t: II, p. 819. 
A propos enfin du vol des serviteurs, question traditionnelle longuement discutée, Bonacina admet sous certaines conditions une compensation sur les biens du maìtre pour le serviteur non payé au juste salaire comme pour le serviteur à qui on refuse de quoi vivre (r). Il admet formellement pour le serviteur le droit de prendre sa subsistance.

$\mathrm{Au}$ total, les théologiens des $\mathrm{XvI}^{\mathrm{e}}$ et $\mathrm{XvII}^{\theta}$ siècles (2) retrouvent et conservent très nettement la pensée traditionnelle du catholicisme sur ce point.

Le point de vue de casuistique et de théologie morale pratique, qui est le leur, les conduit parfois à déclarer juste le salaire qu'on a l'habitude de donner pour tel service dans tel endroit, mais cela n'enlève rien à la force du principe : le travailleur a le droit de vivre de son travail.

Depuis lors, la tradition doctrinale en faveur d'un minimum de salaire se perd et disparait presque.

Rares sont au $\mathrm{xvir}^{\mathrm{e}}$ siècle les auteurs qui maintiennent devant la floraison des théories libérales, les anciennes idées.

On peut citer avec Brentano (3), au xvin ${ }^{\mathrm{e}}$ siècle, d'une part un écrivain allemand, Ehr Wolf, qui, dans un ouvrage publié en 172I, voulait que la taxe des salaires permit au travailleur de vivre avec décence (auständig) et de travailler avec entrain (mit Lust); et d'autre part un auteur anglais, Mortimer, qui maintenait la nécessité de la taxation des salaires (4).

(I) Ibid., t. II, p. 8I9. " Ex dictis colligi potest primo, famulum qui conqueritur, sibi denegari justum stlpendium non posse in rebus domini uti compensatione si re vera stipendium, quod ei traditur, justum sit, nec majus salarium ei debeatur ex justitia, nullo enim titulo potest sibi compensationem facere. Si vero majus stipendium ei debeatur ex justitia, potest sibi compensationem facerc, servatis regulis compensationis. ")

"Idem dic de illo, qui conqueritur denegari sibi justam sustentationem, nam si dominus famulo, quem alere ex contractu tenetur, non perveniat saltem ad infimam sustentationem famulus uti potest compensatione, quia accipit id, quod sibi ex justitia debetur et injuste denegatur. "

(2) Au point de vue critique, sur ces théologiens, cf. Vermeersch : Qucestiones de justitia, pp. $572-573$; Pottier : De jure et justitia, $2^{\circ}$ ed. Liége, 1900, pp. 234-24I; Ryan : Salaire et Droit à l'existence, trad. française, 1 vol. Paris, Girard p. 3 I.

(3) Brentano. English Guilds.

(4) Mortimer, 1730-1810. Elements of Commcrce, Politics and Finance, 1772. 
En résumé, l'idée du minimum de salaire, souvent confondue avec l'idée du juste salaire, n'est pas absolument nouvelle. Telle ces comètes errantes qui n'apparaissent qu'à intervalles fixes, elle a déjà apparu plusieurs fois dans le monde des idées et des doctrines.

Ce n'est guère qu'au xix ${ }^{\mathrm{e}}$ siècle que les conditions économiques et sociales nouvelles devaient, en quelque sorte, la fixer dans notre sphère d'idées et d'action. G'est du jour où l'insuffisance radicale du salaire avec le régime de la liberté illimitée et de la grande industrie apparaissait plus nettement à tous qu'on devait tout naturellement remettre en honneur une doctrine déjà plusieurs fois séculaire. 


\section{CHAPITRE PREMIER}

\section{Le Catholicisme social.}

La division toute naturelle de cette partie de notre exposé sera la suivante :

A) La doctrine du salaire minimum avant l'Encyclique de Léon XIII ;

B) La doctrine du salaire minimum dans l'Encyclique ;

C) La doctrine du salaire minimum depuis l'Encyclique.

\section{A) La doctrine du Salaire minimum avant l'Encyclique.}

Trois questions peuvent se poser si l'on cherche à préciser au point de vue doctrinal la théorie du minimum de salaire :

Sa justification, ses modalités, ses moyens de réalisation.

Sur ces trois points, une réelle divergence se retrouve chez les auteurs du xix siècle qui ont abordé le problème ( $\mathrm{I}$ ).

Villeneuve-Bargemont (2) peut être classé parmi les précurseurs français du mouvement d'idées contemporaines sur le minimum de salaire.

Notre auteur proteste avec indignation contre l'état de fait alors existant : ce qui le révolte, c'est que " quant à l'ouvrier, pourvu qu'il reçoive de quoi ne pas mourir de faim, il doit être satisfait (3) "; c'est sur la main-d'œuvre

(I) Ce sont surtout en Allemagne, Ketteler ; en Autriche, Vogelsang : Die Arbeit und ihr Recht dans Osterreichliche Monatschrift.Bd.V.pp. 462 et suiv.; en Angleterre, le cardinal Manning; en Belgique, Pottier; en France, le Père de Pascal.

(2) Jean-Paul Alban de Villeneuve-Bargemont (1 774-1850). Son principal ouvrage est l'Economie politique chrétienne ou Recherches sur la nature et les causes du paupérisme, 3 vol., Paris. Guillaumin, i84r. Gf. A. Théry, L'œuvre économique de Villeneuve-Bargemont. Thèse. Nancy, IgII, pp. 168 et suiv.

(3) Ec. pol. chrétienne, t. III, p. 277. 
que se rattrapent les fabricants en concurrence, car, " lorsque les premiers besoins sont satisfaits, les produits en quelque sorte superflus ne sont demandés qu'à la condition du bon marché; il faut alors ou que l'entrepreneur baisse ses bénéfices ou que l'ouvrier soit rétribué le moins possible (I)".

“ La science économique anglaise s'est placée à cet égard dans un cercle d'erreurs inextricable, par cela seul qu'elle n'a pas tenu compte de la nature et de la dignité de l'homme et du but moral de la société ».

Le remède est dans la résurrection de la théorie du salaire minimum et dans son application.

Le salaire doit fournir à l'ouvrier, "selon les habitudes et les exigences du pays qu'il habite (2)":

$I^{0}$ De quoi exister convenablement, c'est-à-dire avoir une nourriture saine, des vêtements solides et propres, un logement aéré et qui le mette à l'abri de la rigueur de la saison ;

$2^{\circ}$ De quoi entretenir et faire subsister sa famille qu'on suppose se composer d'une femme et de deux enfants àgés de moins de 15 ans (3);

$3^{\circ}$ De quoi soutenir ses parents vieux et infirmes;

$4^{\circ}$ De quoi faire quelques épargnes pour les jours de repos et de maladie, et enfin pour la vieillesse.

" Si le salaire, conclut Villeneuve-Bargemont, ne peut donner tous ces moyens à l'ouvrier, nous n'hésitons pas à le dire, il n'est plus conforme aux lois non seulement de la nature, de la justice et de la charité, mais encore à celles de la prudence politique (4) ).

Ce salaire vital, c'est la libeṛté qui doit l'assurer grâce à l'association professionnelle : ce n'est qu'exceptionnellement que l'État doit intervenir comme " dans un quasidélit "), c'est-à-dire dans le cas où le salaire est véritablement et manifestement insuffisant.

Ainsi une « juste fixation du salaire devrait être la condition

(I) Ibid., p. 277 , t. III. En même temps, constate Villeneuve-Bargemont, on a le tort de surexciter et de multiplier les besoins de la classe ouvrière.

(2) Ec. politique chrétienue, t. I, p. 285.

(3) Les enfants de 15 ans ou plus travaillent, puisque l'école ne les prend que jusqu'à 13 ou 14 ans.

(4) Economie politique chrétienne, t. I, pp. 289, 290. 
première de toute entreprise d'industrie.... le profit de l'entrepreneur ne devrait se régler qu'après le prélèvement d'un salaire suffisant ( 1 ). $)$

Sans préciser peut-êtré suffisamment les moyens d'aboutir, Villeneuve-Bergemont fut, on le voit, l'un des précurseurs les plus originaux et les plus avancés du catholicisme social.

Ketteler (2) critiqua très vivement l'insuffisance des salaires actuels à faire vivre l'ouvrier.

“ Le salaire est calculé, écrit-il (3), dans toute la force du terme, sur le strict nécessaire, c'est-à-dire sur ce qui est indispensable à l'homme pour se nourrir, se vètir, s'abriter, en un mot, pour assurer son existence physique. Les discussions entre Lasalle et ses contradicteurs ont rendu cela tellement évident qu'il est impossible de le nier sans tromper le peuple. ')

Cet état de choses regrettable tient à ce que l'on a considéré le travail comme une marchandise soumise à la loi de l'offre et de la demande: "Le travail, poursuit-il (4), est devenu une marchandise soumise aux lois qui régissent toutes les autres. Le prix du travail, le salaire, dépend, comme celui des marchandises, de l'offre et de la demande, et le prix de la marchandise est, par conséquent, déterminé d'après les dépenses indispensables de production, mais la concurrence exige que le producteur se procure la marchandise au plus bas prix possible, pour pouvoir la vendre à un prix inférieur. S’il y parvient, il débarrassera peu à peu le marché de tous ceux qui ne peuvent livrer une marchandise de la même qualité à un prix supérieur. Il arrivera même quelquefois que pour faire vivre une industrie qui périclite et prolonger une existence impossible, il vendra au-dessous du prix d'achat, mais après, c'est le désastre et la ruine. Quoique les frais de production déterminent le

(1) Ec. pol. chrétienne, t. I, pp. 275, 276.

(2) Sur Ketteler en général, E. de Girard : Ketteler et la question ouvrière. Berne, Wyss, 1896 . J. Lionnet. Un évêque social : Ketteler. Paris, Béduchaud, rgo3.

(3) Die Arbeiterfrage und das Christenthum, p. 17, éd. de Magonza. I864.

(4) Ibid. p. 17. 
prix de la marchandise, le prix du travail est réglé d'après les besoins stricts de l'homme en fait de nourriture, vêtements et habitation. Pour déjouer la concurrence, le producteur s'efforce de diminuer les frais de production ; s'il y a surabondance de travailleurs, les ouvriers sont fatalement entraìnés, pour assurer leur vie, à se restreindre même sur le nécessaire. Les producteurs sont sur le marché et demandent : Qui veut travailler pour un salaire moindre? et tous s'efforcent alors, dans la mesure de leurs besoins, de demander un prix qui n'est pas l'équivalent de leur travail. Enfin, de mème que pour les marchandises en général, il arrive un jour, jour de désolation, où cette marchandise est offerte au-dessous du prix, ou, pour parler clair, la nécessité oblige l'infortuné travailleur à ne demander qu'un salaire insuffisant pour pourvoir à ses besoins les plus urgents et à ceux de sa famille. Il doit alors se priver, lui et les siens, du strict nécessaire en fait d'alimentation, de vêtements et du logement, parce que son salaire ne peut plus le lui procurer. Être privé du strict nécessaire, mème pour peu de jours, que de misère et de désolation dans ces quelques mots! "

Le remède, il faut le chercher (I) dans un retour aux doctrines sociales du catholicisme. " L'Église peut et doit voler au secours : tous ses intérèts l'y engagent. Elle manquerait envers des millions d'àmes à ce devoir que lui a imposé le Christ si elle ignorait la question sociale et se bornait à vouloir conjurer le péril par l'exercice usuel de son ministère (2). )

La doctrine traditionnelle du minimum de salaire est précisément à remettre en lumière :

" La première revendication de la classe ouvrière, dit Ketteler en 1869 (3), est d'obtenir une augmentation de salaire correspondant à la véritable valeur du travail. Cette revendication est fort équitable. La religion aussi exige que le travail humain ne soit pas considéré comme une marchandise, ni évalué purement selon la fluctuation de l’offre

(1) Sans préjudice des associations coopératives de production auxquelles Ketteler crut, comme Lassalle, pendant assez longtemps. Cf. Nitti, Le Socialisme catholique, p. 130.

(2) Ibid., cité par Nitti, p. 136.

(3) Discours du 25 juillet 1869 , prononcé à N.-D. des Bois, près Offenbach, dans Euvres choisies de M ${ }^{\mathrm{yr}}$ ketteler. Traduction G. Decurtins. Fribourg, B. Weïth, 1892, p. 53. 
et de la demande. " C'est l'association ouvrière qui, comme en Angleterre, permettra surtout d'obtenir cet accroissement de salaires.

“ Certainement cette aspiration à une augmentation légitime du salaire n'est point condamnable. La justice et le christianisme exigent que le travail humain reçoive une rétribution équitable ( $\mathrm{I}$ ). ")

Mais en même temps et dans le même discours, Ketteler rappelle aux ouvriers leurs devoirs : " Même le salaire le plus élevé ne vous procurera une aisance suffisante que pour autant qu'une grande sobriété et une grande économie formeront la base entière de votre vie (2). Il suffit de peu de temps à l'ouvrier intempérant pour absorber le salaire le plus élevé. Que sert, dès lors, le salaire le plus élevé à celui qui est esclave de l'intempérance (3) ?... )

Ainsi Ketteler reprenait la traditionnelle doctrine du catholicisme social : il la posait dans sa portée pratique sans l'analyser en théoricien.

Le Cardinal Manning (4) a insisté surtout sur le principe du minimum de salaire et très fortement posé la nécessité de l'intervention de l'État.

C'est d'abord la ruine de la théorie libérale du contrat libre qu'il consomme : "Pendant des années on nous a rebattu les oreilles en nous parlant du contrat libre, d'indépendance du labeur des adultes, du travail libre et autres cris semblables... Il est évident qu'entre le capitaliste et l'ouvrier il ne saurait y avoir de contrat libre. Le capitaliste a une cuirasse d'or; et s'il demeure obstiné, l'ouvrier sait que la faim le guette. C'est ainsi que le contrat libre est devenu l'Évangile des patrons (5)... ")

Manning, dans sa lettre de r89o au Congrès catholique international de Liége, se déclare partisan convaincu de

(I) Ibid., p. 54 .

(2) Ibid., p. 55

(3) Ibid., p. 56.

(4) Sur l'œuvre de Manning en général, voyez Lemire : Le cardinal Manning.

(5) La Condition du travail, traduction française, p. 98. Paris. Tolra, 1892, postérieur à l'Encyclique. 
l'intervention de l'État : “ Je ne crois pas qu'il soit jamais possible d'établir d'une manière efficace et durable des rapports pacifiques entre patrons et ouvriers, tant qu'on n'aura pas reconnu et fixé publiquement une mesure juste et convenable réglant les profits et salaires, mesure d'après laquelle seraient régis tous les contrats libres entre le capital et le travail ( $\mathrm{I})$. ")

En Italie, le P. Liberatore (2) fut un ardent défenseur du salaire minimum légal. Il affirme que celui-ci aura pour effet de précipiter la ruine et la disparition des industries qui ne seraient pas assez prospères pour le voir fonctionner : " Une industrie qui ne donne pas de quoi payer un minimum de salaire ne mérite pas d'exister; l'activité de la population fera mieux de se porter sur d'autres branches plus fructueuses. Celui qui, par son âge ou par défaut de forces, n'est pas en état de gagner le minimum n'est pas vieux, mais décrépit : il n'est pas invalide à demi, mais tout à fait. C'est la charité qui doit subvenir à son existence et non le travail (3). ")

On trouve encore la trace des préoccupations du Catholicisme social avant l'encyclique relatives au minimum de salaire dans les différents avis publiés par le Conseil des études de l'Euvre des cercles catholiques d'ouvriers (4).

Tel cet avis $n^{\circ}$ VIII publié en mars i 882 sur la nature du contrat de travail, qui résume fidèlement la pensée de l'CEuvre des cercles sur la question (5):

"Que doit procurer le contrat de travail à l'ouvrier au nom de la justice dans l'intérêt de la paix sociale et en vertu du lien moral fondé entre les contractants ?

(1) Manning. Lettre-programme au Congrès international de Liége. 7 septembre 1890, Ass. Cathol., 1890, XXX, p. 396. Cité dans Lemire : Le Cardinal Manning, p. 200.

(2) Principes d'économie politique. Civilta Catholica, numéro du 4 mai 1889 .

(3) Principes d'économie politique. Deuxième partie, chap. vi, art. 7, trad. fr., p. 288.

(4) Euvre des cercles catholiques d'ouvriers. Conseil des Etudes. Questions sociales et ouvrières. I. Régime du Travail. Paris, I883, Lecoffre, édit.

(5) Les passages précédant la citation rapportée au texte établissent que le contrat de travail n'est pas un contrat de vente, peut être exceptionnellement un contrat de socićté, est ordinairement un contrat de location. "Dans le contrat de vente, le rapport est d'homme à chose, mais dans le contrat du travail (locatio conductio) le rapport est d'homme à homme." 
La juste compensation de sa renonciation aux profits de son travail, c'est-à-dire les moyens de satisfaire aux conditions d'une vie honnête selon son état.

Ces conditions sont :

La possibilité pour l'ouvrier de fonder et de posséder un foyer et d'y élever sa famille, selon son état.

L'ascension professionnelle dans son ordre;

La possibilité de l'épargne en vue des mauvais jours (chômage, accidents, maladie, etc.).

Par là seront assurés aux classes laborieuses le bienfait de la paix, et à l'ouvrier la dignité de sa vie, les fruits de son travail, la sécurité de sa vieillesse (I). ")

Le même avis se refuse d'ailleurs à déterminer quantitativement ce minimum : "Mais si l'on voulait préciser le chiffre du salaire, en raison des besoins de l'ouvrier, de la valeur commerciale de l'objet fabriqué, des gains industriels, c'est là une question toute d'application et, par conséquent, hors de la compétence du Conseil (2). »

LUnion de Fribourg (3), qui joua un ròle capital dans la préparation de l'encyclique " Rerum novarum ", arrêta, sur le rapport du R. P. Leckmuhl, S. J., la thèse suivante sur le salaire minimum :

"Le salaire minimum doit immédiatement se régler d'après les besoins de l'ouvrier pour sa subsistance et ne doit point, par conséquent, demeurer au-dessous du taux nécessaire à l'ouvrier, dans les circonstances ordinaires, pour subvenir aux frais de son entretien et à celui de sa famille.

(I) Op. cit., p. 283. Le rapport de M. le comte de Roquefeuil (Ibid., pp. 219-282), qui a précédé et provoqué cet avis, l'éclaire et fait mieux comprendre encore comment c'est surtout du point de vue moral, et sans vouloir en poursuivre toutes les conséquences économiques et juridiques, qu'est posée cette affirmation: "Le patron chrétien a charge d'âme et d'existence de ses ouvriers. "Ibid., p. 272.

(2) Op. cit., p. 285.

(3) Cette Union, dont les travaux se poursuivent de 1887 à 189 I, était composée : pour la Suisse, du député Decurtins et de Python; des Autrichiens féodaux baron de Vogelsang, prince Lichtenstein, comtes Kuefstein, Blome et Belcredi; pour la France, le comte de Mun, Milcent et La Tour du Pin; pour la Belgique, de Hellepulle; pour l'Italie, du professeur Toniolo et du comte Medolago; pour l'Espagne, du professeur Cepeda; pour l'Allemagne, du baron Wambodt; le cardinal Mermillod y représentait la papauté et servait d'intermédiaire auprès du Saint Siège.

Sur l'Union internationale de Fribourg, cf. Léon Grégoire [G. Goyau], Le pape, les catholiques et la question sociale, I vol., Paris, $3^{\mathrm{e}}$ éd. 1899, pp. 26 et suiv.; de Girard, Ketteler et la question ouvrière, Berne, 1896, Wyss édit., pp. n10 et suiv. 
" Partout où le contrat libre entre patron et ouvrier entraine soit l'oppression, soit le danger d'oppression de celui-ci par le premier, les pouvoirs publics peuvent et doivent, suivant les circonstances, exercer leur action afin que les travailleurs reçoivent au moins la subsistance nécessaire pour eux et leur famille (I). ")

Elle précisait aussi le rôle de l'assurance ouvrière obligatoire comme complément de salaire. " Elle est le correctif moral du salaire et, dans les conditions actuelles de l'industrie, complète ce que le salaire peut avoir d'insuffisant par rapport aux nécessités futures ou éventuelles (2). 》

L'ordre du jour de I 886 avait mème comporté le programme d'une entente internationale relative au salaire minimum entre autres questions réglementées (3).

La déclaration de 1888 remise au Pape par M. Mermillod contenait encore ce passage nettement significatif :

" La loi du travail est complètement méconnue. On a oublié les quatre buts que saint Thomas assigne au travail, et on ne le considère plus que de son còté matériel. L'économie rationaliste, faisant complètement abstraction de la dignité de l'homme, n'a en vue que la création des richesses. L'homme est à ses yeux une quantité de force qu'on peut acheter ou vendre comme n'importe quelle marchandise. Aussi refuse-t-on, mème au travailleur, le droit d'acquérir, par son labeur, de quoi couvrir le minimum de ses besoins (4). ")

La question du minimum de salaire avait été également posée devant le Congrès international catholique tenu à Liége, en septembre 1890 (5); un des rapporteurs, M. le comte de Kuefstein, sur une des questions à l'ordre du jour (6), avait abordé la question du salaire : il rappelait

(1) L'Union de Fribourg, Paris, imp. Levé, 1893. Cf. Henri Lorin. "L'orientation sociale de la pensée catholique au xrx siècle", Semaine sociale de Rouen, 1910, compte rendu, Paris, Gabalda, 1911, p. 73 .

(2) Ibid., l'Union de Fribourg.

(3) Cf. H. Lorin, op. cit., p. 7 r.

(4) Rapporté par H. Lorin, loc. cit., p. 72.

(5) Le compte rendu en a paru en volume séparé. On le trouvera plus commodément dans l'Association catholique, i 890 , vol. $\mathrm{XXX}, \mathrm{pp} .395$ et suiv.

(6) Il s'agissait, en principe, de la durée léggale de la journée de travaił des adultes. 
que le gain des moyens de subsistance pour les périodes où il y a impuissance normale de travail, c'est-à-dire pour la vieillesse et l'enfance, doit nécessairement se réaliser pendant la vigueur du travailleur. "L'ouvrier qui s'est confié à un patron doit pouvoir atteindre au moins le moindre but raisonnable de son travail : la sustentation de son existence et de celle de sa famille d'une manière conforme à son état. "Il déclarait que tous les théologiens avaient reconnu à l'État le droit d'intervenir pour prévenir les abus de travail et concluait en faveur de l'intervention ( $\mathrm{I}$ ).

De vives controverses suivirent ce rapport: sur la motion

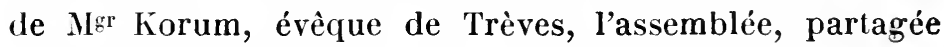
entre diverses opinions, écarta toute discussion relative au salaire. L'accord continuait d'être irréalisable sur cette grave question du minimum de salaire : aucun vou ne fut adopté à ce sujet.

L'idée du comte de Kuefstein était d'ailleurs soutenue énergiquement par une partie de la presse, témoin ce fragment de la Civilta catholica (2 I février I $89 \mathrm{I}$ ), qui semble à la lettre préciser les formules à l'heure actuelle adoptées : " In sudore vultus tui vesceris pane: qu'on ne descende pas au-dessous de cette limite. Les difficultés qui se présentent à l'État sont grandes, il est vrai, mais elles ne sont pas insurmontables. Il n'aura pas lui-même à fixer le minimum, mais qu'il énonce la nécessité inéluctable de ce minimum, quitte à le laisser déterminer par des arbitres honnètes et experts ou par des groupes corporatifs, par une sorte de magistrature de profession, élue par des corporations mixtes de patrons et d'ouvriers dans les divers pays, suivant les circonstances particulières de chaque métier (2). "

Ainsi, avant l'Encyclique, la plus grande diversité de points de vue, en ce qui concerne la justification, les modalités et les moyens de réalisation du minimum de salaire, régnait chez les différents auteurs qui ont abordé cette grave question.

(1) Cf. La réglementation de la durée du travail, par le comte Ch. Kuefstein. Imprimerie Desclée et Brouver, I891. "Abstraction faite du droit, de la morale et de la charité chrétienne, il est évident que l'intérêt bien compris de la société elle-même entre ici en considération. Et la société a incontestablement le droit d'empêcher que sa force économique soit gaspillée, amoindrie, détériorée. "

(2) Cité par l'Association catholique, t. XXXII, I891, p. 724 . 


\section{B) La Doctrine du Salaire minimum dans l'encyclique "Rerum novarum ".}

Léon XIII proclame le principe du salaire minimum dans un passage bien connu :

"Conserver l'existence est un devoir imposé à tous les hommes et auquel ils ne peuvent se soustraire sans crime. De ce devoir découle nécessairement le droit de se procurer les choses nécessaires à la subsistance et que le pauvre ne se procure que moyennant le salaire de son travail. Que le patron et l'ouvrier fassent donc tant et de telles conventions qu'il leur plaira, qu'ils tombent d'accord notamment sur le chiffre du salaire; au-dessus de leur libre volonté, il est une loi de justice naturelle plus élevée et plus ancienne, à savoir que le salaire ne doit pas être insuffisant à faire subsister l'ouvrier sobre et honnête. Que si, contraint par la nécessité ou poussé par la crainte d'un mal plus grand, il accepte des conditions dures que d'ailleurs il ne lui était pas possible de refuser, parce qu'elles lui sont imposées par le patron ou par celui qui fait l'offre du travail, c'est là subir une violence contre laquelle la justice proteste (I). )

Mais en ce qui concerne les trois points doctrinaux ci-dessus énoncés, aucune interprétation formelle n'est acceptée par l'Encyclique :

En ce qui concerne la justification, l'Encyclique semble bien appuyer la doctrine du salaire minimum sur le droit à l'existence ou, plus exactement, sur le devoir de vivre.

(1) Encyclique "Rerum Novarum ». I6 mai I891. Je eite d'après l'édition de Roger et Chernowitz : Lettres apostoliques de Léon XIII, t. III, p. 55. Voici d'ailleurs, à cause de son importance même, le texte latin : "Reapse manere in vita, commune singulis officium est, cui scelus est deesse. Hinc jus reperiendarum rerum quibus vita sustentatur, necessario nascitur : quarum rerum facultatem infimo cuique non nisi quæsita labore merces suppeditat. Esto igitur, ut opifex atque herus libere in idem placitum, ac nominatim in salarii modum consentiant : subest tamen semper aliquid ex justitia naturali, idque libera paciscentium voluntate majus et antiquius, scilicet alendo opifici, frugi quidem et bene morato, haud imparem esse mercedem oportere. Quodsi necessitate opifex coactus, aut mali pejoris metu permotus, duriorem conditionem accipiat, qux, etiam si nolit, accipienda sit, quod a domino vel a redemptore operum imponitur, istud quidem est subire vim, cui justitia reclamat. ») 
Après avoir rappelé (I) que le travail a reçu de la nature une double empreinte, Léon XIII développe comment " ce travail est personnel, parce que la force active est inhérente à la personne et qu'elle est la propriété de celui qui l'a reçue pour son utilité » et montre comment " il est nécessaire, parce que l'homme a besoin du fruit de son travail pour conserver son existence et qu'il doit la conserver pour obëir aux ordres irréfragables de la nature ".

"Si l'on ne regarde le travail que par son aspect personnel, il est assurément au pouvoir de l'ouvrier de restreindre à son gré le taux du salaire. Mais il en va tout autrement si au caractère de personnalité on joint celui de nécessité, dont la pensée peut bien faire abstraction, mais qui n'en est pas séparable en réalité (2). ")

C'est donc du devoir de conserver l'existence que découle (3) le droit de se procurer les choses nécessaires à la subsistance, et de là, puisque le travail est le seul moyen de se les procurer, le minimum de salaire.

Cependant, en dehors de ces textes précis, l'idée de dignité du travailleur, l'idée de justice, en un mot les autres fondements du minimum de salaire se retrouvent aussi dans l'Encyclique.

Eu égard aux modalités, l'Encyclique n'a pas pris parti sur la question du salaire familial : dans le texte principal rapporté ci-dessus, il n'est question que du salaire individuel : " le salaire ne doit pas être insuffisant à faire subsister l'ouvrier sobre et honnête (4). "

Cependant, quelques lignes plus loin apparaît la notion du salaire familial : " L'ouvrier qui percevra un salaire assez fort pour parer aisément à ses besoins et à ceux de sa famille (5) " pourra se constituer un petit superflu et accéder à la propriété (6). Et ailleurs, dans d'autres passages de l'Encyclique, il est nettement question de l'ouvrier chef de famille.

(1) Ibid., Lettres apostoliques de Léon XIII, t. III, p. 55.

(2) Ibid., t. III, p. 55.

(3) Ibid.

(4) Ibid., t. III, p. 55.

(5) Mercedem si ferat opifex satis amplam ut ea se uxorem et liberos tueri commodum queat...

(6) Cf. notamment, p. 27, A propos du droit de propriété. 
En ce qui concerne les moyens de réalisation, on peut également trouver des passages dans l'Encyclique en faveur de la liberté (i) et en faveur de la contrainte légale (2). Le mème texte ci-dessus rapporté continue :

* Mais de peur que dans ces cas 'ou d'autres analogues, comme en ce qui concerne la journée de travail et les soins de la santé des ouvriers des mines, les pouvoirs publics n'interviennent importunément, vu suriout la variété des circonstances des temps et des lieux, il sera préférable qu'en principe la solution en soit réservée aux corporations ou syndicats... ou que l'on recoure à quelque autre moyen de sauvegarder les intérêts des ouvriers, mème si la cause le réclamait, avec le secours et l'appui de l'État (3).

(I) « Mais encore faut-il qu'en tout cela les pouvoirs publics n'agissent qu'avec une très grande circonspection, pour éviter d'empiéter sur les droits du citoyen et de statuer, sous couleur d'utilité publique, quelque chose qui serait désavoué par la raison. "Ibid., Lettres apostoliques de Léon XIII, t. III, p. 6r. Cf. p. 65. "... Que l'Etat protège ces sociétés fondées selon le droit (les corporations); que toutefois il ne s'immisce point dans leur gouvernement intérieur et ne touche point aux ressorts intimes qui lui donnent la vie; car le mouvement vital procède essentiellement d'un principe intérieur et s'éteint très facilement sous l'action d'une cause externe. ")

(2) Quocirca mercenarios cum in multitudine egena numerentur debet cura providentiaque singulari complecti respublica : - C'est pourquoi les salariés qui appartiennent à la classe pauvre en général doivent être entourés par l'Etat d'une sollicitude et d'une vigilance particulière. Ibid., Lettres apostoliques de Léon XIII, t. III, p. 49. On a quelquefois exagéré le sens de ce passage en traduisant : "que l'Etat se fasse à un titre tout particulier la Providence des travailleurs ». G. Anatole LeroyBeaulieu : la Papauté, le Socialisme et la Démocratie, p. r35.

(3) Ibid., Lettres apostoliques de Léon XIII, t. III, p. 57. 


\section{C) La Doctrine du Salaire minimum depuis l'encyclique "Rerum novarum ".}

Sur aucun des trois points ci-dessus indiqués : justification, modalités, moyens de réalisation, l'Encyclique n'avait apporté de solution intransigeante et exclusive.

Aussi l'effort doctrinal s'est-il poursuivi librement depuis le document pontifical : il importe d'indiquer brièvement quelles sont les principales positions actuelles.

\section{I. - LA JUSTIFICATION DU PRINCIPE (I)}

On s'est demandé d'une part si le principe du salaire minimum proclamé par Léon XIII était de stricte justice, d'équité ou de charité, et d'autre part le travail doctrinal s'est poursuivi pour mettre en relief les autres motifs permettant de conclure au salaire minimum.

\section{a) La nature du principe de justice : le devoir de subsistance, base du salaire minimum.}

On a précisé, en se limitant d'ailleurs au travail personnel loué, accompli par l'ouvrier et à l'exclusion des charges de famille (2), que " le salaire est la dette du patron, loueur d'ouvrage à l'égard de l'ouvrier, propriétaire de son travail (3), et que cette dette est de justice commutative (4) ").

Une consultation précise fut d'ailleurs adressée à ce sujet par le cardinal Goossens, archevèque de Malines. Le cardinal Zigliara y répondit formellement en indiquant que

(1) Le Salaire en droit naturel, abbé J. Vosters, Bruxelles ; P. Schwalm, Lecons de philosophie sociale, t. I, p. 324, et t. II, pp. $\mathrm{I} 39$ et suiv.

(2) Cf. plus bas, p. 18.

(3) P. Schwalm, op. cit., t. II, pp. 142 et 149 .

(4) La doctrine traditionnelle distingue en effet entre la justice commutative, celle qui fixe les rapports mutuels entre personnes privées relativement aux choses propres à chacun, la justice légale ou sociale qui concerne les rapports des membres de la société avec la société elle-même et ordonne les activités des membres au bien commun de la société, la simple équité naturelle et enfin la charité. 
l'obligation de payer le salaire minimum était de justice commutative ( $\mathrm{r}$ ).

Cette théorie comporte d'ailleurs certaines restrictions: elle correspond aux circonstances normales; le patron doit payer, lorsqu'il le peut, le salaire nécessaire, le salaire minimum.

Mais en période de crise, cette obligation est suspendue : "Il peut arriver aux époques de crise que le produit brut de l'entreprise ne fournisse pas au patron de quoi payer louvrier suivant le taux normal et que lui-même soit privé du profit qui serait la rémunération légitime de son travail d'entrepreneur. Qui donc, en un tel état de choses, considérerait le patron comme obligé, en vertu de la justice commutative, à payer des salaires qui dépasseraient le taux courant (2)? " "Les moyens de payer, dit encore Ch. Périn (3), à l'ouvrier le salaire normal peuvent manquer au patron par l'effet de causes diverses. L'impossibilité peut provenir d'abord des difficultés qui pèsent sur le monde du travail en général. L’impossibilité peut provenir aussi, mais pour des cas particuliers, de la stérilité relative de tel ou tel ouvrier qui, ne fournissant pas au patron le produit normal du travail pour lequel il est employé, ne peut pré-

(I) La première question posée était ainsi libellée : « Il est dit dans l'encyclique " Rerum novarum » que le patron et l'ouvrier fassent tant et de telles conditions qu'il leur plaira; qu'ils tombent d'accord notamment sur le chiffre du salaire; au-dessus de leur libre volonté, il est une loi de justice naturelle plus élevée et plus ancienne, à savoir que le salaire ne doit pas être insuffisant pour faire subsister l'ouvrier

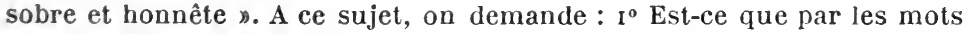
de " justice naturelle », on doit entendre la " justice commutative » ou plutôt l' "équité naturelle? ) La réponse fut : La " justice commutative ». Et plus loin, développant sa réponse, le cardinal Zigliara écrit : "Toutes les fois que l'ouvrage de l'ouvrier est de nature à satisfaire au devoir naturel qu'il a de conquérir la fin immédiate de son travail, si le salaire qui doit lui permettre d'atteindre cette fin n'est pas suffisant pour le nourrir et le vêtir convenablement, il y a en soi et à considérer la nature des choses une inégalité objective entre l'ouvrage et le salaire et donc une lésion de la justice commutative. ) (Association catholique, déc. 1892 , p. 639.)

(2) Abbé Ch. Antoine, "Ie Salaire minimum ", Semaine sociale de Bordeaux, 1909, compte rendu, p. 97 : " Le travail a cessé d'ètre rémunćrateur pour les uns et pour les autres, on ne peut plus demander à la justice du patron de payer à l'ouvrier le salaire normal dont son industrie ne lui fournit plus les éléments; on ne peut plus alors s'adresser ‘u’à la charité ». Ibid., p. 97.

(3) Ch. Périn. "Note sur le juste salaire, d’après l'encyclique " Rerum novarum ). Mons, 1892 , p. 8. 
tendre à un salaire qui répondrait au plein et entier accomplissement de sa tâche. Exigger que, dans ces cas, l'employeur paye le salaire normal, ce serait l'obliger à donner gratuitement du sien à l'ouvrier. Parfois ce sacrifice pourrait être demandé au patron au nom de la charité, mais il ne peut jamais lui être imposé au nom de la justice. "

On a aussi montré comment cette dette de justice se mesurait par les besoins de l'ouvrier; après avoir rappelé que le travail est le moyen nécessaire de gagner sa vie, le P. Schwalm ajoute (I): " Ce principe s'applique par une très simple déduction à la mesure du salaire : le salaire est l'équivalent du travail manuel; donc, puisque le travail manuel vaut pour entretenir l'ouvrier, le salaire vaut autant. L'équivalence du salaire aux besoins de la vie humaine est la conclusion prochaine d'un juste principe de droit naturel (2). " M. l'abbé Naudet vulgarise cette notion en affirmant : "Salaire égale vie mathématiquement (3). »

On a non moins énergiquement maintenu que le salaire payé devait être l'équivalent du travail fourni (4).

C'est enfin par une estimation pratique et commune du travail que cette double équivalence du salaire au travail fourni et aux besoins doit se réaliser (5).

En mème temps, des analyses précises ont porté sur le contenu de cette dette : elle comprend non seulement un juste salaire, ce qui est nécessaire pour faire subsister le travailleur le jour même et le lendemain, mais encore de quoi faire face à l'avenir, selon la formule de M. Boissard :

(I) Op. cit., t. II, p. 147 .

(2) L'auteur appuie ce même principe sur le Droit positif divin, " tu mangeras ton pain à la sueur de ton front ", et sur l'enseignement catholique, en citant l'encyclique de Léon XIII.

(3) Cité Vousters, op. cit., p. ro.

(4) P. Schwalm, op. cit., t. I, p. 327.

(5) «Comment l'appliquer (ce principe d'équivalence)? Il y a là une difficulté spéciale, facile à comprendre: la multitude des ouvriers dans un même atelier ou dans un même métier se compose d'individus dont l'ouvrage fait varie en qualité comme en quantité, dont les besoins personnels varient aussi du plus au moins. Il faut donc que le patron sache estimer le salaire qu'il doit et comme il le doit en vertu du contrat réciproque avec l'ouvrier, maître de son travail, qu'il sache l'estimer avec lui. Donc il y a deux conditions pratiques à réaliser : $\mathrm{I}^{\circ}$ établir une estimation pratique du travail; $2^{\circ}$ l'établir par une entente commune. ") Schwalm, op. cit., t. II, p. I62. 
de quoi entretenir " sa vie, jours de labeurs et jours d'inactivité forcée compris (I) ).

Cette inactivité non volontaire implique " la garantie sous une forme ou sous une autre des divers risques qui menacent le travailleur et se rattachent à un titre quelconque à son travail : accidents, maladie, chòmage, invalidité (2) ).

La démonstration en est facile soit par une analyse du contrat du travail (3), soit par une exacte compréhension de ce que signifie la subsistance du travailleur (4).

Il en est ainsi pour les accidents du travail (5), à propos desquels la règle de droit nouvelle a été pour la première fois posée. Il en est ainsi pour l'assurance contre les maladies professionnelles (6), le chômage (7), pour l'assurance contre l'invalidité et la vieillesse des travailleurs (8).

" Et ainsi il faut, de nécessité humaine et sociale, que la juste rémunération du travail comporte l'assurance de tous ces risques sans distinction (9). $)$

Le contenu du salaire minimum, par cette précieuse analyse, allait donc en s'enrichissant.

"Ainsi, comme l'a dit très justement M. de Mun(ro), la doctrine de l'École repose tout entière sur une idée fondamentale que le travail n'est pas une marchandise comme une autre, mais un acte de la vie humaine dont on ne peut

(1) Boissard. Contrat de travail et salariat, p. 44.

(2) Ibid., Boissard, op. cit., p. 47.

(3) Boissard. "Retraites ouvrières et risque professionnel. " Revue d'É. P., I904, p. 692. - Cf. Ch. Antoine. Cours d'Économie sociale, p. 288 : "Or que recherchent, somme toute, les parties en se liant par le contrat de travail? L'employeur s'efforce d'obtenir l'activité de celui qu'il engage, afin de lui faire produire telle utilité économique. L'employé, lui, eède toute son activité, sa capacité de travail intégrale, moyennant que lui soit assurée son existence actuelle et éventuellement celle des jours oủ il ne pourra plus travailler."

(4) Boissard. Contrat de travail et salariat, p. 214. "Le travail professionnel, quel qu'il soit, doit nourrir celui qui s'y livre dans le présent et lui permettre d'assurer sa subsistance pour les jours de la vieillesse et de l'impuissance."

(5) Boissard, art. cité, p. 696 .

(6) Ibid., p. 697 .

(7) Ibid., p. 697 .

(8) Ibid., p. 698.

(9) Boissard, art. cité, p. 698.

(10) Discours prononcé à Saint-Bricuc. Association catholique, janv. 1894, p. 9 . 
tracer les règles en faisant abstraction de l'homme, qui en est l'auteur et qui doit y trouver le moyen d'assurer dignement sa subsistance ».

b) Les autres motifs d'accepter un salaire minimum.

D'autres (I) ont, dans un raisonnement parallèle, insisté sur la dignité du travailleur; quelques-uns (2) ont voulu faire revivre la théorie canonique du juste prix.

\section{II. - LE SALAIRE FAMILIAL (3)}

La controverse s'est également poursuivie sur ce point (4); les deux opinions se retrouvent avec leurs zélés partisans.

La première, suivie peut-être par le plus grand nombre (5), affirme que le salaire minimum comprend en stricte justice le salaire familial. Pour la soutenir, on a multiplié les argumentations : tantôt on insiste sur l'argument fondamental de la nature du travail, qui est de faire vivre l'ouvrier marié comme l'ouvrier célibataire; tantòt on se base sur le salaire qui doit correspondre aux besoins, c'està-dire faire subsister l'ouvrier et sa famille; plus rarement on invoque une sorte d'amortissement du capital ouvrier, que le patron doit renouveler comme il renouvelle ses machines.

Pratiquement, cette opinion doctrinale se réalise soit par

(1) Ch. Périn. Premiers principes d'économie politique, Paris, 1896 , pp. 389 et 39o. - Verhaegen. Le minimum de salaire, Gand, r892. Pottier. De jure et justitia, Liége, rgoo, pp. 220 et 265. - Ryan. Salaire et droit à l'existence, traduction française. Giard, Paris, 1910, p. 102.

(2) P. Antoine. Cours d'économie sociale, p. 562, Paris, 1899. - A. Vermeersch. Qucstiones de justitia, th. 25, 28, 29, Bruges, rgor.

(3) Cette expression de " salaire familial » est assurément mal venue : ce n'est pas la famille qui travaille, mais l'ouvrier. Il y a donc une certaine contradiction logique dans cette expression. Elle a cependant triomphé en pratique : chacun sait qu'il faut entendre par là le salaire " permettant à l'ouvrier de faire subsister une famille ». Gf. Godts. Salarium minimum et salarium familiale, I vol., Lille, Desclée et Brouwer, Bibl. nationale, $8^{\circ}$ R. 13957 .

(4) G. P. Schwalm. Legons de philosophie socia'e, t. I, p. 337, I vol., Paris, Bloud, igro.

(5) C'est l'opinion de M. de Mun; de l'Association catholique (art. de Decurtins, abbé de Pascal, P. Eschbach, du P. Lecmkuhl, du P. Liberatore); de M. Pottier : Qucestiones de justitia et jure, Liége, 1900, pp. I65 et suiv.; de M. Ryan : Salaire et droit à l'existence, traduction française. Lazare Collin, Giard, 1910, p. I21 ; de M. A. Boissard : "Les exigences de la justice sociale dans le contrat de travail. "Semaine sociale d'Amiens, I907, compte rendu, p. I 40 . 
le salaire familial progressif, soit par le salaire familial moven : pour les uns (1), le salaire de l'ouvrier comprend en quelque sorte deux éléments : Il faut que le célibataire ait droit à la partie fixe qui représente le travail, et que le père de famille ait droit à la partie variable des bénéfices qui représente les besoins (2); c'est le salaire familial progressif. Pour les autres (3), c'est une sorte de forfait, de moyenne qui est accordée à l'ouvrier : "Le salaire aura pour point de départ la somme des biens nécessaires pour répondre aux nécessités de la vie humaine prise dans son ensemble, c'est-à-dire le même travail sera payé au même taux, qu'il soit accompli par un célibataire ou par un homme marié, mais ce taux sera fixé de façon que, bien administré par l'ouvrier, il lui fournisse de quoi satisfaire aux exigences de sa vie, aux différentes périodes de son évolution. " C'est le salaire familial moyen.

Ces deux variantes ne ront pas d'ailleurs sans grandes difficultés pratiques.

La seconde opinion est non moins nette : le salaire minimum ne comprend pas en stricte justice le salaire familial. C'est l'opinion soutenue par le cardinal Zigliara (4) et par le P. Fristot (5).

(I) M. Hyvernat. Association catholique, 1877 .

(2) L'abbé Potier ; l'abbé Naudet.

(3) Abbé de Pascal. L'Église et la question sociale, op. cit., pp. 58-59.

(4) Cardinal Zigliara : Consultation en réponse à Mgr Goossens, archevêque de Malines. Association catholique, déc. 1892, p. 639. Lors du Congrès de Malines, en sept. IIgr, l'archevèque de Malines avait consulté Rome pour savoir si le fait de ne pas payer le salaire familial constituait un péché. Voici le texte exact de la question et de la réponse qui ont donné lieu à de vives controverses :

Qu. An peccabit herus qui solvit quidem mercedem opificis sustentationi sufficientem sed imparem ipsius familiæ alendæ, sive hæc constet uxore et numerosa prole, sive hæc non ita numerosa sit? Si affirmative, contra quamdam virtutem?

Resp. Non peccabit contra justitiam, poterit tamem quandocumque peccare, vel contra, charitatem, vel contra naturalem honestatem.

Le maître pèche-t-il qui paie le salaire suffisant à la sustentation d'un ouvrier, mais insuffisant à l'entretien de la famille, soit que celle-ci comprenne avec sa femme de nombreux enfants, soit que celle-ci ne soit pas nombreuse? Et si oui, contre quelle vertu ?

La réponse fut : Il ne péchera pas contre la justice, mais il pourra parfois pécher soit contre la charité, soit contre l'équité naturelle.

Il s'agissait ici avant tout d'une question pratique de conscience et de responsabilité, bien moins que d'une question doctrinale et théorique. Rome s'est refusée à donner une réponse authentique sur la. question. Vermeersch, Mouvement social, $\mathrm{I}^{\mathrm{er}}$ sem. 1912, 1. 4/7.

(5) Études religieuses, 15 mai 1894, p. 15 r ; 5 janv. 1901, p. 79. 
Elle repose sur deux arguments, l'un de droit, l'autre de fait :

En droit, la relation entre le travail et la famille de l'ouvrier n'est qu'indirecte : c'est ce qu'exprime en langue scolastique le cardinal Zigliara : "Le travail de l'ouvrier ne se rapporte pas premièrement et de soi à sa famille, mais secondairement et par accident, du fait que l'ouvrier partage son salaire avec les siens. De mème que la famille ne contribue pas à l'accroissement de l'ouvrage fait, de même, en justice, elle ne saurait exiger que le salaire dû à l'ouvrage même soit augmenté (I). 》

En fait, l'application du salaire familial n'est pas possible et les patrons ne l'admettraient pas : ce serait donner, en réalité, une prime à la stérilité et à l'emploi des célibataires (2).

Les deux opinions restent en présence et sont, l'une et l'autre, acceptables (3).

\section{III. - LES MOYENS DE RÉAlisation PRATIQUE (4)}

Depuis l'Encyclique, la discussion a pareillement continué sur les moyens de réaliser en fait le minimum de salaire : les uns se déclarent partisans de l'intervention légale, les autres la repoussent avec énergie.

Parmi les partisans de la première opinion, qui soutiennent que cette fixation légale est à la fois juste et pratique, on peut ranger l'abbé de Pascal (5), le P. Leckmuhl, M. Pottier (6) et sans doute aussi M. G. Goyau (7). D'une

(I) P. Schwalm, op. cit., p. 337 .

(2) Cette opinion se complète et se corrige d'ailleurs dans son intégral exposé par une théorie des subventions familiales, dues au nom de l'honnêteté naturelle et de la charité, que le patron peut accorder à ses ouvriers chargés de famille. - Cf. Castelein, S. J. " La participation aux bénéfices et la théorie du salaire "), Réforme sociale, 1893, t. I, p. $29^{3}$.

(3) Léon XIII, par une déclaration de "tolérance réciproque ", a exigé, en 1895 , le maintien des deux théories. Schwalm, op. cit., p. 337. Cf. Association calholique, 15 juin 1895 , pp. 631-632.

(4) Schwalm. Lecons de philosophie sociale, II, p. 170.

(5) De Pascal. L'Église et la question sociale, p. $6 \mathrm{r}$.

(6) Pottier. De jure et justitia, loc. cit.

(7) Léon Grégoire (Georges Goyau). Le Pape, les catholiques et la question sociale, p. 205. 
part, c'est pour eux la solution juste, car l'État étant le gardien de la justice, " toutes les questions de travail, y compris celle du minimum, sont des questions de justice (l) "). D'autre part, c'est là une solution pratique, soit que l'État se contente d'homologuer les décisions des délibérations des patrons et ouvriers corporativement assemblés, soit mème que l'État intervienne provisoirement pour fixer, dans certains cas, le taux du salaire. "Dans les circonstances actuelles, dit le P. Leckmuhl, la réglementation directe et indirecte du salaire paraìt s'imposer à la sollicitude du pouvoir public (2). "

Plus nombreux (3) peut-ètre sont les catholiques sociaux qui ont pris parti en faveur de la seconde opinion et contestent ici le droit d'intervention de l'État en matière de salaire.

Pour eux, cette fixation légale des salaires est pratiquement impossible, injuste, nuisible pour la société.

Elle est pratiquement impossible : "Il n'est pas logique de rendre obligatoires les clauses d'un contrat qui, luimême, n'est que facultatif (4). " Du moment que l'on ne peut forcer à employer des, ouvriers, il est illusoire de vouloir leur assurer un certain taux de salaire par l'effet d'une prescription légale : on se contentera de ne les point employer.

Elle est injuste en second lieu, car elle provoquerait l'élimination immédiate des ateliers de tous les ouvriers âgés ou à demi invalides et leur rejet à la charge complète de l'Assistance publique (5), en même temps qu'elle provoquerait la destruction d'une foule d'industries qui végètent, mais qui contribuent encore à maintenir en activité la population.

Elle est enfin nuisible pour la société, car " toute élévation artificielle des salaires qui serait obtenue par ce moyen

(1) De Pascal, op. cit., p. 61.

(2) P. Leckmuhl. op. cit.

(3) M. Ch. Périn. Note sur le juste salaire d'après l'encyclique "Rerum novarum ", Mons, I892. - M. Joseph Rambaud. Éléments d'économie politique, p. 559. - Gf. Rambaud. Cours d'économie politique, Paris, Larose, Igrı, t. II, p. 19r. - Cf. Jannet. Le Socialisme d'État et la réforme sociale, p. 49. - Le P. Fortier, S. J.

(4) Rambaud. Cours d'économie politique, t. II, p. I9I.

(5) Cf. Jannet. Soclalisme d'État, p. 49. 
provoquerait une hausse non moins artificielle des prix, laquelle aurait pour effet naturel d'altérer le salaire réel et surtout de sacrifier, comme consommateurs, tous ceux des travailleurs qui n'appartiendraient pas aux catégories ainsi protégées ou ainsi capables de se protéger elles-mêmes (I) ). Ce serait alors la fixation d'un prix minimum légal pour toutes les richesses produites par les travailleurs autonomes. La tarification des prix du travail entraîne comme accessoire une tarification générale des prix de chaque chose (2).

Une troisième opinion mixte tend d'ailleurs de plus en plus à prévaloir (3). Sans admettre d'une manière universelle les tarifications légales, on est d'accord pour confier à l’État le soin de sanctionner les minima de salaire fixés par les corporations locales dans certains cas accidentels et exceptionnels.

A défaut d'organisation professionnelle, en l'absence des syndicats patronaux et ouvriers, l'État devra, d'office, constituer des organismes spéciaux, les comités de salaire, auxquels il confiera le soin de déterminer les minima de salaire obligatoires pour la profession.

Comme le dit très nettement M. Henri Lorin (4): "Récemment l'Église, après avoir rappelé le principe du salaire vital par l'encyclique " Rerum novarum », a confirmé son enseignement traditionnel relativement au travail, et elle a tracé les deux voies par lesquelles il est de notre devoir de

(I) J. Rambaud, op. cit. Cours, t. II, p. I9I.

(2) Dans ses Éléments d'économie politique, p. 562, M. Rambaud soulignait : " Hypothèse qui est irréalisable en dehors d'un monde asservi à la réglementation minutieuse et stérile du socialisme le plus envahissant et le plus absolu. ")

(3) R. Jay. La Protection légale des Travailleurs, Paris, Larose, I9ı, p. 303. - H. Lorin. Déclaration à la Semaine sociale de Marseille, 1908, p. 15. - P. Schwalm, op. cit., t. II, p. 177. Voici les conclusions du P. Schwalm à titre d'exemple : $1^{\circ}$ En tant que promoteur du bien commun, l'État peut, de droit ordinaire, fixer par une loi soit le principe d'égalité du salaire à l'ouvrage et, aux besoins, soit son taux particulier; $\mathbf{2}^{\mathrm{e}}$ Mais cette dernière fixation lui est impossible dans la pratique habituelle sous forme directe d'un tarif général des salaires. Elle ne l'est que sous forme de privilège particulier reconnu aux corporations ou exercé accidentellement à leur défaut, et sous forme de sentence exécutoire des justes contrats ainsi dressés. $3^{\circ}$ En tant que promotrices de leur bien commun particulier, les diverses corporations sont, de droit ordinaire, appelées à fixer le taux local et circonstancié des salaires.

(4) Loc. cit., p. 26. 
concourir au rayonnement de l'idée de fraternité dans l'ordre économique : la voie de l'Associatión et la voie de la Législation. ")

Mais on ne saurait trop le souligner, il n'y a pas ici, en la forme, détermination directe du salaire par l'État, salaire minimum légal, il y a seulement contrat collectif obligatoire ( $\mathrm{r}$ ), formation par l'État d'un comité de salaire dont la décision sera souveraine dans tout le métier.

(1) Cf. Raynaud. Le Contrat collectif de travail, I902, Paris, Rousseau, p. 356 ; cf. p. 316 . 


\section{CONCLUSION}

Ainsi la doctrine du catholicisme social pose le minimum de salaire.

Sans doute, on l'a vu, cette théorie n'est pas encore arrêtée en bien des points, et on a peut-être même abusé au lendemain de l'Encyclique des discussions doctrinales sur le minimum de salaire. L'essentiel ici, d'ailleurs, est moins dans les détails que dans l'ensemble (I). Il s'agit de poser comme une des exigences de la conscience chrétienne la réforme du minimum de salaire et d'y atteindre par tous les moyens (2).

Certes il n'est pas indifférent que la réforme soit faite au nom de la charité ou au nom de la justice, et sur ce point, sans doute, l'avenir apportera de nouvelles précisions.

Pour l'instant et du point de vue où nous l'envisageons ici, comme idéal proposé aux masses, il suffit de retenir que le minimum de salaire apparaîtra comme une des revendications légitimes de la conscience contemporaine.

(1) On a encore tout récemment (Semaine sociale de Saint-Etienne, 1912) insisté sur le caractère associationnel du contrat de travail : on entend par là le contrat passé entre deux créatures semblables à Dieu et, par là même, semblables l'une à l'autre; entre semblables, il ne peut exister que des contrats de genre associationnel toutes les fois que l'activité mème de l'homme est en jeu.

(2) L'heure est à l'action et non aux discussions stériles, dit très justement le pape Léon XIII dans l'encyclique "Rerum novarum », op. cit. Lettres apostoliquee, t. III, p. 69: "Que chacun se mette à la part qui lui incombe, et cela sans délai, de peur qu'en différant le remède on ne rende incurable un mal déjà si grave. " - "Que partout donc on agisse sans plus consumer un temps précieux en de stériles discussions, qu'on réalise dans les faits ce qui, dans les principes, ne saurait plus être l'objet d'une controverse. ") (Discours de Léon XIII aux pèlerins ouvriers français, le 19 déc. r89r. - Schwalm, op. cit., t. II, p. 207.) 


\section{CHAPITRE II}

\section{La Doctrine socialiste.}

Il est assez malaisé de dégager, au milieu de la complexité des systèmes et des doctrines, la pensée socialiste (I) sur le minimum de salaire.

A rigoureusement parler, il n'existe pas de théorie cohérente et visant directement ce point (2) : le minimum de salaire apparaît toujours dans la pensée socialiste comme un corollaire, un sous-entendu: le point de vue central n'est pas, surtout chez les socialistes scientifiques, celui de la justice. C'est une sorte de filon interrompu qui renferme une revendication profonde et qui n'effleure qu'à certains points.

Pour nous borner, il suffira d'exposer brièvement la doctrine des deux représentants typiques de la pensée socialiste, Sismondi et Anton Menger (3).

I. Sismondi. - Sismondi (4) est, d'une part, un critique très violent du salaire insuffisant pour vivre et d'autre part, grâce à sa théorie de la garantie professionnelle, un précurseur de l'idée moderne de la réalisation du salaire minimum par l'assurance obligatoire.

Et d'abord, le salaire est trop souvent insuffisant pour

(1) Cf. Polier. L'idée de juste salaire. Thèse. Paris, Giard, p. 218. Anton Menger: Le droit au produit intégral du travail, traduction française. Paris, Giard, rgoo, pp. r 7 et suiv.

(2) Cela résulte nécessairement de ce que le collectivisme, d'une part, poursuit l'abolition du salariat et que le communisme, de l'autre, bouleverse la répartition actuelle en supprimant la propriété privée et le salaire.

(3) Il y aurait une étude intéressante à faire sur les aperçus du socialisme sur le juste salaire. Gf. Polier, op. cit., 234. Mais nulle part, à notre sens, sauf chez les deux auteurs étudiés, l'idée du minimum n'est directement envisagée.

(4) Sur Sismondi, cf. Aftalion. Simonde de Sismondi. Thèse, Paris, Pédone, 1893 .

Sismondi : Nouveaux principes de l'économie politique ou de la richesse dans ses rapports avec la population. 2 vol., Paris, 1819. $2^{\circ}$ édit. 1827 ; Etudes sur l'économie politique, 2 vol., Paris, 1837 et 1838. 
vivre du fait de la concurrence ( 1 ). Le chef d'atelier " s'efforce de ne laisser à l'ouvrier que justement ce qu'il lui faut pour maintenir sa vie et se réserve à lui-même tout ce que l'ouvrier a produit par delà la valeur de cette vie (2). Le bénéfice d'un entrepreneur n'est quelquefois autre chose qu'une spoliation de l'ouvrier: il ne gagne pas parce que son entreprise produit beaucoup plus qu'elle ne coûte, mais parce qu'il ne paye pas tout ce qu'elle coûte, parce qu'il n'accorde pas à l'ouvrier une compensation suffisante pour son travail (3) ").

La conséquence de cet état de choses est le fait que bon nombre de travailleurs retombent à la charge de l'Assistance. " Aujourd'hui il (le fermier) cherche à réduire leur salaire au taux le plus bas possible, à obtenir pour ce salaire le plus de travail possible. Si ce travail les épuise et qu'ils tombent malades, la paroisse y pourvoira; si dans l'intervalle des travaux il y a des saisons mortes, la paroisse y pourvoira; si les champs ne présentent point de travaux propres aux femmes, aux enfants, aux vieillards, la paroisse y pourvoira (4). " Et ailleurs :

"Les manufacturiers de coton ont réduit successivement leurs ouvriers d'un salaire de 20 sous par jour à 15 , à 12 et enfin à 8 sous. Leurs intérèts ayant été absolument séparés de ceux de leurs ouvriers, ils n'ont eu à s'occuper, en traitant avec eux, que des moyens de s'assurer leur service au plus bas prix possible au moment où ils en avaient besoin ; ils les renvoient dans leurs maladies, leur vieillesse ou dans les saisons mortes, pour que la charité publique, les hôpitaux, en Angleterre la paroisse, pourvoient à leur misérable existence (5). ")

Le remède est dans l'application de la théorie fameuse (6)

(I) " Cependant l'ouvrier par son travail journalier produit beaucoup plus que ses dépenses journalières "). Nouveaux principes, t. I, p. 87 .

(2) Nouveaux principes, t. I, p. 103.

(3) Ibid., Nouveaux principes, t. I, p. 92, cf. p. 379. Etudes, t. I, pp. 35, 274.

(4) Nouveaux principes, t. II, p. 353.

(5) Nouveaux principes, t. II, p. 360. "Chacun d'eux oublie d'ailleurs qu'il devra à son tour pourvoir par ses charités privées, par ses institutions aux hòpitaux ou par la taxe des pauvres, à maintenir les misérables qu'il travaille à faire. ") (Ibid.)

(6) Cf. Gide et Rist. Histoire des doctrines économiques, p. 225. Aftalion, op. cit., p. 152. 
des garanties professionnelles : "l'ouvrier a droit à la garantie de celui qui l'emploie (I)".

Sismondi expose, assez confusément d'ailleurs, son idée par deux fois à propos du travail agricole et du travail industriel.

" Mais, dit-il à propos du travail agricole, si le gros fermier ou le gros propriétaire sait qu'il demeurera seul chargé, pendant toute l'année, de la famille du journalier dont il a besoin, il n'a plus d'intérêt à réduire son salaire au plus bas terme ou à tirer de lui plus de travail que ses forces n'en comportent : il ne lui convient plus de choisir la saison la plus avantageuse pour faire l'ouvrage tout à la fois, mais au contraire de le répartir dans le cours de l'année, pour qu'il y ait moins de temps perdu. II ne lui convient plus de faire travailler l'ouvrier le plus robuste, mais au contraire toute la famille également et selon ses forces (2).

Et ailleurs, à propos du travail industriel (3) : " Mais que chaque métier se charge de son propre fardeau, et chaque fabricant reconnaìtra bientòt, s'il est au nom de l'intérêt de sa manufacture de faire baisser les salaires; si lorsque l'entretien permanent d'un homme exige 20 sous par jour, il vaut cent fois mieux les lui donner à lui-mème, en récompense immédiate de son travail, que de lui en donner 8 comme gages et de lui en faire receroir i2 à titre d'aumône (4) ).

Ce principe ainsi posé ne s'explique que d'une seule manière, bien qu'au passage cité Sismondi n'y insiste pas : c'est parce que le salaire est le " revenu du pauvre »(5), qui doit suffire à son entretien pendant l'activité, mais aussi pendant la rémission du travail, qui doit pourvoir à l'enfance et à la vieillesse comme à l'âge viril, à la maladie comme à la santé (6).

(1) Nouveaux principes, t. II, p. 347. Liv. 7, chap. IX, tout le chapitre.

(2) Ibid., p. 354 .

(3) Sismondi convient d'ailleurs que « quoique le principe soit le même, il est beaucoup plus difficile à mettre en pratique pour l'industrie des villes que pour celle des champs; mais il est aussi beaucoup plus essentiel et beaucoup plus urgent d'y recourir. (Ibid. Nouveaux principes, t. II, p. 361.).

(4) Ibid. Nouveaux principes, t. II, p. 360.

(5) Ibid. Nouveaux principes, t. I, p. 379.

(6) Ibid. Nouveaux principes, t. I, p. 379. 
Et encore : “ L'ouvrier est nécessaire à celui qui le paye, comme le paysan à l'ouvrier. L'un fait vivre l'autre : il existe donc, il devrait exister au moins une sorte de solidarité entre eux (I). )

Ainsi le salaire vital, le salaire minimum serait pour Sismondi le résultat immédiat de la garantie professionnelle : tel est " le principe de droit, le principe de justice que la société doit protéger dans l'ouvrier contre la force du commerce qui tend sans cesse à le réduire au-dessous du nécessaire (2) »; c'est, pour prendre les expressions modernes, "l'obligation pour l'employeur d'entretenir à ses frais l'ouvrier pendant les périodes de maladie, de chômage et de vieillesse (3) ».

Sismondi ne se dissimule nullement les conséquences profondes qu'amènerait la proclamation de ce principe : "Sans doute l'effet d'un si grand changement dans la législation (4), en diminuant rapidement cette classe d'ouvriers qui se disputent les uns contre les autres à qui saura le mieux se passer même de ce qui est nécessaire à la vie, et en forçant chaque métier à supporter avec ses propres ressources les peŗtes qu'il aurait attirées sur lui mème par une production hors de saison, serait de faire bientôt reconnaître que plusieurs manufactures, que l'on considère comme gagnantes, perdent réellement; car les secours que la société donne chaque année à leurs ouvriers font plus que compenser leurs bénéfices. Sans doute il s'ensuivrait que plus d'un pays qui ne vit que d'industrie verrait successivement à fermer plusieurs de ses ateliers et que la population des villes, qui s'est accrue outre mesure, diminuerait bientôt, tandis que celle des campagnes recommencerait de s'accroître (5). »

Mais il accepte vaillamment ces perspectives, "car un État doit laisser partir l'industrie qui le quitte, sans effort pour la retenir. Toutes les faveurs que le gouvernement lui

(1) Ibid. Nouveaux principes, t. II, p. 348 .

(2) Ibid. Nouveaux principes, t. II, p. 346 .

(3) Gide et Rist, loc. cit., p. 225.

(4) Sismondi vient en effet de parler ci-dessus sans préciser d'ailleurs des " moyens lents et indirects ) de la législation. Ibid., p. 366.

(5) Ibid., Nouveau.c principes, t. II, p. 367. 
accorde, tous les sacrifices qu'il fait pour la soutenir dans sa décadence ne servent qu'à prolonger la souffrance ou du chef ou des ouvriers, et il ne sauve la manufacture déclinante (I) qu'aux dépens de ceux mêmes qu'elle doit faire vivre (2). ")

Le principe de la garantie professionnelle a d'ailleurs été autrefois pratiqué : " Dans l'organisation toute barbare, toute inhumaine des pays féodaux, des pays d'esclaves, ce principe essentiel de justice n’a point été méconnu. Jamais seigneur n'a songé à mettre ses vassaux, ses serfs, ses esclaves à la charge de la province, dans leurs calamités, leur vieillesse ou leur maladie : il a fort bien senti que c'était à lui seul à pourvoir aux besoins de ceux qui ne les éprouvaient que pour son propre avantage (3). " Ce n'est que de nos jours qu'on « a fait suivre aux producteurs une route diamétralement contraire à celle de l'intérèt de la société (4) ).

On a maintes fois souligné l'imprécision de cette doctrine (5). Sans doute notre auteur n'arrive pas à une revendication nette du salaire minimum, et il reste très indécis (6) sur les moyens de mettre en neuvre la garantie professionnelle (7).

Il n'en est pas moins vrai qu'en face des théories classiques alors régnantes, c'était une véritable découverte et une idée d'avenir, que celle de la garantie professionnelle.

(I) Gf. plus bas la théorie de S. Webb, très analogue sur ce point: infra, p. 36.

(2) Ibid., Nouveaux principes, t. II, pp. 367-368. Par une coïncidence curieuse, c'est à l'Angleterre surtout que Sismondi songe en écrivant ces lignes: " Une seule nation, il est vrai, se trouve dans cette condition forcée. ") (Ibid., p. 368). C'est aussi l'Angleterre qui la première a accepté franchement l'idée du minimum de salaire. Gf. infra, p. 300.

(3) Ibid., p. 351 .

(4) Ibid., p. 359.

(5) Gide et Rist, loc. cit., p. 226; Aftalion, op. cit., p. 156; Polier : L'idée du juste salaire, p. 232.

(6) “ Je l'avoue, après avoir indiqué où est, à mes yeux, le principe, où est la justice, je ne me sens pas la force de tracer les moyens d'exécution. "Ibid., Nouveaux principes, t. II, p. 364.

(7) On a pu trouver certains textes précis (Aftalion, op. cit., p. I62) dans Sismondi pour orienter sa garantie professionnelle dans le sens de l'assurance. Tel encore celui-ci : " Le manufacturier apprendrait que toutes les infirmités qu'il fait gagner à l'ouvrier, il devra les lui payer en autant de journées d'hôpital. ") Ibid., p. 362. 
Le $\mathrm{xix}^{\mathrm{e}}$ siècle devait, on le sait, les mettre en œuvre ( $\left.\mathrm{I}\right)$.

II. Anton Menger (2). - Pour Ant. Menger, le minimum de salaire résulterait implicitement de l'application simultanée du droit à l'existence et du droit au produit intégral du travail pendant la période transitoire, en attendant la réalisation complète de la Cité socialiste.

Le droit à l'existence est ainsi formulé : " Chaque membre de la société a droit à ce que les biens et les services nécessaires à la conservation de son existence lui soient fournis avant qu'il ne soit donné satisfaction à des besoins urgents des autres membres de la société (3). »

Le droit au produit intégral du travail s'énonce ainsi : "Chaque membre de la société a le droit d'exiger que le produit intégral de son travail lui soit assuré par l'organisation juridique (4). ")

La seule suppression de la propriété privée suffirait à les réaliser tous deux : "Même dans une organisation juridique qui aurait supprimé complètement le revenu sans travail, on pourrait obliger chaque citoyen à travailler chaque jour un certain nombre d'heures pour subvenir aux besoins de son existence, tandis que le produit intégral des autres heures de travail serait laissé, dans certaines limites, à sa libre disposition. Cette combinaison du droit à l'existence et du droit au produit intégral du travail, qui allie l'égoïsme à l'altruisme, la liberté à la contrainte, devrait être recommandée pour la période de transition, pendant laquelle les institutions socialistes auraient à régir une masse élevée des principes individualistes (5). ”

Mais ce serait déjà l'avènement de l'État socialiste (6). Dans la société présente, le " contrat de salaire, par lequel le travailleur vend au patron, pour un temps donné et pour un ouvrage donné, sa force de travail (7) 》 reste foncière-

(I) En un sens, toutes les législations modernes sur les assurances sociales se rattachent à l'idée de Sismondi.

(2) Le droit au prodluit intégral du travail, 1 vol. Paris, Giard, 19oo., traduction française.

(3) Op. cit., p. 78 .

(4) Op. cit., p. 15.

(5) Ibid., pp. 20-21.

(6) L'État socialiste. I vol., Paris, Bellais, I904.

(7) L'État socialiste, p. $16 \mathrm{r}$. 
ment injuste, puisque " la liberté des parties contractantes n'y est qu'apparente ". Il reste un contrat de droit privé, et ne perd mème pas ce caractère " quand l'État établit, par le moyen de lois ou de règlements d'administration publique, une journée normale de travail ou un salaire minimum (I). " On voit ainsi combien fragmentaire et provisoire reste chez Anton Menger la notion du minimum de salaire.

(1) Ibid., p. 62. 


\section{CHAPITRE III}

\section{L'Utilitarisme social.}

On a enfin essayé de justifier le minimum de salaire au nom de l'utilité sociale : la réforme s'imposerait au nom de l'intérêt social, voire mème de l'intérêt économique.

C'est surtout S. Webb (I) qui a développé cette doctrine. La thèse peut se résumer dans les trois propositions essentielles suivantes :

a) Le minimum de salaire s'impose au point de vue de l'intérêt social;

b) Le minimum de salaire est conforme à l'intérêt économique;

c) Il doit se réaliser par l'action professionnelle et au besoin, en certains cas spéciaux, par l'action de la loi.

a) Le minimum de salaire s'impose au nom de l'intérêt social.

On montre facilement les conséquences fâcheuses au point de vue social d'un salaire trop bas, insuffisant pour vivre (2).

11 entraîne la dégénérescence physique, morale, intellectuelle de la population ouvrière. Cette dégénérescence constitue un affaiblissement, une dégradation pour la société tout entière : elle entraîne la diminution dans le nombre des jeunes gens bons pour le service; elle constitue un foyer d'épidémies et de maladies contagieuses, elle entraîne une aggravation notable dans les charges de l'Assistance publique; au point de vue moral, elle fait, en quelque sorte,

(I) S. Webb. Industrial Democracy, $2^{\mathrm{e} e}$ édit., t. XXXVI, pp. 589 et 774 et suiv. - Du même : The economics of the minimum wage, Report of conference on a minimum wage, 1906, pp. 20-33.

(2) S. Webb. Rapport cité, p. 27. 
tache d'huile et de l'individu par la famille, le quartier, la ville provoque un abaissement dans le niveau de la moralité publique du pays tout entier.

" L'employeur (I) qui donne du travail à un prix inférieur aux femmes et aux enfants obtient actuellement un double avantage sur les industries qui se suffisent (self supporting trades): d'une part, il se procure, sans aucun débours, de l'énergie prise au dehors gràce à la nourriture qui vient d'ailleurs, et, d'autre part, il soutire parfois des employeurs, rivaux ou placés dans une industrie qui leur fait concurrence, quelque partie d'un revenu qui aurait pu accroître l'énergie utilisée dans un autre métier. "

De plus, ce parasitisme social entraine aussi une dégradation nationale, en ne permettant pas de maintenir les citoyens en force et en santé (2). " En abîmant ainsi le physique, l'intelligence et le caractère de leurs employés, les employeurs diminuent le capital global de la nation (3). ") Les salaires insuffisants empèchent la création d'une nouvelle génération pour remplacer les travailleurs actuels.

\section{b) Il est conforme à l'intérêt économique.}

Le minimum légal de salaire a d'heureux effets sur l'ouvrier, sur le patron, sur l'organisation de l'industrie en général.

Sur l'ouvrier d'abord: "C'est qu'il est fait pour favoriser l'action des deux forces qui amènent le progrès; il tend constamment à la sélection des plus aptes et en mème temps il assure l'excitation cérébrale et les conditions matérielles nécessaires pour l'adaptation fonctionnelle à un niveau plus élevé d'adresse et d'énergie (4). ')

Un siècle entier d'expérience industrielle en témoigne: l'établissement d'un minimum de salaire n'amène pas une suppression de la concurrence entre travailleurs : " il ne

(1) Ibirl., p. 26. A la base de ce raisonnement, l'auteur suppose, ce qui est exact, que les salaires d'appoint payés ne donnent que l'argent de poche et que l'existence des travailleurs qui les regoivent est assurée par leurs parents.

(2) Ibid., p. 27.

(3) Ibid., p. 27.

(4) S. Webb, op. cil. Report, pp. 22-23. 
limite mème pas l'intensité de cette concurrence ni la liberté de l'employeur pour en tirer avantage. Tout ce qu'il produit, c'est de transposer la pression d'un des éléments du contrat à l'autre, du salaire à l'ouvrage, du prix à la qualité. En fait, l'exclusion du contrat de tout élément d'abaissement du prix, soit sous forme de taux minimum de salaire, soit sous forme de trop longues heures de travail, soit sous forme de conditions défectueuses d'hygiène et de santé, se traduit nécessairement par un accroissement de l'influence sur le contrat de tous les autres éléments qui restent (I). ") Aujourd'hui sans minimum le patron, au lieu de choisir le meilleur ouvrier, donnera la préférence à un incapable, à un infirme, à un travailleur en ribote (boozer) ou à un individu de mauvais caractère, pourvu qu'il puisse l'engager à un salaire suffisamment bas. Au contraire, avec le minimum de salaire, le patron est dans l'impossibilité d'abaisser le niveau de ses travailleurs et se trouve dans la nécessité d'élever le niveau du rendement de tous ses employés. C'est même la base de l'accusation si souvent répétée aujourd'hui contre la politique des Trade-Unions fixant le standard, à savoir qu'elle empêche l'employeur de choisir de préférence un ouvrier vieux ou invalide physiquement ou moralement, lorsqu'il y a une vacance à combler. Mais qui ne voit au contraire que l'efficacité de l'industrie est augmentée quand chaque poste est occupe par le candidat le plus propre et le plus capable? Ainsi par l'effet du minimum de salaire, l'employeur, du jour où il ne pourra plus se procurer de la " main-d'œuvre pas chère ", sera contraint de chercher à obtenir, pour le prix qu'il paye, le maximum de force et d'habileté, le plus haut degré de sobriété et d'exactitude et le type supérieur de responsabilité et d'initiative (2). C'est là le premier aspect de son heureuse action sur l'ouvrier: il est un perpétuel stimulant à l'emploi des plus aptes.

Il en est un second: le salaire minimum jouera de la mème façon par sa répercussion sur la mentalité de l'employé. " Le fait que l'esprit de l'employeur est constamment tourné vers la recherche des travailleurs les meilleurs

(1) S. Webh, op. cit. Report, p. 2 I.

(2) Cf. S. Webb, rep. cité, p. 2I, dont nous avons reproduit d'aussi près que possible le développement. 
réagit silencieusement et imperceptiblement sur les employés. " Dans la concurrence que se font entre eux les ouvriers, du jour où il ne pourra plus triompher en offrant des conditions de travail inférieures, le jeune travailleur cherchera à se faire valoir et à se recommander par son caractère sérieux, son habileté technique et sa vaste compréhension. Ainsi en second lieu le salaire minimum est un stimulant réel pour la classe ouvrière tout entière à devenir de plus en plus capable ('I).

Enfin, à un troisième point de vue encore, le salaire minimum, en améliorant les conditions matérielles de la vie des travailleurs (meilleure nourriture, meilleur vêtement, meilleure santé, etc.), auggmentera ainsi encore indirectement leur force productive (2). Pour l'affirmer, S. Webb s'appuic l'une part en ce qui concerne les faits sur les travaux de M. Charles Booth : sur huil millions de persomnes dans le Royaume-Uni, plus d'un million aujourd'hui vivent d'un salaire d'adulte inférieur à une livre sterling par semaine - (25 fr. 22 environ), et d'autre part, en ce qui concerne l'avenir, sur le témoignage de nombreux économistes depuis J. R. M'Culloch jusqu'au professeur Marshall, qụi tous affirment qu'une amélioration dans les conditions de la vie entraîne un accroissement réel de production.

Ainsi, à n'en pas douter, le salaire minimum est arantageux d'abord par son heureuse action sur l'activité économique de l'ouvrier.

Sur le patron ensuite. - "La mise en vigueur d'un salaire minimum est un stimulant réel pour l'invention et l'adoption de nouveaux procédés de fabrication (3). ")

Ici encore c'est l'histoire du Trade-Unionisme qui impose et justifie pareille affirmation : en 1832, la découverte et l'adoption de nouvelles méthodes pour forger et souder les canons de fusils furent directement provoquées par l'obtention de conditions de travail meilleures de la part de tous les ouvriers employés avec les vieux procédés de fabrication; dans l'industrie du coton, l'adoption de la mule " self acting " fut une conséquence immédiate des grèves des

(1) S. Webb. Ibid., rapport cité, P. 22.

(2) S. Webl. Ibidl, p. 22.

(3) S. Webb, rep. cité, p. 23. 
ouvriers fileurs de coton, entre 1829 et 1836 , pour obtenir des tarifs de salaires; dans l'industrie de l'acier, sir Charles Tennant, l'un des plus remarquables capitaines d'industrie contemporains, accepta diverses améliorations techniques précisément devant les revendications de ses ouvriers réclamant un minimum de salaire. Les faits sont donc pertinents. On comprendl d'ailleurs que l'acceptation de règles uniformes dans tous les établissements industriels concentre la pression de la concurrence ( $\mathrm{r}$ ); les patrons sont ainsi sans cesse à l'affùt d'un moyen d'abaisser le coût de production. Le minimum de salaire est bien ainsi en second lieu avantageux par ses heureux effets sur l'activité économique du patron.

Sur l'organisation de l'industrie en général. - Et d'abord " la seule existence d'un minimum de salaire obligatoire a un effet des plus heureux et des plus importants sur la productivité industrielle, en ce qu'il tend constamment à faire passer les affaires dans les établissements les mieux situés, les mieux armés, les plus habilement aménagés et à éliminer les industriels incompétents ou à l'ancienne mode (2). ")

Ici encore c'est à l'aide de faits empruntés à l'histoire du Trade-Unionisme, pour laquelle notre auteur est si documenté, que cette affirmation est établie : l'industrie du coton (filature) montre à merveille cette survivance des plus aptes au fur et à mesure que les conditions du travail deviennent uniformes. Seules subsistent les usines les mieux placées, douées de l'outillage le plus récent et le meilleur, dotées de brevets ou de procédés industriels.

Ce résultat est d'ailleurs durable et va toujours en s'accentuant.

Ensuite l'adoption d'un salaire minimum obligatoire ne produit pas nécessairement la disparition des industries parasites qui ne permettent pas d'octroyer aux travailleurs un salaire minimum (3). En effet, par l'élimination d'une partie des sous-concurrences ouvrières (enfants, femmes,

(1) Dans le cerveau des patrons, dit exactement notre auteur. The enforcement of the common rules in all establishments concentrates the pressure of competition in the brains of the employer. Loc. cit., p. 24 .

(2) S. Webb. lbid., report, p. 24 .

(3) Ibid. S. Webb, rep. cité, p. 28. 
incapables), la demande du travail se trouverait accrue et ce serait une réorganisation de l'industrie qui s'ensuivrait: tous ceux qui peurent travailler trouveraient un emploi, tandis que les "inemployables " seuls (et non comme aujourd'hui les (inemployés )) retombent à la charge de l'Assistance (I).

De toute façon, l’institution d'un minimum de salaire serait avantageuse pour la société tout entière.

e) Le salaire minimum doit se réaliser par l'action professionnelle et dans certains cas spéciaux par liaction de la loi (2).

L'action professionnelle, les contrats collectifs, là où la profession est organisée, obtiendront non seulement un salaire strictement minimum, mais un salaire vital (living uage). Au contraire, dans les métiers non organisés (3) pour les travailleurs " unskilled », l'intervention légale s’impose. Qu'on ne dise pas d'ailleurs que c'est là une réglementation impossible : elle se fait actuellement en NouvelleZélande et en Australie, sous nos yeux. Mais il y a plus: mème en Angleterre, la fixation d'autorité d'un minimum de salaire est journellement poursuivie ; les contrats du gouvernement et ceux des administrations locales depuis (le longues années la réalisent (4). Il s'agit seulement de procéder de même dans l'industrie privée.

En résumé, et c'est la conclusion à laquelle arrive S. Webb, tout compte fait, l'économiste moderne doit conclure que la mise en vigueur, dans chaque profession, d'un minimum légal des salaires, comme la législation analogue de règles

(1) Ibid., pp. 30 et 3 r. Les charges de l'Assistance se trouveraient par là réduites d'autant. "La réforme tend constamment à cette réduction, à la fois en diminuant le nombre des faibles et des dégénérés annuellement mis au monde et en définissant mieux ceux qui existent et qui pourraient ainsi être mis à part et mieux traités."

(2) S. Webb, rap. cité, p. 3r. Op. cit. Industrial Democracy, pp. xu, LI et suivantes.

(3) "Pour les travailleurs hommes ou femmes, mal nourris, mal logés et surmenés, privés de loisirs, sans force pour s'organiser, pour le travailleur à domicile isolé ou l'aide dans un petit atelier - le contrat collectif est complèternent et pour toujours irréalisable (Collective Bargaining is wholly and for ever out of the question). Ibid., Industrial Democracy, p. LI.

(4) Sur ce point, cf. infra, p. $26 \%$. 
communes quant aux heures de travail ou à l'hygiène par les lois de fabrique, aurait de bons, et non de mauvais, résultats pour la communauté considérée dans son ensemble (I).

Il faut avouer, d'ailleurs, que cette réglementation est mème moins gènante que les autres (2).

Telle est la troisième théorie en faveur du minimum de salaire.

Elle nous parait de tous points acceptable : on peut souhaiter que la conscience publique, de plus en plus éclairée et avertie, l'adopte, tout de mème qu'elle a progressivement admis le caractère indispensable de la législation protectrice des travailleurs.

La seule critique qu'on lui puisse alresser, c'est son utilitarisme mème : pour vaincre les résistances pratiques que rencontre l'illée de minimum de salaire, il peut paraître insuffisant de n'invoquer que l'intérèt social, l'utilité sociale. De ce point de vue que répondre aux intérèts aujourd'hui prévalents des employeurs qui refusent la réforme? Comment vaincre les égoïsmes privés avec l'intérèt social, qui reste dans le plan de l'égoïsme? Il faut de toute nécessité un principe supérieur de justice ou de solilarité qui permette de dépasser la réalité présente et d'exiger la mise en vigueur d'un salaire minimum obligatoire.

Sous cette importante réserve, la théorie de l'utilitarisme social est exacte : elle reflète assez ficlèlement le tempérament anglais qui lui a donné naissance et n'a pas été étrangère aux récents progrès du minimum de salaire en Angleterre (3).

(r) Webb. The Economics of the minimum wage. Report cité, p. 33.

(2) S. Webb (Rapport cité, p. 32) rapporte l'opinion de sir George Livesey (Du Gaz de Londres-Sud) qui déclare : "Les règlements d'hygiène et la limitation des heures de travail constituent pour son affaire un bien plus grand obstacle que ne serait un minimum légal de salaires pour les derniers degrés du travail. "

(3) Sur ce dernier point, cf. infra, p. 405. 


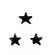

Il serait intéressant de rechercher ici, pour compléter cet exposé doctrinal, l'attitude des autres écoles économiques en face du minimum de salaire.

Toutes, sauf celles précédemment exposées, lui sont hostiles.

Il faut toutefois faire une réserve pour le solidarisme qui supprime en quelque sorte le problème, du moment qu'il envisage comme idéal la disparition du salariat ( $\mathrm{I}$ ).

En attendant cette transformation, l'École de la solidarité serait sous certains rapports favorables au minimum de salaire; la doctrine se présente cependant arec des nuances très caractéristiques.

Il nous suffira de l'esquisser brièvement.

M. Léon Bourgeois dans le solidarisme pose plutòt l'idée du minimum d'existence que celle du minimum de salaire, comme une des applications pratiques de la solidarité :

" Nous supposons un individu qui travaille et qui tire de son travail le salaire qui le fait vivre. La société ne peut pas garantir à chacun de ses membres l'égalité de salaire. Cette égalité n'est ni désirable ni possible. Nais il y a un minimum d'existence, la vie elle-mème, que la société doit d'abord assurer à chacun de ses membres. On a eu raison de dire qu'il n'est pas tolérable qu'un homme meure de faim à còté du superflu des autres hommes. ")

C'est d'ailleurs la société tout entière qui est garante de ce minimum d'existence : "Le secour's de la force commune est dù, pour garantir le minimum de l'existence, à tout associé qui se trouve d'une façon permanente, par suite de son àge ou de ses infirmités, dans l'impossibilité physique ou intellectuelle de se conserver par ses seules forces. Il est dû aussi à tout associé rendu temporairement incapable de se suffire soit par la maladie, soit par les accidents du travail, soit par le chòmage forcé. Cie sont là des

(1) Cf. Ch. Gide. Conférences de propagande. Larose, igoo, p. 5. 
risques sociaux dont la charge doit ètre en partie, tout au moins, supportée par la collectivité (I). »

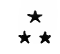

Telle est la doctrine du minimum de salaire; elle est soutenue, on le voit, par des esprits bien différents, voire même opposés, dans leurs doctrines et leurs idées.

Cette rencontre n'est point fortuite d'ailleurs; comme il arrive souvent en histoire de doctrines économiques, c'est ici la réalité, ce sont les faits contemporains qui ont suscité la doctrine. Voyons maintement comment la doctrine réagit à son tour sur les faits.

(r) L'idée de solidarité et ses conséquences sociales, dans Essai d'une philosophie de la solidarité. Conférence et discussion. Paris, Alcan, I902, p. 86 . 


\section{DEUXIÈME PARTIE}

\section{LES FAITS}

Essais de Réalisation du Minimum de Salaire.

Après avoir ainsi étudié la théorie du minimum de salaire, il s'agit maintenant d'en poursuivre la réalisation dans les faits. 


\section{CHAPITRE PREMIER}

\section{L'Histoire.}

L'histoire ( $\mathrm{I}$ ) des réalisations du minimum de salaire pour le passé est fort brève : il s'agit, en l'état actuel au moins de nos connaissances historiques, seulement de quelques très rares tentatives sur la portée desquelles, d'ailleurs, on est loin d'ètre d'accord.

L'antiguité ne paraît pas avoir connu le minimum de salaire; l'esclavage d'une part, les relations entre artisans de l'autre dans le travail libre, n'impliquaient nullement notre problème. En Grèce et à Rome on ne consent pas de fixation de minima de salaires; ce seraient bien plutôt des maxima qui auraient été pratiqués.

De même le moyen àge, malgré la floraison doctrinale constatée ci-dessus, ne parait pas une époque favorable à l'apparition du minimum de salaire. Il est probable que le besoin ne s'en faisait pas sentir, parce qu'il existait bien souvent en fait; la coutume suffisait à garantir le juste salaire et l'opposition entre patrons et ouvriers était loin d'ètre aussi marquée qu'aujourd'hui.

Ce n'est qu'exceptionnellement qu'on trouve de rares exemples de minimum de salaire, exemples d'ailleurs sur lesquels l'accord des auteurs est loin d'ètre établi. Il suffira d'en mentionner quelques-uns :

C'est ainsi que l'on produit une sentence de la prévòté de Paris, d'avril i 270 (2), fixant les prix de façon des draps, qui établit un minimum de rémunération.

C'est ainsi encore, en Angleterre, qu'on a fait état d'un statut de la reine Élisabeth, de $\mathbf{5} 563$, autorisant les juges de paix à fixer chaque année, de concert avec de graves per-

(I) C. Et. Martin-Saint-Léon. Note sur le minimum de salaire à travers l'histoire. Association catholique, 1908, p. 12.

(2) De Lespinasse. Les Métiers et Corporations de Paris du xıv au xvIII ${ }^{\mathrm{e}}$ siecle, t. IlI, p. 140 . 
sonnes (s'ils jugent devoir en convoquer), le taux des salaires, en tenant compte de la disette et de l'abondance du moment. Les juges de paix devaient fixer les salaires par année, semaine et journée, avec ou sans nourriture. Le préambule de cet édit est d'ailleurs curieux : il indique qu'il y a lieu de reviser les anciennes lois, principalement parce que les salaires et redevances fixées par maint statut sont trop faibles et ne correspondent plus au prix réel de la vie; que, par suite, les anciennes lois (ayant édicté des maxima pour les salaires) ne peuvent plus être appliquées sans grande peine pour le pauvre laboureur et artisan ( $\mathrm{I}$ ).

On a voulu voir là l'établissement de salaires minima. La question est des plus discutées.

En ce qui concerne d'abord l'application de ce texte, certains auteurs (2) prétendent que l'édit fut plus favorable aux maitres qu'aux ouvriers : les juges de paix auraient fixé des maxima de salaires. D’autres historiens (3) prétendent au contraire que cet édit, d'abord inappliqué (4), aurait ensuite servi à la hausse des salaires (5) et que les modernes TradeUnions peuvent vraiment invoquer ce texte archaïque à l'appui de leur's récentes revendications.

La question parait douteuse et les contradictions mème dont ce texte était susceptible, en ce qui concerne son application, montrent qu'on ne peut y voir vraiment une réalisation bien nette du minimum de salaire.

On a encore produit divers documents sur la portée desquelles il est difficile d'ètre affirmatif.

II. Hauser parle de luttes soutenues avec un extrème

(1) Martin-Saint-Léon, op. cit.

(2) Unwin. Industrial organization in the sixteenth and seventeenth centuries. Oxford. Clarender Press, 1904, p. 119. - Th. Rogers. Six centuries of worli and wages, Londres, Sonnenschein, 1894, p. 422.

(3) Cunningham. The Growth of English century and commerce on moderı times, 1892. Cambridge University press, p. 44. Cf. Hon. Evelyn. Hubbard. The minimum wage past and present. The Economic Journal. Juin 1912, p. 303.

(4) Un acte de Jacques Ier fixait des pénalités pour tout salaire payé inférieur au taux fixé par le magistrat.

Un acte de Georges 1 , en 1747 , prévoyait que les discussions sur ce point entre maìtres et ouvriers devaient ètre soumises au magristrat quand "aucune tarification ou fixation de salair'es n'aurait été efrectuée cette année-là par les juges de paix pour le comté ». Cf. Economic Journal, act. supra cit., p. 303.

(5) Abrogé par une loi de 1813,53, Geo. III, c. 40. 
acharnement par les compositeurs lyonnais, en 1562, qui revendiquaient l'établissement d'un tarif de salaire " fixé par un nombre égal et pareil de maîtres et compagnons plus anciens, (qui savent et connaissent le labeur (I). )

De mème, certaines monographies d'industrie (2) laisseraient voir conment à l'origine furent établies des listes de salaires minima qui, d'un commun accord, devaient ètre observées pendant deux siècles dans l'industrie dominante de Lyon et de Saint-Etienne.

Une tentative également curieuse (3) est celle qui eut lieu en Angleterre, en 1795 , par le dépôt d'un bill " pour déterminer et fixer les salaires, arrèter et publier les heures de travail de tous les travailleurs de l'agriculture (in husbandry) par jour, semaine, mois et année, avec bière et cidre ou sans, en tenant compte de la valeur de la monnaie et de la prospérité ou de la crise de l'époque ».

D'après la proposition de Samuel Whitbread, un ami et disciple de Fox, déposée à la fin de l'année i 795 , les juges de paix auraient eu le droit de tenir des sessions générales pour ces fixations. En mème temps, une pétition intéressante, déposée par un groupe de travailleurs du Norfolk (4) acceptait complètement le bill et soumettait un système nouveau, faisant varier le prix du travail qui aurait dû en tout temps ètre proportionnel au prix du blé, d'après l'échelle suivante :

Si le blé vaut $14 \mathfrak{f}$ par last (5), le prix du travail sera de I sh. 2 d. par jour.

Si le blé vaut $\mathbf{6} \mathfrak{£}$ par last, le prix du travail sera de I sh. 4 d. par jour.

Si le blé vaut 8 8 par last, le prix du travail sera de I sh. 6 d. par jour.

Et ainsi de suite avec une élévation de i d. pour le salaire par chaque augmeniation de $\mathrm{I} £$ dans le prix du blé.

(1) Hauser. Ouvriers du temps passé, p. 223.

(2) Godart. Histoire de l'ouvrier en soie, à Lyon, p. 777. - Gras. Histoire de la rubannerie de Saint-Etienne, p. rgo6. - En ce sens : Bauer. Questions pratiques de législation ouvrière, 1902.

(3) Cf. J. L. Hammond et Barbara Hammond. The village labourer, $1760-1832$; A. Study in the government of England before the Reform Bill, Londres, Longmans, $191 \mathrm{I}$.

Evelyn Hubbard. " The minimum wages past and present ». Economic Journal, juin 1912, p. 303 .

(4) C'étaient les travailleurs plus particulièrement visés par le bill.

(5) Le last, mesure anglaise de capacité, vaut 29 hectolitres 078 . 
Le bill de Whitbread prévoyait la nullité de tout contrat stipulant des salaires inférieurs à la taxation officielle et des amendes et emprisonnements pour tout travailleur en contravention avec la loi.

Le bill fut déposé avec l'appui de sir W. Young, Fox, Dundas et autres.

En seconde lecture, le I 2 février I $79^{6}$, Pitt s'y montra nettement opposé : dans un grand discours, il combattit l'assertion de Whitbread que les salaires pouvaient s'accorder (lieep pace) avec les prix et la prétention que la misère des travailleurs était diminuée par la bienveillance des employeurs. Il utilisa toute son autorité pour combattre une intervention législative en matière de salaire, toute tentative " pour établir d'autorité ce qui se réaliserait bien mieux par le jeu naturel des principes (I) ». Cela fit échouer le bill. Il fut repris en février I 800 , se heurta avec le mème insuccès à l'opposition de Pitt et échoua de nouveau.

En ce qui concerne l'Angleterre, l'idée sommeilla quelques années encore : une société philanthropique la reprit en I 827 en déposant devant le Comité de l'émigration; le rapport de ce comité y coupa court par l'affirmation suivante : "C'est en vertu d'une ignorance complète de l'action universelle de la loi de l'offre et le la demande réglant le taux des salaires que toutes ces propositions extravagantes ont pu se produire (2). ")

Il faut arriver aux temps tout à fait modernes, pour la France, c'est-à-dire au xire siècle, pour voir se multiplier les rares expériences de minimum de salaire.

C'est ainsi qu'est restée fameuse l'expérience de salaire minimum poursuivie à Lyon, en $\mathrm{I} 83 \mathrm{I}$ (3) : les canuts de Lyon réclamèrent une augmentation de salaire : par suite de la concurrence étrangère, leurs salaires avaient beaucoup baissé (4). Des réclamations très vives se firent entendre à

(1) Discours de Pitt rapporté loc. cit., p. 304 .

(2) Ibid., loc. cit., p. 304.

(3) Levasseur. Histoire des classes ouvrières depuis $1789,2^{\circ}$ édit., t. II, pp. 47 et suiv. - Louis Blanc. Histoire de dix: ans, t. IH, p. 48.

(4) Le salaire, de 4 à 6 francs, était tombé insensiblement à quarante, trente-cind et vingt-cind sous : “ En novembre 1835, l'ouvrier employé à la fabrication des étoffes ne gagnait plus que i 8 sous pour un travail de dix-huit heures par jour. ") Louis Blanc. Histoire de dix: ans, t. III, P. 48. 
la Croix-Rousse; on saisit de ces plaintes le préfet, Bouvieri) umolard. Le i octobre I83 I, le Conseil des prud'hommes avait voté la résolution suivante : "Considérant qu'il est de notoriété publique que beaucoup de fabricants payent réellement des façons trop minimes, il est utile qu'un tarif au minimum soit fixé pour le prix des façons. " Le préfet offrit alors sa médiation officielle.

Sur son invitation, la municipalité de Lyon convoqua, à l'hòtel de ville, une assemblée de 22 ouvriers nommés par leurs camarades et de 22 fabricants désignés par la Chambre de commerce, pour élaborer le tarif. Diverses réunions furent tenues les 2 r et 25 octobre i 83 r. Le tarif fut signé et affiché le 25 octobre, sous la pression des ouvriers.

C'est alors que la résistance des patrons le fit échouer.

Un mémoire signé de ro4 patrons, le io novembre, protestait contre le tarif : le préfet déclara alors que ce tarif n'avait pas force obligatoire. Devant ce revirement éclatèrent les fameuses émeutes de la Croix-Rousse : une répression armée fut confiće au maréchal Soult. Le tarif fut finalement aboli.

Il faut encore mentionner diverses pétitions adressées aux Chambres sous le Gouvernement de Juillet ( $\mathrm{r}$ ) : le sieur Simon, ouvrier serrurier à Caen, par une pétition en date du 18 juin 1843 , demande l'organisation du travail, la limitation de la concurrence, la fixation du taux des salaires et des cenrées de première nécessité. La Chambre des Pairs passe à l'ordre du jour.

De même, le 3 août I 843 , la même Chambre est de nouveau saisie d'une pétition de 300 habitants de Roanne, demandant, au nom de la classe ouvrière, le droit au travail et la fixation officielle d'un minimum de salaire. Sur un rapport défavorable du baron Dupin, la Chambre des Pairs passe encore à l'ordre du jour.

Plus tard, le 26 aoùt I 838 , la Commission du travail de l'Assemblée nationale recevait les délégués des patrons filateurs de laine de neuf départements, ceux-ci venaient soumettre au Comité un projet de décret.

On y lit un article 2 ainsi rédigé : “ Il sera fixé, pour

(1) Journal des économistes, t. IX, 1844, p. 4I. 
l'ouvrier de chaque centre industriel et pour chaque spécialité, un minimum de salaire qui sera arrêté entre les patrons et les ouvriers. ")

Il est à tout le moins curieux de constater cette demande de la réforme du côté patronal en I 848 !

Voici le texte complet de ce projet de décret relevé dans les procès-verbaux de la Commission du travail (I) et encore inédit à notre connaissance :

\section{PROJET DE DÉGRET}

en date du 26 août 1848 , présenté par les filateurs de laine de neuf départements.

PROCÈS-YERBAL DE LA SÉAXCE DU 26 AOUT

L'ordre du jour appelle l'audition de MM. les clélégués des filateurs de laine des départements du Nord, des Ardennes, de la Marne, de l'Aisne, de l'Oise, de l'Eure, de la Seine-Inférieure, de la Seine et de Seine-et-Oise.

Ces messieurs exposent que dans une assemblée d'industriels tenue à Rheims ils ont délibéré le projet de décret suirant qu'ils soumettent à l'Assemblée nationale par l'intermédiaire du Comité du travail :

\section{L'Assemblée nationale,}

Considérant l'impérieuse nécessité d'améliorer le sort de l'ouvrier;

Considérant que dans l'intérêt de l'humanité et afin de donner au travail le plus de garantie possible de continuite, il importe de riglementer les heures de travail;

Considérant que la concurrence basće sur la réduction du salaire est une cause incessante de misc̀re pour l'ouvrier, de crise pour l'industrie et de danger pour la morale et l'ordre public ;

Considérant que par suite de cette concurrence anarchique, le salaire, depuis trois ans, a baissé de $33 \%$ et menace de baisser encore par suite des bas prix de tacon ;

Considérant qu'il importe, par une combinaison bien entendue,

(1) Procès-verbaux manuscrits, t. I, p. I62. Archives de la Chambre des députés, ǰfr, $\mathbf{~}$. 
de régler la production sur les besoins réels de la consommation, afin d'ussurer à l'ouvrier un travail et un salaire constants;

Considérant, en outre, que les intérêts des patrons et des ouvriers étant intimement liés et solidaires et ne pouvant être séparés, il importe de régler également le minimum du prix de façon pour les chefs d'établissements,

\section{Décrète :}

Article premier. - Le maximum de la journée de travail sera de douze heures de travail effectif.

Le travail est interdit les dimanches et autres jours fériés légalement. Il en est de même du travail de nuit, mais seulement pour les métiers à filer en peigné et les métiers à filer en fin en cardé.

Le travail de nuit de préparation est toléré, mais seulement pour deux ans ; passé cette époque, il sera interdit.

Art. 2. - Il sera fixé pour l'ouvrier, dans chaque centre industriel et pour chaque spécialité, un minimum de salaire qui sera arrêté entre les patrons et les ouvriers.

Art. 3. - Il sera pareillement fixé, entre les filateurs et les fabricants de tissus, un minimum de prix de façon de filature. Ce minimum sera basé sur le prix de revient, dans la détermination duquel entrera le minimum de salaire fixć pour l'ouvrier; aucun filateur ne pourra filer au-dessous de ce minimum.

Art. 4. - Pour éviter toute perturbation causée par l'excès de production, il pourra être décrété une réduction des heures de travail quand l'encombrement des produits aura été officiellement constati.

Art. 5. - M. le Ministre du Commerce est chargé de la mise à exécution du présent décret dans les deux mois qui suivront la promulgation et des règlements d'administration publique auxquels son exécution pourra donner lieu.

Paris, 22 août i 848.

\section{Signé :}

Albert Ménage, Poulain, Hindelaxg aîné, Bureau fils, Minval de Roubaix (Nord), Tranchart-Froment, F. Roger, Biétry et fils, Édouard Héniot, A. Pré, vost.

Après quelques explications échangées entre les délégués et MM. Alcan, Gillon, Leblond, de Vogué et Tamisier, M. le Président invite MM. les Délégués à adresser au Comité un mémoire explicatif à l'appui de leur demande, sur laquelle il ne serait pas en ce moment possible de délibérer, en l'absence de documents et de renseignements qui doivent être étudiés pour la solution de cette grave question.

\section{Signé : Astouir.}


- Une autre demande de salaire minimum fut adressée, en I 870, par les “ ouvriers fondeurs en fer » à leurs patrons (I) : la réclamation de o fr. 60 l'heure au minimum avait été formulée dès r 869 (2); elle est reprise le I 6 avril r 870 .

La grève éclata sur cette revendication : la réponse des patrons est intéressante à noter, comme symptomatique de l'état d'esprit alors régnant.

“ Les fondeurs en fer du département de la Seine (3),

Considérant que les immortels principes de $\mathbf{r} 789$, conquis et proclamés par nos pères, ont pour base : Liberté de tous et pour tous ;

Qu'en conséquence, les droits et les devoirs de chaque citoyen ont pour limite les droits et devoirs de ses concitoyens; que c'est faire un acte juste que de résister aux exigences qui tendent à priver une partie des citoyens de la liberté des transactions qui, dans un pays libre, ne doit être autre que celle de l'offre et de la demande, base de l'organisation du travail dans une société civilisée,

Font la réponse suivante aux articles de la lettre des ouvriers fondeurs :

(Sur l'article 1) (4) : Cette demande est injuste, car elle aurait pour résultat d'exclure tous les jeunes ouvriers dont les aptitudes ne seraient pas suffisamment développées pour que les patrons puissent les employer; et elle est inhumaine, car elle aurait pour conséquence immédiate de faire remercier les vieux ouvriers que l'âge ou les infirmités rendraient inhabiles. Les patrons ne peuvent pas plus accepter de minimum que de maximum ; il n'appartient à personne d'établir à l'avance les prix de journée : les prix ne peuvent être fixés que de gré à gré, entre patrons et ouvriers, suivant la capacité et aussi suivant la loi de l'offre et de la demande : c'est à cette grande loi à les régler. ")

- En I875, dans l'industrie du ruban, à Saint-Étienne, on

(1) Office du travail. Les associations professionnelles ouvrieres, t. III, p. 389 .

(2) Le Rappel, 19 et 23 novembre 1869 .

(3) Au nombre de 33. Ibid., p. 397.

(4) Demandant un minimum de salairc. 
relève une intéressante tentative de salaire minimum qui échoua par l'opposition des tribunaux (I).

In syndicat mixte, l'Union de la fabrique de rubans (2), se constitua le ro mai 1875 et élabora un tarif appliqué à dater du mème jour.

90 fabricants d'abord, l'unanimité des fabricants ensuite adhérèrent au tarif.

Cependant, l'année suivante (1876), un des signataires de la convention, M. Henry, ayant manqué à la convention, fut puni par le bureau de l'Union d'une amende de 3 francs, qu'il refusa de payer. L'Union le poursuivit devant le tribunal de Saint-Étienne. Celui-ci, par un jugement en date du 29 juin 1876 , donna gain de cause au fabricant par un jugement dont voici le considérant essentiel :

" Altendu que de cet ensemble de stipulations il résulte que l'ourrier n'est plus libre de discuter ses salaires et ses prix; qu'entre eux se place un syndicat qui ne connaît que la volonté de la majorité des membres de l'association, qui en publie les résolutions et les fait exécuter; que les ouvriers et les patrons de l'Union stéphanoise ne sont pas seulement liés les uns vis-à-vis des autres, mais encore visà-vis des tiers; qu'ils ne peuvent traiter qu'en se conformant aux tarifs votés par le plus grand nombre et dans des conditions de maximum et de minimum qu'il serait impossible de prévoir et qui seraient susceptibles de varier à l'infini; qu’ainsi leur liberté individuelle est aliénée au profit de la majorité s'ils n'en font pas partie, et qu'une telle convention, qu'elle soit à terme ou indéfinie, est absolument nulle, parce qu'elle est contraire aux règles de l'ordre public (3). )

(1) Cf. Office du travail. Les associations professionnelles ouvrières, t. II, p. 35 I.

(2) L'article 2 des statuts de l'Union portait formellement : "Son but principal est l'application d'un tarif minimum et maximum des façons, afin d'assurer aux ouvriers des prix plus rémunérateurs dans les mortes-saisons, les conserver dans l'industrie et permettre un bon entretien des métiers... »

L'article 5 portait que toute contravention au tarif serait punie d'une amende d'un quart du prix de façon porté au tarif, payé par le fabricant, et d'un quart, payé par l'ouvrier, au profit de la Chambre syndicale. Ibid., p. 351 .

(3) Ibid. Office du travail, p. 352. 
Devant ce jugement, l'Union résolut de se dissoudre immédiatement. Le tarif minimum de i 875 n'avait donc vécu qu'un an.

Au total - et sans préjuger des rares découvertes d'histoire économique que l'avenir peut nous réserver - on peut actuellement affirmer que le minimum de salaire n'a pas connu, avant le $x x^{e}$ siècle et mème la fin du $x^{2}{ }^{e}$ siècle, de bien nombreuses ni de bien intéressantes réalisations. Les conditions économiques et sociales n'en avaient point encore révélé la nécessité pratique et le besoin réel; en mème temps que les courants doctrinaux tels que le mercantilisme, qui eùt plutôt admis le maximum de salaire, ou le libéralisme longtemps dominant, qui voit en ce minimum de salaire une violation flagrante des lois économiques, s'opposèrent longtemps soit à tout essai de réalisation pratique, soit même à l'étude préalable du problème. 
L'histoire ne nous fournit donc que des tentatives fragmentaires et isolées. Le problème n'est directement abordé qu'à l'époque contemporaine; il s'agit maintenant d'en étudier la réalisation dans les faits. A cet égard, on peut, semble-t-il, étudier le mouvement contemporain qui converge vers le salaire minimum sous les deux aspects suivants :

$I^{0}$ La réalisation du salaire minimum est tout d'abord cherchée dans certaines voies indirectes, telles que l'introduction des clauses relatives au travail dans les adjudications de travaux publics, l'introduction de la lésion dans le contrat de travail, le fonctionnement des assurances sociales. C'est la réalisation indirecte du salaire minimum;

$2^{\circ}$ Ensuite l'action de l'association professionnelle, celle de la puissance publique, celle de la loi tendant à instituer directement des salaires minima. C'est là un second mouvement de réalisation directe du salaire minimum. 


\section{SEGTION A}

\section{La réalisation indirecte du salaire minimum.}

Le mouvement contemporain a pris à cet égard trois directions qu'il nous faut successivement étudier :

$I^{0}$ L'État et plus généralement certaines personnes morales publiques, comme en France le département, la commune, s'orientent vers le minimum de salaire par l'introduction de clauses relatives aux salaires dans les cahiers des charges des adjudications publiques. C'est un premier courant vers le minimum de salaire par les clanses relatives an travail dans les adjudications de travanx publics.

$2^{\circ}$ Le contrat de travail lui-mème évolue dans ce même sens et l'on songe aujourd'hui à introduire dans ce contrat l'idée de lésion, pour s'orienter vers un salaire vital. C'est un second courant vers le minimum de salaire par l'introduction de la lésion dans le contrat de travail.

$3^{\circ}$ Enfin, la diffusion des assurances sociales qui tend à faire supporter à l'employeur certaines charges sous forme de versements pour les assurances sociales de leurs employés tend aussi à constituer indirectement un salaire minimum, en mettant en œuvre cette idée que le travail doit nourrir son homme et que le salaire, d'ordinaire seul revenu ouvrier, doit suffire à prémunir le travailleur contre les différents risques qui lui incombent. C'est un troisième courant vers le minimum de salaire par la diffusion des assurances sociales en tout ou partie à la charge de l'employeur. 


\section{CHAPITRE II}

\section{Vers le Minimum de salaire par les clauses relatives au travail dans les adjudications de travaux publics.}

Le premier moyen indirect pour favoriser l'établissement d'un minimum de salaire, est l'introduction de clauses relatives au travail dans les adjudications de travaux publics.

L'action de l'État (I) est en théorie tout aussi indispensable qu'efficace. On admettra sans peine, d'une part, que l'État patron, par son importance même, l'État consommateur, doit donner l'exemple à l'industrie privée, et il est indéniable d'autre part que son action, à cause de l'importance de ce consommateur, est une action singulièrement efficace: les ardentes discussions menées autour de ce problème en sont une preuve manifeste.

Les circonstances mêmes dans lesquelles se font en tous pays les adjudications des travaux publics ont partout posé le problème de la même manière; on peut craindre, en effet, que le système d'adjudications, par les rabais nécessaires qu'il comporte, n'ait sa répercussion fàcheuse sur les conditions du travail (2); il s'agit alors tout à la fois de

(I) Par État il faut entendre non seulement l'État strict au sens du mot, mais le département, la commune, les établissements publics; en un mot, tous les organes de la puissance publique.

(2) M. H. Denis (discussion au Conseil supérieur du travail belge, i 894) donnait des eliffres particulièrement édifiants. Voici le résultat des adjudications du nettoyage des locomotives et manutention des combustibles aux chemins de fer de l'État belge :

$$
\begin{aligned}
& 1883 \ldots \ldots 20 \% \text { de rabais. } \\
& 1886 \ldots .60 \% \text { \% } \\
& 1892 \ldots .59 \% \text { de rabais. }
\end{aligned}
$$

Or ce sont là des travaux ne comportant presque exclusivement que de la main-d'œuvre. Office du travail belge : Le minimum de salaire et les adjudications publiques en Belgique. Bruxelles, 19i i, p. 38. 
maintenir le salaire ordinairement pratiqué, ce qui est la première étape et, au delà, de garantir un salaire minimum. La question se présente sous un jour particulièrement favorable, en ce sens qu'elle peut ètre engagée sur ce terrain sans mettre en cause les objections ordinairement élevées contre le salaire minimum en général.

Nous étudierons le problème successivement en France et à l'étranger. 
$I^{\circ}$ Les conditions du travail dans les adjudications de travaux publics en France (I).

Il faut, pour la France, examiner successivement les différents points suivants :

A) Le salaire ordinairement prévu dans les adjudications de travaux publics est le salaire courant et non un salaire minimum à proprement parler.

$B)$ Comment a été appliquée cette clause de salaire courant?

C) Quelles sont les réformes à l'ordre du jour (2)?

(1) Bibliographie : Baudin. Rapport du 3 mars i 899.J. O. Ch. Doc.parlem., 1899. Office du travail. Note sur le minimum de salaire dans les travaux publics, 1896 . Ministère du travail, Conseil supérieur du travail, session de 1903 : les décrets du ro aoùt 1899 sur les adjudications. Marbaret du Basty : Les conditions du travail dans les contrats de travaux publics, thèse, Paris, 1907 .

(2) Il est superflu de faire remarquer ici que nous n'étudions pas la question dans son ensemble, mais seulement dans la mesure où elle touche notre problème du minimum de salaire. 


\section{A) Salaire minimudi - Salatre couraxt}

L'introduction d'une clause relative au salaire dans les cahiers des charges des adjudications de travaux publics peut se présenter sous deux aspects bien différents :

Ou bien l'on stipule que le salaire payé sera conforme aux salaires courants de la profession ou le la région: c'est l'introduction du salaire courant;

Ou bien l'on décide que ce salaire sera suffisant pour faire subsister le travailleur, sera en rapport avec le taux des subsistances : c'est le salaire minimum.

La France en est aujourd'hui au premier système, mais le second a failli triompher. C'est ce qu'il importe de rappeler brièvement.

La question a traversé deux phases successives, que l'on pourrait, pour simplifier, appeler la phase municipale (des origines à r 894) et la phase législative (de r 899 à nos jours). 
Phase municipale. - La question a en effet d'abord été posée derant le Conseil municipal de Paris et devant certains conseils municipaux de villes de province ( $\mathrm{I}$ ).

Très anciennement (2), l'habitude des séries de prix était une pratique courante de l'Administration parisienne : ces séries, comportant le prix des matériaux, des ouvrages, de la main-d'œuvre avaient pour rôle de renseigner l'Administration sur les dépenses probables des travaux. Depuis I835, ces séries de prix sont établies par une commission permanente spéciale (3). La manière dont elles furent établies et la composition de cette commission ont d'ailleurs varié au cours du Xix ${ }^{\mathrm{e}}$ siècle. Les revisions successives qui en furent faites, notamment en 1872 et 1878 , montrent une tendance certaine, une évolution frappante pour passer de la constatation des salaires payés et actuellement en vigueur à l'enregistrement des salaires convenus. Des difficultés nombreuses existaient de ce chef entre l'Administration et les entrepreneurs.

La question fut enfin portée, en 1887 , devant le Conseil municipal.

Celui-ci prit, le 2 I avril 1887 , la délibération suivante, qui était la consécration du salaire minimum :

"Article premier. - Les prix de la série officielle, en ce qui concerne les salaires, seront strictement appliqués aux travaux de la Ville de Paris.

Art. 2. - La série officielle de la Ville de Paris sera revisée annuellement, de façon que les prix des salaires soient toujours en rapport avec le taux des subsistances et les conditions générales de l'existence des travailleurs (4). ")

(1) Cf. Mazoyer. Les conditions du travail dans les chantiers de la Ville de Paris, thèse, Paris, 1899 .

(2) On retrouve des précédents jusqu'au xviri siècle au moins.

(3) En 1838, un employé, M. Maurel, eut l'idée d'en entreprendre l'impression et la publication.

(4) G. Lambeau. Monographies municipales de la ville de Paris. Conditions du travail dans les chantiers communaux. Imp. municipale, Paris, 1896 , p. 1052. Ces délibérations et les rapports qui les précèdent sont formels en faveur du minimum de salaire; témoin ce passage du rapport précédant une délibération du 3ı juillet 1886 :

"L'ouvrier vit au jour le jour, il n'a pas de crédit; il se trouve en face d'un patron qui a du capital, du crédit et qui impose ses conditions. Il faut done protéger le prenier contre la toute-puissance du second. Pourquoi, en Angleterre, le pouvoir public n'intervient-il pas dans ces 
Comme le disait nettement M. Vaillant dans la longue et intéressante discussion qui précéda l'adoption de cette proposition, c'était une orientation très nette vers le minimum de salaire : "Ces prix de série ont été un essai de détermination du salaire minimum. "

Mais, au nom de l'Administration, M. Alphand, directeur des travaux, s'était opposé au rote de ces deux articles; le préfet de la Seine refusa d'approuver la délibération.

Le ministre de l'intérieur d'alors, M. Fallières, écrivait au préfet de la Seine, M. Poubelle, la lettre suivante, le 27 juillet 1887 :

"Cette délibération ne m’a pas paru susceptible d'exécution, et vous devrez vous abstenir de l'approuver. Le principe de l'adjudication publique est la règle pour toutes les entreprises de travaux et de fournitures au nom de la Ville (ordonnance du I4 novembre 1837 ). La Ville a intérêt à obtenir le rabais le plus considérable; or rien ne serait plus contraire à cet intérèt et au principe porté par l'ordonnance que de fixer un prix invariable pour le salaire des olluriers.

D'un autre côté, comment appliquer la délibération du Conseil municipal aux adjudications en cours sans introduire dans ces marchés un élément variable qui détruirait le principe mème de l'adjudication? L'application de cette disposition présenterait, en outre, des difficultés inextricables.

Enfin les Chambres syndicales du bâtiment ont fait, a vec juste raison, remarquer qu'astreindre les entrepreneurs à payer un prix de journée uniforme pour tous les ouvriers serait les obliger à ne point occuper les ouvriers les plus faibles et qui ne pourraient produire qu'un travail hors de proportion avec le prix fixé.

Cette condition serait contraire à la loi de la liberté du travail et de l'industrie.

questions? C'est qu'il y a dans ce pays une organisation ouvrière égale en puissance à l'organisation des patrons, celle des Trade-Lnions. Cette force, qui contrehalance la force du capital, n'existe pas en France. Voilà la signification de l'intervention de la Ville de Paris dans les travaux de la Ville, de l'État dans les travaux de l'État. La Ville et l'État représentent cette force compensatrice qui fait défaut aux ouvriers dans leur lutte contre les patrons. " 
Par ces motifs, Monsieur le Préfet, le Gouvernement a décidé que la délibération du Conseil municipal resterait sans suite. Il ne m'a pas paru nécessaire de l'annuler, puisqu'elle ne peut, par elle-mème, produire aucun effet. ')

Cependant le Conseil municipal de Paris ne veut pas céder; il revient à plusieurs reprises sur sa délibération du 27 avril I 887 (I) pour en assurer l'exécution :

Ainsi deux délibérations du ı juillet 1887 (2) à propos des travaux de l'Exposition universelle et pour la création d'inspecteurs du travail.

Une autre du 27 juillet $\mathrm{r} 887$ invitant l'Administration à introduire les conditions du travail dans les cahiers des charges $(3)$.

Deux autres du i n novembre i 887 et du 3o décembre i 887 au sujet de l'adjulication des travaux de peinture de la Sorbonne et au sujet de la construction projetée de l'école du Livre (4).

Enfin une autre délibération du 30 décembre 1887 relative à la création de cinf inspecteurs ouvriers.

Le Gouvernement porta ces différentes délibérations devant le Conseil d'État (5). Sur avis défavorable de celuici intervint un décret du I 7 mars 1888 annulant les trois délibérations prises par le Conseil, relatives aux conditions du travail (6). Voici les plus intéressants des considérants de ce décret :

$I^{0}$ En ce qui concerne la délibération du 27 avril 1887 :

"Considérant que par cette délibération le Conseil municipal de Paris a imposé aux adjudicataires des travaux de la Ville l'obligation de payer à leurs ouvriers, pour une journée de travail réduite à neuf heures, un salaire uniforme fixé par "la série officielle des travaux de Paris";

(1) Lambeau, op. cit., p. 1085.

(2) Lambeau, op. cit., p. 1066.

(3) Lambeau, ibid., p. 1076.

(4) Lambeau, ibid., pp. I100 et I11 .

(5) Provisoirement et en attendant la décision du Conseil d'État, le Conseil municipal, par délibération du 29 février 1888 , avait décidé que les travaux de la Ville de Paris seraient exécutés en régie, conformément aux conditions mentionnées dans les délibérations soumises à l'appréciation du Conseil d'État. Cette délibération fut ultérieurement annulée par le décret du 17 mars 1888.

(6) Lambeau, op. cit., p. 1176 . 
que le taux de ce salaire est déterminé sans que l'entrepreneur et les ouvriers puissent tenir compte ni de l'état du marché, ni du mérite professionnel des travailleurs;

Considérant que s'il appartient au Conseil municipal de régler, dans l'intérèt de la Ville, les conditions des adjudications, il ne peut, sans sortir de ses attributions et sans porter atteinte à la liberté du travail, substituer une réglementation des prix à l'effet légal des revendications entre patrons et ouvriers;

Considérant, en outre, que la délibération du 27 avril I 887 , après avoir posé le principe d'une revision annuelle du taux des salaires, décide que le résultat de cette revision sera applicable aux travaux entrepris depuis plusieurs années;

Considérant que par cette disposition le Conseil municipal de Paris, au mépris du priacipe de l'irrévocabilité des conventions, s'est attribué le droit de modifier les marchés en cours d'exécution; qu'il altère l'essence mème du contrat d'adjudication, puisque l'entrepreneur, lié définitivement envers la Ville, peut, chaque annće, se voir imposer des charges nouvelles et plus rigoureuses;

Considérant, d'autre part, que l'ordonnance réglementaire du 14 novembre 1837 oblige toute commune à donner avec concurrence et publicité les entreprises pour travaux et fournitures; qu'aucun Conseil municipal ne saurait se soustraire ni directement ni indirectement à cette prescription édictée dans l'intérèt des finances communales ;

Considérant ciue les clauses ci-dessus rappelées de la délibération du 27 avril i 887 ont pour effet de dénaturer le contrat d'adjudication et de restreindre la concurrence; qu'elles sont de nature à éloigner les soumissionnaires ou tout au moins à rendre les rabais illusoires; que le Conseil municipal, en prétendant soumettre les travaux de la Ville de Paris à un régime spécial aussi contraire à la loi qu'à l'intérêt des finances municipales, est sorti de ses attributions et que, par suite, la délibération susvisée tombe sous l'application de l'article 14 de la loi du 14 avril I87 I. ")

Au total liberté du travail et concurrence dénaturée, tels sont les deux arguments essentiels du Conseil d'Etat et du décret d'annulation.

Le préfet de la Seine donna lecture de ce décret au Conseil 
municipal de Paris dans sa séance du 19 mars 1888 . Le Conseil n'accepta pas les motifs du décret ; les conseillers municipaux refusèrent d'assister aux adjudications, qu'il fallut ajourner. Un rapport de M. Sauton répondait point par point au décret d'annulation, et sur la proposition de celuici, le Conseil municipal prit, le 3 I mars I888, une nouvelle délibération ainsi conçue : "La délibération en date du 29 arril 1887 est reprise... (I).»

sur ces entrefaites, le conflit parut un moment se calmer. Le ministère avait changé. Le nouveau ministre de l'intérieur, M. Floquet, ancien préfet de la Seine, ancien conseiller municipal et ancien député de Paris, paraissait plus favorable que son prédécesseur aux desiderata du Conseil municipal de Paris (2).

Des pourparlers engagés entre le Gouvernement et le Conseil aboutirent à une entente, que consacra le Conseil municipal par une délibération du 2 mai 1888 (3). Le Conseil cédait sur quelques modifications secondaires : en ce qui concerne le salaire, au lieu d'un salaire uniforme obligatoire et identique, on acceptait les salaires réglés d'après la série de prix de i88ı. Le principe du salaire minimum était cepen lant maintenu.

Cette nouvelle délibération fut approuvée par le préfet de la Seine, après avis du ministre de l'Intérieur. Des adjudications importantes eurent lieu en juillet I888, avec des rabais aussi considérables que par le passé.

Cependant, trois entrepreneurs (4) écartés des adjudications parce qu'ils n'avaient pas accepté l'article relatif aux conditions du travail, et ayant accordé des rabais plus considérables que les adjudicataires attaquèrent les opérations d'adjudication et les arrètés préfectoraux les approuvant devant le Conseil d'État (5). Ils étaient appuyés par les

(1) Lambeau, op. cit., p. 11g6.

(2) En mème temps, des considérations politiques intervinrent : on craignait de jeter, par des mesures maladroites, le Conseil municipal du còté du parti boulangiste. (Lavy. Rapport à la Ch. des Députés, 18 mars 1898.) Doc. parlem., 1898, n० 3113, p. 809 .

(3) Lambeau, op. cit., p. 1279. - Cf. le rapport Sauton précédant cette délibération (Ibid., p. 1243).

(4) Mu. Caillette, Bourgaux et Cochelin.

(5) Tandis que l'affaire était ainsi pendante devant le Conseil d'État, le Parlement s'occupa de la question : la loi du 3 décembre 1888 , autori- 
Chambres syndicales d'entrepreneurs. Le Conseil d'État rendit sa décision le 2I mars 1890 : deux arrêts étaient ren$\operatorname{dus}(\mathrm{I})$ :

Le premier concernait la demande en annulation de la délibération du Conseil municipal et des adjudications de juillet r9o8, formée par les Chambres syndicales des entrepreneurs de la ville de Paris, et par onze entrepreneurs en leur nom personnel qui n'avaient pas soumissionné dans les adjudications visées. Cette demande était décla rée irrecevable, au nom des principes du contentieux administratif : "Ces actes considérés en eux-mèmes et en dehors de toute adjudication à laquelle les requérants auraient personnellement concouru ne sont pas susceptibles d'ètre déférés au Conseil d'État par la voie du recours pour excès de pouroir. ")

Le second arrèt, visant la demande en annulation des mèmes actes intentée par les trois entrepreneurs écartés de l’adjudication, les léclarait recevables en leur demande et au fond annulait les adjudications de juillet r 888 et les arrêtés qui avaient approuvé ces adjudications :

"Considérant qu'il résulte de l'instruction et qu'il n'est pas contesté que, pour prononcer l'éviction du sieur Caillette, le bureau d'adjudication s'est uniquement fondé sur les réserves formulées par cet entrepreneur contre les dispositions de l'article 15 du cahier des charges, d'après lesquelles l'adjudicataire était tenu de payer ì ses ouvriers un salaire minimum déterminé par la Ville de Paris pour une journée de travail dont elle avait également fixé la durée ;

" Considérant que ces clauses ont été introduites dans le cahier des charges en vertu d'une délibération du Conseil municipal du 2 mai 1888 , qui reproduisait sur ce point les

sant l'imputation d'une somme de 29 millions sur les fonds d'un emprunt de 1886 , contenait un article ainsi conçu : Les cahiers des charges et séries de prix dressés pour l'exécution des travaux faits avec les fonds dudit emprunt ne pourront contenir aucune clause contraire aux dispositions du déeret du 17 mars 1888 , portant annulation des délibérations du Conseil municipal de Paris, en date des 27 avril, 3o décembre 1887 et 29 février 1888 , relatives aux travaux communaux. Toute clause de ce genre sera réputée non écrite.

(1) Rec. des arrêts alu Conseil d'Etat, 189o, p. 316; D. 189I. III. 8r; S. 1892 . III. 87 . 
délibérations dudit Conseil des 27 avril, 30 décembre 1887 et 29 février suivant, lesquelles ont été annulées par décret du 17 mars 1888 , comme portant atteinte à la liberté du travail et des conventions entre patrons et ouvriers, et comme excédant les attributions légales du Conseil municipal ;

"Considérant, au surplus, que l'illégalité desdites clauses a été légalement reconnue par le pouvoir législatif; qu'en effet, l'article 2 de la loi du 3 décembre 1888 , relative aux travaux à exécuter par la Ville de Paris sur les fonds de l'emprunt de 1886 , dispose que les cahiers des charges et séries de prix, dressés pour l'exécution des travaux " ne " peuvent contenir aucune clause contraire aux disposi" tions du décret du I 7 mars I888, portant annulation des " délibérations du Conseil municipal de Paris, en date des " 27 avril, 3 o décembre 1887,29 février I 888, relatives aux " travaux communaux : toute clause de ce genre sera répu" tée non écrite; "

"Considérant que les clauses contre lesquelles le sieur Caillette a formulé ses réserves figuraient parmi celles que le décret et la loi ci-dessus visés ont déclaré nulles et de nul effet, à raison de l'excès de pouvoir dont elles étaient entachées, et que le requérant est fondé à soutenir que leur insertion dans le cahier des charges de l'adjudication dont s'agit ne pouvait leur confẹ́rer un caractère licite et obligatoire à l 'égard des entrepreneurs admis à soumissionner les travaux de la Ville; qu'il suit de là que le refus du sieur Caillette de se soumettre auxdites clauses ne pouvait pas légalement motiver son éviction au profit d'un concurrent, dont le rabais était inférieur au sien; qu'ainsi le sieur Caillette est fondé à soutenir que le préfet de la Seine a excédé ses pouvoirs en approuvant une adjudication dont il avait été écarté par cette unique raison. »

En somme, le Conseil d'État maintint purement et simplement sa jurisprudence antérieure : les arrètés préfectoraux approuvant les adjudications sont annulés comme les délibérations du Conseil municipal, et pour les mêmes motifs.

- Pour la seconde fois, le Conseil municipal de Paris ne céda pas sur les questions des conditions du travail et, par 
conséquent, du minimum de salaire. Il prend deux nouvelles délibérations dans le mème sens :

La première, en date du $\mathrm{I} 3$ juin $\mathrm{s} 89 \mathrm{o}$, sur un rapport de M. Navarre (I), maintenait la délibération précédente du 2 mai 1888.

La seconde, en date du 28 décembre i 890 , sur un rapport de M. Vaillant (2) décidait que les adjudications à venir pour les travaux d'entretien des édifices communaux du I ${ }^{\text {er }}$ avril I89 I au 3i mars I894 contiendraient les mêmes clauses relatives aux conditions du travail.

Naturellement, et comme il fallait s'y attendre, ces deux délibérations furent annulées par décret : la première, par un décret en date du 16 juillet I 890 (3), la seconde, par un autre décret du 23 janvier I 89 r.

Cette fois, ce fut le Conseil municipal qui prit l'initiative de poiter l'affaire devant le Conseil d'État.

Sur la proposition de N.Vaillant, le 9 mars i 89 r, le Conseil municipal maintenait sa délibération du 28 décembre $\mathbf{1} 890$ et invitait le préfet de la Seine à se pourvoir devant le Conseil d'État contre l'annulation par décret en date du 23 janvier i 89 I de ladite délibération (4).

Un nouveau décret du I $^{\text {er }}$ arril I 89 I vint annuler cette nouvelle délibération du 9 mars I89 I (5). Le Conseil d'État refusa d'admettre le pourvoi de la Ville contre le décret d'annulation par un troisième arrèt en date du 25 janvier $1895(6)$.

Cette fois, le Conseil municipal de Paris s'avoua vaincu. Il n'eut plus qu'une ressource, en appeler au Parlement, pour faire triompher sa politique. C'est ce qu'il fit en adoptant la délibération suivante, le 25 mars 1895 :

"Le Conseil maintient intégralement les termes de la délibération du 2 mai i 888 et invite le Bureau à se mettre en rapport avec les représentants de Paris et la Commission du travail de la Chambre des députés pour faire accepter par le Parlement, dans leur intégralité, les clauses et con-

(1) Lambeau, op. cit., p. I63r.

(2) Lambeau, op. cit., p. Ifg9g.

(3) Revue générale d'administration, i 890 , t. III, p. 79.

(4) Id., 1891, t. I, p. 338, et aussi Lambeau, op. cit., p. I70r.

(5) Lambeau, p. 1740.

(6) Revue d'administration, 1895, I, 426 ; D. 1896 . III. II. 
ditions du travail votées par le Conseil municipal, en vue de l'exécution des travaux sur les chantiers communaux de la Ville de Paris (1). ")

En province, un mouvement tout à fait analogue avait. rencontré les mèmes résistances.

Diverses municipalités, Limoges en $\mathrm{I} 89 \mathrm{I}$, Toulon en I 89 I (2), Roubaix en I894, Albi en I894, Toulouse en I896, avaient introduit des clauses du minimum de salaire, les préfets annulaient ces délibérations.

D'autres (3), comme Paris, exprimaient le vœu que la réforme fùt opérée par voie législative.

Près de huit ans de lutte acharnée, plus de quinze délibérations, trois arrêts du Conseil d'Etat, voilà certes beaucoup d'efforts et beaucoup de résistance à propos de cette clause du salaire minimum.

La bataille était perdue sur le terrain municipal. Elle allait l'être aussi sur le terrain législatif.

(I) Lambeau, op. cit., p. 193 r.

(2) Cf., pour les détails, rapport Lavy, Ch., Doc. parlem., 1898, n 3113, pp. 820 et suiv.

(3) Notamment la municipalité de Dun-sur-Auron (Cher). Ibid. 
Phase législative. - On a déjà vu que le Parlement avait, par la loi du 3 décembre i888, d'une manière restreinte (I), il est vrai, tranché la question dans un sens opposé aux prétentions du Conseil municipal de Paris.

Le vote de cette loi marque dans ses détails une première défaite des partisans du salaire minimum. Le projet ne contenait aucune disposition relative aux conditions du travail. Un amendement de M. Bozérian, au Sénat (2), proposait de mettre fin aux difficultés existantes entre le Gouvernement et le Conseil municipal par l'introduction d'un article additionnel ainsi conçu :

"Les cahiers des charges et séries de prix dressées pour l'exécution des travaux faits avec les fonds dudit emprunt ne pourront contenir aucune clause contraire aux dispositions du décret du 17 mars 1888 portant annulation des délibérations du Conseil municipal de Paris, en date des 27 avril, 3o décembre 1886 et 29 février I888, relatives aux travaux communaux. Toute clause de ce genre sera réputée non écrite. ")

En séance, le 16 octobre 1888 , l'auteur de cet amendement déreloppa les raisons déjà expliquées dans son rapport, la nécessité de mettre un terme au conflit existant. En vain M. Bourgeois, sous-secrétaire d'État à l'Intérieur, lui répondit en montrant que la nouvelle délibération du Conseil municipal en date du 2 mai r 888 différait de celles annulées par le décret du I 7 mars I888, que le Gouvernement trouvait acceptables les nouvelles clauses relatives aux conditions du travail. Malgré ses efforts, l'amendement fut voté et devint l'article 2 de la loi.

A la Chambre, des efforts analogues furent tentés par le rapporteur, M. Camille Dreyfus (3). Malgré le rapporteur, le projet fut adopté le 26 novembre i 888 sans discussion, non pas tel que le présentait le rapporteur, c'est-à dire sans l'article en question, mais avec cet article repris à titre d'amendement par deux députés (4).

(1) La loi en question concernait exclusivement les adjudications faites pour les travaux à exécuter sur les 30 millions de francs de l'emprunt de 1886 .

(2) Sénat, Doc. parlem., I888, p. 379, n 441.

(3) Rapport, Ch., Doc. parlem., I888, no 3188, p. 530.

(4) Ch., Déb. parlem., 1808, p. 2649 . 
Ce n'était là qu'une loi de portée restreinte : malgré ce précédent, il restait à statuer sur la question dans son ensemble.

A la suite de la délibération du Conseil municipal de Paris, M. Vaillant et 48 de ses collègues déposèrent sur le bureau de la Chambre une proposition ayant pour but d'autoriser la Ville de Paris à insérer dans les cahiers des charges de ses travaux neufs ou d'entretien les conditions du travail telles qu'elles avaient été définies dans la délibération du 2 mai $\mathbf{r} 888$ ( $\mathrm{I}$ ).

Cette proposition, renvoyée à la Commission du travail, fut l'objet d'un rapport de M. Aimé Lavy, le ıo mars I898 (2).

Celui-ci repoussait la clause relative au salaire minimum pour les travaux de l'Etat, mais admettait pour les départements et les communes la faculté d'insérer "les clauses relatives à la fixation du salaire, à la détermination de la durée de la journée de travail, et toutes autres clauses qui seraient de nature à assurer à la fois la bonne exécution des travaux et des conditions de payement des salaires, d'organisation du travail, d'hygiène et de sécurité en faveur des travailleurs ").

La législature se termina sans que la question fùt discutée. Sous la législature suivante (mai ı898), M. Vaillant reprit sa proposition. En mème temps, une nouvelle proposition de M. Dansette (3), autorisant l'État, les départements, les communes et les établissements publics à insérer dans les cahiers des charges diverses clauses relatives aux conditions du travail, notamment l'obligation pour les entrepreneurs de payer aux ouvriers un salaire égal au salaire normal des ouvriers de la même catégorie dans la localité ou la région. C'était la clause du salaire courant qui devait finalement triompher.

Il y a bien encore une proposition Holtz (4) qui ouvrait la porte au salaire minimum.

Mais toutes ces propositions furent renvoyées à la Commission du travail, et celle-ci, par l'organe de son rappor-

(I) Ch., Doc. parlem., I894, no 741, p. 1055.

(2) Ch., Doc. parlem., i898, n ${ }^{\circ} 3$ i 3, p. 809 .

(3) Ch., Doc. parlem., I898, no 116 , p. 1279.

(4) Ch., Doc. parlem., 1898, n० 301, p. 114. 
teur, M. Baudin, acceptait la clause du salaire courant, en excluant toute idée de salaire minimum (I):

Article $\mathrm{I}^{\mathrm{er}}$. - Dans les travaux exécutés pour le compte de l'État, l'entrepreneur ou le fabricant qui a obtenu un marché, soit de gré à gré, soit par adjudication, sera tenu par les clauses du contrat d'observer les conditions suivantes:

$3^{\circ}$ Payer aux ouvriers un salaire normal égal pour chaque catégorie au taux couramment appliqué dans la ville ou la région où le travail est exécuté, et s'il s'agit de travail à la journée, pour la durée normale de la journée en usage dans ladite ville ou région (2).

La discussion s'ouvrit devant la Chambre le 4 mai i 899 (3). M. Aynard, en ouvrant le débat, eut bien soin de constater que le salaire minimum n'était pas en question : "Encore une fois, le minimum de salaire étant unanimement écarté, je considère qu'il est inutile de le discuter et de défendre, au point de vue de la doctrine, les idées libérales qui s'y opposent. Si la question du minimum de salaire était posée devant la Chambre, ce serait le socialisme en action qui se dresserait devant vous, et nous sommes résolus à le discuter en lui-mème et à le combattre (4) ". Les orateurs acceptèrent, soit du còté des partisans, soit du côté des adversaires de la loi, le nouveau terrain.

En vain, à la séance du lendemain, 5 mai, M. Vaillant (5) reprit énergiquement sa proposition en demandant d'ajouter au projet de la Commission une clause relative au minimum de salaire: M. Vaillant invoquait en sa faveur l'expérience anglaise, posait dans toute son ampleur la question du salaire minimum.

" Ce salaire minimum est, je le répète, dans les travaux publics où il est appliqué, une indication qu'on ne peut pas accepter que des ouvriers travaillent à un niveau de salaire et à un niveau de dépenses de forces par des journées trop

(1) Ch., Doc. parlem., $1899, \mathrm{n}^{\circ} 776$, p. 839 .

(2) En même temps, la même formule triomphait au Conseil supérieur du travail (Décenbre 1897). Gf. compte rendu, Rapport keüfer, p. I17.

(3) Ch., Déb. parlem., 1899, p. 1286.

(4) Itid.

(5) Ch., Déb. parlem., 1899, p. 1305. 
prolongées qui compromettent leur existence, leur santé et leur force; qu'on ne veut pas, d'autre part, cette injure aux devoirs de l'Etat, et de l'autre côté un moyen d'oppression de la vie ouvrière, de diminution de ses conditions d'existence (I). )

Il le justifiait par une théorie assez confuse d'ailleurs, tirée des doctrines marxistes et insistait sur la nécessité pour l'État patron de donner l'exemple: le salaire minimum sera d'autant plus facile à instituer qu'il fonctionnera par région.

Dans une conclusion chaleureuse, M. Vaillant demande à la Chambre "cet acte de justice et de républicanisme ».

Après ce discours, la discussion de la proposition de loi fut renvoyée à une date ultérieure.

Par suite d'un changement de ministère (2), le rapporteur de la proposition de loi, M. Baudin, était ministre des travaux publics dans le nouveau cabinet. Le gouvernement prit l'initiative de régler la question par décret.

Dans une question posée au ministre du commerce et de l'industrie, M. Millerand, en la séance du 4 juillet 1899 (3), M. Beauregard, tout en contestant la légalité des décrets attendus, posait au ministre les deux questions suivantes : "Le ministre a-t-il l'intention d'introduire, dans les décrets qu'il compte prendre, le minimum de salaire et la limitation de la journée de travail? - Entendi-il, dans ces décrets, viser les travaux de l'État, mais ceux aussi des départements et des communes? "

M. Millerand reprocha à M. Beauregard de confondre le minimum de salaire et le salaire courant et normal, en affirmant que c'était seulement ce dernier qu'il s'agissait d'insérer dans les décrets.

Ceux-ci parurent, en date du ro août ı899, dans le sens indiqué.

La clause relative au salaire est identique dans les trois

(1) Ibid., p. 1308 .

(2) Le ministère Ch. Dupuy était renversé le 12 juin et M. WaldeckRousseau lui succédait au pouvoir.

(3) Ch., Déb. parlem., 1899, p. 1812. 
décrets (I). Elle est seulement obligatoire dans le premier, facultative dans les deux autres.

Article ${ }^{\mathrm{er}}{ }^{\mathrm{r}}$. - Les cahiers des marchés de travaux publics ou de fournitures passés au nom de l'État, par adjudication ou de gré à gré devront (pourront pour ceux passés au nom du département, des communes, établissements publics) contenir les conditions suivantes en ce qui concerne la main-d'œuvre de ces travaux ou fournitures, dans les chantiers ou ateliers organisés ou fonctionnant en vue de l'exécution du marché :

$3^{\circ}$ Payer aux ouvriers un saluire normal égal pour chaque profession et dans chaque profession pour chaque catégorie d'ouvriers, au taux couramment appliqué dans la ville ou région où le travail est exécuté.

C'était le triomphe définitif du salaire courant ou normal : le salaire minimum n’avait pas triomphé!

(1) On sait que le premier de ces décrets concerne les conditions du travail dans les marchés des travaux publics passés au nom de l'État; le second dans les marchés passés au nom des départements; le troisième dans les marchés passés au nom des communes et établissements publics. 
B) L'APplication de la Glause du salaire yormal OU GOURANT

Ainsi, une fois la réforme réalisée, le seul salaire assuré dans les adjudications des travaux publics était le salaire courant ou normal ( $\mathrm{I}$ ), et non le salaire minimum.

Celui-là est d'ailleurs nettement défini dans la circulaire ministérielle du 30 septembre 1899 , relative à l'application des décrets du io août :

"Le salaire normal que l'entrepreneur est tenu de payer aux ouvriers employés sur les chantiers ou dans les ateliers de l'entreprise est le salaire courant, le salaire habituel de la ville et de la région, celui que les ouvriers du même corps de métier et de la même catégorie ont coutume de recevoir sur les chantiers ou dans les ateliers de la localité ou des localités voisines. "

Quant au mode de constatation de ce salaire courant, il est expressément prévu par le texte de l'article 3 des décrets du ıo août I 899 qui dispose :

( La constatation et la vérification du taux normal ou courant du salaire (et de la durée normale et courante de la journée de travail) sera faite sous le contrôle du préfet par l'administration intéressée, qui devra :

I $^{0}$ Se référer, autant que possible, aux accords existant entre les syndicats patronaux et ouvriers de la localité ou de la région;

$2^{\circ} \mathrm{A}$ défaut de cette entente, provoquer l'avis de commissions mixtes composées en nombre égal de patrons et d'ouvriers, et en outre se munir de tous renseignements utiles auprès des syndicats professionnels, conseils de prud'hommes, ingénieurs, architectes départementaux et communaux et autres personnes compétentes.

Les bordereaux résultant de cette constatation devront être joints à chaque cahier des charges (2).

(I) Ces deux mots sont pris ici comme synonymes, avec cette nuance que par salaire normal on a voulu maintenir l'idée " qu'il s'agit d'un cours de salaires établi en dehors de l'influence des éléments perturbateurs résultant du système des adjudications et de l'importance des travaux publics ». (Cf. Marbaret du Basty, thèse citée, p. I3o.)

(2) Le premier décret relatif aux marchés passés au nom de l'État ajoute : "Sauf dans les cas d'impossibilité matérielle ». On a voulu ainsi 
Ils seront affichés dans les chantiers ou ateliers où les travaux seront exécutés (I). ")

Ainsi la constatation du salaire normal est faite par les soins de l'administration intéressée. Celle-ci prend pour base les accords syndicaux, s'il en existe, ou, à défaut, prend l'avis des commissions mixtes composées en nombre égal de patrons et d'ouvriers; au surplus, elle s'informe auprès de toutes les compétences.

Enfin la revision de ces salaires reste possible (2).

La double sanction de ces prescriptions est, on le sait, d'une part le droit pour l'administration de retenir le complément de salaire sur les sommes dues à l'entrepreneur ou sur son cautionnement (art. 4 des décrets).

Et d'autre part, l'exclusion temporaire ou définitive des marchés contre l'entrepreneur à la charge duquel des infractions réitérées aux conditions du travail auraient été relevées (art. 5 des décrets).

Tel est dans ses grandes lignes le mécanisme de notre clause. Comment a-t-elle été appliquée?

Pour suivre l'application de la clause relative aux salaires, il y a lieu de distinguer :

$I^{0}$ Les travaux de l'État;

$2^{\circ}$ Les travaux des départements;

$3^{\circ}$ Les travaux des communes et établissements publics. $I^{0}$ Application dans les travaux de l'État. - Une publication déjà ancienne de l'Office du travail (3), datant

réserver les cas d'adjudications urgentes et les cas d'incertitude sur la région des travaux. En ce cas, et malgré quelques contestations, l'entrepreneur n'est pas dégagé de l'obligation de payer le salaire courant. C'est lả d'ailleurs, nous le verrons plus loin, une porte ouverte à l'inexécution des décrets.

(1) Une circulaire ministérielle du 14 novembre 1899 invitait les préfets à former cette commission administrative peu nombreuse, composée de personnes compétentes, indépendantes et désintéressées.

(2) L'article 3 dispose en effet : "Ils (les bordereaux) peuvent être revisés sur la demande des patrons et des ouvriers, lorsque des variations dans le taux des salaires ou la durée du travail auront reçu une application générale dans l'industrie en cause.

Cette revision sera faite dans les conditions indiquées sous les $n^{0 s} \mathrm{I}^{\circ}$ et $2^{\circ}$ du présent article. Une revision correspondante des prix du marché pourra être réclamée par l'entrepreneur ou elfectuée d'office par l'administration quand les variations ainsi constatées dans le taux des salaires ou la durée du travail journalier dépasseront les limites déterminées par le cahier des charges."

(3) Office du travail. Bordereaux: des salaires pour diverses catégo- 
de igo2, donnait déjà un premier aperçu de l'application de notre clause dans les travaux de l'État.

Plus récemment (I) le Ministère du Travail a publié les bordereaux des salaires normaux et courants dressés en r 906 (2) par profession. Il résulte de l'examen de ces bordereaux que dans beaucoup de professions les bordereaux établissent des salaires courants qui sont de véritables minima de salaires; en voici quelques exemples :

Ajusteurs ordinaires, 5 à 6 francs (3); ajusteurs-mécaniciens, 6 à 8 francs; briquetiers, 4 fr. 50 à 5 fr. 50 ; carriers, 3 fr. 50 ; charbonniers, 5 francs; charretiers, 3 fr. 50 à 6 francs; charrons, 4 francs environ; mécaniciens, 5 et 6 francs, etc.

Par contre, tous les salaires relevés sont loin d'ètre aussi favorables et l'on rencontre variables, selon les professions et les métiers, des taux de salaires de 3 francs et au-dessous, surtout pour les femmes et les enfants.

Le document cité (4) se refuse à faire la comparaison entre les bordereaux de salaires de r9o6 et ceux de r9oo. " Encore cette comparaison, à si peu de distance, offriraitelle quelque incertitude. D'abord les localités où les travaux de 1906 ont été exécutés ne sont souvent pas les mêmes que celles de igoo et les salaires varient très sensiblement d'une localité à l'autre de la mème région. D'autre part, l'influence des conditions particulières à chaque travail empêche qu'à un si court intervalle de temps les variations des salaires portés sur les bordereaux puissent ètre imputées sûrement à un changement du taux normal des salaires dans chaque profession. Enfin la multitude des localités et des travaux différents rend la comparaison assez laborieuse. ")

Il est probable cependant, d'après les comparaisons effec-

ries d'ouvriers en 1900 et I9oI, Paris, Imp. nationale, I902. On y retrouve une série de bordereaux de salaires établis en partie d'après les renseignements communiqués par les grandes administrations de l'État.

(1) Ministère du travail et de la prévoyance sociale. Statistique généfale de la France. Salaires et coùt de l'existence à diverses époques jusqu'en 1910, I vol. Paris, Impr. nationale, 1911, pp. 170-381.

(2) Cf. op. cit., p. 13.

(3) Cf. op. cit., p. ז70, etc.

(4) Op. cit., p. 19 . 
tuées à l'aide d'autres documents (I), qu'il y a eu en général, de 1900 à 1906 , une hausse dans le taux des salaires courants.

On ne peut donc être exactement renseigné sur l'application de notre clause en ce qui concerne les travaux de l'État à l'aide de ces documents.

On peut encore se faire une idée de l'application de notre clause dans les travaux de l'État d'après le rapport de la commission interministérielle chargée d'étudier l'ensemble des questions relatives aux adjudications des Travaux publics (2):

Il parait, d'après le résumé des observations présentées par les intéressés, que, d'une part, on ne trouve aucune réclamation en ce qui concerne la non-application dans les travaux de l'État et que, d'autre part, des plaintes ont été adressées constatant la tendance de l'Administration à appliquer les dispositions lu décret en dehors des cas prévus par ce décret, c'est-à-dire en dehors " des chantiers et ateliers organisés ou fonctionnant en vue de l'exécution du marché (3) ".

Dans ses conclusions générales (4), la Commission semble accepter que " l'augmentation des prix dans les adjudications soit due à la hausse des salaires et à l'abstention de certains entrepreneurs ou à leurs exigences motivées tant par la procédure suivie dans les adjudications que par les conditions excessives des marchés et aussi par les charges nouvelles résultant de la réglementation du travail ».

Autant donc qu'on peut se servir de ce document, l'application paraît le principe, la non-application l'exception (5).

(1) Cf. op. clt., p. 20.

(2) Rapport en date du $I$ juin 1909 . Ce rapport n'est pas facile à consulter : nous avons pu le faire gràce à la lienveillante communication du Ministère des Travaux publics. Cf. ci-dessous pour les circonstances oủ fut nommée la commission et son œuvre, p. 91 .

(3) Plainte de l'Union des industries métallurgiques et minières, rap. cité, p. 107 ; de la Chambre syndicale des fabricants et constructeurs de matériel de guerre. Ibid., p. 108.

(4) P. 132, rap. cité.

(5) Pareille impression résulte également de la lecture de la monographie récente de M. Jean Linet, commis des Ponts et Chaussées : Conditions du travail sur les chantiers des Ponts et Chaussées, thèse, Poitiers, 19ri, Masson, édit., pp. 75 et suiv. 
Celle-ci serait encore assez notable :

L'Administration des Beaux-Arts (bâtiments civils et palais nationaux) ne vise, dans ses cahiers des charges, pour l'application du décret du io aoùt, que les travaux exécutés dans les chantiers de l'État (I).

L'Administration des Postes et Télégraphes ne les vise que dans les cahiers des charges relatifs à la fourniture du matériel (2).

La Marine aussi n'en ferait pas une application très étendue (3).

La Commission proposait d'ailleurs d'unifier ces pratiques diverses et votait les résolutions suivantes (4):

( Les dispositions du décret du io aoùt i 899 devraient être inapplicables aux établissements qui exécutent des ouvrages ou fabriquent des produits d'un emploi courant, susceptibles d'ètre livrés indifféremment soit à l'État, soit à d'autres clients (5);

Applicables aux établissements qui travaillent exclusivement ou presque exclusivement pour l'État et aux établissements qui travaillent simultanément pour l'État et pour d'autres clients, si les commandes de l'État sont assez importantes pour qu'un personnel et un matériel spéciaux y soient affectés pendant une période de temps notable, auquel cas c'est à ce personnel spécial que les dispositions du décret doivent être appliquées (6). "

Il y a, malgré ce vœu, une tendance marquée à l'extension croissante de l'application des décrets.

A plusieurs reprises, et tout récemment, divers engagements formels ont été pris devant la Chambre par les ministres compétents pour l'application des conditions du travail dans les adjudications des travaux de l'État (7).

(I) Rapport cité, p. Iog.

(2) Ibid., p. 109.

(3) Instruction relative à l'application du décret du Io août 1899 , du 27 novembre 1899 . - Ibid., p. 109.

(4) Rapport eité, p. 144.

(5) En ce cas, ces établissements ne sont pas tenus d'affecter aux commandes de l'État des ateliers spéciaux.

(6) Pour les cas douteux, le ministre intéressé tranche la difficulté par des décisions d'espèce.

(7) Le Io février I911, par le Ministre des Travaux publics, pour les fournitures d'imprimerie des chemins de fer de l'État; le 16 février. 
Le Ministre du Travail se fait communiquer les bordereaux des salaires des travaux exécutés pour le compte de l'État (I).

$2^{\circ}$ Application dans les travaux des départements (2). Une enquète récente (3) menée par le Ministre du Travail donne les résultats suivants:

\section{I. - PORTÉE D'APPLICATION}

Il parait tout d'abord, en ce qui concerne le champ d'application des décrets, que cette application est loin d'être générale (4).

Dans 15 départements (Ardennes, Ariège, Aube, Cantal, Eure, Gard, Hérault, Landes, Lozère, Haute-Marne, Basses-Pyrénées, territoire de Belfort, Deux-Sèrres, Tarnet-Garonne, Vosges), la clause n'a pas été appliquée du tout.

Dans 20 autres (Ain, Aisne, Charente, Cher, Dordogne, Doubs, Haute-Garonne, Gironde, Ille-et-Vilaine, Isère, Haute-Loire, Maine-et-Loire, Maine, Meurthe-et-Moselle, Pas-de-Calais, Rhòne, Seine, Var, Vaucluse, Vienne), elle fonctionne pour tous les travaux dlépartementaux.

Dans les autres enfin, elle n'est appliquée que pour certaines catégories de travaux:

19ı1, par le Ministre de l'Instruction publique (Bulletin de l'offce du travail, I9I1, p. 290); le 7 mars Igr I, par le Ministre de la Marine (Bulletin de l'Offlce du travail, 1911, p. 412); le 28 juin 1912 par le Ninistre de la Guerre (Bull. Off. du travail, r912, p. 855).

(1) Ainsi que ceux pour le compte des départements, des communes et des établissements publics. Plus de 30.000 fiches ont été ainsi constituées. (Cf. Puech. Rapport sur le budget du Ministère du Travail pour 1911, Doc. parlem., Ch., p. 14.) On nous a personnellement affirmé au Ministère qu'on ne recevait pas de réclamations en ce qui concerne la non-application pour les travaux de l'État. La Marine, longtemps réfractaire, vient de s'y ranger.

(2) Le volume du Ministère du Travail : Salaires et cont de l'existence jusqu'en 1910, déjà cité, donne également divers bordereaux par profession, datant de igo6, se référant aux travaux des départements. Cf. l'application des décrets du io août i 899 , dans les marchés de travaux publics des départements, communes et des établissements publics de bienfaisance (Bulletin de l'offce du travail, igro, pp. 596 et 719 ).

(3) Par une circulaire du 12 juin 1909 , le Ministre du Travail avait demandé aux préfets des renseignements sur l'application des décrets ; l'enquête est l'analyse des rapports adressés au ministre en réponse à cette circulaire.

(4) On sait que la clause relative au salaire est seulement ici, pour les départements, facultative. 
Pour les travaux des bâtiments départementaux, dans I9 départements (I);

Pour les travaux de la voirie départementale, dans I 8 départements (2);

Pour les travaux de construction des chemins de fer et tramways départementaux, dans 9 départements (3);

Pour les fournitures d'imprimés départementaux, dans I I départements (4).

Le plus souvent, des délibérations du Conseil général ont été prises dans le sens de l'application; parfois, au contraire, le Conseil général a refusé formellement cette application; d'autres fois c'est sur l'invitation de l'Administration ou sur celle des syndicats ouvriers que l'application a été obtenue.

Au total, on peut dire que l'application de notre clause n'est que partielle.

\section{II. - MODE D'ÉTABLISSEMENT DES BORDEREAUX}

Quant au mode d'établissement des bordereaux de salaires, " il résulte des réponses fournies que, dans la plupart dés départements, le désir exprimé par la circulaire du I I novembre I 899 ne s'est pas réalisé et que les constatations du taux normal et croissant des salaires... ont été le plus souvent opérées directement par l'administration intéressée (5) ).

La constatation des salaires par application des accords syndicaux (2 départements), par des commissions mixtes composées de patrons et d'ouvriers (I 4 départements), est rare; les commissions administratives, dont la composition est d'ailleurs fort variable, n'ont fonctionné que dans

(r) Allier, Basses-Alpes, Hautes-Alpes, Bouches-du-Rhòne, Galvados, Charente-Inférieure, Côte-d'Or, Côtes-du-Nord, Drỏme, Finistère, LoireInférieure, Lot, Mayenne, Saòne-et-Loire, Haute-Savoie, Seine-et-Oise, Somme, Haute-Vienne, Yonne.

(2) Allier, Basses-Alpes, Alpes-Maritimes, Charente-Inférieure, Côted'Or, Eure-et-Loir, Gers, Loir-et-Gher, Lot, Lot-et-Garonne, Mayenne, Oise, Hautes-Pyrénées, Pyrénées-Orientales, Haute-Saône, Haute-Savoie, Seine-et-Marne, Haute-Vienne.

(3) Alpes-Maritimes, Còtes-du-Nord, Eure-et-Loir, Meuse, Oise, Pyrénées-Orientales, Haute-Saône.

(4) Ardèche, Eure-et-Loir, Gironde, Ille-et-Vilaine, Indre, Jura, Orne, Pyrénées-Orientales, Sarthe, Seine-et-Oise, Yonne.

(5) Bulletin de l'Offlce du travail, art. cité, 19ro, p. 719. 
24 départements; le plus souvent, c'est l'Administration elle-mème (i9 départements) qui établit directement les bordereaux.

Bref l'application de notre clause est loin d'ètre satisfaisante.

Il faut faire exception toutefois pour certains départements qu'il importe de signaler à ce point de vue :

Ce sont, d'une part, l'Indre, le Lot et la Seine-et-Narne, et d'autre part la Seine.

Dans la Seine, la Préfecture est arrivée, à l'aide de commissions administratives spéciales à différentes professions instituées dès le début et d'une commission administrative unique qui lui fut substituée en 1906 , à établir un bordereau général relatif aux salaires et afférent à toutes les professions qui participent aux adjudications des divers services départementaux et municipaux.

Le bordereau de I907 a été élaboré en tenant compte des constatations faites par des commissions mixtes de patrons et d'ouvriers. Depuis deux accords entre syndicats patronaux et ouvriers sont intervenus : l'un, du I 4 novembre 1907 , entre les délégués du Conseil de la Chambre syndicale des entrepreneurs de charpente de la ville de Paris et du département de la Seine et les délégués des organisations ouvrières des ouvriers charpentiers; l'autre entre la Chambre syndicale des entrepreneurs de fumisterie de la ville de Paris et du département de la Seine et Seine-etOise et la Chambre syndicale des ouvriers fumistes en bâtiment. De là les modifications de i 908 (arrètés du 10 janvier et du 4 février i908).

Le bordereau en vigueur à l'heure actuelle est celui approuvé par le préfet de la Seine, le 23 mai igro.

$\mathrm{Vu}$ son importance, en voici le texte intégral (I).

(1) Nous indiquons également la partie du bordereau relative à la durée de la journée de travail pour permettre de se rendre compte du montant global du salaire. 
DIRECTION ADMINISTRATIVE

DES

SERVICES D'ARCHITECTURE

ET DES

PROMENADES \& PLARTATIONS

Bureau Administratif d'Architecture

\section{RÉPUBLIQUE FRANÇAISE}

LIBERTÉ - ÉGALITÉ - FRATERNITÉ

\section{Préfecture du Département de la Seine}

\section{BORDEREAU}

des prix de salaires normaux et de la durée normale de la journée de travail

(Borlereau dressé par la Commission le revision des cahiers des charges à la suite des constatations faites, en exécution des prescriptions du (lécret du Io aoilt I899, par les Commissions mixtes.)

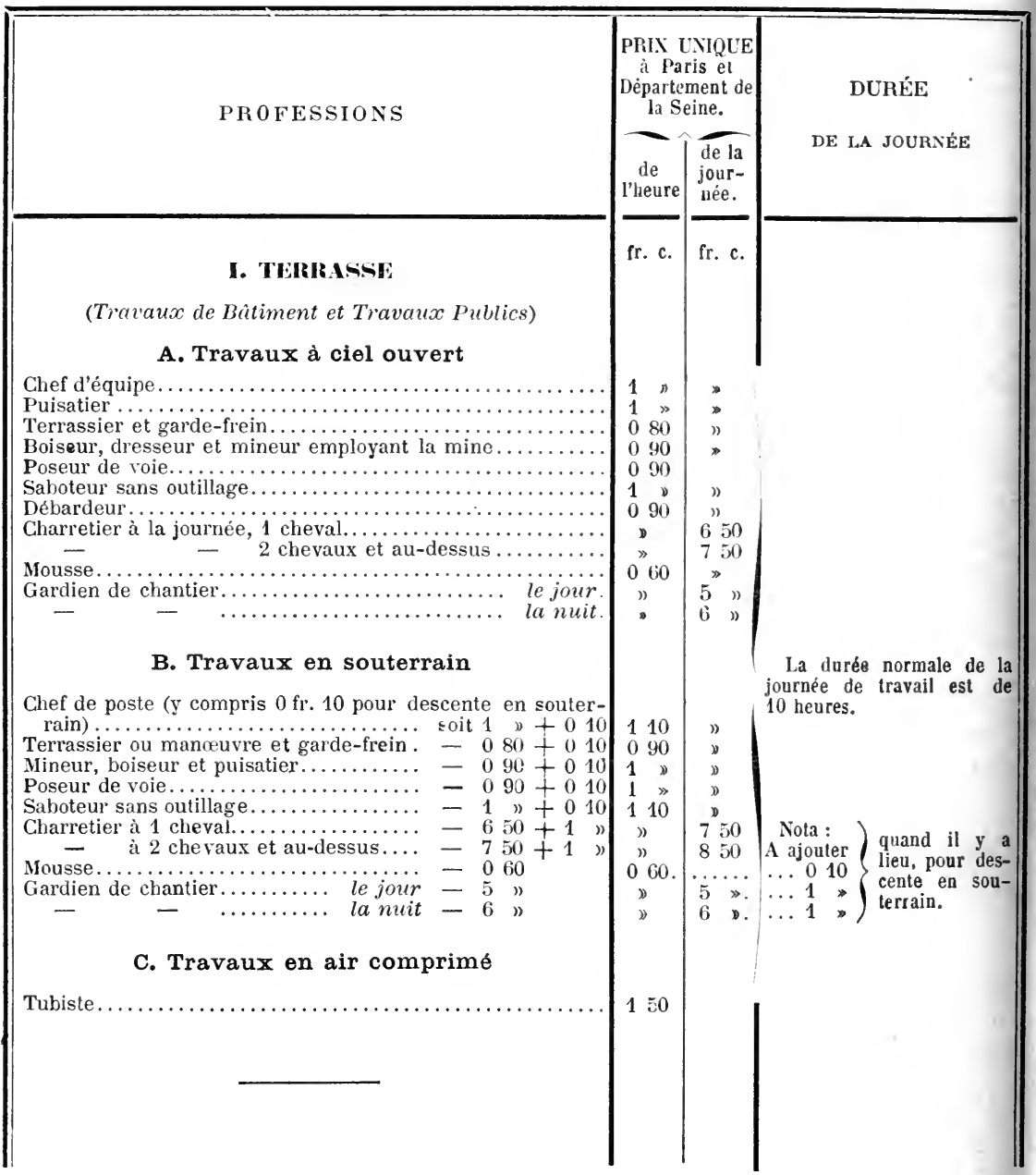


PROFESSIONS

\section{HACONNEIRE (BATIMENT)}

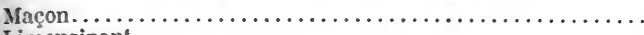
Limousinant

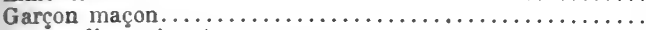

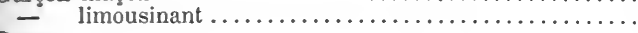

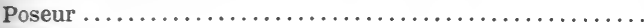
Pinceur. .

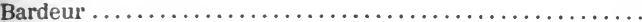

Tailleur de pierre $\ldots \ldots \ldots \ldots \ldots \ldots \ldots \ldots \ldots \ldots \ldots \ldots \ldots$ Ravaleur

Scieur de pierre tendre (ne fournissant pas ses outils).....

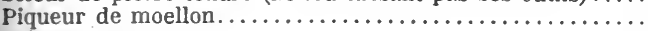
Briqueteur.

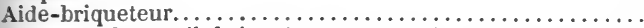
Tourneur de treuil (briqueteur et niaçon).

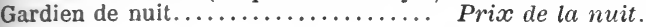

\section{MACONNERIE DE TRAVACI PUBLICS}

Macon.

Aide-macon.

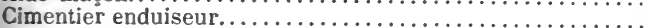

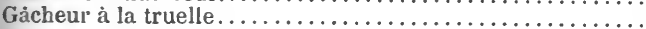

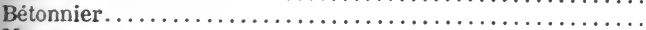

Mousse....

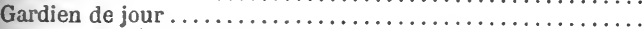

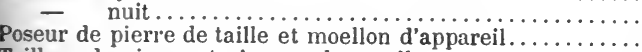
Tailleur de pierre et piqueur de moellon.

\section{SEIRTLREIE FT CIIAPENTE: EN FEIR}

Traceur et chef d'équipe

Forgeron (grande forge) $\}$ (petite - ) $\}^{-}$Forgeron de chantier......

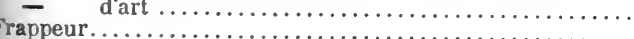

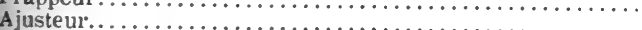

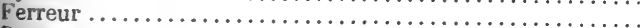

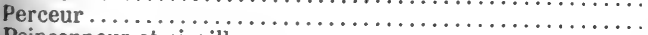

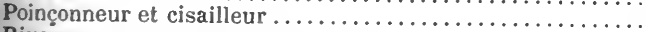

Riveur . . . . . . . . . . . . . . . . . . . . . . . .

Manceuvre (teneur de tas et chauffeur de clous)............

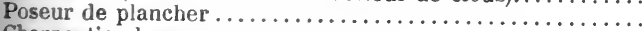

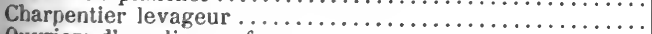

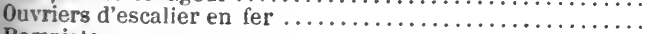

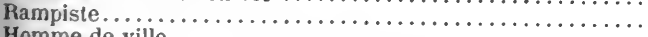

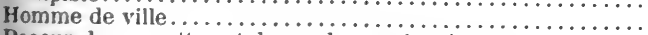

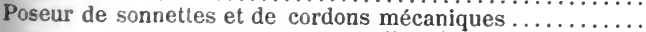

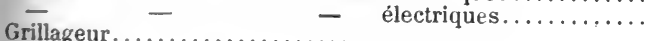

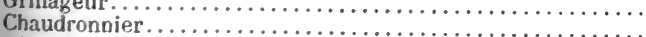

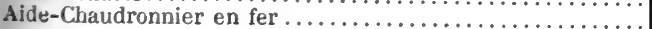

\section{CHARINATL: EN IBOIS}

Charpentier.

Fers de scie (2 scieurs de long)

Charretier à 1 cheval. .

a 2 chevaux........

la journée sur chantier
PRIX UNIQUE

à Paris et

Département de

la Seine.

de

de la
jour-
née.

DE LA JOURNÉE

fr. c.

095

085

070

065

1 )

090

080

130

130

1 1 1

1 D

$\begin{array}{ccc}0 & 0 \\ 0 & 70\end{array}$

$\begin{array}{lrl}0 & 70 \\ 0 & 75\end{array}$

075

》

a durée de la journée de travail est fixee comme suit :

10 heures pendant les mois de mars à octobre inclusivement.

9 heures pendant les mois de novembre et févilier.

8 heures pendant les mois de décembre et janvier.

La durée normale de la journée de travail sur chantier est de 10 heures, elle est de 8 heures pour les tra5 " vaux dans l'air comprimé.

1 D

092

$\begin{array}{ll}0 & 80\end{array}$

092

$0 \quad 62$

$\begin{array}{ll}0 & 75 \\ 0 & 0\end{array}$

075

$\begin{array}{lll}0 & 625 \\ 0 & -5\end{array}$

070

075

060

080

080

$\begin{array}{lll}0 & 80\end{array}$

080

080

0 80

$0 \times 0$

085

070

0 50

6

La durée normale et courante de la journée de travail est de 10 lieures à l'atelier et de 8,9 et 10 heures suivant la saison, dans les chantiers publics.

Été : 10 lieures du 1 er mars au 1 er octobre.

Iliver : 8 heures.

La durée normale de la journée de travail sur chanfier est fixée à 8,9 et 10 lieures, suivant la saison.

5 ( ) Pour les charretiers elle 6 est fixée à 10 lieures sans distinction de saison. 
PROFESSIONS

\section{MLVISLRIE ET PABQTETS}

Menuisier.

Parqueteur sur lambourdes

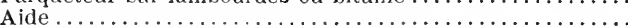

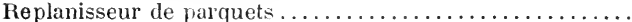

\section{FIUISTEIRI: IDE BATIUENT. TOLEIBIE

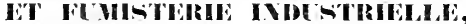

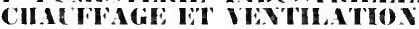

\section{$1^{\circ}$ Fumisterie de Bâtiment et Tôlerie}

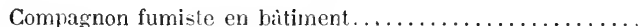

\section{Garcol}

Tôlier

-

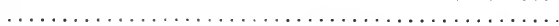

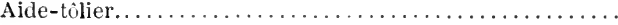

\section{$2^{\circ}$ Fumisterie industrielle}

Compagnon fumiste briqueteur

Garcon

\section{$3^{\circ}$ Chauffage}

Monteur.

Aide-monteur.

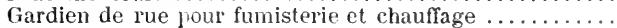

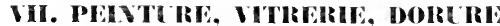

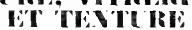

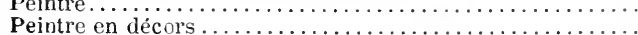

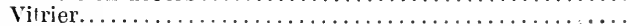

Colleur. . . . . . . . . . . . . . . . . . . . . . . .

Doreur en battiment. . . . . . . . . . . . . . . . . . .

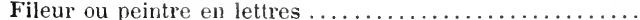

Enduiseur (spécialiste) . . . . . . . . . . . . . . . . . Badigeonneur. .

Gardien de rue.................... à la journée

\section{PAVAG, GRANT, ASPIILTE, BITCUE} (BATIMENT)

\section{1 . Pavage et Granit}

Compagnon paveur en pierre ou en bois

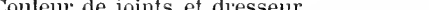

Aide-paveur et manutentionnaire de dépôt .............

Piqueur de grès ou de granit y compris frais d'outils, sans

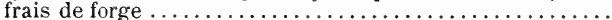

Piqueur de grès ou de granit, non compris frais d'outils

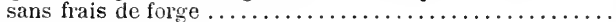
Poseur de granit. . . . . . . . . . . . . . . . . . . .

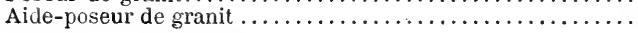

\section{$2^{\circ}$ Asphalte et Bitume}

(Travaux d'Architecture ou Travaux particuliers) Applicateur dasphalte et de bitume $\ldots \ldots \ldots \ldots \ldots \ldots \ldots$ Aide-applicateur - - Bétonnier enduiseur pour fondation de $\ldots \ldots \ldots \ldots \ldots \ldots \ldots$ Aide-bétonnier $\quad-\quad-\quad \ldots \ldots \ldots \ldots \ldots$
DE LA JOURNÉE

I a journée de travail est de 10 heures en été comme en hiver.

1

La durée normale de la journée de travail est : du er mars au 31 oct. de $7 \mathrm{~h}$. du matin à $6 \mathrm{~h}$. du soir avec interrup. de 11 h. à midi, soit pour cette période $10 \mathrm{~h}$. Du 1 er nov. à fin févr., de 7 h. du matin à 5 h. dn soir avec interrup. de $11 \mathrm{~h}$. à à midi, soit pour cette période, $9 \mathrm{~h}$.

La durée de la journée de trava l est de : du 1 or fév. au 31 mars 10 h.; du 1 er au 30 avril $11 \mathrm{~h}$. : du 1 er mai au 31 août 12 h.; du

I er au 30 sept. 11 h.; du ter au 31 oct. 10 h. ; dú 1 er au 31 janvier $9 \mathrm{~h}$.

La darée normale de la ") journée de travail est de 11 4 )) heures.
085

120

090

090

$1 \%$

120

110 085

090

075

070

$1 \gg$

090

090

$\begin{array}{lll}0 & 70\end{array}$

090

070

085

070
Durée de la journée normale de travail : 10 heures - en été, 8 heures en hiver.

$\gg$ 4

La durée normale de la journée de travail est de 10 heures en èté, 9 heures en hiver. 


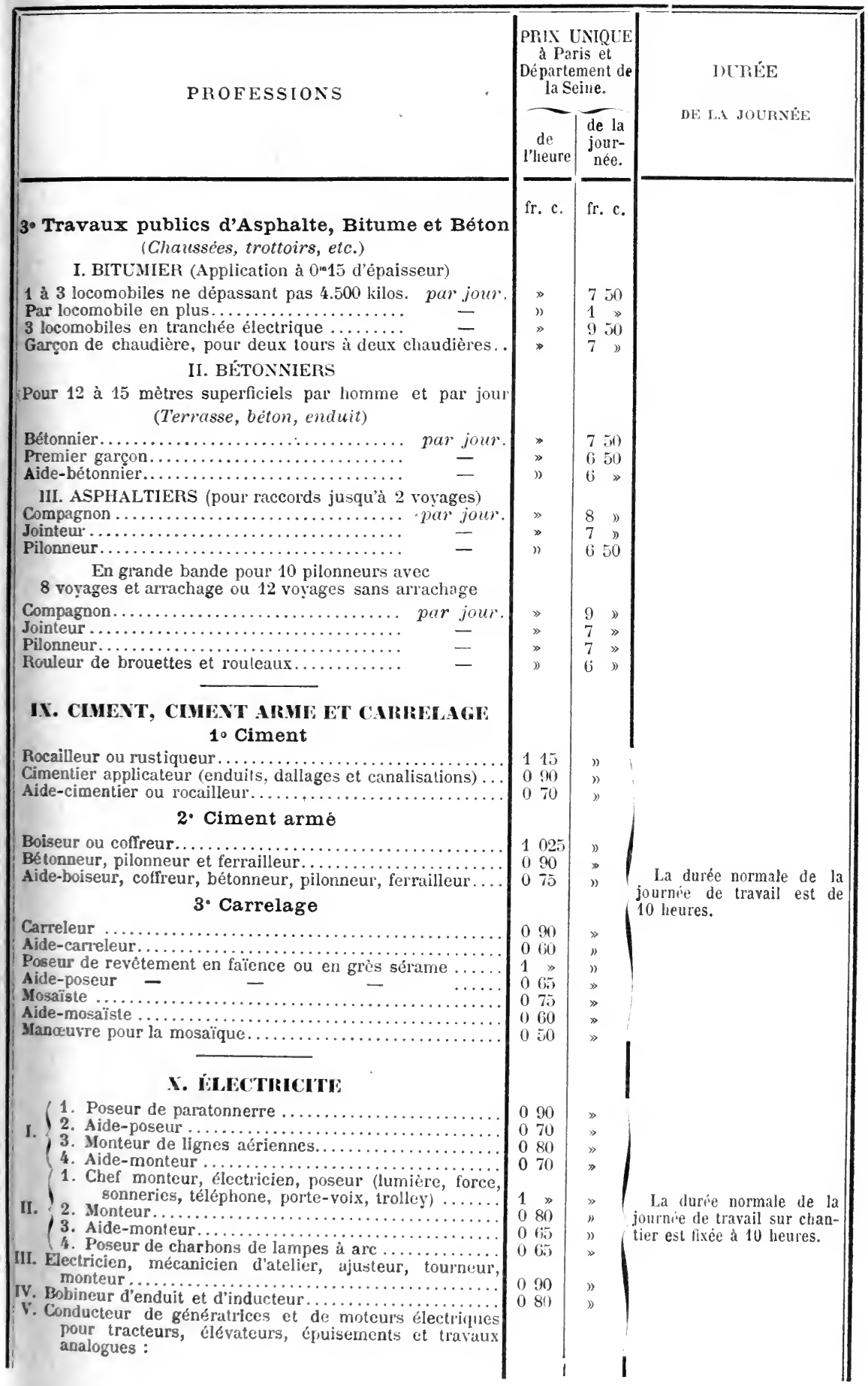




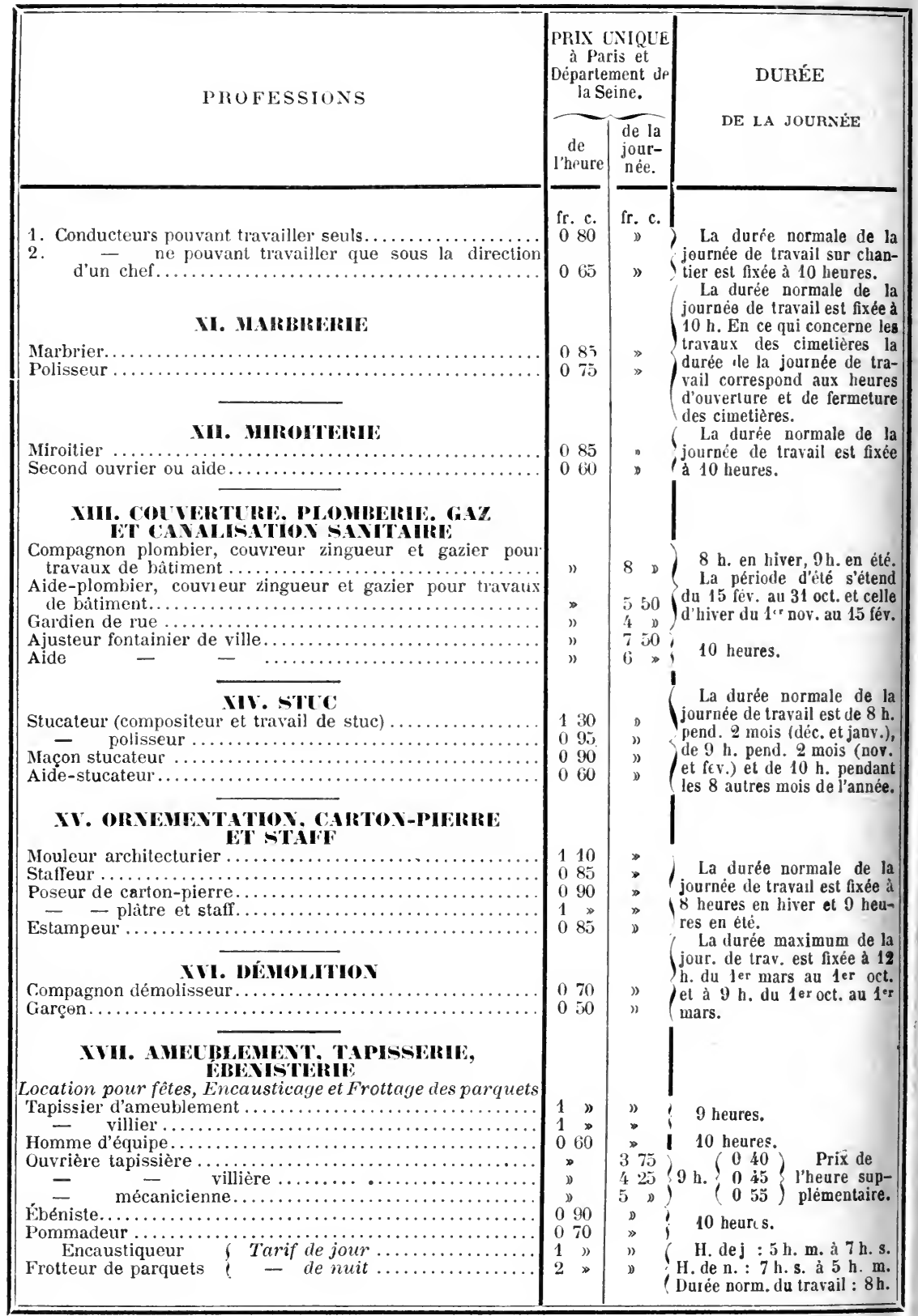

Pour le Directeur administratif des Services d'Architecture

VU ET APPROUVE : Paris, le 23 mai 1910.

Le Sénateur, Préfet de la Seine. et des Promenades et Plantations,

L'Architecte Voyer en Chef, BONNIER.

J. DE SELVES. 
Il existe de ce dernier bordereau une deuxième édition qui diffère de la première, en ce qui concerne les travaux de terrasse en souterrain, par la note suivante :

"Observation. - Travaux à ciel ouvert et en souterrain : Un ticket de I franc par poste sera payé lorsque l'ouvrier travaillera dans une couche liquide de $\mathrm{O}^{\mathrm{m}} \mathrm{0} 5$. "

Le minimum de salaire a été, dès r 9oo, inséré dans les cahiers des charges de certains réseaux de tramways de la région parisienne; les décrets de 1900 contiennent un article 37 ter, $3^{\circ}$, ainsi rédigé :

" Le concessionnaire devra accorder aux ouvriers et employés un salaire minimum de 5 francs par jour de travail effectif ou des appointements de I5o francs par mois (I). ")

Il est probable qu'au fur et à mesure de l'expiration des concessions, la clause sera introduite dans les nouveaux décrets de concession.

Enfin, tout récemment, " le minimum de salaire de I,825 francs a été inséré dans les cahiers des charges des futures concessions de transport en commun : il résulte donc des délibérations du Conseil municipal et du Conseil géné$\operatorname{ral}(2) .1)$

\section{III. - SANCTIONS}

Enfin, les salaires sont-ils effectivement payés?

Le Département de la Seine et la Ville de Paris ont innové en ce qui concerne les sanctions (3) :

Pour faciliter le contrôle de l'Administration, les clauses

(1) Conditions du travail sur les réseaux de tramways de la région parisienne.

Bulletin de l'offce du travail, ı902, p. 32. Il s'agissait en fait du tramway do la rive gauche de Paris, de l'Est parisien, de la Générale parisienne, de la ligne Puteaux-Notre-Dame-de-Lorette (concession Peter), de la ligne Suresnes-La Chapelle et Saint-Ouen-Porte-Maillot (concession Durand), de certaines lignes du Nord parisien, des tramways mécaniques des environs de Paris (lignes Courbevoie-Le Pecq, HouillesRueil-Chatou, Chatou-Montesson, Montesson-Saint-Fargeau, avec minimum de salaire de 4 francs par jour et 120 francs par mois.)

(2) G. Lemarchand. Rapport complémentaire au nom de la Commisslon du personnel, 1909, n० 104, p. 22.

(3) On sait que les décrets de I899 n'avaient prévu comme sanctions que la retenue par l'Administration sur les fonds de l'entreprencur du complément de salaire insuffisant et l'exclusion temporaire ou définitive des adjudications, au cas d'infractions réitérées. 
suivantes ont été insérées dans certains cahiers des charges de la Ville de Paris :

" I ${ }^{0}$ Payement des salaires : Les salaires des ouvriers seront payés sur les chantiers ou dans leur voisinage, lorsque l'ingénieur estimera que leur importance le justifie;

$2^{0}$ Un agent de l'Administration assistera à la paye des ouvriers toutes les fois que l'ingénieur le jugera utile. Cet agent recevra, s'il y a lieu, les réclamations et les transmettra à l'Administration;

$3^{\circ}$ Communication des feuilles de paye : L'entrepreneur devra, à toute réquisition, communiquer à l'ingénieur ou à son délégué les feuilles de paye des ouvriers, indiquant. pour chacun d'eux les heures de travail qui lui sont attribuées ainsi que le salaire payé. "

Chaque infraction aux dispositions ci-dessus et aux autres dispositions du décret donne lieu, sans qu'il soit besoin d'une mise en demeure préalable :

$1^{\circ}$ S'il s'agit d'un ouvrier indùment payé ou employé, à une retenue de i franc par jour et par ouvrier;

$2^{\circ}$ Dans tous les autres cas, à une retenue de 5 francs par jour et par ouvrier.

Le tout sans préjudice de l'application des clauses et conditions générales et de l'exclusion temporaire ou définitive de la liste d'admissibilité aux adjudications de la Ville de Paris.

Le contrôle s'exerce par des tournées mensuelles spéciales, à dates variables, sur tous les chantiers; ces tournées donnent lieu à des procès-verbaux dits " de visite " où les ingénieurs constatent pour chaque entreprise la manière dont les conditions du travail sont pratiquées et les infractions commises.

Ces procès-verbaux sont transmis par les chefs des services techniques au directeur administratif des travaux, qui, après vérification, les approuve et en rend exécutoires, s'il y a lieu, les pénalités indiquées par les cahiers des charges. "

Par une circulaire du i 2 juillet ı 908, le Ministre du Travail faisait connaître ce système dans les départements. Il ne semble pas avoir été beaucoup écouté : 
“ Il semble ressortir des rapports des préfets que si la disposition des décrets relative à l'affichage obligatoire des bordereaux est assez souvent appliquée, par contre, dans un très petit nombre de cas (I), les cahiers des charges d'entreprises départementales ou communales contiennent des clauses analogues à celles qui ont été insérées dans les cahiers des charges de la Ville de Paris (2). ")

Le contrôle a èté improvisé, quand il existe, par des moyens de fortune, tels que surveillance de l'Administration ou surveillance personnelle des membres de la commission administrative.

Mais, dans la très grande majorité des départements, cette organisation de contrôle est très défectueuse.

A en juger par l'application des sanctions (3), on pourrait croire que leur exécution est toujours rigoureuse. Ce n'est là qu'une apparence, le silence est bien plutôt une preuve certaine de leur inexécution dans l'immense majorité des cas.

Il semble bien, d'ailleurs, d'après la jurisprudence (4), que la sanction administrative reste la seule possible : la sanction judiciaire, c'est-à-dire l'action directe de l'ouvrier insuffisamment payé, contre l'entrepreneur n'ayant pas été admise. Un récent arrêt de cassation (5) décide que lorsque l'entrepreneur, même lié par un cahier des charges qui l'oblige à payer le salaire normal, a convenu avec le salarié d'un salaire inférieur, " aucun texte de loi ne prohibe, sous peine de nullité, une convention de cette nature " et que

(1) Dans sept départements seulement, des mesures de eontrôle ont été inscrites dans les cahiers des charges, registres ou carnets de paye, présence de l'ingénieur assistant à la paye, état des salaires, etc.

(2) Art. cité. Bulletin de l'Offce du travail, p. 724. G. Note sur l'application des décrets du 10 aoùt 1899 par la Préfecture de la Seine, id., Bulletin, 1908, p. rog4.

(3) Dans l'enquête citée, une seule application des sanctions (art. 4 et 5 des décrets, retenue et exclusion) a été relevée dans une ville de la Charente-Inférieure.

(4) Cass. civ., 25 mars 1908. Bulletin de l'Offce du travail, rgo8, p. 577. ce. Conseil de préfecture de Moulins. Arrêté du 1 I mai 190\%. Bulletin de l'Offlce du travall, r906, p. 260 . Les décrets du 10 aoùt 1899 sur les adjudications (Bulletin, id., I908, p. 786).

(5) Cass. civ., 23 décembre r908 et 3 mars 1909. S. 1911. I.369, et la note de M. Demogue. Cet arrêt est une nouvelle preuve des difficultés que rencontre le salaire minimum ou ce qui s'en rapproche devant nos juridictions françaises. 
" le décret du ıo août I899 se borne à organiser, dans son article 4, un système destiné à indemniser, s'il y a lieu, l'ouvrier qui se trouverait lésé ( $\mathrm{I}$ ). ")

Au total :

A Paris et dans le département de la Seine surtout, dans quelques départements assez rares d'ailleurs, l'application de notre clause fut donc des plus heureuses.

C'est là une exception sans doute notable, mais une exception, dans l'ensemble des travaux exécutés pour le compte des départements.

$3^{\circ}$ Application dans les travaux des communes et des établissements publics (2). En ce qui concerne l'exécution de notre clause relative au salaire qui est ici facultative, l'enquête signale l'application par les communes et les établissements de bienfaisance dans 55 départements seulement : souvent, c'est à la suite de délibérations spéciales prises à ce sujet par les conseils municipaux que l'application a été faite. On n'est pas fixé sur l'application à tous les travaux ou à quelques travaux seulement.

L'application intégrale de notre clause existe dans les eommunes suivantes pour tous les travaux communaux :

Vichy, Nice, Decazeville, Marseille, Dijon, Besançon, Quimper, Brest, Toulon, Rennes, Saint-Nalo, Saint-Servan, Châteauroux, Bordeaux, Le Puy, Angers, Cherbourg, Châlons-sur-Marne, Reims, communes de l'arrondissement d'Épernay, Vannes, Nevers, Valenciennes, Malo-les-Bains, Bergues, Roncq, Wattrelos, Calais, Boulogne-sur-Mer, Lyon, Paris (3), Amiens, Abbeville, Albi, Poitiers.

Certaines municipalités ont même été plus loin et ont stipulé de véritables minima de salaires :

Ainsi, Roanne a stipulé du concessionnaire de son réseau de tramways un salaire minimum de roo francs par mois;

(I) La circulaire ministérielle du r2 juillet rgo8 a donné des instructions en ce sens aux préfets.

(2) Le volume du Ministère du Travail : Salaires et cont de l'existence, jusqu'en I910, déjà cité, donne également divers bordereaux par professions, datés de 1906, pour les travaux des communes et des établissements publics.

L'application des décrets du ro août 1899 dans les marchés des travaux publics des départements, communes et établissements publics de. bienfaisance. (Bulletin de l'Office du travail, r9ro, loc. cit., p. 599.)

(3) Pour Paris, voir ci-dessus, p. 79. 
Bordeaux également de sa Compagnie concessionnaire de tramways des minima de 4 francs par jour pour les conducteurs et manœuvres, 5 francs pour les wattmen et autres employés $(\mathrm{r})$.

En ce qui concerne les établissements publics, les dispositions facultatives du décret ont été adoptées par des établissements publics de bienfaisance dans I 8 départements (2); le plus souverit des délibérations formelles sont prises en ce sens soit par les Conseils municipaux, soit par la Commission administrative de l'établissement public.

En résumé, sur ce troisième terrain, l'application est encore plus restreinte.

Quant au mode d'établissement des bordereaux, ils sont ici, comme pour les départements, le plus souvent établis directement par l'Administration intéressée (3).

Parfois on applique les bordereaux établis pour les travaux du département (4). Quelquefois, on prend l'avis des intéressés, patrons et ouvriers, soit par des commissions mixtes composées des uns et des autres, soit par d'autres moyens (5). Ici aussi la plus grande variété se rencontre dans les combinaisons, mais la consultation des intéressés reste l'exception.

(r) Bulletin de l'Offce du travail, 1902, p. 36.

(2) Voici la liste des établissements où l'application partielle ou intégrale des clauses a été faite : Hautes-Alpes, hospices de Gap. Aveyron, hospices de Decazeville. Calvados, hospices de Caen. Charente-Inférieure, hospices civils de La Rochelle; bureau de bienfaisance de Rochefort. Cher, hospices de Bourges et de Vierzon. Cotes-du-Nord, hospices de Saint-Brieuc. Ille-et-Vilaine, hôpital du Rosais, à SaintServan. Loir-et-Gher, hospices de Romorantin. Loire, hospices civils de Saint-Etienne et Saint-Rambert. Loire-Inférieure, hôpital mixte d'Ancenis. Loiret, hospices de Pithiviers et Puiseaux. Manche, établissements charitables de Cherbourg. Marne, hospices de Reims; établissements publics de bienfaisance d'Epernay. Nord, hospice et bureau de bienfaisance de Bergues, établissements charitables de Roneq. Seine, établissements de l'assistance publique du département de la seine. Seine-Inférieure, hospices de Rouen et d'Elbeuf. Vendée, hôpilaux et hospices de Fontenay-le-Conte et des Sables-d'Olonne. Hıute-Vienne, hôpitaux de Limoges et de Saint-Junien.

(3) Des Commissions administratives n'ont fonetionné que dans les huit communes suivantes : Vichy, Toulouse, Nantes, Reins, Nancy, Boulogne-sur-Mer, Abbeville, Poitiers.

(4) Ainsi, dans la Seine (ef. ci-dessus, p. 79), dans l'Indre, dans l'Yonne.

(5) Cf. art. cité. Bulletin de l'offlce du travail, 1910, 1). 72 r. 
La revision est rare; dans l'enquète citée, on n'en relève qu'un seul exemple (I).

En résumé, l'application actuelle des décrets du ro aout I 899 est loin d'ètre parfaite.

(I) En 1908, pour les travaux de la construction d'un pavillon à l'hôpital du Rosais, à Saint-Servan. 


\section{C) LES RÉFORMES}

Aussi depuis quelques années certaines idées de réformes se sont fait jour : une Commission interministérielle d'une part, la Commission permanente et le Conseil supérieur de l'autre ont discuté la question.

$\mathrm{I}^{\mathrm{0}}$ L'ceuvre de la Commission interministérielle. - Un décret du 22 juin 1908 (I) a nommé une commission interministérielle pour l'étude des questions relatives aux adjudications de travaux publics.

La Commission constata les résultats ci-dessus exposés : la prédominance de l'Administration seule dans la constatation des salaires, la rareté des commissions administratives, leur caractère temporaire, l'absence fréquente dans ces commissions de représentants de toutes les administrations appelées à commander des travaux de la nature de ceux qui font l'objet de bordereaux. "Ainsi, d'une part, leurs constatations ne sont pas tenues en concordance avec les variations des conditions normales du travail et, d'autre part, ces constatations n'étant pas appliquées à tous les travaux similaires, il existe parfois des divergences entre les salaires et durées du travail prévus pour les ouvriers d'une mème profession occupés, dans une mème région, aux travaux de diverses administrations (2). ")

La Commission interministérielle concluait, en conséquence, par le vœu suivant :

"Instituer dans chaque département une commission qui serait composée des représentants de toutes les administrations civiles et militaires ayant à passer des marchés de travaux ou de fournitures pour l'État et le département, et qui aurait pour mission d'établir et de reviser, quand il y aurait lieu, en se conformant aux prescriptions de l'article 3 du décret, les bordereaux du taux des salaires normaux et de la durée normale de la journée de travail pour toutes les

(1) Bulletin de l'Offle du travail, 1908, P. 675. Cette Commission comprenait des délégués des ministères suivants : Intérieur, Finances, Guerre, Marine, Beaux-Arts, Agriculture, Commerce, Colonies, Travaux publics, Travail.

(2) Bulletin de l'offce du travail, 1910, p. 643. 
catégories d'ouvriers pouvant être employés à l'exécution desdits marchés dans le département (I). »

Ensuite, la Commission interministérielle indiquait plusieurs points à spécifier dans les instructions à adresser aux commissions (2):

Notamment " que le salaire normal et courant dont elles auront à constater le taux est le salaire payé ordinairement au plus grand nombre d'ouvriers d'une mème spécialité de la profession considérée, ne présentant pas une capacité exceptionnelle;

Que, par suite, le salaire des ouvriers d'une capacité supérieure à la moyenne ne doit pas figurer au bordereaú, non plus que celui des ouvriers d'une capacité inférieure; ces derniers devant ètre considérés comme ouvriers d'aptitudes physiques restreintes auxquels s'appliquent les dispositions de l'article 3 du décret,

Et que les taux des salaires peuvent d'ailleurs être fixés non seulement à l'heure ou à la journée, mais aussi aux pièces. ")

Les autres indications étaient relatives à des cas particuliers.

$2^{0}$ L'ceuvre de la Commission permanente et du Conseil supérieur du travail. - D'autre part, le Conseil supérieur du travail, dans sa séance de juillet $\mathrm{r} 908$, a été saisi de la question (3). M. Keüfer avait saisi la Commission permanente d'une note dans laquelle il insistait sur l'inapplication des décrets, due le plus souvent à la négligence ou à la malveillance de l'Administration (4). Il proposait comme sanction à la Commission permanente d'émettre notamment le vœu suivant :

"Seuls seront adjudicataires les patrons qui, depuis une année au moins, appliquent à leur personnel les conditions

(r) Rapport de la Commission interministérielle, p. I42.

(2) Bulletin de l'Offce du travail. Ibid., p. 643.

(3) Les décrets du 1o aoult 1899 sur les adjudications. Rapport de M. Honoré. Procès-verbaux et documents, Paris, Imprimerie nationale, 1908 .

(4) “ Les réclamations ouvrières sont accueillies par des tergiversations constantes; l'opposition administrative est appuyée de vains prétextes et finalement les prescriptions des décrets ne sont pas observées. " Keüfer, note citée dans op. cit., p. II. 
normales du travail constatées par le bordereau établi conformément aux termes des décrets (1) ».

La Commission permanente confia le rapport sur cette question à M. Honoré. Celui-ci invoquait les difficultés présentes d'application, l'impossibilité d'aller plus loin pour l'instant, déclarait que "les décrets ont fait leur temps et c'est à la loi égale pour tous à étendre à l'universalité des travailleurs, sans catégories subtiles et sans distinctions contestables, une sage protection qui sera d'autant plus réelle qu'elle entre et entrera dans les mœurs, plus puissante que les textes de loi ", et concluait par le vœu suivant, adopté par la Commission permanente dans sa séance du 6 avril r 908 :

"Considérant les mauvais résultats obtenus par l'application des décrets du ro aoùt i 890 , la Commission permanente estime que c'est plutôt par des dispositions plus libérales que par de nouvelles réglementations qu'on peut espérer l'amélioration des adjudications au point de vue de l'intérêt public d'abord et aussi du monde des travailleurs, ouvriers comme patrons,

Et par ces motifs repousse les vœux présentés par M. Keüfer. ")

Une intéressante discussion au sein de la Commission permanente précéda l'adoption de ce vœu : un membre, M. Dalle, avait proposé une série d'amendements au texte des décrets, dont l'un notamment confiait à l'Inspection du travail le soin de vérifier le taux normal et courant des salaires. La discussion confirma le fait de l'application très défectueuse, mais le statu quo l'emporta par 6 voix contre $5(2)$.

La question vint devant le Conseil dans sa séance de novembre 1908 (3).

Après une longue discussion générale, le vœu de la Commission permanente et de M. Honoré, qui proposait le main tien du statu quo, fut repoussé par 28 voix contre 22 .

(1) Op. cit., p. 16 .

(2) Une solution plus radicale, proposée par MM. Devilette et Borderel, concluait à la suppression pure et simple des décrets.

(3) Conseil supérieur du travail. Comptes rendus, 1908. Paris, Imprimerie nationale, 1908. Cf. Bulletin de l'offlce du travail, 1908, 1. 1193, compte rendu sommaire. 
La proposition de M. Keüfer légèrement modifiée fut adoptée par 26 voix contre 25 :

" Seuls pourront être adjudicataires des travaux de bÉtat les soumissionnaires qui appliquent à l'ensemble de leur personnel les conditions du travail prévues dans les décrets et constatées suivant les instructions contenues dans les circulaires ministérielles. »)

Le Conseil supéricur émit le vœu que cette proposition soit également appliquée pour les adjudications des départements et des communes (I).

Enfin, en ce qui concerne les sanctions, une longue discussion s'engagea. MM. Jay et Keüfer proposaient l'annulation des adjudications et marchés pour lesquels les cahiers des charges ne contiennent pas les clauses relatives aux conditions du travail. Les auteurs de cette proposition la retirèrent et proposèrent la rédaction transactionnelle suivante (2):

"Le Conseil supérieur est d'aris d'introduire dans le texte des décrets du ı aoùt 1899 les dispositions suivantes déjà appliquées dans le département de la Seine :

« Le cahier des charges stipulera qu'un agent de l'Administration pourra assister à la paie des ouvriers. Le cahier des charges stipulera également que l'entrepreneur devra, à toute réquisition, communiquer à l'Administration les feuilles de paie des ouvriers employés à l'exécution des marchés. »)

Aucune réforme profonde n'était donc proposée ni à la Commission interministérielle, ni au Conseil supérieur du travail (3).

(1) Ce second paragraphe fut adopté par 30 voix contre 24 .

(2) Adoptée par 23 voix contre 0 .

(3) Au point de vue théorique, il faut encore signaler les travaux de la Section de l'Association internationale du Nord pour la protection légale des travailleurs. (L'Application dans la région du Nord et la revision des déerets sur les conditions du travail dans les marchés des Administrations publiques. I br. M., Lille. I908.) La section du Nord de l'A. I. P. L. T. demandait d'une part une application plus vigoureuses des décrets du ro aoùt, et d'autre part d'assez nombreuses modifications à leur texte, dont voici les principales : extension de la portée des décrets à « tout travail spécialement fait en vue de l'exécution du marché », exclusion des adjudications de tout industriel ne payant pas le salaire normal, contrôle de l'Inspection du travail, clauses relatives au travail obligatoire, même pour les départements et les communes, etc., etc. Il faut insister enfin sur une modification particulièrement intéressante au point de vue qui nous 
$3^{0}$ L'action de l'Administration. - Dans ces conditions, on restait dans le statu quo. L'Administration a d'ailleurs repris en main l'application des décrets du ro août i 899 :

Par une circulaire récente du 44 mai r9 Io (I) adressée par le ministre du Travail aux préfets, la question était reprise (2) et diverses mesures suggérées de pure pratique sans apporter d'ailleurs aucune modification aux conditions mêmes des décrets. Le ministre invite de nouveau les préfets à constituer des commissions administratives communes chargées de dresser les bordereaux des salaires et durées du travail à annexer au cahier des charges de tous les travaux effectués pour le compte de l'État, des départements et des communes; précise par des instructions aux chefs de service les divers districts de confection des bordereaux : invite enfin, en rappelant l'exemple de Paris, l'Administration à obtenir le moyen de contròler les salaires effectivement payés.

Un arrèté du 29 décembre I9 Io (3) pris par le ministre des Travaux publics réalise dans ce département bon nombre des réformes demandées. Nous citerons l'article i5 relatif au paiement des ouviriers :

"Le salaire normal des ouvriers est égal, pour chaque

occupe : la fixation des salaires à payer par l'Administration et la généralisation des salaires pour des régions plus étendues et dans le sens. des salaires les plus élevés.

Voici le texte proposé (loc. cit., p. 85) : " L'Administration pourra, soit établir un mème salaire ou tarif pour toute la France, soit, dans le cas d'une trop grande inégalité des salaires, fixer des salaires ou tarifs différents pour les diverses régions de la France. Le salaire ou tarif unique ne pourra ètre inférieur au salaire ou tarif constaté dans celle des localités où s'exerce l'industrie intéressée, où le salaire ou tarif est le plus élevé. Chaque salaire ou t'arif régional ne pourra pas être inférieur au salaire ou tarif constaté dans celle des localités de la région où s'exerce l'industrie intéressée, où le salaire ou tarif est le plus élevé. ")

Il y a là une tendance intéressante pour consolider le salaire courant et reporter la concurrence entre patrons sur le perfectionnement de l'outillage ou l'amélioration des moyens de production. Ce serait un pas de plus dans la voie étudiée vers un minimum de salaire véritable.

(1) Bulletin de l'offce du travail, juin 1910, p. 639.

(2) " Je crois devoir compléter les instructions qui vous ont été fournies jusqu'à ce jour par quelques indications de délail que j'emprunte aux voux et résolutions formulés par le Conseil supérieur du travail dans sa séance de novembre r 908 et aux conclusions de la Commission interministérielle du I2 juin 1908 ». Bulletin, loc. cil., p. 640.

(3) Cet arrêté refond dans un nouveau texte les clauses et conditions générales imposées aux entrepreneurs des travaux des ponts et cliaussées. 
profession et dans chaque région, pour chaque catégorie d'ouvriers, au taux couramment appliqué dans la ville ou la région où le travail est exécuté.

Lorsque l'entrepreneur a à employer des ouvriers que leurs aptitudes physiques mettent dans une condition d'infériorité notoire sur les ouvriers de la même catégorie, il peut leur appliquer exceptionnellement un salaire inférieur au salaire normal.

La proportion maximum de ces ouvriers, par rapport au total des ouvriers de la catégorie, et le maximum de la réduction possible de leurs salaires sont fixés par le cahier des charges.

Le bordereau du taux normal et courant des salaires et de la durée normale et courante de la journée de travail annexé au cahier des charges est affiché par les soins et aux frais de l'entrepreneur $(\mathrm{I})$.

L'entrepreneur est tenu de donner communication à l'Administration, sur sa demande, de tous les documents nécessaires pour vérifier que le salaire payé à ses ouvriers n'a pas été inférieur au salaire normal et courant (2).

Si l'Administration constate une différence entre le salaire payé aux ouvriers et le salaire courant, elle indemnise directement les ouvriers lésés au moyen de retenues opérées sur les sommes dues à l'entrepreneur.

L'entrepreneur paye ses ouvriers et ses employés en se conformant aux prescriptions des lois et règlements.

En cas de retard régulièrement constaté, l'Administration, par application des lois des 26 plu viôse an II et 25 juillet I 89 I, se réserve la faculté de faire payer d'office les salaires arriérés sur les sommes dues à l'entrepreneur. ")

Telle est la mise au point de la clause relative au salaire accomplie par l'une de nos grandes Administrations.

Il serait à souhaiter que les autres suivissent cet exemple.

Une circulaire récente du 30 décembre I9 $10(3)$, adressée aux Préfets, relative à la rédaction des projets, la passation

(I) Ainsi, désormais, l'affichage du bordereau de salaires est à la charge de l'entrepreneur.

(2) Dans le cas où l'entrepreneur ne produirait pas les documents demandés par l'Ingénieur, le Préfet le mettrait en demeure.

(3) Bulletin de l'Offlce du travail, 1911, p. 527. 
des marchés et l'exécution des travaux publics, vient confirmer encore la mème politique.

Ces nouvelles mesures sont en cours d'application. Une Commission administrative unique était constituée dans quatre départements, Ain, Gers, Orne, Haute-Loire, et allait l'être dans deux autres ( 1 ), Hautes-Alpes et Tarn-et-Garonne.

$\mathrm{Au}$ total, pour la France, la question conserve tout son intérèt et toute son actualité.

Nous n'en voulons pour preuve qu'une constatation faite par l'Union des industries métallurgiques et enregistrée en ces termes par le rapport déjà cité de la Commission :

« L'Union des industries métallurgiques signale une autre cause d'augmentation du prix des ouvrages qui serait également une conséquence de l'obligation de payer un salaire minimum. Quand ce salaire, tel qu'il est fixé par le bordereau, est supérieur au prix couramment payé dans l'usine qui a soumissionné des fournitures pour l'État, les ouvriers ont intérêt à ce que l'exécution de la commande dure le plus longtemps possible, et le rendement de la main-d'œuvre diminue (2). ')

G'est bien la preuve qu'au prix peut-être de quelques sacrifices pour le Trésor, une réelle amélioration dans le sort de l'ouvrier a été obtenue par l'application des décrets du ro août i 899 .

C'est aussi la constatation que ce régime reste une exception privilégiée qui attend que le régime ordinaire des salaires dans l'industrie privée s'élève à son heureux niveau.

(1) Renseignements au 25 juin 1910. Bulletin de l'of 1 ce du travail, 1910, p. 721.

(2) P. 107, rap. cité. 


\section{Il. - Les conditions du Travail dans les Adjudications de travaux publics à l'ètranger.}

Le mouvement est également général : il se retrouve aux États-Unis, en Suisse, en Hollande, en Angleterre, en Bel-' gique et en Allemagne.

Comme en France, il s'agit surtout de garantir à l'ouvrier le salaire usuel, le salaire courant et non le salaire minimum.

Nous insisterons tout particulièrement sur trois pays : l'Angleterre, la Belgique et l'Allemagne, où l'expérience a été particulièrement concluante.

\section{$1^{0}$ En Angleterre ( 1 ).}

En Angleterre, la question est fort ancienne. Il faut présenter d'abord un rapide historique de la question, étudier ensuite la situation présente.

\section{a) Historique.}

Le mouvement du minimum de salaire dans les adjudications de travaux publics débuta par la municipalité de Londres.

Les autorités scolaires et le Conseil de Comté de Londres (London County Council) furent les premiers à discuter une réglementation protectrice du salaire de l'ouvrier dans les adjudications les concernant (2).

C'est le School Board de Londres qui le premier s'occupa de la question : au mois de janvier ı 889, un entrepreneur ne payant pas de salaires suffisants, le comité de construction décidait de repousser son contrat et proposait qu'à l'avenir tout entrepreneur s'engageât, lors de la conclusion

(I) Bibliographie : Report of the joint select committee of the House of Lords and the House of Commons on municipal trading. Londres, juillet rgoo. - Report of the joint select commettee of the House of Lords and the House of Commons on municipal trading. - Londres, juillet rgo3. - London County Council. Rates of pay and hours of labour, janvier 1904. - Local government Boards. Rapports annuels.

(2) Hugo. Stcedtverwaltung und munizipal Sozialismus in England. Stuttgart, 1897, pp. 247-248. 
du contrat, à payer aux ouvriers qu'il emploierait un salaire au moins égal au salaire minimum couramment payé dans le métier (I).

Le taux de ces salaires minima était arrêté et adopté par le $S$ chool Board dans sa séance du 7 février 1889 .

Puis, le 3 mars 1889 , le Conseil de Comté de Londres vota sous sa première forme la fameuse clause du juste salaire ou salaire syndical, mieux précisée le 27 mai I892, par laquelle " le salaire et la durée du travail que les syndicats avaient pu établir et réaliser deviennent obligatoires pour les travaux tant en régie qu'en entreprise ».

Tous les entrepreneurs sont tenus de signer la déclaration suivante : " qu'ils observent la durée du travail et payent les salaires ouvriers établis par les syndicats ouvriers dans la localité où l'entreprise est exécutée. Cette durée et ces salaires du travail sont insérés dans le contrat et en font partie intégrante, de telle sorte que des pénalités puissent être appliquées à toutes infractions à la convention ").

Enfin, pour le cas où l'organisation syndicale faisait défaut, le Conseil de Comté vota, le 3 i novembre i893, la disposition additionnelle suivante :

"Là où il n'y a pas de syndicat pour déterminer le minimum de salaire du métier, c'est le Conseil lui-mème qui doit déterminer suivant le taux reconnu et courant le minimum des salaires et le maximum des heures de travail et toutes conditions à observer (2).

En conséquence, le Conseil arrètait le taux de 24 shillings par semaine pour les hommes et de 18 shillings pour les femmes (3), salaire applicable à défaut des tarifications syn-

(1) Voici le texte de cette résolution: "Parlout où sera en vigueur l'échelle des salaires de Londres, l'entrepreneur ne devra pas payer à ses ouvriers un salaire inférieur au salaire minimum constaté dans les différents métiers. Dans tous les autres districts où l'échelle des salaires de Londres ne sera pas en vigueur, l'entrepreneur devra payer à ses ouvriers et à tous autres ouvriers indirectement employés par lui à l'exécution de son contrat un salaire qui ne sera pas inférieur au salaire minimum alors en usage et généralement payé aux ouvriers. ”

(2) Vaillant. Ch., J. O., Déb. parlem., 8 mars i912, pp. 625 et suiv.

(3) En mème temps, pour éviter que l'entrepreneur n'éclıppât à ces diverses obligations au moyen de cessions totales ou partielles de son contrat, ces cessions furent interdites sans le consentement préalable du Conseil. Cielui-ci ne l'accordait que si le sous-contractant s'obligeait à observer les conditions du contrat principal. 
dicales et très raisonnable par rapport aux salaires alors payés à Londres aux ouvriers non qualifiés.

Ces règles furent appliquées à Londres successivement aux travaux de terrassement et de voirie, puis à tous les autres travaux (I).

Quelques difficultés survinrent au début de l'application de ce système, du fait qu'il était spécial à la capitale. Que décider en effet au cas où le L. C. C. ne trouvait pour soumissionner que des entrepreneurs étrangers à Londres(2)?

La généralisation rapide du mouvement permit d'en triompher rapidement.

Bientôt après on étendit à toute l'Angleterre pour les travaux de l'État la réglementation des conditions du travail.

C'est en I89 I que la question a été posée à la Chambre des Communes. On était en présence des maux du sweating system, Un membre de la Chambre des Communes, M. Sydney Buxton, fit alors voter une résolution, le I3 février, connue sous le nom de fair-wages resolution, résolution des salaires équitables.

Elle était ainsi conçue :

"La Chambre décide que dans son opinion c'est le devoir du gouvernement dans tous les contrats par lui passés de prendre des mesures contre les maux récemment mis en lumière devant la commission du sweating system, d'inscrire telles clauses qu'il faudra pour prévenir les abus résultant de la sous-entreprise et de faire tous les efforts voulus pour amener le paiement des salaires courants et acceptés comme tels dans chaque métier. ")

Son auteur a expliqué par la suite (3) que ce texte modéré était alors le seul moyen d'aboutir. " J'ai pensé que le mot

(x) On ajouta même pour les marchés passés pour la fourniture d'objets d'habillement, chapeaux, manteaux, etc., la clause suivante : " Les entrepreneurs s'engagent expressément à faire exécuter dans leurs ateliers mêmes tout le travail que nécessitera l'exécution de ce contrat ", et ce sous peine d'une amende de $100 £$ que le L. C. C. (London County Gouncil) se réservait de retenir sur le prix convenu.

(2) Sur les divers moyens de sortir de cette difficulté alors proposés (obligation de ne confier l'exécution des contrats qu'à des maisons de Londres, qu'à des maisons de la paroisse ou du district intéressé; obligation de tenir compte de la différence des salaires, etc.,) cf. Boverat, Le Socialisme municipal en Angleterre et ses résultats financiers, $2^{\mathrm{e}}$ édition, Paris, Rousseau, 1912, p. 369.

(3) Parliam. Deb., H. of C., 1909, vol. II, p. 429. 
courant était un mot susceptible d'une large interprétation, que c'était un mot non scientifique particulièrement heureux en l'espèce. ")

Avec un sens pratique remarquable, les Anglais comprirent que le salaire courant était la voie normale, la seule possible, qui devait mener au salaire minimum.

Dès 1895 , le premier ministre répondait à une délégation venant lui demander de faire respecter cette clause : "C'est le devoir du gouvernement central et de l'administration municipale, comme donneurs de travail, directement ou indirectement, de donner l'exemple aux autres employeurs et, dans leurs relations avec leur personnel en ce qui concerne les salaires, les heures de travail et les conditions du travail, d'atteindre le niveau le plus élevé possible dans une industrie particulière (I). ")

En r9o5, à Londres, on fit un nouveau pas en avant. Le Conseil de Comté de Londres décida que les listes de salaires et les listes d'heures de travail devaient ètre déposées à l'hôtel de ville, qu'elles devaient être établies par la municipalité sur la recommandation du Comité de travail sur des bases reconnues par les organisations ouvrières, les TradeUnions, et aussi en s'inspirant des conditions usuelles du travail de Londres.

Il y a des revisions fréquentes pour toutes ces listes de salaire en harmonie avec les salaires syndicaux.

Enfin l'action directe est donnée aux ouvriers devant les tribunaux anglais pour le cas où les entrepreneurs paieraient des salaires inférieurs à ceux prévus dans les listes municipales.

Une commission d'enquête, nommée par la Chambre des Communes le I4 mai 1896 et dont les travaux avaient été interrompus par la clôture de la session parlementaire, a vu renouveler ses pouvoirs le 25 février 1897 , et, après avoir tenu treize séances, elle a adopté, le 2 I juillet ${ }_{1} 89-$, un rapport dont nous reproduisons les principaux passages :

"Si la Commission a bien compris la résolution du I 3 février I89r, il n’a jamais été question de faire fixer le taux des salaires par l'État, mais seulement de constater et

(1) Rapporté par M. J. Hodge à la Chambre des Communes, le 10 mars 1909. Parliain. Deb., H. of C., rgog, vol. II, P. $4 \mathrm{I} 6$. 
de garantir le taux minimum courant des salaires dans les divers métiers et les diverses régions.

Cette résolution, appliquée depuis six ans, ne parait pas avoir eu d'influence fâcheuse sur les relations entre employeurs et employés; au contraire, elle paraît avoir contribué à faire conclure des conventions entre patrons et ouvriers sur le taux existant des salaires et sur les conditions usuelles du travail.

Dans l'ensemble, les entrepreneurs ne soulèvent d'objections ni contre la résolution, ni sur la manière dont elle a été appliquée, et les plaintes des ouvriers sur les violations de la résolution ne sont plus aussi fréquentes qu'autrefois. ")

Par deux fois, en 1896 (I) et en 1908 (2), la Chambre des Communes a ordonné une enquête sur l'application de cette résolution dans les Administrations publiques. Leur comparaison marque le réel progrès, en douze ans, de l'application de la clause.

En I898, sur 1,086 districts enquêtés comprenant 17 millions d'habitants, I63 (8 millions I/2 d'habitants, Londres non compris), inscrivaient la clause des salaires dans leurs contrats.

Parmi ces derniers, I 2 districts (5 millions I/2 d'habitants) prenaient pour base les salaires locaux usuels, et 3o districts (I million 300,00o habitants) les salaires des syndicats; 9 districts (comptant environ I million d'habitants) adoptèrent les salaires conformes aux contrats collectifs de la profession.

67 districts n'avaient dans leurs contrats aucune stipulation particulière relative aux salaires.

856 districts (soit environ 7 millions 300,000 habitants) ne s'occupaient nullement des conditions du travail (3).

\section{b) Situation présente.}

Les travaux de l'État. - L'Angleterre est restée longtemps au système du salaire courant. C'est ce que confirme le rapport de i908, déposé par le Fair Wages' Committee :

(I) Select Committee. Report on the Government contracts, 2 vol.

(2) 1908. Fair Wages' Committee. Report wilh appendices, 2 vol.

(3) Internationale Metall-arbeiter. Runkchau, I908. 
“ A notre point de vue, la résolution n'a pas eu pour but d'établir de nouveaux tarifs des salaires, mais seulement d'assurer comme salaires payés pour les travaux du Gouvernement ceux qui sont ordinairement payés par de bons employeurs à des ouvriers compétents dans chaque profession dans le district où le travail est exécuté et d'éviter que les contrats passés par le Gouvernement ne tombassent entre les mains d'employeurs capables l'accepter des prix inférieurs en concurrençant aux rabais leurs rivaux dans le paiement des salaires ( $\mathrm{I}$ ). "

Quant aux sanctions, le rapport poursuit :

"On peut indiquer que la pratique la plus générale dans les différents ministères (nécessairement avec quelques exceptions) est de donner les soumissions à des listes choisies d'établissements dont les conditions de travail et les locaux ont été soumis à enquête et à inspection. ") Un contròle incessant est exercé à cet égard et l'on retire ou l'on suspend les soumissions des établissements dont les locaux ou le taux des salaires ne sont pas satisfaisants.

Une large publicité est donnée à ces adjudications dans les journaux professionnels, pour assurer le contròle des ouvriers. "Dans le cas des travaux de la Guerre, de l'Amirauté et du Post Office, un accord a été passé avec la Commission parlementaire du Congrès des Trade-Unions, par lequel lors des soumissions, copie du contrat est envoyée aux sociétaires des Trade-Unions nommés par la Commission parlementaire pour représenter chaque profession dans les divers districts (3). "

Le système paraît avoir heureusement fonctionné partout où les travailleurs sont organisés, et dans ces cas le salaire courant est d'ordinaire le salaire arrêté par contrat collectif entre les unions patronales et ouvrières (4).

(I) Rapport cité, p. 2. La clause usitée dans la plupart des contrats est la suivante : "Les salaires payés en exécution de ce contrat seront ceux qui sont généralement acceptés comme courants pour chaque métier dans le district oủ le travail est exécuté. »

(2) Ibid., p. 2.

(3) Ibid., p. 3.

(4) Ibid., pp. 4 et 5 . On avait mème demandé de remplacer les mots " salaire courant " par " Salaire accepté par les Trade-Unions ». La Commission s'y refusa (Conclusions, p. 26 ) pour diverses difficultés pratiques. 
Par contre, les difficultés se multiplient et l'application de la Fair Wages' clause est beaucoup plus délicate partout où n'existent pas ces accords, soit à raison du manque d'organisation patronale et ouvrière, soit à raison du caractère isolé et particulier de la profession qui accomplit les travaux (I). Ici, la Commission constate les difficultés d'application et suggère certaines réformes possibles, telles que la fixation d'un salaire minimum au temps ou la création de Comités de salaires ou encore la détermination par l'État des salaires à payer.

"Au total cependant (2), ni les témoignages entendus ni le nombre des réclamations adressées aux ministères (3), eu égard au total des travaux effectués, ne semblent indiquer de notables imperfections dans le fonctionnement de la clause des salaires équitables (4). »

En Angleterre, donc, soit par l'action naturelle des Trade-Unions, soit par les réformes proposées, le mouvement en faveur du salaire courant dans les adjudications de travaux publics s'oriente de plus en plus vers la création d'un minimum de salaires.

La clause des fair wages fut modifiée en mars 1909 .

Une résolution déposée par M. John Hodge, à la Chambre des Communes, le ıo mars I 909 (5), était ainsi conçue :

" La Chambre des Communes est d'avis que la clause des

(1) Ibid., pp. 7 et suiv.

(2) Ibid., p. 4 .

(3) En cinq ans (rg02-1907), les cinq Administrations, Guerre, Amirauté, Travaux Publics, Poste et Stationery Office (bureau d'imprimés), n'ont guère reçu en moyenne qu'une réclamation par semaine : ce qui est peu par rapport au très grand nombre de contrats passés.

Dans le même sens, la déclaration de M. S. Buxton aux Communes, le Io mars rgog. Parliam. Deb., H. of c., r909, vol. II, p. 429 .

En 1909,1600 à 1700 soumissions furent communiquées par l'Administration aux diverses Trades-Unions. Fort peu de réelamations furent retournées. (Ibid.).

(4) Plus récemment, M. Sydney Buxton, postmaster général (Chambre des Communes, Io mars rgog. Parliam. Deb., H. of c., rgog, vol. II, p. 425), affirmait que la clause des salaires équitables a été profitable aux ouvriers sans nuire aux employeurs; qu'elle a favorisé les bons patrons et ouvert les travaux du Gouvernement aux meilleurs ouvriers : " Le profit fut général pour les employeurs, les employés et la communauté. »)

Pour juger de son importance, il faut se rappeler que le crédit annuel pour l'exécution des contrats du gouvernement est d'environ 25,000,000 £, soit 625 millions de francs. (Ibid., p. 428.)

(5) Parliam. Deb., H. of G., vol. Il., 1909, p. 415. 
salaires équitables dans les contrats du Gouvernement doit être modifiée de manière à obliger l'entrepreneur, sous menace de pénalités, à payer à tous les travailleurs qu'il emploie au moins le salaire minimum (the minimum standard rate of wages) reconnu par les Trade-Unions, dans le district où ces ouvriers sont employés (I).....

S'il n'existe pas de minimum de salaires de ce genre dans le district, l'entrepreneur devra payer à son personnel le salaire minimum reconnu par les Trade-Unions exécutant ordinairement ce genre ce travail dans le district le plus voisin (2).... Tout sous-entrepreneur sera astreint aux mêmes obligations que l'entrepreneur (3). ")

En séance et à la suite d'un amendement de M. Buxton, qui soulevait des modifications de détail plutôt que de principe, le texte suivant fut ainsi voté (4):

" La Chambre des Communes est d'avis que les clauses des salaires équitables dans les contrats du Gouvernement devront être modifiées de manière à prévoir ce qui suit :

L'entrepreneur devra, sous peine d'amende ou autre, payer des taux de salaires et observer une durée de travail au moins aussi favorables que ceux reconnus d'un commun accord par les patrons et les Trade-Unions (ou à défaut de tels salaires et durée de travail reconnus, les salaires et durée de travail qui dans la pratique sont appliqués parmi les bons employeurs) dans le district où l'ouvrage est exécuté.

Quand il n’y aura pas de pareils salaires ou pareille durée de travail reconnus ou appliqués (dans les deux hypothèses ci-dessus) dans le district, on devra adopter celles reconnues ou appliquées dans le district le plus voisin présentant des conditions industrielles semblables (5). L'en-

(1) Et aussi à observer la durée du travail et les autres conditions de travail des Trade-Unions dans le district.

(2) Et aussi observer la durée du travail et les autres conditions de travail imposées par les Trade-Unions dans le district le plus voisin.

(3) La discussion fort intéressante à laquelle donna lieu cette résolution montre à merveille le progrès de la conscience publique sur ce point : le devoir du Gouvernement de surveiller le salaire vital des travailleurs fut accepté par tous comme un fait acquis et indiscutable.

(4) Parliam. Deb., loc. cil., p. 425.

(5) Ici d'autres clauses que nous négligeons, relatives à l'observation des autres conditions de travail, à ia sous-entreprise, etc. 
trepreneur sera responsable de l'observation des clauses de salaires équitables par le sous-entrepreneur qu'il choisit. ")

Ainsi, comme on l'a fort bien répété en séance(I) aux Communes, il ne s'agit pas pour le gouvernement de fixer le taux de salaire. Tout ce que l'on demande, c'est que le gouvernement accepte comme équitables (fair) les taux de salaires qui l'emportent dans chaque métier, ceux qui ont été fixés par accord entre employeurs et employés.

En même temps et à l'occasion de cette modification, le même M. Sydney Buxton a donné lecture à la Chambre des Communes (2) de ce qu'il a appelé lui-même le programme administratif pour l'exécution de la "fair wages' clause » :

“ Les entrepreneurs devront garder les propres records du temps de travail de leurs employés, surtout lorsqu'ils travaillent aux pièces.

Les clauses des salaires équitables, lorsque cela sera nécessaire, seront mises bien en vue pour être connues de la population ouvrière.

Les noms des maisons ayant obtenu les contrats du gouvernement sont publiés dans Labour Gazette du Board of Trade.

Il y aura conformité entre les départements dans la rédaction des clauses de salaires équitables traitant des conditions du travail dans les contrats relatifs à une mème industrie.

De plus, en vue d'obtenir l'uniformité des règles administratives et le concours entre les différents départements faisant exécuter des travaux en ce qui concerne l'inspection, l'étude des plaintes et plus généralement l'interprétation des clauses de salaires équitables, il sera constitué un conseil consultatif interministériel qui comprendra un représentant du Board of Trade. »

Ce programme est aujourd'hui appliqué en Angleterre.

Cet exemple montre combien pratique et féconde la voie que nous avons étudiée pour l'introduction du minimum de salaire.

Celui-ci est aujourd'hui une réalité pour le personnel des governments contracts.

Les travaux des municipalités (3). - La grande majorité

(I) Gf. Ibid., p. 420.

(2) Ibid., p. 434 .

(3) House of Commons. Contracts of Local Authorities (Wages) Return, 1905, $\mathrm{n}^{\circ} 307$. 
des villes anglaises est entrée aujourd'hui dans l'application du système.

Les clauses sont à peu près partout les mêmes(I). Nous mentionnerons ici les clauses des villes les plus importantes.

Voici la clause pour tous les contrats passés par la Ville de Londres :

"Pendant toute la durée de son contrat, l'entrepreneur devra observer et remplir les conditions suivantes:

a) I ${ }^{0}$ Payer aux ouvriers (les apprentis exceptés) employés par lui à l'exécution de son contrat les salaires au taux prescrit à la cinquième cédule, et pour chaque infraction à cette clause payer au Conseil comme dommages-intérêts et non comme peine une somme de 5 £.

$4^{\circ}$ L'entrepreneur devra à tout moment, chaque fois qu'il en sera prié par le clerk du Conseil, produire aux fonctionnaires que l'on déléguera à cet effet le livre des heures de travail et de salaires pour que l'on puisse savoir s'il se conforme ou non aux conditions du contrat.

$5^{0} \mathrm{Au}$ cas où un ouvrier employé par l'entrepreneur viendrait à ne pas recevoir le salaire convenu, le Conseil pourra payer à cet ouvrier la différence séparant le montant des salaires que lui a payés l'entrepreneur de celui qu'il aurait reçu; il pourra réduire de toute somme due à l'entrepreneur le montant de ladite différence payée à l'ouvrier (2).

(i) Comme en France, d'autres clauses concernent les autres conditions du travail (prohibition du marchandage, durée de travail, etc...).

(2) Des précautions sont également prises pour assurer le paiement du minimum de salaire par le sous-contractant: défense à l'entrepreneur de céder tout ou partie de son contrat sans le consentement écrit du Council, sous peine d'une amende de 200 £.

Au cas où les entrepreneurs obtiennent la permission de sous-traiter, on inscrit dans les contrats des clauses analogues à eclles rapportées au texte, notamment les deux clauses suivantes :

$3^{\circ}$ " Dans tout sous-traité sera insérée une convention par laquelle le sous-entrepreneur s'engage : $I^{\circ}$ à payer à ses ouvriers les salaires prévus et à ne pas les faire travailler plus que le nombre d'heures fixé dans le cahier des charges; $2^{\circ}$ à faire afficher les clauses de ce sous-contrat et à montrer ses feuilles et livres de travail et d'heures aux fonctionnaires que le Conseil déléguera à cet effet.

$4^{\circ}$ Pour toute infraction à cette convention de la part du sous-entrepreneur, l'entrepreneur paiera $5 £$ au Conseil; et pour charpue infraction aux heures de travail il paiera 5 shillings pour charpe heure de chaque jour et pour chaque ouvrier employé au delà du nombre d'ıeures réglementaires. ") 
b) Au cas où l'entrepreneur contreviendrait à une ou plusieurs des stipulations susdites, le Conseil, au lieu de lui réclamer le versement des dommages-intérêts payables par lui, aura le droit de résilier son contrat.

Enfin on prévoit encore la modification éventuelle aux conditions du travail par la clause suivante (I):

“ Au cas où après la conclusion du contrat un taux différent de salaires ou des heures différentes de travail viendraient à être acceptés par les associations de patrons et les unions ouvrières dans le métier et dans le district où l'ouvrage est fait, le taux des salaires et des heures ainsi modifié sera, à partir de la date de cet accord et pour le temps seulement où il entrera en vigueur, considéré comme substitué au taux prévu dans cette partie de la cédule pour le même genre de travail. ")

Il importait d'insister ici avec quelques détails sur la politique du London County Council qui fut, on le sait, l'initiateur de cette réglementation en Angleterre.

Les autres villes anglaises insèrent des conditions très analogues; il suffit de mentionner ici quelques particularités.

Les unes concernent les adjudications elles-mêmes : à Glascow, Édimbourg, Dundee, Aberdeen, ne peuvent soumissionner que les entrepreneurs et les maisons qui payent à tous leurs ouvriers le standard rate of wages, c'est-à-dire le taux de salaire établi par les Trade-Unions professionnelles et s'il n'y a pas de standard rate, les salaires reconnus justes et équitables dans les districts où l'on exécutera le travail.

Les autres regardent le minimum de salaire lui-même : parfois certaines villes arrêtent elles-mêmes les minima à payer (2), d'autres acceptent les tarifs établis par les ouvriers seuls (3), parfois aussi, on limite aux seuls ouvriers

(I) Insérée facultativement lorsque le L. C. C. juge cette insertion désirable et sur la recommandation expresse du Comité intéressé.

(2) Ainsi à Aberavon : $6 \mathrm{~d}$. par heure, sous peine d'une amende de $I$ \& pour chaque infraction; bon nombre de villes d'Irlande : ainsi Belfast, pour les travaux de la reconstruction de ses tramways, arrête un minimum hebdomadaire de 18 s. 6 d. par semaine (Contrat de novembre r904).

(3) Battersea, Fulham, Shoreditch. 
moyens l'octroi du minimum; ainsi à Halifax, on indique que le standard rate n'est dû qu'à l'ouvrier moyen (average workmann), c'est-à-dire à l'homme capable de lutter à conditions égales avec ses camarades ; en cas de vieillesse, d'infirmité physique ou morale, l'entrepreneur peut s'entendre avec l'intéressé pour arrêter un juste taux de rémunération inférieur au standard (I).

(I) Une clause fréquente est aussi celle qui oblige à donner la préférence, toutes les fois que cela sera possible, aux entrepreneurs locaux ou aux ouvriers de la localité (Gloucester, Folkestone, etc.). 


\section{$2^{\circ}$ En Belgique.}

En Belgique (r), le mouvement est également assez ancien; il est aujourd'hui en plein développement.

\section{a) Histoire.}

La première tentative remonte à I 853 , à Bruxelles : elle est due à l'initiative de M. de Brouckere, bourgmestre de Bruxelles. Frappé de l'insuffisance des salaires payés aux ouvriers stationnaires depuis cinquante ans et de l'augmentation du prix des vivres, il demanda (2) au Conseil communal de Bruxelles de décréter un minimum de salaire pour les ouvriers occupés aux travaux publics entrepris par la Ville. Le Conseil communal se rallia à cette proposition. Une ordonnance affichée par les soins du Collège des bourgmestres et échevins proclamait :

“ I ${ }^{0}$ Que les travaux que la Ville fera exécuter sur états seront réglés par deux heures de travail et payés aux patrons à raison de 64 centimes par ouvrier et de 42 centimes par manouvrier, à la condition expresse qu'il serait compté 50 centimes aux premiers et 34 centimes aux seconds ;

$2^{\circ}$ Que dans tous les cahiers des charges, il sera stipulé que l'entrepreneur s'engage envers la commune à payer à tous les ouvriers et manouvriers les salaires énoncés plus haut. "

Cette première tentative avait un double caractère : d'une part, elle était due à une intervention personnelle du bourgmestre et ne mettait point en jeu l'autorité publique; d'autre part, elle manquait absolument de sanction.

La clause ci-dessus (3) figura au cahier des charges de la Ville de Bruxelles, de r 853 à 1857 . Elle tomba ensuite en désuétude sans avoir produit, du reste, de résultats appréciables (4).

(I) « Le minimum de salaire et les Administrations publiques en Belgique ", Office du travail belge, I vol., I9I I, Bruxelles.

(2) Voir in extenso son rapport: Le minimum de salaire en Belgique, op. cit., p. 4.

(3) Modifiée légèrement en 1855 .

(4) Conseil communal de Bruxelles, séance du 12 janvier 1867 et séance du Conseil communal de Bruxelles du 29 décembre 1887 . 
Le mouvement reprit dans diverses communes, en 1884 et I885 (I), sans succès d'abord; puis de I 888 à I896, la clause du minimum de salaire triompha dans diverses communes (2); en I 896, on avait obtenu les résultats suivants :

8 administrations provinciales sur 9 avaient inscrit dans leurs cahiers des charges des stipulations relatives aux salaires des ouvriers.

Sur 86 administrations communales de communes comptant plus de 8.000 habitants, 47 avaient accepté la réforme (3).

Pendant ce temps, la mème question se posait pour les travaux de l'État. Le Sénat et la Chambre des représentants, saisis en $1888-89$ et $189_{2}-93$ par des pétitions, refusèrent d'accorder «l'intervention directe de l'État dans la question des salaires ").

Le Conseil supérieur du Travail étudia la question en I893 et I894 et rejeta l'idée du salaire minimum pour adopter, comme en France, l'idée du salaire normal et courant (4).

Diverses propositions législatives, pour aboutir enfin, furent faites en i 896 (5) et'en I gor. Comme en France, sans aborder la phase législative, le problème fut résolu par le Gouvernement.

En ı896, M. de Bruyn, ministre de l’Agriculture et des Travaux publics, déclarait à la Chambre qu'il tenterait une expérience partielle du minimum de salaire. Elle fut faite, pour les Travaux publics, à partir du 2 juillet i896. Un arrêté daté de ce jour décida qu'un certain nombre de

(1) A Saint Gilles lès Bruxelles et à Saint Josseten Noode, où la demande d'intervention directe de l'autorité dans la fixation des salaires, fut également repoussée.

(2) Énumérées dans l'ouvrage cité : Le salaire minimum en Belgique, p. 12.

(3) Rapport au Conseil communal de Bruxelles par le bourgmestre, au nom de la Commission d'enquête. Mai 1896 . Op. cit., p. 12.

(4) Lucien Le Foyer. Le minimum de salaire en Belgique, Réforme sociale, 1897, I $^{\text {er }}$ semestre, pp. 48I et 539.

(5) Un amendement de M. Mousset, demandant l'inscription dans les cahiers spéciaux des charges ou adjudications passées par l'État des clauses destinces à garantir aux ouvriers des entreprises de travaux publics un salaire minimum, obtint à la cliambre des représentants 64 voix contre 28 et 7 abstentions (9 juin 1896 ). Le même article fut rejeté au Sénat, par 36 voix contre 16 , le 18 juin. Ann. parlem., 1896 , Ch. des représent., p. 1665 ; Sénat, p. 534. 
clauses devraient être insérées dans les cahiers des charges des entreprises de l'État (I). Voici la clause principale :

I. Bordereau de salaires. - L'entrepreneur doit s'engager, par un bordereau revêtu de sa signature et annexé à sa soumission, à payer aux ouvriers, apprentis et manœuvres chargés de travaux de maçonnerie, de terrassement et de pavage, des salaires qui ne peuvent être inférieurs aux taux indiqués dans ledit bordereau.

Le salaire est payé à un taux de $25 \%$ supérieur à celui fixé dans ledit bordereau, pour le travail en dehors des heures habituelles, y compris les dimanches et les jours de fètes légales.

Un système de sanction et de contrôle complétait cette disposition: un bulletin spécial était remis à l'ouvrier, constatant le taux du salaire extrait du bordereau.

Les sanctions étaient l'obligation de payer le surplus et après deux avertissements à l'entrepreneur, l'exclusion temporaire ou définitive de celui-ci des adjudications de l'État.

L'essai tenté au début, pour un an, se poursuivit jusqu'en I 90 I (2). Une enquête faitè à cette époque démontra que l'application du minimum de salaire n'avait exercé aucune influence sur le résultat des adjudications et que la mesure n'avait suscité aucune difficulté entre patrons et ouvriers (3).

\section{b) Résultats actuels.}

Aussi on décida d'étendre le système à toutes les catégories de métiers employés sur les chantiers mèmes des entreprises, dirigées et surveillées par les agents de l'État (4).

On précisa même, par une dernière circulaire du 9 juillet 1907 , que les chefs de service ne doivent arrêter les taux des salaires qu'après avoir recueilli les renseignements nécessaires auprès des syndicats patronaux et ouvriers, dans la région où ces travaux doivent être exécutés.

(I) Ces clauses n'étaient pas applicables aux travaux faits en atelier.

(2) D'après une nouvelle circulaire du 3 novembre 1897 .

(3) Dépêche du Ministre des Travaux publics, du 26 avril 1909.

(4) Circulaires du 6 novembre 1899 et du 22 mai 1900. 
Aujourd'hui, la clause du minimum de salaire fonctionne dans presque tous les départements ministériels (I).

A l'exemple de l'État, les provinces et les communes belges introduisent progressivement la clause du minimum de salaire dans les cahiers des charges de leurs travaux.

Voici, d'après l'enquète de l'Office du travail belge, les principaux résultats à la date du $3 \mathrm{r}$ décembre $\mathrm{i} 909$ :

Pour les provinces (2), 7 d'entre elles ont admis la clause du minimum de salaire à titre de règle constante et l'appliquent à l'ensemble des travaux entrepris par elles; ce sont : Anvers (3), le Brabant, le Hainaut, Liége, Namur, les deux Flandres.

La province de Limbourg n'a pris jusqu'ici aucun règlement général sur la matière. Un cahier des charges général pour l'entreprise des travaux de voirie vicinale a été mis en vigueur à partir du 27 août r 909 .

La province de Luxembourg, après en avoir fait l'essai, a renoncé à appliquer la clause, "parce que le taux des salaires payés augmente d'année en année et dépasse de beaucoup le minimum qu'il s'agissait primitivement d'imposer (4) $)$.

Au total, 7 provinces sur 9 appliquent intégralement la clause; une ne l'applique que partiellement, la dernière y a renoncé parce qu'elle est superflue. C'est là un beau succès du minimum de salaire auprès des administrations provinciales.

Pour les communes (5), sur les ro4 qui ont fait l'objet de l'enquête :

62 (6) ont déclaré avoir adopté la clause comme règle constante et l'appliquer à tous leurs travaux.

(1) Op. cit., p. 21 .

(2) Op. cit., p. 70.

(3) Un barème général est appliqué dans les provinces d'Anvers depuis le I er janvier 1910.

(4) Lettre du gouverneur de la province du Luxembourg, 27 mars I gog. "Cette situation, continue la lettre, provient de la rareté de la maind'œuvre dans les campagnes. En présence de cette situation, il a paru prudent de ne pas intervenir entre le patron et l'ouvrier, le premier rencontrant déjà bien des difficultés pour se procurer à chers deniers lo personnel qui lui est indispensable pour faire face à ses obligations. ")

(5) Op. cit., p. $7 \mathrm{r}$.

(6) L’Office du travail fait remarquer que dans 62 communes « se trouvent la plupart des grandes villes et presque toutes les communes importantes ). (Op. cit., [1. 72.) 
4 (Anvers, Borgerhout, Lierre et Verviers) l'inscrivent dans tous leurs cahiers des charges, mais seulement à titre d'expérience;

7 n'imposent la stipulation que pour certains travanx importants ;

22 n'adoptent le minimum de salaire que lorsque celui-ci est imposé par la province pour les travaux subsidiés (I);

Enfin 9 n'inscrivent dans leurs cahiers des charges aucune clause relative au minimum de salaire.

$\mathrm{Au}$ total, l'Administration communale semble avoir fait aussi très largement accueil à notre clause de minimum de salaire.

Il faut encore mentionner(2) que le minimum de salaire rayonne au delà. Certaines villes, en effet, telles que Gand, Anvers, Mouscron, Menin, Borgerhout, etc., ont spécifié formellement que les règlements par elles édictés sur le minimum étaient applicables aux travaux subsidiés par elles (3).

\section{c) L'application .}

L'étude de l'expérience belge appelle comme complément indispensable une double question:

Est-ce réellement un minimum de salaire qui est stipulé?

Celui-ci est-il réellement appliqué et quelles sont les sanctions?

En ce qui concerne d'abord la fixation du minimum de salaire(4), une extrème latitude a été laissée en fait aux diverses administrations et leur pratique est très variable (5).

( I) C'est là un procédé de diffusion de la clause de minimum de salaire des plus intéressants et des plus efficaces. On en pourrait, à notre sens, tirer pour la France un précédent des plus topiques.

(2) Op. cit., p. 75 .

(3) En ce qui concerne la portée de la clause, elle s'applique en principe aux travaux de divers ordres exécutés au chantier, exceptionnellement cependant aux travaux exécutés en atelier (op. cit., p. 75).

(4) L'Office du travail belge n'a guère étudié la question (op. cit., p. 47) (qu'en ce qui concerne les travaux provinciaux et communaux.

(5) Au début même on avait laissé aux entrepreneurs eux-mêmes le soin de proposer les salaires minima. On préférait alors à mérite égal dans l'adjudication l'entrepreneur dont les minima étaient les plus avantageux pour l'ouvrier (op. cit., p. 5o). Ce système a aujourd'hui presque partout disparu devant ceux exposés au texte. 
On peut dire d'une manière générale que c'est l'Assemblée provinciale, le Conseil provincial, qui, soit par lui-mème, soit le plus souvent par son organe permanent, la Députation permanente(I), statue après avoir pris plus ou moins l'avis des intéressés (2).

En ce qui concerne lés consultations :

Un premier système, pratiqué dans trois provinces (3), consiste à prendre l'avis du service technique de l'Administration provinciale.

Un second, pratiqué dans une province(4), consiste à consulter successivement les associations patronales, les syndicats ouvriers et les Conseils de l'industrie et du travail.

Un troisième, pratiqué dans deux provinces (5), n’implique aucune consultation obligatoire.

Enfin un quatrième, très archaïque, pratiqué dans deux autres(6), oblige les entrepreneurs à joindre une liste de salaires minima à payer aux ouvriers occupés aux travaux soumissionnés.

Dans les communes, le système est également très variable. A Bruxelles, le Collège échevinal se rallie à un chiffre moyen, formé de ceux proposés par les ouvriers, les patrons et le Conseil de l'industrie et du travail.

A Gand, on tient peu de compte des indications des intéressés.

En un mot, chaque ville suit à ce sujet sa jurisprudence particulière; la majorité prend l'avis des intéressés (7).

Il faut avouer qu'à ce point de vue le système est encore défectueux. Le défaut tenait et tient encore à l'absence de chambres syndicales dans certains métiers. Il serait à souhaiter que l'avis des Conseils d'industrie et du travail, formés de gens compétents et officiellement reconnus, fùt plus souvent demandé et suivi.

(1) Dans toutes les provinces, sauf le Brabant.

(2) C'est à peu près l'analogue de notre Commission départementale, tandis que le Conseil provincial serait l'équivalent de notre Conseil général.

(3) Anvers, Hainaut, Liégre.

(4) Brabant.

(5) Limbourg et Namur.

(6) Flandre orientale et Flandre occidentale.

(7) Op. cit.,. p. 67 . 
Au total, aucune unité dans la manière de fixer les minima de salaires (I).

A parcourir les tableaux de salaires publiés par l'Office du travail belge (2), il paraît bien cependant que dans la grande majorité des cas, c'est véritablement un minimum de salaire qui est introduit dans les cahiers des charges de l'État, des Administrations provinciales et communales.

Reste enfin la question des sanctions; le minimum de salaire introduit dans le cahier des charges est-il effectivement payé par l'entrepreneur?

Ici encore, en l'absence d'un texte législatif imposant une règle générale, les diverses Administrations intéressées ont, en ce qui concerne le contrôle et les sanctions, adopté chacune leur système; il est donc possible seulement d'indiquer les types les plus remarquables (3).

En ce qui concerne le contròle, une clause des plus répandues est l'interdiction du marchandage ou de la sous-entreprise: " 11 est interdit, dit le cahier des charges général de la province du Brabant, d'éluder le salaire minimum par un procédé quelconque, notamment en traitant à forfait avec les sous-entrepreneurs, contremaitres ou mancuvres pour tel ou tel travail déterminé (4). ”

De mème l'affichage, la tenue de livres de paie, la délivrance de feuilles de salaire sont exigés dans tous les règlements (5).

Plus rares sont les systèmes de contrôle spécial : à Liége, à Gand, dans la province de Brabant (6), un système très

(I) Il y a également divergence et variété sur la question de savoir si le minimum de salaire à fixer doit ètre unique ou multiple : c'est la question du salaire différentiel, op. cit., p. 58. La province de Bruxelles en particulier avait établi en 1903 trois sections (Bruxelles - les régions industrielles - le reste de la province) où fonetionnaient trois minima de salaires différents. Cette division fut supprimée en 1908 et l'unification réalisée pour tout le Brabant.

(2) Op. cit., p. 133. Il s'agit ici du résultat actuel obtenu souvent par des majorations suceessives.

(3) Op. cit., P. 193.

(4) Op. cit., p. 143 .

(5) La divergence se retrouve en ce qui concerne la sanction de cette exigence. Certains règlements exigent la communication des feuilles de salaire " à toute réquisition, sous peine d'une amende de 5 francs par jour de retard, à partir du surlendemain de la demande. " Règlement de Saint-Gilles, op. cit., p. 197.

(6) Le Conseil communal et la Députation permanente du Brabant 
efficace de contrôle a été établi : d'une manière générale l'Administration surveille elle-même, parfois par la présence d'un fonctionnaire délégué spécialement à cet effet, la paie du salaire minimum.

En ce qui concerne les sanctions proprement dites, la diversité qui semble ainsi caractériser le système belge se retrouve encore; les sanctions les plus ordinaires sont l'amende ( $\mathrm{r}$ ) et, en cas de récidive, l'exclusion temporaire ou définitive du contractant fautif des travaux effectués pour le compte de la province ou de la commune. On rencontre exceptionnellement quelques particularités que relève l'Office du travail belge : une amende par chaque jour de retard apporté à l'exécution, pour chaque contravention au minimum de salaire(2), ou encore la résiliation du contrat conformément à l'article i 84 du Code civil belge.

En somme, les sanctions semblent satisfaisantes.

En résumé, la Belgique nous offre un exemple intéressant et significatif de la tendance au salaire minimum par l'introduction d'une clause relative au salaire dans les cahiers des charges des travaux de l'État et des Idministrations publiques, régionales ou communales.

Il paraît, d'après l'enquête qui nous a servi de guide dans cette étude, que le minimum de salaire est aujourd'hui une réalité. " De même que le minimum s'est étendu successivement à presque tous les travaux entrepris par les Administrations publiques, c'est l'une après l'autre que les catégories professionnelles ont été appelées à bénéficier des avantages que procure l'application du minimum de salaire (3). ")

Ce n'est pas sans résistances, sans luttes, sans efforts continus que pareil résultat a été obtenu. L'exemple de la Belgique est particulièrement remarquable. Les conditions de liberté et d'absence de réglementation dans lesquelles l'idée a triomphé montre toute la force qui est en elle et tout l'avenir qui lui est réservé dans d'autres pays.

paraissent sous ce rapport, eomme sous bien d'autres, tenir la tète du mouvement.

(1) 3o francs à titre d'exemple pour le règlement de la province du Brabant. Op. cit., p. 203.

(2) Commune de Saint-Gilles: règlement du 20 août ıgoo, op. cit., p. 204.

(3) Op. cit., p. II 7 . 


\section{En Allemagne (1).}

\section{L'Etat.}

L'action de l'État est analogue à celle étudiée précédemment : en 1908 , le Reichstag adopta une résolution capitale en ce sens.

En février igo8, par deux fois, lors de la discussion du budget de la Marine et lors de la discussion du budget de la Guerre, le Reichstag a adopté une résolution portant que les travaux nécessaires à ces deux administrations ne pourraient ètre donnés qu'à des établissements qui respectent les prescriptions légales relatives au travail et qui donnent à leurs ouvriers des conditions au moins égales aux conditions prévues dans les contrats collectifs pour la profession ou la localité (2).

En Allemagne, il y a une tendance très marquée à exiger de ceux qui entreprennent des travaux pour le compte des villes ou des provinces (3) qu'ils paient le salaire déterminé par des contrats collectifs. On s'adresse particulièrement dans l'imprimerie aux maisons " tarif-treue ", c'est-àdire fidèles aux tarifs arrêtés entre les organisations patronales et ouvrières intéressées.

\section{Les Municipalités.}

En Allemagne, les municipalités, comme dans les autres pays, jouissent, en ce qui concerne la fixation des condi-

(1) Bibliographie : L'Action sociale des municipalités allemandes, G. Letourneux. Thèse, Paris, Larose, 1911. - Marie Heller. Das Submissionswesen in Deutschland. Iéna, Fischer, 1907. - Heinrich Koch, Arbeiterausschïsse. Munchen Gladbach, 1907. Volksvereins-Verlag. Kaiserlicher Statisticher Amt. [Abteilung für Arbeiterstatistik] : Die Regelung des Arbeitsverhältnisses bei Vergebung öffentlicher Arbeiten, insbesondere in deutschen Städten. Berlin, Heymann, I907.

(2) R. Jay. Discussion au Conseil supérieur du travail, 1908, Compte rendu, p. 17 .

(3) Il en est ainsi pour le Gouvernement royal de Saxe, le Ministère grand-ducal de Saxe, le Gouvernement ducal de Hesse, l'Administration impériale du canal de Kiel, le Ministère prussien du Commerce et de l'Industrie, l'Administration forestière de Halle, la Chambre des députés du royaume de Bavière et quantité d'autres administrations gouvernementales et municipales de l'Empire. Cf. Lefebvre. Le tarif minimum de salaire dans la typographie frangaise, 1). 24. 
tions du travail dans les adjudications de travaux publics, d'une relative liberté.

Un mouvement tout récent tend cependant, comme dans la pratique française, à l'assimilation complète des travaux municipaux aux travaux de l'État, en ce qui concerne l'application de notre clause :

Dès I 899, dans le grand-duché de Bade, la Municipalité de Pforzheim adoptait les conditions de travail imposées par le Gouvernement pour l'exécution des marchés.

En Bavière, en r 903 , une circulaire du 2 avril insiste sur les devoirs des communes envers le personnel employé indirectement ( $\mathbf{r}$ ).

En Prusse, en i9o4, la Chambre des députés, discutant la condition légale des marchés des travaux publics, désira connaître l'état des mesures prises par les municipalités (2). On observa que l'action communale était fort peu marquée. La Chambre le constata par un vou demandant l'adoption par toutes les communes des conditions spéciales de l'État. Deux circulaires gouvernementales, l'une du Ministre du Travail, en 1905 , l'autre du Ministre des Travaux publics, le 3 mars 1906 , insistaient pour l'exécution de ce vœu : " L'Administration centrale, dit la seconde, attache une grande importance à l'adoption, par les communes prussiennes, des dispositions prises par l'État pour réglementer les conditions du travail dans les marchés de travaux. ")

Malgré ce récent mouvement, on est encore loin d'un statut type.

Une enquête, entreprise en I907 par l'Office impérial de statistique, nous permet de résumer à cette date le développement de la clause relative au salaire. A ce sujet, l'enquète divise les villes en deux catégories :

$I^{0}$ Celles qui fixent elles-mêmes un minimum à la rémunération versée par les entreprises à leur personnel; celles où existent vraiment des minima de salaires. Ce sont Strasbourg et Mulhouse seulement;

(I) Kommunale Arbeiter politik. No II de la Soziale Volksbibliothek. München-Gladbach, Volksvereins-Verlag.

(2) Une seule ville en Prusse, Dortmund, avait à cette époque inséré dans les clauses de ses contrats l'intégralité des dispositions adoptées par l’État. 
$2^{\circ}$ Celles qui, sans prendre sur elles la détermination d'un taux obligatoire de salaire, imposent aux entrepreneurs le salaire courant et le plus généralement pratiqué.

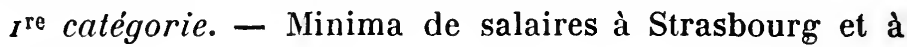
Mulhouse.

L’initiative de Strasbourg est des plus intéressantes (I). Elle débuta par une enquête sur les conditions locales de la main-d'œuvre. La Ville constata une dépression croissante (2) des salaires chez les ouvriers employés indirectement d̀ son service. En r 902, la Ville de Strasbourg institua un taux de salaire minimum horaire pour chaque profession, variant de 25 à 55 pfennigs l'heure. En même temps, en ce qui concerne les travailleurs non qualifiés (ungelernte Arbeiter), elle fixait la somme de 2 marks 5o comme limite inférieure au-dessous de laquelle la rémunération journalière d'aucun ouvrier travaillant à l'exécution des marchés de travaux publics ne pourrait descendre.

Pour quelques métiers très spécialisés, la Ville fixait un minimum journalier. Il est stipulé, en ce cas, que le temps consacré par les ouvriers à la préparation du travail, au transport des outils et des matériaux, au métrage des lieux, ne peut, en aucun cas, donner lieu à une diminution du salaire quotidien.

Enfin, les dispositions ci-dessus ne devaient s'appliquer qu'au cas où il n'existerait aucun contrat collectif entre les syndicats ouvriers d'une profession donnée et les entrepreneurs de travaux publics (3).

Mulhouse adopta un système de minimum de salaire en I 904 . Elle fit une tarification de salaires horaires minima, variable selon les professions, allant de 32 à 60 pfennigs. En aucun cas, un travailleur pleinement capable ne devait toucher moins de 3 marks 20 par jour (4). Le travail aux pièces était interdit. Elle ordonna qu'une affiche reproduisant l'arrêté fixant les minima fût apposée dans tous les chantiers et ateliers.

(1) Soziale Praxis. XVIe année, n6, p. 148.

(2) On constata des salaires journaliers de 1 mark 87 (environ $2 \mathrm{fr}$.)

(3) En 1906, Strasbourg tarifait les heures supplémentaires payées $33 \mathrm{I} / 3 \%$ en sus du salaire ordinaire et les travaux exécutés la nuit ou le dimanche payés $50 \%$ en sus du tarif ordinaire.

(4) Les heures supplémentaires étaient également majorées de $50 \%$. 
Un système sérieux de contrôle était établi : d'une part, les feuilles de paye devaient être présentées par l'entrepreneur sur toute réquisition à des contrôleurs nommés par l'Administration. D'autre part, ceux-ci peuvent assister à la paye des ouvriers.

L'expérience "de minimum de salaire semble avoir été satisfaisante (I).

Le bourgmestre de Strasbourg faisait en effet cette déclaration (2):

" L'interdiction de réduire à moins de 2 marks 5o le montant de la rémunération quotidienne la moins élevée a produit les effets les plus salutaires. Pendant les courtes journées d'hiver, où l'on travaille huit heures seulement, il faut donner aux ouvriers, pour satisfaire aux conditions imposées par la municipalité, un salaire horaire de 3o pfennigs au moins. Antérieurement, on voyait souvent descendre à 24 pfennigs la somme versée pour une besogne de même durée, mais aujourd'hui les individus qui touchent 30 pfennigs en hiver ne consentent pas à voir ce tarif réduit en été. Le taux général de la rémunération se trouve donc amélioré, surtout si l'on considère les parties inférieures de la classe ouvrière : manœuvres, terrassiers, etc... ")

Depuis l'enquête de I907, quelques autres villes ont suivi cet excellent exemple (3).

$2^{\mathrm{e}}$ catégorie. - Salaires courants pratiqués par l'immense majorité des ville (4).

D'après l'enquête de 1907 déjà citée, c'est le cas du plus grand nombre de municipalités : on stipule que le salaire payé par l'entrepreneur sera celui du salaire de la profession correspondante sur le territoire de la commune. Quelques particularités, dépassant ce système que l'on peut appeler de droit commun, sont à relever :

En Bavière, Munich, Augsbourg, Furth, Ratisbonne se refusent à traiter avec des entrepreneurs connus pour n'accorder à leurs ouvriers qu'un salaire notablement inférieur à la moyenne d'usage.

(1) Letourneux, op. cit., p. 115.

(2) Beitrage zur Arbeiterstatistik, no 6, p. 131.

(3) Beitrage zur Arbeiterstatistik, n० 9, 1) 131 .

(4) Beitrage zur Arbeiterstatistik, n" 6, [1. 135. 
,Lugwigshafen inscrit la clause suivante :

"Les ouvriers employés à l'exécution du marché doivent recevoir au moins le salaire usuel de la ville et de la profession; les heures supplémentaires doivent être payées d'après un tarif spécial. Si l'entrepreneur venait à convenir avec son personnel d'attribuer à celui-ci une rémunération collective, cette dernière ne pourrait être calculée de manière à faire décroître le taux quotidien des salaires au-dessous des limites fixées par la ville. "

On rencontre des dispositions semblables encore à Darmstadt dans le grand-duché de Hesse, à Francfort-sur-leMein en Prusse, et à Chemnitz en Saxe.

Dortmund stipule un salaire quotidien de 2 marks 50 au moins pour dix heures de travail.

Enfin un certain nombre de villes exigent, en tout ou en partie, le respect des contrats collectifs existant entre les entrepreneurs et les syndicats ouvriers : telles (I) Munich et Furth (2), Berlin, Breslau, Schöneberg, Cologne, pour toutes leurs adjudications ; telles encore, en Wurtemberg, Stuttgart et Karlsruhe (3), pour leurs commandes d'imprimés; Barmen, pour ses travaux de charpente; Brunswick et Leipzig, pour certaines catégories de marchés. D'autres villes enfin, telles Worms et Offenbach, sans en faire une règle absolue, donnent, dans la majorité des cas, la préférence aux entrepreneurs faisant travailler aux tarifs établis par contrat collectif.

Quelques autres villes enfin (4) se contentent d'une certaine surveillance sur les salaires, en stipulant à leur profit le droit de faire communiquer au magistrat ou aux chefs des services compétents le texte des contrats passés par l'entrepreneur avec les ouvriers ou les sous-traitants (5).

(I) Il faut rappeler ici Strasbourg et Mulhouse citées ci-dessus.

(2) Les récalcitrants sont, pour l'avenir, exclus de tout traité avec l'Administration municipale.

(3) Cette dernière ville se réfère expressément à un contrat collectlf nommément désigné, celui de l'Association générale des imprimeries allemandes (Tarifgemeinschaft der deutsehen Druckereen).

(4) Konisberg, Dantzig, Charlottenbourg, Cassel, Aix-la-Chapelle, Dusseldorf, etc.

(5) Le marchandage est exceptionnellement interdit dans les municipalités allemandes : le plus souvent, le contrat de marchandage doit être autorisé par la municipalité. 
C'est un premier pas dans la voie de l'intervention de la commune dans la question des salaires (I).

La sanction de ces diverses clauses est d'ailleurs fort variable; elle se trouve soit dans le choix des contremaîtres ou chefs de chantier, soit *dans la création d'inspecteurs spéciaux, soit dans l'établissement d'astreintes (2).

On voit, en résumé, que, dans l'ensemble, les municipalités allemandes, en ce qui concerne le salaire, s'en réfèrent aux “ usages locaux ». Quelques initiatives, ci-dessus relevées, montrent que l'on peut et que l'on doit dépasser cette timidité.

Pour être moins avancé dans sa totalité que dans d'autres pays, le mouvement en Allemagne est néanmoins en constant progrès et plein de promesses pour l'avenir.

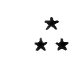

Le mouvement se poursuit avec des vicissitudes diverses en Hollande et en Suisse, en Australie, aux États-Unis, en Espagne.

Il est inutile de répéter ici, une fois de plus, les résultats d'une politique de salaires parfaitement analogue.

Il faut mentionner encore parmi les pays étrangers où la réalisation indirecte du minimum de salaire par l'introduction de la même clause a été poursuivie, le Canada (3). Ce pays a pris de nombreuses mesures pour introduire des salaires équitables dans les contrats du Gouvernement.

(1) Cf. Von de Thiessen. Soziale Tätiglieit der Stadtgemeiden, $4^{\mathrm{e}}$ èd. Gladbach, Berlin I9II.

(2) Beitrage zur Arbeiterstatistik, $\mathrm{n}^{\circ}$ 6, 152.

(3) Cf. Questions pratiques de législation ouvrière, 1901, 1. 29. 


\section{CHAPITRE III}

\section{Vers le Minimum de salaire par l'Introduction de la lésion dans le Contrat de travail.}

Longtemps, en France et à l'étranger, le contrat de travail, par suite du triomphe des idées individualistes, a été laissé entièrement soumis au principe de la liberté des conventions; le législateur n'avait nullement souci de le réglementer. En France encore, l'article i 34 du Code civil dispose : "Les conventions légalement formées tiennent lieu de loi à ceux qui les ont faites. "L'article I I 8 spécifie que " la lésion ne vicie les conventions que dans certains cas ou à l'égard de certaines personnes (I)".

Mais voici que certaines législations étrangères, par des voies diverses d'ailleurs, modifient cette ancienne conception; un très fort courant contemporain se dessine dans le sens de l'introduction de l'idée de lésion dans le contrat de travail (2).

A l'étranger (3), la réforme est aujourd'hui opérée en Allemagne et en Suisse.

En Allemagne, la disposition nouvelle est celle de l'article r 38 du Code civil allemand : "L'acte juridique con-

(r) On sait qu'il s'agit pour les contrats de la vente d'immeubles (lésion de plus des sept douzièmes) et du partage (lésion de plus du quart) et pour les personnes, des mineurs. (Art. 384 G. civ.) Il n'est nullement question du louage d'ouvrage.

(2) P. Gerlier. Des stipulations usuraires dans le contrat de travail. Thèse, Paris, 1907.

(3) Cf. Brants. La Lutte contre l'usure dans les lois modernes, I vol., Paris, Larose, rgor. - E. Lüders. Heimarbeitfragen in Deutschland, rapport à l'Assemblée générale de la Protection des travailleurs. Zurich, 19r2. - Dr Waldemar Zimmermann. Arbeitsvertrag und gute Sitten, Sozial Praxis XXI, nos 16 et 17.

L'idée a été indiquée dès 1891 par Ed. Van der Smissen, professeur à l’Université de Liége : "Études sur le contrat de travail », dans la Revue du monde catholique, Paris, Palmé, 1891. 
traire aux bonnes mœurs est nul. Est nul notamment celui par lequel, en profitant des embarras, de la légèreté ou de l'inexpérience d'une autre personne, on se fait promettre ou accorder à soi ou à un tiers, pour une prestation, des avantages pécuniaires qui excèdent la contre-valeur, de telle sorte que d'après les circonstances, la disproportion est évidente. ")

Ce texte dépasse bien évidemment par sa portée le seul contrat de travail; il est cependant très symptomatique des tendances de l'opinion moderne.

La nullité de l'acte entaché de lésion est ici rattachée à une cause de nullité plus large que la lésion : il y a atteinte aux bonnes mœurs. Dans le système allemand, c'est le juge qui devra l'apprécier d'après les circonstances : c'est la conscience publique qui servira au juge à apprécier la clause du contrat.

Cette extension était une conséquence de l'innovation apportée par le Code civil dans l'appréciation de l'exploitation usuraire. "Au système forfaitaire d'autrefois, dit M. Saleilles, on a substitué la recherche de l'exploitation individuelle pour chaque espèce en particulier, recherche fondée sur la preuve préalable de la disproportion des équivalents. C'est une présomption de fait qui peut faciliter la preuve de la contrainte morale. "

Le critérium est désormais le scandale produit du chef de l'exploitation d'un individu. On entendait consacrer (I) " non pas l'idéal de moralité théorique que le juge peut se faire en soi, ce qui ne serait, sous une apparence d'objectivité, qu'une pure conception subjective, mais l'idéal répondant en fait à la conscience publique et servant de critérium à l'opinion pour apprécier ce que l'on doit appeler les bonnes mours (2)".

Le juge devra donc décider si l'exploitation usuraire est contraire aux bons usages, c'est-à-dire aux usages tels que la moyenne des honnêtes gens les conçoit et les désire (3).

(1) Art. Bulletin de la Société d'études législatives, I906, p. 220.

(2) Saleilles. La Déclaration unilatérale de volonté, Igor, p. 270.

(3) En matière de contrat de travail, ce sentiment des bons usages sera assurément fort délicat à déterminer. Il restera, à défaut de l'unanimité qui manquera, beaucoup de place au sentiment personuel du juge. 
Quelques-unes des applications jurisprudentielles de l'article $\mathrm{s} 38$ sont précisément relatives au contrat de travail (I).

Un jugement de Francfort-sur-le-Mein, du 8 juin I902, annule, pour disproportion évidente entre le travail fourni et le salaire payé, le contrat qui attribuait à un ouvrier de dix-neuf ans le simple entretien (freie station, environ I mark 40), alors que le salaire usuel était dans la localité de 3 marks io.

D'autres décisions annulent le contrat d'une directrice de succursale payée 3o marks par mois, ayant la charge d'une responsabilité écrasante; celui d'une employée vendeuse de vingt ans travaillant onze heures par jour et payée seulement 25 marks par mois.

Encore, le Tribunal industriel de Stuttgart (29 avril 1900) annula pareillement le contrat d'une ouvrière de fabrique payée pour dix heures et demie de labeur quotidien au salaire infime de 25 marks par mois (2).

Enfin, le Tribunal industriel de Berlin ( ${ }^{\text {re }}$ Chambre) a rendu le 27 février igra (3) une intéressante décision concernant le travail à domicile : une ouvrière en vêtements pour dames avait reçu de la firme S. u. M. un salaire dérisoire de 60 pfennigs pièce, pour r 9 vêtements cousus. Cette excessive réduction du salaire, que le Tribunal estimait de $40 \%$ au moins, ne s'expliquait que par la crainte chez l'ouvrière de ne point trouver de travail. Le tribunal appliqua l'article $138 \mathrm{du}$ Code civil et alloua un salaire de I mark par objet.

Sans doute ces décisions ne sont pas aussi nombreuses qu'on aurait pu le croire (4). La jurisprudence allemande

(1) Cf. Brants. La Lutte contre l'usure dans les lois modernes, I vol., Paris, Larose, 1907, pp. r2o et suiv.

(2) Dans cette espèce, l'ouvrière avait quitté, sans observer le délaicongé, son premier patron pour trouver un nouvel atelier où elle gagnait 6o marks. Elle était poursuivie par le premier patron en dommages-intérèts pour inobservation des délais d'usage. Le Tribunal donna gain de cause à l'ouvrière en annulant le contrat usuraire.

(3) Cf. Lüders, op. cit., p. 18.

(4) Cela tient aussi à la date relativement récente de la mise en vigueur du Code eivil allemand et à la tendance de la jurisprudence allemande de limiter la portée de l'innovation, en refusant d'en faire un instrument de perturbation économique ou une arme de guerre sociale. 11 y a tout au plus une demi-douzaine de cas concernant le travail à domicile. Cf. Lüders, op. cit., p. 15. 
tend à admettre (i), pour appliquer l'article i38 au contrat de travail, qu'il faut une disproportion choquante sans nécessité de calcul pour constater l'écart, c'est-à-dire exploitation, et aussi ausbeutung, c'est-à-dire la prise sur un vaincu comme par extorsion. Elle a même admis parfois l'excuse du salaire courant comme une circonstance excluant la disproportion choquante (2).

Cependant ces décisions sont suffisamment significatives pour montrer tout l'intérèt du principe pris par la législation nouvelle. Quand la jurisprudence sera pleinement développée, avec ou sans des modifications législatives (3) nouvelles, le principe de l'exploitation usuraire est appelé à vulgariser la notion d'un salaire juste et raisonnable et contribuera par là à hâter le mouvement vers le minimum de salaire (4).

En Suisse, le nouveau Code civil contient une disposition analogue :

Art. 2i du Code des obligations : " Un contrat dans lequel il y a une disproportion évidente entre la prestation promise par l'une des parties et la contre-prestation de l'autre peut être rescindé, dans le délai d'un an, à la demande de la partie lésée, si la lésion a été déterminée

(1) G. Gerlier, op. cit., p. 132 .

(2) Sur un autre terrain, celui des pratiques commerciales incorrectes, la Cour d'appel de Hambourg avait refusé d'admettre la lésion par ee considérant: "Cela se passe tous les jours ainsi dans le libre commerce.» Le Tribunal supérieur de Leipzig réforma en refusant au juge le droit de puiser les éléments de son information dans " des habitudes professionnelles locales qui pourraient être très incorrectes ».

(3) On a proposé de prendre les arrangements collectifs comme base des bonnes mours, sorte de coutume du métier, dans la profession. Cf. Brants, op. cit.

(4) Il est superflu d'insister sur le caractère forcément limité de cette législation civile en face du mal du travail à domicile. Les intéressés n'ont ordinairement pas la possibilité de poursuive l'employeur devant les tribunaux, et puis, que leur importerait de faire rectifier les conditions de leur emploi, si par là ils perdent cet emplos lui-même? Cf. Lüders, op. cit., p. rg. " Une amélioration de toute une catégorie de salaires, au moyen de jugements basés sur la morale, est pratiquement impossible. » 
par l'exploitation de sa gêne, de sa légèreté ou de son inexpérience (I). $\nu$

On remarquera que cette législation diffère de la précédente sur deux points :

I $^{0}$ La définition de la lésion est ici beaucoup plus large : on n'exige plus, comme en Allemagne, que pour apprécier la disproportion des équivalents on tienne compte des circonstances de fait qui servent à former l'opinion publique. On ne parle même plus de disproportion choquante. La disproportion anormale suffit. C'est une bien plus grande liberté laissée au juge.

$2^{0}$ La sanction n'est plus qu'une nullité relative, dirionsnous en notre droit français, ouverte au seul intéressé et non plus une nullité absolue pour violation de bonnes moeurs (2).

Encore à l'étranger et comme symptôme des idées nouvelles sur notre question, il faut signaler le projet de loi italien de rgo2 sur le contrat de travail, qui était ainsi défini : "Celui par lequel un ouvrier ou autre travailleur manuel s'oblige au service d'un entrepreneur ou patron moyennant un juste salaire (equa retribuzione) que celui-ci s'oblige à lui payer (3). " Les mots du texte sont assurément ambigus et l'on ne sait au juste si l'on visait ainsi le salaire usuraire proprement dit ou le salaire injuste(4)? Cette pro-

(I) Loi fédérale du 30 mars igi complétant le Code civil suisse. (Liv. V, "Des obligations ».) Feuille fédérale suisse, Lxin ${ }^{\circ}$ année, vol. II, $n^{0} 14,5$ avril 1911.

(2) Il faut encore citer l'article 957 du projet hongrois qui renferme un texte analogue au texte allemand et fait de l'exploitation usuraire une violation de l'ordre public.

Il est curieux de constater que tout ce mouvement législatif contemporain à l'étranger a été en quelque sorte abrité sous l'autorité de l'article 6 de notre Code civil (ordre public et bonnes mœurs). Comme le dit M. Saleilles (art. cit., p. 222), est-ce à nous de protester contre l'influence civilisatrice et généreuse qu'on nous attribue ?

(3) G. Bevilacqua. Saggio su la legislazione operaia in Italia. Turin, 1906. Gerlier, op. cit., p. 189, note 2.

(4) 11 paraìt cependant que c'était le salaire usuraire qui était visé. L'un des commentateurs de ce texte (Camillo Cavignari. Studi sul contratto di lavoro, Rome, 1902) affirmait que le juste salaire (equa retribuzione) était déterminé par un critère général, l'absence d'exploitation de l'ouvrier (non sfuttare la condizione del operaio) et le fait de ne 
position fut d'ailleurs repoussée par la Commission du travail de la Chambre italienne.

Également intéressant est le texte de la loi roumaine du 23 décembre 1907 (5 janvier i908) sur les conventions dans l'agriculture (I) :

L'article 45 de cette loi indique pour le cas où le propriétaire ou le fermier, lors de l'engagement, s'est chargé de nourrir le paysan, que la quantité de nourriture fournie ne doit pas être inférieure au minimum nécessaire déterminé par le Conseil supérieur d'hygiène. "La nourriture doit être de bonne qualité, saine et donnée en quantité suffisante. Dans le cas contraire, le paysan peut faire constater par le maire que la nourriture ne répond pas aux conditions prescrites. Si le maire reconnait le bien-fondé de la plainte, il prescrit, dans une décision sans appel signifiée au propriétaire ou au fermier, que la valeur de la nourriture doit ètre payée en argent au paysan (2). ")

En France, on n'en est encore qu'aux projets législatifs. La jurisprudence, en évolution sur d'autres points analogues (3) comme la réduction des obligations excessives ou la modification des clauses pénales excessives, n'a pas pu déroger, en matière de contrat de travail, au principe de la liberté des conventions. Elle reste fixée par divers arrêts de Cassation déjà anciens :

Cass., I 2 déc. I 853 (4), et Cass., 20 déc. I 852 (5).

pas abuser des circonstances dans lesquelles se trouve l'employé par le fait du chòmage ou de tout autre motif indépendant d'une faute de sa part.

(1) Bulletin de l'Offce intern. du travail, 1910, p. 165.

(2) Cf. plus loin aux annexes, p. 502, le texte intégral de cet article 45.

(3) Cf. Duthoit. "L'injustice usuraire vis-à-vis du droit moderne ». Semaine sociale de Rouen, 1910, compte rendu, p. 216.

R. Jay. "La lésion dans le contrat de travail ". Revue populaire d'économie sociale, févr. 1907.

(4) S. 54. I. 333.

(5) S. 53. I. 101. 
“ En droit, toute convention légalement formée tient lieu de loi à ceux qui l'ont faite et c'est une convention légalement formée que celle par laquelle un maître et un ouvrier arrètent librement et de commun accord le montant d'un salaire pour un ouvrage déterminé. "

On ne saurait songer à invoquer, en l'état actuel des textes, ni l'article 6 du Code civil sur l'ordre public, ni l'article I I 4 du Corle civil sur la violence morale.

L'article 6 est d'une application heureusement rare, à cause de la notion fort relative d'ordre public, et ici on ne saurait considérer que la disproportion des équivalents dans un contrat suffit à troubler cet ordre public. D'ailleurs trop souvent l'ordre public, considéré sous le rapport social et politique, si on l'interprète du moins par la conscience contemporaine, ne paraît pas contraire à ces exploitations abusives dans la pensée de la plupart de nos contemporains.

L'article i i 4 du Code civil n'est pas davantage applicable : on ne peut songer à dire que l'exploitation abusive constitue un cas de vice du consentement; en effet, pour que la violence soit admise comme vice du consentement, il faut qu'elle émane soit de l'autre partie, soit d'un tiers. Or, ici, l'état de gêne dans lequel se trouve l'une des parties ne constitue pas, à rigoureusement parler, une part d'intervention ou de pression personnelle émanant du cocontractant. L'article I I 4 est inapplicable ( 1 ).

En l'état actuel de nos textes, une loi est indispensable pour modifier la situation, et à cet égard trois projets sont en présence.

Nous trouvons en présence :

Le projet de la Société d'études législatives, article II ;

Le projet du Gouvernement de I906, article I ;

Le projet de la Commission du travail de la Chambre.

L'article I I de la Société d'études législatives dispose :

" Est considérée comme illicite toute clause du contrat de travail par laquelle l'une des parties a abusé du besoin, de la légèreté ou de l'inexpérience de l'autre pour lui imposer des conditions en désaccord choquant avec les conditions habituelles de la profession et de la région. ") 
Ce premier texte vise, d'après les explications fournies (r), exclusivement le cas d'exploitation individuelle : il subordonne la nullité à l'exploitation abusive et au cas où les conditions du contrat sont en désaccord choquant avec les conditions habituelles de la professión et de la région. La sanction est la nullité qui peut en certains cas entrainer des dommages-intérêts. Le rapporteur, et ceci nous intéresse particulièrement au point de vue qui est le nòtre dans cette étude, espérait une autre sanction, celle de l'opinion publique : "En dehors mème de cette idée de sanction d'ordre pécuniaire, la faculté nécessaire aux intéressés de déférer aux tribunaux les contrats de travail contenant des dispositions léonines aura certainement pour effet de créer des courants d'opinion et sera de nature, dans bien des cas, à prévenir les abus (2).

On peut, arec M. Jay (3), douter de l'efficacité d'un pareil texte. Il laisse subsister les abus les plus regrettables, ceux qui concernent toute une catégorie d'ouvriers dans un milieu donné, par exemple les salaires de famine des ouvriers et ouvrières à domicile, puisqu'ici ces conditions de travail sont consacrées par l'usage. " Le juge devra s'incliner toutes les fois qu'il se trouvera en face de quelques-unes de ces situations où tous les ouvriers d'une région ou d'une profession souffrent des conditions de travail qui leur sont imposées, si par exemple il se trouve en face de certains travailleurs à domicile ou de ces femmes qui, employées dans la lingerie, lans la confection, etc..., ne reçoivent qu'un salaire insuffisant pour vivre (4). ")

Néanmoins les discussions très brillantes à l'assemblée générale de la Société d'études législatives ont montré combien un texte de ce genre pourrait avoir une large portée

(1) Cf. Rapport écrit Perreau. Bulletin de la Société d'études législatives, 1905̄, p. 5ı3. - Rapport oral Perreau. Ibid., 1906, p. 84, et la discussion en séance générale. Ibid., 1øo6, p. 94.

(2) Perreau, Rapport écrit. Bulletin de la Société d'études législatives, 1905 , p. 515.

(3) Cf. Son intervention dans la discussion. Bulletin de la Société d'études législatives, 1906, pp. 87 et 176 .

(4) M. Jay, loc. cit. Il paraît d'ailleurs résulter de la discussion que e'est à dessein et par crainte de l'arbitraire ou d'allure révolutionnaire que la Commission a intentionnellement réduit la portée du texte. Cif. Colson dans la discussion, 1. 178 . 
sociale. Il faut espérer que l'article i I du projet n'est qu'une étape provisoire dans l'évolution des idées et des textes législatifs.

Le second projet est celui du Gouvernement (I) déposé le 2 juillet I go6. Il déclare (art. I I) illicite " toute clause du contrat de travail par laquelle l'une des parties a abusé du besoin, de la légèreté ou de l'inexpérience de l'autre pour lui imposer des conditions en désaccord flagrant soit avec les conditions habituelles de la profession ou de la région, soit avec la valeur ou l'importance des services engagés ").

Ce texte va beaucoup plus loin que le précédent : il permettrait d'atteindre même le cas de lésion usuraire sanctionné par l'usage professionnel ou local. Il permettrait vraiment aux décisions d'espèces de modifier peu à peu la coutume; et la jurisprudence dans ce système pourrait être un facteur efficace de l'évolution du droit.

On lui a reproché (2), il est vrai, de favoriser l'arbitraire du juge et d'engendrer l'instabilité légale du salaire.

Ce projet est d'ailleurs devenu caduc avec la nouvelle législature.

Il y a enfin un troisième texte qui est celui de la Commission du travail de la Chambre (I). Il est ainsi conçu :

" Le contrat de travail peut ètre rescindé avec allocation de dommages et intérèts lorsque ses conditions sont en désaccord flagrant soit avec les conditions habituelles de la profession et de la région, soit avec la valeur ou l'importance des prestations échangées. ")

C'est, pour la définition de l'exploitation usuraire, le texte même du Gouvernement : la nullité est seulement rattachée aux vices du consentement (art. i I 2 du Code civil). On peut craindre alors que l'article i I 5 du même Code, qui déclare que l'action en nullité n'est plus recevable si, depuis que la violence a cessé, le contrat a été approuvé expressément ou tacitement, ne soit une fin de non-recevoir opposée à l'ouvrier qui aurait exécuté le contrat et que, par là,

(1) Ch., Doc. parlem., I906, no 158.

(2) M. Millerand à la Section française de l'Association internationale pour la protection légale des travailleurs. Le Contrat de travail (examen du projet de loi du gouvernement), I vol., Paris, Alcan, 1907, p. 165.

(3) Rapport Chambon. Ch., Doc. parlem., 1907, no 1409, déposé le 27 déc. 1907 . 
l'arme nouvelle que l'on voulait forger ne s'émousse au moment même où il conviendrait d'en faire usage ( $\mathrm{I}$ ).

Au total, à des degrés divers, les textes proposés tendent à introduire la répression civile de l'exploitation usuraire dans le contrat de travail. Ils sont un acheminement vers l'action du juge réformateur des abus (2).

L’Assemblée de Lugano (3), composée des délégués de l'Association pour la protection légale des travailleurs, a voté en i 9 Io la résolution suivante :

"L'Assemblée recommande l'affirmation, dans la législation de chaque pays, du principe permettant d'annuler et de réprimer les contrats stipulant des salaires insuffisants et usuraires. Elle considère ce principe comme essentiel, tout en reconnaissant que les difficultés de son application judiciaire en limitent trop l'efficacité pour que l'adoption de ce principe suffise à résoudre pratiquement, mème en partie, le problème (4). ")

Des discussions auxquelles a donné lieu le vote de cette résolution il paraît bien résulter que le principe nouveau, tout en étant la proclamation du juste salaire, rencontre de sérieuses difficultés pratiques. "L'article I 38 du Code civil allemand, disait M. Jay, rapporteur de la Commission, pourrait être invoqué en faveur des travailleurs à domicile. En fait, il ne l'est pas. Nous pensons qu'il en serait de mème de tout texte de ce genre, de tout texte de pur droit civil, surtout pour cette raison que l'application de pareils textes exige des intéressés des initiatives dont les ouvriers, et surtout les ouvriers à domicile, sont, le plus souvent, incapables (5). ")

(r) Il faut mentionner encore un texte analogue voté par la section française de l'Association internationale pour la protection légale des travailleurs qui ne diffère que par des nuances des précédents. Voir $L e$ Contrat de travail, vol. cité, p. 154, et l'intéressante diseussion à son sujel.

(2) Pour être complet, il faudrait encore rappeler ici le décret de I 848 sur le marchandage qui, dans la pensée de ses auteurs, constituait en lui-même un procédé abusif et amenant incessamment l'exploitation. On sait que, par suite de l'interprétation de la jurisprudence, la portée de ce texte s'est trouvée singulièrement restreinte. On retrouvera dans les projets de réforme, sur ce point, l'expression de la même idée.

(3) Compte rendu de l'Assemblée de Lugano pour la protection légale des travailleurs, 1910 , p. 185.

(4) Ibid.

(5) Compte rendu, op. cit., p. 44. Dans le même sens, M. Brants, ibid. p. 51 . 
Quoi qu'il en soit de l'avenir de ces projets, leur adoption en France aurait certainement son action favorable sur l'introduction du minimum de salaire.

L'accueil fait aux idées nouvelles suffirait à le montrer :

M. Lyon-Caen (I) disait : "C'est entrer dans une voie dangereuse que de confier au juge le soin d'apprécier si le contrat n'est pas désavantageux pour l'un des contractants. C'est lui donner l'appréciation du salaire stipulé ; c'est l'investir du pouvoir de fixer un salaire minimum auquel il aura à comparer le salaire stipulé. ")

M. Berthélemy apercevait nettement les tendances nouvelles et disait à la discussion du projet en séance générale (2), à propos de l'inégalité des parties dans le contrat le travail : "Cela vous choque particulièrement dans le contrat de travail, parce que c'est le contrat des humbles, des petits, et que vous vous intéressez justement au sort des humbles; mais cela vous choquera demain dans le contrat de transport, dans le contrat d'assurance, cela vous choquera partout, et vous serez tentés de substituer à la libre volonté des individus l'intervention légale et le tarif légal; et je vois le temps où le tarif légal viendra fixer les conditions élémentaires de la vie. ")

Pareilles appréhensions sont, de fait, justifiées : il est certain que le jour où l'abaissement du salaire par l'explojtation individuelle sera devenu une cause de lésion dans les contrats, l'idée du minimum de salaire, sans être par cela même réalisée (3), aura fait un grand pas.

La législation nouvelle vaudra surtout pour éveiller l'opinion et la conscience publiques : on verra enfin reculer cette opinion encore trop répandue et que formulait si crûment un directeur d'une grande entreprise : " La science industrielle consiste à obtenir d'un homme le maximum de travail en le rémunérant le moins possible (4). ) Sans doute on n'aura atteint qu'une série d'abus individuels, mais on sait combien ceux-ci sont, en quelque sorte, impliqués par

(I) Rapport sur le projet concernant le contrat de travail à la Société d'économie politique. Journal des Economistes, octobre 1906, p. 88.

(2) Bulletin de la Société d'études législatives, I906, p. 155.

(3) Cf. à ce sujet, P. Gerlier, Des stipulations usuraires dans le contrat de travail, p. 38.

(4) Enquête de la Commission du travail belge en I886, t. I. Rép. 2220. 
l'état présent de nos mœurs et les nécessités pratiques de la concurrence.

Cette pénétration de l'idée de lésion dans le contrat de travail (I) serait certainement un acheminement lent, mais sùr, vers le minimum de salaire.

Il y a là surtout une action indirecte et éducative bien faite pour préparer les esprits à l'idée d'un minimum de salaire. Ce mouvement de fait marque la ruine définitive, il faut l'espérer, de l'ancienne conception libérale : dans un contrat de travail, toutes les clauses, quelles qu'elles soient, sont licites si elles résultent du libre accord des volontés. Il tend à reprendre la théorie de l'injustice usuraire du contrat, si étroitement liée à la théorie du salaire minimum.

(r) Elle implique nécessairement la formation d'une sorte de coutume du salaire juste et convenable. C'est, une fois de plus, le ròle de l'éducation et de l'opinion dans le problème du minimum de salaire. 


\section{CH.APITRE IV}

Vers le Minimum de salaire par la Diffusion des Assurances sociales en tout ou partie à la charge de l'Employeur.

Un troisième mouvement contemporain en faveur du minimum de salaire se dessine encore par la diffusion des assurances sociales en tout ou en partie à la charge de l'employeur.

C'est là certainement un moyen très indirect, mais par contre très répandu, et dont l'efficacité paraît d'autant plus certaine qu'il ne risque pas de soulever les objections que suscite l'établissement direct d'un minimum de salaire obligatoire.

On sait, en effet, par des enquètes précises et des documents incontestables, que le salaire serait, dans bien des cas, à peu près suffisant pour faire vivre l'ouvrier aux époques où il travaille, aux moments où il a réellement la disposition de cet unique revenu. Mais lorsque l'ouvrier est soumis aux différents risques (vieillesse, maladie, incapacité, chômage, accident), le salaire, à lui seul, n'est pas suffisant pour lui permettre d'y faire face : la crise individuelle se déclare, le salaire manque de l'élasticité voulue pour permettre au travailleur d'y parer.

Des études récentes (I) sur les budgets ouvriers le montrent très nettement :

Les enquêteurs de l'Office du travail (2) ont cherché à évaluer les diverses parties du budget ouvrier (logement, chauffage, alimentation), en 1892 , pour une famille de six

(I) Plus anciennement, Engel et Brentano avaient calculé que le prix de la sécurité complète pour l'ouvrier serait de 173 marks (216 fr. 25), ce qui impliquerait un salaire annuel de r.083 marks (1.354 fr.). Beaucoup d'ouvriers restent au-dessous de cette moyenne. Jay. L'assurance ouvrière obligatoire, Revue d'E.P., ı899, pp. 107 et 108.

(2) Op. cit., 1896. 
personnes : les budgets analysés montrent partout le peu d'élasticité du budget et son impossibilité de faire face aux dépenses d'assurance.

L'enquête sur le travail à domicile confirme ces résullats (I).

Diverses statistiques officielles permettent de maintenir la même affirmation :

C'est ainsi que le recensement des industries et autres en Belgique en 1896 (2) établit pour les ouvriers de plus de i 6 ans que sur 67 I.5 I ouvriers :

is 3.000 , soit le I/5 environ, gagnaient moins de $2 \mathrm{fr}$. 50 par jour.

87.000 , soit le I/ 7 environ, gagnaient de 2 fr. 50 à 3 fr. par jour.

I00.00o, soit le I/6 environ, gagnaient de 3 fr. à 3 fr. 50 par jour.

I 6.000 , soit le I $/ 5$ environ, gagnaient de 3 fr. 50 à 4 fr. 50 par jour.

50.000 , soit le I/ io environ, gagnaient plus de 4 fr. 50 par jour.

Et pour les ouvrières de plus de r6 ans, l'enquête signalait :

30.000 ou les 4/ Io environ gagnant moins de I fr. 5o par jour.

37.000 ou les 5/Io environ gagnant de I fr. 50 à 2 fr. 50 par jour.

9.000 ou les I/ Io environ gagnant plus de 2 fr. 50 par jour.

Sur ces données jointes au recensement professionnel français (3) de $\mathbf{I} 896$, une étude récente de M. René Risser (4) établit pour les ouvriers français l'échelle de salaires suivante pour les ouvriers adultes :

I07.I34 gagnant moins de 2 fr. 50 par jour.

278.028 gagnant moins de 2 fr. 50 à 4 fr. 50 par jour.

(I) Office du travail. Enquête sur le travail à domicile, I9IO-II.

(2) Tome XVIII du Recensement des industries et métiers en Belgique, 1896 : les taux des salaires ont été établis d'après les livres de paie des chefs d'entreprise pour la dernière paye normale qui a précédé le recensement, fin octobre 1896 .

(3) Office de travail. Salaires, durée du travail et coût de la vie pour certaines catégories de salariés en Igo6. (Direction du travail.)

(4) Mécanisme historique, actuariel et Jnancier de la loi des retraites ouvrieres et paysannes. Paris, édition des Juris classeurs, I9I I, P. 23. 
47.5 17 gagnant plus de 4 fr. 50 par jour.

28.045 gagnant plus de 5 fr. par jour (I).

9.149 gagnant plus de 6 fr. par jour.

De même pour les ouvrières adultes de plus de i6 ans, l'autre échelle suivante :

30.000 gagnant I fr. 25 par jour.

37.000 gagnant entre $\mathrm{I}$ fr. 5 o et 2 fr. 50 par jour.

9.000 gagnant $3 \mathrm{fr}$. par jour (2).

C'est la démonstration manifeste par la statistique de l'insuffisance des salaires pour l'assurance, bien des fois constatée d'ailleurs.

Ainsi, à l'ordinaire, le salaire manque d'une partie complémentaire pour parer aux différents risques sociaux.

On comprend alors que l'État songe à introduire nécessairement cette partie indispensable sous forme de primes d'assurances dans le système actuel des assurances obligatoires : en mettant à la charge de l'employeur pour totalité ou partie le paiement de ces primes, l'État agit nettement dans le sens d'une élévation de salaires : il s'oriente indirectement mais sùrement vers l'idée du minimum de salaire.

Les assurances sociales - dans la mesure où elles ont été organisées sur le principe de l'obligation - n'ont au fond pas d'autre base sociale et juridique.

Il en est ainsi d'abord pour l'assurance accident fondée, comme chacun sait, sur l'idée du risque professionnel.

"Admettre le risque professionnel, écrit M. Jay (3), n’est-ce pas poser en principe que, en dehors du salaire représentant ce qui est nécessaire pour sa subsistance quotidienne, le patron doit encore à l'ouvrier la garantie de son droit à l'existence le jour où un accident supprime ou diminue sa capacité de travail? "

Sans doute, dès le début, tous n'avaient pas admis cette conception : le risque professionnel apparaissait surtout comme un déplacement de la preuve, un moyen d'assurer

(I) 37.000 ouvriers adultes seulement ont un salaire journalier supérieur à 5 francs.

(2) Le mème auteur arrive comme salaire moyen journalier de l'ouvrier âgé de moins de 16 ans, 1 fr. 27 , et de l'ouvrière de moins de 16 an , o fr. 66.

(3) La protection légale des travailleurs, $2^{\mathrm{e}}$ édition, Paris, Larose, 1910 , p. 285 . 
la réparation de l'accident, lorsque la véritable responsabilité ne peut pas ètre établie (I).

Cependant quelques adversaires éclairés de l'idée nouvelle, Léon Say et M. Yves Guyot, en avaient dès l'origine aperçu toute là portée : "Le risque professionnel c'est le risque de vie», disaitl'un (2). "Nous sommes exposés tous les jours, disait l'autre (3), à des risques de tout genre. Quand des institutions quelconques prennent en charge les risques professionnels en déchargeant l'individu de toute responsabilité, elles premnent à leur compte ou au compte de la collectivité le risque de tout le monde, et cela conduit loin. "

Et aujourd'hui, sans peut-ètre qu'on s'en rende toujours exactement compte, la notion du risque professionnel, étendue et élargie, ne se peut plus concevoir que comme la conséquence de cette idée que l'employeur doit à l'employé un salaire suffisant pour lui permettre de vivre, comme un corollaire de l'idée de salaire minimum.

Sans cela, comment expliquer les extensions successives de la loi et de la jurisprudence? Comment justifier l'extension du système aux entreprises commerciales par la loi du I2 avril igo6? Comment comprendre la jurisprudence française sur l'article I $^{\text {er }}$ de la loi du 9 avril I 898 appelée à déterminer les éléments constitutifs de l'accident professionnel et à interpréter les termes par le fait ou à l'occasion du travail (4)?

Comment justifier aussi les décisions sur le caractère incessible et insaisissable du capital substitué à la rente qui a, comme elle, une cause alimentaire. (Arrêts Cass., 17 nov. I908 et 18 nov. I908).

(1) C. Congrès international des accidents au travail, 1889, t. II, p. 208.

(2) Léon Say, cité par M. Yves Guyot. Ibid., p. 208.

(3) Ibid., p. 208.

(4) Cass., arrêt du 18 février 1908. S. I9ı. I. 25I; Cass., arrèt du 17 juillet 1907. S. 10. 1. 206. Tout accident survenu au lieu et à l'heure du travail doit être considérć comme arrivé à l'occasion du travail; le risque professionnel mis à la charge du patron n'est pas seulement inhérent à la besogne assignée à chaque ouvrier, mais à l'ensemble des moyens mis en œuvre pour atteindre une production déterminée. L'obligation du chef d'entreprise d'assurer la sécurité de ses ouvriers ne cesse que là où son autorité prend fin et il doit protéger ses employés contre leur propre imprévoyance. Cr. Pic. Traté élém. de législ. ind., $2^{e}$ édit., ıgł2, pl). $9^{1} 7$ et suiv. 
Les autres assurances sociales n'ont pas d'ailleurs un autre fondement : "c'est en réalité l'industrie obligée de garantir l'ouvrier et sa famille contre les risques qui les menacent (I). " Déjà, dès 1889 , M. Dejace avait fort exactement entrevu l'idée : "Si l'État s'arroge le droit de prémunir l'ouvrier contre les suites fàcheuses de tous les accidents industriels, si dans ce but il fait table rase de la responsabilité de droit commun et lui substitue l'obligation pour les patrons d'assurer leur personnel, s'il intervient lui-mème dans le paiement des indemnités, si à tout le moins il garantit l'avenir financier des syndicats d'assurance, pourquoi s'arrêter à ces demi-mesures? L'ouvrier ne souffre pas seulement des suites de la maladie ou des accidents, il souffre aussi des suites de la vieillesse. L'âge raidit son bras, la faiblesse trahit sa volonté; puis il y a les infirmités précoces, le chômage, les crises industrielles.

L'État va-t-il intervenir (2)?"

M. Boissard montre non moins nettement, dans un article justement apprécié (3), comment la loi sur les accidents du travail était " grosse des développements nécessaires - prévus ou insoupçonnés - du principe promulgué par elle, développement dont, on le sent de jour en jour plus nettement, il y a lieu de dégager, et à très brève échéance, la formule de réalisation pratique ". Toutes les assurances sociales (accidents, invalidité, vieillesse, chòmage, maladie professionnelle) incombent, comme charge, à l'employeur, au nom du risque professionnel.

Il ajoute très exactement: "Sans doute, et dans ce sens nouveau le risque n'est plus professionnel, parce qu'il est créé par la profession même, mais encore peut-il être dit professionnel en tant qu'il incombe à la profession, à ceux qui en ont la direction, c'est-à-dire à l'entreprise, et que sa garantie fait partie intégrante de la juste rémunération du travail (4). )

Ainsi l'assurance obligatoire est incontestablemeut une

(1) Say, op. cit., p. 285.

(2) Congrès international des acciden's du travail, i889, t. Il, p. 202.

(3) "Retraites ouvrières et Risque professionnel ", Revue d'Écon. polit., ı904, p. 691, reproduit dans l'ouvrage du même auteur : Contrat de travail et Salariat, p. 217, 1 vol., Paris, Bloud, 1910.

(4) Ibid., p. 699 . 
manière détournée, mais certaine, de réaliser, partiellement au moins, le minimum de salaire.

Or on sait quelle est, à l'heure présente, la diffusion mondiale de ces assurances sociales (I) : l'assurance accidents a pris, de nos jours, notamment sous forme d'assurance obligatoire (2), une extension prodigieuse (3).

L'assurance vieillesse et l'assurance invalidité se sont également beaucoup développées (4).

L'assurance maladie existe aussi dans certains pays comme assurance obligatoire (5).

L'assurance chòmage, pour ètre plus en retard, commence à faire également quelques progrès (6).

Au total, la diffusion des assurances sociales dans tous les pays et dans chaque pays à une classe chaque jour croissante d'intéressés est un moyen puissant de réalisation indirecte du minimum de salaires lorsque tout ou partie de la prime est à la charge du patron.

On s'en rendra mieux compte encore par les quelques résultats statistiques suivants :

Les primes ou cotisations annuellement encaissées par les

(1) Gf. Les Assurances sociales en Europe, Bulletin de l'Offlce du travail français, 1912, pp. 256, 367, 472, $715,810$.

(2) Il faudrait relever aussi l'évolution législative au sein de chaque pays qui se fait sans cesse dans le sens d'une extension du domaine de l'assurance.

(3) Empire allemand (loi du 6 juillet 1884 refondue le 30 juin 1900 et codifiée dans le Code impérial des assurances du i9 juillet ig11), Autriche (lois du 28 déc. 1887 et du 20 juil. 1894), Hongrie (loi r9 de 1907), Luxembourg (lois du 5 avr. 1902, 21 avr. 1908 et 20 dée. 1909), Norvège (Jois des 23 juil. 1894 , 12 juin 1906, 30 juin 1908, 9 juin, 8 et 18 août 1911 ), Serbie (loi du 29 juin, 12 juil. 1910), Suisse (loi fédérale du 13 juin I9II) et Roumanie (lois des 25 janv.-9 fév. I912).

(4) Pour ne citer que les pays où fonctionne l'assurance obligatoire : Allemagne (loi des 22 juin 1889 et 13 juil. 1899 modifiée par la loi du 20 déc. I9I I), Autriche (loi du I6 déc. I906), France (loi du 5 avr. Igro modifiée par la loi du 27 févr. 1912), Serbie (loi des 29 juin-12 juil. 1910), Luxembourg (loi du 6 mars igri), Grande-Bretagne (maladie et invalidité, loi du 16 déc. I9I1), Roumanie (loi des 25 janv.-7 fév. I912).

(5) Suède (loi du 4 juil. I910), Serbie (loi des 29 juin-r 2 juil. r9 9 Io), Roumanie (loi du 25 janv. I912), Grande-Bretagne (loi du i6 déc. I9ri), Norvège (loi du 18 sept. I909), Russie (loi du 20 nov. I9I1).

(6) C. en ce sens la loi anglaise du í décembre I9II (art. 84 à 115) qui établit l'assurance chómage obligatoire dans certaines professions (construction mécanique, fonderie, constructions navales, carrosserie, bàtiment et terrassement) et met l'assurance pour $\mathrm{I} / 3$ à la charge du patron. Cf. Bulletin de l'Offlce du travail, igr2, p. 65. 
Sociétés d'assurance accidents (I) en France atteignent les chiffres suivants (2):

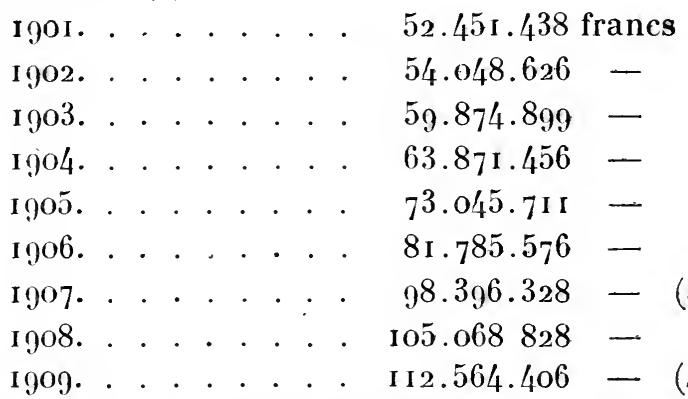

Il faut encore mentionner le chiffre appréciable du fonds de garantie : les versements patronaux y figurent, en r 909 , pour la somme de 2.289.I42 fr. 7 I (5).

Une enquête du Temps (6) a récemment móntré l'élévation des charges industrielles du fait des lois de prévoyance sociale; la marine marchande, d'après ce document, accuse 10.977.00o francs d'augmentation (7), soit près de $25 \%$ des salaires, dont I.I57.15 I francs pour la seule Compagnie transatlantique.

Un moulin, qui paye annuellement 50.000 francs de salaires, déclare avoir supporté une augmentation de $7.843 \mathrm{fr}$.

Pour un couturier employant $8 \mathrm{I} 5$ personnes, la prime d'assurance est de 2.500 francs (accidents) et de $4.000 \mathrm{fr}$. (retraites), etc...

Quelque sujets à caution que soient ces chiffres, ils illustrent nettement l'accroissement indirect des salaires réalisé par les lois de prévoyance sociale.

(I) On sait que l'assurance, sans être obligatoire, est tout entière à la charge du patron.

(2) Paulet. Les Assurances sociales en France, 1905-I908. Congrès international des accidents du travail, Rome, 1908. Compte rendu, vol. I, p. 368.

(3) $8^{\circ}$ rapport sur l'application de la loi du 9 avril 1898 , Paris, BergerLevrault, 191 , p. 61 .

(4) Soit une prime moyenne de 2 fr. 32 pour 100 francs de salaires assurés : ceux-ci se montent en 1904 à 4.856 .040 .803 francs. lbid., $8^{\mathrm{a}}$ rapport, p. 63 .

(5) Ibid., 8e rapport, p. 80.

(6) F. Monméja. Le prix des lois sociales. Temps, 2 1-27. juillet, 2 août 'g11.

(7) Ainsi obtenus : assurance obligatoire, r.075.000 franes; retraites, I.350.000 francs; loi de I 907 sur l'organisation du travail à bord (augmentation du personnel), 8.552.00o francs. 
Pour l'Allemagne, si l'on prend le quart de siècle i 885 I 909 ( $\mathbf{r}$ ), on constate que les cotisations des patrons atteignent une somme globale de 4.792.100.000 marks, se décomposant ainsi :

Assurance maladie : 1.345.300.000 marks ;

Assurance accidents : 2.177.700.000 marks;

Assurance invalidité et vieillesse : 1.269.100.000 marks (2).

Les mèmes cotisations atteignent (3) en rgog 4i 3.497.700 marks, et en 19 г 427.988 .900 marks.

Une étude récente (4) a essayé de totaliser les charges sociales de l'industrie allemande, soit annuellement I milliard 60 millions 970.000 marks (5), en les opposant aux charges sociales de l'industrie anglaise, qui seraient de 808.000.00o de marks.

La méthode monographique souligne cette progression : c'est ainsi que, d'après la mème source (6), les charges sociales ont monté en Allemagne, pendant ces dix dernières années, plus rapidement que les salaires :

A Cologne-Deutz, les charges sociales des "Vereinigten Stahlwerke van der Zypen ", qui étaient en I904 de 4,33\% des salaires, sont en r 9 Io de $5,78 \% / 0$.

De mème pour les "Westfälischen Drahtwerke ", ces mêmes dépenses passent de $2,6 \%$ des salaires en r 900 à $3,2 \%$ en i 9 ro.

Encore augmentation pour les « Elberfelder farbenfabri-

(1) Résultats statistiques de l'assurance ouvrière en Allemagne pendant le dernier quart de siècle 1885-1909. Bulletin des assurances sociales, 1910 , p. 438.

(2) Voici, a titre d'indication, les indemnités payées pendant la même période (ici entrent en compte la contribution ouvrière et la majoration de l'État):

$$
\begin{aligned}
& \text { Assurance maladie . . . . 3.983.200.000 marks. } \\
& \text { - accidents. . . . . I.803.900.000 - } \\
& \text { - invalidité et vieillesse. 1.864.100.000 - } \\
& \text { Total. . . . } 7.651 .300 .020 \text { marks. }
\end{aligned}
$$

(3) Bulletin de l'office du travail, 1912, p. 159 .

(4) De Futz Diepenhorst. Efrets des charges sociales sur la puissance d'exportation de l'industric allemande. Revue écon. intern., avril 1912, p. 118.

(5) Auxquels il faudrait ajouter 13.600 .000 marks pour l'assurance privée accidents. (Cf. loc. cit., pp. 123 et suiv.) Ces chiffres sont donnés en prenant toutes les charges sociales (versements des ouvriers et de l'État, et non plus seulement comme ci-dessus les versements patronaux).

(6) Diepenhorst, loc. cit., p. 124. 
ken " de $2,8 \%$ en I 907 à $3 \%$ en r 909 ; pour les "Maschinenbauanstalt Humboldt ", de $\mathrm{I} \%$ en I 888 à $3 \%$ en r 909 ; pour les "Vereinigten Königs und Laurahütte », de 4,54\% du salaire en r 900 à $7,22 \%$ en r 909 ; enfin pour les " Gutehofmingshütte " $3 \%$ en I 89 I et $6 \%$ en I 908 (I).

Pour l'Angleterre, les prévisions des actuaires en application de la loi du I6 décembre I 9 I I comportent également des chiffres fort élevés en ce qui concerne la contribution patronale (2) pour le fonctionnement des diverses assurances.

Ces quelques chiffres suffisent à montrer la part considérable d'accroissement de salaire ainsi réalisé indirectement grâce aux primes d'assurance.

Incontestablement le développement des assurances sociales est une voie de réalisation indirecte mais efficace du minimum de salaire.

(I) Cf. P. Steller. Erhöhung der Gestehungskosten der deutschen Industrie durch sozialen Lasten, Cologne, I9II, pp. ro et suiv.

Cette augmentation suscite mème certaines plaintes et certaines alarmes de la part de l'industrie allemande, comme en témoigne l'article précité. C'est d'ailleurs plus encore une question de rythme et de lenteur dans la réforme qu'une opposition de principe à l'extension de la législation sociale.

(2) 148.350 .000 francs pour l'année 191 I (cotisations patronale et ouvrière maladie).

Bulletin de l'offce du travail, 1912, p. 720. 
Avec l'étude des cahiers des charges des adjudications de travaux publics, de l'idée de lésion dans le contrat de travail et de la diffusion des assurances sociales, nous n’avons pas épuisé les moyens indirects de promouvoir et de faciliter le minimum de salaire.

Il en est encore bien d'autres, mais plus lointains encore, et auxquels, pour cette raison, il est inutile de consacrer de fort longs développements.

C'est, par exemple, le label ou marque syndicale (I) apposée sur les produits des producteurs qui réalisent certaines conditions de travail acceptables.

Le label de la Fédération du Livre, dont la silhouette est bien connue (2), en est un des plus fameux, mais non unique exemple.

C'est encore l'action des Ligues sociales d'acheteurs (3) qui intervient de bien des manières : par l'éducation sociale des consommateurs, elles préparent l'opinion publique à accepter le minimum de salaire; par la publication de Listes blanches, elles mettent parmi les conditions de la bonne maison le payement d'un salaire convenable (4); par l'action auprès des patrons, elles améliorent les conditions du travail et hâtent le jour où le salaire minimum sera possible (5); par leur action auprès des autorités publiques, enfin, elles soutiennent les projets législatifs dont nous aurons à parler plus loin. Comme type en quelque sorte de cette action des Ligues, nous insisterons sur la récente intervention de la Ligue suisse, en fareur d'un label dans la fabrication de manteaux pour dames, tricotés à la main.

En I9Io, en Suisse, dans la fabrication des manteaux pour dames tricotés à la main, une trentaine de maisons don-

(I) Bibliographie : Choppé. "Le label ", thèse, Paris, I908. - Raynaud. Le label devant la loi nationale et la loi internationale. Revue de droit international privé, igi.

(2) Voir à la couverture du présent volume.

(3) M. Deslandres. L'Acheteur, son róle économique et social, r vol., Paris, Alcan, IgII, surtout pp. If 62 et suiv.

(4) Op. cit., p. 299.

(5) Surtout les Ligues américaines :

La Ligue nationale américaine proclame (Deslandres, op. cit., p. 13) 
naient de l'ouvrage à faire à domicile dans les vallées bernoises de l'Emmenthal, et dans le Val de Travers. Les ouvrières ggagnaient un faible salaire, pas très élevé, mais encore admissible. Survint un concurrent qui abaissa tellement les prix et les salaires que tout le métier était menacé et que les anciennes maisons auraient dù baisser leurs prix de plus d'un tiers.

L'une des maisons fabricantes s'adressa alors à la Ligue sociale d'acheteurs suisse.

Celle-ci conseilla aux anciennes maisons de s'entendre pour fixer un salaire minimum, s'engageant à le faire connaître dans les diverses régions, pour empêcher les ouvriers d'accepter la concurrence au rabais.

Sept maisons s'entendirent le 2 I octobre rgro (I), pour arrêter un salaire de o fr. 20 l'heure.

que l'intérêt de la communauté demande que tous les travailleurs reçoivent un salaire leur permettant une vie convenable, fair living wages...

La Ligue de New-York (Deslandres, op. cit., p. 9) proclame un type de bonne maison (mars igo8):

Une bonne maison est celle où le salaire égal est payé pour travail égal sans tenir compte du sexe et dans laquelle aucune femme âgée de 18 ans ou plus - et qui a un an de métier - ne reçoit pas moins de 6 dollars par semaine; dans laquelle les salaires sont payés chaque semaine; dans laquelle le salaire minimum pour les enfants est de 3 dollars I/2 par semaine, avec les mêmes conditions pour le paiement.

Ces conditions n'existaient pas dans le type primitif de 189 r. Il s'agit de l'industrie en général.

La Ligue de New-York rencontra d'ailleurs de grandes difficultés pour sa liste blanche. Cf. Deslandres, op. cit., p. 10.

(1) Voir (Deslandres, op. cit., p. 3or) le texte de ce contrat collectif : "Les soussignés, fabricants de manteaux tricotés à la main pour dames, s'engagent à observer pour le paiement des ouvriers et entrepreneurs le tarif minimum suivant :

\begin{tabular}{|c|c|c|}
\hline $\begin{array}{c}\text { MANTEAUX A MANCHES } \\
\text { AVEC DESSINS }\end{array}$ & $\begin{array}{l}\text { POLR LES PIÉCES } \\
\text { TRICOTÉES }\end{array}$ & $\begin{array}{l}\text { POLR LA COUTURE } \\
\text { DES PIÉCES }\end{array}$ \\
\hline Longueur . . . . $\mathrm{o}^{\mathrm{m}} 6 \mathrm{o}$ & $5 \mathrm{f} . ")$ & of. 60 \\
\hline ..... $\mathrm{I}^{\mathrm{m}} \mathrm{IO}$ & $10 \%$ & ” \\
\hline
\end{tabular}

En outre, pour l'entrepreneuse, ro \% des prix indiqués pour le contrôle du travail et l'envoi franco des marchandises aux fabricants.

Les fabricants restent libres de payer en tout temps des prix supérieurs à ceux de ce tarif.

Pendant la morte saison, du $\mathrm{x}^{\mathrm{er}}$ janvier au 3r mars, il est permis de faire un rabais de $15 \%$ au plus.

Pour les marchandises avariées, salies ou inutilisables pour la vente, il est permis d'infliger une réduction proportionnée au dommage.

Les entreprencuses sont tenues de payer strictement aux ouvrières 
La Ligue ayant approuvé cette convention la répandit dans tous les villages intéressés, par les facteurs, les institutrices, les femmes de médecins et de pharmaciens. Elle chercha aussi à obtenir l'adhésion de nouvelles maisons.

C'est dans ces conditions que les signataires de l'accord, comprenant la force et la puissance de la Ligue, lui demandèrent de leur conférer l'emploi de son label. Une nouvelle convention, avec faculté d'accession, fut signée entre la Ligue et les maisons adhérentes au nombre de onze : la Ligue entre autres conditions a notamment stipulé à son profit le droit d'inspection ( $\mathrm{r}$ ).

Ces faits et ces conventions, pour récents qu'ils soient, nous montrent par le détail la méthode précise et rigoureuse par laquelle une Ligue sociale d'acheteurs peut contribuer à l'établissement et à la réalisation d'un minimum de salaire. Sans doute, dans l'espèce il ne s'agit que d'un

les prix ci-dessus indiqués, faute de quoi elles payeront aux fabricants : pour une première contravention, loo francs d'amende, et pour une récidive, 200 francs.

Cette convention est valable pour deux ans, à dater du $\mathrm{I}^{\mathrm{er}}$ janvier I9I I.

Berne, 21 octobre 1910.

Signatures. 》

(I) Voici, à raison même de son originalité, le texte de cette nouvelle convention (Deslandres, op. cit., p. 3or), en date du I $^{\text {er }}$ janvier I911.

Après avoir rappelé par divers attendus la situation rapportée au texte, le contrat poursuit :

"En conséquence, les parties en cause conviennent ce qui suit :

$I^{\circ}$ Cette convention, ainsi que chacune des estampilles employées, sera numérotée $\mathrm{n}^{\circ} \mathrm{I}$.

$2^{\circ}$ L'estampille ci-dessus, label, sera attachée par le fabricant soussigné aux manteaux tricotés à la main pour dames qu'il fait fabriquer. Ce label sera constitué par une étiquette de carton blanc reproduisant, en impression de couleur bleue, le type du label déposé; le modèle de l'étiquette est accepté par la Ligue sociale d'acheteurs; le eliché du label sera fait aux frais de la L. S. A.; l'impression des étiquettes sera à la charge du fabricant.

3. Le fabricant soussigné est autorisé à mettre sur son papier ì lettres, sur ses factures et autres imprimés commerciaux l'indication suivante: "Fabrication de manteaux tricotés à la main pour dames, ayant obtenu le label de la Ligue sociale d'acheteurs. ")

Mais il n'est pas autorisé à reproduire sur ses imprimés une copie du label.

$4^{\circ}$ Le fabricant soussigné s'engage :

I. - A observer strictement la convention du 2 I octobre igro pour le paienent des ouvrières et intermédiaires pour la durée de deux ans, à
partir du I $^{e r}$ janvier $19 \mathrm{I}$;

II. - A consentir au contrôle par la Ligue sociale d'achetrurs des conditions hygriéniques de cette fabrication; a cet efret, il promet:

a) De communiquer sur demande i une personme accéditée far la Ligue sociale d'acheteurs et n'ayant aucun intérêt persomel, direct 
sulaire de o fr. 20 l'heure, faible mais encore appréciable par rapport aux o fr. I3 souvent donnés par d'autres maisons. C'est surtout le mécanisme de la collaboration de la L. S. A. au salaire minimum qu'il était intéressant de relever (I).

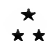

Il y aurait encore lieu de signaler un mouvement d'idée fort analogue à celui que nous venons d'étudier dans l'agriculture.

Sans doute, l'idée de minimum de salaire n'y est pas inconnue et c'est une revendication à laquelle on a déjà songé pour les ouvriers agricoles (2).

Mais ici encore il $y$ a un certain nombre de mesures actuellement en vigueur ou proposées qui tendent indirectement à assurer un minimum d'existence aux travailleurs de la terre, fermiers ou métayers.

ou indireet, dans eette industrie, les noms de toutes les localités à lui eonnues où l'on tricote à la nain ces manteaux pour la vente;

b) De tenir un registre des ouvrières auxquelles il donne directement des manteaux à tricoter à la main et de mettre ce registre sur demande à la disposition de la personne ci-dessus désignée;

c) De prendre en considération les observations de cette personne relatives aux conditions hygiéniques du travail des ouvrières.

III. - Le fabricant soussigné promet en outre de ne donner l'estampille à aucun tiers et de n'autoriser personne à la reproduire ni pendint, ni après la durée du présent contrat.

IV. - Il n'emploiera l'estampille pour aucune autre marchandise que pour les manteaux tricotés à la main pour dames.

$5^{\circ} \mathrm{Si}$ ces conditions n'étaient pas remplies, le fabricant soussigné s'engage à cesser de suite, sur l'avis du Conseil central de la Ligue soeiale d'acheteurs, de se servir de l'estampille, à rendre à la L. S. A. le cliché du label, à détruire ou à rendre à la L. S. A. toutes les étiquettes qui resteraient entre ses mains et à supprimer de tous ses imprimés les mentions du label.

Le nom du fabricant auquel le label aurait été retiré sera rendu public.

Réserve est faite du recours juridique, conformément au Code.

Cette convention est valable jusqu'au I $^{\text {er }}$ janvier 1913 .

Fait à ..... )

(1) Cf. E. Pieczynska-Reichenbach. Du rôle qui incombe aux ligues d'acheteurs dans le domaine du travail à domicile. Rapport au Congrès international du travail à domicile, Zurich, sept. 1912.

(2) Cf. Compère-Morel. Dise. à la Ch., 21 nov. 1911. J. O., 22 nov. 1912. "Le jour où nous aurons développé les syndicats, ne serait-il pas possible d'instituer un minimum de salaire d'aceord avec les Conseils municipaux? Les intéressés pourraient trouver un terrain d'entente en se réunissant dans une salle de la mairie : les deux parties proposeraient leurs prix et discuteraient en hommes sensés. » 
Il suffira, à titre d'indication, de signaler ici la loi roumaine de 1907 , fixant un prix maximum de fermage, les projets de suppression de l'impôt colonique en France concernant plus spécialement les métayers de l'Allier, elc... L'étude détaillée de ce nouveau mouvement, plus spécialement agraire, nous entrainerait trop loin : il suffit de poser son parallélisme avec le mouvement étudié.

11 faut enfin, en terminant sur ce point, indiquer parmi les moyens indirects de promouvoir le minimum de salaire une série de mesures encore plus lointaines, comme celles qui contribuent à la prospérité de l'industrie, à la diminution du coùt de l'existence, à une meilleure répartition des impôts, etc... Mais ce sont là des facteurs si nombreux, si complexes et si lointains, qu'ils nous feraient sortir du cadre déjà suffisamment vaste de cette étude. 


\section{SECTION B}

\section{La Réalisation directe du Salaire minimum.}

Dans cette nouvelle direction et en vue de réaliser d'ores et déjà le salaire minimum, on rencontre l'intervention de facteurs bien distincts qu'il faut étudier successivement :

$\mathrm{I}^{0}$ Le salaire minimum peut être l'œuvre de l'association professionnelle;

$2^{0}$ Le salaire minimum peut ètre l'œurre de la puissance publique (Etat, départements, municipalités);

$3^{\circ}$ Le salaire minimum peut être l'œuvre de la lo $i$. 


\section{CHAPITRE $V$}

\section{L'œuvre de l'Association professionnelle.}

L'association professionnelle est le défenseur naturel des conditions du travail dans le métier ou la profession.

Il faut étudier successivement ce mouvement en Angleterre, en France, dans les autres pays. 
Io En Angleterre.

La politique des Trade-Unions, en faveur du minimum de salaire, est déjà fort ancienne et remonte assez loin dans le cours du dix-neuvième siècle. Voyons-en rapidement tout à la fois l'histoire, les principes et les résultats :

a) L'histoire. - C'est progressivement, comme l'ont fort bien montré B. et S. Webb, dans leur " Histoire du TradeUnionisme ", que la revendication du minimum de salaire apparut au premier plan des revendications ouvrières.

L'une des étapes les plus curieuses de cette évolution est assurément l'abandon du système de l'échelle mobile (I).

On sait en quoi consistait ce système : à prendre, par exemple, la première échelle mobile établie en 1875 pour les mines de charbon de la Galles du Sud (2); le système était le suivant : chaque shilling de hausse ou de baisse dans le prix de vente de la tonne de houille devait amener une augmentation ou une réduction corrélative de $7 \mathrm{I} / 2 \%$ dans le taux des salaires. Le prix de vente qui servait de base à l'échelle était le prix du charbon gras, pris au quai d'embarquement (3), à un port du pays de Galles (Cardiff, Newport, Swansea ou Barry).

Ce système obtint, tant dans l'industrie houillère que dans les autres branches de l'industrie, une très grande vogue (4).

Puis, par un brusque revirement de la politique des

(1) Raynaud. Une industrie sans grèves, I vol., Paris, Rousseau, I905, pp. 35 et suiv. - Echelle mobile de salaires en Angleterre, Munro. Revue d'Économie politique, I891, pp. 329-330. - Olph. Galliard. "Les Échelles mobiles de salaires "). Revue d'Économie politique, 1911, p. 493.

(2) On cite une plus ancienne et première application de l'échelle mobile (sliding scale) en 1840, dans le Sud du Staffordshire, par un industriel du nom de Thornicroft.

(3) Free on board.

(4) Pour les mines, elle fonctionna au Durham : mars 1877, décembre 1878 , octobre 1879 , décembre 1881 , avril 1882 , décembre 1883 , juin 1884 , juillet 1887 ; en Galles du Sud, de 1875 à 1903. - Cf. Raynaud. Une industrie sans grèves, p. 35, pour les détails de ce fonctionnement; dans le Northumberland, le Yorkshire, le Lancashire, etc... Dans les districts métallurgiques du Nord, entre 187 I et 1882. Cf. Ashley. The Adjustement of wages. I vol., Londres, Longmans, 1902. 
Trade-Unions, l'échelle mobile disparut au début du vingtième siècle ( $\mathrm{r}$ ).

Les ouvriers adressaient à l'échelle mobile divers reproches :

a) D'abord, disaient-ils, en garantissant aux patrons la possibilité de contrats à longs termes, on exaspérait la concurrence des patrons entre eux. Les réductions de prix ne profitaient en somme qu'aux consommateurs, sans que les mineurs pussent réclamer aucun avantage, tant que les prix restaient au même niveau.

b) En second lieu, le système de l'échelle mobile leur paraissait encore défectueux, parce qu'il ne permettait pas de s'opposer efficacement aux réductions de salaires provoquées par la baisse du prix de vente.

c) Enfin, et surtout, les ouvriers reprochaient à l'échelle mobile d'ètre en contradiction avec le principe du minimum de salaire : ce n'est point le prix de vente qui doit fixer le salaire, mais bien plutôt le salaire qui doit commander le prix de vente (2).

Au total, la disparition de l'échelle mobile ouvrait la voie à la proclamation des principes du minimum de salaire et d la réalisation pratique de ce minimum.

b) Les principes (3).

Ce n'est qu'à la longue, au prix de bien des essais et de bien des efforts, que se dégagea ce que Webb appelle le "Standard rate " (4), c'est-à-dire le paiement du travail selon un étalon identique, uniforme dans son application, ou encore, en une formule plus précise peut-être, identique rémunération pour identique effort. Il fallut, au fur et à mesure que les faits en imposaient la nécessité, faire triompher ce principe tout à la fois dans les métiers où s'appliquait le salaire au temps et ceux où triomphait le salaire aux pièces. L'expérience montra bien vite que pareil standard rate, dans un système de concurrence industrielle, ne pouvait être maintenu que si les conditions du travail

(1) L'échelle mobile fut abandonnée définitivemeut : en 1895, pour les mines de Durham et Northumberland; en 188I, pour le Yorkshire; en 1889, pour la métallurgie; en 1903, pour la Galles du Sud.

(2) Cf. Raynaud. Une industrie sans grèves, 1). 40.

(3) Webb. Industrial Democracy, 2 vol., Londres, Longmans, I897.

(4) Webb. Industrial Democracy, vol. I, II). 278-323. 
étaient arrêtées non par contrat individuel, mais par contrat collectif ( $\mathrm{I}$ ). De là, les efforts des Trade-Unions pour obtenir la reconnaissance et l'application du contrat collectif.

Ainsi, le contrat collectif apparaît comme une nécessité, - la politique du standard rate, non comme un but en soi, mais comme un moyen.

Il faut remarquer, d'ailleurs, que cette politique, à l'heure présente, n'a pas encore abouti partout à la réalisation d'un minimum de salaire proprement dit; elle n'implique pas d'ordinaire une certaine somme de monnaie à payer par semaine. De plus, les standard rates sont loin d'être uniformes (2) et aucune politique d'ensemble n'existe encore parmi les diverses Trade-Unions sur la possibilité de cette uniformité.

Néanmoins, la politique du standard rate est un acheminèment certain vers le minimum de salaire.

En application de ces principes, le mécanisme anglais d'établissement du minimum de salaire est à peu près le suivant :

Dans les métiers organisés, il existe des Trade-Unions patronales ou ouvrières; les salaires sont arrètés par contrat collectif par des comités de salaires locaux : en cas de désaccord avec un de ces comités un mécanisme de conciliation ou d'arbitrage (local, régional ou national) a d'ordinaire le dernier mot.

\section{c) Les Résultats.}

Aujourd'hui, on peut affirmer que le minimum de salaire est une réalité dans la plupart des grandes industries anglaises. Partout où les forces patronales et ouvrières sont organisées, le contrat collectif a permis d'aboutir à cet heureux résultat $(3)$.

Essayons d'indiquer sommairement quelques-unes des clauses les plus importantes actuellement en vigueur :

(i) On comprend, en effet, que, par suite de la concurrence, chaque employeur est entrainé à tomber au-dessous de la base arrêtée pour réaliser une diminution du prix de revient. Pour les détails, cf. Webb, op. cit.

(2) Cf. Webb, op. cit., vol. I, p. 320.

(3) Report on Collective Agreements between employers and workpeople in the United Kingdom. Board of Trade, Londres, r9ro. 
Dans le Batiment ( $\mathrm{I}$ ). - Depuis igo4, les salaires sont l'objet d'une tarification régionale dont la base est déterminée par les deux organisations patronales et ouvrières :

D'une part, la Fédération nationale des Employeurs du Bàtiment (The national Federation of Building Trades Employers);

Et, d'autre part :

La Société ouvrière des Poseurs de briques (Operative Briclilayer's Society, London);

L'Union ouvrière des Poseurs de briques de Manchester (Manchester Unity of operative Briclilayer's);

L'Union des Maçons (Operative Stonemasons);

Les Charpentiers et Menuisiers unis (Amalgamated carpenters and joiners);

L’Union générale des Charpentiers et Menuisiers (General Union of carpenters and joiners),

Et les Charpentiers et Menuisiers associés (Associated carpenters and joiners).

Un organisme compliqué de bureaux de conciliation ( bureau national, 4 bureaux centraux, 66 comités locaux ou de district) permet d'aboutir à la signature des accords.

Il en est de même pour les ouvriers maçons, dont les salaires sont, en dernière analyse, réglés par la Fédération nationale des Employeurs du Bàtiment de Grande-Bretagne et d'Irlande, l'Association nationale des Maîtres plàtriers et l'Association nationale des Ouvriers plàtriers.

A Londres, par exemple (2), le standard rate (la base du salaire) est, par heure, de ro $1 / 2 \mathrm{~d}$. (environ I franc) pour les poseurs de briques, charpentiers et menuisiers; de Io $1 / 2$ d. (environ I franc) pour les maçons autres que les fixeurs; pour les fixeurs, de II $1 /{ }_{4} \mathrm{~d}$. (environ I fr. 20 ), et de I I d. (environ I fr. Io) pour les plâtriers et plombiers (3).

Dans le district de Birmingham (4), d'après le contrat en

(1) Rapport cité, pp. I et suiv.

(2) Contrats de 1906 affectant 35.000 travailleurs. Rapport, 1. 5.

(3) Ce qui, avec 50 heures en hiver et $4 / 4$ en été par semaine, domne un salaire minimum de 50 francs environ par semaine.

(4) Rapport cité, p. II. 2.000 travailleurs y sont soumis. 
vigueur depuis le $\mathrm{I}^{\mathrm{er}}$ avril $\mathrm{I} 9 \mathrm{IO}$, pour les poseurs de briques la base de salaires est de $91 / 2$ d. par heure.

Dans les districts de Manchester et de Salford, le salaire, d'après le contrat du 14 aoùt 1909 , est de $91 / 2 \mathrm{~d}$. pour les maçons (stonemasons).

A Liverpool et dans le district, de ro d. par heure pour les charpentiers et menuisiers (2).

A Bolton, de mème pour les peintres de maisons (house painters), de $9 \mathrm{~d}$.

On le voit, il n'y a pas un salaire minimum uniforme (3): celui-ci varie avec les régions, mais un organisme national coordonne les diverses décisions des organismes locaux.

(1) Ibid., p. 14.

(2) Ibid., p. 17.

(3) Celui-ci est presque toujours au temps. 
Dans Les Mines (I), c'est encore par le contrat collectif universellement répandu que le minimum de salaire s'est partiellement introduit et persiste encore.

Ces contrats collectifs stipulant des minima de salaires sont d'ailleurs d'une portée variable, les uns couvrant une vaste superficie, les autres spéciaux à certaines mines isolées. Les Bureaux de conciliation et Comités de salaires ont pris dans cette industrie une très remarquable extension. La méthode pour déterminer ces minima consiste à prendre pour base les salaires à une époque donnée et à déclarer que les salaires ne pourront osciller autour de cette base que dans des limites arrêtées d'avance.

C'est ainsi que dans les Federated Districts, qui com. prennent les mines de Lancashire, Cheshire, Yorkshire sud et ouest, Nottingamshire, Derbyshire, Shropshire, Leicestershire, Warwickshire, une partie de Staffordshire et la Galles du Nord, le contrat actuellement en vigueur du 25 février i 904 , prolongé à plusieurs reprises, stipule :

"Le taux des salaires ne pourra être inférieur à $35 \%$ (2) au-dessus de la base (rate of wages) de r888, ni monter audessus de $60 \%$ au-dessus de la même base : toute modification dans le taux des salaires ne pourra excéder $5 \%$ en une seule fois. ")

La politique suivie par le Comité des Federated Districts, consacrée d'ailleurs par de nombreuses clauses des accords, est que le prix de vente n'est pas le seul facteur des salaires, que celui-ci, au contraire, est dominé et commandé par le taux des salaires.

On estime à 378.00o le nombre des travailleurs visés par ce contrat collectif.

En même temps, il est fréquent dans l'industrie des mines de trouver dans les contrats la stipulation d'une moyenne de comté (county average) : c'est un salaire journalier. Les salaires effectivement payés, fixés à la tàche et variables selon les conditions du travail (difficulté de l'extraction, richesse de la couche), doivent être tels que les ouvriers se procurent dans tous les cas cette moyenne de comté.

(1) Cf. Raynaud. Cne industrie sans grèves. Les Comités de salaires dans les mines anglaises, $x$ vol., Paris, housseau, 190/4. Ral]. cit., p. 24 .

(2) Aujourd'hui, depuis l'accord du 18 décembre 1903,37 1/2\%. 
Beaucoup d'autres centres miniers (Cumberland, Radstock, Bristol, South-Staffs et Worcestershire est, etc.) suivent de plus ou moins près le taux fixé dans les Federated Districts.

En Écosse, un système analogue existe : le salaire ne peut descendre au-dessous de $50 \%$, ni monter au-dessus de I00 \% par rapport à la base de I 888 depuis l'accord du 3o juin r 904 : une véritable échelle mobile a été rétablie dans le dernier contrat du 23 mai i 9 Io. Une échelle des prix de vente de la tonne de houille a été ainsi dressée :

\begin{tabular}{|c|c|c|}
\hline Prix. & Salaires. & \\
\hline 7 s. $5,45 \mathrm{~d}$. & $50 \quad \%$ & \\
\hline 8 s. I,45 d. & $561 / 4 \%$ & $\begin{array}{c}\text { Au-dessus } \\
\text { de }\end{array}$ \\
\hline 8 s. 5,45 d. & $621 / 2 \%$ & de \\
\hline 9 s. 1,45 d. & $683 / 4 \%$ & $\begin{array}{l}\text { la base } \\
\text { de }\end{array}$ \\
\hline 9 s. $5,45 \mathrm{~d}$. & $75 \quad \%$ & \\
\hline 9 s. $9,45 \mathrm{~d}$. & $8 \mathrm{I} \%$ & \\
\hline s. $\mathrm{I}, 45 \mathrm{~d}$. & $871 / 4 \%$ & \\
\hline
\end{tabular}

Pour chaque variation du prix de vente, à chaque échelon de l'échelle, il y aura augmentation ou diminution de salaire . de $61 / 4 \%$.

Le système est analogrue pour les mines du Northumberland et de Durham, de Cumberland et de la Galles du Nord: la base est ici les salaires de 1879 .

On trouve même parfois une échelle de salaires variable avec l'âge de l'ouvrier : de 13 à 2 I ans, par exemple, dans les mines de Coalville (Leicestershire).

Derrière ces contrats collectifs, on trouve encore des listes de salaires pour chaque mine qui mettent en application les principes : les herscheurs sont ordinairement payés à la tàche, les autres ouvriers du dessous, les ouvriers de la surface étant généralement payés au temps.

Dans les mines autres que le charbon et les carrières, des échelles mobiles de salaires assez fréquentes ou des contrats collectifs analogues établissent des minima de salaires.

Cependant, tout récemment ( $\mathrm{I}_{\mathrm{IO}} \mathrm{I}_{\mathrm{1}} \mathrm{I}_{\mathrm{I}}$ ), un mouvement nouveau s'est dessiné dans les mines de charbon pour aller plus loin : le minimum de salaire fonctionnait déjà en fait 
et, dans la très grande majorité des cas, on voulut en faire le droit reconnu et la règle générale.

\section{a) Les négociations entre patrons et ouvriers.}

La question fut posée dans les mines du Pays de Galles pour une catégorie particulière de travailleurs : les hommes employés dans les endroits difficiles (abnormal places) (I), où, avec un travail plus intense, l'ouvrier abat une quantité moindre de houille que ses compagnons et ne peut, par suite, par le salaire à la tàche, atteindre le minimum de salaire espéré.

Ces difficultés (2), jointes à la hausse des denrées, soulignées aussi par les meneurs partisans de méthodes plus violentes (3), amenèrent une agitation profonde en I9IoI9I I et firent poser d'une façon plus précise la revendication du salaire minimum. Le contrat collectif de mars i 9 Io, signé pour cinq ans et relatif au Pays de Galles, n'ayant pas résolu la question, une longue grève éclata dans cette région. Les mineurs du Pays de Galles, soutenus par les mineurs d'Écosse, furent assez heureux (4) pour intéresser à la question la Fédération des Mineurs de Grande-Bretagne (5).

La question fut posée à la Conférence nationale de la

(1) Dans certaines mines du Pays de Galles, les veines de charbon, nombreuses et minces, sont séparées par des couches stériles que le pic du mineur doit attaquer pour retrouver plus loin la houille : il est payé sur la quantité de charbon abattue. Il y a bien quelques indemnités pour la besogne supplénentaire, regardées comme insulfisantes par les intéressés.

(2) A la suite de la loi de 8 heures, le gain moyen de l'ouvrier était descendu de 7 sh. 9 p. à 6 sh. 7 p. r/2. (Western Mail, 22 sep. 1909.)

(3) Cf. Mantoux. La grève des mines en Grande-Bretagne, Rev. de Paris, 15 avril 1911, p. 745. - Sur les nouveaux aspects du syndicalisme anglais, cf. Correspondant, 15 fév. 1912.

(4) D'après l'article 21 des statuts de la Fédération : "Toutes les fois qu'une Fédération ou un District est attaqué sur une question de salaires ou de conditions du travail, ou, avec l'approbation d'une Conférence spécialement convoquée à cet effet, a fait des notifications pour améliorer les conditions du travail ou obtenir une augmentation de. salaires, une conférence générale doit être convoı́uée pour envisager l'éventualité d'une action commune. »

(5) Celle-ci avait d'ailleurs, dès 19og, inscrit le minimum de salaire comme article de son programme théorique : il s'agissait d'ailleurs alors d'un minimum obtenu par contrat collectif el variable dans chaque district. 
Fédération, qui s'ouvrit le 14 juin 19 I : des pourparlers pour une solution amiable se poursuivirent sans succès tout l'été. Enfin, le 6 octobre ig i, la Fédération convoqua une nouvelle conférence pour aviser. Il y fut décidé que la corporation entière réclamait l'établissement immédiat d'un minimum de salaire dans chaque district et soutiendrait au besoin par une grève générale cette revendication (I).

L'accord ne parvint pas à s'établir.

Les patrons de la Galles du Sud et d'Écosse invoquèrent les contrats existants (2): ils se refusaient à examiner toute revendication de leurs ouvriers relative au taux du salaire avant l'expiration desdits contrats.

Ceux des districts fédérés (Federated Area) acceptèrent le principe du minimum de salaire, et des négociations, avec espérance d'aboutir, furent entreprises.

Aussi la Conférence de novembre igI I, tout en rappelant les résolutions précédemment adoptées, s'ajourna au 20 décembre igr en votant les deux résolutions suivantes $(3)$ :

"La Conférence, ayant pris connaissance des rapports de chaque district sur la question du minimum de salaire, est satisfaite d'apprendre que les districts et comités rattachés au Comité anglais de conciliation ont obtenu de la représentation patronale du Comité la reconnaissance du principe du minimum de salaire pour tous les hommes et enfants, travailleurs du sous-sol. La Conférence, en conséquence, est d'avis de s'ajourner, pour permettre à de nouveau $x$ efforts d'obtenir une solution satisfaisante.

La Conférence, ayant pris connaissance des rapports de tous les districts sur la revendication du salaire minimum

(I) Voici la résolution votée : "La Fédération prendra immédiatement ses dispositions pour assurer un salaire minimum individuel dans chaque district pour tous les hommes et enfants travaillant dans les mines fédérées, sans aucune exception pour les places difficiles. Au cas où les employeurs refuseraient de l'accepter, l'article 21 fonctionnera pour obtenir l'assentiment général. Une conférence sera nécessaire pour décider de l'action à entreprendre, d'après l'article 2i. )

... Des entrevues devaient avoir lieu dans chaque district entre employeurs et employés : on en devait rapporter le résultat à la conférence du 14 novembre. (Cf. Labour Gazette, 1912, mars, p. 82.)

(2) Le contrat collectif de Galles du Sud, signé en I910, n'arrivait à échéance qu'en r9r5. Celui d’Écosse n'expirait qu'en juillet r9r2.

(3) Labour Gazette, mars 19r2, 1). 83. 
individuel pour chaque district, est d'aris que la meilleure voie à suivre pour aboutir le plus rapidement possible, dans les circonstances présentes, est de négocier par régions (nationally); elle donne pouvoir au Comité exécutif de la Fédération de formuler les revendications de chaque district, de s'aboucher avec les propriétaires de mines de Grande-Bretagne et de convoquer aussitôt après, pour lui en référer, une conférence nationale. Toutefois, cette résolution n'empèchera ni ne gènera en aucune façon les négociations actuellement en cours dans les divers districts de la Fédération. ")

A la conférence du 20 décembre ig I tenue à Londres, on décida de soumettre au vote des membres de la Fédération la question suivante:

"Êtes-vous d'avis de dénoncer les contrats (c'est-à-dire de faire la grève générale) pour faire triompher le principe d'un salaire minimum pour tous les travailleurs (hommes et enfants) du sous-sol en Grande-Bretagne? "

Le vote eut lieu en janvier : le résultat en fut proclamé à la Conférence de Birmingham tenue le i 8 janvier ı 9 I 2 : une grande majorité (I) se prononçait en faveur de la grève. La conférence décida de commencer la grève au début de mars, tout en faisant une nouvelle démarche auprès des patrons pour reprendre les négociations.

Une nouvelle conférence tenue à Londres le 2 février I 9 I 2 formula le programme des revendications :

$I^{0}$ Les revendications suivantes doivent être formulées comme demandes de minimum de salaire individuel pour chaque district pour les ouvriers aux pièces à front de la veine (at the face of the coal) :

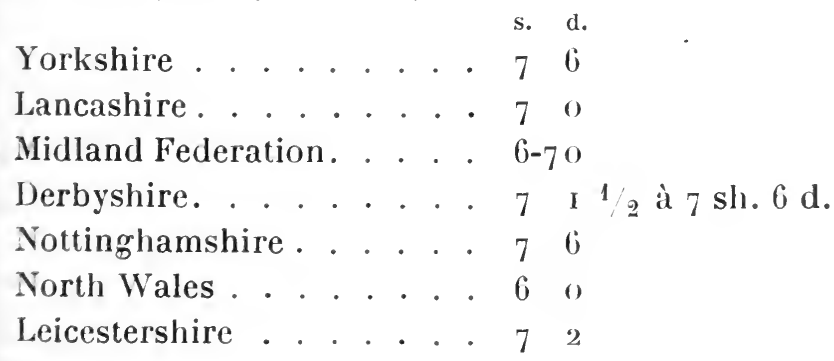

(1) 445.801 pour, contre 115.721 contre. 


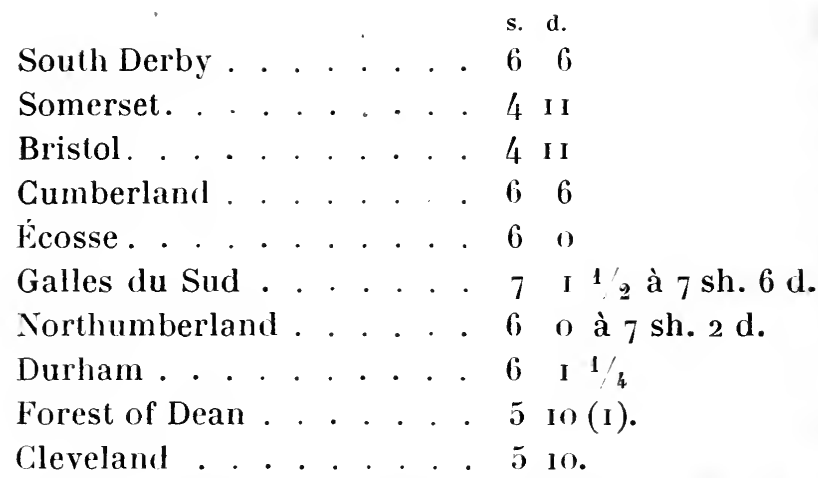

$2^{0}$ Aucun travailleur adulte du sous-sol ne pourra recevoir un salaire inférieur à 5 sh. par couche.

$3^{\circ}$ Les salaires minima individuels pour tous les travailleurs aux pièces autres que les herscheurs devront être fixés par les districts eux-mèmes et ètre aussi près que possible des salaires actuels.

$4^{\circ} \mathrm{Vu}$ leur complexité et la difficulté de les fixer d'une manière générale, les salaires payés au temps (par jour) aux travailleurs du sous-sol seront laissés à la fixation de chaque district ; on s'efforcera de les arrêter par catégories localement dans chaque district.

$5^{0}$ Les accords pour les salaires des apprentis (boys) sont de la compétence des districts : ces salaires ne devront pas ètre inférieurs aux salaires actuels ni en aucun cas inférieurs à 2 sh. par jour.

Une conférence réunit à Londres, le 7 février, les représentants des employeurs et des employés; l'accord ne put s'établir. Voici le texte des deux déclarations patronale et ouvrière (2):

Déclaration patronale: “ Les patrons sont disposés à accepter la proposition établissant que chaque travailleur à leur service recevra un salaire journalier équitable pour un travail journalier équitable, mais ils sont convaincus que le principe du paiement en proportion du montant du travail accompli est le seul qui puisse ètre appliqué avec succès aux ouvriers qui extraient le charbon (coal-getters).

Ils conviennent qu'il y a des cas où, en raison des diffi-

(I) Ultérieurement ramené à $5 \mathrm{sh} .6 \mathrm{p}$.

(2) Labour Gazette, p. 83, mars 1912, loc, cit. 
cultés dues à des conditions exceptionnelles de l'endroit du travail, un ouvrier, tout en faisant de son mieux, est incapable de gagner ce qu'il gagnerait dans des circonstances ordinaires. Pour de pareils cas spéciaux, les patrons reconnaissent la nécessité d'un régime spécial à établir et sont prêts à discuter avec les ouvriers les moyens d'y arriver.

En approuvant les déclarations précédentes, les districts qui sont actuellement liés par des contrats réservent leurs droits en conséquence et les districts compris dans la sphère du Comité anglais de conciliation réservent leur droit de continuer leurs négociations. "

Déclaration ouvrière en réponse à la précédente :

"Les représentants ouvriers des mineurs expriment leur regret de voir les patrons refuser d'accepter le principe du salaire minimum individuel pour tous les hommes et apprentis du sous-sol ; il ne peut y avoir aucune solution du présent conflit tant que ce principe ne sera pas reconnu.

En fait, cependant, ils n'ont aucune envie de voir un arrêt effectif dans l'industrie minière anglaise et se déclarent disposés à rencontrer les patrons ultérieurement pour une discussion nouvelle, si les patrons en expriment le désir ( $\mathrm{I}$ ). ")

Le 13 février I9ı2, la Fédération des mineurs tint à Londres une réunion où la résolution précédente du 7 février fut confirmée. La Conférence s’ajourna le lendemain en donnant au Comité exécutif le soin de la convoquer de nouveau quand il le jugerait convenable.

On entre alors dans une nouvelle phase : celle de l'intervention gouvernementale qui devait aboutir au Coal Mines Bill.

\section{b) L'intervention gouvernementale.}

Pendant que se prolongeaient ces pourparlers, les craintes de la grève devenaient chaque jour plus menaçantes. De

(1) Pendant ce temps, les contrats avaient été dénoncés pour le Ier mars. En même temps, les districts fédérés (pour lesquels le principe du minimum de salaire avait été reconnu par les patrons) avaient vu se réunir le Comité de conciliation ( 23 janv.) qui avait nommé une sous-commission spéciale pour étudier la question. Diverses réunions furent tenues (I9 et 20 fév.) pour aboutir à un accord. Le 20 février, on annonça que les mineurs ne pouvaient accepter les propositions qui leur étaient faites. (Labour Gazelle, mars i912, p. 83.) 
divers còtés et dans différents milieux on s'adressa au Gouvernement pour lui demander d'intervenir ( $\mathrm{I}$ ).

Le 20 février, le premier ministre, M. Asquith, adressait aux patrons des mines et au Comité exécutif de la Fédération la lettre suivante (2):

“ Le Gouvernement de Sa Majesté a suivi avec une attention soutenue et une anxiété croissante le développement de la présente crise dans l'industrie minière. Jusqu'à l'heure actuelle, il a conservé quelque espoir que des moyens pourraient être trouvés par négociation directe entre les parties en cause pour conjurer le désastre d'un arrèt national de l'industrie. Comme, cependant, la date approche où les dénonciations pour cessation du travail arrivent à terme, le Gouvernement de Sa Majesté ne peut se cacher que la perspective va diminuant de voir des arrangements amiables, pour l'ensemble des mines du pays, conclus avant cette échéance.

“Point n'est besoin d'insister dans cette lettre sur les très graves conséquences, à la fois pour les industries du pays et toutes les classes de consommateurs de charbon, qui suivraient inévitablement un arrèt généralisé de l'industrie minière. S'il se prolongeait, il provoquerait un arrêt général de toute l'industrie et le Gouvernement de Sa Majesté ne peut laisser se produire une telle catastrophe sans avoir fait au moins tout son possible pour l'éviter.

“ Dans ces circonstances, j'ai reçu une communication du Conseil industriel de conciliation (3) qui, comme vous le savez, a été nommé l'an dernier pour prévenir et arranger les conflits du travail, qui m'invite, dans la situation critique présente, à faire les démarches nécessaires immédia-

(1) Déjà, lors de la discussion le l'Adresse, le i5 février, M. RamsayMacdonald, au nom du Labour party, avait demandé l'institution obligatoire du minimum de salaire dans toutes les industries. Cette manifestation ne pouvait évilemment avoir aucun résultat pratique, mais soulignait la solidarité des masses ouvrières avec les mineurs.

(2) Le texte est identique, sauf en ce qui regarde la date de la conférence.

(3) Ce Conseil est l'organisme officiel de conciliation établi par une loi du io octobre 1911 : il comprend 13 représentants du patronat et I3 représentants des ouvriers, nommés pour un an par le Board of Trade et choisis parmi les membres du bureau des organisations professionnelles. 
tement pour réunir une conférence des représentants de l'industrie minière, pour discuter la situation grave à laquelle on est parvenu et envisager la possibilité d'arriver par n'importe quels moyens à conjurer le désastre d'un arrêt national de l'industrie.

"Le Gouvernement de Sa Majesté a pris en très grande considération cette communication et j'invite, en conséquence, les patrons des mines de tout le pays à venir conférer avec moi et quelques-uns de mes collègues au Foreign Office jeudi prochain 22 février, à 3 heures.

"Je suis, etc...."

Les deux parties acceptèrent l'invitation du premier ministre et la conférence des représentants des patrons et des ouvriers se réunit au Foreign Office le 22 février (I).

Les délégués ouvriers déclarèrent qu'ils étaient obligés d'attendre l'avis d'une Conférence de la Fédération annoncée pour le mardi suivant (2).

On prit rendez-vous pour le mardi suivant 27 février. Le 27 février, la Conférence des mineurs donnait mandat à ses délégués de tenir ferme tout à la fois sur le principe du salaire minimum et sur les minima arrêtés le 2 février par la Fédération.

La réunion du 27 février entre représentants des deux parties eut lieu comme convenu : la Fédération nomma même un Comité consultatif moins nombreux pour poursuivre les pourparlers. Dans les diverses réunions qui eurent lieu alors, le premier ministre proposa aux deux parties, à titre de transaction, le compromis suivant :

$1^{0}$ Le Gouvernement de Sa Majesté estime, après mûre réflexion, que certains des ouvriers travaillant dans les mines ne peuvent arriver, pour des raisons indépendantes de leur volonté, à gagner un salaire minimum raisonnable;

(1) Le Gouvernement était représenté par MM. Asquith, Sydney, Buxton, Sir Edward Grey et M. Lloyd George. 9o patrons s'étaient fait représenter. Du côté des mineurs, le bureau de la Fédération : M. Enoch Edwards, président; M. Robert Smillie, vice-président; M. William Abraham, trésorier; M. T. Ashon, secrétaire.

(2) En même temps, à la demande du ninistre, les représentants des patrons des mines avaient nommé une commission consultative qui se réunit les 23 et 26 février avec les membres du gouvernement; dans ces différentes séances, la position des patrons des mines eu égard au minimum de salaire fut pleinement préciséc. 
$2^{0}$ Il pense également qu'il est possible d'établir un tel salaire en tenant compte des conditions particulières à chaque district ; mais, que d'autre part, les patrons doivent obtenir des garanties contre les abus possibles ;

$3^{\circ}$ Le Gouvernement de Sa Majesté est disposé à s'entretenir avec les parties sur les meilleurs moyens pour mettre en pratique ces conclusions par des conférences régionales entre mineurs et propriétaires, qui auraient lieu en présence de personnes désignées par le Gouvernement;

$4^{\circ}$ Dans le cas où certaines de ces conférences n'aboutiraient pas à un règlement complet dans un temps raisonnable, il appartiendrait aux représentants nommés par le Gouvernement de Sa Majesté de décider sur les points en litige, de façon que les principes ci-dessus énoncés reçussent partout leur application ( $\mathrm{I}$ ).

C'était la reconnaissance du principe et l'espoir que les négociations directes pourraient encore aboutir.

Quel fut l'accueil des intéressés fait aux propositions du Gouvernement?

Les patrons se divisèrent : les plus nombreux (2) - les deux tiers environ - se déclarèrent prêts à accepter le principe du salaire minimum (3) et à suivre la procédure proposée.

La minorité, formée des propriétaires d'Écosse, du Northumberland et de la Galles du Sud (4), repoussait formellement la proposition du Gouvernement.

(1) Labour Gazette, mars i912, p. 84.

(2) Les patrons faisant partie du bureau anglais 'de conciliation : Lancashire, Yorkshire, Midlands et Galles du Nord; ceux de Durham, de Cumberland.

(3) Voici, à titre d'exemple, la résolution votée par les représentants des patrons faisant partie du Bureau anglais de conciliation :

" ${ }^{\circ}$ Les patrons des mines pour les districts fédérés acceptent les propositions faites par le Gouvernement de Sa Majesté;

" $2^{\circ}$ En acceptant les propositions, les propriétaires de mines attendent du Gouvernement la confection d'accords qui les mettra à même d'envisager avec confiance la mise en vigueur de ces contrats pour l'avenir; ils espèrent que le Gouvernement prendra ses précautions pour que de tels accords lient les deux parties pour une durée raisonnable.

(4) Voici, à titre d'exemple, la résolution votée par les représentants de la Galles du Sud :

"Les propriétaires des mines de la Galles du Sud s'en réfèrent strictement au contrat collectif actuel, qui prend fin, par préavis, au plus tôt le 31 mars 1915 .

“ Après l'examen le plus minutieux, ils sont unanimes à déclarer qu'ils ne peuvent accepter les propositions du Gouvernement. ») 
Du côté ouvrier, la Conférence de la Fédération des mineurs s'était réunie pour examiner les propositions du Gouvernement et avait arrêté la résolution suivante :

" La Conférence est d'accord pour affirmer de nouveau la résolution précédemment adoptée le 7 courant par le Comité exécutif et les dix-sept représentants supplémentaires des divers districts, et répète qu'il n'y aura aucune solution au conflit actuel tant que le principe du salaire minimum individuel pour tous les travailleurs du sous-sol n'aura pas été reconnu par les propriétaires de mines.

Les représentants des mineurs consentent encore à rencontrer les propriétaires de mines au jour que ceux-ci leur indiqueront, pour discuter les taux de salaires minima de chaque district, comme précédemment dans des réunions spéciales de cette Fédération. "

Ils repoussaient ainsi toute solution qui eût impliqué un arbitrage obligatoire et maintenaient les minima précédemment fixés.

Les pourparlers se poursuivirent encore les jours suivants (I) (29 fév. et I ${ }^{\text {er }}$ mars) sans grands changements. On aboutit à une " impasse " (2). Au fur et à mesure que le Gouvernement obtenait quelques concessions auprès de quelques patrons (3) sur le principe, ceux-ci se montraient plus intransigeants sur les négociations dans chaque district, qu'ils voulaient raisonnables et non dominées par les tarifications unilatérales préalables du 2 février, en mème temps que les représentants des ouvriers se déclaraient liés par un mandat impératif et déclaraient que tout ce qu'ils pouvaient faire était d'en référer à leurs commettants.

Cependant la grève était déclarée et devenait bientôt générale (4).

Après une dernière tentative de conciliation en date

(I) Des négociations particulières eurent lieu entre le Gouvernement et les patrons réfractaires de Northumberland, d'Écosse et de Galles du Sud. Ceux-ci adhérèrent aux résolutions $\mathrm{x}$ et 2 du compromis gouvernemental, mais maintinrent leur résolution précédente de ne pouvoir payer ce minimum sans garanties précises d'un certain travail équivalent à effectuer (Labour Gazette, mars 1912, p. 85).

(2) M. Asquith aux Communes, 5 mars 1912.

(3) Ceux d'Écosse et de Galles avaient quitté Londres, déclarant que seule une loi les obligerait à accepter le minimum de salaire.

(4) Elle débuta le 26 février dans le Derbyshire. 
des II, I2, I3 et I/4 mars I9I2 (I), le Gouvernement fit paraître la note suivante, qui déclarait close l'ère des négociations et promettait le dépòt d'un projet de loi sur la question (2):

"Le Gouvernement a fait tout ce qui était en son pouvoir pour aboutir à une solution par un accord et est arrivé, avec un extrème regret, à cette conclusion que cet accord était impossible: d'autres mesures doivent être prises.

Le premier ministre a, en conséquence, décidé que le Gouvernement demanderait au Parlement une affirmation par la loi (a legislative declaration) qu'un minimum de salaire raisonnable, accompagné de garanties corrélatives pour la protection des employeurs, serait une clause obligatoire du contrat de travail des ouvriers qui sont engagés pour le travail souterrain dans les mines. En ce qui concerne l'importante question du montant de ce minimum pour les divers bassins houillers, le premier ministre, sans lier le Gouvernement à un mécanisme particulier et déterminé, indique que les minima de district seront fixés par un comité de conciliation, composé de représentants des patrons et des ouvriers avec un président neutre et impartial, soit choisi par les parties, soit, si cela est nécessaire, nommé par le Gouvernement (3). "

\section{c) L'application du "Coal Mines Bill ".}

Le "Coal Mines Bill ", présenté le I9 mars, fut voté rapidement pour mettre fin à la grève (4).

Ce qu'il importe de souligner ici, c'est que, jusqu'au dernier moment, le Gouvernement espéra une entente; il y eut mème un ajournement de débat pendant trois jours, du 23 au 26 mars, aux Communes.

(I) Elle échoua pour les mêmes causes que les précédentes.

(2) On a très vivement critiqué et on critiquera encore très ardemment cette loi (Coal Mines Bill). Pour la juger impartialement, il faut, nous semble-t-il, se rappeler que c'est une loi de circonstance et qu'au point où on était arrivé le 17 mars, l'alternative se posait impérieusement entre la prolongation de la grève sine die et la solution pacifique imposée par la loi. (Cf. en ce sens. Mantoux, art. cité, Contra Yves Guyot, art. cité. Temps, mars 1912 , etc.)

(3) Labour Gazette, mars 1912, p. 86.

(4) Cf. plus bas, p. 326 . 
La grève, grâce à une heureuse politique de la Fédération, cessa au début d'avril.

La loi n'avait fait, en somme, que consacrer législativement le principe; les contrats collectifs de district en assurent actuellement l'exécution.

Aucun chiffre de minimum (I) n'y est inséré; la loi n'a pas assumé de fixer directement le minimum de salaire qui doit résulter des travaux des comités de district.

On a, depuis lors, procédé à la constitution des joints districts Boards; dans bon nombre de cas (2), l'accord a pu s'établir entre les parties pour le choix de l'arbitre indépendant; ailleurs (3), c'est le Board of Trade qui a procédé aux nominations.

Les premières sentences d'application (awards) viennent d'être publiées :

Pour le district de Northumberland, d'après la sentence de lord John Charles Mersey, arbitre nommé par le Board of Trade, voici les principaux tarifs en vigueur (4):

Ouvriers : Ouvriers au temps (datalers), 4 sh. 9 d. par jour.

Ouvriers aux pièces (piece-worlimen), 5 sh. $6 \mathrm{~d}$. par jour.

Apprentis : Apprentis ouvriers au temps (boy datalers) :

De $14 \dot{a}$ i 6 ans, 2 sh. par jour.

De $16 \grave{a}$ I 8 ans, 2 sh. 9 d. par jour.

De 18 à $2 \mathrm{I}$ ans, 3 sh. 6 d. par jour.

Apprentis aux pièces, quel que soit l'âge, $4 \mathrm{sh}$. par jour.

Délégués (deputies) : 5 sh. $6 \mathrm{~d}$. par jour.

Mécaniciens du sous-sol (underground enginemen):

Ouvriers, 5 sh. 6 d. par jour.

Apprentis, 4 sh. par jour.

(1) Unn amendement de M. Enoch Edwards, présenté aux Communes, prévoyant le tarif du 2 février, fut repoussé par 367 voix contre 6j. Un autre, portant un minimum général de $5 \mathrm{sh}$. ( $6 \mathrm{fr}$. 25) par jour pour les hommes et de 2 sh. $(2$ fr. 50$)$ pour les apprentis, fut également repoussé par 367 voix contre 55 .

(2) Lancashire, Derbyshire, Nottinghamshire, South Wales.

(3) Cf. la liste des arbitres nommés ou élus. Labour Gazette, avril 1912, p. 126 .

(4) Awards under the Coal Mines (Minimum Wages) act. 1912. Labour Gazelle, mai igr2, pp. I6f et suiv. 
En mème temps, ont été élaborées les règles de district prévues par la loi ; voici, à titre d'exemple, les plus intéressantes :

$\mathbf{I}^{0} 5 \mathrm{sh} .8 \mathrm{~d}$. par jour pour les ouvriers aux pièces qui fournissent leurs propres explosifs.

$4 \mathrm{sh}$. par jour pour les ouvriers datalers, et $5 \mathrm{sh}$. par jour pour les ouvriers aux pièces dans les petites houillères (small collieries), c'est-à-dire employant au travail du fond (underground) moins de 30 personnes.

$2^{\circ}$ Un ouvrier aux pièces qui a atteint l'àge de 57 ans, un dataler qui a atteint l'àge de 63 ans seront considérés comme ouvriers âgés au sens de la loi et seront exclus du droit au minimun de salaire.

$3^{\circ}$ Un ouvrier qui, à raison de causes phỵsiques, est incapable de donner le travail ordinairement fourni par un homme dans sa position à la mine, sera regardé comme ouvrier infirme au sens de la loi et sera exclu du droit au minimum de salaire.

$4^{\circ}$ Un ouvrier devra, pendant les heures de travail, s'appliquer à sa besogne avec diligence et faire son travail de façon convenable, sans quoi (sauf le cas où ce défaut de travail tient à quelque cause sur laquelle il n'a pas d'action et pour laquelle il aura prévenu, aussitôt que possible, un contremaître de la mine) il sera déchu de son droit au minimum.

$5^{0}$ Un ouvrier perdra son droit au minimum de salaire pendant une paye (I) s'il a quitté son travail un jour sans congé ou sans excuse raisonnable.

$6^{\circ}$ Un ouvrier perdra son droit au minimum de salaire pour le jour où il refuse ou néglige de travailler selon les instructions raisonnables de son contremaître, d'accomplir la besogne qu'on lui dit d'achever, perd du temps en se rendant à sa place de travail ou au travail assigné, quitte sa place de travail ou son travail avant l'heure fixée.

Le mème règlement poursuit en prévoyant encore une série d'hypothèses (faute de ne point apporter des outils, de ne point s'en servir, cas où la couche d'abatage est incom-

(1) C'est-à-dire le temps qui s'écoule entre les jours de chaque paiement de salaire. 
plète, combinaison du salaire aux pièces et du minimum, etc., etc...). Application de ces diverses règles est faite par accord entre l'ouvrier et le contremaître, à défaut par deux représentants du patron, d'une part, et de membres de la branche locale de l'association ouvrière d'autre part, à défaut par un arbitre choisi par les parties sur une liste établie par le comité de district, ou enfin tiré au sort sur la même liste (art. ı3). Enfin le règlement prévoit la délivrance de certificats pour constater la perte du droit au minimum (art. i5).

La minutie et le détail de ces règles permettent d'espérer que, grâce à l'éducation des deux parties, le minimum de salaire pourra heureusement fonctionner.

Pour le district de North Staffordshire (I), le Comité de district a prévu les minima suivants (2):

Tâcherons (Contracting colliers), 7 sh. par jour.

Ouvriers herscheurs autres que les tâcherons, 6 sh. 6 d. par jour.

Chargeurs (Loaders), 6 sh.

Ourriers qui creusent (Crutters) (3), 6 sh. 6 d.

Aide des ouvriers qui creusent (Assistant crutters), 5 sh. 9 d.

Ouvriers au temps et boiseurs (Datalers and timbers), 5 sh. 6 d.

Aide d'ouvriers au temps (Datalers assistants), 5 sh.

Ramasseurs surveillés (Paclier worliing under provision), 5 sh.

Surveillants d'extraction (Coal cutters' attendants), $5 \mathrm{sh}$. $9 \mathrm{~d}$.

Aide-surveillants (Assistants to coal cutters' attendants), 5 sh.

Garçons de charge (Onsetters) (4), 5 sh. $6 \mathrm{~d}$.

(I) Un tarif légèrement inférieur est applicable aux houillères du Cheadle District.

(2) Le Comité de district a également élaboré un règlement contenant des dispositions de détail analogues à celles ci-dessus rapportées. Cf. Labour Gazette, mai ig12, p. 168.

(3) Le " crutter ", en langage technique du Staffordshire, est l'ouvrier qui creuse une galerie à portée du puits pour atteindre une couche de charbon à travers les roches.

(4) L'onsetter est l'ouvrier qui charge les wagons dans l'ascenseur au fond du puits. 
Chauffeurs et mécaniciens (Motormen and enginemen), $5 \mathrm{sh}$.

Convoyeurs (Roadmen), 5 sh.

Apprentis : 14 ans, 2 sh.; 15 ans, 2 sh. $11 / 2$ d.; 15 ans 4 mois, 2 sh. $3 \mathrm{~d}$.; 15 ans 8 mois, 2 sh. $41 \frac{1}{2}$ d.; 16 ans, 2 sh. $6 \mathrm{~d}$.; 16 ans 4 mois, 2 sh. $71 \frac{1}{2}$ d. ; 6 ans 8 mois, 2 sh. 9 d. ; i 7 ans, 2 sh. $101 / 2$ d. ; 17 ans 4 mois, 3 sh.; 17 ans 8 mois, 3 sh. $1 / 2$ d.; 18 ans, 3 sh. 3 d.; 18 ans 4 mois, 3 sh. $4 \frac{1 / 2}{d}$. ; 8 ans 8 mois, 3 sh. 6 d.; 9 ans, 3 sh. 7 1/2 d.; 19 ans 4 mois, 3 sh. 9 d.; 19 ans 8 mois, 3 sh. 10 $1 / 2$ d.; 20 ans 4 mois, 4 sh.; 20 ans 6 mois, 4 sh. 3 d.; 21 ans et au-dessus, 4 sh. $6 \mathrm{~d}$.

Pour le district de Leicester, d'après la sentence du I9 mai I9I2 de l'arbitre Arthur O'Connor K. C., nommé par le Board of Trade, une échelle semblable de minima, variant de 6 sh. 2 d. à 4 sh. Io d. par jour a été pareillement établie pour les diverses catégories d'ouvriers ( $\mathrm{I}$ ).

Pour l'Écosse, les trois présidents du Comité mixte de district ont fixé les taux de salaires minima suivants :

$5 \mathrm{sh}$. Io d. pour piqueurs et assimilés (rouleurs, conducteurs, etc.)

5 sh. 6 d. pour les mineurs proprement dits.

5 sh. 6 d. pour boutefeux et ouvriers employés au tir des coups de mines.

5 sh. pour réparateurs et boiseurs.

$4 \mathrm{sh} .9$ d. pour tous les autres ouvriers adultes du fond.

Des minima allant de 2 sh. 2 d. à $4 \mathrm{sh} .6 \mathrm{~d}$. pour les jeunes ouvriers de 14 à $2 \mathrm{I}$ ans (2).

Le 3 I mai i 9 I 2 , 6 comités sur 22 avaient complété la fixation des taux minima de salaires : 6 n'avaient pas encore fixé complètement la tarification nouvelle; c'étaient: Galles du Sud, West Yorkshire, Derbyshire, Nottinghamshire, Somerset et Bristol.

Voici le tableau de ces déterminations, comparées aux taux de salaires réclamés par les ouvriers (3):

(I) Ainsi qu'un règlement contenant des dispositions analogues à celles ci-dessus rapportées. Labour Gazette, mai 1912, p. I69.

(2) Circulaire du Comilé des Houillères du 20 juin 1912, $\mathrm{n}^{\circ} 451 \mathrm{r}, \mathrm{p} .3$.

(3) Circulaire du Comité des Houillères du 8 juin 1912, n 4500, p. 2. 


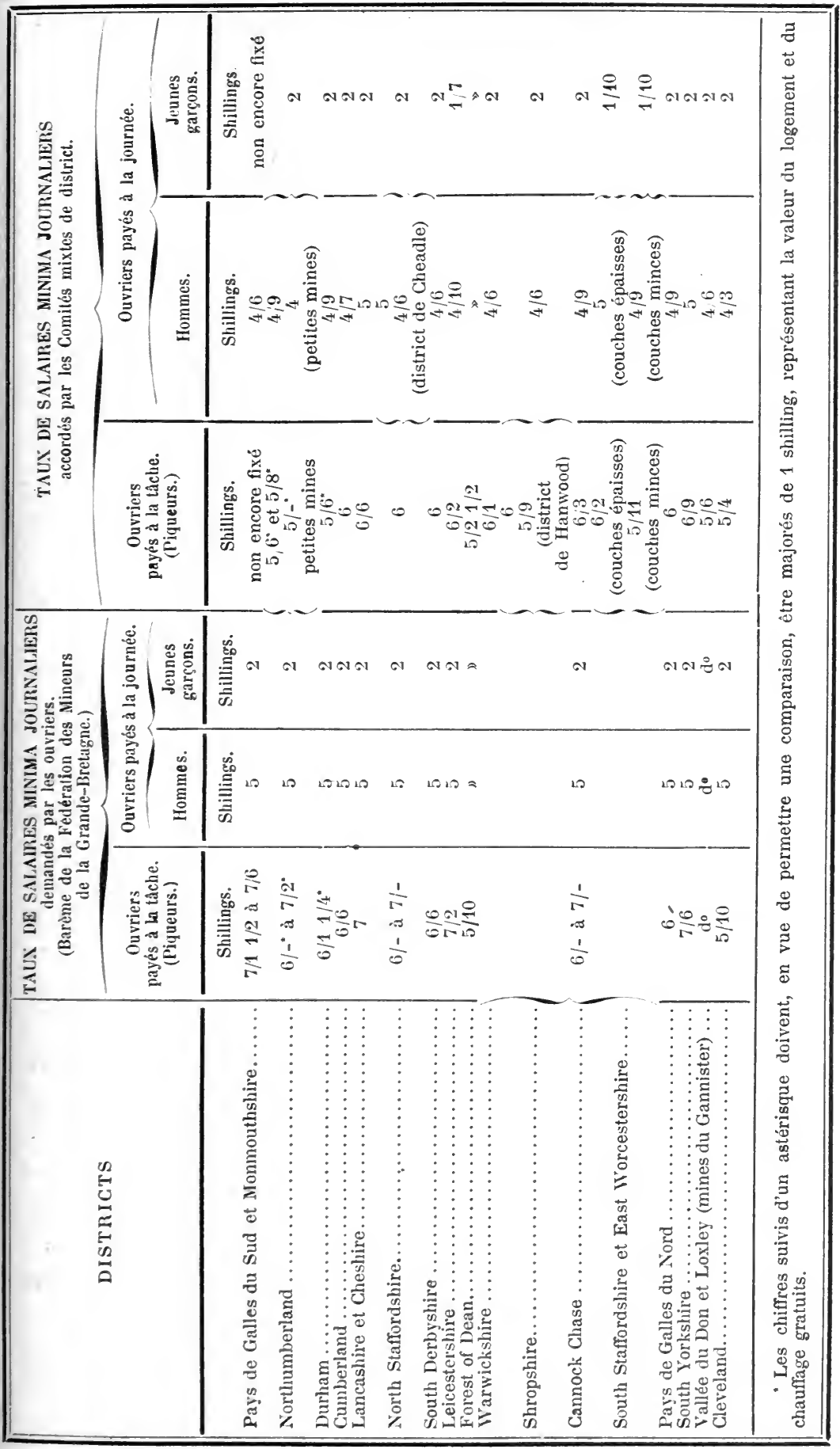


La Conférence de la Fédération des mineurs de la GrandeBretagne, réunie à Londres les 2 I et 22 mai I9ı2, a voté les résolutions suivantes $(\mathrm{I})$ :

“ La présente Conférence, après avoir entendu les rapports sur les décisions déjà prises par différents Comités de district, en exécution de la loi sur le salaire minimum, regrette que, malgré que le premier ministre et ses collègues eussent déclaré, à plusieurs reprises, que le plus bas taux minimum de salaires pour ouvriers adultes du fond devrait, en tout cas, être un salaire qui, raisonnablement, permît à l'ouvrier de vivre (should be a reasonable living wage), elle se trouve aujourd'hui en face d'un certain nombre de décisions (awarls) fixant le taux de minimum de salaire pour ouvriers adultes du fond à une somme inférieure à ce que doit être un salaire correspondant au coût normal de la vie.

" La Conférence exprime en outre le regret que dans leur application du deuxième alinéa du paragraphe 2 de la loi sur le salaire minimum, certains présidents aient refusé de tenir compte des salaires moyens gagnés par les ouvriers payés à la tâche.

" La Conférence proteste avec la plus grande énergie contre lesdites décisions et elle demande au Gouvernement de prendre des mesures immédiates pour remédier à la situation faisant l'objet de ces plaintes.

"La Cónférence charge le Comité exécutif de demander une entrevue au Gouvernement et de convoquer le plus tôt possible une nouvelle Conférence, à laquelle il rendra compte de ladite entrevue. ")

On ne signale guère de difficultés (2) que pour le seul district de Galles du Sud; les ouvriers réclamaient un salaire minimum de 5 sh. par jour; l'arbitre lord $S^{t}$ Aldwyn a confirmé les propositions des propriétaires de mines et sanctionné des minima variables de $4 \mathrm{sh} .2 \mathrm{~d}$. à $4 \mathrm{sh} .9^{1 / 2} \mathrm{~d}$. Les ouvriers firent des récriminations, allant jusqu'à demander la démission de l'arbitre, qui n'avait pas voulu sanctionner leurs prétentions (3).

(1) Circulaire du Comité des Houillères, 8 juin rgr2, p. r.

(2) Cf. Journal des Économistes, mai 1912, p. 348.

(3) Toute décision a été différée jusqu'à ce que la question ait pu ĉtre 
Au total, les premières nouvelles actuellement reçues de l'application de la loi sur le minimum de salaire permettent d'en espérer la loyale et sincère application.

examinée par la Conférence de la Fédération des mineurs de la GrandeBretagne, réunie le 2 I mai ıgı. Circulaire du Comité des Houillères, $n^{\circ} 4488$, p. 3 . 
Dans les industries métallurgiques, c'est l'échelle mobile de salaires qui prévaut encore, plus particulièrement dans les industries du fer et de l'acier; le minimum de salaire n'est exceptionnellement stipulé que pour certaines catégories particulières d'ouvriers.

Dans l'industrie de la fabrication des machines (engineering) par un contrat (I) du I $^{\text {er }}$ octobre I907, passé entre la Fédération des Employeurs constructeurs de machines (The Engineering Employers' Federation) et les diverses associations ouvrières (2), les clauses relatives au minimum de salaire ont été insérées et valent d'ètre relevées :

\section{Clause 3. Travail aux pièces.}

Les employeurs et les employés ont le droit de pratiquer le travail aux pièces, pourvu que :

$I^{0}$ Les prix à payer soient fixés par accord entre le patron et l'ouvrier ou les ouvriers qui font l'ouvrage ;

$2^{0}$ Le gain journalier de chaque employé soit garanti sans tenir compte de ses salaires aux pièces;

$3^{\circ}$ Le travail supplémentaire et les gratifications pour le travail de nuit soient payés en sus des tarifs aux pièces, dans les conditions actuellement usitées dans chaque usine pour le travail au temps;

Clause 5 : Rémunération des ouvriers sliilled.

"Les employeurs ont le droit d'employer des ouvriers à " un taux de salaires satisfaisant tout à la fois pour le “ patron et l'ouvrier ou l'ouvrière intéressé.

a En fixant la rémunération des ouvriers skilled, le patron " prendra en considération le taux en usage dans le district " pour l'ouvrier complètement entraîné et skilled.

" Les Unions, en renonçant à tout droit de se mêler du " salaire des ouvriers autres que leurs membres, ont le " droit dans leur capacité collective de convenir du taux de

(I) Ce contrat englobe environ roo.ooo ouvriers du métier, c'est de beaucoup le plus important dans cette branche d'industrie.

(2) Ce sont : The Amalgamated Society of Engineers, the Steam Engine Makers' Society, the United Machine Workers' Association.

Depuis, d'autres Unions ont adhéré au contrat : The national united Society of Smiths and Hammermen, the Society of Amalgamated toolmakers, Engineers and Machinists, the Scientific instrument Makers' Trade Society, the United Kingdom society of Amalgamated Smiths and Strikers. Rapport cité, p. 85. 
" salaires auquel leurs membres peuvent accepter de tra" vailler.

"Les modifications générales dans le taux des salaires " pour un district seront négociées entre l'Association " locale des Employeurs et les représentants locaux des "Trade-Unions ou Unions intéressées (I). "

On rencontre ici dans leur expression détaillée, consacrés dans un contrat collectif qui est comme la charte du métier, les principes ci-dessus dégagés du minimum de salaire entendu dans son sens véritable. Une série d'accords locaux vient ensuite déterminer les salaires au temps et aux pièces.

(1) Rapport cité, p. 87 . 
Dans les constructions navales, le dernier accord signé le 9 mars I909, qui régit presque toute l'industrie, ne comporte pas, à proprement parler, de minimum de salaire: c'est une industrie où les salaires sont presque entièrement aux pièces, et il était difficile d'arriver à une base aussi nette qu'avec un salaire au temps. Cependant diverses garanties accordées par les patrons pour la fixation des salaires par contrats collectifs locaux, pour éviter les modifications brusques et trop considérables ( $\mathrm{I}$ ), pour résoudre les difficultés portant sur les questions de salaire, montrent ici, comme ailleurs, le succès de la politique trade-unioniste.

(I) Chaque changement général dans les salaires ne doit pas dépasser $5 \%$ pour le travail aux pièces et 1 shilling par semaine ou 1/4 d. par heure pour le travail au temps. 
Les industries textiles comprennent l'industrie du coton (filature et tissage), de la laine, la bonneterie, la dentelle, la soie : partout prévaut la politique trade-unioniste qui aboutit au principe du minimum de salaire.

\section{I. - INDUSTRIE DU COTON}

\section{a) Filature.}

Dans l'industrie de la filature du coton, le contrat collectif général, connu sous le nom de Broolilands Agreement( $\mathrm{I}$ ), ne comporte que des dispositions générales sur les intervalles et le montant des variations de salaire, le mécanisme de conciliation et de fixation des salaires par des accords locaux. Ce sont les contrats collectifs locaux (Piece price List) qui établissent le fonctionnement (lu minimum de salaire. Le principe est le suivant (2) : les salaires des ouvriers filateurs sont aux pièces, proportionnels à la production, mais déterminés par rapport à une base de salaire au temps.

En d'autres termes, le tarif aux pièces par unité de production est calculé de manière à rendre l'ouvrier capable de gagner contre un certain travail (standard), en un temps déterminé, une certaine somme d'argent (standard). On verra plus clairement le mécanisme de ce système par l'étude des deux grands contrats locaux, l'Oldham List et la Bolton List.

Dans l'Oldham List (3), le tarif est basé sur le paiement d'une certaine longueur actuelle de coton produite, chaque machine étant munie d'un indicateur automatique ou compteur qui marque le nombre d'écheveaux fabriqués (chaque écheveau est de 840 yards) (4).

Si cette mesure de la longueur de la laine produite était le seul élément à considérer, le problème du paiement d'après la production serait très simple, mais comme le

(1) Rapport cité, p. 140 .

(2) Contrat passé en $189^{2}$, plusieurs fois modifié, encore en vigueur.

(3) Ce contrat date de 1876 , avec révisions ultérieures : le principe en est d'ailleurs toujours resté le même. Cf. Rapport cité, p. I4I.

(4) Le yard vaut 914 millimètres. 
mécanisme de la production varie également, la question devient beaucoup plus difficile.

Aussi a-t-on tenu compte, pour une approximation plus exacte de la production, d'abord du nombre de broches, ensuite de la longueur du mouvement de la machine (Iraw) (I), qui représente la longueur du coton pouvant être aisément et convenablement filé, trié et enroulé sur les dévidoirs (cops) de chaque broche en une opération.

Avec ces éléments, la base des tarifs est ainsi déterminée : un nombre donné de broches faisant trois draws de 63 inches chaque (c'est-à-dire trois mouvements d'aller et retour, sur une étendue de 63 inches en 50 secondes) représente un certain taux de salaire hebdomadaire (2). à diviser entre le fileur et ses assistants dans une certaine proportion.

Voici un extrait du contrat (3):

$\begin{array}{cc}\begin{array}{c}\text { Nombre de douzaines } \\ \text { de broches. }\end{array} & \begin{array}{c}\text { Salaire hebdomadaire (2) } \\ \text { du fileur. }\end{array} \\ 36 & 25 \mathrm{~s} .6 \mathrm{~d} . \\ 37 & 25 \mathrm{~s} .8 \mathrm{~d} . \\ 38 & 25 \mathrm{~s} . \text { Io d. } \\ 40 & 26 \mathrm{~s} .2 \mathrm{~d} . \\ 50 & 27 \mathrm{~s} . \text { IO d. } \\ 90 & 34 \mathrm{~s} .6 \mathrm{~d} . \\ \text { I00 } & 36 \mathrm{~s} .2 \mathrm{~d} . \\ \text { I I } 6 & 38 \mathrm{~s} . \text { IOd. }\end{array}$

Salaire hebdomadinire (2) des assistants (piecers).

I I s. $6 \mathrm{~d}$.

I I s. $6 \mathrm{~d}$.

I I $6 \mathrm{~d}$.

I I s. $6 \mathrm{~d}$.

I 4 s. $6 \mathrm{~d}$.

$28 \mathrm{~s}$.

$33 \mathrm{~s}$.

$36 \mathrm{~s} .6 \mathrm{~d}$.

Ces tarifs s'appliquent lorsque les métiers marchent à la vitesse normale : 63 inches aller et retour en 5o secondes.

Quand cette vitesse standard est dépassée, un supplément de salaire est accordé : il varie selon le nombre des broches, mais augmente d'une quantité fixe pour chaque seconde en plus des 50 du standard (4) : l'avantage donné par l'accroissement de la production se partage par moitié entre l'employeur et les employés.

(1) Le draw est ainsi le temps que dure le remplissage de la bobine. L'équivalent technique français est " monture ».

(2) La semaine était de 56 heures $1 / 2$ jusqu'au $1^{\text {er }}$ janvier 1902, aujourd'hui de 55 heures $1 / 2$. Les chiffres du tableau se rapportent à une semaine de 56 heures $1 / 2$.

(3) Celui-ci donne le salaire global du fileur et des assistants.

(4) Voir le tableau. Rapport cité, p. 142. 
D'autres clauses plus détaillées encore et qu'il n'est pas utile de reproduire (I) s'efforcent de poursuivre le même but : la concordance exacte des salaires et de la production. Celles-ci suffisent pour montrer la complexité et aussi la difficulté du minimum de salaire dans l'une des principales industries anglaises.

Le système de la Bolton List est sensiblement analogue (2).

\section{b) Tissage.}

Dans le tissage du coton, le système est basé sur des principes analogues : en dehors des contrats collectifs généraux réglant la procédure de fixation des salaires et la solution des conflits, des tarifs aux pièces (piece Price List) existaient en assez grand nombre, aujourd'hui en grande partie unifiés dans une liste uniforme applicable à toute l'industrie.

De mème ici on a essayé de baser le salaire sur la production (3); c'est encore par la détermination d'une base ou standard qu'il a fallu procéder. Le tarif appliqué dans le Nord et le Nord-Est du Lancashire en vigueur depuis 1892 avec diverses retouches de détail comporte un gros volume; voici la clause relative au standard (4):

" La base sur laquelle le tarif uniforme repose est le

(I) C. id. Rapport, p, 145.

(2) Dans la liste de Bolton, par exemple, la base est au poids : un écheveau du poids de roo lbs, au lieu de la longueur comme pour celle d'Oldham.

(3) Quelques détails techniques sont indispensables à rappeler ici :

L'opération du tissage ne commence qu'au moment où la chaine (warp), consistant dans les fils longitudinaux de la pièce à tisser, est mise en place sur le métier. Les fils utilisés pour la chaine sont ce qu'en termes de tissage, on appelle " twist ", c'est-à-dire la torsion chaine. Ces fils, ou encore bouts, passent entre les ouvertures appelées dents (lents) du peigne [reed ou rot].

L'action du métier consiste à passer au travers de la chaîne des fils croisés (trame). Ces fils sont portés par la navette (shuttle) qui, par un rapide va-et-vient, passe tantòt au-dessus, tantòt au-dessous des fils de chaine. La trame ou fils croisés est appelée encore pick, c'est-à-dire fils de trame. Le salaire varie selon quatre éléments :

a) L'épaisseur des fils de chaìne, leur nombre par pouce de largeur, la largeur totale de la piece tissée;

b) La finesse et le serré de la chaine;

c) La longueur totaie du tissu;

d) La nature et la qualité de la matière employée.

(4) Rapport cité, p. 173. 
métier dont le peigne mesure 45 pouces (inches) tissant dans les conditions suivantes:

Largeur: 39,40 ou $4 \mathrm{I}$ pouces ;

Peigne (1): 6o intervalles ou trous, 2 fils par chaque trou et 60 fils par pouce;

Fils de trame: i5 fils de trame par quart de pouce avec I I $/ 2 \%$ ajouté pour la contraction;

Longueur : roo yards de 36 pouces mesurés au compteur. Tout supplément à un nombre exact de yards payé en proportion :

Chaine : le numéro de chaîne 28 ou plus fin;

Trame : du numéro 3 I inclus au numéru 100 inclus;

Prix : 30 d. ou 2 d. par fil de trame."

Des clauses spéciales très fréquemment appliquées en fait prévoient les variations en dehors de cette base; des modifications au salaire sont calculées selon la largeur des métiers, les conditions particulières de la fabrication, etc... On comprend ainsi que la détermination des salaires individuels soit une opération compliquée et délicate : sans entrer dans ces détails, on voit que le principe du minimum de salaire a triomphé dans le tissage du coton.

Des contrats collectifs analogues établissent des systèmes semblables pour les tissages de tissus en couleurs et les autres spécialités de l’inclustrie du coton.

\section{II. - INDUSTRIE DE LA LAINE}

L'industrie de la laine est loin d'ètre aussi avancée; les contrats collectifs y sont beaucoup moins développés, certains tarifs, tels que celui d'Huddersfield (2), existent cependant.

L'industrie de la bonneterie (3) (Hosiery trade) jouit aussi, comme les autres industries textiles, du contrat collectif. Un tarif de 1895 pour le Leicester, l'un des principaux centres de cette industrie, prévoit un tarif détaillé aux pièces des divers articles de bonneterie: les

(r) Ou encore Duite.

(2) Le système est assez analogue à celui exposé au texte pour le tissage du coton. Cf. Rapport cité, p. I87.

(3) Rapport cité, p. rigr. 
salaires y sont ordinairement fixés par ıoo douzaines de paires.

Une politique analogue à celle décrite ci-dessus tient compte des répercussions des conditions de la fabrication sur les salaires.

Les industries de la soie (I) et de la dentelle (2), tout au moins de la dentelle mécanique, sont soumises au même régime; on y constate de la même manière l'établissement d'un salaire de base avec des variations autour de ce standard rate.

Au total, la politique du minimum de salaire a triomphé, malgré de sérieuses complications techniques, dans les industries textiles.
(I) Ibid., p. 2 II.
(2) Ibid., p. 199. 
Les industries du vêtement ( $\mathrm{I}$ ) nous offrent un exemple intéressant de minimum de salaire; il importe d'y insister.

L'industrie de la chaussure (Boot and Shoe Trade) a subi dans ces dernières années de profondes transformations par l'introduction du machinisme; on y trouve la fabrication à la main en voie de décadence et la fabrication à la machine en continuel développement; dans ces deux branches de l'industrie, c'est le travail aux pièces qui domine. Le développement de l'industrie mécanique donna l'occasion d'établir de nouvelles listes de prix connues sous le nom de "quantities statements ", tarifs quantitatifs, où l'on tenait compte de la capacité de production des nouvelles machines; le principal objet de la politique du salaire fut alors de déterminer un équivalent en travail à fournir comme contrepartie d'un salaire hebdomadaire garanti par l'employeur.

Si donc on néglige l'industrie du cousu à la main (Handsewn worli) (2) pour s'en tenir au travail mécanique, on constate le triomphe du contrat collectif dans des conditions particulièrement originales :

Le salaire minimum hebdomadaire (3) est accordé, mais en retour l'employeur se réserve le droit propre d'exiger une production donnée (4).

En ce qui concerne le montage et le finissage de la chaussure, d'importants contrats collectifs généraux et concernant le métier tout entier furent passés en i 895. C'était le moment le plus critique de la transformation de la fabrication à la main en fabrication mécanique. Le principe est posé dans un accord de 1895 signé par une conférence tenue au Board of Trade sous la présidence de sir Courtenay Boyle:

" La Conférence est d'avis qu'un tarif aux pièces ou des tarifs pour les ouvriers monteurs ou finisseurs travaillant à la machine et les ouvriers dont le travail est en relation

(I) Rapport cité, p. 226.

(2) Des tarifs aux pièces très détaillés y sont en vigueur.

(3) La semaine ordinaire est aujourd'hui de 52 heures $1 / 2$ (contrat collectif du 26 janv. 1909), mais les divers contrats établissant le minimum de salaire se réfèrent à la semaine alors en usage dans l'industrie au moment où ils ont été conclus.

(4) Quelques détails techniques sont ici encore nécessaires : la fabrication de la chaussure à la machine comprend, en général, une série d'opérations dont les plus importantes sont le montage et le finissage qui occupent la majorité des ouvriers du métier. 
avec les précédents est désirable. Pareils contrats doivent être basés sur la capacité actuelle d'un ouvrier moyen. Tout industriel doit avoir le choix entre l'adoption du tarif aux pièces ou la continuation du travail au temps : il est entendu que l'ensemble des ouvriers travaillant à une opération quelconque sera mis à l'un ou à l'autre systìme et qu'aucun nouveau changement n'aura lieu avant six mois. ”

Des Comités mixtes d'employeurs et d'employés furent nommés pour appliquer cette résolution. Un Comité général fut constitué pour établir les bases du nouveau tarif. ll aboutit aux déterminations suivantes :

I ${ }^{0}$ Il n'y aura pas plus de deux classes de salariés;

$2^{0}$ La classification sera dominée par la matière première des tiges ;

$3^{\circ}$ En ce qui concerne la capacité de l'ouvrier moyen, les salaires moyens actuels de cet ouvrier pour chaque opération dans chaque district seront constatés et serviront à établir les tarifs de salaires aux pièces.

Note. - Il est entendu en ce qui concerne le salaire de base que seules les usines payant le salaire minimum accepté, ou ayant un tarif accepté, ou se conformant aux conditions acceptées, seront prises en considération. »

D'après ces principes, qui consacrent la politique du minimum de salaire, des accords locaux ont été passés.

A Londres, pour le travail des femmes, on a établi la base (standard) :

" Button or balmoral : I I 1/2 in. military heel; puff toe; 7 in. at back seam of leg: machine sewnchannels down; or brass rivets; pumps or welts; finished round strip or black waist. ")

La chaussure type ainsi déterminée, les salaires payés pour le montage ou le finissage d'une paire de ces bottines type est appelé prix de base (groundwork price $e_{\text {) }}$. Le salaire varie aussi suivant la qualité de la matière première (I).

C'est en r9o6 seulement que fut conquis le minimum de salaire : un arbitrage du Board of Trade rendu par une sentence du 28 avril igo6 arrêta :

" 30 shillings par semaine de 54 heures sera le salaire de

(I) Voir le tableau. Rap. cité, p. 235. 
base minimum entre les parties pour les ouvriers adultes qualifiés employés au montage et au finissage à Londres. La question de la possibilité pour un travailleur de gagner et de recevoir ledit minimum de salaire, si elle est discutée au point de vue de l'âge et de l'habileté ou à tout autre point de vue, sera tranchée entre le patron et les TradeUnions par le Comité mixte au cas où ceux-ci ne pourraient se mettre d'accord. ")

Ainsi à l'heure actuelle, en ce qui concerne le montage et le finissage à la main, les ouvriers de la chaussure cousue à la machine, à Londres, ont un minimum de salaire hebdomadaire sans préjudice de salaires extra, proportionnels à un supplément de production.

De même à Leicester, le principal centre de l'industrie de la chaussure anglaise, un tarif aux pièces, signé le 9 novembre I 898, existe pour les ouvriers monteurs à la machine; un autre, du 5 mai i go/, pour les ouvriers finisseurs. Pour ces derniers, il existe aussi un minimum de salaire hebdomadaire.

Le contrat est assez intéressant pour mériter une traduction complète :

Clause $7(2)$ : Tous les industriels et tous les ouvriers accepteront le tarif aux pièces-charte de métier (the Pieceworli statement) dans son intégralité comme base du paiement; mais le système de travail sera le travail au temps et les salaires des ouvriers seront déterminés et calculés selon le montant de l'ouvrage accompli au tarif établi par l'accord pour chaque opération ou procédé de fabrication (3).

Note. - Cette clause signifie qu'un ouvrier devra s'arranger à fournir une quantité de travail donnée contre un salaire donné. S'il en fournit plus, il sera payé pour le surplus au tarif du contrat; s'il fournit moins que la quantité convenue, une déduction correspondante sera effectuée; mais pour

(1) Op. cit., p. 245.

(2) Les premiers articles du contrat du 5 mai 1904 sont relatifs à la durée du contrat ( 3 ans), à la tacite reconduction, sauf dénonciation

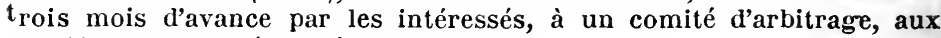
modifications de détail nécessaires, etc...

(3) Il y a en effet, comme on va le voir, combinaison du travail aux pièces et au temps, en ce sens que l'ouvrier gagne un certain salaire convenu à condition de fournir une certaine quantité de travail promis pendant la semaine. 
donner à la clause son plein effet, aucun ouvrier, au-dessus de 20 ans, ne sera engagé sans la clause de salaire minimum, sauf autorisation spéciale.

" Le salaire minimum : explication de la base sur laquelle le contrat est construit. - En exécution du contrat-charte pour le finissage, tout ouvrier àgé de 20 ans sera engagé à un salaire minimum de 29 shillings par semaine (I) qu'il peut s'attendre à gagner au tarif du contrat-charte pour toute semaine complète. Si l'ouvrier à qui l'on fournit la besogne ne peut se procurer ce chiffre de salaire en travaillant à plein (should he fail to do this when supplied with a full quantity of work), soit par inaptitude physique, soit par lenteur dans son activité industrielle, le patron ou l'ouvrier devront aussitôt s'adresser aux représentants de l'Union pour obtenir l'autorisation de payer l'ouvrier au taux de salaire qu'il s'est montré lui-mème capable de gagner (for a permit to pay the man the wages he has shown himself capable of earning); cette autorisation sera accordée par les représentants de l'Union; à défaut de cette autorisation, le patron aura la liberté de renvoyer le travailleur de son usine de la manière ordinaire. Si l'ouvrier arrive à gagner plus que $29 \mathrm{~s}$. par semaine (2), il sera payé pour le travail en sus au tarif fixé par le contrat-charte.

Le Comité décide que tout industriel qui aura adopté le contrat-charte devra payer le salaire minimum à la date où il commence à appliquer ce contrat-charte.

8. Dans tous les cas où les ouvriers sont présents aux usines, à la disposition des employeurs, il leur sera fourni de louvrage pour au moins une demi-journée, sauf si la courte journée est appliquée dans l'usine : en ce dernier cas, les ouvriers ne devront pas commencer le travail plus tard que neuf heures le matin et devront travailler jusqu'au moment du dîner (3) ; si on exige leur présence pour l'après-midi, il devra leur être fourni de l'ouvrage pour une période d'au moins deux heures; si on leur fournit moins de deux heures d'ouvrage, ils seront payés comme pour

(1) Aujourd'hui 3o shillings, par une sentence du Comité de conciliation et d'arbitrage de la chaussure, à Leicester, en date de janvier r 908 : soit environ $37 \mathrm{fr} .50$.

(2) Cf. note ci-dessus.

(3) Midi environ, selon les moeurs anglaises. 
deux heures au taux du salaire hebdomadaire convenu. Exception est faite aussi pour le cas d'interruption dans les machines d'une usine après l'entrée des ouvriers, ou pour le cas de maladie ou d'absence d'un ouvrier qui intéresserait l'organisation du travail dans l'usine, auxquels cas les ouvriers seront autorisés à quitter l'usine sur-le-champ.

9. Ce contrat-charte est applicable à tous les ouvriers de 20 ans et au-dessus... (1)

Io. Dans le but de représenter clairement les dispositions de chaque partie du contrat-charte, des paires de chaussures ou de tiges (soles), selon ce qu'il faudra, seront obtenues, montrant le caractère et la qualité du travail dans chaque opération industrielle prévue par le contrat-charte. Ces paires de chaussures ou tiges seront munies d'un cachet de cire par le président du Comité du contrat pour le finissage et partagées: l'une des chaussures ou tiges gardée par le secrétaire de l'Association des patrons, l'autre par le secrétaire de la branche $n^{0}$ I de l'Union nationale, pour qu'on puisse s'y référer en cas de désaccord sur la signification d'un procédé ou d'une qualité de l'ourirage.

I . En arrètant cc contrat-charte, il est entendu que les industriels feront circuler l'ouvrage dans les divers ateliers avec le meilleur rendement possible. ")

Des contrats collectifs règlent aussi le sort des clicliers : c'est encore le système des tarifs quantitatifs.

Le salaire minimum pour les clicliers dans l'industrie de Northampton est de 30 shillings par semaine (2), avec exi-

(I) La clause 9 se poursuit par les dispositions transitoires suivantes: "La situation actuelle à l'usine des enfants et jeunes travailleurs restera sans changement (en attendant la solution du comité nommé à cet effet), mais pour éviter les conflits et malentendus, le Comité du contrat pour le finissage serait heureux si les industriels voulaient garder à leur service les ouvriers touchant à leurs 20 ans et voir s'ils gagnent en une semainc de plein travail le minimum de salaire. Si un conflit s'élève relativement à la diminution de besogne pour les travailleurs àgés de 20 ans, les représentants de l'Union devront demander le concours d'un des membres du Comité du contrat-charte pour régler la différence à fixer. ")

(2) Sentence arbitrale du 22 juillet 1907 : le contrat est conclu pour trois ans à dater du 17 aoùt 1907 et soumis à la dénonciation des deux parties par préavis trois mois d'avance. On a pris comme base la production moyenne des clickers pendant les trois semaines se terminant le 28 aoùt, le 4 septembre et le i s septembre 1909 pour déterminer le taux moyen de salaire au temps que chaque ouvrier était en droit de réclamer. 
gence d'un certain travail à fournir, obtenu par l'application du tarif aux pièces : la liste de prix, dénommée " quantities statement ", a été arrêtée par une cour d'arbitrage nommée par le Board of Trade, sur la demande du Bureau de conciliation et d'arbitrage de la chaussure de Northampton. En mème temps, si un cliclier trouve possible de dépasser ce taux de production et se montre capable plusieurs semaines de suite de produire pour 32 shillings, par exemple, on accepte que ce travailleur ait droit, dans l'avenir, à un salaire de 32 shillings par semaine, à condition pour lui de maintenir sa production plus abondante. D'un mot, le minimum de salaire suit ici les accroissements possibles de la productivité du travailleur.

Enfin, le système a été étendu par un contrat collectif général du 26 janvier I 909 aux ouvriers mâles âgés de 18 à 2 I ans, ayant au moins trois ans d'expérience du métier avant leurs 18 ans.

Ce salaire minimum varie selon le taux du salaire minimum pour les adultes : si ce dernier est de 3 o shillings, il est ainsi fixé :

A partir de l'âge de 18 ans, 18 shillings par semaine.

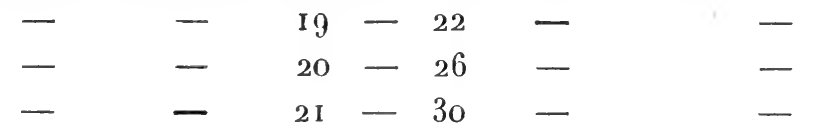

Si le minimum général est inférieur à 30 shillings, une échelle graduée (I) calcule ainsi le minimum de salaire pour les ouvriers de 18 à 2 I ans :

En atteignant l'âge de 18 ans 19 ans 20 ans

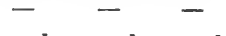

Quand le salaire minimum général est 26 s. 15.6 I9 22.6

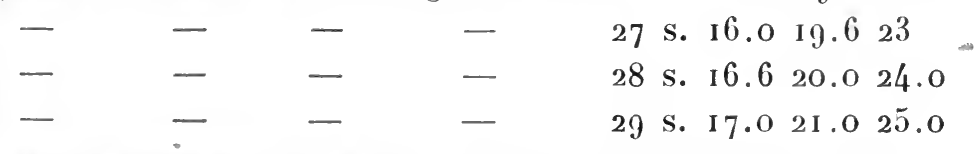

Des clauses spéciales des contrats collectifs généraux (2) prévoient encore la procédure à suivre pour l'obtention du

(1) Contrat collectif complémentaire du 28 juillet rgog, op. cit., p. 252 .

(2) Contrat du 26 janvier 1909 pour les ouvriers âgés de 21 ans; contrat du 28 juillet igog pour les ouvriers de 18 à 21 ans (youths). 
minimum de salaire : la procédure est sensiblement la même dans les deux cas.

L'intéressé qui réclame l'application d'un minimum de salaire notifie (verbalement ou par écrit) à un patron l'âge qu'il vient d'avoir et réclame le minimum ou le nouveau minimum. Cet avis doit être donné huit jours au moins avant la date où l'application du nouveau tarif est réclamée. Si pendant la première semaine pendant laquelle application lui en est faite, le patron décide qu'il n'est pas qualifié pour gagner le minimum, l'ouvrier sera payé à ce salaire minimum pour cette semaine-là, mais à la fin de la semaine cessera automatiquement de gagner ce salaire, à moins qu'un arrangement satisfaisant n'ait été passé à son sujet entre le patron et les représentants de la Trade-Union.

En ce qui concerne les apprentis (boys) au-dessous de I 8 ans, le minimum de salaire n'existe pas encore.

Ainsi, soit par contrats collectifs particuliers à un patron et à ses employés, soit, plus rarement, par contrats collectifs généraux entre les patrons et l'Union nationale des ouvriers de la chaussure, le minimum de salaire est aujourd'hui une réalité dans l'industrie de la chaussure (I).

(1) Nous trouvons bien ici l'application de notre formule finale : " Le salaire le plus bas encore convenable qui puisse être payé. "Cf. plus loin, p. 451 . 
L'industrie de la confection (tailoring trade) (I) nous offre une application différente, mais également intéressante, du minimum de salaire.

Les conditions du travail sont ici encore réglées par contrat collectif. Le système de paiement le plus ordinaire est le tarif aux pièces, mais dans la majorité des cas avec une base au temps spéciale, un nombre déterminé d'heures et de minutes étant accordé pour l'achèvement des diverses opérations. La liste des tarifs aux pièces a reçu, dans le métier, l'appellation de " $\log »(2)$.

La base du tarif, l'étalon sur lequel est construit le log est le tarif pour l'ouvrage dépensé à la confection d'un costume complet (a plain garnment) (3) effectué avec certaines étoffes et matières premières prises comme type. Les variations dans l'emploi des matières premières entraînent des modifications de salaire; les diverses complications du costume sont aussi payées en dehors et en sus, sous le nom d' " extra ".

Ainsi, il y faut insister, le salaire sera obtenu en multipliant le tarif à l'heure par le nombre d'heures allouées pour chaque opération (4). C'est ainsi que le gain de l'ouvrier à l'heure ou à la journée variera selon son habileté et sa rapidité à l'ouvrage (5). Si, par exemple, on alloue à un ouvrier dans le tarif I h. I/4 pour mettre le col d'un habit, et s'il fait cette opération en une heure, il sera payé pour une heure de travail comme s'il y avait passé I h. I/4.

Ce sont des tarifs locaux qui fixent ces listes de salaires.

Ainsi, à Londres, un tarif de r89 I (6), modifié une dernière fois le 20 mai igog, énumère les diverses opérations

(1) Rapport cité, p. 257 .

(2) Les tarifs diffèrent évidemment selon que l'ouvrage est fait tout entier à la main ou tout entier à la machine à coudre. Cf. Blaliburn machine Log. Op. cit., p. 265.

(3) Parfois cette confection du costume complet ne comprend pas les poches.

(4) Non plus comme ci-dessus dans le bàtiment, par exemple, des heures réellement dépensées au travail.

(5) Le log prend alors le nom technique de "lime log ». Dans quelques cas plus rares, on spécifie le salaire aux pièces sans référence au temps : c'est alors le " money log ", par exemple, dans la confection pour dames du West End à Londres.

(6) Modifications successives en 1893, 1900, 1906 et 1908. 
nécessaires à la confection d'un vètement qui revient à un total de 32 h. $3 / 4$ (I); dans les provinces : Galles, Écosse et Irlande, des déterminations analogues, mais légèrement. différentes (2): le prix de l'heure est fixé définitivement, selon les circonstances pour les diverses régions (3).

Il n'y a donc pas, en apparence, salaire minimum, mais temps maximum à dépenser pour gagner un salaire donné; c'est donc, on le voit, conformément à la notion indiquée (4), le salaire le plus bas encore convenable qui puisse ètre payé pour un travail donné (5).

L'industrie de la chapellerie jouit aussi partiellement d'un salaire minimum, obtenu par un salaire hebdomadaire correspondant à une semaine définie (6), déterminé, comme pour la chaussure (7), par un tarif aux pièces et une production déterminée de l'ouvrier (8).

(I) C'est ce qu'on appelle le "start ".

(2) L'unification toutefois a été réalisée pour l'Écosse.

(3) Gf. op. cit., pp. 259 et suiv.

(4) Cf. ci-dessous Conclusion, p. $45 \mathrm{r}$.

(5) 35 shillings pour la mise à la forme et le hardening, 34 shillings pour le hand planking ou feutrage à la main dans le district de Denton, op. cit., p. 272.

(6) 55 heures $\mathrm{r} / 2$ le plus ordinairement.

(7) G. ci-dessus, p. 184 .

(8) Dans d'autres régions, comme à Londres, il n'existe qu'un tarif aux pièces arrêté par contrat collectif, op. cit., p. 273. 
Les industries du livre (I) sont encore un exemple précieux du succès du minimum de salaire par le contrat collectif. Les tarifs d'imprimerie établis par contrats collectifs stipulant une rémunération convenable pour la besogne accomplie sont la règle ; de même le salaire minimum expressément stipulé. Nous le rencontrons à Londres, dans les tarifs en usage (2); c'est ainsi que le tarif pour livres et ouvrages de ville prévoit, pour certains ouvriers (3) compositeurs, 39 shillings de salaire minimum pour la semaine de $52 \mathrm{~h}$. I $/ 2$; ainsi encore que la nouvelle échelle des journaux comporte un minimum de salaire de $3 £ 3 \mathrm{sh}$. par semaine de 42 heures, sans préjudice des heures supplémentaires. Lors de l'introduction des linotypes, un salaire minimum de $45 \mathrm{sh}$. par semaine de 48 heures fut stipulé en février i 892 . D'autres contrats règlent les salaires en province et contiennent des minima du mème genre.

De même les mécaniciens (4), les ouvriers employés aux rotatives (5), les correcteurs (6) ont également des salaires minima hebdomadaires garantis par contrat. Le salaire minimum est aussi très répandu dans l'imprimerie proprement dite.

La reliure connaît, à Londres, d'après un contrat de I893, modifié en igo3, un minimum de salaire de $35 \mathrm{sh}$. pour une semaine de 48 heures. Ce salaire est obtenu par l'application d'un tarif aux pièces, basé sur cette constatation « qu'un homme d'adresse et d'habileté peut gagner au moins I sh. par heure ".

(1) Op. cit., pp. 275 et suiv.

(2) Op. cit., p. 285. Les autres tarifs sont le Book and Jobbing Scale, et le Parliamentary Scale, tarif pour impression des documents parlementaires.

(3) Ce sont les compositeurs engagés pour plus de 15 jours.

(4) 39 s. par semaine de 52 h. I/2 à Londres.

(5) Minima variables et s'échelonnant suivant les machines et le

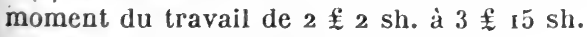

(6) $42 \mathrm{sh}$. par semaine de $52 \mathrm{~h} .1 / 2$. 
L'industrue des chemins de fer (1) jouit aussi depuis quelques années, pour certaines catégories de travailleurs, du minimum de salaire; des accords particuliers entre chaque Compagnie et ses employés le stipulent expressément, en fixant le salaire hebdomadaire.

ll est surtout usité pour les mécaniciens et chauffeurs, les aiguilleurs, etc... Ainsi, par exemple, la London and North Western Railway Company a, par accord du 2 février ı 909 , stipulé une série de salaires hebdomadaires minima, avec des indemnités de résidence, etc., en même temps qu'est fixé le temps de travail correspondant.

Les dockers et les travailleurs des ports ne connaissent le plus souvent que des salaires au temps (à l'heure) arrêtés par contrats collectifs. Quelques-uns d'entre eux sont très détaillés (2); un petit nombre (3) stipulent, à proprement parler, un salaire minimum journalier.

C'est l'exception, comme il fallait s'y attendre, dans ce métier unskilled.

D'autres industries moins importantes pratiquent encore le minimum de salaire :

Dans la tonnellerie, le contrat collectif de Burton-onTrent (4) prévoit, avec des tarifs aux pièces très détaillés, des salaires minima journaliers variant de 5 sh. 9 d. à 8 sh.; celui de Liverpool (5) prévoit un salaire minimum journalier de 6 sh. 6 d. pour une journée de travail variable selon les saisons de l'année.

Dans l'industrie du meuble (6), certains contrats, commé celui de Liverpool (ébénisterie), prévoient ụn salaire fixé à l'heure, qui est ici de io d. l'heure.

(x) En Angleterre, cette industrie est, on le sait, sous le régime de la concurrence libre, et il y a une quarantaine de compagnies. Cf. Rapport, p. 3 г3.

(2) Rapport, p. 344 .

(3) Ainsi 6 sh. pour 9 heures, d'après un contrat de I908 entre l'Association des maitres arrimeurs de Londres et la Ligue pour la protection du travail des arrinieurs réunis, rap. cit., p. $358 ; 4$ sh. 6 d. pour divers ouvriers déchargeurs de grain du port de Bristol (rap. cité, p. 349), etc., etc. ; également à Cardiff et à Newport pour les ouvriers employés au déchargement des bateaux (rap. cité, p. 352).

(4) Rapport cité, p. 365 .

(5) Ibid., p. 371 .

(6) Ibid., p. 373 . 
Dans l'industrie du verre, la fabrication des bouteilles, localisée dans le Yorkshire et le Lancashire, comporte un salaire minimum hebdomadaire collectif pour le fabricant, le souffleur et le cueilleur, correspondant à la fabrication d'un nombre donné de douzaines de bouteilles (I). Parfois aussi dans d'autres districts, comme le Nord de l'Angleterre (2), il n'y a pas d'équivalent de production comme contre-partie du salaire promis (3). Il arrive encore que si la production est inférieure au nombre de bouteilles stipulé pour assurer le paiement du salaire minimum, une réduction proportionnelle est opérée sur la base de ce salaire minimum.

Les industries de l'alimentation connaissent un système analogue :

Dans la boulangerie (4), à Liverpool, le salaire, arrèté toujours par contrat collectif, est, par semaine (5), de 36 shillings pour les contremaîtres, 28 shillings pour les salariés adultes; à Glascow (contrat de rgro), il est de 35 sh. par semaine pour les ouvriers boulangers, et de $37 \mathrm{sh}$. pour les travailleurs qui commencent de bon matin.

L'industrie de la pêche connaìt exceptionnellement aussi le salaire minimum, par exemple à Aberdeen.

Il n'est pas inconnu non plus dans la fabrication des brosses (6).

$\mathrm{Au}$ total, le salaire minimum a aujourd'hui droit de cité dans l'industrie anglaise par l'effort de l'association professionnelle; il y fait chaque jour de nouveaux progrès.

En résumé, on est arrivé au salaire minimum de deux façons :

(1) Ibid., p. 376. Actuellement (contrat de rgog du Yorkshire) I £ I6 s. pour le fabricant, I $£$ I $4 \mathrm{~s}$. pour le souffleur, I $29 \mathrm{~s}$. pour le cueilleur.

(2) Excepté Blaydon, où le système est le mème que celui du Yorkshire et du Lancashire.

(3) Parfois, au contraire, comme dans le Lancashire, il est de plus stipulé que le patron fournira la quantité de matière première nécessaire pour que l'ouvrier puisse se faire le minimum de salaire convenu.

(4) Itid., p. 388.

(5) La semaine de travail est toujours rigoureusement définie dans les accords : 6o heures par semaine avec le travail de jour et 48 heures avec le travail de nuit à Liverpool; 53 heures normalement à Glascow et 48 heures pour le cas où le travail commence de bon matin (early men).

(f) Ibid., p. 396 . 
Ou bien dans les cas de tarifs au temps, on stipule une certaine quantité d'ouvrage à faire dans un temps donné, to do a fair day's work; on promet de faire sa bonne besogne journalière.

Ou bien dans les cas de tarifs aux pièces, on s'arrange pour que l'application de ce tarif produise comme contrepartie du travail accompli en un temps donné une certaine somme d'argent jugée suffisante.

Mais, on le voit, le minimum de salaire purement quantitatif, c'est-à-dire une somme d'argent promise sans contrepartie de travail - "each worliman's day rate » - est l'exception (I).

L'expérience anglaise met en lumière la vraie définition pratique du minimum de salaire : le salaire le plus bas encore convenable qui puisse être payé. Les diverses nécessités pratiques spéciales à chaque industrie multiplient à l'infini les combinaisons pratiques pour réaliser la formule.

(1) On ne le trouve guère que dans la mécanique, Engineering Trade, exceptionnellement dans la confection des bouteilles. 
Pour l'Angleterre, il importe de mentionner en terminant un dernier et intéressant courant : c'est celui du minimum de salaire dans la coopération.

La coopération anglaise tend, on le sait, à se suffire à ellemême et a très largement abordé aujourd'hui le domaine de la production ( $\mathrm{I}$ ).

Le personnel des coopératives est aujourd'hui très considérable : il compte dans l'ensemble, 66.00o employés dans les magasins de gros ou de détail et 44.000 ouvriers environ dans les fabriques, organisé en une puissante union, l'AUCE, the Amalgamated Union of Cooperative employees (2).

Le salaire mininum est aujourd'hui en voie de réalisation pour les ouvriers et ouvrières de la Wholesale (3).

Voici, d'après M. Cernesson (4), le tableau des salaires moyens dans les établissements productifs de la Wholesale anglaise :

\begin{tabular}{|c|c|c|}
\hline \multicolumn{2}{|c|}{$\begin{array}{l}\text { Nombre } \\
\text { d'employés. }\end{array}$} & $\begin{array}{l}\text { Salaire } \\
\text { moyen. }\end{array}$ \\
\hline I & 167 & I. 079 fr. \\
\hline & 105 & I . . 88 I \\
\hline & 2 I 2 & I .032 \\
\hline
\end{tabular}

Chaussures (Leicester, Heckmondwike, Ruhsden) ......... 3. . . 4 I I.357

Meubles (Broughton) . . . . . . . $\quad 74 \quad 2.038$

Bougies (Irlam) . . . . . . . $402 \quad$ I.418

Lard (Harthpool). . . . . . . . . . $34 \quad$ I.466

Biscuits (Crumpsall) . . . . . . $494 \quad$ I. I 76

Conserves anglaises (Middleton). . . $440 \quad$ I.194

Tabac (Manchester). . . . . . . $404 \quad 986$

Moulins (Dumton, Silvertown). . . . . $\quad 270 \quad 2.684$

Imprimerie (Manchester) . . . . . $627 \quad$ I 2/4

Total et moyenne. . $\overline{7.430} \overline{\mathrm{I}_{3} \mathrm{I}_{2} \mathrm{fr}}$

(1) Cf. Cernesson. Les Sociétés coopératives anglaises, I vol., Paris, Rousseau, 1905 .

(2) Gide. Les Sociétés coopératives de consommation, $2^{\mathrm{e}}$ édit., Paris, Colin, 1910, p. 238.

(3) Plus de 500 sociétés l'ont accepté en ce qui concerne les hommes. Cooperative News, 25 mai i912.

(4) Op. cit., p. 462. 
Dans la Wholesale écossaise, le salaire total moyen, en I 9o3, aurait été de r.o93 francs, augmenté d'une part importante, $4 \%$ des chiffres de salaires effectivement payés, soit 295.825 francs, sous forme de participation aux bénéfices ( $\mathrm{I}$ ).

Encore pour apprécier ces moyennes, faut-il tenir compte de la présence d'un grand nombre de femmes et enfants parmi les employés des Wholesales, ce qui avec les taux de salaire moins élevés qui leur sont octroyés, abaisse la moyenne. M. Cernesson estime que le salaire moyen d'un jeune ouvrier de 20 à 25 ans doit varier de r.50o à 2.000 francs; celui d'un ouvrier plus âgé, entre 2.000 et 3.000 francs (2). Il paraît donc que l'on puisse affirmer que le salaire minimum dans le monde de la production coopérative est en voie de réalisation complète.

Le mouvement est moins avancé pour les employés proprement dits.

Le taux minimum de 24 shillings ( 30 francs) par semaine pour les hommes à partir de $2 \mathrm{I}$ ans et de 17 shillings (2I francs) pour les femmes a été proposé comme raisonnable (3).

Cependant au Congrès des Trade-Unions, en rgog, on a affirmé qu'il n'y avait qu'un seul tiers des sociétés coopératives, environ 500, qui se conformaient à cette règle (4).

Plus récemment (5), la question du minimum de salaire pour le personnel des coopératives anglaises a été de nouveau agitée.

La Société d'Enfield présenta une résolution demandant au Magasin de gros de mettre en application une échelle de salaires pour femmes et jeunes filles, dans toutes les subdivisions (departements) où aucun tarif syndical pour les femmes n'était en vigueur. Cette échelle prévoyait un

(I) Ibid., Cernesson, op. cit., p. 485.

(2) Op. cit., p. 463.

(3) Gide. Op cit., p. 240, note I.

(4) On a même indiqué à cette occasion qu'il y avait certaines coopératives où le salaire des jeunes gens employés ne dépassait pas 2 sh. 6 d. (3 fr. par semaine).

(5) Cooperative News, 16 et 23 décembre 1911, 6 janvier 1912. 
minimum de salaire hebdomadaire de 5 shillings à 14 ans, s'élevant jusqu'à 17 shillings à 20 ans (I).

La Société de Leicester présenta un amendement tendant à effacer la restriction : là où aucun tarif syndical pour les femmes n'était en vigueur.

Un autre amendement, présenté par la Coopérative d'Oldham, demandant d'ajourner la question à un an, pour permettre aux directeurs du Magasin de gros la mise en application complète de l'échelle (2).

A cette occasion, les directeurs du Magasin de gros (C. W. S. Cooperative Wholesale Society) publièrent un important rapport (3), donnant l'état de choses actuel en ce qui concerne les salaires du personnel féminin.

Sur un total de 7,072 femmes et jeunes filles employées par le Magasin de gros :

4.I2 I touchaient un salaire inférieur à l'échelle demandée (4),

2.95̃ touchaient un salaire égal ou supérieur à celui de l'échelle demandée (5).

Ce qui représente comme salaire moyen pour l'ensemble un salaire hebdomadaire de 13 shillings 2 deniers par employée.

En même temps, le rapport invoquait pour repousser l'acceptation d'une échelle uniforme une série de raisons longuement détaillées :

Le Magasin de gros emploie des employées de catégories très diverses, dont un grand nombre aux pièces (6); l'acceptation d'un minimum rigide, applicable dans toutes les professions et toutes les régions est pleine de périls.

(I) Voici l'échelle complète :

Age :
Salaire : $\frac{14 \text { ans }}{5 \mathrm{sh} .} \frac{15 \mathrm{ans}}{7 \mathrm{sh} .} \frac{16 \text { ans }}{9 \mathrm{sh} .} \frac{17 \mathrm{ans}}{11 \mathrm{sh} .} \frac{18 \text { ans }}{13 \mathrm{sh} .} \frac{19 \text { ans }}{15 \mathrm{sh} .} \frac{20 \text { ans }}{17 \mathrm{sh} .}$

(2) Il y aurait, d'après le C. W. S., seulement r.6r6 femmes, sur les 7.072 employées par le C. W. S., jouissant d'un tarif syndical élaboré par une Trade-Union; la motion d'Enfield eut done, telle quelle, visé 5.456 femmes, soit plus des trois quarts du personnel employé. Elle fut ultérieurement retirée.

(3) Cooperative News, in nov. I9I I, p. 1422.

(4) Ce qui représente pour cette catégorie (personnel féminin de tout åge) il sh. 8 d. par employée.

(5) Ce qui représente pour cette catégorie (personnel féminin de tout àge) 15 sh. 4 d. par employée.

(6) 3.359 femmes et filles aux pièces contre 3.713 au temps. 
De plus, la marge est mince entre le prix de revient et le prix de vente et la concurrence avec le commerce si aiguë " qu'une augmentation de salaire notable (I), sans une augmentation parallèle des prix et sans garantie d'achat de la part des sociétés adhérentes, influerait fâcheusement sur les résultats de l'affaire ".

D'autre part, une augmentation de prix dans les magasins de vente changerait le courant des affaires, amenant une diminution dans la main-d'œuvre et des pertes pour le Magasin de gros.

Le rapport souhaite la généralisation de comités de salaires, fixant des minima pour tous les établissements d'un même métier.

" Même à se placer au point de vue des travailleurs, il leur serait désavantageux, en ce qui concerne l'échelle de salaires, que celle-ci ne comportât point une certaine base correspondante de productivité (2); pareille méthode aurait pour résultat de ne plus faire employer que les travailleurs d'un certain âge, ayant l'habitude acquise du métier. ")

Le rapport concluait (3) en exprimant la confiance que les délégués des sociétés repousseraient la motion d'Enfield.

Une longue réplique (4) élaborée par le Comité central de la Women's Cooperative Guild chercha à réfuter les objections précédentes : son principal et quasi unique argument est l'urgence de la réforme, en dépit des obstacles, à cause du caractère vital du salaire : “Plus élevé en sera le coût, plus urgente apparaît la réforme! " Très habilement - et c'est au fond la question principale - les partisans du minimum de salaire répliquèrent : "Si les bonis coopéra-

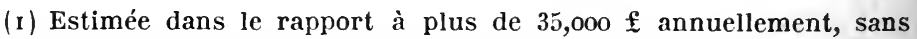
préjudice d'une élévation probable du salaire des employés travaillant déjà au-dessus du minimum qui demanderaient probablement un réajustement de leurs salaires, soit une augmentation totale de 60,000 $\mathfrak{f}$ au moins par an.

(2) Il importe de souligner ici encore la conception anglaise du minimum de salaire qui ne va pas sans un équivalent de travail. Cf. plus loin Conclusion, p. $45 \mathrm{I}$.

(3) Il rappelait aussi toutes les améliorations sociales effectuées par la C. W. S. pour son personnel.

(4) Cooperative News, 18 novembre I911, p. 1462. 
tifs ne résultent que de la pratique des bas salaires, les coopérateurs doivent envisager le fait que si $35.000 £$ vont aux profits, ils prennent ainsi l'argent à une classe de travailleurs mal payés dont le salaire est au-dessous du niveau de subsistance. ")

La question fut discutée dans une série de meetings locaux et régionaux : le Comité central de la Women's Cooperative Guild mena une ardente campagne en faveur de la réforme. Le projet fut accepté dans quelques subdivisions (I) (Sud-ouest, Galles du Sud), repoussé dans le plus grand nombre. On a compté (2) 978 votes pour et 1527 contre, dans les diverses réunions locales.

Elle fut enfin portée, en décembre I9I I, à la réunion de Manchester, réunion trimestrielle du Magasin de gros, où la majorité des délégués des coopératives anglaises se prononça (3) contre le minimum de salaire.

De la discussion résulta cette constatation que i 2 sociétés seulement payaient des salaires à l'échelle indiquée, tandis que plus de r.00o ne le pratiquaient pas (4). Le point de vue commercial (niveau des prix) a paru l'emporter sur le point de vue social (amélioration des conditions du travail). Le dilemme reste d'ailleurs posé devant les coopérateurs anglais (5).

L'application de la nouvelle échelle semble commencer petit à petit dans les diverses sociétés.

La question de principe reste à l'ordre du jour. Elle a été reprise, en mai ı 9 I2, au Congrès de Portsmouth (6) et le principe du minimum de salaire de nouveau proclamé.

(I) On sait que l'Angleterre, au point de vue coopératif, est subdivisée en grandes régions territoriales.

(2) Cooperative News, 6 janvier 1912.

(3) Sur l'amendement de Leicester, 84 votes pour, contre 602, soit avec la représentation des voix 589 pour, 1.654 contre; sur la proposition d'Enfield, 344 votes pour, contre 552, soit avec la représentation des voix 488 pour, 2.299 contre. (Cooperative News, 23 déc. I9I1, p. I6Ir.)

(4) Cooperative News, 23 décembre 1911, p. 16ro.

(5) Cooperative News, 1912, 24 février, 2 mars, 13 avril, etc.

(6) Cooperative News, I ${ }^{\text {er }}$ juin 1912. 


\section{$2^{\circ}$ En France.}

Le minimum de salaire est beaucoup moins répandu en France. Cette moindre diffusion tient incontestablement à l'allure de nos syndicats français, à leurs divergences de méthode et à leur bien moindre souveraineté dans chaque profession (I).

G'est surtout avec le contrat collectif que le minimum de salaire commence à pénétrer, par l'effort de l'association professionnelle, dans certains métiers, et d'une façon très fragmentaire, principalement dans le bâtiment, les industries du livre et du papier, les mines.

D'après une enquète récente de l'Office du travail (2) sur les contrats collectifs en I9I\%, une clause de salaire minimum (3) figurerait dans 230 contrats sur les 252 conventions collectives signalées en ig1o, ce qui représente une proportion de $91,3 \%$, et dans 194 contrats sur les 202 conventions collectives signalées en i 9 I , ce qui représente une proportion de $96^{\circ} \%$.

Le mème document analyse la répartition de ces diverses conventions établissant un minimum en ce qui concerne les modalités du salaire (4).

I53 conventions (soit $77,3 \%$ ) portent un salaire fixé exclusivement au temps : horaire dans ioo cas, journalier dans 37 cas, hebdomadaire dans 5 , mensuel dans 3.8 prévoient simultanément ces diverses modalités.

20 conventions prévoient un salaire fixé exclusivement aux pièces.

I 7 prévoient un salaire fixé à la fois au temps et aux pièces (5).

Il a paru utile de reproduire ici ces renseignements à titre d'indication : ils sont absolument insuffisants pour

(I) Qu'on songe qu'aux derniers résultats connus (Les Syndicats professionnels au $\mathrm{I}^{\text {er }}$ janvier I9II, Bubletin de l'Office du travail, 1911, p. I 184), le total des syndiqués ne dépassait pas I.029.238 dans l'industrie et le commerce : ce qui représente une proportion moyenne de $10 \%$ environ au maximum!

(2) Bulletin de l'offlce du travail, г91, p. 474.

(3) Il est difficile de se rendre un compte exact de sa portée.

(4) Bulletin de l'Offlce du travail, 1912, p. 462, Statistique des conventions collectives de travail signalées en I9II.

(5) Ibid., p. 464. 
arriver à la connaissance précise de l'état de faits existant : il faudrait pour cela une enquête du genre de l'enquête anglaise précédemment analysée, que nous ne possédons malheureusement pas.

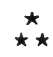

Dans le bâtiment, le minimum de salaire existe bien souvent en fait, sinon en droit. Malheureusement, sa fixation par un salaire au temps sans équivalent en travail a donné lieu, dans ces dernières années, à de sérieuses difficultés.

L'un des derniers contrats collectifs en vigueur est celui de 1909 , dans la région parisienne, pour le bâtiment.

D'après l'article 4 de ce contrat (I), les salaires par heure sont fixés, d'un commun accord, de la façon suivante :

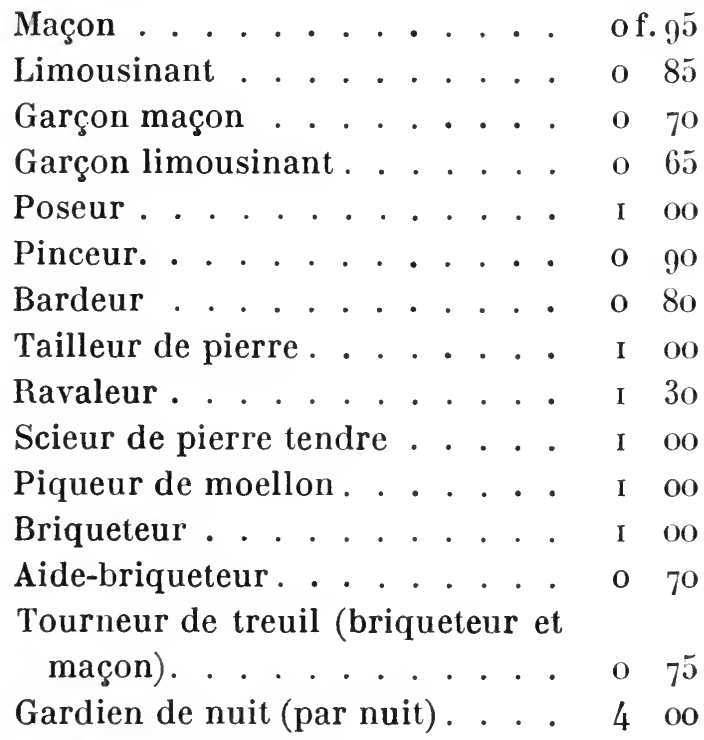

Le même article stipulait :

"Les ouvriers s'engagent à fournir un rendement de travail proportionnel au salaire et tel qu'il sera déterminé dans un tableau annexé au présent contrat et dressé par la Commission mixte (2). ")

(r) Fédération nationale des travailleurs de l'industrie du bâtiment. Procès-verbaux sténographiques des réunions des délégations ouvrières et patronales (sept. 1909), p. 236. Paris, Maison des Fédérations, 33, rue Grange-aux-Belles.

(2) Le même article stipulait eneore :

"Ce tableau sera établi d'après les bases de la série élaborée par la 
Les commissions nixtes prévues n'ont jamais fonctionné et le contrat de 1909 est aujourd'hui partiellement dénoncé ( $\mathrm{I}$ ).

De même, en province, de très nombreux contrats de travail (2) stipulent pour les diverses catégories de métiers du bâtiment des salaires horaires très variables qui constituent souvent de véritables minima.

Deux difficultés s'opposent actuellement à ce que le minimum de salaire soit garanti en droit et consacré nommément par contrat (3) : d'une part, le patronat est toujours dans une large mesure opposé à la pratique du contrat collectif; d'autre part, les travailleurs ne sont pas encore assez éduqués ni assez groupés pour apprécier comme il conviendrait l'utilité de cette réforme. La revendication d'un minimum de salaire reste un des articles du programme de la Fédération nationale des Travailleurs de l'industrie du bâtiment (4).

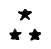

Dans les industries du livre et du papier. - Grâce aux patients et longs efforts de la Fédération du Livre, on peut affirmer que le minimum de salaire est aujourd'hui de pratique courante (5).

Société centrale des architectes français et la Société des architectest diplômés par le Gouvernement, adoptée par le Sous-Secrétariat d'Éta des Beaux-Arts, pour le règlement des travaux des bâtiments civils et palais nationaux (édition igo9).

"En cas de désaccord sur l'établissement de l'unité de travail, les parties s'en rapporteront à la décision des architectes.

" Le contrôle du rendement se fera sur une durée de huit jours de travail. )

(1) La seule base générale de salaire pour le bâtiment à Paris reste les prix de série de la Ville de Paris. (Cf. supra, p. 80.) On nous a affirmé, en aoùt 1912, à la Fédération nationale du bâtiment, que les ouvriers dans bon nombre de métiers étaient mème payés à un salaire horaire légèrement supérieur aux tarifs de série : devant la revendication de la journée de neuf heures, les patrons ont préféré accorder une légère augmentation de salaire, sans engagement par contrat collectif.

(2) Cf. Fédération nationale des travailleurs de l'industrie du bâtiment. Annuaire 1912. Paris, 1912, Maison des Fédérations, pp. 171 et suiv.

(3) Il n'existe à l'heure actuelle d'autre garantie d'application des tarifs adoptés que l'organisation professionnelle tant patronale qu'ouvrière.

(4) La question du minimum de salaire dans le batiment est très intimement liée à tout le problème du contrat collectif et à la délicate question de son observation.

(5) La Fédération du Livre, fondée en r881, compte au I er janvier ı110, 
Il existe des tarifs de section pour les typographes. D'ordinaire le minimum établi par contrat collectif est un minimum journalier, basé sur le prix de l'heure. "Le salaire minimum va dans les différentes sections de province de 4 fr. 50 c. par jour (27 fr. par semaine) à 6 fr. 50 c. (39 fr. par semaine). A Paris, il est de $7 \mathrm{fr} .20$ c. par semaine)(I). )

Voici, à titre d'exemple (2), les clauses relatives au salaire pour le contrat collectif de Paris (3):

"Article $\mathrm{I}^{\mathrm{er}}$. - Les prix de composition sont déterminés par le nombre de lettres bas de casse contenues dans chaque justification, en prenant pour base l'ordre successif des vingtcinq lettres de l'alphabet (de a à z) du caractère employé. Dans le cas où la lettre appelée, par son ordre, à parfaire la justification ne pourrait pas entrer, elle sera remplacée par une autre lettre ou espace quelconque. Le calibrage sera établi avec la fonte primitive neuve.

Art. 2. - Les prix de composition, payés au mille de lettres, sont tarifés ainsi qu'il suit:

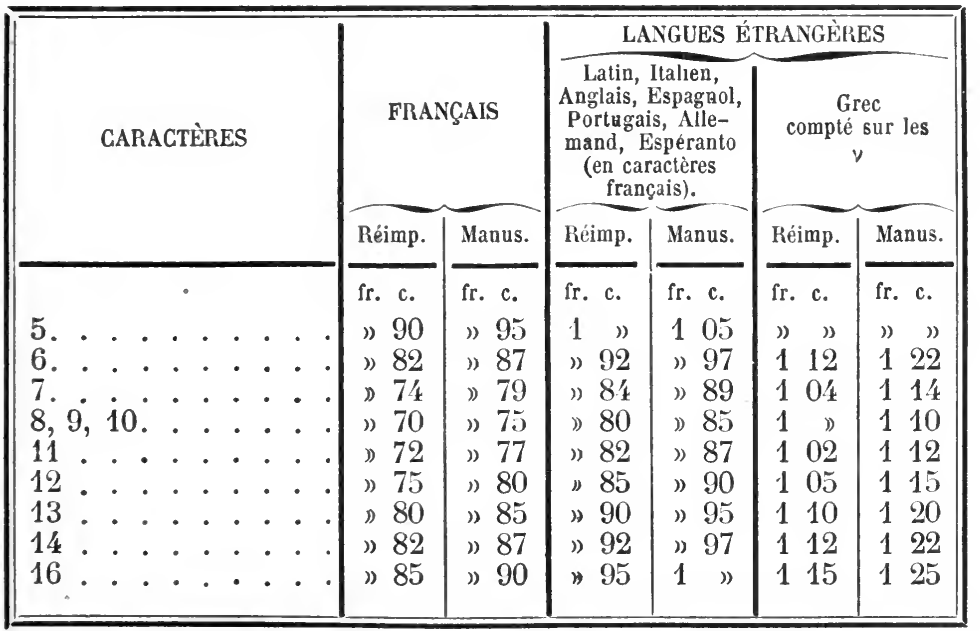

répartis en 14 groupes régionaux et 170 sections, II.937 membres sur un total de 25.037 travailleurs du livre, soit, $4768 \%$.

(I) o fr. 80 c. l'heure pour la journée de 9 heures. Quelques maisons à Paris font encore 10 heures. Le minimum de salaire est alors de $8 \mathrm{fr}$.

(2) Secrétariat typographique international à Stuttgart. Les organisations ouvrières dans l'industrie du Livre, III série. La situation au

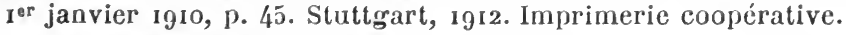

(3) En vigueur depuis le 18 avril 1906.

Chambre syndicale typographique parisienne. Tarif du prix de maind'œuvre. Paris, Imprimerie Nouvelle. 
Art. 84. - Le prix de la journée de conscience, fixée à neuf heures de travail, est de $7 \mathrm{fr} .20$ au minimum.

Art. I63. - Il n'est admis aucune diminution sur les salaires supérieurs à ceux du présent tarif payés au moment de sa présentation. Les travaux aux pièces antérieurement payés à un taux supérieur au précédent tarif seront augmentés d'un neuvième ( $\mathrm{I}$ ). ')

Dans un nombre de cas encore appréciables, le salaire est aux pièces. La composition à la casse des corps 9 et ro est payée à raison de o fr. $50 \mathrm{c}$. au moins par r.0oo lettres calibrées. En ce cas, les divers contrats collectifs en vigueur stipulent des tarifs aux pièces équivalents, de façon que le travailleur puisse réaliser approximativement le minimum journalier.

Aucune garantie, au cas aujourd'hui de beaucoup le plus fréquent de tarif au temps, n'est stipulée pour obtenir un certain rendement de l'ouvrier; comme l'indique le beau nom de " travail en conscience ", c'est affaire à régler individuellement entre l'employeur et l'employé(2).

Un mouvement tout récent tend à réaliser une certaine unification entre ces minima de salaires aujourd'hui variables selon les contrats passés par chaque section, selon la diversité du coùt de la vie (3).

Au congrès de Bordeaux (igro), un projet de tarif type stipulant un minimum de salaire de 5 francs pour le travail en conscience (4) a été adopté et une Ciommission nommée pour

(I) Le tarif, très compliqué, comprend 169 articles où sont longuement détaillées les différentes catégories de travaux.

(2) Pour les apprentis, jusqu'à la troisième année, le salaire est fixé au gré de l'appréciation du patron; puis il s'élève graduellement pour atteindre le minimum de la section après la cinquième année d'apprentissage (Ibid. Les organisations ouvrières de l'industrie du Livre, p. 45.)

(3) Cf. IX eongrès national de la Fédération française des Travailleurs du Livre. Lyon, 5-10 juin i9o5. Paris, Impr. Nouvelle, r9o5, p. 24. $\mathrm{X}^{\circ}$ congrès national de la Fédération française des Travailleurs du Livre. Bordeaux (18-23 juillet I910). Paris, Impr. Nouvelle, p. I 86.

(4) Ainsi qu'un tarif pour les prix de composition :

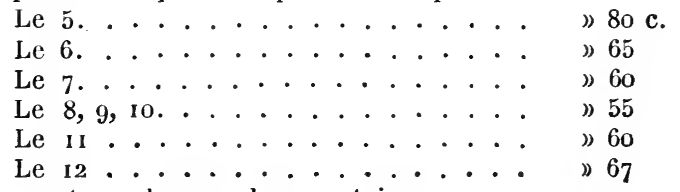

avec additions et surcharges dans certains cas. 
en poursuivre la réalisation. On espère à la Fédération du Livre arriver, sinon à l'unification complète, au moins à l'unification par groupes territoriaux(I) sur la base du contrat collectif le plus important de la région.

Au total, grâce à la politique poursuivie par la Fédération du Livre, le salaire minimum est aujourd'hui une réalité pour tous les travailleurs organisés.

Dans les mines, le salaire est à la tâche le plus ordinairement fixé par contrat collectif(2). Il existe un salaire de base, correspondant aux salaires d'une époque déterminée, majoré de primes calculées en pourcentages. Les ouvriers ont prétendu à plusieurs reprises transformer ce salaire de base en salaire minimum (3).

Malgré de très louables et très intéressants efforts, les mineurs français n'ont pas encore obtenu le minimum de salaire qu'ils souhaitaient (4) : la Fédération nationale des mineurs demandait un minimum de salaire de 6 francs pour les ouvriers proprement dits, de 5 fr. 5 o et de 5 francs pour les aides. La discussion se renouvela à maintes reprises, notamment à propos des conventions d'Arras entre

(1) Dans les quatorze groupes régionaux qui divisent la France au point de vue typographique.

(2) Cf. un bon résumé de la situation actuelle dans le rapport de M. Ajam, au nom de la Commission chargée d'examiner le projet de loi sur le régrime général des mines, par M. Ajam. J. O., Ch., Doc. parlem., I911, $\mathrm{n}^{\circ}$ 1172, p. $9^{68}$.

(3) La journée moyenne de fond est, dans le Nord, d'après les fameuses conventions d'Arras, tenues en I891, 1893, I899, І900, г902, I906, 19o9, de 4 fr. 80, majorée d'une prime actuelle de $20 \%$. En vertu d'une convention toute récente $\mathrm{du} 26$ août I9I2, la prime vient d'être majorée de $5 \%$, dont $3 \%$ seront applicables le $1^{\text {er }}$ octobre 1912 et $2 \%$ à partir du I ${ }^{\text {er }}$ avril I913, avec promesse de non-modification jusqu'au I $^{\text {er }}$ juillet igi5. Cif. Musée social, Sept., p. 302. - Dans les mines du Centre, en vertu du dernier contrat collectif du 22 juillet I9ro, le salaire de base est (5 fr. $40 \mathrm{c}$. par journée de piqueur), majoré d'une prime (o fr. $25 \mathrm{c.}$ ) par jour pour les ouvriers de l'intérieur et (o fr. 15) pour ceux de l'extérieur. Ibid., Ajam, p. 968.

(4) G. Benoît-Duquesne. Les Conventions d'Arras relatives au salaire des mineurs. Thèse, Nancy, Igog, I vol., Lille, Saulai, Igo8. 
les Compagnies et leurs ouvriers (I). Ceux-ci d'ailleurs semblent avoir l'idée d'un minimum fixe indépendant de toute production (2). Les Compagnies répliquent sans peine que ce minimum de salaire sans minimum de production serait une prime à la paresse, qu'elles seront forcées de renvoyer les ouvriers qui ne pourront atteindre ce minimum et qu'arec la loi de 8 heures ce minimum de production serait fort aléatoire. De plus, les Compagnies émettent la prétention d'établir en face de ce minimum un maximum pour compenser les pertes causées par le minimum en temps de crise. La revendication reste néanmoins chère aux ouvriers et la question reste à l'ordre du jour.

Le minimum de salaire existe encore, notamment à Marseille, pour une catégorie d'ouvriers où l'on ne s'attendait guère à le rencontrer : les dockers.

D’après les usages et le contrat collectif de rgo3 (affiche verte), les dockers sont des journaliers embauchés à la journée : c'est par essence l'instabilité la plus complète dans le travail : le contremaitre peut refuser demain l'ouvrier qu'il a embauché aujourd'hui, et inversement l'ouvrier peut ne pas se présenter à l'embauche si cela lui plaît. Les inconvénients du système sont sérieux : les entrepreneurs ne peuvent compter sur les ouvriers qu'ils ne connaissent pas et ceux-ci n'ont aucun intérêt à se montrer assidus. Aussi certains patrons ont-ils établi une catégorie d'ouvriers spé-

(I) Cf. notamment la résolution déposée par les ouvriers lors du dernier renouvellement d'aoùt 1912 : "Il apparaît à tous que le minimum de salaire devrait être la garantie la plus certaine accordée contre une rémunération insuffisante de l'ouvrier ». Ibid. Mus. soc. Ann. 1912, p. 302.

(2) L'éducation des mineurs commence d'ailleurs sur ce point et M. Basly disait dans la réunion du Congrès de Lens (1908) : " Il faut bien aussi dire aux mineurs, quand on leur parle du minimum de salaire, que ce minimum sera calculé sur un rendement donné. Il faut qu'ils sachent qu'il ne suffira pas évidemment de descendre dans la mine, de donner mollement ses coups de pic pour avoir droit au minimum de salaire : il faudra une production donnée pour un minimum de salaire donné. Il faut dire cela au mineur qui ne semble pas se faire de cette question une idée très exacte. " Cité par Duquesne, op. cit., p. 129 . 
ciaux, nommés " attitrés ». Les ouvriers promettent d'être toujours effectivement présents à l'embauchage et s'engagent à fournir tout le travail qui leur est commandé. En retour, l'entrepreneur promet à l'attitré de lui donner la préférence constante à l'embauchage et lui garantit pour l'ensemble des travaux qu'il effectue un nombre de journées, nuits et heures supplémentaires tel que le salaire annuel qui lui sera acquis ne sera pas inférieur à 1.500 francs $(\mathrm{I})$.

On voit comment ici par une nécessité industrielle le minimum de salaire corrélatif à un minimum de travail a été spontanément introduit. Il parait d'ailleurs que cette mesure restreinte fonctionne à la satisfaction des employeurs et des employés.

En résumé, et par comparaison avec le mouvement anglais, la conquềis du salaire minimum par l'association professionnelle est beaucoup moins avancée. Le problème à résoudre pour la France est au fond, d'une part celui de la souveraineté économique du syndicat tant patronal qu'ouvrier et d'autre part celui de l'application du contrat collectif. Ce n'est que du jour où d'un côté le syndicat assez fort et assez puissant saura imposer des conditions de travail et en particulier de salaires relativement uniformes pour tout le métier et ou de l'autre les contrats collectifs

(I) Voici expressément l'article 2 du contrat d'embauchage en vigueur des attitrés :

" En cette qualité, M. .... jouit concurremment avec ses collègues de la préférence constante de l'embauchage, après les ouvriers commissionnés, tant sur le chantier de MM. ..... que sur ceux de leurs collègues, entrepreneurs unis. En outre, il lui est garanti un nombre de journées, nuits, dimanches et heures supplémentaires, tel que le salaire annuel qui lui sera acquis sur les bases du tarif de 1903 ne sera pas inférieur à 1.500 francs.

La garantie ci-dessus sera acquise à M. ..... sous la seule réserve de sa présence effective sur les cliantiers et de l'exécution par lui des ordres reçus.

Elle serait réduite proportionnellement en cas de mise de campo, maladie, accident ou absence." 
en vigueur seront ( $\mathrm{I}$ ) scrupuleusement et loyalement observés de part et d'autre, que le salaire minimum deviendra une réalité pour nos travailleurs français (2).

(I) Ces deux progrès sont d'ailleurs intimement liés l'un à l'autre.

(2) Cette position du problème explique et justifie tout à la fois la brièveté de notre étude sur le mouvement français : pour l'étudier en détail, il eùt fallu ici reprendre tout le problème du contrat collectif. Du point de vue qui nous occupe dans ce livre, il suffit de constater que la marche "vers le minimum de salaire » est ici moins accentuée qu'ailleurs. 


\section{3o Dans les autres Pays.}

Le mouvement de réalisation directe du minimum de salaire par l'association professionnelle se poursuit également dans les autres pays : nulle part cependant on ne le trouve aussi avancé ni aussi général qu'en Angleterre.

En Allemagne, la grande enquête menée sur le contrat collectif ( I) montre, comme l'enquête anglaise, une relative diffusion du minimum de salaire.

En ' 1910, I 76 conventions collectives sur 2.360 entrées en vigueur dans l'année I909, intéressant 5.107 entreprises et 38.246 personnes, établissaient des taux forfaitaires avec garantie d'un minimum de salaire (2).

Sans dépouiller ici cette enquête, nous utiliserons la méthode monographique en décrivant en détail les efforts réalisés dans une seule industrie.

Il faut insister à cet égard sur le salaire minimum dans les imprimeries allemandes, obtenu ici encore par l'action des organisations professionnelles.

C'est en I 896 qu'après bien des années d'efforts (3) fut élaboré le tarif actuel : des modifications de détail seulement lui furent apportées depuis.

Ce tarif, « expression reconnue par les patrons et les ouvriers imprimeurs de l'Empire allemand des bons rapports entre eux et du maintien de la justice et du bien (4)",

(1) Der Tarifvertrag im Deutschen Reich. Bearbeitet im Kaiserl. Statistichen. 3 vol., Berlin, I 906.

(2) Bulletin de l'Offce du travail français, 1910, p. 134т. Supplément au Reicharbeitsblatt, août rgro.

(3) L'organisation professionnelle dans l'imprimerie est d'ailleurs fort ancienne : l'Union des maîtres imprimeurs d'Allemagne fut fondée en 1869; l'organisation ouvrière est également assez ancienne. Déjà, en 1873, un premier tarif minimum uniforme, avec surcharges locales correspondant au prix de la vie, avait été élaboré par une Commission mixte. Dans cette période s'élaborèrent les institutions décrites au texte. Des applications temporaires, partielles, des revisions, des grèves marquent cette période de débuts. Gf. G. Lefebvre, Le tarif minimum de salaire dans la typographie francaise, pp. is et suiv., I br. I9Io. Pour abréger, et malgré l'intérêt de cette histoire, nous prenons seulement l'organisation actuellement existante.

(4) C'est la devise même d'un tarif antérieur, celui de 1878 , maintenue depuis. 
devint de plus en plus la loi commune de toute l'industrie ( 1 ).

Voici dans ses traits essentiels l'organisme complet de ce $\operatorname{tarif}(2)$ :

Il comprend quatre rouages essentiels :

La Commission du tarif (Ausschusz).

Le Comité du tarif (Tarifamt).

Les Offices régionaux (Kreizeamte).

Les Tribunaux d'arbitrage (Shiedsgerrichte).

I ${ }^{\circ}$ La Commission du tarif. C'est l'organe qui est chargé d'élaborer le tarif et de le modifier, l'organe législatif, si je puis dire.

Elle est composée de 18 membres, soit 9 patrons et 9 ouvriers, élus au suffrage universel par tous les patrons et tous les ouvriers (3) à raison de deux délégués (l'un patron et l'autre ouvrier) par région (4). Ne sont éligibles que les patrons ayant signé le tarif et les ouvriers travaillant dans des maisons ayant signé et observant ce tarif.

(1) Voici d'ailleurs la marche progressive de son application :

En $1897,1.63$ I firmes dans 469 villes et occcupant 18.340 ouvriers.

$\begin{array}{rrrrrrr}1898,2.030 & - & 647 & - & - & 22.468 & - \\ 1899,2.704 & - & 883 & - & - & 27.449 & - \\ 1900,3.115 & - & 1.002 & - & - & 30.630 & - \\ 1901,3.372 & - & 1.030 & - & - & 34.307 & - \\ 1902,3.464 & - & 1.043 & - & - & 36.527 & - \\ 1903,4.250 & - & 1.315 & - & - & 39.464 & - \\ 1904,4.559 & - & 1.382 & - & - & 41.483 & - \\ 1905,5.134 & - & 1.552 & - & - & 45.868 & -\end{array}$

(Tableau rapporté par M. Lefebvre, op. cit., p. 23.)

(2) Nous citons d'après la deuxième édition du tarif I902, traduite dans la brochure de M. Lefebvre, op. cit., p. 28.

(3) Au point de vue typographique, l'Allemagne est divisée en 9 régions (Kreize):

$I^{\text {ro }}$ région : Brême, Hambourg, Hanovre, Schleswig-Holstein, Lubeck, Mecklembourg, Schwerin et Mecklembourg, Strelitz. Chef-lieu : Hanovre. $2^{\mathrm{c}}$ région: Westphalie, etc. Chef-lieu : Crefeld.

$3^{\mathrm{e}}$ région : Hesse rhénane, etc. Chef-lieu : Francfort.

$4^{\text {e }}$ région : Bade et Wurtemberg. Chef-lieu : Stuttgard.

$5^{\text {e }}$ région : Souabe et Bavière (Augsbourg, Munich, Nuremberg, Wutsbourg). Chef-lieu : Munich.

$\sigma^{\mathrm{e}}$ région : Saxe, Thuringe, Magdebourg et Anhalt. Chef-lieu : Halle.

$7^{\circ}$ région : Saxe (Dresde, Leipzig, Chemnitz). Chef-lieu : Leipzig.

$8^{\mathrm{e}}$ région : Brandebourg, Poméranie. Chef-lieu : Berlin.

$9^{\text {c }}$ région : Silésie, Posen, Prusse orientale et occidentale. Chef-lieu : Breslau.

(4) Chaque région nomme, en outre, tant du côté patronal que du côté ouvrier, deux " premiers délégués suppléants » et deux « deuxièmes délégués suppléants ». 
Cette Commission est élue pour trois ans, renouvelable par tiers.

$2^{\circ}$ Le Comité de tarif est l'organe d'exécution ( $\mathrm{I}$ ) : il est composé de 3 patrons et de 3 ouvriers nommés par la Commission du tarif; il est, comme le dit l'article ı9, "le cœur de l'organisation générale ", le " point central permanent vers lequel doivent converger toutes les demandes, toutes les observations ayant rapport au tarif ". Il est chargé de veiller à l'application et à l'exécution du tarif en vigueur, de le propager auprès des ouvriers et des firmes qui ne l'ont pas accepté, d'intervenir en cas de conflit et en dernier ressort (2) pour statuer sur les conflits que le tarif aurait pu faire naître, surtout d'intervenir d'une manière amiable pour prévenir les conflits.

$3^{\circ}$ Les Offices régionaux (Kreizeamte) sont les organes chargés d'assurer l'application locale du tarif : ils sont formés des deux délégués régionaux, patron et ouvrier, présidents; de leurs premiers suppléants, vice-présidents; de leurs deuxièmes suppléants et des présidents des tribunaux d'arbitrage de la région, membres.

Leur rôle est nettement défini (3) (art. 44) : "L’Office régional constitue un des organes du tarif et travaille sous la direction du Comité du tarif; il est chargé, en outre, de fixer et de proposer les surcharges locales des différents lieux d'imprimerie de sa région et du règlement des affaires régionales qui lui sont indiquées soit par la Commission du tarif, soit par le Comité du tarif. ")

$1 l$ est intéressant de relever les principes inscrits dans le contrat collectif, qui fait la loi de la profession, relatifs à l'établissement des surcharges locales.

(1) Article 13 du tarif : "L'application des décisions de la commission du tarif, ainsi que la réglementation des rapports des adhérents entre eux, au point de vue de l'introduction du tarif, incombent au Comité du tarif des imprimeurs allemands. ")

(2) Après l'intervention des offices régionaux et des tribunaux d'arbitrage.

(3) Leur création est d'ailleurs postérieure à celle de l'ensemble : c'est une tentative de décentralisation; la Commission du tarif, surtout en ce qui concerne la délicate question des surcharges locales, n'a pas cru pouvoir statuer par elle-même : elle s'est déchargée de ce soin sur les Offict:s régionaux, intermédiaires nouveaux entre elle et les membres adhérents. Bien entendu, les décisions des Offices régionaux sont susceptibles de recours, en cas de non-entente, devant le Comité du tarif. 
L'article 5r dispose :

“ Il est donné comme devoir aux Offices régionaux d'établir les surcharges locales d'après les quatre thèses ci-dessous, établissant un principe :

$I^{0}$ Les surcharges locales doivent avant tout tenir compte des conditions de cherté de l'existence;

$2^{\circ}$ Les surcharges locales des villes ou lieux de région doivent être calculées et proportionnées d'après celles du chef-lieu de la région;

$3^{\circ}$ La concurrence ne doit entrer en considération que d'une façon minime pour l'établissement des surcharges locales ;

$4^{\circ} \mathrm{La}$ possibilité d'établissement, d'introduction et de maintien des surcharges locales doit être envisagée : ces dernières seront établies de telle façon que leur quotité ne devra pas être supérieure ou inférieure de $5 \%$ à la réalité des faits constatés par la statistique remplie par les Conseils communaux. ")

Pour l'établissement de ces surcharges, il est recommandé aux Offices régionaux (art. 52) de tenir de larges réunions où des délégations extraordinaires de patrons et d'ouvriers seront entendues avec voix consultative seulement.

$4^{\circ}$ Enfin les Tribunaux d'arbitrage (Shiedsgerrichte). C'est l'institution de conciliation et d'arbitrage chargée de faciliter l'application du tarif.

lls sont composés (I) d'au moins deux et au plus cinq patrons et d'autant d'ouvriers, ainsi que de deux suppléants par membre, nommés à l'élection (2).

Leur compétence est nettement spéciale : "Les Tribunaux d'arbitrage, dit l'article $65 a$ ), ont été institués dans le but d'aplanir les difficultés survenant entre les patrons et les ouvriers par suite de l'application et de l'interprétation du tarif; tous les autres différends se produisant dans la vie corporative sont soumis aux tribunaux ordinaires de justice. »)

(I) Il en est eréé dans tous les chefs-lieux de région et aussi, sur la proposition de deux niembres adhérents joints à deux ouvriers fidèles au tarif, dans les grands centres d'imprimerie.

(2) Les membres de la commission du tarif, par conséquent les délégués régionaux, ne sont pas éligibles pour les tribunaux d'arbitrage : toutefois ils ont le droit d'assister aux séances desdits tribunaux, de prendre part à la discussion avec voix consultative seulement (art. 60). 
Des dispositions minutieuses (art. 58 à ıoo) du tarif règlent le fonctionnement de ces Tribunaux d'arbitrage d'une manière très réaliste et très vécue et avec une extrême souplesse : on n'a pas oublié, avec raison, que l'essentiel était ici l'accord des intéressés et on a tout subordonné au désir d'obtenir cet accord; c'est ainsi que la part faite à la conciliation est considérable : "Le Tribunal peut être appelé à donner d'abord son avis sur les cas litigieux, non seulement comme juges, mais encore comme collègues. ') L'appel est porté devant le Comité de tarif (art. 93). Enfin, et c'est la disposition la plus curieuse et la plus intéressante au point de vue de la paix sociale et de l'esprit dans lequel a été passée cette réglementation contractuelle : l'intervention du Tribunal d'arbitrage ne doit pas interrompre le travail.

L'article 87 dispose :

" Une cessation du travail précédant un appel au Tribunal d'arbitrage est contraire aux règles du tarif : le ou les ouvriers qui se mettraient dans ce cas seraient privés de la protection des Tribunaux d'arbitrage et des Bureaux officiels de placement; par contre, un ouvrier ou une collectivité d'ouvriers ne peut voir son travail suspendu par le fait qu'il ou qu'elle aurait fait convenablement de justes réclamations basées sur le tarif. ")

Donc, ni grève, ni renvoi, ni lock-out en cas de conflit : telle est l'intention formelle du règlement adopté.

En fait, les Tribunaux d'arbitrage ont largement fonctionné : de 1896 à I 908 , ils ont tranché 390 cas, dont 2 I 2 décisions concernaient des plaintes ouvrières (I). Dans 64 cas, une conciliation fut réalisée par les présidents sans le secours des Tribunaux d'arbitrage (2).

(1) Lefebvre. Op. cit., p. 4 I. Il y a eu pendant la mème période 42 plaintes patronales; 44 cas furent arbitrés par des concessions égales et réciproques, I5 cas furent écartés parce que l'une ou l'autre des parties adverses n'observait pas le tarif ; dans 16 cas les tribunaux se déclarèrent incompétents; 3 I plaintes furent repoussées par suite de ballottage : sur ces 3r plaintes, 2 r firent appel au Comité du tarif, dont les décisions furent favorables aux ouvriers dans in cas, dans io autres cas aux patrons plaignants; 9 jugements, rendus par les tribunaux d'arbitrage, furent déclarés mauvais par le Comité du tarif.

(2) Nous ne pouvons insister davantage sur cette institution fort intéressante à étudier au point de vue de la paix sociale. 
Grâce à ce mécanisme compliqué (I), grâce à l'esprit d'union et d'entente des deux parties, le tarif impliquant le minimum de salaire est devenu une réalité basée sur la fidélité des deux parties à leurs engagements (2).

Le tarif minimum hebdomadaire de ro6 pour six journées de neuf heures de travail, pauses non comprises, sans compter les surcharges locales, est le sui$\operatorname{vant}(3)$ :

Compositeurs, conducteurs et autres imprimeurs :

Jusqu'à l'âge de 2 I ans, 2I marks 5o, soit environ 26 fr. 87 .

De 2 I à 23 ans,

Au-dessus de 23 ans,
22 marks,

22 marks 6 ,
27 fr. 50. 28 fr. 13.

Comme dans des systèmes anglais précédemment étudiés, ce minimum de salaire est basé sur un tarif de travail aux pièces (4) qui permet à l'ouvrier normal au moins de l'obtenir.

(i) Encore négligeons-nous ici les Bureaux officiels de placement (Arbeitnachweise) qui, dans tous les grands centres importants, sont institués pour fournir aux ouvriers, selon leur spécialité, du travail dont le prix est réglé par le tarif. Cf. Lefebvre. Op. cit., pp: 56 et suiv.

De même, il est peu intéressant d'insister ici sur la question des frais, cependant minutieusement réglés, auxquels donne lieu l'application du tarif, 30.000 marks (37.500 francs) pour les cinq années, I897 à 1901 : ils sont, en principe, supportés par la caisse du tarif, alimentée par les cotisations annuelles des patrons et des ouvriers adhérents (art. 119), les publications, etc.

Les communications officielles concernant le tarif sont publiées dans le Journal des Imprimeurs allemands, organe patronal, et dans le Correspondant, organe ouvrier.

(2) Sanctionnée d'ailleurs par diverses règles et pratiques intéressantes : radiation du tarif, en cas d'inexécution, prononcée par le Comité du tarif (art. I Io); obligation pour les patrons de ne faire travailler qu'aux conditions de tarif; pour les ouvricrs, de n'accepter du travail qu'aux mêmes conditions (art. 111); signalement des récalcitrants, ete.

(3) Lefebvre, op. cit., p. 69 .

(4) Voici ce tarif de composition aux pièces et à la main, toujours en pfennigs, sans tenir compte des surcharges locales:

\begin{tabular}{|c|c|c|c|c|c|}
\hline CORPS & FRAKTUR & $\frac{\text { ANTIQLE }}{\begin{array}{c}\text { en } \\
\text { allemand }\end{array}}$ & $\underbrace{\text { CURSIVE }}_{\begin{array}{c}\text { en langues } \\
\text { étrangères }\end{array}}$ & RUSSES & GRECS \\
\hline 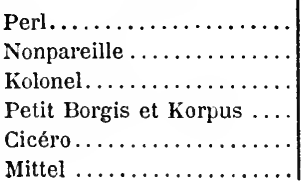 & $\begin{array}{l}52 \\
42 \\
39 \\
36 \\
39 \\
40\end{array}$ & $\begin{array}{l}55 \\
44 \\
41 \\
38 \\
40 \\
42\end{array}$ & $\begin{array}{l}57 \\
46 \\
42 \\
39 \\
41 \\
43\end{array}$ & $\begin{array}{l}53 \\
43 \\
41 \\
37 \\
39 \\
41\end{array}$ & $\begin{array}{l}57 \\
46 \\
43 \\
40 \\
42 \\
41\end{array}$ \\
\hline
\end{tabular}


Les surcharges locales pour permettre de tenir compte des variations dans le coût de la vie viennent majorer cette base dans des proportions variables (I) depuis $25 \%$ à Berlin, à Hambourg, $20 \%$ à Leipzig, 17 I $/ 2 \%$ à Francfort, Stuttgart, Wilhemshaven, Munich, I $5 \%$ à Breslau, etc., jusqu'à $2 \mathrm{I} / 2 \%$ dans des centres de moindre importance comme Worms, Swinemunde, etc.

Voici, à titre d'exemple, deux types (2) de bordereaux, l'un pour le travail en conscience, l'autre pour le travail aux pièces, qui donnent une idée du système :

TYPE DE BORDEREAU DE CONSGIENGE VILLE DE BERLIN

Dates.
I4. Semaine du I/4-20 août . . . . . . . . . . ${ }_{2}^{\text {I }}{ }^{\text {Pf. }}$

3 heures supplémentaires dimanche à $40 \mathrm{pf}$. I 20

15. 2 heures supplémentaires lundi à $40 \mathrm{pf}$. . . $\quad$ o 80

16. I heure supplémentaire mardi à 40 pf. . . $\frac{0 \quad 40}{23 \quad 9^{\circ}}$

$25 \%$ surcharge locale. . . . . . . \begin{tabular}{rr}
$5 \quad 97$ \\
\hline
\end{tabular}

Total. . . . $\underline{2987}$

TYPE DE BORDEREAU AUX PIÈCES VILLE DE BERLIN

Dates.

M. Pf.

Semaine du 14-20 août.

Histoire des Grecs.

69 lettres $\times 45$ lignes $=3$, 105 lettres $\times$ i 6 pages $=49,700$ lettres $\times 36$ pf..$\quad 17 \mathrm{~m} .89$ เ 500 interlignes $\times 9 \mathrm{I} / 2 \mathrm{pf} . . . . .1 \mathrm{I} \mathrm{m.} 43$

5 heures supplémentaires à $0.0 \quad$ I9 $\quad 32$ \begin{tabular}{rr}
2 & 40 \\
\hline 21 & 72
\end{tabular} $25 \%$ surcharge locale. $5 \quad 43$

Tотак. . . . . $\overline{\underline{27 \quad 25}}$

Il paraît (3) que la très grande majorité des imprimeries allemandes, plus des 5/6, est aujourd'hui au régime du tarif. Grâce à un contrat collectif largement respecté, le salaire minimum est aujourd'hui devenu une réalité dans l'imprimerie allemande.

(1) Cf. Lefebvre, op. cit., p. 70, le tableau complet par régions des différentes surcharges locales du tarif allemand.

(2) Ibid., Lefebvre, p. 72.

(3) Lefebvre, op. cit., p. 26. 
Tout récemment, à la date du I $^{\mathrm{er}}$ janvier $\mathrm{I} 9 \mathrm{I} 2$, le tarif de I 9o6, conclu pour cinq ans, vient d'être renouvelé avec quelques modifications ( $\mathrm{I}$ ) :

Le nouveau minimum hebdomadaire pour les compositeurs, directeurs de machines, correcteurs, stéréotypeurs et électrotypeurs est désormais le suivant :

Jusqu'à l'âge de 2 I ans, 23 marks 5o, soit 29 fr. 37 .

De 2 I à 24 ans, $\quad 24$ marks, soit $30 \mathrm{fr}$.

Au-dessus de 24 ans, 25 marks 6 , soit 3i fr. 88.

Ce qui constitue sur le tarif précédent des augmentations respectives de $\frac{2 \text { fr. } 50,}{2 \text { marks, }} \frac{2 \text { fr. } 50}{2 \text { marks }}$ et $\frac{3 \text { fr. } 75 .}{3 \text { marks. }}$

Les pourcentages régionaux ont été également augmentés de plus de $10 \%$ en moyenne.

Ces modifications, demandées par les ouvriers, sont dues à l'élévation du prix de la vie : elles se traduisent par une

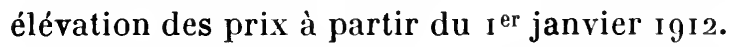

Également intéressante à un autre point de vue, cette fois par son échec au lieu de son succès, la tentative du minimum de salaire tentée en novembre igI I, dans la confection pour dames, à Berlin (2). Un tarif détaillé, élaboré par les membres des organisations professionnelles ouvrières unis aux intermédiaires avait été élaboré avec des minima de salaires aux pièces. Il fut repoussé par les grands confectionneurs et, malgré une grève de trois semaines, échoua par suite de la formation d'un syndicat jaune d'entrepreneurs qui vint briser la grève. Cet échec survenu dans des conditions exceptionnelles (3) montre combien le contrat collectif a parfois de peine à réussir tant que l'association professionnelle ne possède pas, comme c'était ici le cas (4), la souveraineté du métier.

Au total, l'Allemagne est nettement orientée, elle aussi, vers l'obtention du minimum de salaire par contrat collec-

(I) Wages in the Book printing trade in Germany. Labour Gazette, janvier 1912 , p. 8.

(2) Cf. Lüders. Heimarbeitfragen in Deutschland, Berlin 1912. Rapport précité à l'Assemblée de l'Association internationale pour la protection légale des travailleurs, Zurich, 1912, pp. 21 à 24.

(3) Il y avait union de tous les intéressés, l'opinion publique était favorable aux revendications des travailleurs, etc.

(4) Sur la nécessité de l'intervention légale au cas du travail à domicile, cf. ci-dessous. 
tif. Celui-ci devient au delà du Rhin de plus en plus fréquent.

En Autriche, un mouvement parallèle se dessine.

En I907, 33I contrats, concernant 3.397 entreprises et 55.73 I ouvriers, sur les 784 contrats collectifs signalés dans l'année; en I908, 224 contrats, englobant 3.28 I entreprises et 31.786 ouvriers, sur les 483 contrats collectifs signalés dans l'année, règlent seulement le minimum de salaire.

De plus, les contrats réglant à la fois le minimum de salaire et le prix du travail à la tâche sont :

En 1907 , au nombre de 182 , concernant 2.840 entreprises et 67.673 ouvriers,

Et en I908, au nombre de 130 , englobant i.686 entreprises et $18.99^{2}$ ouvriers ( 1 ).

Pour incertaines et incomplètes que soient ces statistiques, elles montrent que là encore le mouvement de réalisation du minimum de salaire par l'association professionnelle est en plein développement.

On pourrait poursuivre ainsi l'étude du mouvement vers le minimum de salaire par l'association professionnelle dans les autres pays. On arriverait à des résultats fort analogues, quoique moins marqués encore.

Il n'y a guère que l'industrie du livre qui se signale à peu près dans tous pays comme jouissant de véritables minima de salaires.

Voici, à cet égard, le tableau tout récemment publié par le Secrétariat typographique international (2). C'est, à notre connaissance, le premier de ce genre qui ait été ainsi dressé (3).

(1) Bulletin de l'Offce du travail français, 1910, p. 1343. Die Kollectiven Arbeits und Lohnverträge in Osterreich; Abschlüsse und Erneuerugen des Jahres 1907; Vienne, 1909. - Id. ... des Jahres r9o8; Vienne, 1910.

(2) Cf. Secrétariat typographique international à Stuttgart. Les organisations ouvrières dans l'industrie du livre, III série. "La situation au $r^{\text {er }}$ janvier 19ro. ") Stuttgart, r9r2, Imp. coopérative, pp. roo et 101.

(3) Toutes les sommes sont indiquées en francs et centimes. La conversion a été faite d'après le tableau suivant :

I mark allemand $=\mathrm{I}$ fr. $25 ; \mathrm{r}$ couronne d'Autriche-Hongrie $=\mathrm{I}$ fr. 05; I florin de Hollande $=2 \mathrm{fr} .10 ; \mathrm{I}$ couronne des États scandinaves $=\mathrm{I} \mathrm{fr} .40$; I livre sterling d'Angleterre $=25$ franes; I rouble russe $=2 \mathrm{fr}$. 65 ; I piastre turque $=0 \mathrm{fr} .222 ; \mathrm{I}$ piastre égyptienne $=0 \mathrm{fr} .25 ; \mathrm{r}$ dollar des États-Unis = 5 fr. 20. 


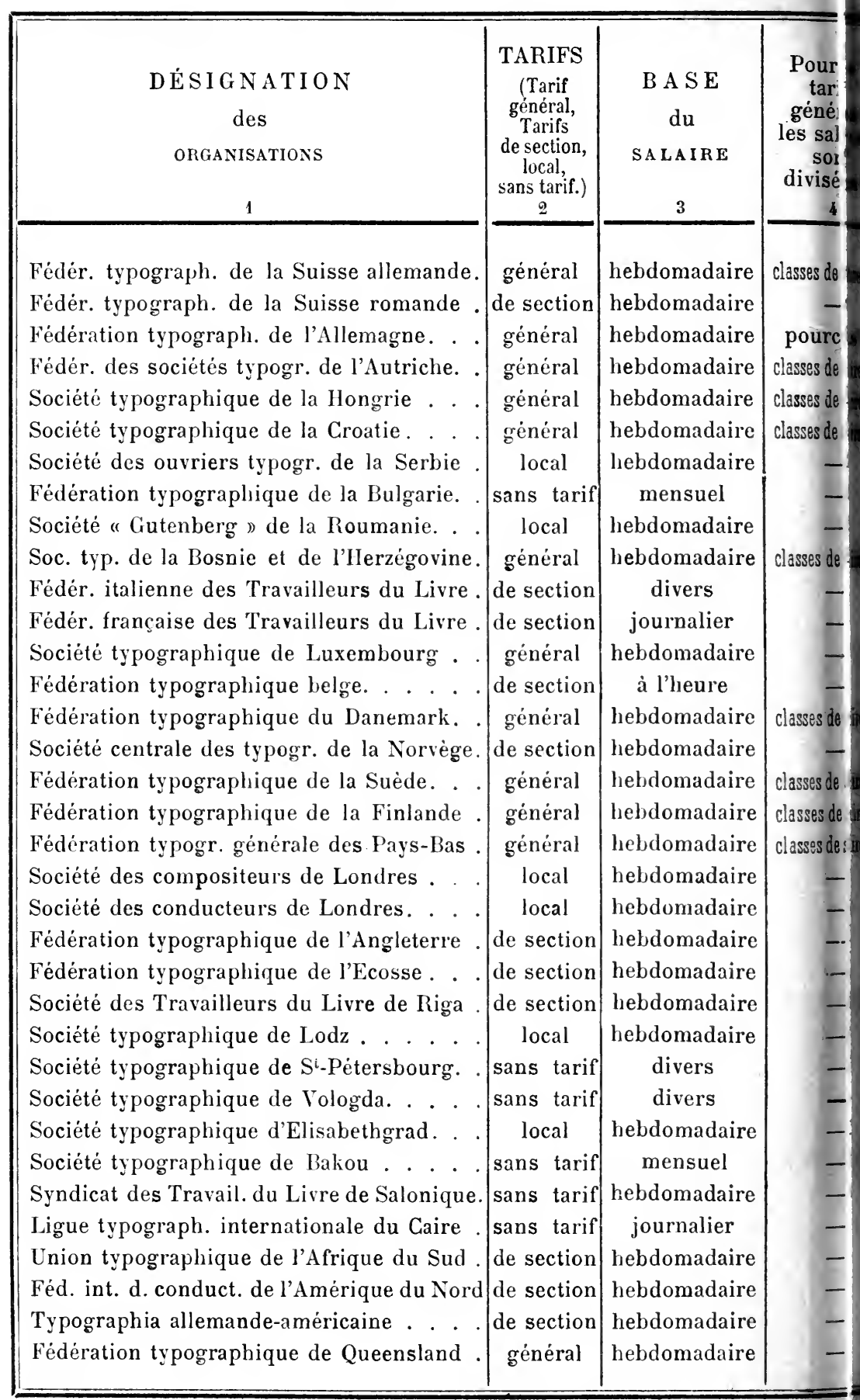




\begin{tabular}{|c|c|c|c|c|c|c|c|}
\hline \multicolumn{3}{|c|}{ IRE HEBDOMADAIRE MINIMUM } & \multirow{2}{*}{$\begin{array}{c}\text { SALAIRE } \\
\text { moyen } \\
\text { par semaine } \\
\text { de tous } \\
\text { les } \\
\text { ouvriers } \\
8 \\
\end{array}$} & \multicolumn{2}{|c|}{$\begin{array}{c}\text { DURÉE DU TRAVAIL } \\
\text { par semaine } \\
\text { prescrite par le tarif }\end{array}$} & \multirow{2}{*}{ 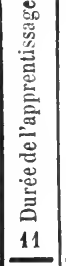 } & \multirow{2}{*}{ 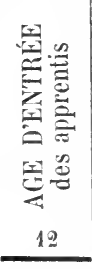 } \\
\hline $\begin{array}{l}\text { positeurs } \\
\text { casse } \\
\text { rimeurs } \\
\text { - sortie } \\
\text { ntissage } \\
5 \\
\end{array}$ & $\begin{array}{c}\text { des } \\
\text { ouvriers } \\
\text { plus } \\
\text { âgés } \\
6 \\
\end{array}$ & $\begin{array}{c}\text { des } \\
\text { compositeurs } \\
\text { à la machine } \\
7 \\
\end{array}$ & & 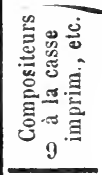 & $\begin{array}{c}\text { Compositeurs } \\
\dot{a} \text { la } \\
\text { machine } \\
10 \\
\end{array}$ & & \\
\hline r. & Fr. & Fr. & Fr. & Heures & Heures & Ann. & Ans \\
\hline is. 50 & $31.50-40$ & $39.375-50$ & - & $\begin{array}{l}53 \\
53\end{array}$ & $\begin{array}{l}48 \\
48\end{array}$ & $\begin{array}{l}4 \\
4\end{array}$ & $\begin{array}{c}14-16 \\
15\end{array}$ \\
\hline-36 & $30-36$ & 42 & 39 & $\begin{array}{r}53 \\
-31 / 4\end{array}$ & $48,531 /$ & 4 & $\begin{array}{l}15 \\
14\end{array}$ \\
\hline-36.25 & $31.25-39.06$ & $39.06-48.83$ & 一 & $531 / 2$ & $48,53^{1 / 2}$ & 4 & 14 \\
\hline 7.30 & $25.20-34.65$ & $35.28-52.67$ & 38 & $521 / 2$ & $48,521 / 2$ & 4 & 14 \\
\hline-29.40 & $23.10-36.70$ & $29.40-44.10$ & $41.80,28.82$ & $521 / 2$ & $491 / 2,51$ & 4 & 14 \\
\hline-32.55 & 3'.65 & 52.50 & 39.90 & 54 & 48,54 & 4 & 14 \\
\hline-24 & $26-30$ & - & - & 51 & - & 4 & 14 \\
\hline 2 & $18-24$ & 30 & - & $51-54$ & 48 & 4 & 13 \\
\hline 2 & $30-35$ & 40 & 33 & 54 & 48 & 4 & 12 \\
\hline 22.05 & $27.30,29.40$ & $40.95,43.05$ & 37.80 & 51 & 45,51 & 4 & $13-14$ \\
\hline- & $16-36$ & $36-46.80$ & - & $54-60$ & $42-48$ & 5 & $12-15$ \\
\hline - & $27-43.20$ & 40 & 35 & 54 & $42-48$ & 5 & 13 \\
\hline $0-24$ & 30 & 37.50 & 35 & 54 & 48 & 4 & 14 \\
\hline- & $21-35.10$ & $24-38.10$ & - & $54-64$ & $51-60$ & 6 & 14 \\
\hline $0-35$ & $32.20-39.20$ & $42-47.60$ & 39.13 & 48,54 & 48 & 5 & 14 \\
\hline - & $28-36.40$ & $44.80-56$ & 40 & 54 & 48 & $4-5$ & 15 \\
\hline .36 .40 & $30.80-44.80$ & $4 \dot{4} .80-56$ & 42 & 48,54 & 48 & 4 & 16 \\
\hline- & $25-31.25$ & $28.75-36$ & 29.50 & 51 & 46 & 5 & 15 \\
\hline .20 & $20-28$ & $2 \cdot 4-32$ & 24 & 57 & 57 & - & 14 \\
\hline- & 48.75 & 56.25 & 59 & $521 / 2$ & 48 & 7 & 14 \\
\hline - & $47.50-71.25$ & - & - & $521 / 2$ & - & 7 & - \\
\hline - & $37.50-47.50$ & $42.19-53.44$ & - & $52-53$ & $48-50$ & 7 & 14 \\
\hline - & $31.25-45$ & $37.50-53.12$ & - & $49-54$ & $46-521 / z$ & 7 & 14 \\
\hline 26.50 & $29.15-42.40$ & $37.10-53$ & - & 54 & 51 & 4 & 15 \\
\hline .10 & $26.50-47.70$ & - & - & 54 & - & 4 & 15 \\
\hline $5 \overline{5}$ & $22.92-27.56$ & $25-86$ & 27.825 & 54 & 54 & $4-5 \mid$ & $12-14$ \\
\hline - & $7.95-21.20$ & - & - & $48-54$ & - & $3-4$ & - \\
\hline .25 & 26.50 & - & 19.88 & 54 & - & - & 12 \\
\hline .15 .46 & $21.63-28.24$ & $43.26-55.65$ & - & 47 & 47 & $4-5$ & 15 \\
\hline 89 & $10-26.65$ & - & 17.77 & 54,60 & 一 & 3 & 15 \\
\hline - & $30-60$ & $42-75$ & - & 48 & - & - & - \\
\hline- & $90-150$ & - & 120 & 48 & - & $5-7$ & $14-16$ \\
\hline - & $85.80-208$ & - & 109.20 & 48 & - & - & - \\
\hline - & - & 一 & - & 48 & 一 & 5 & $14-16$ \\
\hline . & $65-75$ & $81-25$ & - & 44,48 & 42 & 6 & 14 \\
\hline
\end{tabular}


En résumé, le développement et la diffusion du salaire minimum par l'association professionnelle reflètent directement la force et le caractère réformiste des syndicats dans les divers pays: le salaire minimum est le fruit immédiat de la souveraineté de l'association professionnelle dans le métier. On comprend à cet égard que les nombreuses et diverses causes qui arrêtent ou retardent le mouvement syndical dans les divers pays, sont directement et par le fait même des obstacles à la diffusion du minimum de salaire, obstacles dont il est impossible de prévoir et de prédire la plus ou moins prochaine disparition. 


\title{
CHAPITRE VI
}

\section{L'œuvre de la puissance publique.}

\author{
(État. départements et communes.)
}

Le salaire minimum est en second lieu réalisé directement par la puissance publique (État, subdivisions territoriales, communes) pour les ouvriers et employés qui travaillent en régie.

Au nom de l'idée de l'État, patron modèle, applicable aussi aux autres formes de la puissance publique, de nos jours la réforme a été assez généralement adoptée.

On comprend sans peine, surtout avec un régime électif et démocratique, que la puissance publique accorde un régime favorable au point de vue des conditions du travail aux ouvriers et employés directement à son service.

On y voit avec raison un double avantage : l'amélioration des salaires de cette catégorie d'ouvriers d'une part, et d'autre part le bon exemple ainsi donné aux employeurs de l'industrie privée.

Par contre, on insiste, non sans raison, sur l'accroissement de dépenses et par là même de charges pour le contribuable qu'entraîne fatalement cette politique sociale. Il s'agit ici d'ailleurs de procéder avec mesure et de ne pas compromettre, par une rapide réalisation, une cause en soi excellente.

Étudions ce nouvel aspect des faits successivement dans les divers pays. 


\section{A) En France.}

Il faut naturellement envisàger l'œuvre de l'État, des départements et des communes :

\section{I. - L'ACTION DE L'ÉTAT}

Nombreux (I) sont les ouvriers et employés de l'État (2); on peut les classer en deux catégories bien distinctes:

$I^{0}$ Les ouvriers soumis au régime du monopole (tabacs et allumettes, poudres et salpêtres, postes et télégraphes, monnaie);

$2^{0}$ Les ouvriers des manufactures de l'État en concurrence avec l'industrie privée (chemins de fer, arsenaux, manufactures d'armes, imprimerie nationale, Sèvres, Gobelins, etc.).

(1) Près de 200.000 travailleurs à l'heure actuelle.

(2) Dorénavant, en vertu de l'article 152 de la loi de finances du 8 avril i910, un tableau des indemnités de traitements de tous les fonctionnaires, agents, sous-agents, employés et ouvriers de l'État doit être publié, à partir de $19 \mathrm{I}$, tous les einq ans. Le premier de ces tableaux a paru en IgI $(J . O$ du 3o sept. IgI I, édit. ordinaire, p. 7884). Malgré ses lacunes dont fait mention le rapport du Ministre du Travail et de la Prévoyance sociale, ce tableau, en l'état actuel de la statistique, est un document précieux pour étudier la question des traitements et salaires du personnel ouvrier de l'État. Nous le citerons plus loin sous la rubrique : Rapport statistique générale lle la France, avec la référence à la page de l'Officiel pour chaque série de chiffres utilisés. 
a) Les ouvriers soumis au régime du monopole (I).

Les ouvriers des tabacs et des allumettes (2), ceux des poudres et salpètres, les employés des postes et télégraphes sont dans une situation spéciale, qui facilite l'octroi d'un minimum de salaire : les nécessités industrielles pour l'établissement d'un prix de revient minimum ne conditionnent pas ici étroitement le taux des salaires (3), les facilités de recrutement sont grandes; en un mot, le jeu de la concurrence n'est plus ici le même que dans l'industrie privée: l'État patron peut être sans peine le patron modèle (4).

Les ouvriers des manufactures de tabacs (5) jouissent de fait d'un salaire minimum ou plus exactement d'un salaire basé sur la cherté de la vie dans les localités où sont situées les manufactures. Le salaire minimum résulte plus encore des solutions adoptées en diverses circonstances et des instructions adressées aux directeurs (6) que de textes formels et explicites.

"Pour déterminer le taux des salaires des manufactures, on prend comme base la cherté de la vie des localités où elles sont situées. Environ tous les cinq ans, l'Administration procède à une enquête d'ensemble et adresse aux directeurs un questionnaire détaillé permettant, sinon de calculer le prix de la vie pour une famille ouvrière dans chaque

(1) Cf. Ch. Mannheim. De la condition des ouvriers dans les manufactures de l'État (tabacs, allumettes). Thèse, Paris, I902, Giard et Brière. Compte annuel de gestion des monopoles.

Rapport statistique générale de la France, J. O., 1911, p. 1500.

(2) Au nombre de plus de 20.000. Manheim, op. cit., p. 2.

(3) Cf. Manheim, op. cit.

(4) Cf. Ribot. Disc. à la Ch. des députés, r 5 mars 1895. J. O., Ch., Déb. parlem.

(5) On sait qu'il existe vingt manufactures de tabacs et services annexes : Bordeaux, Cbâteauroux, Dieppe, Dijon, Issy-les-Moulineaux, Le Havre, Le Mans, Lille, Lyon, Marseille, Morlaix, Nancy, Nantes, Nice, Orléans, Pantin, Paris (Reuilly), Riom, Tonneins, Toulouse. De plus, à Limoges, les ateliers spéciaux.

(6) Circulaire de r882, par exemple : "L’Administration n'a jamais hésité à prendre l'initiative de toutes les mesures qu'elle jugeait utiles à l'amélioration de la situation du nombreux personnel qu'elle emploie... elle tient à marquer sa place, sinon à l'avant-garde, du moins au premier rang de l'industrie dans la voie progressive que les salaires tendent à suivre. (Cité par Manheim, op. cit., p. I12.) 
ville siège d'un établissement, tout au moins de se rendre compte de la cherté relative (1). )

Les statistiques accusent d'ailleurs les résultats de celte politique des salaires.

"Les salaires payés (au 3 I décembre I908) correspondent pour 9 heures de travail à un gain moyen de 6 fr. 49 pour les ouvriers et de 4 fr. 34 pour les ouvrières (2). "

Ce salaire moyen s'obtient en prenant le quotient de la somme totale gagnée par un ouvrier ou une catégorie d'ouvriers, pendant un laps de temps donné, par le nombre des heures de présence comprises dans cette période et multipliées par 9 (3).

Ce salaire moyen a d'ailleurs été en augmentation constante ces dernières années (4).

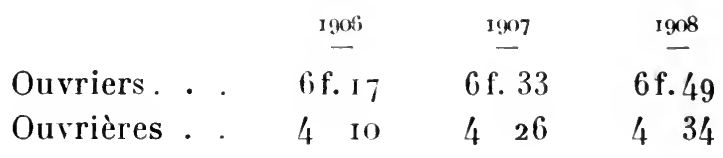

Les minima de traitements fixés par le décret du 14 janvier 1908 rapportés par le tableau de la Statistique générale de la France sont les suivants (5):

Chefs de section principaux des manufactures : $3.400 \mathrm{fr}$.; chefs de section des manufactures et chefs d'atelier : $2.700 \mathrm{fr}$; contremaîtres principaux : $2.700 \mathrm{fr}$.; contremaîtres : 2.050 fr.; surveillants: 1.600 fr.; contremaitresses principales : 1.900 francs; contremaîtresses : I.50o fr.; surveillantes : $\mathbf{1 . 2 0 0 ~ f r . ; ~}$ concierges : r.6oo et $1.225 \mathrm{fr}$; garçons de bureau : 800 et I. 425 fr., etc.

On peut, grosso modo, affirmer que la plupart des ouvriers des tabacs jouissent aujourd'hui en fait, sinon en droit, d'un véritable minimum de salaire.

(1) Manheim, op. '́cit., p. I15.

(2) Les manufactures de tabacs et d'allumettes de l'État en rgo8 (personnel et salaires). Bulletin de l'office llu travail, ig10, p. 490.

(3) C. Manheim, p. i13, op. cit.

(4) Ibid. Bulletin de l'Office du travail, i910, p. 490.

(5) Rapport statistique générale, J. O., 1911, p. 1500. 
Les ouvriers des manufactures d'allumettes (I) sont dans une situation parfaitement analogue.

"Les salaires payés au 3 I décembre I908 correspondent pour neuf heures de travail à un gain moyen journalier de 7 francs pour les ouvriers et de 5 fr. 34 pour les ouvrières (2).

Ici encore il y a une forte progression.

Le salaire moyen a été respectivement:

\begin{tabular}{|c|c|c|c|}
\hline & 1906 & 1907 & Ig08 \\
\hline Pour les ouvriers, de & 6 f. 93 & $6 \mathrm{f} .94$ & $7 \mathrm{f}$. \\
\hline Et pour les ouvrières, de. & $5 \quad 15$ & $5 \quad 28$ & $5 \quad 34$ \\
\hline
\end{tabular}

Les ouvriers du service des poudres (3) sont, au point de vue des salaires qui nous intéressent, répartis en deux catégories: les ouvriers de la fabrication et les ouvriers de métier (4):

Les ouvriers de la fabrication sont répartis en six classes, dont voici la moyenne pour i9 Io:

Prix de l'heure:
o fr. 40 au début.
o fr. 44 après 6 mois.
o fr. 48 après 3 ans.
o fr. 5 I après 6 ans.
o fr. 53 après io ans.
o fr. 56 après 15 ans.

(1) On sait qu'elles sont au nombre de six : Pantin-Aubervilliers, Marseille, Trélazé (Maine-et-Loire), Bègles (Gironde), Aix-en-Provence, Saintines (Oise).

(2) Bulletin de l'offce du travail, г9г, p. $49 \mathrm{I}$.

(3) H. Lacape. Conditions des ouvriers du service des poudres. Thèse, Paris, 1910, Jouve.

(4) Les ouvriers de la fabrication sont ceux qui s'oceupent des opérations propres aux poudreries; les ouvriers de métiers ou ouvriers d'art sont occupés aux machines, aux ateliers de construction ou de réparation, dans les tonnelleries. Leur nombre total au I ${ }^{\text {er }}$ octobre rgog était de 4.212, ainsi répartis: Marseille, 34; Bordeaux, 34; Lille, 3o; Vonges, 190 ; Saint-Chamas, 3 ıо ; Toulouse, 118; Saint-Médard, 879; Angoulême, 760 ; Le Ripault, 309; Pont-de-Buis, 505; Moulin-Blanc, 445; Esquerdes, 203 ; Sevran-Livry, 395. Cf. Lacape, op. cit., p. 10. 
Les ouvrières de la fabrication sont, elles aussi, divisées en cinq classes, dont voici la moyenne pour i910:

Prix de l'heure :

o fr. 26 au début.

o fr. 29 après Io mois.

o fr. 3 I après 3 ans.

o fr. 32 après 6 ans.

o fr. 35 après io ans.

La journée de travail étant depuis 1908 de huit heures et demie de travail effectif (1), on voit que pour les ouvriers tout au moins il existe pratiquement un salaire vital (2).

Les ouvriers de métier sont eux aussi payés à l'heure. Chaque poudrerie possède un tarif particulier arrêté par le ministre sur la proposition du directeur; ce tarif prévoit une limite maxima et une limite minima des salaires dans chaque profession par jour de $4 \mathrm{fr}$. 35 à $7 \mathrm{fr}$. 50 pour les ouvriers en métaux, de $4 \mathrm{fr}$. 30 à $6 \mathrm{fr}$. 55 pour les ouvriers en bois, de $3 \mathrm{fr}$. 60 à 5 fr. $9^{5}$ pour les chauffeurs, de 4 à 6 fr. pour les autres, à la poudrerie d'Angoulême, par exemple (3).

Il faut noter enfin que le salaire à la tàche, qui subsiste pour $20 \%$ du personnel environ (4), assure, d'après la circulaire du 29 aoùt rgo3, un gain dépassant le salaire à la journée, le supplément étant variable suivant " la nature du travail et sa continuité $)$.

(I) Ibid. Lacape, p. 41.

(2) Au salaire de base s'ajoutent d'ailleurs deux primes : une prime de $o$ fr. o6 par heure aux ouvriers travaillant des matières acides; une prime de o fr. 30 par jour en 1909 pour tous les ouvriers et ouvrières de la fabrication. Les heures supplémentaires sont payées $10 \%$ en sus du travail ordinaire; le travail de nuit, entre 9 heures du soir et 5 heures du matin, $50 \%$ en sus. Ibid. Lacape, pp. 27 et 42 . On obtient, en tenant compte de ces suppléments, $4 \mathrm{fr} .20,4 \mathrm{fr} .55,4 \mathrm{fr} .90,5 \mathrm{fr} .25$, $5 \mathrm{fr}$. 40 et $5 \mathrm{fr} .55$ comme prix de la journée de travail pour les ouvriers de fabrication.

(3) Le salaire moyen des ouvriers des poudres est voisin de $5 \mathrm{fr} .50$. Lacape, op. cit., p. 36 .

(4) Il ne s'applique aujourd'hui pour les brications qu'au travail des ouvrières (triage des déchets de coton, bottelage des poudres B) et à la carbonisation, à la fabrication de l'acide nitrique, aux travaux de menuiserie et de charpenterie, de tonnellerie. Il peut aussi s'appliquer pour les travaux d'emboìtage et d'emballage, pour le transport, l'empilage, le rangement des matières premières des emballages, des combustibles, des matériaux de construction. Il est aujourd'hui l'exception (Ibid., Lacape, p. 31), par suite de l'hostilité de la classe ouvrière. 
On peut donc affirmer que les ouvriers du service des poudres jouissent, pour la plupart, en fait, d'un salaire minimum (I). L'expression se trouve formellement inscrite dans une réponse ministérielle de 1909 aux revendications des ouvriers concernant la suppression du travail à la tàche (2).

Une commission mixte consultative, créée en vertu d'une circulaire ministérielle du 28 aoùt igo8, " pour les questions concernant l'organisation générale du travail et le fonctionnement industriel des établissements de la guerre (3), a voulu d'ailleurs aller plus loin et a émis le vœu suivant, relatif aux salaires :

"La Commission émet le vœu que l'on mette à l'étude la question de faire entrer les nécessités de l'existence comme élément d'appréciation de la détermination du salaire et que l'on cherche les moyens de faire arriver l'ouvrier, par une combinaison tenant compte à la fois de l'ancienneté et de l'aptitude, à un salaire progressif, de façon à atteindre le maximum à quinze ans de service (4). ")

Ce n'est pas encore le minimum de salaire nettement proclamé (5), c'est toutefois l'application progressive de l'idée que le coùt de l'existence doit entrer en ligne de compte dans la détermination du salaire.

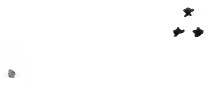

Les ouvriers et employés des postes, télégraphes et télé-

(1) Il est dû en partie aux efforts de la Fédération ouvrière des poudreries et raffineries de France.

(2) Lacape, ibicl., p. 153.

(3) La commission comprend douze représentants de l'Administration de la guerre et neuf représentants du personnel des établissements.

(4) H. Lacape, op. cil., p. 148. Le Ministre de la Fuerre paraît avoir approuvé en principe cette résolution en mai rgog.

(5) Le rapport de M. de Moüy, au nom de la Commission précitée, conclut au rejet de la revendication ouvrière du minimum de salaire. On a invoqué comme motifs la divergence d'appréciation des ouvriers, l'hésitation du Parlement à accepter pour l'industrie privée l'obligation du minimum de salaire, pour rejeter le minimum de salaire uniforme. - Cif. G. Maurette. De la conditi,n du personnel civil des établissements de la guerre. Thèse, Toulouse, 1911, Destrem, p. ig2. 
phones ( $\mathrm{r}$ ) réclament depuis longtemps le minimum de salaire; tous ne l'ont pas encore obtenu (2).

Dès I9or, M. Sembat, rapporteur du budget des P. T. T. pour igo2, écrivait : " Non seulement dans l'intérêt de ses employés, mais dans l'intérêt de tous, pour la bonne exécution des services et la satisfaction du public, comme pour l'exemple national et le progrès social, l'État employeur doit assurer, à chacun de ceux qu'il emploie, ce minimum de bien-être qui suppose un salaire suffisant pour ses besoins et ceux de sa famille. "

La situation des employés des postes, télégraphes et téléphones est bien diverse; il faut distinguer la situation des ouvriers adultes, des femmes et des enfants, et dans chaque catégorie établir de nombreuses sous-distinctions.

a) Les ouvriers adultes. - Il faut envisager ici :

Les surnuméraires et commis, au nombre de i6.700 environ;

Les receveurs, au nombre de 3.0oo environ;

Les facteurs, au nombre de 42.000 environ;

Les gardiens de bureau et autres sous-agents, au nombre de 2.500 .

Les surnuméraires et commis débutent à 600 francs par an (3), ils gagnent ensuite r.200 et r.500 francs par an; puis après trois ans 1.800 francs et ensuite, par avancements successifs de trois en trois ans, des salaires qui atteignent 4,000 francs et 4.500 pour les commis principaux (4).

(1) Ludger Collet. Des conditions du travail dans l'Administration des postes et télégraphes. Thèse, Paris, 1910, Giard. Rapports parlementaires de la Chanbre et du Sénat sur le budget des postes, télégraphes et téléphones.

(2) Le personnel se divise administrativement :

En agents (surnuméraires, commis, dames employées, receveurs et receveuses), au nombre de 39.000 environ;

En sous-agents (facteurs, gardiens de bureau, etc.), au nombre de 57.000 environ,

Sans parler des ouvriers des services techniques, au nombre de 4.500 environ.

Soit un personnel total de plus de 100.000 unités, exactement 106.500 en 1910, d'après le chiffre donné par M. Dalimier dans son rapport à la Chambre pour le budget des P. T. T., 1912. [J. O., Doc. parlem., 1911, p. 2167.$]$

(3) I fr. 65 par jour n'est certes pas un salaire suffisant pour vivre.

(4) A ces salaires s'ajoutent quelques indemnités de résidence, de foo francs au maximum à Paris. 
On peut affirmer, avec tous ceux qui se sont occupés de la question (I), que ce sont là des salaires trop faibles : ce n'est guère qu'à la moitié de sa vie que le surnuméraire arrive à un salaire convenable et suffisant.

Les receveurs des postes, spécialement ceux des grands bureaux, sont plus favorisés que les commis au point de vue de leur rétribution : d'un minimum de r. 100 pour les bureaux simples et 3.000 pour les bureaux composés, ils atteignent 4.500 pour les premiers et 8.000 pour les seconds, avec divers émoluments qui améliorent beaucoup leur situation pécuniaire.

Les facteurs (2) sont loin de connaitre les minima de salaires : les facteurs ruraux ou locaux débutent à 800 francs de salaire annuel et peuvent alteindre r.200 francs par avancements successifs de 50 francs tous les trois ans; au bout de vingt-quatre ans, le facteur rural arrive ainsi à un salaire quotidien de 3 fr. Io (3).

Les facteurs urbains sont mieux traités, mais ne jouissent pas davantage de salaires minima. Leur traitement varie de $\mathrm{r}, 300$ francs à $\mathrm{r} .700$ francs; ils avancent de classe tous les trois ans et augmentent de roo francs par chaque promotion de classe.

Les facteurs-receveurs touchent de r. Ioo à r.50o francs, avec appointements supplémentaires et logement gratuit (4).

Les gardiens de bureau débutent à 1.300 francs pour

(I) Cif. Gautier. Rapport au Sénat sur le budget général de 1909 (Ministère des Travaux publics, des Postes et Télégraphes). - Dumont. Rapport à la Chambre pour le budget général (P. T. T.) de r910. Ch., Doc. parlem., 1910, n० 2767, p. 2224.

(2) Au I er janvier r 909 , on comptait 41.307 facteurs commissionnés, parmi lesquels 22.574 facteurs locaux et ruraux, 9.880 facteurs de ville et 3.602 facteurs-receveurs.

(3) M. Sembat (Rapport pour le budget de rgo3) écrivait justement : "Il est déplorable qu'un homme qui fournit toute sa journée à l'État ne puisse recevoir en échange une rémunération convenable et doive employer ses soirées à des besognes étrangères, se faire cordonnier ou tailleur, pour nourrir sa famille. ") Cies salaires, relativement bas, s'expliquent historiquement. Cf. Collet, op. cit., p. i13. Les traitements inférieurs à 600 francs par an étaient jadis, avant 1870 , la règle.

(4) Tous les facteurs reçoivent de plus de l'Administration leurs uniformes, une indemnité de chaussures de 50 francs par an; quelques-uns touchent une indemnité de résidence. Il faut ici tenir compte aussi des étrennes, qui constituent une augmentation parfois appréciable de salaire. 
atteindre au maximum 2.000 francs après vingt-quatre ans de service, par avancement de oo francs tous les trois ans.

Ces divers traitements sont cependant le résultat d'améliorations successives votées par le Parlement pendant ces dernières anmées (I).

Ils sont loin de constituer cependant, pour leurs titulaires, des minima de salaires.

Une proposition a été déposée en ce sens par M. A. Groussier (2), à la Chambre, pour établir un minimum de traitement; il s'agirait de donner un salaire minimum :

De 3 francs par jour dans les communes de 3.000 habitants et au-dessous,

De 3 fr. 50 par jour dans les communes de 3.00 I à Io.0oo habitants,

De 4 francs par jour dans les communes de io.00I à 50.000 habitants,

De 4 fr. 5o par jour dans les communes de plus de 50.000 habitants,

De 5 francs par jour pour les communes du département de la Seine.

Ce projet se heurtait, sans parler de la question de principe, à diverses difficultés : la suppression de l'égalité de traitement pour les employés du mème grade sur tout le territoire français, l'inégalité consécutive de la réforme au point de vue des retraites (3), etc.

Le principe du minimum de salaire a été toutefois posé en ce qui concerne les ouvriers supplémentaires, par un décret du 29 mars i 902 : leur salaire est fixé à 5 francs par jour (4).

Il serait grandement désirable que les traitements de début fussent progressivement relevés et que l'on parvînt à octroyer aux sous-agents des postes de véritables minima de salaires.

(I) Les crédits votés pour les traitements des sous-agents ont passé de 45.691 .686 francs en 1900 à 60.8I 7.6 I 7 francs en 1908 . Cf. Collet, op. cit., p. II 7 .

(2) J. O., Ch., Doc. parlem., I907, p. 47.

(3) Cf. Collet, op. cit., p. I 20.

(4) Cf. Bourguin. De l'application des lois ouvrières aux ouvriers et employés de l'État. Paris, Rousseau, 1902, p. 27. 
La réforme reste à l'ordre du jour (I).

b) Les femmes. - Il faut, à cet égard, distinguer :

Les receveuses, au nombre de 4.500 environ;

Les dames employées, au nombre de 10.000 environ;

Les aides, au nombre de 8.000 environ.

Les receveuses (2), chargées de la gestion des petits bureaux de poste, jouissent d'avantages sensibles : le logement gratuit, diverses indemnités de service qui leur constituent dans l'ensemble un véritable salaire minimum de fait.

Les dames employées, recrutées au concours, reçoivent un traitement annuel qui varie de I. Ioo francs à 2.200 francs par an (3). Ici encore, I. Ioo francs par an, soit 2 fr. 90 par jour, n'est pas un véritable salaire minimum, surtout dans les centres où se trouvent les bureaux de poste importants (4). On souhaiterait ici de véritables minima de traitements.

La réforme a été amorcée par un décret du 28 avril i 908 (5), fixant le salaire journalier de début des lingères et femmes de service de Paris (P. T. T.); le laux de 3 fr. 50 , comme traitement de début, a été adopté aussi bien pour les lingères et femmes de service en titre que pour celles recrutées à titre de main-d'œuvre exceptionnelle.

(I) Dans sa deuxième séance du 2 février rgro, la Chambre, au cours de la discussion du budget des postes et télégraphes, a voté une proposition de résolution déposée par MI. Dumont, steeg et Bourély, acceptée par le Gouvernement, ainsi conçue : "La Chambre invite le Gouvernement à constituer une commission extra-parlementaire où les catégories principales du personnel des postes, télégraphes, téléphones seront représentées et entendues, qui aura pour mandat d'adapter aux responsabilités et aux charges des fonctions exercées et de coordonner, dans un esprit d'équité, les traitements, pensions et salaires, aussi bien du personnel titulaire que du personnel auxiliaire. )" (Bulletin de l'offce du travail, r9ro, p. 195.)

(2) On n'accède d'ailleurs à ce grade qu'après de nombreuses années de service administratif.

(3) Par avancements succe:sifs de 100 franes tous les deux ans environ. Il y a aussi des indemnités de 50 à 100 franes par an dans quelques centres importants. Ici encore la situation présente résulte d'améliorations sensibles pendant ces dernières années.

(4) L'admission des femmes dans l'administration des postes avait été, en principe, décidée dans le but de réaliser des économies. La question se complique ici de la coneurrence entre hommes et femmes : l'Association générale des agents avait demandé que le traitement maximum des dames employées égalàt les deux tiers du traitement maximum des commis.

(5) J. O. du 20 mai 1908, p. 3535 Bulletin de l'offce dlu travail, r9o8, p. 590 . 
Les aides, presque ignorées de l'Administration, sont payées par les recereurs.

Leurs salaires sont encore plus bas et par suite tout à fait insuffisants : avec le logement et la nourriture, elles touchent io à 30 francs par mois, rarement davantage.

Leur sort est d'ailleurs très variable, selon les personnes qui les emploient. Elles sont parfois payées en partie sur le propre traitement des receveurs, qui reçoivent, pour " frais d'aide ", des indemnités parfois trop limitées ( $\mathrm{I}$ ).

II. Ch. Dumont (2) écrivait à ce sujet en I9 Io: "Il y a de la part de l'Administration, comme de la part des receveurs, une véritable exploitation dont la victime est l'aide, pauvre jeune fille abandọnnée des pouvoirs publics, devenue souvent la bonne de la receveuse et qui attend péniblement ses dix ans de service pour passer l'examen spécial de dame. L'Administration a la responsabilité morale des misères d'un nombreux personnel qu'elle ne connaît pas, mal payé ou payé de promesses. Ce mode d'exploitation est peut-ètre économique pour le Trésor, il est en tout cas indigne d'une grande Administration (3). "

Un arrêté en date du 4 juillet r goo a précisé les conditions de recrutement des aides et fixé les bases du cadre de ces auxiliaires, sans grand succès d'ailleurs, et sans toucher à l'importante question des salaires (4).

c) Les enfants, au nombre de 3.500 jeunes facteurs.

La plupart sont employés au transport des télégrammes à domicile. Ils sont payés de deux manières :

Les uns touchent des traitements fixes, variant de 400 à 900 francs par an.

Les autres sont payés à la tâche, d'après le service effectué, c'est-à-dire le nombre de télégrammes distribués : ils arrivent ainsi parfois à se faire 100 francs par mois.

Étant donné que ce salaire est ordinairement un salaire

(1) L'insuffisance de crédit serait d'environ 600.000 francs. Cf. rapport. Dalimier, budget des P. T. T., Ch., 1912, J. O., Doc. parlem., p. 2178.

(2) Rapport précité pour le budget des P. T. T., 1910.

(3) On a dit avec justesse (Collet, op. cit., p. 104) que cette exploitation rappelait par certains còtés le sweating system. Les abus sont parfois ici moins criants ou moins remarqués, parce que l'aide est d'ordinaire une employée nourrie.

(4) Ibid. Rapport Dalimier, P. T. T., 1912. Ch., Doc. parlem., I91 I, p. 2178 . 
d'appoint, que ces enfants virent pour la plupart chez leurs parents, on peut dire que les jeunes télégraphistes sont relativement bien payés $(\mathrm{I})$.

Voici, d'après une communication de l'Administration des postes, télégraphes, téléphones, les traitements minima au I ${ }^{\text {er }}$ mars I9 I $2(2)$ :

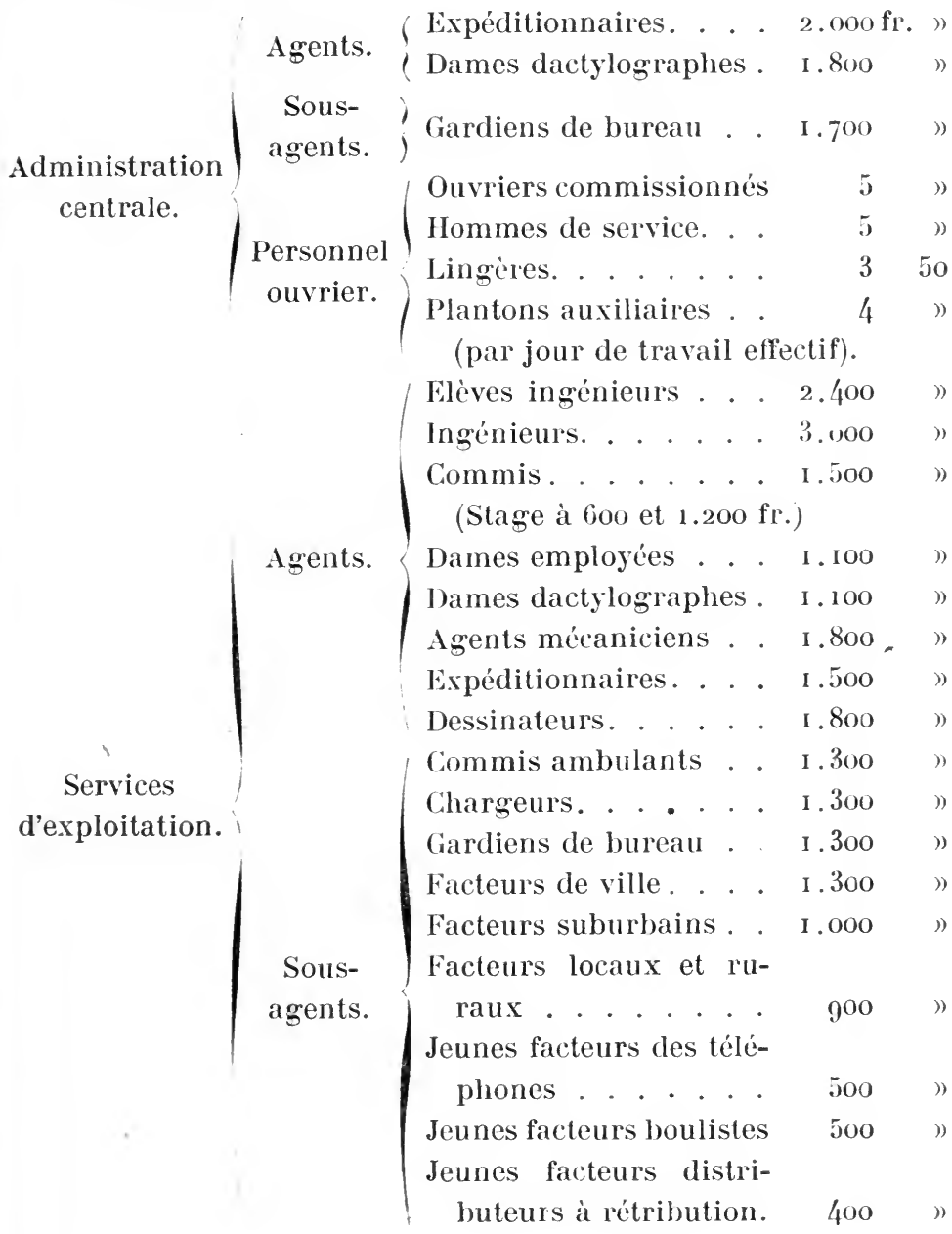

(r) Peut-être, d'ailleurs, ces avantages présents sont-ils obtenus au détriment de leur situation future : le manque dapprentissage et d'instruction professionnelle risquent de les faire se trouver un jour sans situation.

(2) C. Dumont. Rapport pour le budget des P. T. T., I910. Annexe XIV. Tableau indiquant la comparaison de la situation des diverses catégories de personnel en 1898 et 19 ro, édition spéciale du rapport, p. 402. 
Femmes de service.

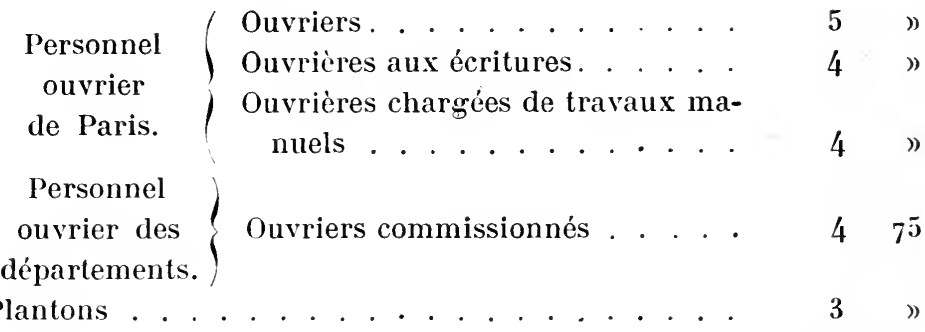

Une indemnité variable suivant les résidences est allouée aux agents et sous-agents en fonctions dans quelques localités. Elle est de 400 francs à Paris pour les agents et de 300 francs pour les sous-agents. Les ouvriers ne touchent pas d'indemnité de résidence.

En résumé, dans le personnel des postes, le minimum de salaire, le salaire vital apparaît comme une très rare exception dont jouissent seulement quelques catégories peu nombreuses d'employés privilégiés ( 1 ).

Aujourd'hui la question est soumise aux travaux d'une Commission extra-parlementaire nommée par décret du 7 avril i9 I. Cette Commission a pour mission de " rechercher et de proposer les moyens d'adaptation aux responsabilités et aux charges de fonctions exercées et de coordonner dans un esprit d'équité les traitements, salaires et indemnités $)$.

La Commission extra-parlementaire (2) a entendu, sans les discuter, les vœux émis par les associations et les représentants du personnel; elle a recueilli sur chacun d'eux l'avis de l'Administration avec évaluation de la dépense que la réalisation de cette réforme entraînerait. Un rapporteur général a été nommé et procèdle en ce moment (fin I9II) à l'examen de tous ces documents (3).

(I) Il y aurait beaucoup à faire à cet égard. On a calculé (Gáauthier. Rapport sur le budget général de 1908, P. T. T., au Sénat) que les dépenses pour le personnel par rapport au total $(55 \%$ en $1906,58 \%$ en 1907) sont moins élevées en France qu'à l'étranger (Angleterre, 1906, $62 \%$ o, 1907, $63 \%$; Allemagne, r 906 et $1907,62 \%$ ).

Les recettes des P. T. T. ont passé de 329.013 .573 francs en 1908 à $36 \mathrm{r} .080,200$ francs en 1910, soit une augmentation de $9,74 \%$; l'auginentation de l'effectif du personnel dans le mème temps n'a été que de 4,02 \%. Cf. Dalimier. Rapport cité, p. 2167.

(2) La Commission extra-parlementaire aura à examiner la généralisation du minimum de salaire.

(3) Cf. rapport Dalimier pour le budget des P. T. T., 1912. Ch., J. O., 
Un récent projet de loi voté à la Chambre (I) améliore encore la situation du personnel des postes (2), en application des mesures proposées par la Commission extra-parlementaire : le traitement du district des sous-agents est fixé à I. IOo francs.

Lors de la discussion, un amendement proposé par M. Ch. Dumont (3) porta le salaire minimum du personnel ouvriel spécialisé de 5 fr. à 5 fr. 50 . La question de principe réserve faite des applications progressives - en ce qui concerne le minimum de salaire, ne parut faire aucune difficulté devant la Chambre.

On proposa même (4) une indemnité familiale de io fr. par mois et par enfant, à partir du troisième, à tout membre du personnel des P. T. T., du personnel des douanes, du personnel des contributions indirectes, dont le salaire ne dépasse pas 2,400 fr. Sur les déclarations du ministre indiquant que la Commission du budget était saisie de la question des indemnités familiales dans leur ensemble, la proposition fut retirée par ses auteurs.

Au total, la réforme du minimum de salaire semble de plus en plus acceptée pour cette catégorie des employés de l'État.
Les ouvriers de l'Administration des Monnaies et Mé- dailles paraissent jouir au contraire de salaires minima : le salaire moyen, d'après le rapport pour le budget de l'Admi- nistration des Monnaies et Médailles i 9 I 2 (5) ressortait dans le courant de ig I aux chiffres suivants :
$\begin{array}{rrr}\text { Salaire moyen des graveurs . . . . } & \text { Iof. I } 7 \\ - & 8 \mathrm{f.} 2 \mathrm{I} \\ - & \text { des ouvriers de métier. . . } & 6 \mathrm{f.} 5 \mathrm{I}\end{array}$

Doc. parlem., $\mathrm{n}^{\circ} 1258$, pp. 2145 et suiv. Le rapporteur de 1912, en conséquence, s'est imposé une certaine réserve en ce qui concerne les revendications des diverses catégories du personnel. Ibid., p. 2166.

(1) Deuxième séance du r2 juillet 1912. J. O., Ch., Déb. parlem., p. 2307.

(2) Ainsi que celle du personnel des Contributions indirectes et des Douanes : 29.990 .852 francs sont prévus pour le personnel des postes.

(3) Soit une augmentation de dépenses de 128 .30r francs.

(4) Voir la disposition additionnelle de M. Chalamel et autres. J. O., loc. cit., p. $23 \mathrm{r} 3$.

(5) $\Lambda$. Weber. Rapport sur le budget de 1912. (Monnaies et Médailles. J. O., Ch., Doc. parlern., Ann., no 1232, p. ri20.) Le personnel ouvrier de la Monnaie comprend : 4 graveurs, 5 r ouvriers de métier, 224 ouvriers ordinaires. Ibid., rapport, p. II 19. 
Ces résultats actuels ont été obtenus par trois augmentations successi ves accordées à la demande du syndicat ouvrier des Monnaies et Médailles : la première, en juillet 1906, a augmenté tous les salaires de 25 centimes par jour; un certain nombre d'ouvriers ont mème bénéficié à cette date d'une augmentation générale de 5o centimes. En janvier 1908, M. Caillaux a accordé à tous les ouvriers de la Monnaie une augmentation journalière de o fr. 25 ; enfin, par arrèté du 2 novembre Igog, M. Cochery a donné au même personnel une nouvelle augmentation générale de 25 centimes, avec

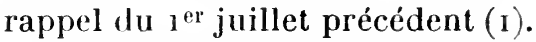

Les salaires sont d'ailleurs progressifs à l'ancienneté : un ouvrier ordinaire dont le salaire est inférieur à 5 fr. 25 bénéficie d'un relèvement de salaire de 25 centimes tous les deux ans. Quand son salaire atteint 6 fr. 25, il est dans l'obligation d'attendre quatre ans pour bénéficier d'un nouveau relèvement de 25 centimes, et ensuite l'avancement a lieu de quatre en quatre ans (2). Un ouvrier de métier dont le salaire est inférieur à $7 \mathrm{fr}$. 75 a droit à un relèvement de salaire de 25 centimes tous les deux ans. Quand son salaire atteint 8 francs, il doit attendre quatre années pour bénéficier d'un nouveau relèvement de 25 centimes et ensuite l'avancement a lieu pour lui de quatre en quatre ans (3) dans les mèmes conditions que pour les ouvriers ordinaires.

Au total, on peut conclure, en ce qui concerne cette première catégorie des ouvriers et employés de l'Etat soumis au régime du monopole, que la réforme du minimum de salaire est aujourd'hui en voie de réalisation : les conditions particulières où ils se trouvaient placés expliquent qu'ici le mouvement ait été assez rapide et que la revendication du minimum de salaire n'ait pas rencontré de sérieux obstacles.

(I) Réponse de l'Administration au rapporteur sur les revendications ouvrières. Rapport cité, p. ıı . Les ouvriers réclamaient encore, le 29 mars igr I, au Ministre des Finances, une nouvelle augmentation de o fr. 25, en invoquant l'idée du minimun de salaire variable avec la eherté de la vie. "Cette demande est-elle juste? Incontestablement, si l'on part de ce principe que le salaire doit être assez élevé pour permettre aux salariés de faire face aux charges de l'existence, sans qu'ils aient recours à des expédients. ") Lettre du Syndicat au Ministre des Finances, en date du 29 mars 1911 , rapportée in extenso dans le rapport eité, p. I II9.

(2) Depuis le ${ }^{\text {er }}$ janvier igi2. Avant, de cinq en cinq ans.

(3) Même observation qu'à la note 2. 
b) Les ouvriers soumis au régime de la concurrence.

La réforme, en ce qui concerne cette seconde catégorie d'ouvriers, est plus délicate à accomplir et par suite moins avancée : on comprend en effet que l'État se trouve ici placé dans la situation d'un industriel ordinaire et que les nécessités de la concurrence le mettent dans une siluation beaucoup plus difficile pour accorder à ses ouvriers et employés un minimum de salaire.

La difficulté a été très nettement exprimée à propos des travailleurs municipaux; elle est la mème pour les travailleurs de l'État: "L'ouvrier qui construit un tramway pour le compte d'un entrepreneur recevrait-il un salaire plus élevé parce que le tramway qu'il conduit sera un jour propriété municipale et non pas propriété d'une Compagnie? Si l'on a raison d'augmenter artificiellement le salaire dans un cas, il faut le faire aussi dans l'autre ( $\mathrm{r}$ ). ")

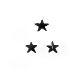

Le personnel des chemins de fer de l'État (2) se compose, comme on le sait, du personnel de l'ancien réseau d'État et du personnel du nouveau réseau (Ouest racheté), aujourd'hui en très grande partie placés sur le mème pied (3).

Les salaires et traitements du personnel sont actuelle-

(I) J. Darwin. Municipal Tralle, Ig03, chap. II. Cf. toute la discussion qui suit la eitation rapportée au texte.

(2) Perrissoud. Rapport sur le budget général de l'exercice I9I2. (Budget annexe des chemins de fer de l'État. Ch., J. O., Doc. parlem., no 1257.) - Dominguez. De la situation matérielle et ale la condition juridique des employés des chemins de fer du réseau de l'État. Thèse, Rennes, 1907. Imprimerie des Arts et Manufactures.

(3) Le personnel pour le service de lexploitation était au 31 octobre 1911 de 24.904 personnes au total, se décomposant ainsi : agents commissionnés, 22.744; auxiliaires supplémentaires, 2.160. Déclaration de M. Augagneur à la tribune de la Chambre des députés, à la denxième séance du 8 décembre igr. J. O., Ch., Déb. Darlem., p. 3764. Il est au total (chiffres insérés dans l'annexe du projet de budget pour 1912), au 30 juin 1911 , de 69.347 agrents. 
ment (I) réglés par l'ordre général $n^{0} 325$ approuvé par décret du 22 janvier i 9 Io (2).

Voici d'après ce décret ĺes chiffres pour les quatre derniers groupes (XI à XIV) comprenant le personnel plus exclusivement ouvrier.

Les chefs de station, électriciens, facteurs chefs, souschefs de gare, sous-chefs d'équipe technique, surveillants techniques, formant le groupe XI, gagnent de r.50o à 3.000 francs, selon la classe à laquelle ils appartiennent.

Les brigadiers de bureau, chauffeurs, chefs de pose, chefs d'équipe (mouvement, magasins et nettoyage du matériel), chefs de halte, chefs de train, commis d'ordre, élèves wattmen, facteurs enregistrants et visiteurs (groupe XII), gagnent de r.35o à 2.400 francs, selon la classe à laquelle ils appartiennent.

Les aides-électriciens, aiguilleurs, brigadiers de la voie, camionneurs, distributeurs, facteurs, gardes-freins, gardiens de bureau, sous-chefs d'équipe (mouvement, magasins et nettoyage du matériel), formant le groupe XIII, gagnent de I.200 à 2.100 francs, selon l'une des sept classes où ils sont arrivés.

Les facteurs-gardes, garçons de magasin, gardes de la voie, hommes d'équipe, poseurs, touchent de 1.050 à $1.400 \mathrm{fr}$., selon leur classe (groupe XIV).

Enfin, en ce qui concerne les femmes, les employées principales sont payées de 1.800 à 3.600 francs, selon les classes, et les employées de 1.200 à 2.200 francs, également selon leur classe (3).

Lors du vote du budget de i 9 I , les Chambres ont fixé un minimum de 1.200 francs comme traitement de début;

(1) Depuis longtemps la question a été reprise à propos de chaque discussion du budget des chemins de fer de l'État : notamment pour le budget de igo9. Le 21 novembre igo8, la Chambre, sur la proposition de M. Roch, avait voté la résolution suivante : La Chambre, confiante dans la sollicitude du Gouvernement pour les agents des chemins de fer de l'État, l'invite à inserire au budget du futur exercice un crédit destiné à relever les salaires des eatégories du personnel les moins rétribuées du réseau. »

(2) Cf. Pćrissoud. Budget des chemins de fer de l’État, I912. J. O., Ch., $\mathrm{n}^{\circ}{ }_{1257}$, (Annexes), p. 3. Ce régime a été déclaré exécutoire à partir

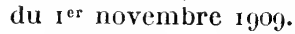

(3) Diverses indemnités de résidence, variant pour les groupes envisagés au texte de 350 à 450 francs au maximum, peuvent être accordées. 
c'est une amélioration sensible pour les employés du groupe XIV, sans être encore un véritable minimum de salaire.

L'application de cette dernière mesure, par les charges financières qu'elle entraìnait (I), n'a pu encore être intégralement appliquée : ce qui a donné lieu à quelques réclamations du personnel (2).

Lors de la même discussion, le salaire minimum de $5 \mathrm{fr}$. par jour avait été demandé par MM. Roch et Colly pour les cheminots (3). M. Berteaux, alors président de la commission du budget, avait insisté sur la nécessité de tenir une promesse antérieure, malgré l'imprudence financière qu'elle comportait (4).

On marche progressivement vers cette solution (5). La réforme est appliquée intégralement pour tout agent ou débutant à Paris à partir du I ${ }^{\text {er }}$ octobre I $_{9}$ I : il touche un salaire de I.200 francs plus une indemnité de résidence aujourd'hui portée à 600 francs.

On peut ainsi affirmer que s'il n'est pas encore partout généralisé à cause des difficultés financières (6), le minimum de salaire sera demain une réalité pour le personnel des chemins de fer de l'État (7).

Le personnel civil des établissements de la Guerre (8) est particulièrement nombreux (9). On se contente pour l'ins-

(r) Plus de 34 millions de francs.

(2) Gf. Périssoud. Rapport cité, p. 46, et Ch., Déb. parlem., I re séance du 8 décembre ı9i,$J . O .$, p. 3373 .

(3) Ch., Déb. parlem., Ire séance du 7 juin r9ı1, p. 532.

(4) Ibia., Ch., Déb. parlem., p. 536.

(5) C. Discussion à la Chambre du budget de r9i2, Iro séance du 8 décembre igir, J.O., p. 3373 .

(6) Le réseau de l'État a dépensé pour le personnel, en I909, 40 fr. 45 par 100 francs de recettes, alors que les autres Compagnies dépensaient 29 fr. 55. Cf. Périssoud. Rap. cité, p. 56.

(7) Un conseil de réseau, prévu par les articles 56 et suivants de la loi de finances du 13 juillet $19 \mathrm{I}$, est appelé aujourd'hui à donner son avis sur toutes les modifications de traitement proposées. (Cf. art. 58, I $2^{\circ}$.)

(8) G. Maurette. De la condition du personnel civil des établissements de la Guerre. Thèse, Toulouse, I9I I.

(9) Sans parler des ouvriers des poudres et salpêtres (ci-dessus, p. 227), 
tant de pratiquer la règle que le salaire des ouvriers des deux sexes dans les divers établissements doit être au moins égal au salaire normal et courant des professions similaires de l'industrie privée (I).

On évalue pour 1910 à 4 fr. 75 pour les ouvriers et à $2 \mathrm{fr}$. 50 pour les ouvrières le salaire moyen dans les établissements de la Guerre (2).

Ce personnel est d'ailleurs groupé en la Fédération nationale des ouvriers civils et ouvrières des magasins administratifs de la Guerre qui, dans une série de congrès de igo2 à I912, à maintes reprises a posé formellement la revendication d'un salaire minimum.

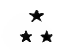

Les ouvriers des arsenaux (3) de la Marine (4) jouissent également d'un salaire minimum, cependant en moins directe relation avec le prix de la vie que celui des ouvriers des tabacs et allumettes ou celui des ouvriers de la Guerre.

Le taux des salaires des ouvriers des arsenaux et établissements de la Marine a été, dans ces dernières années, l'objet de

ce personnel, alu ${ }^{\text {er }}$ janvier ${ }^{1909}$, comprenait ${ }_{17.522}$ salariés, ainsi réflartis :

Musée de l'armée, 21; service géographique, 62; fourrages, 127; vivres, 133 ; écoles militaires, 139 ; génie, 178 ; habillement et campement, 884; artillerie, 15.695 .

(1) Circulaire, 29 avril et 8 novembre 1903, vol. LXV, pp. 267 et 358.

(2) Maurette, op. cil., p. 168.

(3) Il s'agit des ouvriers des arsenaux, e'est-à-dire de l'ensemble des ateliers, magasins, bassins, ete., dépendant de nos einq grands ports de guerre : Cherbourg et Toulon (armements et réparations), Brest, Lorient, Rochefort (constructions neuves) et des établissements hors port de la Chaussade (Guérigny) et de Ruelle, ainsi que de l'usine d'Indret (fabrication des plaques de blindage et des obus). Cif. J. RoyerCollard. Les ouvriers des arsenaux. Thèse, Dijon, rgor. Paris, Larose.

(4) L. Ribeyrol. De la condition économique et juridique du personnel oluvier des arsenaux et établissements hors ports de la Marine. Thèse, Paris, 1909, Jouve. - P. Painlevé. Rapport sur le budget général de l'exercice 1912 (Ministère de la Marine). J. O., Ch., Doc. parlem., r911, $n^{\circ}$ 1244, p. 1459 .

Les conditions du travail dans les arsenaux et autres établissements de la Marine et dans les établissements similaires de l'industrie privée. Bulletin de l'Office du travail, 1910, p. 252. 
nombreuses modifications qui l'ont fait évoluer dans le sens de la réforme étudiće : il importe d'y insister brièvement.

Le décret du r 2 janvier I 892 assignait pour chaque catégorie d'ouvriers un taux de salaire compris entre deux limites, I'une inférieure (I), l'autre supérieure :

Les chefs ouvriers gagnaient par jour (2) de $4 \mathrm{fr} .20$ dे $5 \mathrm{fr} .40$.

Les ouvriers permanents gagnaient par jour de 2 francs à 4 fr. 70.

Les ouvriers temporaires gagnaient par jour de 2 francs à $4 \mathrm{fr} .70$.

Les chefs journaliers gagnaient par jour de $2 \mathrm{fr}$. 5o à 3 fr. 50 .

Les journaliers permanents gagnaient par jour de i fr. 80 à 2 fr. 90 .

Les journaliers temporaires gagnaient par jour de I fr. 80 à 2 fr. 90 .

Les apprentis gagnaient par jour de o fr. 60 à 1 fr. 50 .

La loi de finances de 1897 releva les limites inférieures de quelques-unes de ces catégories de travailleurs; on se rapprochait d'un véritable salaire minimum : 2 fr. 30 pour les ouvriers, 3 fr. 9 o pour les chefs journaliers, $3 \mathrm{fr}$. 30 pour les journaliers.

Dans ces limites, l'Administration restait souverainement maìtresse du taux du salaire de chacun (3). Des plaintes des ouvriers amenèrent une réglementation nouvelle contenue dans le décret du 2 juin Igoo; celui-ci pose le principe d'un salaire fixe à la journée augmenté pour quelques ouvriers de primes à l'ancienneté ou à la capacité (4); c'était prati-

(1) La limite inférieure, comme on le voit par les chiffres donnés au texte, n'était pas à proprement parler, dans tous les cas, un salaire minimum vital, c'est-à-dire suffisant pour vivre. C'était toutefois le principe d'une fixation du salaire au-dessus d'un certain niveau.

(2) Le salaire au temps est, en elfet, dans la marine, la règle; le salaire à la tàche, l'exception.

(3) Les ouvriers se plaignirent alors que cette réglementation trop vague laissât libre cours aux pratiques d'arbitraire et de favoritisme.

(4) Les deux pour les ouvriers permanents, la dernière seulement pour les ouvriers stagiaires. 
quement des salaires minima qui étaient ainsi établis (r), grâce à cette élévation des salaires. Seuls les apprentis et les ouvriers temporaires ne profitèrent pas de la réforme (2).

De nouvelles modifications eurent lieu par le décret du I 2 avril I $9^{02}(3)$ : le salaire fixe minimum des ouvriers permanents (groupe B, ${ }^{\text {re }}$ catégorie, $2^{\mathrm{e}}$ classe, et $2^{\mathrm{\theta}}$ catégorie, $2^{\mathrm{e}}$ classe) était porté de 2 fr. 50 à 3 francs; celui des ouvriers stagiaires (groupe $\mathrm{C}, 2^{\mathrm{e}}$ catégorie, une classe) (4) de 2 fr. 30 à 2 fr. 50 .

Les années I903 et I904 profitèrent d'augmentations de crédit qui accrurent les salaires sous forme de modifications au système des primes. De même en 1905 des modifications de détail furent opérées sans toucher à l'immeuble. En r9o6, il n'y eut aucune augmentation de crédits.

Enfin, un décret du i 3 juin ı 907, resté la base de la tarification actuelle, est venu remanier encore, pour les augmenter, l'échelle des salaires. Voici les salaires fixes, véritables

(I) Voici le tableau complet de ces salaires incorporés à l'article rer du décret du 2 octobre 1900 , qui les établissait :

\begin{tabular}{|c|c|c|}
\hline $\begin{array}{l}\text { Désignation et composition } \\
\text { des catégories et des classes. }\end{array}$ & $\begin{array}{l}\text { Salaires } \\
\text { fixes. }\end{array}$ & $\begin{array}{l}\text { Total maximum des } \\
\text { primes (ancienneté } \\
\text { et capacité). }\end{array}$ \\
\hline
\end{tabular}

Groupe A. - Chefs ouvriers.

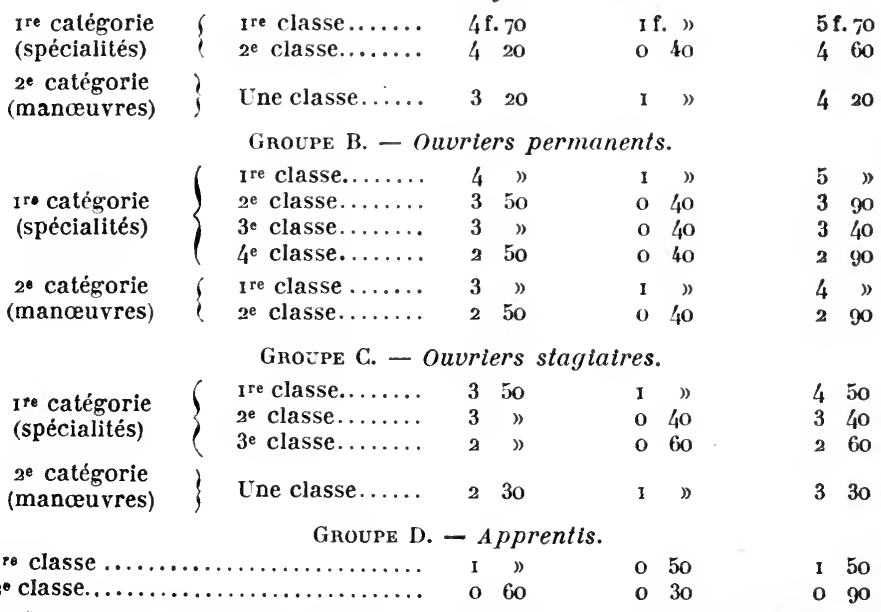

(Ce tableau est extrait de l'op. cit. de Ribeyrol, p. 139; pour la formation de chaque groupe, cf. ibid., p. I41).

(2) On les avait dédommagés par l'amélioration des conditions d'avancement.

(3) Cf. tableau. Ibid. Ribeyrol, p. 143.

(4) Se reporter au tableau en note ci-dessus. 
minima (I), qu'il établit pour chaque catégorie d'ouvriers (2):

Groupe A. - Ouvriers de spécialités.

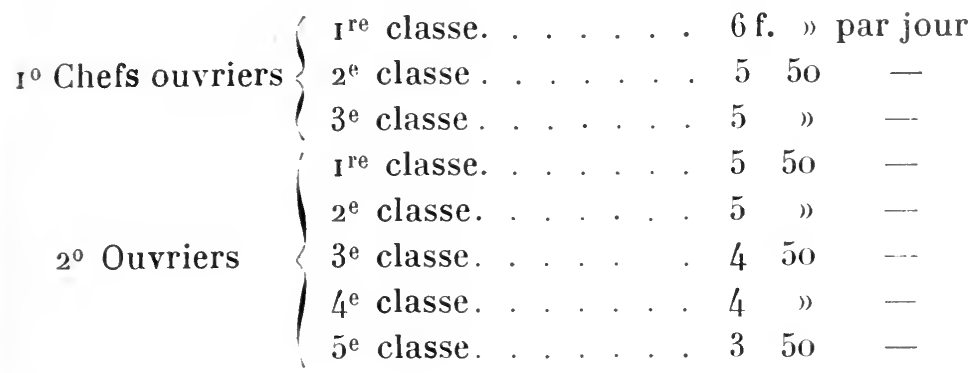

Groupe B. - Ouvriers manœuvres.

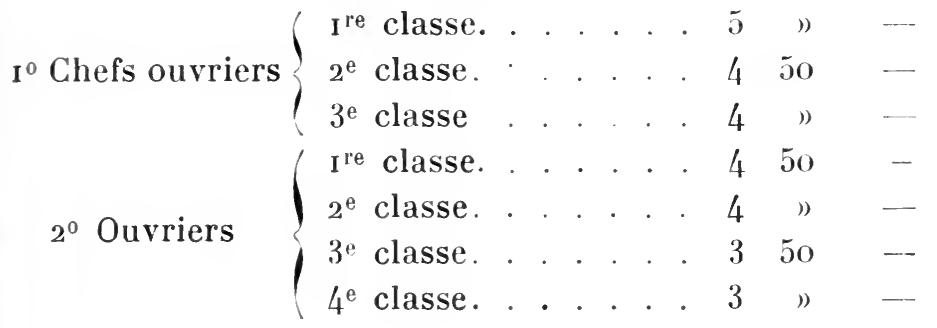

Groupe C. - Aides-ouvriers.

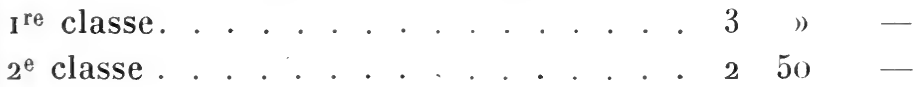

Groupe D. - Apprentis.

$\mathrm{I}^{\mathrm{re}}$ classe. . . . . . . . . . I 50

$2^{\mathrm{e}}$ classe . . . . . . . . . . . . I I 1 -

$3^{\mathrm{e}}$ classe . . . . . . . . . . . . 0 o $60-(3)$

Les salaires du personnel rentrent aujourd'hui dans la

(1) Au-dessus des minima, il est établi dans charque port ou établis" sement une échelle des salaires : elle est préparíe par une commission mixte après enquète, approuvée par le préfet maritime ou le directeur de l'établissement.

(2) L'article 5 du décret pose le principe que " tout le personnel d'une même classe touche un salaire uniforme, payé à la journée et exclusif de toute augmentation permanent(: ).

(3) Ce lableau est extrait da l'op. cit. de Ribeyrol, p. 146.

Cf. Bulletin de l'offlce du travail, 19 to (p). rit., p. 256. 
compétence de la Commission mixte consultative (I) instituée le 20 aoùt igog.

Il est possible que cette représentation professionnelle accentue le mouvement en faveur du minimum de salaire : le principe est posé, mais l'application en est parfois défectueuse (2).

Une série de mesures transitoires dont l'effet s'achève en ce moment (I9I2) a permis d'uniformiser les salaires par classe $(3)$.

Un décret tout récent du I 2 mars I9I2 (4) portant réorganisation du persomnel ouvrier immatriculé des arsenaux et établissements de la Marine contient un article 2 relatif aux salaires ainsi conçu :

Art. 2. - r. Tout le personnel d'une mème classe reçoit un salaire uniforme payé à la journée.

2. Le salaire est fixé comme suit (5):

$$
\text { Groupe A.- Spécialités. }
$$

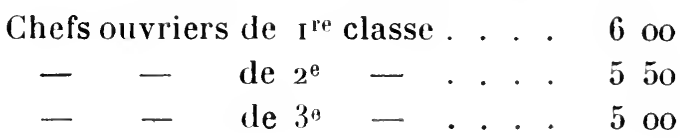

(I) Voici sa composition :

Le sous-seerétaire d’État de la Marine, président;

14 représentants de l'Administration de la Narine ( 10 de l'Administration centrale et 4 pris dans le personnel des ports);

Io représentants élus du personnel ouvrier, savoir : 1 délégué des chefs ouvriers; 4 délégués des ouvriers des spécialités des constructions navales; 1 délégué des ouvriers des spécialités des autres services (artillerie, flotte, etc.); 2 délég'ués des ouvriers-manœuvres et aidesouvriers pour l'ensemble des services; I délégué des ouvriers aux écritures et ouvriers dessinateurs; I délégué des ouvriers et ouvrières en régie (pour l'ensenble des services).

Elle a d'ailleurs un ròle purement consultatif à l'égard des salaires et les autres questions concernant l'organisation du travail et le fonctionnement industriel.

(2) Cf. tableau des salaires moyens par port ou établissement en 1908 . Bulletin de l'Office du travail, rgio, p. 256. Par exemple, le salaire moyen des ouvriers des spécialités pour les cinq classes était de 3 fr. 94 à Cherbourg, 3 fr. 87 à Brest, 3 fr. 82 à Lorient, etc. Nous croyons inutile de reproduire ici tout ce tableau, qui ne donne pas les salaires réels payés aux ouvriers de chaque spécialité.

(3) Pour les détails, cf. Ribeyrol, op. cit., p. 147.

(4) J. O. du 15 mai i912, p. 4465. Cf. Bulletin de l'Office du travail, 1912, p. 611 .

(5) Pour une durée effective de travail de huit heures par jour ou de quarante-huit heures par semaine, $2^{\mathrm{e}}$ décret du 12 mai rg12. (Ibid. J.O., 15 mai 1912, p. 4465.) 
Chefs ouvriers de $4^{\mathrm{e}}$ classe . . . 450

Ouvriers de $\mathrm{r}^{\mathrm{re}}$ classe. . . . . 550

- de $2^{\mathrm{e}}-\ldots . .500$

- de $3^{\mathrm{e}}-$. . . . 450

- de $4^{\mathrm{e}}$ - . . . . 400

Aides-ouvriers de I $^{\text {re }}$ classe. . . 3 oo

- $\mathrm{de}^{\mathrm{e}}-\ldots .250$

Apprentis de $\mathrm{I}^{\mathrm{re}}$ classe.... . 200

- $\mathrm{de}^{\mathrm{e}}-\ldots . . .150$

- de $3^{\mathrm{e}}-\ldots . . \quad$. $\quad$ oo

- de $4^{\mathrm{e}}$ - . . . . 060

Groupe B. - Manœuvres.

(A titre transitoire)

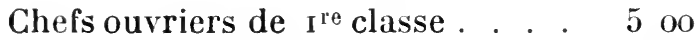

- $\quad$ de $2^{\mathrm{e}}$ - ... 450

- - de $3^{\mathrm{e}}$ - . . 400

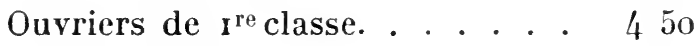

- de $2^{\mathrm{e}}$ - .... 400

Un second décret du 18 mai r 9 I2 (I) relatif au statut des ouvriers et ouvrières auxiliaires embauchés dans les arsenaux et établissements de la Marine contient l'article 6 suivant, relatif à la détermination des salaires :

“ I. Le salaire des ouvriers et ouvrières auxiliaires est déterminé d'après le taux normal et courant des salaires dans la région pour les industries similaires et, à défaut d'industries similaires, en tenant compte des conditions locales de cherté de la vie (2).

2. Dans chaque port ou établissement, il est établi, pour chaque profession, une échelle des salaires journaliers fixant le salaire minimum et le salaire le plus élevé auquel puissent prétendre les ouvriers et ouvrières pour la profession dans laquelle ils sont employés.

3 . Le salaire d'admission des ouvriers et ouvrières auxiliaires est fixé par le directeur, sur la proposition de la Com-

(r) J. O. du 2 r mai rgr2, p. 4632. Bullelin de l'office du lravail, r912, p. 612 .

(2) On remarquera combien ce texte est une affirmation nette du minimum de salaire. 
mission d'admission qui apprécie la valeur professionnelle du candidat après l'essai prévu à l'article 2 ci-dessus. Il est revisé à l'expiration du stage de six mois, au moment de l'admission dans le cadre du personnel auxiliaire.

4. La composition de la Commission d'admission est réglée par voie d'arrèté ministériel. "

On a beaucoup discuté sur les résultats du salaire minimum au temps sur la production : on regrettait notamment la suppression complète du salaire à la tâche votée à la Chambre le 2 I février igo2 et appliquée par M. Pelletan (I). Le nombre des torpilles fabriquées à Toulon était tombé de

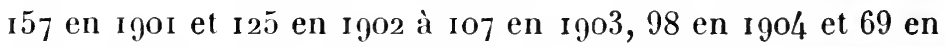
Igo5. D’une manière générale, l'avancement fonctionnant d'une façon automatique, l'augmentation régulière des salaires amenèrent un désintéressement regrettable des ouvriers à l'égard du rendement du travail.

Divers systèmes ont été proposés pour remédier à cet inconvénient grave.

Il faut mentionner surtout le système de M. Laubœuf, ancien ingénieur en chef des constructions navales de la marine de l'État (2); le principe de ce système est dérivé de celui des primes horaires: il consiste essentiellement à évaluer les bénéfices dus à l'augmentation de production, par rapport à un temps alloué avant de commencer le travail, ou temps étalon; ces bénéfices seraient partagés entre l'État et l'ouvrier selon une proportion fixée d'avance. Ce système se

(1) En 1906, sur les instances du Sénat, le Ministre de la Marine prit des engagements formels de rétablir le travail à la tàche. En conformité à ses engagements, une circulaire du 27 juin 1906 vint superposer au système en vigueur un système de primes à la production. C. Ribeyrol, p. 152. L'expérience fut faite d'abord par le port de Toulon pour les torpilles (I ${ }^{\text {er }}$ aoùt Igof) et généralisée ensuite (Dépêche du II oct. 1go3) sur tous ces points. Cf. Cuvinot, rapport sur le budget de la marine, Igo6, Sénat, J. O., Doc. parlem.

L'article 25 du décret 13 juin 1907 est ainsi conçu :

"Les agents du personnel ouvrier payés à la journée pourront recevoir des primes à la production, déterminées par des tarifs spéciaux approuvés par le Ministre et résultant du travail exécuté par eux. Ils pourront également, mais seulement de leur plein gré, être payés aux pièces, suivant des tarifs approuvés par le Ministre. "

(2) Revue maritime et fluviale : io septembre et 25 octobre 1907.

(3) Ce système est connu sous le nom de système Halsey : il a été pratiqué dans la marine française de 18 I à Ig02 et l'est encore aujourd'hui dans la marine anglaise. 
combine d'ailleurs avec des salaires minima assurés à l'ou$\operatorname{vrier}(\mathbf{I})$.

Il est indispensable, si l'on veut maintenir les salaires minima acquis, de les combiner avec une réforme permettant d'assurer la productivité de l'arsenal (2).

Les derniers décrets (3), notamment celui du 18 mai r9 I 2 relatif aux ouvriers et ouvrières auxiliaires, semblent apporter un commencement de solution en ce sens (4).

Le personnel de la manufacture des Gobelins (5) est, au contraire, dans une situation assez précaire : les traitements de début sont de 1.200 francs, avec un maximum de 3.600 francs, sans préjudice de faibles primes de travail.

Voici, d'après les tableaux de la statistique générale de la France (6), un aperçu des salaires en 19 I . Salaires annuels :

Chef des ateliers, 4.500 à 6.000 francs; sous-chefs, 3.600 à 4.500 francs; artistes tapissiers, 1.200 à 3.600 francs; souschef teinturier, 3,600 à 4.000 francs; teinturiers, r.600 à 3.600 francs; préparateurs, r.200 à 2.400 francs; gagistes, I.200 à $\mathrm{I} .800$ francs, etc.

'Il en est de même dans la manufacture de Beauvais (7), où le minimum de salaire ne paraît pas exister pour la majorité des travailleurs :

Chef des ateliers, 4.000 francs; sous-chefs, 3.300 francs; dessinateurs, 3.200 francs; employés de magasin, 2.600 francs ; artistes ouvriers ou artistes tapissiers, 2.600 francs ; ćlèves,

(1) 3 fr. 50 par jour, par exemple, pour un ouvrier de spécialité avec les tarifs actuels.

(2) Ceei confirme une fois de plus notre idée fondamentale que le salaire minimum n'est possible qu'avec un eertain travail ou une certaine quantité de produits assurés.

(3) G. ci-dessus, p. 247 .

(4) Art. 7 du décret du 18 mars 1912 (auxiliaires). - "Pour tous les travaux qui s'y prêtent, les ouvriers peuvent être rémunérés aux primes ou aux pièces, d'après des tarifs spéciaux approuvés par le Ministre. "

Art. 8. - "Les ouvriers et ouvrières auxiliaires peuvent recevoir des avancements sous forme de primes de ro centimes dans des conditfors à déterminer par un arrêté ministériel. "

(5) Cf. rapport de M. Simyan pour le budget général de I9I2 (Service des Beaux-Arts). Ch., Doc. parlem., I906, no 1247.

(6) J. O. du 3o septembre 1911 , annexe, p. 1520.

(7) Ibld. J. O., 1911, annexe, p. 1521. 
I. I00 francs; couseuses, 2.200 francs; hommes de service, I. 400 francs.

\section{$\star \star$}

Pareillement à Sèvres (I), les traitements de la Manufacture nationale sont loin de comporter de véritables minima. En voici un aperçu sommaire pour rgI. Traitements annuels :

Chef des ateliers de fabrication, 7.000 francs ; surveillant de fabrication, 2.496 francs; sculpteurs, 1.800 à 2.840 francs ; décorateurs, mouleurs, répareurs, I.440 à 5.000 francs; aide de laboratoire et cuiseur de mouffles, 1.440 à 3.600 francs; tourneurs, 1.440 à 4.200 francs; chef ouvrier, couleur de moules, 3.000 francs; ouvriers couleurs de moules, I.440 à 3.000 francs ; tourneurs d'étuis, 1.440 à 2.600 francs ; émailleurs, 1.440 à 2.600 francs; briquetiers fumistes, r.800 à 2.700 francs; mécanicien, 2.496 francs; batteurs de pâtes, I.440 à I.80o francs; polisseurs, 1.440 à 2.100 francs; chefs ouvriers des fours et des moules, 1.800 à 2.700 francs; aides d'ateliers, 1.440 à I.800 francs; émailleurs et découpeurs, 840 à r.50o francs; dessinateurs d'épures, 2.700 francs; fileurs, doreurs, I. 140 à 2.600 francs; poseurs de fonds, 1.440 à 2.600 francs; imprimeurs, $1.4 / 40$ à 2.600 francs; monteurs et ciseleurs, I.440 à 3.000 francs; chefs ouvriers décalqueurs, 1.400 francs; ourrières décalqueuses et brunisseuses, 840 à r.500 francs; aides d'ateliers, 1.560 à r.800 francs; dame dactylographe, r.872 francs, etc., etc...

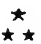

Les oluviers de l'Imprimerie nationale (2) jouissent eux, pour la plupart (3), en fait, d'un salaire minimum : le sys-

(1) Ibid., J. O., ıяг. Annexe. Rapport cité, p. i520. Fixation au 25 mars igio.

(2) Cf. de Ramel. Rapport sur le budget annexe de l'Imprimerie nationale, 191. J. O., Ch., Doc. parlem., n ${ }^{\circ}$ 1234, p. 1135. Les compositeurs sont au nombre de 308. (De Ramel, op. cit., p. i 38. .)

(3) Le personnel de l'Imprimerie nationale se décomposait ainsi en octobre 1909 :

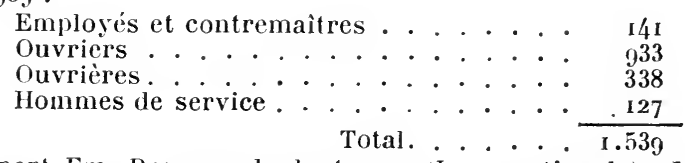

Ex. rapport Em. Brousse, budget 19 Io (Imp. nationale). J. O., Ch., Doc. parlem., n' 2747 , p. I626. 
tème de travail pour les compositeurs est double, la commandite égalitaire d'une part, le travail individualiste à la tiiche de l'autre (I).

Les ouvriers en commandite égalitaire (2) arrivent à se faire en moyenne environ i f francs par jour pour une journée de travail qui est en moyenne de huit heures et demie.

Ce système, en usage depuis Igoo, fonctionne à la satisfaction générale (3); il parait avoir la préférence des ouvriers dans la force de l'àge (4). On en demande mème la généralisation complète (5).

Les ouvriers individualistes se plaignent d'être moins bien traités. Leurs salaires moyens sont inférieurs aux salaires des commanditaires.

Ils demandent une répartition égale des travaux entre les deux systemes, par la Direction, sans distinction particulière.

Au total et sans qu'il y ait aucun texte sur ce point, les ouvriers de l'Imprimerie nationale jouissent en fait d'un salaire minimum.

Voici, toujours d'après la mème source, le rapport de la statistique générale de la France sur les tableaux de traitements, les minima de traitement du personnel ouvrier (6) :

(I) A peu près réparti également quant au nombre des ouvriers. Au I $^{\text {er janvier }} 19 \mathrm{l}$, parmi les compositeur's, 153 travaillaient en commandite, 155 étaient individualistes.

(2) On sait que la commandite égalitaire est le salaire à la tàche collectif pour tous les membres du groupe : ce salaire global se partage ensuite également entre ceux-ei, de façon que chacun touche la mème somme par heure de travail. Elle s'oppose à la commandite au prorata, où le salaire se divise, au contraire, proportionnellement à la tàche de chacun (somme des lettres levées en un temps donné).

(3) L'Inıprimerie nationale jouit d'ailleurs d'une dotation spéciale, e'est-à-dire de certains travaux qui lui sont exclusivement réservés : le Bulletin des lois, le Bulletin des brevets d'invention, le Catalogue de la Bibliothèque nationale.

(4) Les anciens ouvriers ayant plus de vingt ans de service n'y figurent que dans la proportion de 9 contre 61 au travail individualiste: au contraire, pour les ouvriers ayant moins de vingt ans de service, on compte 142 commanditaires contre $9 / 4$ individualistes. Gr. de Ramel, rapport cité, p. ir 38 .

(5) Actuellement, certaines elauses des statuts de la commandite égalitaire pratiquée à l'Imprimerie nationale en restreignent l'application : il faut : $1^{\circ}$ être ouvrier syndiqué (art. $1^{\mathrm{er}}$ ); $2^{\circ}$ aceepter que la commandite s'inscrive collectivement et percoive obligatoirement les cotisations syndicales, les souscriptions de grève, etc. (art. 3.)

(6) Ibid., rapport. Statistique générale de la lrance. J. O., I911, p. I50 I. 
Chefs de service, 6.0oo francs; sous-chefs de service, 5.000 francs; correcteurs, 3.500 francs; prote principal, 4.800 francs; sous-protes, 3.600 francs; commis principaux, 3.600 francs; commis comptables, 2.300 francs; commis expéditionnaires, 2.000 francs; préposés à la livraison, aux achats et objets divers, garçons de caisse, 2.000 francs; concierges et garçons de bureau, r.80o francs, etc...

Tout récemment ( $\mathrm{I}$ ), à la suite d'une réorganisation de l'Imprimerie nationale, effectuée par un décret du 26 juin I 9 I I, le personnel ouvrier de l'Imprimerie nationale a estimé que cette réorganisation se faisait "au détriment des salaires et proposé la régie ouvrière comportant l'autonomie de chaque service $)$.

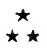

Ainsi le minimum de salaire tend à se généraliser pour les ouvriers et employés de l'État.

Il faut mentionner une récente proposition (2) déposée à la Chambre, le 30 novembre igr I, ayant pour objet d'assurer un minimum de salaire au personnel secondaire et aux ouvriers et ouvrières des administrations de l'État; elle comporte un article unique ainsi conçu :

(1) Temps, \& mars I912. Le personnel, réuni en assemblée à la Bourse du travail, le 3 mars 1912 , a voté un ordre du jour dont voici les passages essentiels :

"Considérant que le régime administratif depuis de longues années n'a pu exploiter industriellement l'Imprimerie nationale, que les attaques dont notre établissement est l'objet devant le Parlement et dans la presse sont justifiées par l'inorganisation des services et par le gàchis résultant fatalement de l'ineompétence des chefs, qu'un préjudice grave est porté à l'État, aux ouvriers et aux contribuables par le discrédit jeté sur l'établissement, et que l'énormité des frais généraux est la seule explication de l'augmentation du prix de revient, décide de substituer au régime administratif un régime organique de régie ouvrière, de remplacer les fonctionnaires incapables et désintéressés par des producteurs responsables et intéressés, de créer un organisme central, coordonnant tous les rouages et donnant à la régie une gestion exclusivement ouvrière, de porter à la connaissance du Ministre des Finances et des pouvoirs publies ledit projet de régie et de faire les démarches utiles pour le faire adopter. ")

(2) Proposition de AI. Aubriot et de plusieurs députés socialistes. J. O., Ch., Doc. parlem., Annexe $\left.n^{\circ}{ }_{1} 396,1\right) .287$. Renvoyée à la Commission du travail. Le minimum de salaire serait de 1.835 francs pour le personnel habitant Paris et la Seine, et varierait par.régions. (Exposé des motifs, loc. cit.) 
"A partir du rer janvier ı912, il sera établi un minimum de salaire de début pour les employés du personnel secondaire et des ouvriers et ouvrières des administrations de l'État. Ce salaire sera calculé, par région, sur les prix de série des entreprises privées ou sur les prix imposés par les décrets du ro aoùt r 899 aux concessionnaires des services publics placés sous le contrôle de l'État. ")

En l'état actuel des choses, il est loin encore d'être la règle générale. 


\section{II. - LAATION DES DÉPARTEMENTS}

Il suffira de mentionner ici pour mémoire cette action des départements : rares ( $I$ ) sont en effet, aujourd'hui, en France, les ouvriers et employés directement au service du département. Une étude détaillée des budgets départementaux montrerait sans doute un mouvement analogue à celui précédemment étudié pour l'État et à celui qui va suivre concernant les municipalités.

(1) Sans parier des fonctionnaires départementaux proprement dits (archivistes, etc.), il s'agit surtout ici du personnel employé dans certains hospices, asiles, etc., et autres institutions appartenant au Département.

Il s'agit aussi de quelques expériences locales encore à leurs débuts : ainsi le département de la Còte-d'Or exploite ses tramways en régie

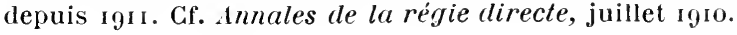




\section{IIl. - L'ACTION DES MUNICIPALITÉS}

D’abord un mouvement tout récent se dessine en France en faveur de l'introduction du minimum de salaires pour les employés de mairie (I).

Ceux-ci comprennent les agents de la police municipale, les agents du service des travaux, les employés d'octroi, les concierges (cimetière, mairie, etc...), les secrétaires et employés de mairie.

Tous ces travailleurs municipaux sont loin, en règle générale, à l'heure présente, de jouir d'un traitement suffisant.

Une Commission extra-parlementaire, nommée le 23 mai r9o6 (2), clôtura ses travaux par une décision spéciale sur les traitements:

" Un tarif des traitements minima à allouer aux secrétaires et employés de mairie sera établi, en prenant pour base le chiffre de la population de chaque commune, par les soins du Ministre de l'Intérieur, qui le portera à la connaissance des préfets. Ceux-ci inviteront les Conseils municipaux à relever les traitements qui seraient inférieurs audit tarif. ")

On compte, pour hâter la réforme, sur deux facteurs farorables :

C'est, d'une part, le concours de l'État et du Département pour payer les employés de mairie occupés à des services les concernant (3);

(1) J. Delaroue. Les employés de mairie. Étude sur le contrat de travail. Thèse. Paris, igr r, Brodard.

(2) Nommée par le Ministre de l'Intérieur et chargée d'étudier les modifications à apporter à l'article 88 de la loi du 5 avril r884, en ce qui concerne les secrétaires et employés de mairie, et toutes les mesures susceptibles d'améliorer leur situation matérielle et morale.

(3) On lit dans la Tribune des Instituteur's de Seine-et-híarne, mars I9 I : "Qu'à notre traitements contribuent les trois facteurs suivants : la Commune, le Département, l'État; la première pour un denii, chacun des deux autres pour un quart. "

Quelques progrès ont été faits en ce sens : les départements donnent déjà une rétribution aux secrétaires de mairic pour le travail qui concerne la protection du premier àge. La loi du 5 avril 1910 prévoit une somme minime de einq centimes par assuré pour le secrétaire de mairie qui dresse la liste des assurés.

Enfin la Commission extra-parlementaire précitée a voté la résolution 
C'est, d'autre part, en ce qui concerne les instituteurs, la possibilité de subordonner l'autorisation d'emploi accordée à l'octroi d'un salaire minimum. On demande, en ce sens, " qu'un tarif minimum soit fixé par le Conseil départemental, pour toute autorisation donnée à un instituteur d'exercer le secrétariat de mairie » ( $\mathrm{I}$ ).

La question a d'ailleurs été également étudiée dans les divers congrès des maires de France (2), qui se prononcèrent en faveur de l'établissement d'un statut des employés municipaux (3).

Le Congrès de 1908 a voté un projet de règlement municipal du contrat de travail, où on lit l'article 9 suivant (4):

"Les traitements minima et les augmentations de salaire seront déterminés par les délibérations du Conseil municipal, toujours susceptibles d'être modifiées, sans que pourtant un employé puisse jamais avoir, l'année suivante, un traitement moindre que celui de l'année précédente. "

Depuis longtemps aussi les intéressés eux-mêmes ont insisté en faveur de la réforme.

Dès i 9o5, le Congrès national des secrétaires et employés de mairie a émis le vœu suivant :

" Qu'il soit dressé, pour chaque département et par règlement d'administration publique, un tarif des traitements qui seront dus, à l'avenir, par les communes aux secrétaires et employés de mairie, réserve faite des suppléments facultatifs, et que ce tarif soit gradué d'après la population des communes (5). ")

Cette revendication de " l'Union nationale des employés de mairie ") est reproduite dans une note remise au Minis-

suivante : “ Le Gouvernement et les Conseils généraux sont invités à contribuer pour part à la rétribution des services rendus par les employés de mairie aux Administrations de l'État et du Département. »)

(I) Delaroue, op. cit., p. $19^{2}$.

(2) Delaroue, op. cit., p. 48, notamment au deuxième congrès des maires (10 décembre 1907 ) et au troisième congrès des maires (1908).

(3) Il y eut de nombreuses divergences, quant au mode d'établissement de ce statut, par la loi et uniforme, ou par les Conseils municipaux et infiniment varié. On semble s'ètre arrêté à une solution transactionnelle en rgro: la loi se contenterait d'imposer aux communes l'obligation de faire un statut, un contrat de travail municipal.

(4) Delaroue, op. cit., p. 237.

(5) Cité par Delaroue, op. cit., p. 79 . 
tère de l'Intérieur le I5 mars I9I I ( 1 ); on y lit, en ce qui concerne les traitements :

( Le statut (2) ne règle pas la question des traitements. Actuellement, la plupart des employés communaux, malgré un travail écrasant, gagnent moins que les facteurs ruraux et mènent, eux et leur famille, une existence misérable.

La fixation des traitements étant laissée au bon plaisir des maires, sans qu'aucun minimum ne soit imposé (3), il s'ensuit que quantité de malheureux fonctionnaires communaux sont l'objet d'une exploitation scandaleuse.

L'Union nationale, à qui une enquète officieuse sur les traitements et le prix de la vie dans les diverses régions a révélé des faits navrants, avait demandé au Ministère précédent de faire procéder d'urgence, par les préfets, à une enquête, qui dénoncerait la profondeur lu mal; il allait être procédé à cette enquète quand le Ministère a démissionné. En renouvelant sa demande, l'Union a l'espoir que le Ministère actuel l'ouvrira d'urgence et saura imposer à bref délai à toutes les communes l'obligation de donner des traitements raisonnables à leur personnel. ")

Au total, soit qu'on envisage les dispositions du Gouvernement, l'attitude des maires ou les réclamations de l'Union nationale des employés de mairie, il paraît que la question du minimum de salaire, sans ètre encore mûre, est cependant nettement posée devant l'opinion publique (4).

(I) Rapportée par Delaroue, op. cit., annexe, p. 232.

(2) Il s’agit du projet de statut des fonctionnaires déposé par le Gouvernement le 30 juin igro.

(3) C'est nous qui soulignons.

(4) Voici, à titre d'exemple, le projet de règlement d'administration publique présenté par l'Association amicale des employés de mairie de la Charente-Inférieure, le 3 I octobre i910:

" Art. 7. - Les employés des services administratifs communaux sont divisés en secrétaires généraux, chefs de division, chefs de bureau, rédacteurs et expéditionnaires. "

Les traitements de début de ces divers employés ne pourront, en aucun cas, être inférieurs aux minima déterminés par les tableaux ci-après :

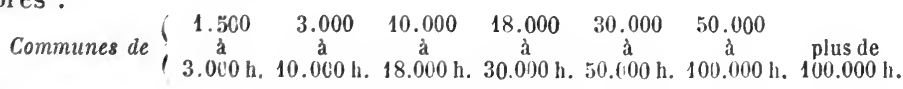

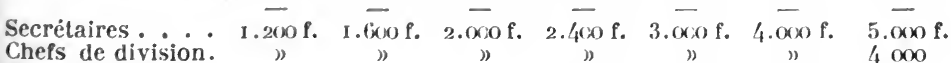

Chefs de division. " " " "

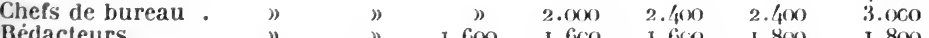

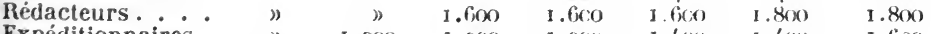

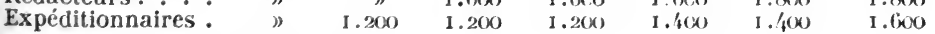

Cf. Delaroue, op. cit., p. 222. 
La Ville de Paris s'est, la première et depuis quelques années, orientée dans le sens de l'octroi d'un minimum de salaire aux ouvriers de ses services municipaux (I).

Ceux-ci sont très nombreux, rr.934, d'après les chiffres donnés au rapport de M. Dausset (2).

Le salaire minimum de 5 francs par jour, pour dix heures de travail, est aujourd'hui, surtout depuis rgog (3), un fait acquis.

Pour bon nombre d'entre eux (ouvriers du bâtiment), ce minimum est atteint et souvent dépassé, grâce à un salaire aux pièces; le salaire mensuel de 26 jours de travail, avec deux jours de repos payés, les met, en face des ouvriers de l'industrie privée, à l'abri du chòmage.

Le principe est à peu près acquis (4); son application semble assez étendue : " les bénéficiaires pour ı 9 Io, écrivait

(I) Les conditions du travail des ouvriers des services municipaux de la ville de Paris. Bulletin de l'offce du travail, 1909, p. 988.

Dausset. Rapport sur le budget général de la ville de Paris pour 19i2, I912, $\mathrm{n}^{\circ} 95$.

(2) Rapport Dausset, loc. cit., p. 362 (le rapport prévoit même le chiffre de 12.132 pour I912).

Voici la répartition par services de ces travailleurs municipaux :

Direction des travaux :

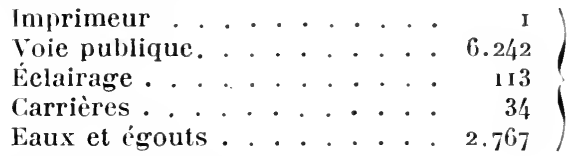

Direction de l'architecture. . . . . . . . . 935

Direction des affaires municipales :

Inhumations .......

Pompes funèbres . . . . .

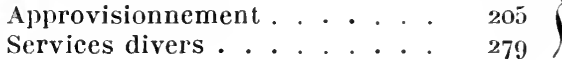

Divers :

Matériel, beaux-arts, imprimerie, octroi,

enseignement. . . . . . . . .

Total général. . . . . $11.9^{34}$

(3) Une délibération du 3i décembre 1909 accordait le minimum de salaire annuel de 1.825 francs à une très grande partie du personnel ouvrier.

(4) " Sur le fond de la question, nous reconnaissons excellent le principe d'un minimum de salaire de 1.825 francs ", disait, en 1909 , M. G. Lemarchand. Rapport au nom de la Commission du personnel. Rapport au Conseil municipal de Paris, Igog, $\mathbf{n}^{\circ}$ 3I, p. 30. Le chiffre de I.825 francs avait été posé par M. Roche, secrétaire général des Travailleurs municipaux. 
en Igog M. Le Marchand (I), seront relativement peu nombreux, puisque l'indemnité personnelle et transitoire des ouvriers en service est souvent supérieure ou égale au nouveau salaire alloué. )

Il résulte des tableaux de salaires publiés que la majorité des ouvriers et travailleurs municipaux dépasse ce minimum (2).

Un travail de consolidation, si l'on peut dire, est en ce moment entrepris pour remplacer les allocations personnelles et transitoires par l'application du principe de 365 jours payés. Cette revendication très importante des syndicats consistant à payer aux ouvriers 365 jours par an, au lieu de 336 jours, qu'ils touchent actuellement pour 3or jours de travail effectif, a été accueillie par le Conseil (3) et la réforme se réalise progressivement (4).

Le personnel des transports concédés est également assimilé au personnel municipal (5).

En ce qui concerne les omnibus, la clause relative aux salaires stipule un minimum de 1.825 francs pour les hommes et de r.277 fr. 50 pour les femmes occupées d'une manière permanente; les employées temporairement reçoivent un salaire de o fr. 35 l'heure $(6)$.

Il faut mentionner aussi la situation très favorable au point de vue du minimum de salaire du personnel du chemin de fer métropolitain de Paris (7).

(I) Rapport complémentaire au nom de la Commission du personnel, $1909, \mathrm{n}^{\circ} 104$, p. 22 . Un crédit de 1.137 .000 francs a été voté le 12 juillet Igog pour améliorer les salaires des ouvriers municipaux des trois directions : travaux, architecture et affaires municipales (Ibid., p. 5).

(2) Rapport complémentaire Lemarchand, I909, n 104, pp. 6 et suiv. - Dausset. Rapport général pour le budget de la ville de Paris IgI2, 1911, $\mathrm{n}^{\circ} 95$, pp. 347 et suiv.

(3) G. Lemarchand. Rapport au nom de la Ciommission du personnel sur l'allocation des journées supplémentaires au personnel ouvrier, en vue de réaliser les 365 jours payés. $1910, \mathrm{n}^{\circ} 77$ bis.

(4) Par contre, pendant une période de cinq années, à partir du I $^{\text {er }}$ janvier I $91 \mathrm{l}$, aucune demande tendant à la revision des échelles des salaires de traitements du personnel technique et ouvrier de tout ordre et de toute catégorie ne sera examinée. Ibid., p. 5.

(5) Sur cette question de l'assimilation, cf. en 1908 le rapport de M. Heppenheimer et la discussion au Conseil municipal de Paris. Les conclusions de ce rapport furent adoptées et l'assimilation votée le I mars igog. Cf. Bulletin municipal offlciel du 3 mars igog, p. I1 85.

(6) Pour une journée de travail de liuit heures et demie.

(7) Marcel Bezançon. Condition du personnel du chemin de fer métropolitain de Paris. Thèse. Paris, ıgog, Rousseau. 
Le projet primitif de cahier des charges donna lieu, en ce qui concerne la clause du minimun de salaire, à de longues et fameuses discussions.

Sur la réclamation du Syndicat national des travailleurs des chemins de fer, en date du 6 mai ${ }_{1} 8_{97}$, M. Berthelot, rapporteur de la commission du Métropolitain, avait inscrit un article I 8 ainsi rédigé :

" L'exploitation devra ètre organisée de façon à satisfaire aux prescriptions suivantes :

$\mathrm{I}^{0}$ Les salaires ou appointements des ouvriers et employés devront être payés à la quinzaine et ne pourront être inférieurs à 150 francs par mois (I)... »)

Le concessionnaire est tenu à la stricte observation des conditions de travail ci-dessus énumérées, sous peine de déchéance.

Le concessionnaire éventuel, la Compagnie générale de traction, accepta cette clause. Plus tard, la Comınission y ajouta un second paragraphe: "Les hommes employés temporairement recevront un salaire qui ne pourra être inférieur à 5 francs par jour (2). ")

En séance publique, le Conseil municipal adopta sans débat le projet de convention, dans ses séances des 5, 7 et 9 juillet $1897(3)$.

Mais le projet devait encore être soumis au Conseil des ponts et chaussées et au Conseil d'État.

Devant la première de ces deux assemblées (4), le rapporteur critiqua vivement notre clause de minimum de salaire; les conditions relatives au personnel augmentaient les charges de $50 \%$; elles étaient de nature à " porter atteinte à la loi naturelle de l'offre et de la demande et, par suite, à

(I) Procès-verbaux de la Commission du Métropolitain. Séance du 25 mai 1897 , p. 5. Délibération Veber, 21 mai 1897 . Procès-verbaux, p. 346.

(2) Annexe du rapport Berthelot, $n^{\circ} 75$ de 1897 .

(3) On avait soumis ce projet à deux jurisconsultes; MM. Dubuit et Aubert avaient vivement critiqué le projet, les clauses relatives au personnel contribuant, à leur sens, à fausser le contrat : celui-ci est de sa nature commutatif; ces clauses en font un contrat aléatoire. Que ferait la Ville si le concessionnaire était acculé à la faillite ou à la ruine ? Note consultative des deux jurisconsultes cités. Bezançon, op. cit., p. 102 , en note.

(4) Rapport de M. Lorieux, inspecteur général des ponts et chaussées, p. 56 . 
apporter quelques troubles dans l'industrie parisienne "; elles étaient enfin contraires à l'ordre public comme créant artificiellement une hausse des salaires. Le rapporteur proposait, en conséquence, la suppression pure et simple de la clause ayant trait au minimum de salaire. Le Conseil, après discussion, adopta, le 15 novembre 1897 , l'avis du rapporteur ( 1 ).

Au Conseil d'État, l'opposition fut également très vive (2). Pour proposer la suppression de l'article $\mathrm{I} 8, \S \mathrm{I}^{\mathrm{er}}$, de notre clause, le Conseil d'État invoquait les deux arguments déjà connus (3) : l'argument de la concurrence dans les adjudications et l'argument de la liberté du travail.

L'argument de la concurrence : Une ordonnance formelle, en date du 14 novembre 1837 , oblige toute commune à donner avec concurrence et publicité les entreprises pour travaux et fournitures. Or l'insertion d'une clause relative au minimum de salaire écarte nécessairement certains concurrents, diminue l'offre, fausse la concurrence (4).

L'argument de la liberté du travail et des contrats : Cette liberté, proclamée par la loi du 2 mars I 9 I I, inscrite dans l'article i 34 du Code civil, est formelle : imposer certaines conditions, notamment le minimum de salaire, à l'une des parties, c'est violer cette liberté (5).

(I) Documents relatifs au Métropolitain. Avis du Conseil général des ponts et chaussées, pp. 22 et 23 . La discussion sur le minimum de salaire est assez curieuse devant cette assemblée : un membre y vit, comme le rapporteur, une atteinte à la liberté de l'offre et de la demande, une hausse artificielle de la main-d'œuvre, une infraction à l'ordre public; un autre prit en main les intérêts de l'État et déclara qu'il y avait danger à exciter le personnel des chemins de fer à réclamer une augmentation de salaire. D'autres repoussèrent la clause au nom des ouvriers, en montrant qu'on écartait ainsi les ouvriers moins jeunes ou moins vigoureux au préjudice des mieux doués. Le directeur des chemins de fer argua raisonnablement pour l'incompétence du Conseil en cette question. Cf. Bezançon, op. cit., p. ro6.

(2) Cf. séance du 20 janvier I898. Avis du Conseil d'État.

(3) C. supra, p. 60.

(4) En ce qui concerne ce premier argument, on peut sans peine le réfuter : quant à la concession du Nétropolitain, on avait écarté le procédé mécanique de l'adjudication pour celui des pourparlers de gré à gré. De plus, le minimum de salaire avait été introduit dans la convention en remplacement d'une clause de participation aux bénéfices, offerte spontanément par le demandeur en concession et réalisant une charge équivalente. Rapport $n^{\circ} 75$ de 1897 , p. 22.

(5) Tout revient au fond à savoir si le principe de la liberté des contrats peut être invoqué : on n'est pas ici en matière de droit privé, 


\section{Restait enfin l'intervention législative (I):}

Le projet de déclaration d'utilité publique fut déposé devant la Chambre le i2 février 1898 (2). Le projet écartait, en acceptant les avis des deux assemblées consultées, la clause relative au minimum de salaire : "La première de ces clauses, disait-il en parlant de notre minimum, est en désaccord avec la jurisprudence, qui a toujours admis, dans les actes de concession, le principe de la liberté des conventions entre patrons et ouvriers, et qui ne peut ètre modifié que par une loi générale. "

Le projet, rapporté par M. Argeliès (3), fut adopté à la Chambre le I $^{\text {er }}$ mars I 898 , et au Sénat (4) le 22 mars.

La loi du 30 mars i 898 déclarait l'utilité publique du chemin de fer métropolitain de Paris. Elle contenait un article 5 :

( Les dispositions des paragraphes ${ }^{0}{ }^{2}$ et $2^{\circ}$ de l'art. 16 de la convention précitée du 27 janvier 1898 seront supprimées. ”

La clause relative au minimum de salaire avait officiellement disparu du contrat de concession.

Cependant, à défaut d'engagement juridique, le personnel du Métropolitain allait, par bonheur, jouir de l'engagement moral de la Compagnie générale de traction.

Par une lettre en date du 29 mars 1898 , adressée à M. Thuillier, président de la Commission du Métropolitain, M. Heurotte, président du Conseil d'administration de la Compagnie générale de traction, prenait l'engagement. formel d'appliquer à son personnel le salaire minimum (5).

mais de droit public; l'Etat, les départements, les communes sont ici parties à l'acte. On conçoit fort bien que l'Administration impose ses conditions dans le contrat de travail. On peut aussi soutenir que le contrat de travail n'est pas exclusivement de droit privé.

(I) Le Métropolitain, étant un chemin de fer d'intérêt local, devait en effet être déclaré d'utilité publique par une loi.

(2) Ch., J. O., Doc. parlem., I898, no 3026.

(3) M. Argeliès (rapport, Ch., J. O., Doc. parlem., 1898, no $3083,4^{\mathrm{e}}$ partie, 552) se montrait favorable au minimum de salaire, mais s'inclinait devant l'avis défavorable du Conseil d'État, en espérant le vote de la loi générale alors attendue. Cf. ci-dessus, p. 68.

(4) M. Poirier (rapport, Sén., J. O., Doc. parlem., 1898, n 130) concluait dans le mème sens.

(5) Voici le texte de cette lettre citée par M. Bezançon, op. cit., p. 115: CONPAGNIE GÉNÉRALE DE TRAGTION

A Monsieur Thuillier, président de la Commission du Métropolitain, Conseil municipal de Paris.

Monsieur le Président,

La Chambre des députés et le Sénat viennent de ratifier successive- 
Sur ces engagements, le rapporteur, M. A. Berthelot (1), ne regrettait pas outre mesure la suppression de la clause relative au minimum de salaire. G'était là une grave restriction de principe, faite pour attrister les économistes, mais non le personnel, ni ceux qui cherchaient pour lui des avantages pratiques. Il demandait au Conseil municipal de ratifier la convention telle quelle avec la Compagnie concessionnaire.

Celui-ci vota dans son ensemble le projet de convention dans sa séance du 9 mars r 908 (2).

Le personnel du Métropolitain jouissait ainsi, en fait, sinon en droit, du minimum de salaire.

L'avenir a d'ailleurs justifié cette confiance.

Le personnel du Métropolitain, qui comprend plus de 4.200 agents (3), jouit en majorité du salaire minimum de I 5 o francs par mois pour les hommes et d'un salaire mini-

ment le projet de loi ayant pour objet la déclaration d'utilité publique du chemin de fer métropolitain et le Conseil municipal va être appelé également à donner sa sanction définitive.

Parmi les modifications apportées par les pouvoirs publics à l'ancien cahier des charges et à la convention figure la suppression des paragraphes I et 2 de l'article 18 de cette convention. Or, lorsque nous avons été entendus par la Commission du Conseil municipal, nous avons spontanément déclaré que nous étions décidés à accorder aux ouvriers et employés du Métropolitain les conditions de travail libellées à l'article 18 de la convention telles qu'elles ont été rédigées par cette Commission, d'accord avec nous et adoptées par le Conseil, le 9 juillet 1897 .

Nous avons toujours été résolus à exécuter ces engagements, même en l'absence de l'obligation qui nous en serait imposée. Vous pouvez donc être assuré que nous attribuerons à nos ouvriers et employés aussi bien le minimum de salaire spécifié au paragraphe I et la journée de dix heures spécifiée au paragraphe 2 que les autres garanties stipulées en leur faveur.

Veuillez agréer, etc.

Paris, le 29 mars 1898 .

\section{Le Président du Conseil d'administration, Signé : Hevrotte.}

(I) Rapports et documents du Conseil municipal, $1898, \mathrm{n}^{\circ} 24$. Le rapporteur indiquait de plus que la Compagnie concessionnaire n'aurait aucun intérêt financier important à éluder les deux obligations supprimées; il exprimait de plus l'espoir de voir bientôt votée la loi autorisant les communes, les départements et les établissements publics, contraignant l'État à insérer les clauses relatives aux conditions du travail dans les adjudications de travaux publics. Cf. ci-dessus, p. 68.

(2) En séance, M. Rousselle regretta l'absence d'un engagement juridique liant formellement la Compagnie concessionnaire.

(3) Exactement au 26 mai 19094.210 agents ainsi répartis : mouvement, 2.570 ; matériel, 704 ; traction, 331; voie et accès, 331; service électrique, II 7 ; usine, 214 ; direction, 43. 
mum de 5 francs par jour, pour les travailleurs temporaires.

Cinq francs par jour, c'est le traitement de début au service du mouvement des hommes d'équipe ou gardes-voitures, au service du matériel des nettoyeurs et aides-ouvriers, au service de la voie des aides-poseurs, au service du matériel fixe électrique, des manœuvres ou aides-ouvriers, au service des usines et sous-stations des manœuvres ( $\mathrm{I}$ ).

Le tableau des salaires du personnel (2) montre que ce minimum n'est nulle part un maximum, et qu'il est souvent dépassé, même comme traitement de début.

La seule lacune est pour les femmes, dont les appointements sont des plus modiques : les dames employées dans les services centraux du Métropolitain reçoivent seulement 90 à $\mathbf{2} 0$ francs par mois (3).

A la tribune du Conseil municipal de Paris, on a plusieurs fois dénoncé les bas salaires du personnel : sous la réserve des femmes, il ne paraît pas que ces critiques soient justifiées.

Le salaire minimum est donc là encore une réalité bienfaisante.

La ville de Lyon, en vertu de l'arrèté municipal du 9 mars I 906 , mis en vigueur le I $^{\mathrm{er}}$ janvier 1907 (4), a attribué au personnel subalterne de ses régies municipales (5), un minimum de salaire correspondant aux besoins nécessaires de l'existence, et au personnel entier des traitements avançant automatiquement avec l'ancienneté.

(I) Le salaire journalier de 5 francs par jour, au premier échelon de la hiérarchie, est formellement inscrit dans les conditions d'admission du personnel. Cf. Bezançon, op. cit., p. 200.

(2) Cf. Bezançon, op. cit., pp. 124 et 125 . Salaires au 26 mai 1909.

(3) Ce sont là des salaires d'appoint ordinairement donnés à des fermmes ou veuves d'agents.

(4) Bulletin municipal officiel de Lyon, I I mars 1906, p. 145. Cf. Éd. Herriot. La condition du personnel de la ville de Lyon. Annales de la régie directe, 1909, p. 129.

(5) Ces régies municipales comprennent le service des eaux; une régie intéressée des immeubles dans le quartier Grolée. 


\section{B) A l'Étranger.}

Un mouvement analogue se poursuit à l'étranger dans les divers pays : il faut l'examiner successivement en Angleterre, en Allemagne, en Belgique et en Italie. 
ANGLETERRE

Voici, d'après le discours de M. Tenant, secrétaire parlementaire du Board of Trade, aux Communes, le 26 avril r 9 I I (I), quelques renseignements sur l'application de la Fair Wages' resolution dans les travaux de l'État.

Pour la Guerre, à Woolwich, le minimum hebdomadaire a passé de 2r shillings en 1906 à 24 shillings en r 9 I I, avec une rémunération extra, qui l'augmente encore de $6 \mathrm{~d}$. par semaine.

Le Post Office accuse lui aussi de sérieux progrès : le personnel fixe (established staff) du district de Londres a profité des relèvements suivants :

De $\mathrm{r} 905$ à $\mathrm{r} 9 \mathrm{r}$, les trieurs (sorters) ont vu leur minimum de salaire porté de $45 \mathrm{~s} .5 \mathrm{~d}$. à $49 \mathrm{~s} .7 \mathrm{~d}$. ;

Les télégraphistes au bureau central, de 44 s. Io d. à 49 s. 3 d.;

Les employés de guichet (counter cler/is) et les télégraphistes, de 45 s. 3 . d. à 48 s. 2 d. ;

Les postiers (postmen) de $30 \mathrm{~s}$. ̀̀ 32 s. ıo d.;

Enfin les aides-trieurs (sorting clerlis) et les télégraphistes, de 35 s. 5 d. à 37 s. 9 d.

Le montant total de ces améliorations (2) a été de $680,000 £$ par an.

L’Amirauté a pareillement pratiqué des élévations de salaires qui se montent à $6.100 \mathfrak{£}$ en r 906 . $4.500 \mathfrak{f}$ en 1908 ,

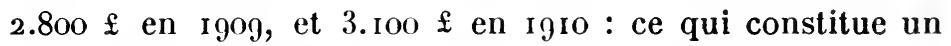
accroissement moyen de charges de $71.000 £$ par an.

La Fair Wages' clause est maintenant inscrite dans tous les contrats de ce département.

(1) Parliamentary Debates, I9II, vol. XXIV, p. I92I. A propos d'un projet de résolution invitant le Gouvernement à octroyer un salaire hebdomadaire de 3o shillings à tous les ouvriers et employés qu'il occupe. Cf. plus loin, p. 415.

(2) $\mathrm{Y}$ compris quelques autres avantages : uniformes, assistance médicale, etc. 
Les municipalités anglaises ont accompli de notables progrès, ces dernières années, pour hâter l'octroi d'un minimum de salaire à leurs ouvriers et employés.

L'œuvre du London County Council (I) est, à cet égard, bien connue.

Les divers tableaux publiés accusent de notables augmentations de salaires et d'importantes réductions de la journée de travail.

C'est ainsi, par comparaison d'abord avec les conditions de travail du personnel des anciennes compagnies absorbées, que l'on constate en igo3 une augmentation de $15 \%$ sur les salaires que payait l'ancien Metropolitan Board of Worlis; les bateliers (boatmen), qui en I888 recevaient 25 shillings par semaine de 72 heures de travail, touchent en I go3 27 shillings pour une semaine de 48 heures l'hiver et 54 heures l'été ; les soutiers (coal trimmers) qui avaient 26 shillings pour 6o heures, gagnent en rgo3 29 shillings pour 54 heures, etc., etc.

De même les salaires (2) de toutes les professions ont considérablement augmenté (3).

A Birmingham (4), les salaires payés dans les différents services municipaux ont beaucoup augmenté (5).

(1) London County Council : Rates of pay and hours of labour. Londres, 1904. Il faut tenir compte toutefois du caractère politique de ce document, publié deux semaines avant les élections municipales.

(2) Les agents de police (constables) passent de 24 et 25 sh. pour 58 h. I/2 à 27 sh., en I903, pour 48 et 54 heures; les mécaniciens lengine drivers) de $33 \mathrm{sh}$. pour 60 heures à $38 \mathrm{sh} .6$ d. pour 56 heures.

De 1899 à 1903 , le salaire des maçons passe de $9 \mathrm{~d}$. ̀̀ $10 \mathrm{~d}$. I/2 par heure pour une semaine qui se réduit de $56 \mathrm{~h}$. $1 / 2$ à 50 heures; les salaires des charretiers montent de 26 sh. à 33 sh. et leurs heures de travail diminuent de 68 heures à 60 heures: les marteleurs (hammermen) augmentent de $6 \mathrm{~d}$. I/2 à $7 \mathrm{~d}$.; les jardiniers de $24 \mathrm{sh}$. ̀̀ $27 \mathrm{sh}$. par semaine; les plombiers voient leur salaire horaire passer de $9 \mathrm{~d}$. à i I d.; les scieurs de 6 et $7 \mathrm{~d}$. I/ 2 à $10 \mathrm{~d}$.; les tourneurs de $6 \mathrm{~d}$. I/ 2 à $8 \mathrm{~d}$. $3 / 4$ et $9 \mathrm{~d} . \mathrm{I} / 4$; les charrons de $7 \mathrm{~d}$. I/2 à 9 d., etc.

(3) Il s'ensuit une augmentation de dépenses de 300.000 £ à 350.000 里 par an.

(4) Vince. History of the Corporation of Birmingham. 3 vol., Birmingham, Ig02.

(5) Voici quelques minima de salaires à titre d'exemple :

Police. - Constables : 24, 25, 26, 28, 30, 31 et 32 shillings par semaine, selon le temps de service; sergeants : 40 shillings.

Hygièe. - Charretiers : 25 shillings pour 54 heures par semaine, en 
Les salaires des ouvriers non qualifiés ont également beaucoup augmenté, surtout dans les municipalités socialistes ( $\mathrm{I})$.

En un mot, le salaire des ouvriers des municipalités anglaises est stable, élevé et parfois supérieur même aux salaires fixés par les Trade-Unions (2).

1897 ; conducteurs de voitures de vidange, voitures à ordures : minima augmentés de 2 shillings en 1890 , etc.

(1) Sheffield : le salaire des chauffeurs du destructor est porté à 3o shillings par semaine en rg04.

A Bermondsey (Londres), le salaire des égoutiers est porté à 30 shillings par semaine,

A East Ham, celui des égoutiers est fixé à 3o shillings.

A Finsbury, charretiers et laniers (flushers), également 3o shillings.

A Poplar et à Saint-Pancras, balayeurs, 3o shillings.

(2) Sur les critiques soulevées par cet accroissement du salaire des ouvriers municipaux, cf. L. Darwin. Municipal Trade, Igo3, chap. II. 
ALLEMAGNE

On pourrait en ce qui concerne les régies ou monopoles exercés par l'État en Allemagne (I) poursuivre une étude analogue à celle qui vient d'être faite pour la France et l'Angleterre. On constaterait un mouvement marqué, quoique moins avancé peut-ètre, en faveur du minimum de salaire. Les documents (2) nous manquent pour en esquisser d'une manière complète les résultats.

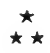

Les municipalités allemandes (3) se sont engagées dans la mème voie. Elles ont essayé, partiellement encore il est vrai, d'assurer à leurs ouvriers municipaux un chiffre de salaire assez élevé pour garantir une certaine sécurité et pour soustraire le salaire aux variations dues à la concurrence.

Quelques-unes d'entre elles ont directement abordé la fixation du salaire minimum.

C'est tantòt un salaire minimum absolu, c'est-à-dire une somme au-dessous de laquelle le salaire ne peut absolument pas descendre : 3 marks par jour à Breslau, 25 pfennigs l'heure à Erlangen, 3 marks par jour pour les hommes, 2 marks par jour pour les femmes à Munich (4).

Tantòt il n'y a qu'un salaire minimum relatif, c'est-à-dire se référant à une base connue.

Ainsi, à Charlottenbourg, le salaire d'un ouvrier munici-

(1) Chemins de fer. Mines.

(2) Cf. passim. Colson. Revue des questions de transports. Revale politique et parlementaire, mai 19г. - Rossignol. De quelques tentalives du gouvernement prussien pour étendre son influence sur la propriété minière. Thèse. Paris, Igo8.

(3) Von de Thissen. Soziale Täigheit der Stadtgemeiden. $4^{\circ}$ édition, Berlin, Gladbach, I9I. - G. Letourneux. L'action sociale des municipalités allemandes. Thèse. Paris, Rousseau, 19I1, p. 64.

(4) Parfois le minimum n'existe que pour une catégorie seulement, ainsi les travailleurs incomplètement invalides occupés par générosité: a Darmstadt, Giessen, Strasbourg, ils ne peuvent recevoir moins de 2 marks; ainsi les femmes balayeuses, à Mulhouse, travaillant 2 ou 3 heures par jour, reçoivent 80 pfennigrs au moins. 
pal ne peut descendre au-dessous du salaire nórmal d'un travailleur de mème catégorie dans la commune; à Karlsruhe, le prix de la journée de travail adopté est celui qui est payé par la caisse communale d'assurance maladie.

La plupart des municipalités allemandes ne vont pas aussi loin ( $\mathrm{I}$ ): elles se contentent pour le présent de tarifer les salaires, en donnant la préférence aux salaires au temps et en développant de plus en plus les salaires hebdomadaires et mensuels, voire mème annuels (2).

On constate de ce chef une augmentation appréciable des salaires dans ces dernières années, comme en témoigne le tableau suivant.

Deux enquêtes furent entreprises, en i 902 et I 907 , dans 33 grandes villes occupant environ 50.000 ouvriers; elles montrent par leur comparaison que ce mouvement de fixation des salaires marque une marche certaine vers les minima de salaires.

\begin{tabular}{|c|c|c|c|c|}
\hline & \multicolumn{2}{|c|}{1902} & \multicolumn{2}{|c|}{1907} \\
\hline & $\begin{array}{c}\text { Nombre } \\
\text { d'ouvriers. } \\
-\end{array}$ & $\stackrel{0 \%}{-}$ & $\begin{array}{c}\text { Nombre } \\
\text { d'ouvriers. }\end{array}$ & $\stackrel{\circ}{-}$ \\
\hline Moins de 3 marks . & 9.407 & 26,7 & 4.705 & 9,4 \\
\hline 3 à 4 marks. . . & 21.009 & 59,5 & $27.9^{67}$ & 56,0 \\
\hline 4 à 5 marks. & 4.185 & 11,9 & 14.356 & 28,7 \\
\hline 5 marks et plus. & 678 & I,9 & $2 \cdot 9^{32}$ & 5,9 \\
\hline
\end{tabular}

Enfin les mèmes documents montrent que la moyenne de salaire de l'ouvrier municipal était en r 902 de 3 marks 28 et en 1907 de 3 marks 76 , soit une augmentation de $14,6 \%$ o.

Le mouvement vers le minimum de salaire se manifeste encore sous une troisième forme: l'octroi de suppléments de salaire variant avec la situation de la famille (4).

A Francfort-sur-le-Mein, les salaires des ouvriers munici-

(I) Il y a encore tout un ensemble de suppléments de salaire et gratifications dont il faut tenir compte. Gf. Letourneux, op. cit., p. 68.

(2) Nombre des ouvriers municipaux payés au temps $\%$ :

$\begin{array}{cccc} & \text { Salaire au jour. } & \text { Salaire à la semaine. } & \text { Salaire au mois. } \\ 1902: & 87,3 & 5,0 & 7,7 \\ 1907: & 78,9 & 5,3 & 15,8\end{array}$

Ex. Beitrage zur Arbeiterstatistik, $\mathrm{n}^{\circ}$ 9, p. 10.

(3) Beitrage zur Arbeiterstatistik, no 9, p. 12. - Thissen-Trimborn. Soziale Tätigkeit der Stadgemeinden. $4^{\mathrm{e}}$ édition, 1911, p. 26. Volksvereins Verlag.

(4) Letourneux, op. cit., p. 70. 
paux sont gradués selon les charges de la famille; l'écart va jusqu'à 40 pfennigs par jour dans les deux premières classes et jo pfennigs dans les autres.

A Strasbourg, les salaires sont uniformes pour tous les individus possédant moins de trois enfants. Au-dessus de ce chiffre, ils comportent une bonification de 5 , Io et $15 \%$, suivant que le nombre d'enfants atteint 4, 6 ou 8.

De mème à Crefeld des allocations mensuelles sont données proportionnellement au nombre d'enfants (I).

D’un mot, les municipalités allemandes s'orientent lentement vers le minimum de salaire.

(I) Des combinaisons analogues à Hanau, Mayence, Francfort. 
BELGIQUE

L'État belge ( I) a dù lui aussi faire une série de louables efforts pour l'amélioration des salaires de son personnel de chemins de fer. Le mouvement est d'ailleurs assez récent et date au plus de sept ou huit ans (2). De très lourds sacrifices ont été faits pour le personnel, spécialement pour le personnel inférieur (3).

Le Ministère aurait fixé, paraìt-il (4), le salaire minimum à $2 \mathrm{fr} .40$.

Les traitements restent en général assez bas : les chauffeurs gagnent $9^{\circ}$ francs par mois, dont il faut déduire $8 \%$ pour la retraite, et arrivent, au bout de 15 ans, à I 20 francs par mois (5).

Les machinistes débutent à I 20 francs, gagnent 140 après 7 ou 8 ans de service, I6o après I5 ou 16 ans, I80 après 23 ou 24 ans, et arrivent enfin au maximum de 200 francs.

Les gardes des trains gagnent de 83 francs à 180 francs; les serre-freins, de go à 120 francs (6).

On a calculé que, en laissant de côté le personnel ouvrier, plus de $63 \%$ du personnel, des fonctionnaires et employés gagnent moins de 2.000 francs par an et plus de $28 \%$ moins de 3. I00 francs $(7)$.

C'est, on peut l'affirmer, une des revendications les plus

(1) Le réseau comprenait, en $1909,4.272$ kilomètres de chemins de fer exploités par l'État en Belgique, contre 386 kilomètres exploités par les Compagnies. Le chiffre brut des recettes d'exploitation est de 308.600 .000 francs, en I910. Cf. Bulletin de la statistique générale de la France, oct. I9I, p. 14. - Cf. Devys. Les chemins de fer de l'État belge. Thèse. Paris, 1910, p. 191.

(2) En 1904, le 15 février, M. Anseele disait à la Chambre des représentants : " La moyenne des salaires des ouvriers de la voie est de 2 fr. 22 , alors que les camionneurs de Bruxelles gagnent 3 fr. 20 et les employés des tramways 3 fr. 43. " Ch., Annales, I904, p. 636.

(3) En 1906, l'augmentation des salaires et traitements comptait pour $30 \%$ dans l'accroissement des dépenses de l'exercice.

(4) C. M. Teschaud. Les chemins de fer de l'État belge. Revue politique et parlementaire, io juin ı906, p. 505.

(5) Ch. belge des représentants. Séance du 17 fév. I904. Annales, p. 640.

(6) Ch. belge. Séance du 18 fév. 1904. Annales, p. 663. Sénat. Séance du 17 mars igo4. Annales, p. 255.

(7) Ch. belge. Séance du 12 fév. 1904. Annales, p. 61 I. 
fréquentes que celle de l'augmentation des traitements du personnel.

Des documents parlementaires et en particulier des rapports annuels sur le budget des chemins de fer résulte cette double impression :

D'une part, une fraction seulement du personnel du réseau de l'État et plus généralement des ouvriers et employés de l'État jouit à l'heure actuelle d'un véritable minimum de salaire.

D'autre part, la réforme va sans cesse en s'élargissant et par le vote annuel de crédits importants, le nombre des bénéficiaires de ce salaire minimum va croissant.

Voici quelle était la situation en I 9 Io (I) :

$$
\begin{array}{cc}
\text { Effectif } & \text { Nombre } \\
\text { par catégories. } & \text { d'augmentation. }
\end{array}
$$

Fonctionnaires et employés ayant

un traitement de 3.000 francs

ou plus. . . . . . . . . . 3.83 I 649

Employés et autres agents commissionnés ayant un traitement ou salaire de 2.000 à 3.000 francs .

$$
5.828 \quad \text { I. } 088
$$

Employés et autres agents commissionnés ayant un salaire inférieur à 2.000 francs . . . . . I I.468 4.169 Facteurs des postes . . . . $5.886 \quad 2.4 \mathrm{I} 7$

Ouvriersen possession d'une rémunération égale ou supérieure à 3 francs par jour au 3i décembre $1909 . . . . . . . .49 .905 \quad 33.895$

Ouvriers en possession d'une rémunération inférieure à 3 francs par jour au 3 I décembre I909 • I3.048 $\quad$ I5.102

Il faut noter enfin la pratique du salaire familial, par exemple dans les postes, où un supplément annuel de 40 francs par enfant de moins de 14 ans et au-dessus de 3 aux agents dont la rémunération ne dépasse pas i.ooo fr.

(1) Polet. Rapport sur le budget des chemins de fer, postes et télégraphes pour igro. Doc. parlem., Ch. des représentants, session igog-1910, annexe au $n^{\circ} 107$, p. 591 . 
En Belgique (I), il faut indiquer l'action des municipalités en faveur du salaire minimum des secrétaires commu$\operatorname{naux}(2)$.

La législation (3) leur assure un véritable salaire minimum : leur traitement est en effet fixé par le Conseil communal, sous l'approbation du Conseil provincial, d'après un tarif de minima variables selon le nombre d'habitants.

(1) Delaroue. Les Employés de mairie. Thèse, Paris, I911, p. 121.

(2) La fonction de secrétaire communal comporte des attributions légales (secrétariat du Conseil municipal) et une responsabilité propre (il doit authentiquer les copies et extraits d'actes émanant de l'Administration communale). Il correspond ainsi beaucoup plus au receveur municipal qu'à notre secrétaire de mairie. Cf. Delaroue, op. cit., p. I30.

(3) Lois des 30 mars I836, 3o mars 186 I, 3o décembre 1887 et 3 juillet 1894 . 
L'État italien semble avoir suivi pour le personnel de son réseau une politique qui s'oriente vers le minimum de salaire, déjà en partie réalisé :

Une partie du personnel jouit aujourd'hui du minimum de salaire (I).

Voici un aperçu des tarifs :

Les serre-freins (minimum de salaire annuel, y compris tous les accessoires), I.464 fr., les gardes-freins ( $1.976 \mathrm{fr}$.), les chefs serre-freins (I.908 fr.), conducteurs ( $.968 \mathrm{fr}$.), les chefs de train (2.220 fr.), les chauffeurs (I.79o fr.), les mécaniciens (3.180). Par contre, les aides débutent à I.200 francs, les employés à 1.500 fr., les facteurs sont à $9^{5}$ francs par mois.

La Suisse a vu se poser les mêmes problèmes pour son nouveau réseau fédéral : les salaires du personnel ont été également relevés (2).

Ainsi l'œuvre de la puissance publique en faveur du minimum de salaire se poursuit à l'heure présente tant en France qu'à l'étranger. Ici encore la réforme n'est pas accomplie pour tous : cependant de l'ensemble des faits cidessus relevés résulte un incontestable mouvement vers le minimum de salaire. C'est presque au jour le jour qu'on en pourrait marquer et suivre les rapides progrès.

(x) Cf. Colajani. Annales de la régie directe, III, no 26, p. 243. - Cf. Thomas. Rapport sur les conventions et garanties d'intérêt. Ch., Doc. parlem., I9II, n 1256, p. 206r. - De Pomaride. Chronique dans les Annales de la régie directe, déc. Igı.

(2) De Lavergne et P. Henry. Les chemins de fer suisses et la gestion fédérale. Revue politique et parlementaire, juillet 19I . - Milhaud. Chemins de fer suisses avant et après le rachat. Annales de la régie directe, octobre igir. 


\section{CHAPITRE VII}

\section{L'Euvre de la loi.}

Une remarque préalable et de capitale importance s'impose au début de cette nouvelle étude :

On s'imagine d'ordinaire - c'est la conception courante et vulgaire - que la fixation d'un minimum légal des salaires comporte l'inscription d'un certain taux de salaire minimum - 5 francs par jour par exemple - établi directement et ne varietur par le législateur pour toutes les professions et toutes les régions.

Rien de plus absurde et de plus irréalisable que cette conception : l'étude des législations en vigueur montre qu'il n'en est pour ainsi dire jamais ainsi.

Ce que fait pratiquement le législateur, c'est de créer l'organe, le plus ordinairement le Comité de salaires, chargé d'élaborer par profession et par région les minima de salaires applicables : il donne d'avance force obligatoire et valeur juridique aux déterminations qui seront faites par les intéressés eux-mêmes.

Ainsi, au sens strict des mots, il n'y a pas fixation d'un minimum légal des salaires, mais intervention pour sanctionner les décisions des employeurs et des employés obligatoirement mis en présence pour fixer des minima (I).

A l'heure actuelle, les interventions positives peuvent se classer en deux catégories :

$1^{0}$ Législation confiant à des Comités de salaires le soin d'établir des minima de salaires (Australie et Angleterre);

$2^{0}$ Législation confiant à une Cour industrielle d'arbi-

(1) C'est purement et simplement un contrat collectif légal substitué au contrat collectif libre qui fait défaut par manque d'organisation professionnelle ou pour toute autre raison. 
trage le soin d'établir des minima de salaires (NouvelleZélande et quelques autres colonies d'Australie) (I).

Il faut les étudier successivement, en insistant sur la première méthode, de beaucoup la plus importante et la plus pratique (2).

(I) II faut ici mentionner une toute nouvelle et très intéressante direction législative : c'est la législation des diverses puissances coloniales réglementant le contrat de travail des travailleurs immigrants de la possession. Cif., par exemple, une ordonnance des établissements de Malacca (Bulletin de l'Offlce intern. du travail, I906, p. 31 I) relative. à la protection des travailleurs hindous et fixant une rétribution minima en argent ( 5 annas, $\mathrm{I}$ fr. 10 ) et en nature I livre $\mathrm{I} / 2$ de $\mathrm{riz}$ par jour, 2 livres de lentilles, 2 livres de poisson salé, I livre de beurre conservé, I livre de sel par mois). La question est trop nouvelle pour qu'il soit possible de l'étudier complètement : il suffit de signaler cette autre apparition curieuse et cette réalisation intéressante du minimum de salaire.

(2) Paul Boyaval. La lutte contre le sweating system : le minimum légal de salaire, l'exemple de l'Australie et de l'Angleterre. I vol., Paris. Alcan, Igr2, avec une préface de M. le comte A. de Mun. 


\section{I. - Législations confiant à des Comités de salaires}

le soin d'ètablir le minimum de salaire.

\section{Section A : l'Australie.}

Il faut étudier successivement les trois questions suivantes:

I. - Antécédents de la loi.

II. - Principales dispositions.

III. - Résultats actuels.

\section{I. - ANTÉCÉDENTS DE LA LOI}

La colonie de Victoria est le premier pays qui, en ${ }_{189} 6$, ait appliqué le système des Comités de salaires, bientôt suivie par d'autres colonies, Nouvelle-Galles du Sud, Queensland, Australie du Sud.

En ce qui concerné les antécédents de cette législation, on peut relever facilement les deux caractères essentiels suivants :

Toutes ces législations prétendent remédier aux maux du sweating system et n'arrivent à consacrer la création de Comités de salaires qu'en dernière analyse et comme remède ultime, après que tous les autres palliatifs ou correctifs au sweating ont été sans succès essayés et tentés. C'est une législation in extremis, pourrait-on dire.

Un second caractère doit ètre également souligné : en face des très grandes difficultés que rencontre la nouvelle législation, celle-ci n'apparaìt au début que comme temporaire et provisoire; c'est une expérience qui est tentée; mais avec une prudence digne d'éloges, le législateur se met résolument à l'école des faits et, soit par la souplesse du mécanisme créé, soit par des retouches fréquentes au texte primitif, laisse en somme et malgré les apparences l'action individuelle et l'action professionnelle dominer la contrainte légale. C'est en second lieu une législation expérimentale. Il faut établir ce double caractère des législations à étudier. 
En Australie, les antécédents de la loi et son histoire (I) sont nettement une preuve - et ceci est vrai pour les diverses colonies - du caractère de remède in extremis de cette législation.

Dans l'État de Victoria, une bonne partie de la législation de fabrique de 1873 à 1896 marque un effort, impuissant d'ailleurs, pour combattre les maux du sweating : la loi de i 885 (2) notamment prescrit l'obligation pour le patron de tenir une liste des ouvriers travaillant pour lui à domicile. Une autre loi de ${ }_{1} 893$ (3) décide que les prix payés pour le travail à domicile devaient désormais ètre communiqués à l'inspecteur en chef des fabriques. Les travaux préparatoires de la loi de 1896 (4) montrent également que le projet Peacock (5) voulait originairement subordonner le travail à domicile à une autorisation spéciale donnée par l'inspecteur en chef : on substitua par la suite à cette formalité de l'autorisation celle de l'enregistrement. Ce n'est donc qu'à défaut d'autre remède efficace qu'on arriva en ${ }^{8} 8_{9} 6$ aux Comités de salaires (Special Boards) dans les quatre industries les plus exposées au sweating : vètements et effets d'habillement, meubles, boulangerie (6).

L'opinion publique, éclairée par de remarquables rapports parlementaires et extra-parlementaires, poussa sans cesse dans le sens d'une lutte efficace contre le sweating system. Il est curieux de noter d'ailleurs dans l'un des deux rapports de i 884 , où fut pour la première fois émise l'idée de Conseils de Comités de salaire sous la forme de Conseil central et de Cours locales de conciliation, l'aveu très net des membres de la Commission qui déclarent s’inspirer comme précédents des Conseils de prud'hommes français (7). C'est

(1) Cf. Aves. Report on the wages board and industrial conciliation and arbitration acts of Australia and New Zealand. Londres, 1908. Bulletin de l'office international du travail. Année I907 et suivantes.

(2) 49. Vict., no 862. The Factories and Shops Aet 1885 .

(3) 57. Vict., $n^{\circ}$ 1333. The Factories and Shops Act 1893.

(4) Bulletin de l'offce international du travail, 1907, p. vir.

(5) Sir A. Peacock, chef du secrétariat et ministre de l'Instruction publique dans le cabinet Turner, est l'auteur du projet qui devint la loi du 28 juillet 1896 .

(6) Clothing and Wearing (including boots and shoes; furniture : baking);

(7) Aves, rapport cité, p. 12. 
donc, déformée sans doute et assurément mal comprise, une institution d'origine française qui nous revient de l'étranger : une fois de plus peut-ètre, comme pour les jeux et les sports, en croyant accueillir une nouveauté, c'est notre bien français que nous reprendrons : mais il est sans doute plus beau, puisqu'il nous arrive de l'étranger!

La législation de l'Australie du Sud nous apporte le même enseignement : la première loi qui parle des Comités de salaires les institue sans leur donner de pouvoirs et poursuit la lutte contre le sweating par l'enregistrement des travailleurs en dehors de l'usine et l'obligation de tenir une liste des travaux qui leur sont donnés (I). Les dispositions de cette loi relatives aux Comités restèrent lettre morte jusqu'en igo/. Ce n'est que plus tard et devant l'insuccès des autres mesures proposées qu'on donna force légale en ig07 aux déterminations des Comités de salaires. Ici encore ceux-ci n'apparaissent qu'à la dernière extrémité.

La mème histoire se reproduit à peu de chose près pour l'État de Queensland : en igo6, le projet des Comités de salaires apparaît devant les maux croissants du sweating (2): on le repousse jusqu'aux deux lois d'avril r 908 et de décembre Ig08 (3), époque à laquelle les exemples voisins font céder les résistances.

La situation est plus complexe en Nouvelle-Galles du Sud, où se combinent les deux courants législatifs, celui des Comités de salaires et celui de la Cour d'arbitrage. Cependant ici encore les Comités de salaires fixant des minima apparaissent comme remplaçant en I908, par la loi du 24 avril (4), le système de la Cour d'arbitrage.

Les différentes législations australiennes sont donc bien une solution extrème du problème, à laquelle il semble qu'on n'ait eu recours qu'après avoir épuisé tous les autres moyens.

Cette législation est aussi, elle est surtout une législation expérimentale, et c'est sur ce second caractère qu'il nous faut maintenant insister.

(1) Aves, rapport cité, p. 77 .

(2) Cf. rapport Aves, p. 82.

(3) Bulletin de l'Offce international du travail, t. VIII, r9o9, p. LIv.

(4) Bulletin de l'offce international du travail, 1908, p. cxiv. 
La première loi qui établit les Comités de salaires à Victoria, celle du 28 juillet 1896 (I) fut seulement votée pour une période de quatre ans (2) : pendant son application, deux lois, l'une du 24 décembre I896 (3) et l'autre du 27 septembre 1897 (4), s'inspirant des premiers résultats de l'expérience, modifiaient dans un cas donné la composition d'un Comité ou donnaient au Gouvernement le droit de suspendre les décisions d'un Comité de salaire. La loi du 20 février I 900 prorogea de deux ans (5) la loi précédente de 1896 , tout en modifiant la législation existante sur de nombreux points de détail. Survint alors, et c'est la preuve manifeste du caractère expérimental de notre législation, ce que les Anglais appellent la rupture de la législation. Divers projets étaient à l'étude en juillet rgo2 et n'avaient pas abouti. A ce moment le Parlement de Victoria fut dissous soudainement le ro sep-

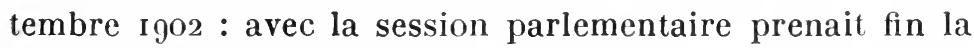
validité de la législation existante. Pendant près de trois mois, il n'y eut dans l'État de Victoria aucune législation sur les fabriques et magasins en vigueur (6). Toutes les déterminations des Comités de salaires cessèrent du mème coup d'avoir force légale.

La situation fut régularisée par une loi du 5 décembre I902 (7) remettant en vigueur les anciennes lois et règlements d'administration publique, mais pour un an seulement, jusqu'au 3i octobre igo3.

En 19o3, nouvelle prorogation par la loi du 3o octobre igo3 (8), avec nouvelles modifications au fond, jusqu'au 3 I décembre igo5.

Enfin la loi du 6 octobre r9o5 (9) est venue consolider et rendre applicable d'une manière durable la législation existante sans en rien la modifier : ainsi, après neuf ans

(1) 6o. Vict., $\mathrm{n}^{\circ}$ 1445. The Factories and Shops Act 1896 .

(2) Plus exactement jusqu'à la fin de la première session parlementaire suivant le I $^{\text {er }}$ janvier 1900 .

(3) The Factory and Shops Amendement Act 1896 , 60. Vict., n 1476.

(4) The Factory and Shops Act 1897, 61. Vict., n० 1518.

(5) Jusqu'à la fin de la session alor's en cours et ensuite jusqu'à la fin de la session postérieure au ier mai r 902.

(6) Factory Report, I902, p. 3.

(7) 2 Edward VII, n० 1804 . The Factories and Shops Continuance Act 1902.

(8) 3 Edward VII, $n^{\circ} 1857$. The Factories and Shops Act 1903.

(9) 5 Edward VII, n 1975 . The Factories and Shops Act 1905. 
d'expérience et neuf lois successives le système des Comités de salaires était définitivement adopté.

Encore faut-il ajouter que depuis la mème méthode a été suivie : la législation est définitive, mais on ne se prive pas de l'amender. Cinq lois successives sont intervenues : l'une de détail du i2 décembre igo5; l'autre, beaucoup plus importante, du 23 décembre 1907 ; la troisième encore, du 2 mars I 909, étendant à de nouvelles professions les Comités de salaires sont des preuves péremptoires que malgré les apparences actuelles et la loi dite de consolidation, la législation de Victoria reste aujourd'hui encore expérimentale.

Enfin deux autres lois de 1910 ( 1 ) sont intervenues :

La première, du 4 janvier, expérimentale toujours (2), étend les pouvoirs des Comités et leur donne de nouveau le droit de déterminer le nombre et les taux de salaires des apprentis et jeunes ouvriers.

La seconde déclare que des Comités de salaires seront créés dans de nouveaux métiers et de nouvelles professions pour lesquelles le Parlement aura passé une résolution déclarant opportune cette création.

Dans les autres États australiens, la législation pour être moins abondante n'en est pas moins formée comme à Victoria par des apports successifs. L'Australie du Sud a, elle aussi, sa loi de consolidation en date du 2 I décembre 1907 et ce n'est que devant le succès partiel des Comités de salaires qu'on s'est décidé à les étendre à de nombreuses professions (3).

Il y a plus : dans toutes ces législations le mode de création de nouveaux Comités de salaires, tantôt l'avis d'une des deux Chambres, tantôt l'avis de toutes les deux, parfois la seule autorité du gouverneur, permet une souplesse assez grande pour adapter le mécanisme aux nécessités pratiques.

(r) An Act to amend the factories and shops Act, 4 janvier r9ro. Annuaire de la législation du travail, r9ro, p. 347.

Cf. Labour Gazette, 1911, p. 195 .

(2) Elle doit rester en vigueur jusqu'au 3r décembre rgr2.

(3) Voir la liste des industries où fonctionnent des comités de salaires, art. 78 de la loi du 21 décembre i907. Bulletin de l'Offlce intern. du travail, 1908, p. 348 . Il faut mentionner aussi la loi du 23 décembre 1908 (Bulletin de l'offce intern.du travail, I909, p. Lxxiv), modifiant certains points de détails. 


\section{II. - LES DISPOSITIONS DE LA LOI}

La législation australienne a manifestement inspiré la législation anglaise; celle-ci est d'ailleurs beaucoup plus intéressante pour nous; aussi suffira-t-il d'indiquer sommairement les grandes lignes de la législation australienne pour insister avec plus de détails sur la législation anglaise.

a) Législation de Victoria.

J'insisterai seulement sur les traits les plus saillants de la législation de Victoria; deux points de vue guideront nos développements:

Il faudra souligner quelques questions particulièrement délicates de cette législation australienne.

Puis dégager de l'évolution législative accomplie les renseignements intéressants.

La loi du 28 juillet 1896 , confirmée d'ailleurs sur ce point par la loi confirmative du 6 octobre $\mathbf{1} 905$, établissait, dans les industries précitées, des Comités de salaires composés de io membres ( 5 patrons et 5 ouvriers), plus un président pris hors du Comité.

Le mode de formation de ces Comités était le suivant : en principe (art. 77 de la loi du 6 oct. i 9o5), ces membres sont nommés par le gouverneur; ordinairement, avant cette nomination, le ministre peut, par voie de notification dans la Governement Gazette (journal officiel) désigner des personnes comme représentants des patrons et comme représentants des ouvriers, ayant qualité pour être nommées membres du comité. Si dans le délai de 2 I jours aucune objection n'est faite par un cinquième au moins des employeurs ou des employés, la désignation est transformée en nomination.

Le plus souvent, ces désignations sont faites avec tant de soin que les objections sont rares (I).

(1) Rapport Aves, p. 17, note 2. Cf. rapport Aves, pp. 20 et 167. 
Si, au contraire, une objection valable a été soulevée, les membres sont élus de quelque côté qu'ait été prise l'initiative de la protestation. Les règles de l'élection sont prévues pour cela dans les règlements; en voici le résumé :

La liste des électeurs pour les employeurs est dressée par l'inspecteur en chef d'après la liste des patrons enregistrés (I).

Celle des électeurs pour les employés est également dressée par l'Administration et basée sur les rapports des employeurs. Ceux-ci doivent, sur les modèles de rapports distribués par l'Administration, déclarer tous leurs employés des deux sexes âgés de $\mathrm{r} 8$ ans et au-dessus.

Les bulletins de vote sont envoyés par la poste et peuvent être retournés par la même voie ou placés dans une urne dans les bureaux de l'inspecteur en chef des fabriques.

Le président du Comité est nommé par le Gouverneur et choisi en dehors du Comité sur la présentation des membres de ce Comité.

Les Comités de salaires procèdent alors à l'élaboration du tarif minima des salaires. La loi de Victoria rgo5 (art. 87, 88 et 89) leur donne le droit de fixer à leur gré soit des prix ou tarifs de salaires aux pièces, soit (2) des prix ou tarifs de salaires au temps, soit à la fois aux pièces et au temps (3).

Là est en effet le délicat problème de taxation; encore faut-il remarquer que le législateur de Victoria donne l'antériorité et la préférence comme base d'évaluation au salaire au temps:

"Art. 89. - Si, en vertu de la présente loi, une décision du Comité spécial fixe pour un travail, à la fois des prix ou

(I) A Victoria, l'obligation de l'enregistrement est imposée par la loi, sous peine d'amende (art. 23 de la loi de $1(05)$.

(2) L'article 83 indiquait comme règle aux limites pour la détermination des minima dans les deux cas "les prix et tarifs de salaires moyens qui ont été effectivement payés par des patrons honorablement connus (reputable employers) à des ouvriers de capacité moyenne". Si ces prix et tarifs moyens sont jugés insuffisants par le Comité, il est dessaisi, et c'est la Cour d'appel en matière industrielle qui statue en toute liberté. Cet article a été abrogé par l'article II de la loi du 23 déc. 1907.

(3) Toutefois, dans l'industrie de la préparation ou fabrication totale ou partielle de vêtements ou effets d'habillement hors de l'usine ou de l'atelier, il ne pourra être fixé que des salaires aux pièces (art. 87). 
tarifs de salaires aux pièces et des prix ou tarifs de salaires au temps, les prix ou tarifs de salaires aux pièces devront toujours avoir pour base les prix ou tarifs de salaires au temps (I). ")

Ce choix se comprend si l'on songe que les Comités ont encore le droit (art. 9o) de fixer le maximum d'heures hebdomadaires de travail auxquelles correspondent les salaires au temps ainsi déterminés.

Enfin les déterminations de salaires entrent en vigueur à la date fixée par le Comité, et au plus tòt trente jours après la date de la décision. Ils demeurent exécutoires, sous peine d'une amende, jusqu'à nouvelle décision.

Un double recours est ouvert contre eux : d'abord les déterminations sont susceptibles de modifications ou de cassation par la Cour d'appel en matière industrielle (art. I00). Ensuite le gouverneur peut suspendre pour six mois les décisions des Comités, et alors le Comité cède et modifie sa décision - ou au contraire, il la maintient sans modification; en ce second cas, l'arrêté suspensif du gouverneur est révoqué - au plus tard dans les quatorze jours par un nouvel arrêté pris en Conseil.

La sanction de ces arrêtés (art. II9) est une amende de Io $£$ pour la première infraction, de 5 à $25 \mathfrak{f}$ pour la seconde, de 5 o à $500 \mathfrak{f}$ pour la troisième et les suivantes. La preuve $\left(\right.$ art. $\left.98,4^{\circ}\right)$ de paiement de salaires conformes ou non conformes aux minima de la détermination des Comités incombe dans tous les cas au défendeur : ce qui est d'une importance capitale.

On en aura fini avec l'étude des principales dispositions de la législation de Victoria en indiquant encore les résultats intéressants de l'expérience législative de cette colonie en ce qui concerne le mode de vote et les dispositions légales au sein de ces comités. La loi du 5 décembre Ig02 (2) (art.9) avait décidé que dans certains comités (3) une majorité spéciale -7 voix si les io représentants des ouvriers et des

(1) Malgré cela, le même article stipule expressément que la décision des Comités de salaire ne sera pas attaquable si le second tarif (aux pièces) donne un gain supérieur ou inféricur au premier (au temps).

(2) Bulletin de l'Offce intern. Alu travail, rgo2, t. I, p. 646.

(3) Fabrication de boissons gazeuses, d'engrais artificiels, dinandiers, fondeurs, ouvriers en cuir et poseurs de fourneaux. 
patrons étaient présents, 4 voix, dont 2 des patrons et 2 des ouvriers, dans le cas où 6 représentants seulement sont présents - était nécessaire pour les décisions de ces Comités. Mais en i 903 , par la loi du 30 octobre (I), on renonça à ce système d'une majorité spéciale et l'on revint à l'ancienne pratique de la majorité absolue, avec droit du président de départager les votants au cas d'égalité des voix dans les deux sens. On peut retenir de cet épisode législatif un effort pour assimiler autant que possible le contrat collectif légal au contrat collectif volontaire et y voir un hommage indirect, mais certain, à la prépondérance des mœurs sur la contrainte législative.

b) Autres États.

Voici maintenant dans un tableau comparatif un aperçu de la législation des autres États d'Australie.

(1) Bulletin de l'Office intern. du travail, ı904, t. III, p. 384. 


\begin{tabular}{|c|c|c|c|c|c|c|c|c|c|}
\hline $\begin{array}{l}0 \\
\frac{7}{3} \\
0 \\
0 \\
0 \\
0 \\
0\end{array}$ & 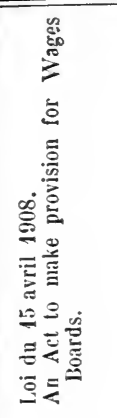 & 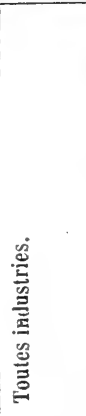 & 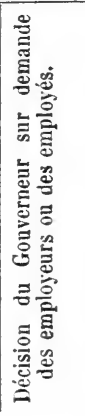 & 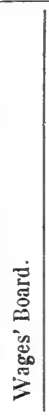 & 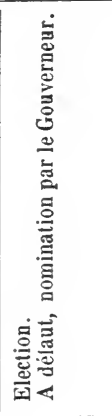 & 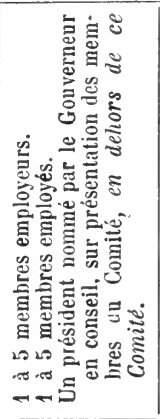 & 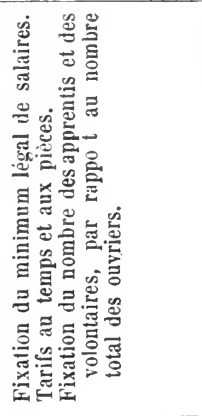 & 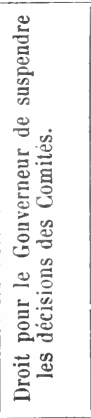 & 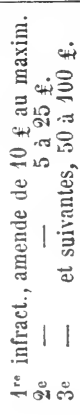 \\
\hline 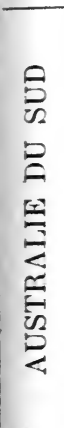 & 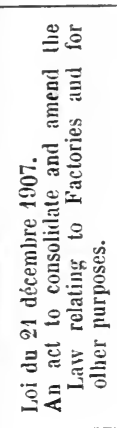 & 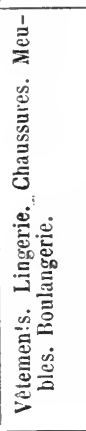 & 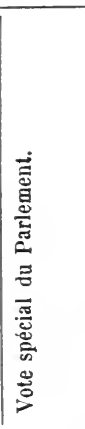 & 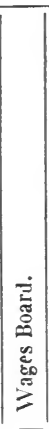 & 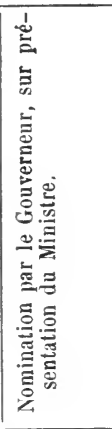 & 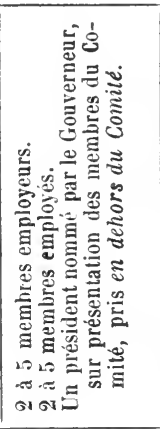 & 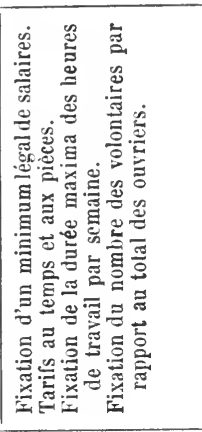 & 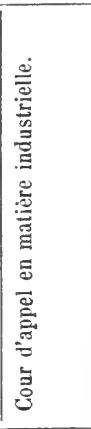 & 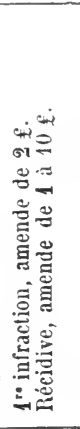 \\
\hline 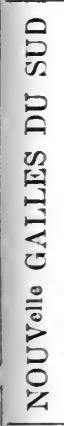 & 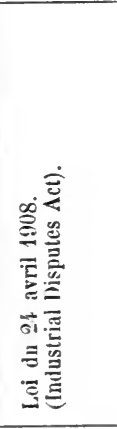 & 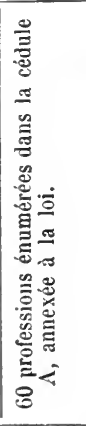 & 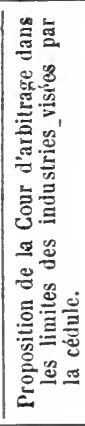 & 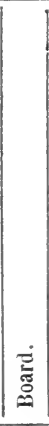 & 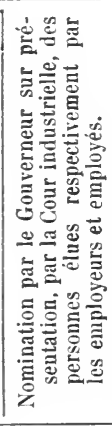 & 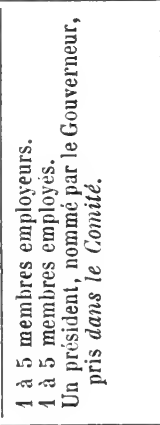 & 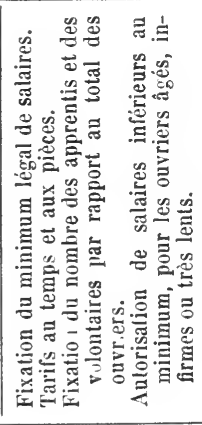 & 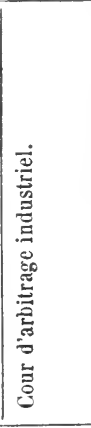 & 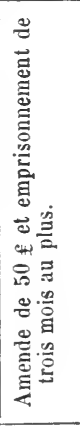 \\
\hline 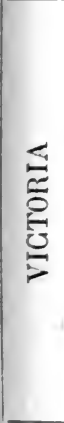 & 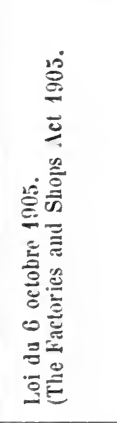 & 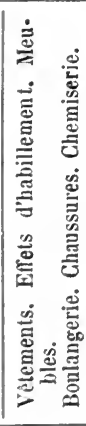 & 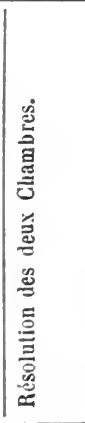 & 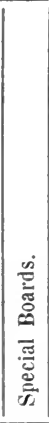 & 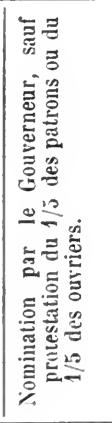 & 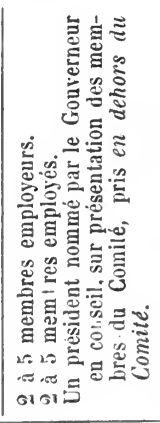 & 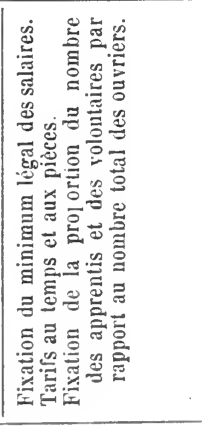 & 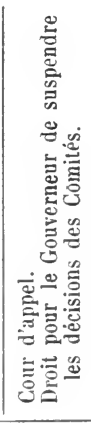 & 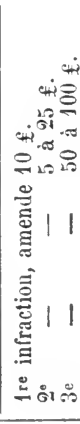 \\
\hline & 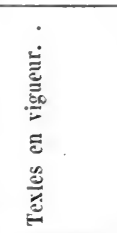 & 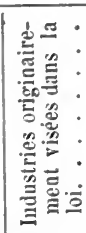 & 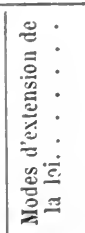 & 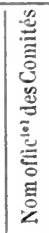 & 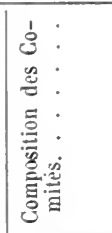 & 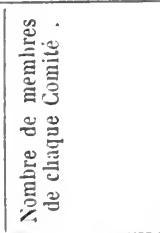 & 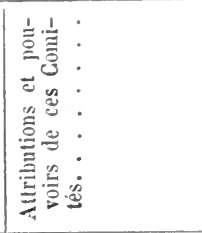 & 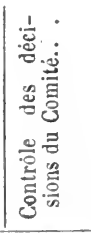 & 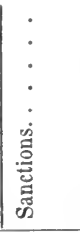 \\
\hline
\end{tabular}


D'après ce tableau, on constate que les législations du Queensland, de l'Australie du Sud et de la Nouvelle-Galles du Sud (I) reproduisent, à quelques détails près, la législation modèle de Victoria, que ces États ont entendu adopter et imiter.

Une loi toute récente, du I5 avril I9I2, vient de remanier sur certains points de détail le système de la NouvelleGalles du Sud, qui reste le mème dans ses grandes lignes, c'est-à-dire Cour d'arbitrage (2) et Comités de salaires.

Ces Comités sont aujourd'hui composés de trois ou cinq membres : un président nommé par le Ninistre et deux ou quatre membres choisis moitié parmi les ouvriers, moitié parmi les employeurs de l'industrie représentée par le Comité. Ces Comités sont nommés pour trois ans.

Leurs attributions restent en principe les mêmes : ils sont saisis soit à l'initiative du Ministre, de la Cour et des employeurs et employés intéressés. L'appel a lieu devant la Cour d'arbitrage dans les trente jours de la notification aux parties.

(1) Il suffira d'indiquer, en ce qui concerne la Nouvelle-Galles du Sud, que le système établi par la loi de rgos combinait le système néozélandais de la Cour d'arbitrage avec celui des Comités de salaire de Victoria. Les Comités de la Nouvelle-Galles du Sud ( 1 président et 2 à 10 membres, mi-partie patrons, mi-partie employés) étaient créés par le Ministre sur la proposition de la Cour d'arbitrage, soit que celle-ci agisse de sa propre initiative, soit qu'elle agisse sur la proposition des employeurs ou des Trade-Lnions. Cif. Bulletin tle l'Office international du travail, igo8, p. cxiv.

(2) Cif. plus loin, p. 338. 


\section{III. - LES RÉSULTATS}

Comment fonctionne le mécanisme des Comités de salaires?

Telle est la dernière question qu'il nous reste à examiner.

Il est difficile de se rendre un compte exact de l'effet de cette législation; pour le faire aussi complètement que possible, nous envisagerons successivement :

a) L'action des Comités de salaires et les résultats obtenus au point de vue du salaire;

b) Les appréciations critiques portées sur les résultats.

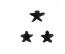

a) Les résultats de l'expérience australienne d'après l'action des Comités de salaires ( $\mathrm{I}$ ).

Aujourd'hui (2), la presque totalité de la classe ouvrière est soumise au système des Comités de salaires (3). Il y avait, à la fin de s9 1o (4), d'après le rapport de l'inspecteur en chef de Victoria, 9i Comités de salaires (5) comprenant I 10.000 employés : le nombre des déterminations de salaires en vigueur à la même époque était de $7 \mathrm{I}$, bien observées dans l'ensemble, eu égard au nombre des employeurs et des employés.

(I) Report of the Royal Commission appointed to investigate and report on the operation of the Factories and Shop Laws of Victoria (1902-r9o3). Robt. S. Brain. Government Printer. Melbourne.

Rapports annuels de l'inspection des fabriques à Victoria.

Robert Boehringer. Die Lohnämter in Victoria. Leipzig, Duncker et Humblot, I911.

John Hoatson. Victorian minimum wage System. Report of Conference on a minimum wage. Londres, 1907 , p. 75 .

(2) Il y eut, en effet, au début, quelques difficultés : mauvaise volonté, méfiance, difficulté d'établir des tarifs, en un mot quelques tàtonnements.

(3) En 1907, 7r comités englobant 50.000 ouvriers sur 70.000.

$\begin{array}{lllll}\text { En r } 1908, \text { les Comités } & - & 55.000 & - & 76.000 . \\ \text { En } 1909, & - & 75.000 & - & 79.000 .\end{array}$

On y a, en effet, adjoint en igo9 les ouvriers des mines.

Cf. R. Broda. La flxation légale des salaires. Paris, Giard, I912, p. 48.

(4) Labour Gazette, octobre i91 1, p. 396.

(5) Sur lesquels quatre n'avaient pas encore été constitués. 
D'après un tableau publié par l'inspecteur en chef dans son rapport de 1904, des tableaux furent dressés pour 37 métiers ou branches de métiers, montrant l'augmentation moyenne des salaires hebdomadaires : l'augmentation moyenne, pour ces 37 accroissements de salaires, est de 4 s. 6 d.; les déterminations sont des plus variables, depuis I d. par jour pour les potiers (ovenmakers) jusqu'à I I s. 4 d. pour les tonneliers (coopers) (I).

L'augmentation dans les huit métiers où domine le travail féminin est de près de $2 \mathrm{~s}$. dans les trois métiers de l'habillement : confection, chemiserie, vêtements de dessous (clothing, shirt and underclothing); l'augmentation moyenne est de I s. 4 d. (2).

Le sweating a à peu près disparu, comme le montrent les quelques cas typiques suivants :

a) Un finisseur de pantalons gagnait en $18_{9} 3$, pour io à I 2 heures par jour, un salaire hebdomadaire de $5 \mathrm{~s}$. : le minimum est aujourd'hui ( $19 \%$ /) fixé à 20 s. Les travailleurs aux pièces y gagnent 2 I s. 5 d.;

b) Un finisseur de chemises bon travailleur gagnait par jour, en I89o, 2 s. 6 d. au maximum; d'autres ouvriers de ce métier, en travaillant sans arrèt, gagnaient, en 1893-94, 7 à $8 \mathrm{~s}$. par semaine. Le maximum est maintenant de $16 \mathrm{~s}$.;

c) Des ouvriers confectionneurs de chemises gagnaient, avant la détermination des Comités, 2 s. 4 d. par douzaine; depuis la détermination (1898), 3 s. 3 d.; les finisseurs, avant la détermination, $41 / 2 \mathrm{~d}$. par douzaine, sont, depuis celle-ci, à $8 \mathrm{~d}$. par douzaine, etc. (3).

Il résulte d'ailleurs du tableau détaillé des salaires moyens établis par les Comités, dressé par M. Bœhringer (4), que, de 1896 à 1907 , le salaire a, en général, considérablement augmenté.

Enfin la comparaison entre les métiers où est appliqué le système des Comités et ceux où il n'existe pas est encore singulièrement significative :

Le rapport précité de 1904 accuse 224 travailleurs dans la

(I) Hoatson, op. cit., p. 79.

(2) Ibid., Hoatson, p. 79 .

(3) Ibid., Hoatson, p. 79 .

(4) Op. cit., Die Lohnämter in Victoria, p. 128. 
partie de l'industrie du vètement où n'existent pas de Comités : leur salaire est de I s. 6 d. inférieur à celui deș 5. I 3 travailleurs jouissant du système des Comités.

De mème, 208 ouvriers de confection dans les districts non réglementés ont un salaire moyen de 7 s. 2 d., tandis que celui des 6.224 ouvriers jouissant des Comités est de I 2 s. 2 d. par semaine.

Tous ces faits concordent pour établir de façon certaine l'heureuse action des Comités de salaires sur le taux de la rémunération des travailleurs.

Il y a lieu de noter enfin que les minima établis ne sont pas, comme on l'avait prétendu, les moyennes effectivement payées :

Dans sept métiers masculins, la moyenne des salaires effectivement payés dépasse de $3 \mathrm{~s} .71 / 2$ d. le mininum fixé; ailleurs, dans dix autres métiers féminins, l'écart est de 2 s. 3 d.

Dans l'industrie du vêtement, les minima étaient, en r 904 , respectivement de 25 s., 30 s., 40 s., 45 s. et óo s. : le salaire moyen était de $53 \mathrm{~s}$. par semaine (I).

\section{$\stackrel{\star}{\star \star}$ \\ b) Les résultats de l'expérience australienne d'après les témoignages critiques.}

Nous ne pouvons, bien entendu, faute d'enquète personnelle, apporter ici que des témoignages de seconde main de publicistes français ou étrangers qui ont étudié sur place l'expérience du minimum légal de salaire.

Voici la revue rapide des principaux jugements portés sur la législation nouvelle tant en France qu'à l'étranger (2).

La plupart des auteurs français manquent de netteté dans leurs conclusions :

“ Doctrines et théories, écrit M. Deschars (3), n’ont guère

(r) Hoatson, p. 83.

(2) Nous écartons, bien entendu, de cette revue les livres et articles d'auteurs qui n'ont pas vu.

(3) Ch. Deschars. L'organisation du travail en Australie. Revue politique et parlementaire, septembre 1908, p. 592. 
encore subi ou n'ont pas encore enduré les épreuves et les réalités de la vie courante. Nous connaîtrons leur degré de résistance au contact des faits. ")

M. Albert Métin (I) disait : "En somme, l'institution des Conseils de Victoria est, comme le dit justement l'inspecteur en chef, la première tentative légale faite dans le monde pour réprimer le sweating system : elle est allée tout droit au moyen le plus héroïque, fixation d'un salaire minimum; elle s'est heurtée à deux grancles difficultés : l'exclusion des ouvriers lents et maladroits et la fixation du salaire aux pièces. " Il était sans doute trop tôt pour porter un jugement définitif.

Autrement significatifs sont les témoignages anglais: nous insisterons tout particulièrement sur les deux plus importants, celui de M. Reewes et celui de M. Aves.

M. Reewes (2), qui étudiait la législation des Comités de salaires en vue de son introduction éventuelle en NouvelleZélande, énonçait un jugement des plus favorables sur l'effet d'ensemble de la législation de Victoria :

"Sans nier que la loi de r 896 ait été et soit chaudement critiquée dans cette colonie et sans affirmer qu'elle soit actuellement (3) sortie de la phase d'expérimentation, j'affirme que les industries de Victoria en ont tiré parti pour prospérer et regagner la place qu'elles occupaient en I 890 , mais qu'elles avaient si lamentablement perdue après la panique financière et l'effondrement communément appelé le krach agraire de Melbourne (the Melbourne land boum). En I89o, quand Victoria jouissait de la prospérité inouïe qu'elle devait après payer si cher, le nombre des bras employés dans les fabriques de la colonie était de 47.813. En I894, au moment du maximum de la crise, le nombre en tombe à 34.268. En I9oo, il s'est élevé à 52.898. Quel que soit donc le résultat de la loi sur le minimum de salaire, durant les quatre années d'application, elle n'a pas été, en général, ruineuse ni accablante (4). 》

(1) Législation ouvrière et sociale en Australie et Nouvelle-Zélande. I vol., Paris, Imp. nationale, I90I, p. 99 .

(2) The minimum wage law in Victoria and South Australia. Economic Journal, rgor, vol. XI, p. 334 .

(3) Ceci est écrit en rgor.

(4) Art. cité, p. 334 . 
Et plus loin : "A voir les choses en gros, les Comités n'ont pas échoué. Dans leur effort pour réorganiser six métiers sweated, ils ont réussi pour quatre et partiellement réussi dans les deux autres... Ils ont aidé le bon patron contre le patron au rabais et le patron sweater. Les prix pour le consommateur n'ont pas été élevés d'une manière appréciable par leurs réformes : le public ne saurait donc se plaindre. En faisant leur part aux erreurs, ils ont amélioré le sort des travailleurs. Un progrès réel a été accompli dans une cause légitime et Victoria a beaucoup de raisons de reprendre la grande expérience sur de nouvelles bases en faisant un nouvel essai avec des conditions nouvelles (I). ")

Le mème auteur a précisé, en la confirmant, cette appréciation, lors du meeting anglais sur la question (2) :

"Sans doute nos lois, je le maintiens, ne sont pas une solution définitive du problème industriel; elles sont un essai courageux, humain et couronné de succès pour faire quelque chose, ').

Il insiste, par des exemples, sur l'utilité du rouage des comités de salaires, en indiquant qu'il faut, dans la constitution de ces bureaux, faire une large place aux TradeUnions.

Le second témoignage anglais est celui de M. Aves, qui fut chargé par l'Angleterre, et avant l'élaboration de la loi actuelle, d'aller étudier sur place la législation australasienne (3).

Ses conclusions, optimistes dans leur ensemble, ne laissent pas que d'être modérées en la forme. M. Aves remarque que les efforts de la législation de Victoria se sont faits jusqu'ici sentir pendant une période de prospérité, et que le sweating aurait peut-être disparu automatiquement par le développement de la colonie. Cependant les Comités ont eu une influence incontestablement heureuse.

Voici, d'ailleurs, le texte même de la conclusion de M. Aves en ce qui concerne les Comités (4) :

(1) Ibial., p. 341 .

(2) National Anti Sweating League. Londres, 1907. Report of Conference on a minimum wage, p. 69 .

(3) Ernest Aves. The Wages Board and Industrial Conciliation and arbitration Acts of Australia and New Zealand. 1 vol., Londres, 1908.

(4) Rapport cité, p. 123. 
“ En ce qui regarde plus particulièrement le remède des Comités spéciaux, on a vu que l'expérience australienne, d'après les métiers où elie a été appliquée, a été, pour la plus grande partie, limitée aux diverses branches de l'industrie du vêtement. Ces métiers se sont développés dans une petite communauté riche, grandement centralisée et comparativement homogène, également éloignée, sauf dans quelques cas isolés, des extrêmes de la pauvreté ou de la richesse. Les comités ont réussi à une époque de prospérité croissante, dans des conditions où le travail a été souvent rare et sur des marchés doublement protégés par la loi et leur position géographique. L'opinion publique, cependant, a été capable d'envisager assez aisément le champ tout entier de l'industrie, une connaissance intime a pu s'établir des individus et des cas individuels, rarement possible dans des communautés plus étendues...

L'expérience de Victoria, quoique valable et intéressante, n'est donc pas entièrement concluante, parce que trop brève, trop simplifiée et trop exclusivement liée à une ère de prospérité économique...

Les Comités ont permis, dans le travail à domicile et dans la fabrique, et probablement au delà même des métiers où ils existaient, d'atteindre un certain niveau de salaire. On a confiance en eux pour marquer un point au-dessous duquel, même avec une réaction, les salaires ne sauraient tomber sans grande difficulté.

Ils ont eu une action considérable et bienfaisante sur le public, gràce à leurs propositions et déterminations, à lá publicité qui leur était donnée et à la consécration officielle qu'ils avaient reçue. "

On le voit donc, le rapporteur Aves, tout en réservant comme il convenait la transposition projetée de la loi de l'Australasie à l'Angleterre, conclut en somme en faveur des bons résultats du système, en insistant sur leur action favorable et éducative.

D'ailleurs le fait mème qu'après de nombreux débats et une étude approfondie, l'Angleterre a accepté le système des comités de salaires australasiens, en l'adoptant, n'est-il pas 
une preuve certaine de leurs résultats dans l'ensemble favorables (I)?

Il reste enfin à examiner une troisième source de documents qui peut encore nous renseigner sur l'expérience étudiée : ce sont les documents officiels des États intéressés et les témoignages recueillis auprès des patrons et des ouvriers par divers enquèteurs, notamment par M. Aves.

Les documents officiels de Victoria (2) sont, en général, favorables à l'expériences des Comités de salaires.

Dès I 90I, un inspecteur des fabriques de cet État pouvait affirmer : "Il n'y a plus maintenant de sweating dans l'industrie du vètement de l'État de Victoria. Dans le court espace de trois années, toutes les circonstances ont changé. Il n'y a plus à enregistrer de plaintes sur le sweating terrible; il n'est plus parlé de misérables intérieurs et de salaires plus misérables encore. La majorité des industriels reconnaît maintenant que la loi a été favorable aux bons travailleurs aussi bien qu'aux employeurs (3). ")

Les nombreux extraits de rapports officiels rapportés par M. Aves (4) semblent, en général, être dans le même sens.

Le rapport de igo4 (5) d'un Comité spécial de l'Australie $d u$ Sud chargé d'enquêter sur les résultats du système d̀ Victoria s'exprime aussi nettement; M. Aves (6) en résume ainsi les conclusions :

a) Les salaires ont considérablement augmenté dans le plus grand nombre des professions;

b) Un grand nombre d'ouvriers ont été rejetés du métier;

c) Il s'en est suivi une limitation fâcheuse du travail des jeunes, qui a constitué un grand malaise (7);

d) Les travailleurs à domicile ont diminué beaucoup en nombre et quelques-uns ont beaucoup souffert;

(r) Cf. Raoul Jay. Discussion au Conseil supérieur du travail, nov. rg1o. Compte rendu, pp. 15 et suiv.

(2) Report of the Chief Inspector factories, workrooms and shops. Melbourne. Annuel.

(3) Cité par Reewes. State Experiments in Australia and New Zealand. r902, p. 57.

(4) Rapport cité, p. 208.

(5) Pp. XiII, vi, viI.

(6) Rapport cité, p. 79 .

(7) A cette époque, les Comités de salaire avaient encore le pouvoir de limiter le nombre des apprentis. 
e) Un certain nombre d'usines ont fermé ;

$f$ ) La tendance est de prendre le minimum de salaire pour un maximum;

g) Le travail s'est fait en fabrique, et les employés ont dû accomplir une besogne plus dure;

h) La loi est tournée dans un certain nombre de professions ;

i) Dans l'industrie du meuble, les Chinois se sont développés au détriment des Européens;

j) Les grèves ont disparu;

k) Les femmes ouvrières ont beaucoup profité de la loi ;

l) Le sweating, dans l'industrie du vêtement en général, a disparu;

m) L'industrie du vètement est la seule dans laquelle employeurs et employés sont, dans l'ensemble, satisfaits du système des Comités.

En conséquence, le Comité concluait à la formation de nouveaux Comités dans deux industries nouvelles pour l'Australie du Sud.

Les résultats de l'enquête personnelle de M. Aves (I) ne paraissent pas moins favorables :

A la question ainsi posée : Trouvez-vous que le système des Comités de salaires est avantageux pour votre propre industrie?

33 réponses affirmatives, I 7 négatives, 5 douteuses furent obtenues.

A la question analogue : Trouvez-vous que le système des Comités de sataires est avantageux pour l'ensemble de la nation (community)?

3 I réponses affirmatives, I 7 négatives, 6 douteuses furent faites.

Enfin à la question Approuvez-vous le système des Comités de salaires adopté à Victoria? 33 réponses favorables, dont 25 des employés de Victoria, furent faites; 3 négatives seulement.

(1) Rapport cité, p. ı66. Cette enquête a été menée par l'auteur dans les trois pays intéressés (Victoria, Nouvelle-Galles du Sud, NouvelleZélande) dans les milieux industriels et officiels. (Cf. détails, rapport cité, p. I6r.) 
Notons enfin que 26 employeurs à Victoria même étaient, en 1907 , partisans d'une extension du système ( 1 ).

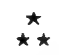

En ce qui concerne l'application du système dans les États autres que Victoria, c'est-à-dire à Queensland, en Nouvelle-Galles du Sud et en Australie du Sud, Ies renseignements sont moins abondants.

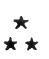

Pour la Nouvelle-Galles du Sud (2) cependant, la loi nouvelle de igo8 est plus populaire auprès des employeurs qu'auprès des employés. Les Trade.Unions sont plutôt contre elle.

En r 909, I08 Comités de salaires furent nommés; 73 ont rendu leurs sentences; 20 siégeaient encore en fin d'année. Les bureaux ont résolu avec succès un certain nombre de petits conflits et quelques difficultés de plus grande importance. Mais les pénalités contre la grève n’ont pas empêché les grandes associations de faire grève, apparemment avec impunité (2).

Cependant, dans l'ensemble, on est satisfait du système, au moins en ce qui concerne la détermination des minima de salaires (4).

En ce qui concerne l'Australie du Sud (5), un tableau publié par M. Aves montre quel était, en rgo8, l'état des salaires obtenus par les Comités de salaires :

(1) Rapport cité, p. 26.

(2) Clark. Recent changes in Australasian laws against strikes. Qualerly journal of Economics. May, 1910, p. 561.

(3) C'est surtout au point de vue de la prévention des grèves que le système a été très défectueux. De grandes grèves éclatèrent en 1909: des mesures spéciales furent prises et les meneurs condamnés. Cf. Clark (art. cité).

(4) Rapports consulaires du vice-consul français à Melbourne pour 1908, 1909 et 1910, eités par Boyaval. La lutle contre le Sweating System. I vol., Paris, Alean, 1912, p. 297, note 1.

(5) Rapport Aves, op. cit., p. 77. 
$-29^{8}-$

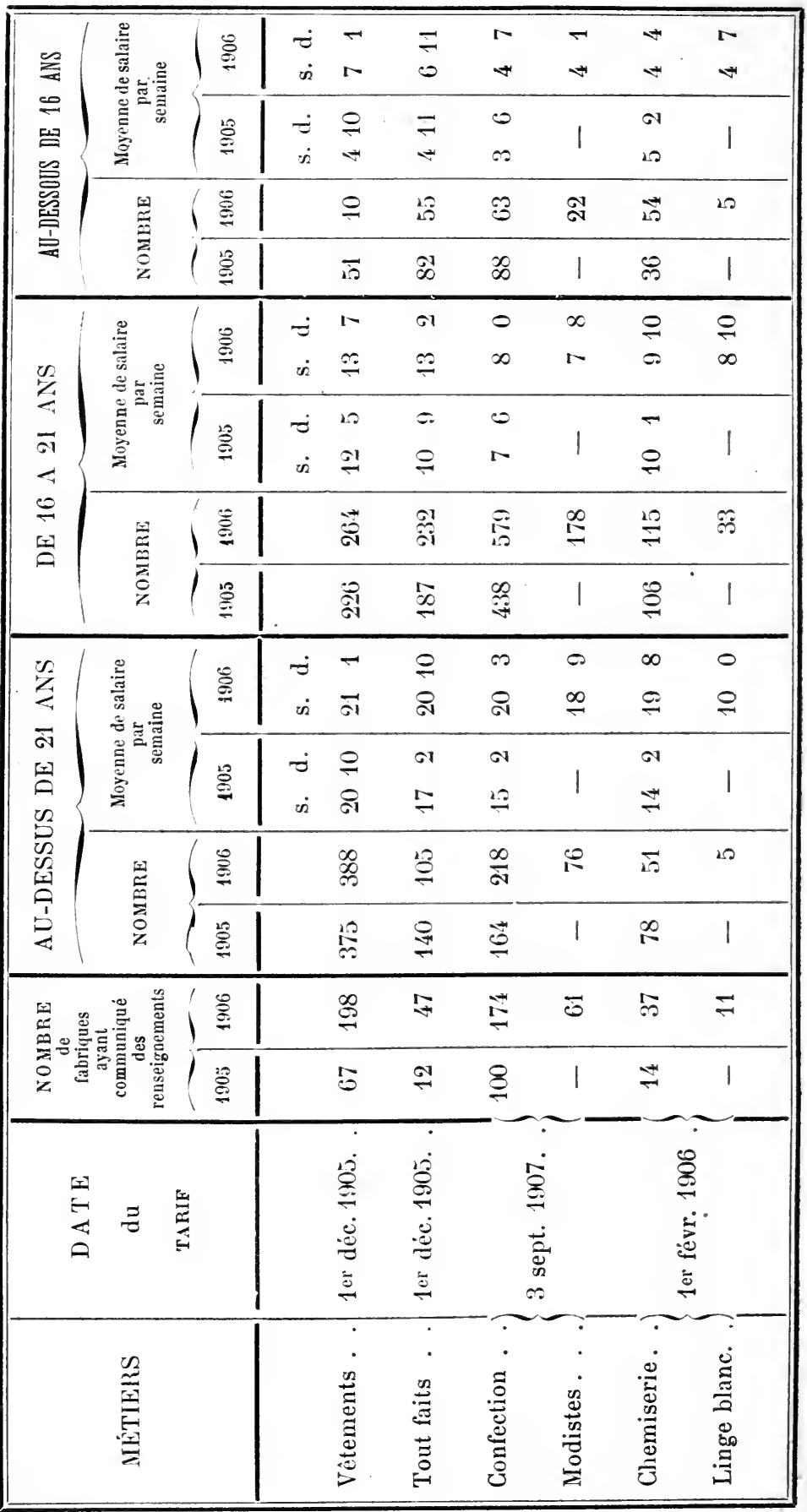


M. Aves déclarait à l'époque l'expérience trop courte et trop confuse pour obtenir les conclusions bien probantes : de plus, et jusqu'en 1907 ( I), il n'existait aucun moyen de donner valeur légale aux déterminations des Comités et leur observation était purement volontaire. Seule la souveraineté économique de la majorité des employeurs et des employés en assurait le respect.

Au total, on peut, semble-t-il, conclure que l'expérience australasienne est plutôt favorable et qu'elle paraît avoir réussi. L'augmentation constante et continue du nombre des comités, l'adoption de la législation de Victoria par les pays voisins, les témoignages recueillis sur place par les divers enquèteurs ci-dessus cités semblent, dans la mesure où il est possible de s'en rendre compte, pouvoir être valablement invoqués comme preuves du succès pour l'expérience tentée.

(I) Rapport de l'inspecteur en chef du 30 aoùt 1907 . 


\section{Section B : l'Angleterre.}

La loi anglaise sur les comités de salaires est celle du 20 octobre sgog.

Il faut pour elle aussi étudier :

I. - Les antécédents de la loi.

II. - Les dispositions de la loi.

III. -- Les résultats actuels.

\section{I. - LES ANTÉCÉDENTS DE LA LOI}

Comme la loi australienne, la législation anglaise est une législation in extremis et une législation expérimentale.

C'est d'abord une législation in extremis.

La loi anglaise du 20 octobre Igo9 parait bien aussi l'adaptation d'une idée ancienne, celle du Comité des salaires, à une situation désespérée du travail à domicile.

L'idée des Comités de salaires a en effet un long passé théorique chez nos voisins, en mème temps qu'une brillante histoire pratique.

St. Mill (I) en démontrait l'inefficacité et l'inutilité. Plus tard, Sidney Webb (2), dans son Histoire du TradeUnionisme, en construisait déjà la théorie économique. Sir Charles Dilke, après avoir soutenu, en 1877 , une controverse à ce sujet avec M. Deakin, le futur premier ministre australien, et défendu son idée au Congrès de Bruxelles (I 89 I), la présentait, dès I 895 , comme amendement à une loi sur les fabriques. En 1898, il faisait l'objet d'une proposition spéciale, toujours renouvelée depuis à chaque législature. On n'a pas oublié comment les excès du sweating soulignés par l'opinion publique et divulgués par la National anti Sweating League amenèrent enfin la réalisation de cette vieille idée. Encore fallut-il plus de deux ans depuis le pro-

(1) Principes d'économie politique. Chapitre intitulé : Moyens de combattre les bas salaires.

(2) Histoire du Trade-Unionisme, traduction française, 1897 , p. 136. Paris, Giard et Brière. 
jet Henderson (Sweated Industries Bill) aux communes jusqu'au vote définitif de la loi; la discussion parlementaire anglaise, avec ses différentes étapes, permet de suivre les progrès de l'opinion : on en arrive, à la lumière des faits, à prendre de plus en plus confiance, en présence de l'inefficacité de tous les autres, dans ce dernier remède proposé (I).

La législation des Comités dè salaires est bien une législation in extremis.

C'est ensuite une législation expérimentale.

La loi anglaise révèle pareillement ce caractère si curieux et bien anglo-saxon du législateur soumis aux faits et à la leçon de l'expérience.

Elle ne s'applique, on le sait, provisoirement qu'à quatre industries :

$\mathrm{I}^{0}$ Confection de vètements tout faits et sur mesure en gros, et toutes autres branches du vètement dans lesquelles le ministre du Commerce estime que le système de confection est, en général, semblable au système le plus usité dans le gros;

$2^{0}$ Fabrication de boîtes ou parties de boîtes manufacturées en tout ou en partie avec du bois, du carton, des copeaux de matières similaires;

$3^{\circ}$ Finissage de la dentelle et des filets à la mécanique; travaux de raccommodage et de reprisage dans le finissage des rideaux à la dentelle;

$4^{\circ}$ Fabrication des chaînes martelées et rivées à la main ou au marteau c̀ pédale (2).

Quant aux autres industries, la loi pourra leur être, dans l'avenir, déclarée applicable par voie d'ordonnances provisoires (provisional orders).

La tarification des salaires se fait, nous le verrons (3), lentement et en quelque sorte par étapes.

L'étude des travaux parlementaires anglais montre jusqu'à l'évidence cette préoccupation de se soumettre aux

(I) Cf. plus loin, p. 407 .

(2) C'est le texte même de la cédule, annexée à la loi, emprunté au Bulletin de l'offce international du travail, 1910, p. 36 : il montre avec quelle minutie le législateur a délimité le champ actuel de l'expérience.

(3) Gr. plus loin, p. 314 . 
faits. On sait que le projet de M. Henderson (Sweated Industries Bill) était beaucoup plus radical que le projet du Gouvernement transformé aujourd'hui en loi : d'après ce projet, les fixations de salaire minima devaient être faites immédiatement et du premier coup et non pas après six mois et sur proposition, comme elles le sont aujourd'hui. De mème, à maintes reprises, le Gouvernement dut calmer l'impatience des adversaires du sweating, trop pressés et trop désireux d'aboutir, qui voulaient dès le début élargir le champ d'application de la loi.

Enfin la très grande latitude laissée au Board of Trade dans la constitution des comités qui peuvent être formés soit à l'élection, soit à la nomination du Gouvernement, soit en mélangeant les deux systèmes, est encore la preuve d'un sérieux effort pour respecter les diversités spécifiques des industries et profiter des leçons de l'expérience. Le Board of Trade, d'ailleurs, est complètement entré dans ces vues du législateur et les divers règlements qu'il vient de publier réservent des interprétations possibles et par là même des modifications, en mème temps que la durée des pouvoirs des nouveaux Comités de salaires est strictement limitée.

Ainsi souplesse, désir de se laisser faire par la vie, mobilité, durée limitée, tels sont les principaux caractères que nous révèlent les antécédents de la législation. Il semble qu'avec une louable procédure le législateur esquisse en pointillé le trait que la réalité de demain viendra tracer en plein; il est tout près, d'ailleurs, à rectifier son premier jet et l'œuvre ne sera jamais pour lui définitive, subordonnée qu'elle demeure aux perpétuelles transformations des faits et aux innombrables contingences de la pratique.

On pourrait résumer ce caractère si original de nos deux législations en disant que si ce sont des lois, elles le sont aussi peu et aussi discrètement qu'il est possible ( $\mathrm{r}$ ).

(I) Ces antécédents de nos lois n'étaient pas inutiles à rappeler pour les replacer dans leur cadre, les mettre sous leur vrai jour. Notre législateur français, parfois trop convaincu de sa souveraineté et de sa toutepuissance, saura, nous l'espérons, puiser dans cette double expérience des leçons de modestie, de prudence, voire même de timidité, qui seront pour lui un précieux gage de succès dans l'œuvre délicate qu'il songe à aborder. 


\section{II. - LES DISPOSITIONS DE LA LOI}

L'étude de la loi du 20 octobre rgog (r) sur les Conseils d'industrie (Trade Boards Act) peut ètre faite en examinant successivement les cinq points suivants :

$\mathrm{I}^{0}$ Portée actuelle et extension future de la loi;

$2^{\circ}$ Constitution des Comités de salaires;

$3^{\circ}$ Fonctionnement:

$4^{\circ}$ Sanctions;

$5^{0}$ Dispositions secondaires.

a) Portée actuelle et extension future de la loi.

On a vu plus haut que quatre industries seulement pour commencer tombent sous le coup de la loi : l'industrie du vètement tout fait et sur mesure, la fabrication des boîtes, l'industrie de la dentelle et des filets à la mécanique, la fabrication des chaînes.

Quant à l'extension future de la loi, l'article I ${ }^{\mathrm{er}}, \S 2$, décide :

" Le Ministre du Commerce peut, par une ordonnance provisoire, rendre la présente loi applicable à toute industrie désignée non encore soumise à la loi, s'il considère que le taux des salaires courants dans une branche quelconque de ladite industrie est exceptionnellement bas, en comparaison avec celui pratiqué dans d'autres professions et $s^{\prime} i l$ estime que, vu la situation de cette industrie, il convient de la soumettre à la présente loi. "

Cette ordonnance provisoire doit être approuvée par le Parlement, qui la confirme.

De même le Ministre du Commerce (art. I ${ }^{\text {er }}$ §3) peut soustraire à l'application de la loi telle industrie qui lui convient : " $\mathrm{Si}$, à un moment quelconque, le ministre du Commerce estime que dans une quelconque des industries soumises à la présente loi, les conditions de travail se sont modifiées au point de rendre inutile l'application de la 
présente loi, il peut, par une ordonnance provisoire, soustraire ladite industrie à l'application de la loi. "

Enfin, c'est encore le Ministre du Commerce (art. 2, § r er) qui est le seul juge de l'opportunité de la création des comités de salaires.

Ainsi, et c'est le premier trait caractéristique de la législation anglaise, des pouvoirs très larges sont donnés au Ministre du Commerce sous le contrôle du Parlement, pour déterminer la portée et l'application de la loi.

Celle-ci, d'ailleurs, s'applique à tous les travailleurs employés dans l'industrie considérée, soit en fabrique ou en atelier, soit à domicile (art. 4 de la loi).

\section{b) Constitution des Comités de salaires.}

En ce qui concerne ce second point, le législateur anglais s'est contenté de poser quelques principes, s'en rapportant pour le surplus aux règlements pris par le Ministre du Commerce pour l'élaboration des détails.

Voici d'abord les seules exigences légales posées dans l'article i I :

$\mathrm{I}^{0}$ Les conseils comprendront un nombre égal de représentants des patrons et de représentants des ouvriers;

$2^{\circ}$ Les femmes peuvent, tout comme les hommes, faire partie des conseils d'industrie ;

3o Il pourra y avoir élection - ou présentation - ou élection pour partie et présentation pour partie; il suffira que les ouvriers à domicile, « là où ils se rencontreront en proportion notable, soient représentés ").

$4^{\circ}$ Le président de chaque bureau, choisi parmi les membres, est désigné par le ministre du Commerce qui nomme également le secrétaire;

$5^{\circ}$ Les délibérations d'un Conseil ne peuvent être annulées parce qu'une vacance s'est produite dans son sein ou pour cause de vice dans la nomination, l'élection ou la présentation d'un membre;

$6^{0}$ Le quorum nécessaire est la présence d'un tiers au moins des représentants (ouvriers ou patronaux) et d'un membre nommé;

$7^{\circ}$ Sur tous les points non spécialement fixés par la loi ou 
par le règlement, les Conseils sont souverains pour fixer leur mode de fonctionnement.

On voit par là encore comment la loi anglaise s'efforce, une fois les parties en présence, de leur laisser la plus grande souplesse et la plus grande initiative et d'arriver, en quelque sorte, bien qu'il s'agisse ici d'un contrat collectif légal, à se rapprocher le plus possible du contrat collectif librement arrèté par les intéressés.

C'est donc dans les règlements du Ministre du Commerce qu'il faut chercher maintenant le surplus d'indications en ce qui concerne la constitution des comités.

Ces règlements ont paru : ils sont aujourd'hui au nombre de quatre :

Le premier en date est celui du 25 novembre igog (I) pour l'industrie des chaînes martelées et rivées à la main ou au marteau à pédale.

Le second est celui du 27 avril I910(2) pour l'industrie des boîtes ou parties de boîtes en papier-carton, copeaux et matières similaires.

Le troisième est celui du 4 mai igro (3) pour le finissage des dentelles et filets confectionnés à la machine.

Le quatrième, enfin, est daté du 25 juillet igio(4) pour la confection des vêtements tout faits et en gros, pour les personnes du sexe masculin.

Analysons rapidement cette législation complémentaire : nous en verrons encore toute la souplesse.

Le nombre des membres des quatre comités jusqu’à présent réglementés est très variable: 15 à 17 dans l'industrie des chaînes, I 9 à 23 dans celle de la dentelle, 35 à $4 \mathrm{I}$ dans l'industrie des boîtes en papier, 29 à 37 dans celle des vètements tout faits et en gros pour hommes.

Le mode de composition de ces comités est également très variable; dans chacun d'eux on distingue trois éléments : $I^{0}$ L'élément officiel (5) composé des membres nommés

(1) Texte. Bulletin de l'offce intern. du travail, t. IX, 1910, p. 133.

(2) Texte. Ibid., t. IX, 1910, p. 383.

(3) Texte. Ibirl., t. IX, r910, p. 385.

(4) Texte. Ibid., t. IX, 1910, p. 440.

(5) Cet élément officiel doit être inférieur à la moitié du nombre total des représentants patronaux et ouvriers. (Art. I3, dernier raragraphe, de la loi de r909.) 
directement par le Board of Trade, le plus ordinairement au nombre de trois ( $\mathrm{I}$ );

$2^{0}$ L'élément patronal. Selon la faculté indiquée, cette représentation patronale est, soit intégralement nommée à l'élection (boìtes en papier, chaînes), soit choisie par le Board of Trade, sur la présentation des intéressés (industrie dentellière), soit pour partie élue ( 10 membres), et pour partie désignće sur présentation (3 membres) par le Board of Trade (industrie du vêtement);

$3^{0}$ L'élément ouvrier. De la mème manière on rencontre ici soit l'élection intégrale (chaînes) (2), soit la nomination sur présentation (boîtes en papier (3), industrie dentellière, vêtement).

Le président et le vice-président du comité sont nommés par le Board of Trade, désignés ordinairement parmi tous les membres du comité; parfois ils doivent être obligatoirement choisis parmi les membres officiels (industrie des chaînes).

Les comités sont formés pour trois ans.

Signalons enfin les règles pour le vote au sein du comité : ici encore, grande souplesse dans les limites du principe de l'égalité des deux représentations patronale et ouvrière; tantôt le Conseil (chaînes) est souverain pour prendre luimême les dispositions à cet effet; tantôt le règlement (boîtes, industrie dentellière, vètement), prévoit les moyens exprès d'assurer cette égalité; ou bien la partie en majorité décidera qu'un ou plusieurs membres s'abstiendront; ou bien le président (ou à son défaut le vice-président) peut renvoyer la question à une prochaine séance.

Dans l'industrie dentellière enfin, le règlement contient en outre cette clause spéciale, qui, tirée de la pratique des comités de salaires dans l'industrie privée, est vraisemblablement appelée à devenir le droit commun (4) des futurs comités.

(I) 3 à 5 cependant dans l'industrie du vètement.

(2) 4 délégués sont élus par les hommes, 2 par les femmes.

(3) On remarquera la liberté avec laquelle le système est appliqué : dans l'industrie des boìtes en papier, il y a élection intégrale pour l'élément patronal, nomination sur désignation pour l'élément ouvrier.

(4) Cf. cependant pour les Comités de district dans l'industrie du vêtement le règlement du ı mai rgı. Bulletin de l'Offlce international du travail, I9I1, p. 379 . 
"Il reste entendu que dans toute question de minimum de salaire, le président, ou en son absence le vice-président, peut, s'il le juge convenable, et doit, à la demande de la majorité absolue des représentants patrons ou ouvriers, faire voter les membres par catégorie; en pareil cas, le vote de la majorité des membres présents de l'une ou de l'autre catégorie prenant part au scrutin constitue le vote de cette catégorie. Dans un vote de ce genre, les membres nommés (par le Ministre) ne prennent pas part au scrutin; si le vote accuse une divergence d'opinion, la question est tranchée par le vote, à la majorité, des membres nommés par le Ministre (I). ")

En un mot, le Board of Trade est seulement la cheville ouvrière, l'agent excitateur du contrat collectif arrêté par les parties qui doit régir le métier. Telle est l'idée générale qui résume et supporte toute la réglementation relative à la composition des comités.

\section{c) Fonctionnement des Comités de salaires.}

Chaque Comité de salaires est nommé pour l'ensemble de la profession dans tout le Royaume-Uni. Il peut cependant instituer des Comités industriels de districts (district trade committees) qui fonctionnent pour des circonscriptions déterminées (2). Ces Comités locaux sont chargés d'établir les tarifs minima (au temps ou aux pièces) pour leurs circonscriptions. Ce sont eux qui, dans le mécanisme anglais, proposeront et tiendront au courant le contrat collectif légal pour leur région. La loi exige expressément que le Comité central ne fixe jamais un tarif sans rapport du Comité local, soit pour l'établir, l'annuler ou le modifier. C'est l'organe d'étude et de proposition. Le Conseil central reste l'organe décision, et c'est là un pouvoir qu'il ne peut déléguer (art. I2, §3).

(i) Article 8 du règlement du 4 mai rgro. Loc. cit. Bulletin de l'offce intern. du travail, 1910, p. 386.

(2) Les Conseils locaux comprennent des membres du Conseil central et aussi des personnes étrangères, mais représentant des patrons ou des ouvriers de l'industrie : des règlements spéciaux en fixeront le fonetionnement. Un règlement du 22 juillet s 9 Io (Bul. de l'off. intern. du travail, 1910, p. 438) est venu fixer ces règles, très analogues à celles étudiées ci-dessus. 
Un troisième rouage, enfin, est prévu par la loi anglaise : c'est le Sous-Comité permanent (substanding committee), qui est chargé, pourrait-on dire, du service des réclamations. "Les Sous-Comités permanents sont chargés, dit l'article $12, \$ 2$, d'examiner les demandes de tarif minimum aux pièces spécial et les plaintes adressées au Conseil en vertu de la présente loi, ainsi que le renvoi des demandes ou plaintes auxdits Sous-Comités. ")

Ceci indiqué, étudions maintenant comment vont être établis les tarifs minima de salaires par les Comités de salaires. Telle est, en effet, leur mission propre établie par l'article 4 (I):

"Les conseils d'industrie doivent, conformément aux dispositions de la présente section, fixer, dans leurs industries, le taux minimum du salaire au temps (désigné dans la présente loi sous le nom de tarif minimum au temps; ils peuvent en outre fixer le taux minimum général des salaires aux pièces dans leurs industries (désigné dans la présente loi sous le nom de tarif minimum général aux pièces). Les taux de salaires (au temps ou aux pièces) peuvent être établis en vue d'être appliqués soit à l'industrie tout entière, soit à un procédé spécial de travail ou à une catégorie spéciale d'ouvriers de l'industrie, soit à unè circonscription particulière. ")

Il y a lieu, dans cette élaboration de tarif, de distinguer, pour plus de clarté, trois phases :

a) La phase préparatoire.

b) La phase mixte.

c) La phase obligatoire.

a) La phase préparatoire. - C'est la période de formation et d'élaboration du tarif. Le Comité fait connaître le taux qu'il se propose de fixer et examine toutes les objections qui peuvent lui être présentées dans un délai de trois mois.

Elle se termine par la publication; art. $4, \S 3$. Le Conseil

(r) Ce n'est d'ailleurs pas Ia seule : l'article 3 de la loi considère encore les Comités de salaires comme offices de renseignements : ils sont compétents pour examiner toutes les questions industrielles qui leur seront soumises et adresser des rapports. Nous négligerons ce côté de leur activité qui ne rentre pas dans l'objet de cette étude. 
publie tout tarif minimum au temps ou tout tarif minimum général aux pièces établi par lui.

b) Avec la publication commence la phase mixte. En ce moment, la tarification, sans ètre obligatoire, peut être considérée comme la coutume ou l'usage du métier; il s’appliquera (art. 7) :

$\mathrm{I}^{\circ}$ A défaut de stipulation écrite (I);

$2^{\circ}$ Au cas ou un patron informe le Conseil par écrit qu'il accepte le tarif et s'y soumet (2);

$3^{\circ} \mathrm{Au}$ cas enfin de travaux accomplis pour le compte de l'État ou des communes (3).

Cette phase mixte dure normalement six mois. Passé ce délai, deux alternatives peuvent se présenter :

Ou bien le ministre rend une ordonnance déclarant le tarif obligatoire, et l'on tombe dans la phase 3 ci-après,

Ou bien le ministre rend une ordonnance suspensive, et alors, au bout de six mois, le Conseil peut de nouveau réclamer une ordonnance obligatoire. Le ministre y accède ou rend une nouvelle ordonnance suspensive (art. 5). Et cela peut continuer théoriquement ainsi. Le tarif est supendu tant que l'ordonnance obligatoire n'est pas rendue.

c) La phase obligatoire. Elle commence, nous l'avons vu, à l'ordonnance obligatoire.

(1) Art. $7, a)$. - «Dans tous les cas où le tarif minimum est applicable, le patron doit, en l'absence d'une convention écrite stipulant le contraire, payer aux personnes à son service un salaire au moins égal au tarif minimum ; en pareil cas, la personne employée peut se faire rembourser la différence par son patron. ")

(2) Art. 7, b). - ( Le patron peut informer par écrit le Conseil d'industrie qui a fixé le tarif minimum qu'il accepte de se voir appliquer obligatoirement le tarif : en pareil cas il est tenu de payer aux personnes qu'il emploie un salaire au moins égal au tarif minimum et il est passible, en cas contraire, des amendes qui pourraient lui être infligées, si le Ministre du Commerce avait rendu une ordonnance rendant le iarif obligatoire et si cette ordonnance était en vigueur. ")

(3) Art. 7, c). - «Aucun département ministériel, non plus qu'aucune autorite locale, ne peut passer un contrat indiquant l'emploi de maind'œuvre soumise à un tarif minimum, avec un patron qui n'aurait pas fait au Conseil une déclaration conforme à la disposition ci-dessus. "

Une exception est cependant prévue pour le cas de travaux exécuté; ou à exécuter pour le compte de la commune dans l'intérêt général : en ce cas, une ordonnance ministérielle peut, par voie d'ordonnance, dans les limites et pour la période y stipulées, suspendre l'application do cette disposition." 
A dater de ce jour, tout patron est tenu de payer les minima que comporte le tarif ( $\mathrm{I}$ ).

Est nulle et sans valeur toute convention relative au paiement des salaires contraires aux présentes dispositions (art. 6, 5 $5^{\circ}$.

La loi a cependant réservé le cas des ouvriers infirmes ou incapables, qui peuvent obtenir une autorisation spéciale (permis), les exemptant du tarif minimum obligatoire au temps.

Remarquons enfin que les mêmes dispositions s'appliquent au cas d'annulation ou de modification de tarifs : les Comités de salaires restent toujours maîtres d'y procéler; ils y sont obligés sur la requête du Ministre du Commerce (art. 4, $\S 4$ ).

\section{d) Sanctions.}

Elles sont au nombre de deux :

Une sanction pénale,

Une sanction civile.

La sanction pénale comporte l'application, sur cọndamnation sommaire, d'une amende de 500 francs au plus par. contravention et d'une amende de 125 francs au plus par jour, après cette condamnation, tant qu'il n'est pas en règle (art. 6, I ${ }^{\circ}$ ).

La sanction civile comporte la restitution de la différence entre les sommes payées en réalité et les sommes prévues par les tarifs minima (2). La preuve est d'ailleurs à la charge du patron (art. 6, $4^{\circ}$.)

11 faut remarquer de plus que, d'après l'article 9 , le mot

(I) Art. 6, $\left.\mathrm{I}^{\circ}\right)$. - " Lorsque le Ministre du Commerce, conformément à la présente loi et par voie d'ordonnance, a rendu obligatoire un tarif minimum fixé par un Conseil, le patron doit, dans les cas où ledit tarif est applicable, payer à toute personne à son service un salaire au moins égal, toutes retenues déduites, au salaire minimum. »

(2) Art. $6,2^{\circ}$. - " En condamnant un patron, aux termes de la présente section, pour n'avoir pas payé à une personne à son service un salaire au moins égal au tarif minimum fixé, le tribunal peut, par son jugement, obliger le patron condamné à payer, en plus de l'amende, les sommes qu'il considère comme dues en salaires aux personnes employées, en calculant ces salaires sur la base du tarif minimum : cette facultẻ d'ordonner un paiement de salaires en vertu de la présente section n'enlève nullement à la personne employée le droit de poursuivre par d'autres' voies le recouvrement des salaires qui lui sont dus. ") 
patron doit ètre pris en un sens très large : c'est celui, quel qu'il soit (boutiquier, marchand ou commerçant), qui " conclut expressément ou implicitement avec un ouvrier un contrat impliquant l'exécution d'un travail pour lequel un tarif minimum a été fixé en vertu de la présente loi ».

L'application de la loi est confiée à l'inspecteur du travail ou aux autres départements ministériels dont les agents sont en rapport a vec le personnel industriel soumis à la loi (art. 14).

Les pouvoirs de ces inspecteurs sont des plus larges; d'après l'article 15 , ils peuvent :

a) Exiger du patron la production des feuilles de paie ou autres documents relatifs aux salaires, exiger des personnes faisant travailler à domicile les états de paiements effectués à des ouvriers à domicile; examiner et vérifier ces documents et en prendre copie;

b) Demander à toute personne intéressée, faisant travailler à domicile ou travaillant à domicile, les renseignements qu'elle possède en ce qui concerne les noms et adresses des personnes acceptant ou donnant, selon le cas, du travail à domicile et en ce qui concerne les versements dus pour ce travail;

c) Pénétrer à toute heure raisonnable dans les fabriques ou ateliers et dans tout endroit où se fait la distribution du travail aux ouvriers à domicile;

d) Examiner et recopier toute liste d'ouvriers à domicile tenue par un patron ou une personne donnant du travail au dehors.

Tout obstacle mis à l'accomplissement de cette mission entraîne une amende de i 25 francs au plus pour chaque contravention; toute tromperie pour l'abuser est passible, sur condamnation sommaire, d'une amende de 5oo francs au plus et d'un emprisonnement de trois mois au plus, avec ou sans hard labour.

Malgré ces graves sanctions, le législateur voudrait arriver à une application amiable de la loi; c'est ainsi que d'après l'article $ı, \S 2$, avant de commencer les poursuites a॥ nom de l'ouvrier, comme c'est son droit, " le Conseil peut et si c'est la première fois qu'il est appelé à poursuivre un patron - doit faire de son mieux pour que ledit patron en soit informé, et ce en vue d'arriver à un règlement amiable ». 
Par un sentiment très exact des réalités sociales, le légis lateur anglais, en ces délicates questions, place sa confiance plus encore dans la libre adhésion des intéressés que dans la contrainte légale, qui n'est que le moyen ultime de coercition.

\section{e) Dispositions secondaires.}

Vu la longueur des développements qui précèdent, on nous excusera de faire ici un choix et de nous borner à l'essentiel.

Il est intéressant de marquer cependant au point de vue financier que la loi prévoit les émoluments et frais des membres nommés et des secrétaires des Conseils d'industrie. C'est là une conception bien anglaise que tout travail mérite salaire et que pour avoir de la bonne besogne il faut payer son homme. Tous les frais nécessités par la loi sont à la charge du Trésor.

On sait aussi que. la loi est entrée en vigueur le ${ }^{\text {er }}$ janvier igro.

La plus large publicité est assurée pour faire connaître la loi et son délicat mécanisme ( $\mathrm{I}$ ).

Le seul point délicat que nous voulions examiner en détail est celui de la coexistence des deux tarifs an temps et aux pièces.

Les Comités de salaires ont les pouvoirs pour fixer les deux catégories de tarifs minima.

Ils peuvent mème fixer pour un patron un tarif minimum spécial aux pièces, applicable à la seule usine de ce patron ; ils en restent d'ailleurs toujours maìtres (art. 4, $\$$ ).

C'est dans l'équivalence des deux tarifs que sera assurément l'une des plus certaines difficultés d'application de la loi. A cet égard, les règlements du Board of Trade et les règles intérieures des Conseils statueront. Cependant la loi a posé quelques principes curieux écrits dans l'article 8, dont voici le texte :

" Le patron qui fait travailler aux pièces doit, lorsqu'il existe un tarif minimum au temps, mais quand il n'existe

(I) Il faut mentionner encore cette disposition fort curieuse et symptomatique, art. $4, \$ 2$.

« Si un Conseil déclare au Ministre du Commerce qu'il lui est, dans un moment donné, impossible de fixer un tarif au temps, conformément à la présente section, le Ministre du Commerce peut, pour ce cas particulier, relever le Conseil de ses obligations. ” 
pas de tarif minimum aux pièces, ètre considéré comme payant des salaires inférieurs au tarif minimum (I).

I $^{0}$ Dans le cas où un tarif minimum aux pièces spécial a été fixé,conformément à la présente loi, pour les personnes au service du patron, si les salaires payés par lui sont inférieurs à ce tarif minimum aux pièces spécial;

$2^{\circ}$ Dans le cas où il n'a pas été fixé de tarif minimum aux pièces spécial, s'il ne peut établir que le salaire aux pièces effectivement payé représenterait en l'espèce, pour un ouvrier ordinaire, au moins la somme d'argent que rapporterait le tarif minimum au temps.

Nous avons ainsi achevé l'exposé des dispositions de la loi anglaise.

Dans l'ensemble et pour nous résumer, on voit que l'idée maìtresse dont elle s'est constamment inspirée, qui l'éclaire et la domine, est l'intention d'imiter en somme, au cas de salaire minimum obligatoire, le système d'ores et déjà existant, qui a fait ses preuves, de salaire minimum stipulé dans l'industrie privée par le moyen du contrat collectif.

Les tarifs doivent ètre établis par les intéressés; ils restent modifiables et revisables. Les personnages officiels, les membres directement nommés par le Board of Trade sont le plus souvent les instigateurs de l'œuvre à accomplir. Ils suppléent au défaut d'organisation existante dans les métiers où la loi s'applique.

La loi anglaise est au premier chef une loi supplétive et complémentaire de l'initiative privée. Elle est aussi peu qu'il est possible pour une loi impérative et contraignante. Au moins, pour l'élaboration des tarifs, elle propose plus qu'elle n'impose.

Ce sont au fond les intéressés largement représentés qui restent souverains, comme il convient, pour la détermination des minima de salaires. Les Conseils, nous l'avons vu, peuvent, sous réserve des dispositions de la présente loi et des règlements ainsi rendus, régler comme ils l'entendent leur mode de fonctionnement (art. I I, $7^{\circ}$ ).

(r) La traduction du Bulletin de l'office du travail, porte ici les mots : "tarif minimum aux pièces spécial", ce doit être par erreur. Bulletin, 1910, p. 3o. Le texte anglais dit seulement : "Be deemed to pay wages at less than the minimum rate." 


\section{III. - LES RÉSULTATS DE L'EXPÉRIENCE ANGLAISE(I).}

La loi anglaise du 20 octobre igog n'est en vigueur que depuis un peu plus d'un an et demi(2).

La lenteur avec laquelle il est procédé, avant d'aboutir, aux tarifications prévues est une preuve du soin et de la minutie de nos voisins.

Il importe d'étudier successivement l'action des Comités dans les quatre industries visées par la loi.

Toutefois il importe de remarquer qu'une certaine relation s'est établie entre les quatre expériences poursuivies concurremment. Les divers employeurs intéressés ont en effet désigné un même sollicitor pour les représenter dans les divers Comités (3).

En mème temps, un autre trait commun des divers Comités est la part importante prise dans leur fonctionnement par l'élément extra-professionnel, par l'intervention de personnes étrangères au métier que leurs occupations dans la vie ou l'intérèt qu'elles portent à ces questions rendent particulièrement compétentes.

Ce nouveau facteur, capital dans le fonctionnement de la loi, est dù à l'absence d'organisation professionnelle chez les ouvriers (4), à la réserve silencieuse des femmes dans les diverses industries réglementées; en un mot, le défaut d'organisation professionnelle fut partout une grosse difficulté qu'il fallut tout d'abord surmonter (5). C'est surtout

(I) Miss Constance Smitl. Conférence à la Ligue sociale d'acheteurs, le 3 mars 1911, publiée dans le Bulletin de la Ligue, 1911, n², p. $9^{2}$.

J. Mallon. The Trade Boards Act., dans The Women's Industrial News. Avril 1912, p. 55.

L'application de la loi sur les Trade Boards. Bulletin de l'offce du travail, 1912, p. 596 .

Miss Constance Smith. Le fonctionnement des Conseils d'industrie, chargés de fixer des tarifs minima des salaires en Grande-Bretagne Rapport à l'Assemblée générale de l'Ass. intern. pour la protection légale des travailleurs. Zurich. Sept. I9I2.

(2) On sait qu'elle est entrée en vigueur le ${ }^{\text {er }}$ janvier 1910.

(3) Bulletin de l'Office du travail, art. cité, p. 607.

(4) Sur les difficultés de trouver une représentation ouvrière, cf. l'article de sir George Askwith : Soziale Praxis, 9 janvier I911, p. 489.

(5) Cf. miss Constance Smith. Rapport cité, I912. Rapport du Bureau de l'Association intern. pour la protection légale des travailleurs. Zurich, 1912, p. 2. 
dans l'industrie de la dentelle que cette difficulté fut sensible. " Il eût même été impossible d'assurer une représentation suffisante aux ouvrières, si par surcroît de prudence le Board of Trade n'avait pas décidé qu'il n'y avait pas lieu d'insister dans chaque cas particulier pour que les représentants ouvriers fussent choisis uniquement parmi les ouvriers actifs eux-mèmes (I). ')

\section{a) L'industrie des chaînes martelées à la main ou au marteau à pédale.}

C'est ce Comité qui a été institué le premier et qui a abouti le premier, parce que l'industrie visée présentait un minimum de difficultés.

Cette industrie ne comprend qu'un personnel assez restreint, environ 2.000 travailleurs, hommes et femmes (2); elle est concentrée à Cradley Heath, près de Birmingham.

Le Comité pour la fabrication des chainnes martelées à la main ou au marteau à pédale a suivi de point en point la procédure légale.

La première réunion du Comité a eu licu à Cradley Heath, le 7 janvier i9ı.

Ce Comité a donné avis, comme le veut l'article 4, $\$ 3$, de la loi, qu'il a fixé deux tarifs (3):

Un tarif minimum au temps,

Et des tarifs généraux aux pièces : l'un pour les chaìnes rivées à la main ou au marteau à pédale, l'autre pour les chaînes martelées d'un diamètre compris entre $3 / 8$ d'inch (4) et $I_{7} / 3_{2}$ d'inch, le troisième enfin pour les chaines martelées qui est un tarif local.

(I) Miss Constance Smith. Rapport cité, I912, p. 6.

(2) La chaîne martelée est faite prineipalement par des femmes, en général dans de petits ateliers ou dans des échoppes attenantes à leur logement. "Tous les membres d'une mème famille, lit-on dans la notice publiée par le Board of Trade, travaillent parfois ensemble à faire des chaînes martelées, y compris les enfants qu'on commence souvent à y employer très jeunes. Beaucoup d'ouvrières travaillent à ce métier pour compléter le salaire d'un mari' ou d'un père, et non pour se faire une existence indépendante ; souvent elles se livrent à ce travail durant les loisirs que leur laisse le ménage. ") Les chaines rivées sont au contraire faites principalement par des hommes.

(3) Labour Gazette, février 1911, p. 44.

(4) L'inch (pouce) anglais est de 25 millimètres. 
Avis a été donné au Board of Trade, conformément à la loi.

Celui-ci vient, par deux arrêtés tout récents du 23 février I 9 I et du 24 mai i 9 I ( I), de déclarer ces tarifs obligatoires (2).

Pour les petites chaînes, le Conseil de salaires a fixé à o fr. 15 le minimum de paie pour les forgerons (3). Le tarif général est de $21 / 2$ d., soit o fr. 3o environ par heure. Ces tarifications nouvelles constituent une augmentation de 70 à $100 \%$ sur les salaires antérieurement payés (4). Le Comité a jusqu'ici fonctionné à la satisfaction générale et l'on pourra porter le salaire au temps jusqu'à $3 \mathrm{~d}$. (o fr. 35 environ).

Tels sont les seuls résułtats officiels actuellement connus.

Une difficulté assez curieuse s'éleva quand on vint à promulguer le nouveau tarif.

La nouvelle loi a provoqué la formation spontanée de groupements professionnels de patrons et d'ouvriers. En dehors des patrons de la fabrication de la chaine déjà syndiqués, un petit nombre de patrons non syndiqués, dans la région de Kradley, se sont associés à un groupement de middlemen et cherchaient à différer l'application de la loi (5) en signant avec leur personnel une convention écrite. Le personnel refusa de signer la convention proposée; les patrons répliquèrent par un lock-out qui dura quatre mois. Soutenus par le public, les ouvriers triomphèrent (6).

Cette victoire a évité l'échec dans la première application

(1) Labour Gasette, mars I9ı, p. 85; juin 19ı, p. 203.

(2) C'est le commencement de la troisième phase, phase obligatoire. La publication des tarifs était en effet du 22 aoùt I910, et l'on sait qu'il faut un délai de six mois.

(3) Paul Louis. Un problème social. Revue bleue, 3 I décembre 19 ro.

(4) Renseignements particuliers dus au secrétaire de la National Anti Sweating League.

(5) On sait, en effet, que le tarif n'est pas obligatoire pendant un délai de six mois pour le patron qui réussit à faire avec ses ouvriers une convention écrite : certains patrons espéraient ainsi en faisant signer une convention de ce genre à leurs ouvrières, accumuler pendant les six mois un gros stock de chaines martelées et se débarrasser ensuite de leur personnel.

(6) De même, dans la branche du marteau à pédale, où dominent les ouvriers du sexe masculin, pareille tentative échoua après un lock-out de quinze jours. 
de la loi, échec qui eût risqué de compromettre tout son fonctionnement.

Enfin, le Comité de salaires a également fixé le nombre et les conditions de l'apprentissage : le salaire de début est fixé à 5 francs par semaine, la durée de l'apprentissage limitée à deux ans, la proportion des apprentis soumise à l'appréciation du Comité de salaires.

On estime aujourd'hui d'une manière unanime que les nouveaux tarifs sont sensiblement plus élevés que les anciens, sans qu'il soit facile de chiffrer exactement le gain obtenu. M. Mallon ( $\mathrm{r}$ ) estime que d'après les anciens tarifs peu d'ouvriers arrivaient à gagner 7 francs par semaine : la plupart n'atteignaient peut-être pas 6 fr. 25 ; avec le nouveau tarif à l'heure, le salaire, pour une semaine de cinquante-quatre heures, serait environ de 14 francs (2).

Pour les chaînes fabriquées au marteau à pédale, par les hommes surtout, des minima de salaire de $5 \mathrm{~d}$., $5 \mathrm{~d} .7 / 8$ et $7 \mathrm{~d}$. l'heure ont été établis : ce qui, pour une semaine de cinquante-quatre heures, peut donner des salaires de 28 à 39 francs (3).

Cette élévation des prix a pu se faire sans difficultés par suite de l'absence de toute concurrence étrangère, même sur les marchés d'Europe. L'introduction possible du machinisme a, d'autre part, empêché un accroissement plus considérable du taux des salaires.

$\mathrm{Au}$ total, l'expérience dans cette première industrie l'industrie des chaînes - marque un plein succès de la loi sur les Comités de salaires.

B) L'industrie des boîtes à papier (Paper boxmaking), où fonctionne un second Comité de salaires, se présentait dans des conditions techniques toutes différentes.

Trois difficultés principales rendaient plus délicate la mission du Comité de salaires :

a) Cette industrie, qui occupe environ 50.000 travail-

(1) Article cité.

(2) M. Mallon estime même qu'avec certains prix aux pièces l'augmentation des gains serait de $80 \%$ et même plus.

(3) Il faut remarquer que les tarifs en vigueur ont été adoptés eu fin de compte à l'unanimité : ce qui permet de bien augurer de leur application à l'industrie tout entière, Cif. Smith. Rapport cité, 1912, p. 4 . 
leurs, (I) est disséminée par tout le pays, dans un grand nombre de villes en Angleterre, dans le pays de Galles et en Écosse;

b) Le travail s'effectue principalement en usine;

c) Cette industrie présente un caractère marqué d'instabilité - du fait de la mode qui fait varier la forme et le dessin des boîtes - du fait aussi que les établissements de certaines industries (allumettes, chocolats, moutardes, biscuits, chaussures, dentelles, cigarettes, etc.) sont euxmêmes leurs propres fabricants de boîtes.

La première réunion du Conseil eut lieu les i I et I $2_{2}$ août I9ro.

Un premier conflit divisa d'abord les employeurs et les employés en ce qui concerne la partie de la réglementation à établir. Dès la première réunion du Conseil, les employeurs réclamaient, en application du règlement du Board of Trade du 22 juillet igro, la formation de Commissions industrielles du district et affirmaient la compétence de ces Commissions pour statuer sur la question des tarifs; les ouvrières réclamaient, au contraire, la discussion d'un tarif au temps par le Comité central. Ces dernières ont obtenu une victoire plus apparente que réelle; on décida de statuer au Comité central sur les tarifs, en établissant un tarif minimum uniforme au temps, mais en renvoyant pour l'application aux Commissions de district (2).

"Les séances des Commissions de district, écrit M. Mallon (3), durèrent près d'un mois et n'avancèrent guère les choses. Les employeurs, agissant suivant un plan concerté (4), proposaient à chaque Commission un tarif minimum que le Board of Trade avait déjà rejeté et les ouvriers ripostaient en énonçant des exigences auxquelles on ne pouvait faire droit (5). A mesure que les réunions succé-

(i) En grande partie des femmes et des filles.

(2) Il en fut de même d'un projet relatif à l'apprentissage.

(3) Article cité.

(4) Les employeurs avaient choisi pour les représenter dans toutes les commissions un seul et unique sollicitor; les ouvriers en avaient fait de même pour M. Mallon, si bien que la discussion fut menée par les mêmes leaders sur tous les points du pays.

(5) Nême opposition de point de vue pour l'apprentissage, en ce qui concerne sa durée et le nombre des apprentis. 
daient aux réunions, il devenait de plus en plus évident que les deux parties se réservaient pour une lutte finale au sein du Trade Board, alors muni de tous les renseignements nécessaires (I) ).

Le Trade Board, comité central, se réunit le 22 février rgi I. Après de longues discussions, on décida de fixer, par un avis du 6 avril I9I I (2), les étapes suivantes :

Le salaire minimum au temps pour les ouvrières en fabrique (3) serait de 2 d. $3 / 4$ par heure, du I $^{\text {er }}$ juin I 9 I I au 3 I janvier I 9 I 2 .

De 3 d. par heure, à partir du I er février I 9 I 2.

De $3 \mathrm{~d} .1 / 4$, par heure, à partir du I er février I 9 I 3 (4).

En mème temps, le salaire des apprentis pour une semaine de cinquante-deux heures s'élevait progressivement de 5 fr. 60 pour le premier semestre jusqu'à I/4 fr. 40 après le sixième.

Mais bientôt le Comité revint sur cette tarification, en grande partie devant la résistance des membres employeurs du Conseil.

Une nouvelle tarification fut publiée par un avis du I $^{\text {er }}$ septembre i 9 I I (5).

Le salaire minimum au temps dans toute l'industrie, pour les ouvriers à domicile comme pour les ouvrières en fabrique, devait être de $3 \mathrm{~d}$. par heure (o fr. 35 ) (6).

Ces salaires devaient se payer net, sans aucune déduction ni retenue.

(1) Cette réunion des Commissions de district aboutit surtout à dégager les conditions locales du travail et à faire comprendre que des variations trop brusques dans les salaires ou le régime de l'apprentissage pourraient être funestes à l'industrie, alors en pleine extension.

(2) Labour Gazette, avril igir, p. I25.

(3) A l'exclusion des femmes qui sont employées dans le métier à un ouvrage extraordinaire ou à titre d'aides (in work incidental or ancillary).

(4) Les représentants des patrons n'avaient pas accepté ce dernier échelon.

(5) Réserve faite de l'Irlande, pour laquelle un comité de 13 membres $(4$ représentants des patrons, 4 représentants des ouvriers, 4 membres nommés par le Board of Trade) a été constitué le 23 août rgrr. (Labour Gazette, sept. 191 r, p. 327.) Il a fait ses propositions le 2 octobre 1911.

(6) Labour Gazette, septembre i91 I, p. 327. Ce salaire ne représente encore dans certains cas rue des salaires hebdomadaires inférieurs à ro shillings, notamment pour les ouvrières à domicile, (Iui se font de 7 à 8 shillings. 
Les apprenties recevront le salaire minimum au temps suivant :

[par semaine.]

Pour la I $^{\text {re }}$ période de six mois d'emploi... 4 s. o d.

$\begin{array}{llll}2^{\mathrm{e}} & - & - & 5 \mathrm{~s} .0 \mathrm{~d} . \\ 3^{\mathrm{e}} & - & - & 6 \mathrm{~s} .0 \mathrm{~d} . \\ 4^{\mathrm{e}} & - & - & 8 \mathrm{~s} .0 \mathrm{~d} . \\ 5^{\mathrm{e}} & - & - & 9 \mathrm{~s} .0 \mathrm{~d} . \\ 6^{\mathrm{e}} & - & - & \text { 10 s. } 6 \mathrm{~d} .\end{array}$

Les tarifs hebdomadaires ci-dessus s'entendent de la semaine de 52 heures, mais ils sont sujets à réduction ou augmentation proportionnelle, selon que le travail effectivement fourni par l'apprentie n'atteint pas ou dépasse 52 heures ( $\mathrm{I}$ ).

Un délai de trois mois pour les objections courait à dater du 4 septembre ig I .

La période de trois mois expirée, et à la suite de diverses observations présentées, le Board of Trade rendit son ordonnance en décembre i 9 I I : les chiffres ci-dessus furent adoptés, en augmentant le salaire minimum des apprenties, suivant l'âge d'entrée plus ou moins élevé (2).

"Ces prescriptions relatives à l'apprentissage sont de la plus haute importance dans une industrie où le développement du machinisme, la division du travail et la spécialisation des ouvriers ont atteint ces dernières années un degré si perfectionné que des enfants quelque peu développées peuvent exécuter aujourd'hui, sans peine, des opérations qui étaient réservées autrefois aux femmes adultes (3). »

Ces prix, adoptés définitivement par le Board of Trade le

(1) Une amélicration importante obtenue par le Comité de salaires est de faire payer $6 \mathrm{~d}$. (environ $\mathrm{o} \mathrm{fr}$. 70) à toute ouvrière passant une partie de la journée à la fabrique (matin ou soir) et se mettant à la disposition du patron sans remporter de l'ouvrage. C'était, en effet, un abus fréquent que ces attentes et pertes de temps, sans donner d'ouvrage aux ouvrières.

(2) Ainsi le minimum de salaire des apprenties est, en principe, de $4 \mathrm{sh}$. ( 5 francs) pour le premier semestre; toutefois, l'apprentie débute à $5 \mathrm{fr}$. 60 , si elle commence à travailler entre 15 et I $_{7}$ ans; à $6 \mathrm{fr}$. 25 , si elle commence à travailler entre 17 et 20 ans; à $7 \mathrm{fr}$. 50 , si elle a 20 ans et au-dessus. L'apprentissage dure trois ans, à dater du jour de l'entrée dans l'industrie.

(3) Miss Constance Smith. Rapport cité, p. 8. 
I I mars I9I2 n'ont pas encore été rendus obligatoires : ils le seront en septembre I9 2 .

On n'a pas ici arrêté ni mème discuté de tarif aux pièces à cause de la diversité des produits (I).

Il est difficile, de l'aveu même des personnes compétentes, de chiffrer l'augmentation de salaire que vaudra aux ouvriers l'application des nouveaux tarifs : le salaire reste essentiellement variable selon les opérations et les régions.

Malgré les difficultés de sa tâche, ce secona Comité de salaires a malgré tout obtenu tout ce qu'il était possible actuellement d'obtenir pour l'application de la loi.

c) L'industrie de la dentelle (2), par contre, présentait moins de difficultés, au moins pour la portion de l'industrie où était créé le Comité de salaire.

Cette partie de l'industrie, qui occupe environ Io.0oo travailleurs, surtout des femmes, est localisée autour de Nottingham, encore qu'elle y soit très dispersée : plus de 700 entrepreneuses répartissent l'ouvrage : bien peu d'ouvriers travaillent directement pour le fabricant (3).

La première réunion du Comité eut lieu à Nottingham, le 22 septembre i9 ro: il a abouti, comme on va le voir, assez rapidement (4).

Le Comité a donné avis le I9 août Ig I I (5) du salaire minimum au temps de $2 \mathrm{~d} .{ }^{3}{ }_{4}$ l'heure (6) pour toutes les fabrications du métier désigné.

(1) Sur ce point, résistance des employeurs qui Ie prétendent impossible; par contre, les ouvrières prétendent qu'il serait possible au moins pour les principales catégories de boìtes confectionnées à domicile.

(2) On n'a d'ailleurs abordé qu'une partie de l'indu,trie dentellière. La loi vise " le finissage de la dentelle et des filets à la mécanique, travaux de raccommodage ou de reprisage dans le finissage des rideaux ").

Le Comité n'est établi que " pour cette branche de l'industrie dentellière où on finit les dentelles et filets confectionnés à la machine, non compris le finissagre des filets unis fabriqués à la machine».

(3) Le problème, toutefois, y était plus délicat par un autre còté, à cause de la concurrence étrangère de la France, de la Suisse et aussi de l'Allemagne.

(4) Son action était facilitée par une expérience antérieure de tarification (prix à payer aux entrepreneuses), qui avait échoué faute de mesures précises pour en faire profiter les ouvrières.

(5) Labour Gazette, septembre i9ir, p. 327.

(6) On constatait, auparavant, des salaires de o fr. Io pour deux ou trois heures de travail. (Cif. Broda, op. cit.) 
Il a fixé le salaire hebdomadaire des apprenties, qui varie selon leur àge, leur ancienneté ou leur spécialité, mais qui doit ètre au moins de $5 \mathrm{~s}$. (6 fr. 25) pour une semaine de 54 heures ( $\mathrm{I}$ ).

Enfin, le Comité a établi une équivalence entre le salaire minimum au temps et les prix aux pièces, pour quatre des opérations du métier. Ces prix s'entendent pour des articles de qualité courante; des prix plus élevés (non spécifiés) seront payés pour des qualités meilleures. Enfin, " quand le fabricant n'emploie pas d'entrepreneuse, et que l'ouvrière prend son travail directement au magasin, un supplément à déterminer d'un commun accord sera payé (2) ").

C'est, on le voit, l'entrepreneuse rendue responsable du paiement du salaire minimum : elle devra obtenir du fabricant un prix supérieur à celui qu'elle paye à l'ouvrière (3).

Ces tarifs ont été déclarés obligatoires par une ordonnance du Board of Trade, en date du I9 février I912 (4); les sanctions prévues ont été appliquées. Dans certains cas cependant, le Board of Trade s'est réservé pour les ouvriers au temps atteints d'infirmités ou d'incapacité le droit d'autoriser leur emploi à des salaires inférieurs.

De mème ces tarifs ont été étendus par un ordre du Board of Trade, en date du I4 mars I9I2 (5), à la dentelle fabriquée avec les machines à ourdissage (warp machine) : "Le salaire minimum au temps est de 2 d. $3 / 4$ par heure, pour tous les ouvriers autres que les apprentis, et les salaires au temps spéciaux aux apprentis, fixés le I 8 août I9ı I, et rendus obligatoires par l'ordonnance du

(1) Le Comité de salaires intervient pour délivrer à l'apprentie un certificat sur une demande faite à l'entrée dans le métier : avant de le remettre, le Comité recherche si, étant donné le nombre déjà existant des apprenties, la postulante a des chances de recevoir une instruction professionnelle convenable; il peut retirer le certificat si les conditions exigées ne se retrouvent plus.

(2) On a stipulé également un supplément de salaire de I farthing ( 2 centimes $6 / 10$ ) pour les cas où le travail serait fait avec du fil à torsion double, au lieu du fil à torsion triple : celui-là plus cassant que celui-ci et comme tel nécessitant un surcroìt de temps et de travail amenant auparavant un moindre salaire. Cf. miss Constance Smith. Op. cit., p. 6.

(3) G. Mallon, op. cit.

(4) Labour Gazette, mars i912, p. 87.

(5) Labour Gazette, mars 1912, p. 88. 
I9 février I9I2 s'appliquent à toutes les personnes employées au temps aux opérations de l'ourdissage. ")

On croit que ces nouveaux tarifs amélioreront réellement les salaires des ouvrières (I), on espère que cette augmentation ne précipitera pas l'introduction des machines dans ces parties de l'industrie de la dentelle.

Ici encore le Comité de salaires a fait son œuvre.

d) L'industrie des vêtements tout faits et sur mesure.

On s'est borné d'abord aux vètements d'hommes pour lequel un Comité a été institué le 25 juillet 19 IO.

Mème ainsi limitée, cette industrie est assurément la plus importante des quatre industries actuellement réglementées. L'industrie de la confection est répandue sur tout le pays : une très grande diversité existe entre les nombreuses entreprises : fabriques dotées d'un outillage moderne, petits ateliers, travail en chambre; on rencontre ici toute la série des variétés industrielles qui ont leur répercussion nécessaire sur la fixation des salaires des travailleurs des deux sexes qui y sont employés, sans que les statistiques permettent actuellement d'en chiffrer ni le nombre, ni la proportion.

Le Comité a décidé de consulter, avant toute fixation de minimum de salaire, les sept Comités du district (2).

Puis le I I novembre I9I I (3) il a abouti à la tarification suivante :

Pour les ouvriers, il distingue deux catégories :

Les ouvriers ordinaires (male worliers), 6 d. l'heure (6o centimes environ), à l'usine ou en chambre.

Les apprentis (male learners), un salaire minimum au temps, pour la semaine de 50 heures, gradué depuis 4 shillings $2 \mathrm{~d}$. pour les personnes âgées de moins de 15 ans;

(1) Iei encore une comparaison numérique est difficile, car les anciens tarifs sont, dans l'ensemble, mal connus.

Les tarifs sont d'ailleurs encore assez mal appliqués : il y a quelques éversions du fait des placeuses-intermédiaires.

(2) Cf. Labour Gazette. Avril 1911.

(3) Labour Gazette. Nov. 1911, 1). 405 (pour une semaine de 51 heures). 
jusqu'à 23 shillings i I d., pour les personnes âgées de 22 à 23 ans ( 1 ).

Pour les ouvrières, le projet distingue de même :

Les ouvrières ordinaires (female worliers), à l'usine ou en chambre, $31 / 2$ d. par heure (environ 35 centimes) (2).

Pour les ouvrières apprenties (female learners), un salaire minimum au temps, pour la semaine de 50 heures, gradué depuis (3) 3 shillings pour les jeunes filles entrant dans le métier au-dessous de $\mathrm{i} 5$ ans, jusqu'à $\mathrm{I} 3$ shillings $6 \mathrm{~d}$. pour les jeunes filles achevant leur apprentissage.

On espère que cette tarification pourra, comme les autres, ètre rendue exécutoire (4).

Les tarifs proposés pour les ouvriers sont aujourd'hui renvoyés devant les commissions industrielles de district (5).

On attend l'expiration du délai légal pour mettre en vigueur cette réglementation; ici encore, les modifications (qu'elle est appelée à apporter aux salaires seront très variables, selon les régions et les prix antérieurement pratiqués.

Miss Constance Smith (6) conclut ainsi :

"Un fait est certain : celui que l'établissement d'un salaire minimum ne présente pas de difficultés insurmontables même dans les industries les plus compliquées, et que de l'aveu des patrons qui font autorité, il existe dans quatre industries assujetties à la loi une marge suffisante pour permettre de porter les salaires au niveau de ceux payés par les patrons appartenant à la classe qui rétribue le mieux les travailleurs. Telle est la conclusion qui s'impose au point de vue législatif. Quant à l'organisation de

(I) Le minimum de 6 d. par heure pour les hommes serait acquis à partir de 22 ans.

(2) Notamment, le salaire au temps par heure est éventuellement pour les femmes fixé à 3 d. I/4 (o fr. 325).

(3) La gradation est faite eu égard à l'âge des apprentis et en raison du temps de service.

Les salaires minima fixés sont nets de toute retenue.

(4) Diverses modifications de détail ont été opérées par le Board of Trade, le 4 avril 1912. Cf. Labour Gazette, i912, p. 131.

(5) Labour Gazette, sept. I91. Un Comité pour l'Irlande a été nommé le 23 août 19 II.

(6) Rapport cité, I9I2, p. 10. 
l'administration, l'expérience n'a pas encore été poussée assez loin pour qu'il soit permis de formuler dès à présent un jugement définitif.

Mais étant donnée la bonne volonté avec laquelle les ouvrières qui font partie des quatre industries soumises à la loi sur les conseils d'industrie et mème les ouvrières qui faisaient autrefois le désespoir des organisateurs s'appliquent à s'organiser, il est permis de croire que les travailleurs qui bénéficient du minimum de salaire continueront à agir dans leur propre intérèt et de manière à empêcher de plus en plus les infractions à la loi ou l'évasion de ses dispositions. ")

Au total, la prudence que nous constatons dan: 'application de la législation anglaise est manifeste. S'il est prématuré d'affirmer, sauf pour l'industrie des chaìnes, un relèvement général des salaires, on peut tout au moins, en présence du mouvement de groupement et d'association qu'elle a provoqué, constater à son actif un important et précieux succès (I), gage probable du succès définitif.

(I) C'est l'avis de tous ceux qui se sont occupés de la question : "Ce qu'il y aurait à craindre surtout, si l'organisation ouvrière ne se réalisait pas complètement, ce serait des fissures dans l'application des prix fixés, surtout en ce qui concerne les ouvrières à domicile. "Bulletin de l'Offce du travail, 1912, art. cité, p. 608. 


\section{LE COAL MINES BILL}

La législation anglaise vient tout récemment de s'enrichir d'une nouvelle loi proclamant le principe du minimum de salaire à fixer par des Comités de salaires.

Il s'agit de la grande industrie des mines (I).

La loi pose d'abord le principe du salaire minimum, en affirmant (art. I, $\$$ I) qu'il sera stipulé dans chaque contrat de travail de chaque ouvrier du fond dans les mines de charbon un salaire qui ne pourra être inférieur au salaire minimum fixé en vertu de la présente loi et applicable à ce mème employé.

Toutefois trois exceptions sont réservées (art. I, $\$$ i in fine et art. $1, \$ 2)(2)$ :

\section{Les ouvriers infirmes ;}

Les ouvriers trop àgés ;

Les ouvriers qui auraient perdu leur droit au bénéfice du minimum de salaire pour avoir manqué aux conditions de régularité et de probité de travail déterminées dans les règlements de district.

\section{Détermination du minimum de salaire.}

Le soin d'établir les minima de salaires (art. 2) incombe aux Comités mixtes de district (3) (Joint District Boards).

(1) Le bill serait, paraît-il, applicable aussi à certaines mines de fer (stratifled ironstone).

(2) Ce sont les règlements arrêtés par les Comités de district qui fixent les règles d'application pratique de ces exceptions.

(3) La cédule annexée à la loi prévoit actuellement les districts miniers suivants :

Northumberland, Durham, Cumberland, Lancashire et Cheshire, South Yorkshire, West Yorkshire, Cleveland, Derlyshire, South Derbyshire, Nottinghamshire, Leicestershire, Shropshire, North Staffordshire, South Stafford et East Worcestershire, Cannock Chase, Warwickshire, Forest of Dean, Bristol, Somerset, North Wales, South Wales (y compris Monmouth), la majeure partie de l'Écosse.

Lorsqu'une mine, situće dans l'un de ces districts, aura été, dans un but industriel (for industrial purposes), traitée comme mine située dans un district voisin, cette mine sera, pour l'application de la Ioi, considérée comme située dans ce dernier district, si les deux Comités de district en décident ainsi. 
Ces Comités seront composés de délégués ouvriers et patronaux et présidés par une personnalité indépendante, avant voix prépondérante en cas de partage, nommée soit par les deux groupes de membres, soit par le Gouvernement.

Ces Comités établissent un salaire minimum général (r). Aù cas où il serait prouré que l'application de ce salaire minimum général est préjudiciable aux intérèts particuliers de telle mine ou de tels ouvriers, le Comité de district établira un salaire minimum spécial, inférieur ou supérieur au précédent, selon les cas.

Les mèmes Comités établissent les règlements généraux du district.

\section{Durée de validité des minima.}

Enfin, le taux de salaire minimum et les règlements fixés par les Comités de district (art. 3) ne pourront ètre modifiés par eux qu'aux deux conditions suivantes :

I $^{0}$ A n'importe quel moment, par consentement mutuel des employés et des employeurs ;

$2^{0} \mathrm{Au}$ bout d'une année d'application et sous réserve d'un préavis de trois mois, si un groupe suffisamment important d'employeurs et d'employés le réclame.

A cet égard, les patrons avaient demandé, lors de la discussion, des garanties plus précises en ce qui concerne l'exécution des contrats collectifs portant des minima (2).

Il faut espérer que les Joint District Boards trouveront le moyen, par des réglementations locales, d'assurer l'accom-

(I) Aucune précision n'est faite à cet égrard : l'articte 2, en vertu d'un amendement de M. Sydney Buxton, président du Board of Trade, porte seulement :

"Rien dans cet acte ne pourra porter atteinte ì l'efiet de quelque convention antérieure en vigueur ou résultant des coutumes pour le paiement des salaires à un taux supérieur au minimum de salaire établi. En outre de cet acte et en établissant un mininum de salaire, te Joint District Board devra tenir compte du taux moyen du salaire, quotidien payé aux ouvriers de la classe pour laupelle le minimum de salaire doit être établi. "

Sur les conditions dans lesquelles a été voté ce texte, cf. Yves Guyot. Le minimum de salaire des mineur's dans l'industrie britannique. Journal des Economistes, 15 avril 1912, p. 5.

Bulletin de l'OfJlce du travail, mai I912, p. 488.

(2) Cif. supra, p. I 66 . 
plissement d'un certain travail comme contre-partie du ninimum accordé.

\section{Dispositions transitoires.}

Le bill contient enfin deux séries de dispositions transitoires:

a) L'article I, $\$ 3$, porte que les dispositions de la loi relatives à l'application du salaire minimum vaudront mème alors que le taux de ce salaire minimum n'aura pas encore été fixé et que l'ouvrier pourra réclamer de son employeur le paiement de ce qui lui serait dù en vertu de la loi sur le salaire minimum, à n'importe quel moment, lorsque le taux de ce salaire minimum aura été fixé. C'est donc le droit pour l'ouvrier de réclamer rétroactivement le paiement du minimum après le jour où il aura été fixé et, par suite, la possibilité pour lui de reprendre le travail sans attendre les décisions des Comités de district.

b) L'article 4 prévoit, d'une part, le cas où deux semaines après le vote de la loi, dans un district quelconque, aucun Joint District Board n'aurait pu ètre constitué : en ce cas, le Board of Trade pourrait désigner telle personne qui lui semblerait convenable pour tenir l'Office du District Board. Le mème article 4 prévoit, l'autre part, le cas où, dans le délai de cinq semaines après le vote de la loi, le Comité de district n'aurait pu se mettre d'accord pour la fixation du salaire minimum ou l'établissement de règlements de districts. En ce cas, le président du comité devrait lui-mème fixer le taux du salaire minimum et arrèter les règlements nécéssaires.

Telle est dans ses grandes lignes la nouvelle loi anglaise. On voit qu'elle se contente en somme, et quoi qu'on en ait dit (I), de consacrer dans une large mesure l'organisation

(I) C.f. Paul Leroy-Beaulicu. Ec. Fr., 23 mars I9r2, p. 4r7. L'introduction en Europe de la législation australienne sur le régime du travail: " Il est déplorable de voir le Gouvernement britannique montrer un aussi fatal exenple de faiblesse et d'imprévoyance. L'avenir prochain montrera que ce parti pris de soumission des pouvoirs publics aux injonetions des syudicats ouvriers, non seulement avilit le Gouvernement et la législation, mais transforme en crise permanente une secousse passagère. ") 
professionnelle existante; c'est à tout prendre le système des Comités de salaires qui est une fois de plus législativement consacré, en même temps que l'inscription dans la loi du salaire minimum.

Il s'agit, il est vrai, de l'industrie minière, l'une des premières industries anglaises et, par là mème, la proclamation de ce principe a fait, avec le nouveau bill, un pas énorme.

Quelles que soient les circonstances de fait tout occasionnelles d'où la loi a voulu sortir le pays (I), il est certain que le seul fait du vote de la loi aux majorités que l'on sait montre combien la réforme correspondait à l'état d'esprit général et à l'opinion publique anglaise (2).

(1) Cf. ci-dessus, pp. 159 et suiv.

(2) Cf. ci-dessous, p. 414 . 


\section{II. - Législation confiant ả une Cour industrielle d'arbitrage le soin d'ètablir le minimum de salaire.}

Trois autres pays d'Australasie, la Nouvelle-Zélande, l'Australie occidentale et la Confédération australienne(1), ont suivi une méthode législative différente : c'est l'institution de la Cour d'arbitrage obligatoire. Bien que cette législation soit moins directement dirigée (2) contre l'insuffisance du salaire que celle des Comités de salaires ci-dessus étudiée, les sentences arbitrales rendues par la Cour d'arbitrage ont abouti souvent en fait à la fixation du minimum de salaire: il importe donc d'esquisser brièvement ce mécanisme et ses résultats (3).

\section{I. - La Nouvelle-Zélande.}

L'histoire législative de la Nouvelle-Zélande serait fort intéressante à étudier en détail (4) : elle montrerait comme précédemment le caractère expérimental de cette législation.

C'est en I894, par la loi du 3 I aocit, qu'à la suite de grandes grèves, le Ministre du Travail d’alors, M. P. Reewes, déposa et fit voter une loi sur les Comités de conciliation et la Cour d'arbitrage. La loi, comme le portait alors son titre, tendait à " encourager la formation d'Unions industrielles et de Trade-Unions et à faciliter la solution des conflits professionnels par voie de conciliation et d'arbitrage »: la grève et le lock-out - c'est l'idée fondamentale - étaient interdits pendant la procédure : la conciliation n'avait que le caractère d'un avis ou d'une proposition, qui ne liaient

(1) A. Métin. Le Socialisme sans doctrine, Paris, Igor.

Nogaro. L'arbitrage obligatoire, Paris, 1905.

A. Métin. Le mouvement social en Australic, Musée social, Mém. et Documents, $1909, \mathrm{n}^{\circ} \mathrm{I} 2$.

(2) Elle vise directement, comme on sait, la suppression de la grève par le système de l'arbitrage obligatoire.

(3) Il est bien entendu que l'exposé qui va suivre n'est pas un exposé complet de toute la législation étudiéc : clle est envisagée ici exclusivement du point de vuc qui nous préoccupe dans cette étude, au seul point de vue du minimum de salaire.

(4) V. infra, p. 474, l'énumération complète des lois de Nouvelle-Zélande.

Sur cet historique on trouvera un substantiel résumé dans le Bulletin de l'Offlce intern. du travail, t. VII, rgo8, p. cix. 
les parties qu'après leur adhésion. La Cour d'arbitrage, compétente sur la demande de l'une des parties ou du Comité de conciliation, prononçait en dernier ressort et donnait soit un simple avis, soit une sentence obligatoire. Seuls les intéressés aux conflits (I) pouvaient profiter du mécanisme nouveau : la loi ne concernait, à strictement parler, que la conciliation et l'arbitrage.

Il suffira ici, pour résumer l'évolution législative considérable de 1894 à 1908 , d'insister sur deux idées capitales :

$r^{0}$ L'évolution se fait dans le sens de la réglementation progressive du métier tout entier par le nouveau mécanisme.

C'est ainsi que d'une part la loi no 40 de r 898 confère à la Cour le droit de fixer un minimum de salaire pour les travailleurs de toutes professions et des salaires inférieurs pour les ouvriers âgés ou de capacité moindre;

C'est ainsi encore que la loi du 20 octobre $1900 \mathrm{n}^{\circ}{ }^{5} \mathrm{I}$ assujettit à la loi les non-syndiqués et les commis de magasins; décide que les sentences des Conseils de conciliation et de la Cour d'arbitrage pourront ètre déclarées applicables à la colonie tout entière, à des catégories d'industrie et à des industries connexes ;

C'est dans le mème sens de la réglementation croissante qu'interviennent les lois du 20 novembre igo3 $n^{0} 62$ et les lois suivantes en assujettissant les associations industrielles à la sentence, en chargeant les inspecteurs des fabriques de l'application des sentences.

$2^{\circ}$ L'évolution se fait en second lieu par oscillations successives entre la conciliation et l'arbitrage, l'une et l'autre dominant tour à tour.

En r894 et en r 900 surtout, les Tribunaux de conciliation et la Cour d'arbitrage constituaient deux degrés de juridiction, le second degré ne pouvant ètre aborlé avant le premier.

En igor, en vertu de la "Willis clause", l'arbitrage devient prépondérant : les parties obtiennent le droit de s'adresser directement ¿̀ la Cour d'arbitrage, sans passer par les Tribunaux de conciliation. 
En I 908, au contraire, on restitue à la conciliation son rôle en décidant qu'aucun différend ne pourrait être porté désormais devant la Cour avant d'avoir été transmis à un Conseil de conciliation : l'avis de ce dernier n'est plus par lui-mème obligatoire.

La loi actuellement ( 1 ) en vigueur est la loi cle igo8, intitulée loi consolidlant certaines dispositions légales prises par l'Assemblée générale concernant le règlement des conflits industriels par voie de conciliation ou d'arbitrage (2).

Le mécanisme comprend deux degrés :

$\mathrm{I}^{0}$ Des Conseils de conciliaticn (Local conciliation Board) composés d'un nombre égal de patrons et d'ouvriers (3) et d'un président désintéressé : le droit d'élection n'appartient qu'à des associations d'employeurs et d'employés dùment enregistrées.

Ceux-ci rendent des avis de propositions qui sont acceptées par les parties et deviennent contrats collectifs par l'accord des deux parties.

$2^{0}$ La Cour d'arbitrage (Supreme Courl of arbitration), formée de trois membres, un président choisi par le Gouverneur, parmi les juges en fonction de la Cour suprème (4), l'un des assesseur's désigné par les associations de patrons, l'autre élu par la Fédération des Únions ouvrières et nommé pour trois ans.

Entre autres attributions, la Cour rend des sentences fixant les minima de salaires d'après l'article 98 :

"La Cour pourra dans sa sentence, ou par une ordonnance rendue à la requète de quelqu'une des parties à un moment quelconque pendant la durée de la sentence, fixer un taux minimum de salaire ou d'autre rémunération, en

(I) Cf. ci-dessus, p. 288.

(2) An act to consolidate certain enactements of the general Assembly relating to the settlement of industrial disputes by conciliation and arbitration, $1908, \mathrm{n}^{\circ}$ 82. Bulletin de l'Office intern. du travail, $1908, \mathrm{p} .350$.

Cif. en appendice les dispositions essentielles de ce texte.

(3) Ordinairement deux de chaque catégorie.

(4) Aujourd'hui, depuis la loi du 3 décembre rgro, art. 4 (Bul. Offlee intern. du trav., igiı, p. 68), les deux fonctions peuvent se cumuler. Cette même loi a également modifié les conditions légales de l'enregistrenient des Unions : jusqu'en ıgro, le changement de titre d'une Union industrielle, par un formalisme remarquable, rendait caduques toutes les discussions de la Cour d'arbitrage à son égard. Il n'en est plus de même aujourd'hui. Cf. art. 2, $\$ 2$. 
prévoyant spécialement un taux inférieur dans le cas où un salarié serait incapable de gagner le minimum fixé.

Ce taux inférieur sera, dans tous les cas, fixé par tel Tribunal, suivant telle procédure et sous réserve de telles conditions qu'il aura été spécifié dans la sentence ou l'ordonnance. ")

La pénalité dont dispose la Cour pour assurer l'exécution de la sentence est une amende de $500 £$ ( 2.500 fr.) qui peut être prononcée soit contre un patron, soit contre un syndicat ouvrier.

Résultats. - La jurisprudence de la Cour a de fait assuré l'établissement de nombreux minima de salaires pour beaucoup de professions ( $\mathrm{I}$ ).

Un tableau publié par M. Métin (2) montre les améliorations de salaires dans le métier de la couture pendant les dix premières années d'application de la loi (1897-I9o6).

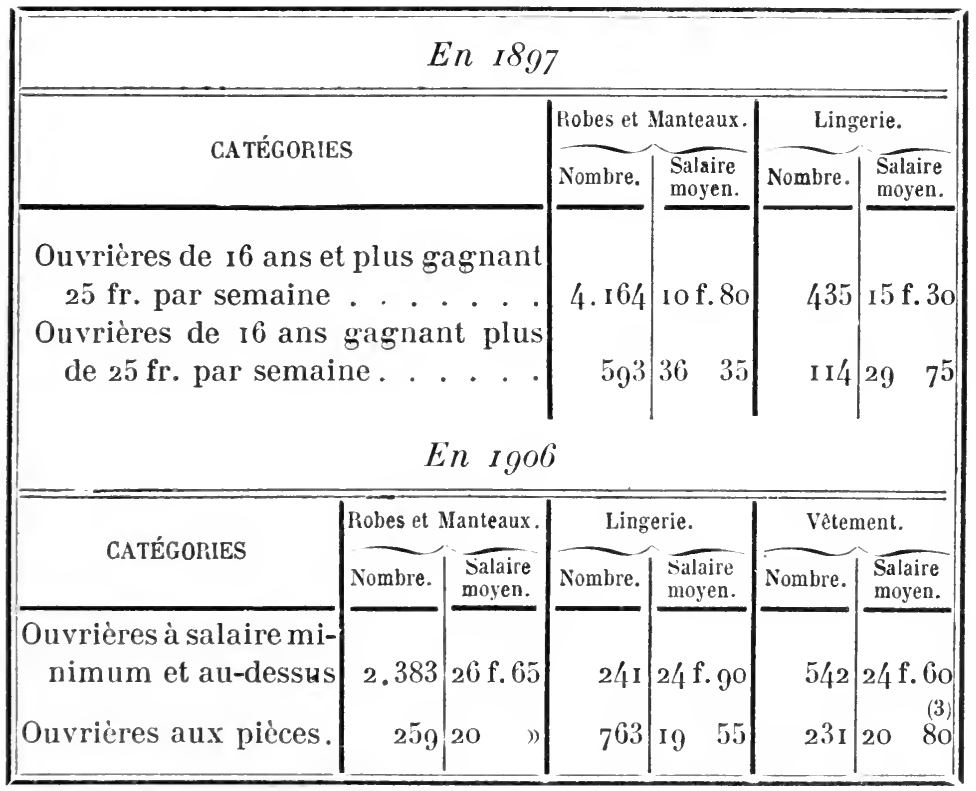

(1) Cif. Aves. Report on the Wagres Boards, op.cit., p.94, la liste complète des sentences jusqu'au 3 I mai 1907 et l'indication de nombreux minima de salaires.

(2) Le mouvement social en Australasie, Musée social, mém. et docum., Igog, p. 282.

(3) Par comparaison, en Tasmanie, où il n'y a aucune réglementation, le salaire est de 15 francs par semaine pour l'ouvrière en confection de 20 à 26 ans et au bout de trois à cinq ans de pratique. 
Fixation par la loi d'un salaire minimum pour les apprentis. - Indépendamment de cette législation d'ensemble, il existe aussi en Nouvelle-Zélande un courant législatif fixant directement dans la loi les minima de salaires des ourriers et apprentis.

Il importe aussi d'en retracer brièvement l'histoire :

Au début, c'est l'àge seul qui est pris en considération.

Le premier texte est celui de la loi du 2 I octobre I 899 , amendé le 8 novembre igor (I).

L'article $3 \mathrm{I}$, $§$ I, était ainsi conçu :

" Pour empêcher que des personnes puissent ètre occupées dans des fabriques sans recevoir une juste rémunération, les dispositions suivantes sont applicables :

$\mathrm{I}^{0}$ Toute personne occupée, à quelque titre que ce soit, dans une fabrique, a droit à la rémunération de son travail par le chef d'établissement moyennant un salaire convenu, qui ne peut, en aucun cas, être inférieur à 5 shillings par semaine pour les garçons et filles àgés de moins de seize ans et qui doit, à partir de cet àge, augmenter annuellement de 3 shillings au minimum jusqu'à l'àge de vingt ans. ")

Puis la loi de ${ }^{1902}$ (2) a ajouté au texte précédent, après le mot convenu:

" Mais qui, en aucun cas, ne peut être inférieur à 5 shillings par semaine pendant la première année de travail de toute personne âgée de moins de 20 ans et qui, pendant chaque année de travail ultérieur dans la même profession, doit augmenter de 3 shillings au minimum par semaine jusqu'à l'âge de vingt ans. "

C'était donc non plus seulement l'âge, mais encore la capacité professionnelle estimée, d'après l'expérience acquise, qui servait de base à la fixation du minimum.

Une nouvelle modification fut opérée par la loi du 3i octobre 1905 (3) :

L'article 2, remplaçant l'ancien article $3 \mathbf{I}$, $\mathbf{I}^{0}$, décidait :

"Toute personne employée à un titre quelconque dans une fabrique aura le droit de réclamer du patron le paie-

(1) Bulletin de l'Offce intern. du travail, 1902, p. 548.

(2) Loi $\mathrm{n}^{\circ} 55$ de 1902. Bulletin de l'Offlce intern. du travail, p. 103, t. VII, 1908, p. I.

(3) Bulletin de l'offce intern. du travail, 1908, p. 103. 
ment de son travail au taux convenu, lequel ne sera, en aucun cas, inférieur :

a) A 5 shillings par semaine pour les personnes de moins de vingt ans, pendant la première année de leur occupation, arec une augmentation annuelle d'au moins 3 shillings par semaine jusqu'à leur vingtième année;

b) A I 7 shillings par semaine la première année, et 20 shillings les années suivantes, pour les personnes de vingt ans et plus, qui auront été employées dans une fabrique ou dans différentes fabriques pendant quatre ans au moins. ”

C'était maintenant exclusivement la capacité professionnellequi était prise en considération pour les personnes àgées de plus de 20 ans.

Enfin l'évolution s'acheva avec la loi de rgo7: l'àge de la personne n'est plus du tout pris en considération, mais uniquement la durée des services dans la profession; ainsi le fixe l'article 14 de la loi du 25 novembre i 907 (I) :

"Toute personne occupée à un titre quelconque dans une fabrique a droit à la rémunération de son travail đ'après stipulation: la rémunération doit ètre au moins de 5 shillings par semaine pendant la première année de son emploi dans l'industrie, de 8 shillings par semaine pendant la seconde année, I I shillings pendant la troisième, etc..., avec une augmentation de 3 shillings par semaine pour chaque nouvelle année de travail dans une même profession, jusqu'à ce que soit atteint le salaire de 20 shillings par semaine; après quoi, le salaire minimum doit être de 20 shillings par semaine. ")

La constatation de la durée des services dans la profession se faisait d'après un certificat qu'était tenu de délivrer le chef d'établissement (2).

Tel est, dans ses grandes lignes, le système de la NouvelleZélande.

(1) 7. Ed. VII, n 73. Bullelin de l'offce inlern. du travail, 1908, p. 106.

(2) Loi de 1905, articles 3 et 4. Ibid. Bulletin, 1908, 1). 104. 


\section{II. - L'Australie occidentale.}

L'Australie occidentale a adopté, elle aussi, le système arbitrage néo-zélandais par une loi du i9 férrier 1902 , The Industrial and Conciliation Act (1).

Le système est, ’̀ quelques nuances insignifiantes (2) près, celui de Nouvelle-Zélande; il suffira de citer ici le texte essentiel, l'article 89 :

"Dans sa sentence ou par ordonnance rendue à la demande d'une des parties, à tout moment, pendant que la sentence est en vigueur, la Cour pourra fixer un minimum de salaire ou d'autre rémunération, en formulant des dispositions spéciales pour la fixation d'un taux inférieur pour le cas où un ouvrier serait incapable de gagner le minimum fixé.

Le taux du salaire inférieur sera, dans tous les cas, fixé par tel Tribunal, dans telle forme et suivant telles conditions qui seront spécifiées dans la sentence ou dans l'ordonnance. »)

L'expérience y fut moins heureuse qu'ailleurs (3) :

D'une part, les Bureaux de conciliation n'ont fonctionné que jusqu'en r9o3, en partie, dit M. Aves (4), à cause des pouvoirs moins étendus qu'on leur avait accordés, en partie aussi à cause de l'insuffisance des hommes qui les composaient;

D'autre part, la Cour a eu quelques déboires dans son fonctionnement et dans les résultats obtenus; à deux reprises, deux juges, nommés d'Angleterre membres de la Haute Cour de justice, mirent comme condition à leur acceptation de ne point être nommés présidents de la Cour d'arbitrage, et cette fonction fut, jusqu'à présent, exercée par les titulaires, à contre-cœur (う). En ce qui concerne les

(1) Annuaire de la Législation du travail belge, r902, p. 240.

(2) La Cour d'arbitrage se compose ici, comme pour la Confédération australienne (ef. infra, p. 341), d'un juge unique, un membre de la Haute Cour de justice.

(3) Cf. Rapport Aves. Op. cit., pp. 114 et suiv.

(4) Loc cit., p. 114 .

(5) M. Aves (Rapport cité, ibid.) y voit une manifestation des désirs de séparer les fonetions d'arbitrage des fonctions purement judiciaires. 
résultats, le système a réussi pour les travailleurs des mines d'or de l'Est et échoué pour les travailleurs de la charpente (I).

Pour les premiers, le salaire minimum légalement fixé est pratiquement et de beaucoup dépassé, d'au moins $20 \%$ en moyenne.

Pour la seconde, le salaire minimum de 7 s. 3 d. par jour (2) ne put ètre appliqué, les ouvriers l'ayant trouvé insuffisant et ayant cessé le travail.

Ce fut, dit M. Aves (3), la faillite (the brealidown) du système de l'arbitrage obligatoire dans ce pays. Ce n'est pas d'ailleurs, dit le même auteur, une raison suffisante pour condamner dans son ensemble cette législation.

Postérieurement, une loi du 2 I décembre rgog (4) est venue donner à la Cour d'arbitrage le droit de statuer sur la question de l'apprentissage et le droit de faire des apprentis.

(1) Aves. Ibid., pp. I I6-II7.

(2) Il faut, pour apprécier ce taux, se rappeler que le coût de la vie est en Australie occidentale extraordinairement élevé.

(3) Ibid., p. 116.

(4) Bulletin de l'Office intern. du travail, ig10, p. 295. 


\section{III. - La Nouvelle-Galles du Sud.}

Il faut enfin mentionner, à titre rétrospectif tout au moins, la Nouvelle-Galles du Sud, qui a suivi, de rgor à Igo8, la méthode de l'arbitrage obligatoire pour revenir, comme on l'a vu (r), en igo8, à celle des Comités de salaires.

La loi du ıo décembre igor (2) ne prenait dans le mécanisme de l'arbitrage obligatoire qu'un des deux rouages, celui de la Cour industrielle d'arbitrage seul (3).

Cette Cour, composée de trois membres, le président, choisi parmi les juges de la Cour suprême et nommé par le Gouverneur; le premier assesseur, nommé également par le Gouverneur sur une liste proposée par les Unions industrielles d'employeurs ; le second assesseur, nommé par le Gouverneur sur une liste proposée par les Unions industrielles d'ouvriers (4), avait, entre autres attributions, le droit de fixer des minima de salaires d'après l'article 36 du texte:

( Dans son arrèt ou dans une disposition prise à la demande des parties en cause, la Cour a le droit, tant que la sentence arbitrale demeure en vigueur :

a) De fixer le taux minimum de salaire ou d'autres indemnités et d'édicter les prescriptions pour la fixation de ce salaire, sous la réserve de la fixation d'un taux de salaire inférieur pour les employés qui sont incapables de gagner le salaire minimum prescrit; il est procédé à cette fixation de la manière et aux conditions incliquées dans la sentence arbitrale ou dans la disposition, ainsi que par le Tribunal désigné dans l'une ou l'autre. ")

La sanction était une amende de 5oo $£$ au maximum.

La compétence de la Cour n'existait qu'à l'égard des Trade-Unions enregistrées qui, seules, pouvaient s'adresser

(I) Supra, p. 288.

(2) Industrial Arbitration Act. Bulletin de l'office intern. du travail, I902, t. 1, p. I7I.

(3) Cette loi était due à l'initiative de M. Bernhard Wise, attorney général, à la suite du rapport de M. Backhouse sur la loi néo-zélandaise et en imitation partielle de celle-ci.

(4) La Cour pouvait, pour les questions techniques, s'adjoindre deux assesseurs supplémentaires. 
à elle. Mais la Cour pouvait déclarer ses sentences applicables à l'État de Nouvelle-Galles du Sud tout entier.

La loi de igor rencontra de sérieuses difficultés d'application (1): beaucoup de minima furent cependant fixés et devinrent applicables au métier tout entier.

On signale (2) l'encombrement des affaires devant la Cour et la complication des détails de procédure, l'incompétence technique des membres de la Cour qui devaient apprendre les questions à eux soumises (3), l'attitude hostile de la presse quotidienne, l'incertitude de la juridiction sur la portée de ses sentences (4) comme principales causes d'insuccès, au moins en ce qui concerne la suppression des grèves.

Les déterminations de minima de salaires furent nombreuses, parfois inappliquées.

C'est ainsi qu'à Sydney des équipes de débardeurs accomplissent leur besogne à raison de tant par tonne au lieu d'exiger le salaire syndical de $\mathrm{I}$ fr. 55 par heure : le travail au temps avait été seul réglementé dans cette profession par la Cour (5).

Ailleurs on use de moyens encore plus ingénieux : dans l'industrie de la chaussure, le patron renvoie certains ouvriers à domicile. Ceux-ci, devenus artisans, achètent au patron la matière première et lui vendent leur produit fabriqué.

Des coiffeurs louent un fauteuil dans une boutique à un employé au lieu de lui donner un salaire fixe (6).

On procède en igó̃ à une refonte complète de la loi pour éviter ces subterfuges. La loi du 30 juin r go5́ substitue à la Cour permanente une Cour temporaire, qui se réunit sur la convocation du gouverneur.

Composée d'un juge de district président et de deux

(1) Aves. Rapport cité, P. Ir.

Métin. Le mouvement social en Australasie, art. cité, P. 285.

(2) Ibid., pp. 136 et 137. En 1907, on comptait ror sentences et 82 contrats.

(3) Victor S. Clark. Recent changes in Australasian laws against strikes. Quaterly journal of Economics, mai 1910, p. 56r-

(4) Aves. Rapport cité, p. I1 .

(5) Beeby. Cité par Nogaro. Arbilrage obligatoire, ph. 55 et 56.

(6) Bulletin de l'offce intern. du Iravail, Igo8, 1). 93. 
personnes assesseurs nommées conformément à la loi précédente, cette Cour provisoire a d'ailleurs les mêmes pouvoirs et les mêmes attributions que la Cour permanente.

Mais cette loi de igoj̃ n'est votée que pour trois ans et cesse d'être applicable le 30 juin $\mathbf{g} 98$.

On la remplace alors par la loi du 24 avril 1908 qui acceptait le principe des Comités de salaires en maintenant d'ailleurs en appel la Cour d'arbitrage (I).

(I) C.f. supra, p. 288 . 


\section{IV. - Confédération australienne.}

La loi fédérale du i5 décembre i904, Commonwealth conciliation and arbitration Act (I) a organisé pour la Confédèration tout entière un système analogue (2).

La Cour fédérale d'arbitrage est ici composée, ce qui la distingue de toutes les autres, d'un seul membre, un président. Cet office est confié par le Gouverneur général à un des membres de la Haute Cour de justice d'Australie.

D'après l'article 40, la Cour a le droit de fixer un minimum de salaire :

" Dans sa sentence ou par ordonnance rendue à la requète d'une partie, la Cour pourra, à tout moment, aussi longtemps que la sentence est en vigueur:

Fixer un minimum de salaire ou de rémunération et, en pareil cas, prendre, à la requète l'une partie ou de toute autre organisation ou personne liće par la sentence, des mesures pour permettre au Tribunal à désigner de fixer, suivant tel mode et sous telles conditions qui seront déterminés dans l'orlonnance ou la sentence, un taux moins élevé pour les ouvriers incapables de gagner le minimum ainsi établi. »

La Cour dispose pour l'exécution de la sentence du droit de demander des garanties aux organisations intéressées et aussi du droit de condamner à une amende de 200 francs au maximum (3).

(1) Bulletin de l'offce intern. du travail, 1. IV, Igo5, 1. 52r. Modifiéc par une loi du 13 décembre $1909\left(n^{\circ} 28\right)$ sur certains points de détail. Annuaire de l'Offlce du travail belge, Igog, P. 407, et une loi da 29 aoùt 1910 $\left(\mathrm{n}^{\circ} 7\right)$. Annuaire de l'Office du travail belge, 1910, 1). 273.

(2) La loi organise un mécanisme pour résoudre les conflits industriels concernant plusieurs Ėats - il s'agit de conflits industriels en général; ceux concernant l'agriculture et les autres métiers du mème genre, les domestiques de l'industric pastorale, nommément exclue, sont, depuis rglo, compris dans la toi.

"Art. 4. - Industrie désigue les affaires, commerees, fabriques, entreprises, professions, services des travaux, sur terre ou sur eau, dans lesfuels des personnes sont employées moyennant salaires, gaiges, iatérèts des récompenses, et comprend une branche délerminée d’industrie ou une catégorie entière d’industris, (texte de igro). ")

(3) Bien entendu, en dehors de la question du minimum de salaire qui nous intéresse seule ici, la Conr a une compétence très étendue; la loi s'applique à tout ee qui concerne " le travail, les salaires, les 
On signale (1) deux applications de la loi en matière de minimum de salaire :

La première est relative aux maitres et officiers de la marine marchande d'Australie.

Voici, à titre de document, la sentence du juge de la Cour suprême O' Connor (2) en mai r 907 :

"... J'en viens maintenant à la question de savoir si les maîtres et autres officiers de marine sont à présent convenablement rémunérés et, dans la négative, quels salaires ils doivent recevoir.

Je dois tout d'abord déterminer les principes d'après lesquels la question doit ètre tranchée. La loi n'en a exprimé aucun et n'a donné directement ou indirectement aucun éclaircissement. La question tout entière est laissée à l'appréciation souveraine de la Cour. Cette appréciation souveraine, cependant, doit se conformer à quelque principe général, applicable à tous les cas, et je vais essayer de mon mieux de formuler quelque règle d'ensemble en la tirant d'un point de vue général, des intentions du règlement interprété d'après ses dispositions et de la nature de l'affaire. Après mùre considération de la loi et du cas qui m'est soumis, le seul principe - et encore peut-on à peine l'appeler ainsi, - est le suivant : la Cour, dans chaque cas, doit arranger le conflit d'une manière qui paraisse juste et raisonnable aux deux parties. En déterminant cette solution juste et raisonnable, il faut prendre en considération les droits certains des parties.

Le droit de l'ensemble des employés, qui leur est reconnu par la loi est, lorsque le conflit est porté devant la Cour, d'obtenir une sentence leur accordant des salaires convenables, fair wages, et non, comme le soutiennent ceux qui confondent l'établissement d'un fonds de salaire avec le

heures, les privilèges, droits et devoirs des employeurs et employés, le mode et les condilions d'emploi et de refus d'emploi, et en particulier, sans limiler les termes généraux de cette définition, renferme toule matière relative aux relations des employeurs et employés, emplois, emplois avee préférence, renvois ou refus d'emplois de tout particulier, de personne de tout sexe et àge, membre ou non de toute organisation, association ou compagnie, et toutes réclamations faites à propos d'un contrat collectif $)($ art. $4, b)$.

(1) Rapport Aves, p. 119. Cf. p. 215.

(2) Rapport Aves, p. 215. 
droit au salaire, une participation aux profits. Sauf dans les coopératives, les employés ne sont en aucun sens des coparticipants de leurs employeurs. Ils ne courent aucun risque financier et ne supportent aucune responsabilité.

D'autre part, le droit de l'employeur est d'arranger et de diriger son affaire à sa manière sans aucune intervention d'aucun genre - sauf si la Cour le juge nécessaire, pour consacrer le droit donné par la loi aux employés à un juste salaire.

En appliquant ces principes dans la présente affaire, je trouve tout d'abord qu'il n'y a pas de question de salaire vital engagée. Quelques témoignages ont été produits par les plaignants pour montrer que la paye d'un officier de troisième rang, to $£$ par mois, n'était pas un salaire de vie suffisant pour un officier et sa femme. Les témoignages établissent que, bien qu'il existe quelques officiers de troisième classe qui ne soient plus jeunes, l'emploi est d'ordinaire confié à de très jeunes hommes qui l'obtiennent en moyenne avant 24 ans et où ils ne restent que peu d'années. Pour un homme de cet âge, ce salaire est d'une manière générale un salaire supérieur au salaire de vie. La question, par conséquent, se ramène à cette autre : les maîtres et officiers sont-ils bien payés pour la besogne qu'ils font ( $\mathrm{I}$ )...? ")

Dans ce premier conflit, la sentence rendue modifia peu de choses et n'eut pas de peine à s'imposer.

La seconde application eut lieu en juin i g07, dans l'affaire des tondeurs : les salaires déterminés par la Cour suprème représentée par le même magistrat de la Cour suprème, O'Connor, sont de $22 \mathrm{sh}$. à 24 shillings, selon les districts. Coïncidant avec une période de prospérité, elle ne rencontra aucune difficulté et fut bien accueillie.

Mais bientôt des difficultés s'élevèrent quant à ce droit de la Cour : à la suite de la législation douanière de ı9o6 (2) qui imposa aux produits protégés par la douane des taxes de consommation jusqu'à concurrence du montant des droits protecteurs, on introduisit dans la loi certaines dispositions déclarant la protection sujette à revision ou à

(i) Il conclut plus loin sur ce point dans le sens de l'affirmative.

(2) The Custom and Tariff Act, $\mathrm{n}^{\circ} 14$, rgof. 
atténuation, c'est-à-dire l'exemption des taxes dans certains cas, notamment si les autorités déclarent que ies salaires payés sont justes et raisonnables.

Deux sentences furent rendues en application des dispositions nouvelles :

L'une est un contrat collectif préparé par le juge O'Connor à Adélaïde, prévoyant un tarif provisoire de minimum de salaire pour la fabrication des instruments agricoles de l'Australie du Sud;

L'autre rendue par lejuge Higgins établissait, à propos des travailleurs non (qualifiés, le tarif de salaire au temps qu'il fallait payer pour jouir d'une exemption des droits (I), soit 7 shillings par jour.

La question fut portée derant la Haute Cour de justice d'Australie qui, par un arrêt du 26 juin I907, déclara inconstitutionnelles les dispositions de la loi douanière de 1906 relative aux salaires, le pouvoir de légiférer en matière de salaires étant une attribution des États particuliers (2).

La Confédération australienne ne renonça point d'ailleurs pour cela à la politique du minimum de salaire lié à la protection (New Protection).

Les primes accordées pour la fabrication de certains articles sont supprimées si les articles ne sont pas fabriqués dans des conditions de salaire convenables et raisonnables (3). Voici, à titre d'exemple, l'article i d de la loi du 14 décembre 1908 :

" I ${ }^{\circ}$ Quiconque prétend à une prime, en vertu de la présente loi, doit, en adressant sa demande au Ministre, y annexer un relevé des salaires qu'il paye à ses ouvriers pour la fabrication des produits en faveur desquels il sollicite la prime;

( $2^{0} \mathrm{Si}$ le Ministre constate que les salaires:

(r) Cf. rap. Aves, P. 2r6. A propos de cette sentence, M. Higgins définit les termes: salaire juste et raisonnable : e'est celui qui correspond aux besoins normaux de l'employé moven, envisagé comme un être humain vivant dans une communauté civilisée : "The normal need of the average employee regarded as a human being, living in a civilised community $)$.

(2) Cf. Aves., rap. cité, P. I19 et P. 216, note $i$.

(3) The Bounties Act 1907. Loi du 14 décembre 1908 pour l'industrie du fer. Bull. de l'Office intern. du travail, 1908, p. 284. Cf. p. Lxxxvir. 
a) sont en totalité ou en partie inférieurs aux taux normaux fixés par un Tribunal industriel de la Confédération ou d'un État particulier;

b), à défaut de taux normal de ce genre applicable en l'espèce, sont inférieurs aux salaires normaux pratiqués d'ordinaire dans le lieu de fabrication des produits;

c) à défaut de salaires normaux de ce genre, si sur requête adressée par le ministre au président de la Cour fédérale de conciliation et d'arbitrage, ils ne sont pas reconnus par ce dernier ou par un juge de la Cour suprême d'un des États confédérés ou par un tribunal industriel d'un des États composé d'un ou plusieurs membres, auquel le ministre aurait déféré l'affaire, comme étant justes et raisonnables (fair and reasonable), il pourra retenir la totalité ou une partie de la prime (I). ")

Ainsi, à tout le moins, sans conserver son pouvoir de décision, la Cour fédérale d'arbitrage est appelée à déclarer ce qu'elle entend par salaire juste et raisonnable.

Grâce à cette disposition, une certaine uniformité entre les divers États de la Confédération arrivera probablement à s'établir.

Ainsi on évolue en Australasie, tant dans le groupe des États à Comités de salaires que dans celui des États à arbitrage obligatoire, vers un minimum de salaire.

La plupart des États ont d'ailleurs enregistré législativement cette évolution ainsi qu'en témoigne le tableau suivant :

(1) Cette dernière addition c) était motivée par la situation de fait de la Tasmanie, où il n'existait alors ni Comité de salaire ni arbitrage obligatoire et où cependant l'industrie du fer, pour lapuelle on légiférait, était appeléc à se clévelopper. 
$-346-$

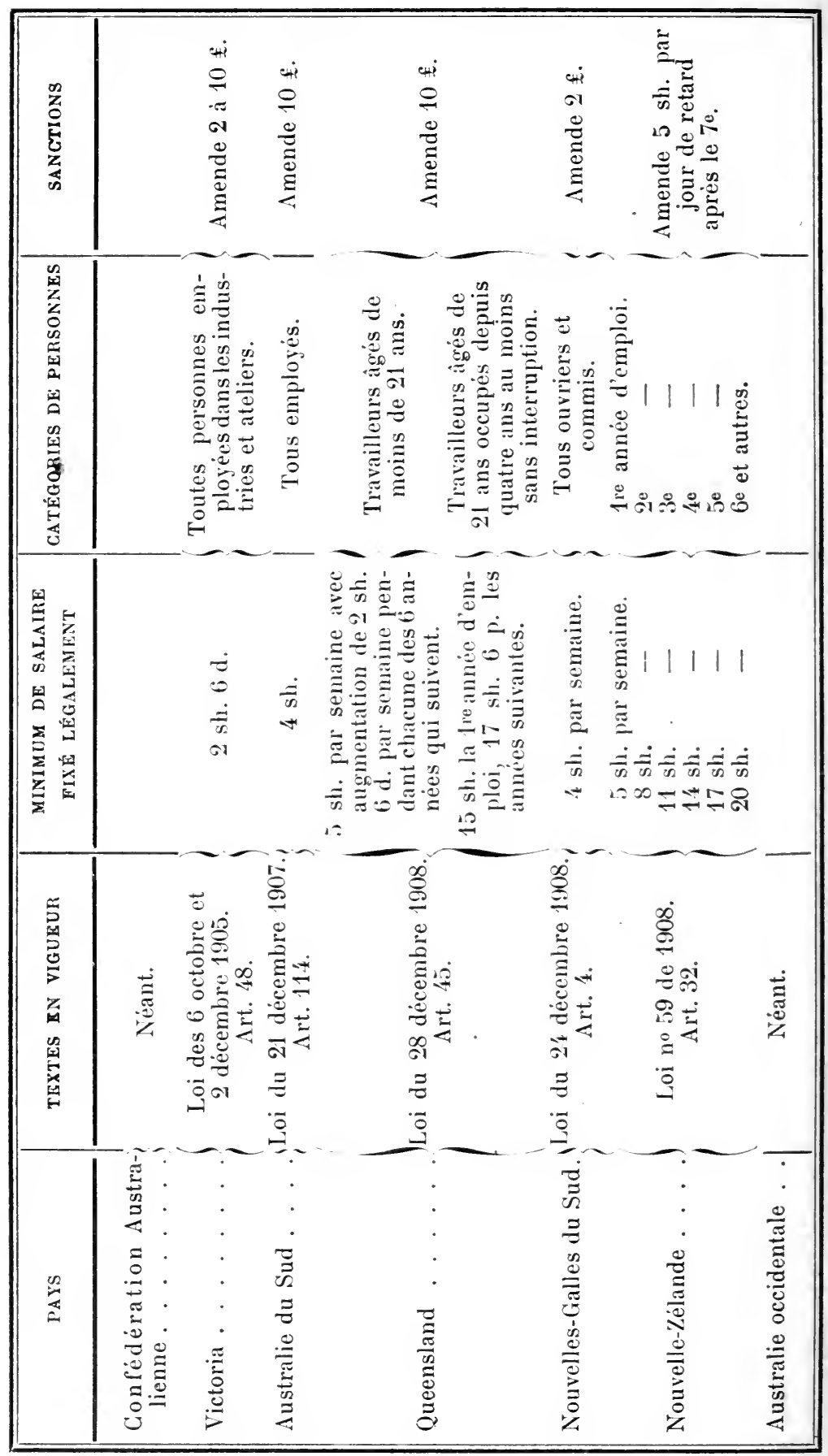


Il faut signaler enfin la loi roumaine du 23 décembre i 907 qui contient une série d'articles relatifs au salaire minimum légal des ouvriers agricoles (I).

La loi ne fixe pas le minimum, mais délègue le soin de cette fixation à des Commissions régionales qui doivent tenir compte, dans leur appréciation, des conditions économiques et du coût de la vie.

Ce minimum peut varier et sera révisé tous les cinq ans. Les Commissions régionales doivent prendre comme base les prix moyens pratiqués dans chaque région pendant une durée de trois ans (2).

Les sanctions sont, en cas de fraude volontaire du patron, une amende pouvant s'élever jusqu'à 500 francs. Un inspecteur agricole régional, président de la commission régionale, vérifie la régularité des contrats agricoles et peut demander d'office au juge de paix leur annulation.

La loi est d'ailleurs, paraît-il, assez mal appliquée (3).

(1) Cif. Constantin Grégoresco. Sur la politique agraire en Roumanie. Thèse, Paris, 1912, Paris, Giard.

(2) La loi ne s'applique qu'aux contrats conclus par des Roumains plus de trente jours avant l'exécution des travaux respectifs dans la localité.

(3) Cf. Grégoresco, op. cit., p. 205. "Quant à la loi sur les contrats agricoles, son échec est généralement reconnu. Le contrat agricole, quoique passé dans les formes légales, ne respecte pas en réalité les principes de la loi. » 


\section{CONCLUSION}

Dans quelle mesure ces deux législations australasienne et anglaise sont-elles utilisables pour notre France? C'est ce que les discussions et l'analyse du mouvement des réformes auront à déterminer.

Il est permis cependant de dégager, dès maintenant, la conclusion qui semble s'imposer.

L'étude qui précède a mis en lumière, semble-t-il, une double affirmation:

D'abord, la législation sur le minimum de salaire est bien une réalité: le double édifice que nous venons de regarder est une réponse péremptoire par lui seul - mole. sua stat - aux timides, aux hésitants, aux négateurs a priori d'une intervention efficace dans le redoutable problème du travail à domicile. Quoi qu'on dise et quoi qu'on objecte, c'est un fait qu'un minimum obligatoire existe aujourd'hui dans deux pays: l'Angleterre et l'Australie, qui, nous l'avons vu, n'ont pas l'air pour cela de s'en trouver plus mal. L'expérience est faite et la législation à établir est possible.

L'idée nouvelle a trouvé sa voie par le biais du contrat collectif obligatoire. Sur ce premier point, aucune contestation ne paraît possible : l'expérience australasienne et l'expérience anglaise ont au moins le très grand mérite d'avoir lumineusement établi l'intervention efficace du législateur.

Ensuite - et cette seconde leçon des faits est peut-être plus importante encore que la première - le législateur australasien comme le législateur anglais a cherché à intervenir le moins possible. Cette soumission aux faits, cette confiance dans l'initiative individuelle soutenue et stimulée par la loi sont, nous y avons insisté, des caractéristiques 
essentielles du tempérament anglo-saxon. De loin, l'œurre parait entièrement artificielle, je veux dire fabriquée de toutes pièces et imposée d'autorité; de près, elle est surtout réaliste, c'est-à-dire pénétrée de la spontanéité des forces patronale et ouvrière qu'elle met en présence et sur lesquelles elle compte avant tout pour réaliser son œuvre (I). Tout, dans les législations que nous venons d'analyser, accuse cette intention : souplesse du mécanisme, délais accordés, application progressive des tarifs, variété dans la composition des Comités. D'un mot - et la chose est manifeste surtout pour l'Angleterre, - le contrat collectif légal qu'on impose n'est, dans ses détails, que l'imitation aussi exacte que possible du contrat collectif libre, malheureusement inexistant dans les industries visćes par suite du manque d'organisation professionnelle.

Ici, sans doute, sera vraie, une fois de plus, la grande parole de Bacon : "On ne commande à la nature (à la nature inanimée comme à la nature sociale) qu'en lui obéissant. ")

Oser et obeiir aux faits, tels sont les deux conseils de l'expérience étudiée.

Le minimum légal de salaire n'est point un rêve : comme l'association professionnelle, comme la puissance publique, la Loi est encore un puissant moyen direct d'aboutir dans certains cas.

(I) Ceci résulte jusqu'à l'évidence de toute la discussion parlementaire anglaise : le bill est toujours présenté, soit aux Communes, soit aux Lords, comme un mécanisme artificiel analogue à celui qu'a su constituer l'industrie libre. 



\section{TROISIÈME PARTIE}

\section{PERSPECTIVES D'AVENIR : LES CHANCES DE RÉALISATION DU MINIMUM DE SALAIRE. L'OPINION PUBLIQUE}

Malgré ces tentatives de réalisation indirectes ou directes, notre société moderne n’a pas encore accueilli le minimum de salaire.

Il reste donc à se demander quelles sont ses chances d'avenir, quel est, à son sujet, l'état actuel de l'opinion publique.

Pour le retracer, nous chercherons successivement :

$I^{\circ}$ Les objections actuelles contre le minimum de salaire; $2^{0}$ Les projets et les réformes en France;

$3^{\circ}$ Les projets et les réformes à l'étranger. 


\section{CHAPITKE PREMIER}

\section{Les objections actuelles contre le minimum de salaire.}

L'idéal du minimum de salaire rencontre, il ne faut pas se le dissimuler, une opposition très forte, à l'heure actuelle, auprès des esprits contemporains, et pour beaucoup cette politique du minimum de salaire n'est qu'une utopie qui n'a aucune chance d'aboutir.

Il importe donc, tout d'abord, de discuter scientifiquement les objections qu'on lui oppose et de juger par là de sa valeur scientifique.

On peut classer en trois catégories les objections les plus couramment élevées contre le minimum de salaire :

a) Le salaire obéit à des lois naturelles, à des déterminations fixes et invariables contre lesquelles on ne saurait élever la détermination arbitraire d'un minimum. C'est l'objection faite au nom de la science économique : le minimum de salaire est impossible ;

b) A le supposer possible, en second lieu le fonctionnement pratique d'un minimum de salaire se heurterait à des difficultés pratiques insurmontables. C'est l'objection faite au nom de la pratique : le minimum de salaire est irréalisable ;

c) Enfin, à le prenclre comme possible et réalisable, l'établissement d'un minimum de salaire serait une chose mauvaise et nuisible à la prospérité générale, il va à l'encontre d'une organisation économique sainement comprise et habilement ménagée. C'est l'objection faite au nom de l'intérêt social : le minimum de salaire est nuisible et mauvais.

Examinons ces trois catégories d'objections ( $\mathrm{I}$ ) :

(1) Hubert Valleroux : Le minimum légal de salaire. Rapport et discussion : la réunion annuelle de la Société d'économie sociale, Réforme sociale, $1895,2^{\circ}$ sem., p. 302 . 


\section{I. - Le Minimum de salaire est-il impossible?}

Cette première objection est faite du point de vue scientifique au nom des lois naturelles de l'économie politique. On prétend que celles-ci déterminent le salaire d'une façon trop certaine et trop rigoureuse pour que la fixation artificielle des salaires par intervention puisse venir la modifier.

Cependant, à prendre une à une les lois du salaire, il n’apparaît pas que cette détermination soit aussi précise et aussi rigoureuse qu'on l'affirme. Ni les lois générales de l'économie politique (loi de l'offre et de la demande et loi du salaire nécessaire), ni les lois spéciales (loi du fonds de salaires, loi de la productivité de travail) ne paraissent, pour autant qu'elles sont établies, jouir de ce caractère de précision et de contrainte ( $\mathrm{I}$ ) : d'une part, le travail n'est point une marchandise; d'autre part, ces diverses lois ne sont vraies que toutes choses égales d'ailleurs : ce qui réserve précisément l'intervention d'un autre facteur, l'organisation professionnelle s'exprimant par le contrat collectif.

De plus, toutes les théories économiques (2) contemporaines sur le salaire sont unanimes à conclure, dans le sens

(I) Cf. Raynaud. Le Contrat collectif de travail, r vol., Paris, Rousseau, I902, pp. I 76 et suiv.

Nous comptons d'ailleurs reprendre quelque jour cette démonstration dans un ouvrage plus général.

(2) Cf. Levasseur. Salariat et salaires, r vol., Paris, Doin, r909, p. 2 r. "Le salaire est une résultante de plusieurs causes"): l'auteur en énumère six et ajoute un etc...

Cornélissen : Théorie du salaire et du travail salarié, r vol., Paris, Guillaumin, r9o8, pp. 645 et suiv. : Les formules d'une théorie générale des salaires.

Ch. Gide : Cours d'économie politique, $2^{\circ}$ édit., I9rr, p. 66r. "Le prix de la main-d'œuvre est déterminé :

I' D'abord par toutes les causes générales qui agissent sur la valeur générale de toutes choses et que l'on peut, si l'on veut, résumer en gros dans la formule de l'utilité finale.

$2^{\circ}$ Et aussi par certaines causes spéciales à la marchandise travail parce que cette marchandise-là se trouve ètre en même temps un homme, parmi lesquelles les plus agissantes sont le sentiment grandissant qu'acquiert l'ouvrier de son importance sociale et les organisations auxquelles il a recours pour faire valoir ses droits. ") 
d'une certaine contingence ou tout au moins d'une pluralité marquée des facteurs du salaire.

Au total, on ne peut, en l'état actuel de nos connaissances, affirmer aucune détermination préfixe, fatale et immuable du salaire. La porte reste largement ouverte à l'interventionisme qui en fait, on l'a vu, s'est introduit avec succès. 


\section{II. - Le Minimum de salaire est-il irrẻalisable?}

Les adversaires du minimum de salaire poursuivent la discussion sur un second terrain : toute tentative pour établir pareil système est vaine, affirment-ils encore, parce qu'elle se heurte à des difficultés pratiques insurmontables. Celles-ci sont surtout mises en lumière dans l'hypothèse d'un minimum légal; la plupart portent aussi contre le minimum conventionnel ( $\mathrm{I}$ ).

a) Et tout d'abord, les déterminations de minima de salaires seront inefficaces par suite de la collusion entre patrons et ouvriers qui se mettent d'accord pour échapper à la tarification imposée (2). Voyez, dit-on, comment les choses se passeront en pratique : dans tel métier, la menuiserie par exemple, le salaire à la journée est fixé à tel prix minimum, 5 francs par exemple. Tel petit patron, gêné par ce taux, est sur le point de fermer boutique. L'ourrier pressé et désireux de travailler viendra trouver le patron et lui dira : "Faites-moi travailler. - Je ne peux pas, répliquera le patron. - Qu'à cela ne tienne, répliquera l'ouvrier, prenez-moi à $4 \mathrm{fr}$. 50 . Voici les cinquante centimes que vous me redonnerez; nous serons ainsi en règle avec la loi. J'aime mieux travailler pour $4 \mathrm{fr}$. 5o que de ne pas travailler du tout. " Et ainsi l'accord des intéressés viendra perpétuellement tourner les tarifications légales.

On pourrait - et cela, affirme-t-on, se voit mème dans la pratique - trouver des hypothèses analogues au cas de tarifications conventionnelles.

La réponse à l'objection est cependant facile : l'hypothèse sur laquelle on raisonne est bien évidemment celle dans laquelle la tarification est à ce point gênante que l'em-

(I) G. W. Gough. Economic Journal, sept. 1905.

(2) "Quelle loi promulgueriez-vous contre des conventions particulières que patron mauvais et ouvrier faible et souffreteux passeront dans l'intimité d'une entrevue sans témoin?" Ch. Lagasse de Loeht. Communication à la Société belge d'économic sociale. Réforme sociale, 16 avril 1892, p. 572 .

" Toute taxation des salaires ne peut être qu'une œuvre négative et non une cuvre positive, en ce sens fue l'on ne peut forcer à employer des ouvriers. P. Leroy-Beaulieu : Traité d'économie politique, $2^{n}$ édit., t. II, p. 483. 
ployeur préfère fermer boutique plutôt que de s'y conformer. Sans cela, on ne comprendrait pas que cet ouvrier acceptât de ne gagner que $4 \mathrm{fr}$. 5o, alors qu'il pourrait gagner 5 francs. Or il est illégitime d'affirmer à priori que la tarification et l'établissement d'un minimum de salaire seront a ce point et par eux-mèmes ipso facto gênants pour l'employeur. Celui-ci y aura collaboré directement ou par des représentants; il est donc infiniment probable que l'établissement d'un minimum aura été fait d'une manière assez large pour ne pas condamner à cette fàcheuse alternative les employeurs : fermer ou payer au-dessous du minimum. Normalement, donc, les choses ne se passeront pas ainsi.

Que si, enfin, dans des cas tout à fait exceptionnels (I), par suite de tarifications abusives et mal faites, pareille hypothèse se réalisait, on peut remarquer d'une part qu'une exception ou une non-application n'est pas une raison suffisante pour condamner tout un système : il y a des violations des lois sur la clurée du travail. Est-ce une raison pour les supprimer? Et d'autre part même, en ce cas limité et extrême, la fixation d'un minimum de salaire a encore son effet : elle sert d'étiage et de niveau dans le contrat individuel qu'on analyse; sans cela, l'ouvrier accepterait de travailler pour beaucoup moins encore que 4 fr. $50-$ 4 francs ou peut-être moins. Le minimum réglementé par la loi ou la convention collective est un correctif nécessaire à l'inégalité des deux parties au contrat.

En résumé, l'hypothèse visée est exceptionnelle et, mème en ce cas, le minimum aurait son utilité; telle est la double réponse à faire à cette première forme de l'objection tirée de l'impossibilité pratique.

b) On insiste en second lieu sur les difficultés du fonctionnement des Comités de salaires appelés à établir les minima. - Dans la plupart des métiers où le minimum de salaire sera le plus utile, c'est-à-dire dans ceux où sévit le sweating system, il n'existe aucune organisation du métier, ni association professionnelle patronale, ni association professionnelle ouvrière. Comment, dès lors, trouver les

(I) Sur la rareté de ces cas, cf. Hoatson : Victorian minimum wage system. Report on conference on a minimum wage, Londres, 1907, p. 8r. 
membres de ces Comités de salaires? Comment les choisir? L'élection comporte une série de difficultés pratiques, dont la plus grande est l'établissement de la liste des électeurs, qui impliquerait la divulgation des noms des syndiqués. La nomination par le Gouvernement se heurte également à de sérieux obstacles. Enfin, qui aura assez d'autorité pour imposer une tarification aussi délicate?

Il faut avouer que le problème est difficile à résoudre, mais il ne paraît pas insoluble, si l'on en juge par l'expérience australienne et l'expérience anglaise. L'essentiel, semble-t-il, en ce qui concerne la formation de ces Comités, est de ne pas avoir de système uniforme, rigide et fixe. Comme l'a fort bien dit M. Churchill, président du Board of Trade, dans la discussion de la loi anglaise (I), " il serait absurde d'appliquer les mêmes instructions au cas de bonne santé qu'au cas de maladie. Il ne faut pas considérer ces métiers comme des abstractions mortes. Ils vivent, je dirai presque que ce sont des organismes conscients, et chaque métier doit être étudié et traité différemment. Aucune règle générale n'est applicable. Il n'y a pas de traitement tout fait pour la maladie; on ne peut amener la guérison plus rapide par une augmentation de la dose du remède. Des médecines différentes, des régimes différents, des opérations différentes sont nécessaires dans chaque cas et chaque cas nécessite un effort personnel, un encouragement et un soin personnels de la part des individus, s'il s'agit réellement d'apporter le remède espéré contre le mal. C'est la justification de la grande souplesse de procédure et des pouvoirs presque discrétionnaires du Board of Trade dans le projet. ")

C'est donc par une adaptation détaillée de chaque Comité de salaire à chaque métier et à chaque industrie que le fonctionnement de ces Comités sera possible (2).

c) Enfin, toujours à ce même point de vue des impossibilités pratiques, on objecte, en dernier lieu, que le taux minimum

(r) House of Commons, 28 avril rgog. Parliamentary Debates, r9o9, p. 387 .

(2) Il faudra mème, dans certains cas, aller plus loin et renoncer, comme l'ont fait certains projets français, anx Comités de salaires pour d'autres organisations et d'autres mécanismes. 
légal ou conventionnel tendra à devenir le taux moyen des salaires et qu'ainsi la tarification jouera comme un obstacle à l'élévation possible des salaires. La coutume et l'habitude, à en croire les partisans de ce point de vue, ont un rôle prépondérant dans la détermination du niveau des salaires : une fois la tarification adoptée, elle deviendra de style et il n'y aura guère de chances de voir les salaires dépassér ce minimum.

On peut répondre que pareil résultat serait déjà, par luimême, un progrès, puisqu'il assurerait à tous le salaire vital. Mais la crainte n'est pas fondée : l'expérience de la pratique anglaise et australasienne (I) montre que les tarifcations conventionnelles ou légales sont bien restées des minima, au-dessus desquels les capacités individuelles, les valeurs personnelles, les circonstances spéciales ont su faire monter les salaires.

Au total, aucun des inconvénients signalés ne paraît décisif contre le fonctionnement du minimum de salaire, que la pratique a victorieusement montré possible. Il s'agit, en somme, ici, de considérations plus théoriques que pratiques. C'est ce que disait très nettement, dans une discussion au Conseil communal de Bruxelles (2), un adversaire du salaire minimum devenu partisan de l'innovation : " J'ai donc changé d'avis? Oui, dans une certaine mesure. Et pourquoi? C'est ce que je vais vous exposer.

Messicurs, il est évident, pour ceux qui suivent avec loyauté et bonne foi les phénomènes sociaux, que l'économie politique, cette science qui avait pour principe classique le laisser-faire et le laisser-passer, se préoccupe trop des théories et ne tient pas un compte suffisant des faits qui se passent journellement sous nos yeux.

Or en matière économique, je l'ai dit souvent au cours de nos discussions, il faut, à mon avis, s'inquiéter très peu des principes et beaucoup des faits. Une chose est certaine, c'est que les objections que l'on opposait d'une façon absolue au principe du minimum de salaire étaient basées avant tout sur des considérations théoriques. ")

(I) G. Hoatson, op. cit., p. 83.

(2) Séance du 9 janvier $188_{9} 3$, p. 23. 
III. - Le Minimum de salaire est-il nuisible et contraire à l'intérêt génẻral ?

Enfin, la discussion se déplace encore et l'on affirme, en troisième lieu, que le minimum de salaire serait nuisible et contraire à l'intérèt général.

Pour le montrer, on se place soit au point de vue national et spécial d'un pays, soit à un point de vue absolu et abstrait. Examinons successivement ces deux argumentations.

A) Tout d'abord, affirme-t-on, le minimum de salaire est mauvais et nuisible au point de vue de l'économie nationale d'un pays donné. A maintes reprises, dans la discussion anglaise, on vit revenir cet argument de la concurrence étrangère : si un pays s'engage le premier dans cette voie, il sera indiscutablement dans une situation inférieure sur le marché mondial par rapport à ses rivaux industriels, et ce sera simplemement la disparition du métier réglementé, qui succombera devant la concurrence étrangère.

L'argument ainsi présenté comporte une double réponse théorique et pratique :

Théoriquement, il n'est nullement impossible d'espérer qu'un jour viendra où la Législation internationale arrêtera un minimum de salaire international, ou, plus exactement, des dispositions d'ordre international seront prises en vue de l'établissement d'un minimum de salaire. Celui-ci sera sans doute variable et d'un taux différent dans les divers pays, comme il est actuellement différent pour les régions d'une même nation. Mais une base unique et commune pourrait être adoptée.

La question a été à maintes reprises examinée et des vœux émis en faveur du salaire minimum international (I).

En ce qui concerne plus spécialement le salaire minimum dans les industries où règne le travail à domicile, une réunion tenue à Londres le 27 avril igo8 et organisée par 
l'Anti Sweating League (1) envisagea la possibilité d'une convention internationale au sujet du minimum de salaire. Les rapports de MM. A. Fontaine et Vanderwelde envisagèrent, avec une échéance assez lointaine, la possibilité de pareils accords.

Une telle solution ne pourra évidemment intervenir qu'après que le problème aura reçu dans les différents pays une solution nationale.

Sans doute les difficultés de réaliser pareille législation(2) sont grandes et le jour de son acceptation et de sa mise en vigueur encore lointain.

L'échéance ainsi reculée du minimum de salaire international appelle une seconde réponse à l'objection de la concurrence étrangère.

Pratiquement on peut affirmer, avec S. Webb(3), que si le résultat d'un minimum de salaire est de rendre l'industrie plus efficace et plus productive, il n'est point la peine de perdre de temps à démontrer qu'il ne peut placer le pays dans une situation désavantageuse pour sa concurrence avec l'étranger. La preuve est déjà faite en ce qui concerne la législation ouvrière en général : la limitation des heures de travail, la réglementation des conditions d'hygiène imposées par la loi n’ont pas influé sur le commerce international de l'Angleterre: il en serait de mème de la fixation d'un minimum de salaire. Cette absence d'action fâcheuse et mème cetteaction bienfaisante s'expliquent par un déplacement de la concurrence et par une sélection plus heureuse des plus aptes dans chaque métier en mème temps que par un stimulant puissant des inventions techniques et du machinisme. Au surplus, en fait, l'exemple tout récent de l'Angleterre permet d'ajouter au raisonnement la leçon des faits. Dans les diverses industries où les comités de salaires fonctionnent, on n'a pas constaté de recul appréciable.

En résumé donc, l'argument de la concurrence interna-

(I) Tulletin de la Ligue sociale d'acheteurs, 3• trim. Igo8. Une discussion sur le minimum de salaire international, p. 169 .

(2) Sur la législation internationale, ses progrès et ses difficultés, cf. Raynaud, Droit international ouvrier, Paris, Rousseau, I905.

(3) Industrial Democracy. Longmans, 1902, et aussi communication à la conférence sur le minimum de salaire. Londres, 24-26 octobre 1906. National anti sweating League. Londres, 1907, p. 25. 
tionale est une sorte de refrain dont on abuse sans cesse dans cette discussion comme dans les autres. Il n'est pas possible scientifiquement de lui accorder l'importance qu'on lui prête.

B) Enfin la controverse se poursuit; c'est d'un point de vue général et abstrait, au nom des réalités économiques, que les adversaires du minimum de salaire le condamnent en dernier lieu, en prétendant :

I $^{\circ} \mathrm{Qu}$ 'il diminue la productivité industrielle;

$2^{\circ} \mathrm{Qu}$ 'il supprime la concurrence;

$3^{\circ}$ Qu'il élimine fatalement les ouvriers âgés et moins productifs ;

$4^{\circ}$ Qu'enfin il est nuisible au consommateur par l'élévation fatale des prix qu'il provoque.

Il faut maintenant exposer et discuter ces quatre affirmations.

\section{$\mathbf{I}^{\circ}$ Le minimum de salaire diminue-t-il la productivité} industrielle?

C'est là une des craintes maintes fois exprimées (I) à l'égard du minimum de salaire. Aujourd'hui, dans notre organisation économique actuelle, le grand ressort de la productivité industrielle est le mécanisme des prix fonctionnant automatiquement en régime de liberté. Du jour où l'ouvrier serait assuré d'un salaire quotidien suffisant pour vivre, n'y aurait-il pas à craindre qu'il se désintéressât de la production et que par là même les quantités produites vinssent à décroître d'une manière très sensible. On invoque à l'appui de ces raisons l'expérience ci-dessus rappelée du minimum de salaire dans les établissements de la marine française, où l'on constate un abaissement notable dans la production de nos arsenaux de igoo à r 904 .

On peut répondre à la fois en théorie et en fait:

En théorie, il paraît certain que l'objection qui serait plausible contre un minimum absolu fixé au temps sans équivalent corrélatif de travail(2) ne vaut pas contre la

(1) Paul Leroy-Beaulieu, Traité théorique et pratique d'économie politique. Paris, 3e édition, Guillaumin, t. II, p. 483.

(2) Cf. Conclusion ci-après, p. 449. 
conception du minimum de salaire que l'on peut préférer, c'est-à-dire contre le salaire le plus bas encore convenable qui se puisse payer pour un ouvrage donné. Avec la garantie d'un certain résultat de travail, c'est-à-dire d'une certaine production, il est clair qu'il n'y a pas chance de voir diminuer la productivité industrielle.

En fait, les récentes expériences de minimum de salaire actuellement pratiquées (I) n'ont pas révélé de diminution appréciable dans la production du métier.

M. Aves et les enquètes qu'il a menées sur ce point permettent d'affirmer que les comités de salaires n'ont pas eu d'effet appréciable sur la production, au moins d'après la majorité des réponses analysées (2).

En Angleterre aussi les premiers résultats de l'expérience paraissent permettre semblable affirmation(3).

A Victoria il y avait, en I 896, 3.370 usines avec 40.8I4 ouvriers. En i904, au moment où les deux tiers des ouvriers (exactement 44.500) jouissaient du système des comités de salaires, il y a 4.623 unités avec 63.270 ouvriers, soit un accroissement du nombre des ouvriers de plus de $50 \%$ (4).

\section{$2^{0}$ Le minimum de salaire supprime-t-il la concurrence?}

C'est là encore l'une des objections les plus communes contre la fixation d'un minimum de salaire. " En graduant la rémunération sur les besoins de l'ouvrier, plus ou moins bien appréciés, et non sur les résultats du travail, elle aurait beaucoup de chances de réduire la demande des bras (5). " On montre comment, gêné par cette limite fixe, le patron ne pourra plus faire descendre la rémunération du travail aussi bas qu'aujourd'hui.

La réponse à cette objection a été maintes fois faite et merveilleusement formulée par S. Webb : “La méthode de

(1) Exception faite sur l'expérience de la marine française, où il y a eu réellement diminution de la production, pour les raisons ci-dessus exposées. Cf. supra, p. 248.

(2) Aves, rapport cité, p. 48.

(3) Parliam. Deb. H. of C., I9I I, 26 avril, vol. XXIV, pp. I 882 et suiv.

(4) Hoatson, loc. cit., p. 82 et p. 85.

(5) Paul Leroy-Beaulieu. Traité théorique et pratique d'économie politique, $3^{\mathrm{e}}$ éd., Paris, Guillaumin, I 900 , t. II, p. 489 . 
la règle uniforme ne limite pas l'intensité de la concurrence ou la liberté du patron d'en profiter. Tout ce qu'elle fait est de transférer dans le marché la pression d'un élément sur un autre, du salaire sur le travail, du prix sur la qualité (I). "

Il est certain, en effet, que du jour où pour un mème travail on ne pourra plus payer moins, l'employeur s'efforcera d'exiger pour un même salaire une productivité plus grande ou un travail plus soigné.

Ici encore l'expérience australasienne et l'expérience anglaise apportent sur ce point une précieuse confirmation à la théorie indiquée ci-dessus (2).

M. Aves, dans son rapport (3), souligne cette transposition dans l'action de la concurrence.

Bon nombre de patrons sont aujourd'hui du même avis.

\section{$3^{\circ}$ Le minimum de salaire élimine-t-il fatalement} les ouvriers ágés et moins productifs?

Cette troisième objection est en quelque sorte la suite et le prolongement de la précédente : du jour où des minima seront fixés, n’y a-t-il pas lieu de craindre (4) que les ouvriers âgés, infirmes ou moins productifs ne trouvent plus à s'employer, et cependant " pour eux un salaire faible vaut mieux que point de salaire du tout (5)".

L'objection comporte, à notre sens, une double réponse : il est possible, l'expérience des Trade-Unions anglaises ainsi que les résultats des Comités de salaires le démontrent, de fixer, avec des garanties mûrement élaborées, un régime d'exception visant spécialement le cas des ouvriers de cette

(1) Industrial Democracy, p. $7 \mathrm{I} 6$.

(2) Cf. supra, pp. 33 et suiv.

(3) Op. cit., p. 46.

Cf. Métin. Le Socialisme sans doctrines, pp. 142-144, où l'auteur montre pour un salaire supérieur un accroissenent des tàches journalières.

(4) Paul Leroy-Beaulieu. Traité théorique el pratique d'économie politique, $3^{e}$ éd., Paris, Guillaumin, I900, t. II, p. 490 : "Tous ceux, notamment, qui, par incapacité ou fainéantise, ne pourraient fournir un travail net correspondant à la rémunération minima fixéc seraient sùrs de demeurer sans occupation. ")

(5) Hubert Valleroux. Le minimum légal de salaire. Rapport à la Société d'économie sociale, 14 mai $189^{5}$. Réforme sociale, $1895,2^{\mathrm{e}} \mathrm{sem}$., p. 305. 
catégorie : on adoucira ainsi pour ces travailleurs l'application de la réforme.

Mais, d'autre part, on peut admettre à un point de vue absolu que les conditions du travail à domicile, par rapport à celles du travail en atelier ou à l'usine ( $\mathrm{r}$ ), présenteront toujours une marge suffisante pour écarter pour longtemps encore l'éventualité d'une suppression complète du travail pour ces travailleurs au rabais (2).

En somme, en fait, la mesure proposée pourra ne pas ètre nuisible aux travailleurs âgés et moins productifs à titre de régime transitoire, et en théorie le minimum de salaire généralisé et universellement appliqué supprimerait précisément ces cas anormaux et pathologiques : ou bien l'ouvrier sans ressources retombera à la charge de l'Assistance, ou bien, gràce à un salaire suffisant et à un esprit d'épargne et de prévoyance qu'il faut développer, l'ouvrier âgé ou infirme ou incapable n'aura plus besoin de recourir au salaire, lorsqu'il n'est plus à mème de fournir un travail convenable.

\section{$4^{\circ}$ Le minimum de salaire est-il une cause fatale d'élévation des prix?}

Enfin les adversaires du minimum de salaire se placent au point de vue du consommateur et affirment que l'adoption d'un minimum de salaire, soit par la voie professionnelle, soit par la voie légale, aurait pour conséquence fatale et certaine une augmentation générale des prix de vente (3). On ajoute que l'argument est doublement frappant à notre époque de vie chère et dans nos pays démocratiques: est-ce au moment où le prix de la vie augmente d'une façon si considérable, et pour les petites bourses surtout, qu'il convient de majorer le prix des objets de large consommation?

(1) Notamment la diminution des frais généraux et la non-application dans une large mesure de la législation protectrice des travailleurs.

(2) Cf. Paul Boyaval. La Lutte contre le sweating system, I vol., Paris, Alcan, I9II, P. 222.

(3) Rambaud. Paul Leroy-Beaulieu, op. cit. 
Cette objection appelle une double réponse de principe et de fait.

En principe, il faudrait, pour que l'affirmation fût prouvée, connaître les différents éléments du prix de revient et notamment les profits. On ne peut, en l'état actuel des choses, affirmer qu'une majoration dans un des éléments du prix de revient se traduit toujours par une majoration du prix de vente : tout dépend de l'état du marché et des conjonctures économiques (I).

En fait, les divers essais de minimum de salaire actuellement pratiqués montrent que l'élévation des prix n'est pas une conséquence fatale de la réforme (2).

M. Aves affirme dans son rapport (3) que, dans les métiers où le salaire a monté, la hausse corrélative du prix de vente ne s'en est pas toujours suivie : l'effet de l'augmentation de la rémunération a été presque insignifiant sur le prix de revient.

M. Mény (4) a calculé que pour les chapeaux de dames, alors vendus $4 \mathrm{fr} .80$, une majoration des salaires, portés de 2 fr. 60 à 3 fr. 5o, n'amènerait qu'une augmention de o fr. 23 dans le prix de revient par chapeau.

Les enquêtes officielles (5) ou privées (6) confirment ces observations.

Ces résultats s'expliquent par la portion très minime sur l'ensemble du prix que représente le salaire, surtout dans la confection à domicile (7).

Enfin - à supposer même qu'un certain renchérissement

(r) Sur cette délicate théorie économique, cf. Bourguin. La mesure de la valeur de la monnaie, Paris, Larose, 1896, pp. 245 et suiv., notamment p. 25r : "Cette influence des éléments du coùt de production sur le prix de revient est plus ou moins énergique, suivant les circonstances.

(2) Cf. Boyaval, op. cit., p. 226.

(3) Aves. Rapport cité p. 55. Il donne à cet égard des réponses négatives à des questionnaires sur la hausse des prix.

(4) Le minimum de salaire dans le travail à domicile. Sem. sociale de Bordeaux, 1909. Compte rendu, p. 272.

(5) Office du travail. Enquête sur le travail à domicile dans l'industrie, t. III, P. 226.

(6) Déposition de $\mathrm{M}^{\mathrm{me}}$ Juillerat, au nom de la Ligue sociale d'acheteurs, devant le Conseil supéricur du travail, le 25 avril 1910 . Procèsverbaus, p. 72 .

(7) 5 à Io \%, affirme M. du Marroussem dans son enquête sur le vêtement à Paris. Office du travail. La petite industrie, t. II, p. 659. 
dùt se produire - il faudrait encore l'accepter, car il s'agit là d'une question de justice et un pareil bon marché est trop chèrement payé de la souffrance et de la misère des travailleurs n'ayant pas de quoi vivre, pour qu'il soit humain et raisonnable d'en souhaiter le maintien ( $\mathrm{I}$ ).

$\mathrm{Au}$ total, aucune des objections présentées contre l'idéal du minimum de salaire ne paraît décisive et péremptoire. Une critique scientifique impartiale nous a permis d'en faire justice.

(x) L'action croissante des Ligues sociales d'acheteurs permettra d'ailleurs de plus en plus de vérifier si l'augmentation demandée est justifiée. Cif. Deslandres. Le Rôle social de l'acheteur, I vol., Paris, Alcan, 1911 . 


\section{CHAPITRE II}

\section{Les Projets et les Réformes en France.}

La question du minimum de salaire a fait en France de rapides progrès pendant ces quatre dernières années (I9o8-I9II), à propos surtout du problème du travail à domicile. Il serait cependant erroné de croire qu'avant ces dernières et toutes récentes manifestations la question y fùt totalement inconnue.

\section{I. - Les propositions socialistes.}

On trouve tout d'abord la réforme du minimum de salaire comme un des articles du programme socialiste et plus spécialement comme l'une des réclamations traditionnelles du parti socialiste unifié (I).

L'histoire parlementaire de ces propositions de lois socialistes serait longue à écrire : il suffira d'indiquer ici les

(I) Le minimum de salaire a été longtemps inscrit au programme officiel du parti socialiste français. Peu après sa constitution (congrès d'octobre 1879), le parti vota son programme au congrès de Paris, juillet 1880 , préparé par Karl Marx, Fr. Engels, Jules Guesde, Lafaroue et Lombard; il comportait un article 2 : "Minimum légal des salaires déterminé chaque année d'après le prix local des denrées ». De Seilhac. Les congrès ouvriers en France. Paris, Colin, I899, p. 6o. L'échec de ce programme aux élections de $\mathrm{I} 88 \mathrm{I}$, où il parvint à peine à réunir 60.000 voix dans toute la France, en amena la modification sur certains points. De plus, Lafargue (lettre du 24 octobre 1880, citée par de Seilhac, op. cit., p. 104) qualifiait le minimum des salaires d'absurdité scientifique. Par contre, Guesde y voyait la chair et le sang du parti ouvrier. Ces discussions amenèrent au congrès de Saint-ĺtienne (sept. 1882) la suppression de notre article. Il fut réintroduit lors d'un congrès régional broussiste tenu à Paris en 1885 (de Seillac, op. cit., p. 130) : "Réduction de la journée de travail à huit heures au maximun avec fixation, dans chaque corporation, d'un minimum de salaire. " Opportunisme, nécessité électorale, attitude vis-à-vis du salariat appelé à disparaître, de nultiples raisons expliquent ce silence officiel. La réforme u'en resta pas moins dans l'idéal du parti. 
principales, en soulignant le caractère certainement utopique de la plupart d'entre elles :

C'est ainsi qu'à la séance de la Chambre du 27 juin I898 (I) M. Vaillant et plusieurs de ses collègues socialistes déposent une proposition de loi tendant à établir un salaire minimum pour tous les ouvriers, ouvrières, employés et employées des travaux, emplois et services de l'État (2) : 5 francs par jour et 35 francs par semaine, tel est le niveau uniforme que l'on préconise (3). Ce taux de salaire devait faire partie intégrante du contrat de l'État pour les travaux exécutés et les fournitures fabriquées pour le compte de l'État. Aucune suite ne lui fut donnée.

Sous la législature suivante (I902-I906), des propositions analogues sont faites par les mèmes députés.

M. Vaillant (4) demande pour les travailleurs agricoles un salaire minimum et reprend sa proposition précédente (5).

M. Clovis Hugues (6) la réclame pour les ouvriers du bâtiment : il s'agit d'accepter pour chaque profession et dans chaque catégorie les séries de prix de chaque ville ou, à leur défaut, les taux couramment appliqués.

M. Chauvière (7), enfin, dépose un projet de résolution le 4 mars 1904 , tendant à la fixation d'un minimum journalier de 5 francs pour les ouvriers, ouvrières et employés du petit personnel du garde-meuble.

On rote, comme toujours, le renvoi à la Commission du travail, sans aboutir davantage.

Même tactique, sans plus de succès d'ailleurs, sous la législature г9o6-ı 9 Io : les propositions déjà mentionnées sont reprises $(8)$; il y faut joindre dans le mème sens une

(1) J. O., Ch., Doc. parlem., 1898, no 115 . Cf. ci-dessus, p. 68.

(2) La proposition demandait en même temps pour les mêmes travailleurs la journée de huit heures.

(3) Art. 2 de la proposition citée.

(4) J. O., Ch., Doc. parlem., 1903, no 917 , p. 491 .

(5) J. O., Ch., Doc. parlem., 1905, no 2 198, p. 3.

(6) J. O., Ch., Doc. parlem., I903, no 1275, p. 139.

(7) J. O., Ch., Doc. parlem., 1904, n० 1159, p. 235.

(8) Proposition Vaillant pour tous les ouvriers, ouvrières, tous les employès et employées. J. O., Ch., Doc. parlem., I906, nº 374, p. 58. Proposition Vaillant pour les ouvriers et employés de l'État. J. O., Ch., Doc. parlem., I906, $\mathrm{n}^{\circ} 375$, p. 61 . 
proposition de M. Jules Coutant (I) ąyant pour but d'assurer un minimum d'existence aux travailleurs des deux sexes et une proposition Basly (2) spéciale aux ouvriers et employés dans les mines et minières.

Cependant l'intention d'aboutir était réelle : on le vit bien par les efforts des auteurs de ces diverses propositions pour greffer la réforme sur une autre et obtenir à titre accessoire et subsidiaire ce qui n'aboutissait pas à titre principal. On essaya de lier la réforme du minimum de salaire d'abord à la loi sur la prime à la sériciculture, ensuite à la réforme douanière elle-mème.

La discussion se poursuivit à la Chambre les I9, 2 I et 24 mai i goy sur les primes à accorder à la sériciculture et à la filature de la soie. Une série d'amendements relatifs au taux des salaires furent déposés en séance : trois visaient directement le minimum.

C'était, d'une part, un amendement de MII. Devèze, Pastre, François Fournier, Louis Dumont et Louis Dreyfus subordonnant l'octroi des primes à la sériciculture, à la condition d'un salaire minimum de 2 francs aux ouvrières fileuses;

C'était, d'autre part, une disposition additionnelle de MM. Pastre, Devèze et F. Fournier faisant varier les salaires avec les cours de la soie (3).

C'était, enfin, une proposition de résolution de MM. Louis Dumont, etc..., ainsi conçue : " La Chambre, résolue à réglementer les conditions du travail des ouvriers et ouvrières des filatures de soie, notamment en ce qui concerne l'établissement d'un minimum de salaire et la durée de la journée de travail, invite le Gouvernement à

(1) J. O., Ch., Doc. parlem., 1907, no 1043, p. 848.

(2) J. O., Ch., Doc. parlem., I906, n 595, p. 318.

(3) En voici le texte :

"Ún règlement d'administration publique devra prévoir dans les ateliers la suppression des ouvriers hommes et devra fixer le salaire des ouvrières de la façon suivante :

$I^{\circ}$ Minimum de 2 franes;

$2^{\circ}$ Le salaire sera fixé à 2 fr. 25 quand les cours de la soie seront de 50 francs à 60 francs le kilogranme;

$3^{\circ}$ Le sillaire sera fixé à $2 \mathrm{fr}$. 50 si les cours passent de 60 francs à 70 francs;

$4^{\circ} \mathrm{Au}$-dessus de 70 francs, le salaire sera fixé à 3 francs. "

Cf. Rapport Péronnet. Cilı., Doc. parlem., ı gog, $1^{\circ} 257$ ı. 
soumettre sans délai à la Commission du travail des propositions dans ce sens." "

Toutes ces propositions et amendements furent renvoyés à la Commission du travail. Celle-ci ne put rien proposer de précis, faute d'informations et de textes, et estima, comme l'indique son rapporteur (I), que de toute nécessité, en une matière particulièrement lélicate, l'initiative d'une réglementation devait venir du Gouvernement. Celui-ci, convoqué et représenté par M. Cruppi, ministre du Commerce, refusa de prendre l'initiative demandée : "En ce qui touche l'établissement d'un salaire minimum, dit à la Commission M. Cruppi comme représentant le Ministre du Travail empêché, par un projet dont le Gouvernement prendrait l'initiative, je déclare que le Gouvernement n'est point disposé à le faire, ni à répondre favorablement à l'invitation contenue dans le projet de résolution qui vous est soumis. "

C'était un refus catégorique : la Commission, par l'organe de son rapporteur, conclut en rapportant purement et simplement le projet de résolution indiqué ci-dessus. Inutile de dire qu'il ne fut pas voté en séance et que la loi du i i juin 1909, relative aux encouragements spéciaux à donner à la sériciculture et à la filature de la soie fut votée et promulguée sans contenir aucune disposition relative au salaire minimum.

On avait une première fois manqué la jonction de la réforme sociale à la réforme économique.

On devait bientòt recommencer une tactique semblable à propos de la discussion de la réforme douanière : il s'agissait, on le sait, de modifier la loi du i janvier 1892 qui régit les échanges de la France avec l'étranger : la discussion était ouverte devant la Chambre, lorsque, le 29 décembre Igo9 (2), M. Vaillant proposa un article $8 \mathrm{ter}$ ainsi conçu :

"Dans toutes les industries, commerces, exploitations, bénéficiant d'un tarif ou de droits protecteurs, les ouvriers et employés ne pourront travailler plus de huit heures par jour et plus de quarante-huit heures par semaine. Ils

(I) Ibid., Rapport Péronnet, p. 5.

(2) Ire séance. Ch., Déb. parlem., r909, p. 3857. 
auront au moins trente-six heures consécutives de repos hebdomadaire. Il sera établi pour eux, par délibération commune de leurs syndicats professionnels et de leurs patrons, un salaire minimum en rapport avec les conditions locales de l'existence.

Ce salaire minimum sera fixe pour un tiers et variable pour les deux autres tiers de son montant, considéré comme répondant aux dépenses particulièrement variables de consommation alimentaire essentielle (pain, viande, lait, sucre), d'éclairage et de chauffage, dont les prix de détail seront déterminés régionalement par un service de statistique institué à cet effet.

Chaque trimestre, une décision du Tribunal de prud'hommes de la région sanctionnera en rapport avec ce taux des prix de détail, s'il a augmenté, l'augmentation correspondante des deux tiers variables du salaire des ouvriers et employés.

Sans qu'il en puisse résulter aucune entrave pour la liberté du développement de la législation ouvrière de chaque pays, il sera, ̀̀ chaque convention commerciale, recherché d'établir, comme minimum commun, les conditions de travail de celui des pays contractants où la protection légale du travail et des travailleurs est le plus avancée (I). ")

M. Vaillant, ne se dissimulant pas le sort de son amendement, explique en quelques mots les motifs de sa présentation.

Il indique que son système est l'expression d'une méthode nouvelle directe par le citoyen Adolphe Braun, dans le dernier numéro du Kampf de Vienne.

Il s'agit d'établir un minimum invariable et de faire suivre par les deux autres tiers la hausse des salaires.

Le rapporteur général, M. Jean Morel, indique que ces questions ne sont pas de la compétence de la Commission des douanes.

Il demande le renvoi à la Commission du travail. "Ces questions doivent être examinées hors de la révision douanière, dans laquelle elles n'ont rien à faire et parce 
qu'elles sont assez graves par elles-mêmes pour faire l'objet d'un débat séparé, réfléchi et approfondi (I).

M. le Ministre du Commerce s'associe aux observations de M. Morel.

Sur ces déclarations, le renvoi à la Commission du travail ainsi demandé est voté par 490 voix contre 65.

Le renvoi à la Commission du travail, c'était, après le précédent de la sériciculture, l'échec de la manœuvre tentée et cette fois encore la jonction ne fut pas opérée. La question du salaire minimum dormait dans les cartons de la Chambre.

Enfin, et sous la présente législature (I910-1914), on retrouve la persistance de cette tradition du Parti Socialiste Unifié, manifestée par des propositions de loi analogues: leurs auteurs leur ont même donné de plus considérables développements, n'ignorant pas toute l'actualité de la question du problème posé par le travail à domicile. Il est curieux de noter ici brièvement l'influence de la législation anglaise et de l'idée des Comités de salaire sur les propositions socialistes.

C'est d'abord la reprise de la proposition Basly (2), tendant à l'établissement d'un salaire minimum pour tous les ouvriers employés dans les mines et minières ; l'exposé des motifs indique que l'établissement d'un minimum de salaire pour tous les ouvriers des mines est le moyen de prévenir efficacement les grèves et les conflits nombreux dans cette industrie : le contrat collectif paraît à son auteur le moyen d'y arriver.

L'article ${ }^{\text {er }}$ de la proposition énonce le principe d'un salaire minimum légal : il est fixé (art. 2) dans chaque arrondissement minéralogique par des Commissions mixtes, composées pour un tiers des délégués des exploitants et pour les deux autres tiers de représentants désignés en assemblée générale dans le sein des syndicats ouvriers. Les préfets sont chargés de veiller à l'exécution de la loi (art. 3). Des sanctions pénales en assurent d'ailleurs le fonctionnement : amende de 50 à 500 francs pour toute infraction

(1) Ibid., p. 3859 .

(2) J. O., Cih., Doc. parlem., 1910, n 149, p. 503, déposée le 21 juin 1910. 
commise en ne payant pas le taux du salaire minimum; emprisonnement de trois mois à trois ans et amende de 500 à 5.000 francs " contre tout chef d'exploitation, aggent ou contremaitre qui, par fraude, violence, menaces de perte d'emploi ou privation de travail, refus d'embauchage, aura contraint un ou plusieurs ouvriers à travailler à un salaire inférieur au minimum légal $)$.

C'est ensuite la reprise de la proposition Vaillant (I), ayant pour objet l'institution de la journée de huit heures et d'un salaire minimum pour tous les ouvriers, ouvrières et pour tous les employés et employées (2). L'exposé des motifs rappelle la théorie marxiste de la valeur, le surtravail imposé par le patron à l'ouvrier et marque la place de la réforme dans le programme socialiste : " Il importe, en attendant que l'organisation syndicale impose le tarif syndical correspondant aux besoins, plus humainement compris, de la vie ouvrière, qu'un salaire minimum soit établi pour la sauvegarder dans ses éléments matériels d'entretien $"$.

Le projet prévoit, quant à l'élablissement du minimum de salaire, un double système :

" Pour tous les travaux de métiers ou industries, de commerce ou d'agriculture où existent une organisation et un tarif syndical, le salaire sera celui de ce tarif syndical.

“ Où ce tarif n'existe pas encore, un salaire équivalent ou tout au moins minimum sera provisoirement établi par délibération et entente entre les délégués de la Confédération générale du travail, les délégués des ouvriers syndiqués des industries en cause et les patrons : il devra exactement répondre aux conditions locales de l'existence (art. I I). )

Ce salaire minimum irréductible sera, par ailleurs, fixé

(1) J. O., C'h., Doc. parlem., ı1ı, n 469, p. I14, déposée le I7 novembre igio.

(2) La loi serait applicable dans les usines, manufactures, mines, minières et carrières, ateliers et chantiers de quelque nature que ce soit, publics et privés, domestiques et de famille, laï̊ues ou religieux. docks, entrepòts, transports, voies urbaines, fluviales, maritimes, voies ferrées, forêts, grandle culture et culture industrielle ou intensive, entreprises de commerce, magasins, bureaux et tous autres étalblissements et lieux de travail, de production, de commerce et ('échange (art. I). 
pour un tiers et variable pour les deux autres tiers de son montant, considérés comme répondant aux dépenses particulièrement variables de logement, chauffage, éclairage, etc., et de consommation alimentaire essentielle (pain, viande, lait, sucre, etc.), dont les prix de détail seront déterminés régulièrement par un service de statistique. Aussi chaque trimestre, cet élément variable sera-t-il soumis à révision : une décision du Tribunal des prud'hommes de la région sanctionnera, en rapport avec ce taux des prix de détail, s'il a augmenté, l'augmentation correspondante des deux tiers variables du salaire des ouvriers et employés. L'Inspection du travail est chargée de l'application de lạ loi.

Tel est le mécanisme idéalement simple de la proposition Vaillant : les salaires varieront automatiquement et mécaniquement pour assurer le minimum d'existence!

La proposition de M. J. Coutant (I) cherche à justifier dans un vague exposé de motifs la nécessité d'un minimum de salaire, constate le taux excessivement bas de beaucoup de salaires et fait appel à l'État. C'est aux Conseils généraux que l'auteur s'adresse : ceux-ci devront, tous les ans, d'accord avec les Conseils d'arrondissement, après avis des Conseils municipaux, établir dans une de leurs sessions et pour l'année qui suivra un minimum d'existence pour les travailleurs, les femmes et les enfants de treize à dixhuit ans ; ce triple minimum sera établi pour chaque catégorie de travailleurs. Il devra ètre ensuite soumis à l'approbation préfectorale (art. 2) et affiché dans les mairies. Les sanctions contre tout paiement d'un salaire inférieur au minimum sont ici de $\mathrm{I} 6$ à 3,000 francs d'amende et de six jours à trois ans de prison (art. $\mathrm{I}^{\mathrm{er}}$ ).

Enfin, et pour clore la série, la proposition Cuny (2) est celle qui s'inspire le plus directement de la législation anglaise.

Pour son auteur, le minimum de salaire serait le prélude

(1) J. O., Ch., Doc. parlem., I910, n² 26r, p. 608, déposée le 5 juillet 1910. Elle est, elle aussi, une reprise au début de la législature : l'auteur avait fait déjà une proposition analogue le is juin s907 (J. O., Ch., Doc. parlem., 1907, $\mathrm{n}^{\circ}$ 1043).

(2) J. O., Ch., Doc. parlem., 1910, n 545, p. 168, déposés le 5 décembre 1910. 
de l'ère du contrat collectif de travail. En voici les plus essentielles dispositions :

Le salaire minimum est établi par des Comités de salaires (art. ${ }^{\text {er }}$ ). Il existe un Comité de salaires par chaque profession qui a son siège au chef-lieu du département (art. 2 et 3). Le nombre de ces Comités et leur sphère d'autorité sont fixés par décret sur la proposition du préfet, après avis du Conseil général (art. 4).

Les Comités, composés de douze membres, sont élus : six par les employeurs, six par les employés (art. 5) (I).

"Le Comité a pour mission de fixer, en ce qui concerne la profession soumise à sa juridiction, un tarif minimum de salaire, tant pour le travail à l'heure que pour le travail aux pièces (art. r3). " Avant d'arrèter le tarif, une certaine publicité est faite par voie d'affiches dans toutes les mairies, communiquant les chiffres proposés (art. I4).

L'appel de la décision du Comité de salaires est possible dans le mois qui suit sa publication devant un Comité central ainsi composé : douze délégués des Comités de salaires de plusieurs départements, membres élus, et les présidents de la Chambre de commerce, du Tribunal de commerce, du Conseil des prud'hommes du chef-lieu d'arrondissement où siège le Comité, membres de droit.

Les décisions du Comité ont force de loi dans le département; il est défendu de payer un salaire inférieur au tarif minimum (art. 20) sous peine d'une amende de 20 à $500 \mathrm{fr}$. par chaque employé ou ouvrier, amende portée au double en cas de récidive (art. 2I), sans préjudice de l'obligation pour le patron de rembourser le surplus. L'action en réclamation de salaire se prescrit par deux ans (art. 23).

La question du salaire minimum a été reprise récemment à propos de la modification du régime des mines en France pour les ouvriers mineurs. Toutefois, le rapporteur de la Commission des mines, M. Ajam (2), déclare qu'après un

(I) Les listes électorales sont établies par les inspecteur's du travail sur une déclaration faite au mois de janvier de chaque année par les employeurs et employés. Des rectifications y sont opérées à la demande des intéressés (art. 8 et 9).

(2) Rapport fait au nom de la Commission des mines, chargée d'examiner le projet de loi sur le régime général des mines, par M. Ajam, déposé le 11 juillet 1911. J. O., Ch., Doc. parlem., r911. Annexe no 1172, p. 967- 
minutieux examen, l'idée de l'introduction d'une clause de salaire minimum dans les concessions a été écartée : elle se heurte à la nature particulière du travail minier. Le rapporteur montre que le salaire à la tâche est une modalité nécessaire pour le travail du fond. Il conclut, en conséquence : "Obliger par avance le concessionnaire d'une mine à garantir un salaire minimum de la main-d'œuvre, c'est supprimer tout encouragement à la production. L'institution d'un salaire minimum est d'ailleurs illusoire si on laisse à l'exploitant le droit de renvoyer l'ouvrier qui produit insuffisamment. L'observation prouve que pour obtenir une production normale il est nécessaire de récompenser l'effort intensif et que, malgré tous les stimulants, la production a plutôt tendance à devenir moindre. Le salaire minimum, en obligeant le concessionnaire à renvoyer les ouvriers de rendement faible, serait une source de conflits incessants ( $\mathrm{I})$. ")

On remarquera que cette position du rapporteur ne vaut que contre un minimum de salaire déterminé au temps (2) sans minimum de production. Il ne serait pas impossible, en s'inspirant des exemples anglais rapportés ci-dessus (3), de conserver et d'adopter un minimum de salaire soudè à un minimum de production et obtenu par une combinaison de salaire à la tâche.

Plus récemment, le 7 mars 1912 (4), M. Albert Thomas transmettait au Parlement les revendications des ouvriers mineurs français, au nombre desquelles figure le minimum de salaire.

Le Gouvernement, par l'organe de M. Léon Bourgeois, ministre du Travail, lui répondait : "La Chambre comprendra qu'il n'est pas possible au Gouvernement d'envisager la fixation d'un taux légal des salaires. La méthode très heu reuse appliquée depuis vingt ans dans le Nord et le Pas-deCalais pour la fixation contractuelle du salaire, les conventions conclues dans d'autres bassins ont été le résultat des

(I) Ibid. Rapport cité, p. 968. La Commission des mines a en conséquence orienté son effort vers la participation aux bénéfices.

(2) C'est d'ailleurs celui que réclament les ouvriers mineurs.

(3) Supra, pp. I69 et suiv.

(4) Ch., J. O., Déb. parlem., 8 mars 1912, p. 630. 
discussions entre les représentants des patrons et des ouvriers. Le Gouvernement a toujours fait et continue de faire tout ce qui dépend de lui p.our aider à la conclusion de ces conventions. (Très bien! Très bien!)

C'est là qu'il voit - l'expérience l'a démontré - la solution à la fois pratique et rapide du problème du salaire, la plus sûre garantie de la stabilité et de la paix nécessaires aux chefs d'industrie et aux travailleurs. ”

On trouvera peut-être que cette longue analyse insiste plus qu'il n'aurait fallu sur les propositions de loi socialistes. Il nous a paru cependant que leur simple exposé était leur meilleure réfutation. Toutes elles ont un commun défaut de se tenir loin, très loin parfois, de la réalité et, comme telles, d'être rigoureusement inapplicables. Malgré quelques correctifs et atténuations, elles se rattachent toutes à cette idée d'un minimum de salaire absolu, unique, pour ne pas dire uniforme. Elles ont peut-ètre leur utilité en maintenant devant la classe ouvrière et devant l'opinion publique le mythe dans toute son intransigeance et toute son idéale beauté. Elles représentent l'Idée du minimum de salaire, mais elles restent en plein ciel. Il n'y a aucune chance, par cette voie rigide et droite, de le voir jamais réalisé.

Tel est le premier courant d'opinion qu'il soit possible de dégager en France; les propositions socialistes ne manquent ni de ténacité, ni de hardiesse. On peut douter de la bonté de leur méthode, assurément outrancière, pour marquer un nouveau pas vers le minimum de salaire. 


\section{II. - Les propositions de Comités de salaires pour le travail à domicile.}

Une seconde phase du mouvement de réforme en France se dessine au lendemain du vote de la loi anglaise (20 octobre rgog) sur les Comités de salaires.

La question du travail à domicile (I) était certes depuis longtemps à l'ordre du jour en France comme dans les autres pays.

La question fut mise à l'ordre du jour des travaux parlementaires par le dépôt du projet de M. de Mun le 2 avril ıgo9 (2), modifié par un second projet du ıo juin ıg Io (3). L'auteur, dans un long exposé des motifs, insistait d'une part sur les maux dont souffrent les ouvriers travaillant à domicile, en utilisant à cet égard la récente enquête faite par l'Office du travail français (4), mettant en lumière l'impuissance de l'initiative privée, action patronale ou action ouvrière, rappelant enfin les précédents législatifs des pays étrangers (Australasie et Angleterre). Voici, vu son importance, le texte in extenso de cet intéressant projet sur les Comités de salaires :

\section{PROPOSITION DE LOI}

Article premier. - Des Comités professionnels chargés d'établir des salaires minima peuvent être institués par le Ministre du Travail pour toute industrie occupant des ouvriers et des ouvrières à domicile.

\section{I. - Organisation.}

Art. 2. - L'arrêté d'institution est pris par le Ministre, après consultation de la Commission permanente du Conseil supérieur du travail et des Conseils du travail de la région intéressée.

(I) Sur le travail à domicile qui ne touche qu'indirectement notre sujet, cf. G. Mény. Le Travail à domicile : ses misères, ses remèdes, I vol., Paris, Rivière, 19 Io.

(2) J. O., Ch., Doc. parlem., 1909, no 1453.

(3) J. O., Ch., Doc. parlem., I910, no 42, p. 474.

(4) Office du travail. Enquête sur le travail à domicile dans l'industrie de la lingerie, t. I, Paris, 1907; depuis lors t. II, Centre (1909); t. III, Nord et Nord-Est (1909); t. IV, Midi (I9II); t. V, résultats généraux (19II). 


\section{Il détermine :}

$1^{0}$ La profession ou les professions similaires ou connexes soumises à la juridiction du Comité de salaires ;

$2^{\circ}$ La circonscription territoriale sur laquelle s'étend cette juridiction ;

3n Le nombre des membres du Comité.

Toute personne ou syndicat intéressé peut demander au Ministre l'établissement d'un Comité de salaires.

Art. 3. - Les membres du Comité de salaires sont élus moitié par les employés et moitié par les employeurs des professions soumises à sa juridiction, dans les conditions fixées par l'arrêté ministériel.

Au cas où l'une des parties se refuse à élire des représentants, ces représentants sont désignés par le Ministre du Travail.

Les membres des Comités sont élus ou désignés pour quatre ans. Ils sont indéfiniment rééligibles.

Art. 4. - Sont électeurs et éligibles, sans distinction de sexe, les personnes majeures inscrites sur les listes formées en exécution de l'article 7 de la présente loi.

Sont également éligibles les anciens employés ou employeurs ayant appartenu à la profession pendant au moins dix ans.

Art. 5. - Dans les quinze jours qui suivront leur élection ou désignation, les membres du Comité de salaires sont appelés à nommer un président.

Le président doit être élu à la majorité absolue des membres du Comité. Si la majorité absolue ne peut être obtenue, le président est nommé par le Ministre du Travail, qui doit le choisir en dehors de toute profession industrielle ou commerciale.

Art. 6. - Dans le mois qui suit la publication par le Journal offlciel de l'arrêté créant un Comité de salaires, tout employeur exerçant dans la circonscription établie par cet arrêté le métier visé est tenu de fournir à l'inspecteur du travail la liste exacte et complète des ouvriers et ouvrières qui travaillent à domicile pour son compte.

Au cas où l'employeur n'est pas directement en rapport avec l'ouvrier travaillant pour son compte, l'entrepreneur ou l'intermédiaire est tenu de faire cette déclaration.

Art. 7. - Il est formé, par les soins de l'Inspection du travail, une liste des personnes s'adonnant dans la circonscription établio à la profession visée et connues tant par les déclarations prescrites à l'article précédent que par la déclaration justifiée de tout intéressé.

Cette liste est divisée en deux parties, contenant l'une les noms et adresses des employeurs, l'autre les noms et adresses des employés travaillant à domicile.

Elle est revisée chaque année à l'époque fixée par le Ministre.

Art. 8. - Un exemplaire de cette liste est déposé à la mairie de 
toute commune de la circonscription où une ou plusieurs des personnes inscrites sont domiciliées.

Art. 9. - L'industriel ou l'entrepreneur est tenu de déclarer dans la huitaine, à l'inspecteur du travail, tout changement survenu dans le personnel qu'il emploie à domicile.

\section{II. - Fonctionnement.}

Art. 10. - Le Comité se réunit, sur convocation du président, à la mairie du chef-lieu désigné pour la circonscription par l'arrêté qui l'a institué, aussi souvent qu'il en est besoin, mais au moins une fois par an.

Le président est tenu de réunir le Comité chaque fois qu'il en est requis par la moitié de ses membres.

Art. ıı. - Toute décision d'un Comité de salaires peut être prise par la majorité des membres présents, pourvu que le nombre de ces membres atteigne le quorum fixé par le Ministre du Travail dans son arrêté créant le Comité. Le chiffre nécessaire au quorum ne sera pas supérieur à la moitié du nombre total des membres du Comité et la formation du quorum ne dépendra pas du nombre proportionnel des patrons ou employés présents.

Art. 12. - Le Comité est chargé d'examiner toute demande d'établissement de salaires minima relative aux travaux de la profession pour laquelle il a été créć. Cette demande peut lui être faite par l'un de ses membres, par l'inspecteur du travail, ou par tous syndicats ou personnes intéressés.

Art. 13. - Le Comité détermine le salaire minimum que doit recevoir par heure l'ouvrier de capacité moyenne. Ce salaire peut varier suivant la nature des travaux ou les différentes parties de la circonscription soumise à la juridiction du Comité.

Le Comité devra, toutes les fois que ce sera possible, établir des séries de prix minima pour les diverses opérations que comporte la profession.

Pour les opérations non visées aux séries de prix, l'employeur doit prouver, dans chaque cas particulier dont le tribunal serait saisi, que les conditions faites à l'ouvrier sont telles qu'elles permettent au travailleur de capacité moyenne d'obtenir le salaire minimum fixé à l'heure.

Tout employeur aura le droit de soumettre à l'homologation du Comité de salaires le tarif minimum adopté par lui pour le travail aux pièces.

Les salaires minima ainsi déterminés devront être intégralement payés à l'ouvrier et sans aucune déduction pour la rétribution des entrepreneurs ou sous-entrepreneurs.

Le commerçant qui offre au public l'objet confectionné à domicile est civilement responsable de l'insuffisance des salaires payés par l'entrepreneur ou le sous-entrepreneur, sauf recours contre ces derniers. 
Art. 14. - Les décisions des Comités de salaires sont publiées de la façon fixée par le Ministre.

Ces décisions ont force de loi dans la circonscription à l'expiration des trente jours qui suivent cette publication, à moins qu'un appel ne soit formé. Mais le Comité peut renvoyer leur application à une date plus éloignée.

Art. 15. - Un Comité central, composé de délégués des Comités des salaires régionaux et représentant l'ensemble de la profession, pourra être chargé de reviser et de coordonner les tarifs établis par les divers Comités de la profession intéressée.

Art. 16. - Il peut être interjeté appel contre les décisions d'un Comité, par le Ministre du Travail ou par tous syndicats ou personnes intéressés, devant le Comité central prévu à l'article précédent et, à son défaut, devant la Commission permanente du Conseil supérieur du travail, qui décident en dernier ressort.

Le délai d'appel est de trente jours et court du jour de la publication.

\section{III. - Contrôle et sanction.}

Art. 17. - Tout industriel, commergant ou intermédiaire qui donne de l'ouvrage à effectuer en dehors de son établissement ou de ses dépendances doit tenir à jour un registre spécial sur lequel sont inscrits les noms et adresses des ouvriers et ouvrières employés par lui, la nature et la quantité du travail effectué par chacun et le salaire payé.

L'industriel, le commerçant ou l'intermédiaire qui n'est pas directement en rapport avec l'ouvrier travaillant pour son compte doit y inscrire les noms et adresses des entrepreneurs ou sousentrepreneurs auxquels il s'adresse.

Ce registre doit être présenté à toute réquisition de l'inspecteur du travail.

Art. 18. - Un livret individuel sera remis par les soins de l'employeur aux personnes travaillant dans les conditions spécifiées au paragraphe I $^{\text {er }}$ de l'article précédent. Il y sera fait mention par l'employeur, et sans omission, du travail effectué et du salaire payé, conformément aux indications du registre institué par l'article précédent.

Art. 19. - Quiconque, dans la circonscription assujettie, sera reconnu coupable d'avoir payé ou offert une rémunération du travail inférieure au minimum fixé sera passible pour la premiére fois d'une amende de 16 à 300 francs, et en cas de récidive d'une amende double pour chaque délit.

L'amende sera appliquée autant de fois qu'il y aura de personnes indiquées dans des conditions contraires à la présente loi.

Art. 20. - Toute infraction aux prescriptions des articles 6, 9, 17 et 18 de la présente loi sera punie des peines prévues à l'article précédent.

Art. 21. - Les actions résultant des articles précédents peuvent 
être exercées par les syndicats représentant une profession intéressée.

En cas d'inaction du Ministère public, le Tribunal peut être directement saisi par l'inspecteur du travail.

Art. 22. - L'employé lésé par un payement fait à un taux inférieur au minimum fixé par le Comité de salaires peut toujours demander aux employeurs le complément de son salaire, sans préjudice de plus amples dommages-intérêts s'il y a lieu.

Cette action se prescrit par trois ans à compter, pour chaque payement, du jour où il a été effectué.

C'était, en somme, l'adaptation à notre législation française du système anglais.

D'autres, sans aller aussi loin, préconisaient, tel M. Engerand ( $\mathrm{I}$ ), un certain nombre de mesures provisoires tendant, par la publicité, à divulguer les bas salaires et à faire l'éducation du public, en attendant l'établissement- d'un minimum de salaire reculé à une époque indéterminée.

Ces deux propositions furent renvoyées à la Commission du travail de la Chambre, le i2 juillet igı.

En même temps ou plus exactement quelques mois après la première proposition de M. de Mun, le Gouvernement, par l'organe du Ministre du Travail d'alors, M. Viviani, saisissait la Commission permanente du Conseil supérieur du travail, le ıo janvier I9 Io, d'un avant-projet (2) qui ressemblait assez sensiblement au projet primitif de M. de Mun (3): la base de cet avant-projet était la constitution en Comités de salaires des Comités du travail créés en vertu de la loi du 17 juillet 1908 (4).

La Commission permanente, dans sa séance du 2 I fé-

(I) Proposition Engerand, tendant à protéger les salaires des travailleurs et travailleuses à domicile, déposée le 2 I juin rgro. J. O., Ch., Doc. parlem., $1910, \mathrm{n}^{\circ}$ เ60, p. 1275 . La disposition essentielle de cette proposition était l'obligation mise à la charge de l'employeur de tenir un livret pour chaque travailleur à domicile mentionnant les conditions du travail, le montant de charque paiement effectué, les réductions apportées pour malfaçons et la clurée du travail ainsi rémunéré.

(2) Le texte de cet avant-projet a été publié dans le rapport Honoré cité ci-dessus, p. I.

(3) Les nuances entre l'avant-projet ministériel et le projet de Mun sont assez délicates et dénuées d'ailleurs aujourd'hui d'intérêt : ils différaient surtout en ce qui concerne la compétence des Conseils d'industrie à créer. Cf. Honoré. Rapport au nom de la Commission permanente. Conseil supérieur du travail. Paris, Imp. nat., 1910, pp. I et Ir.

(4) On sait, par ailleurs, que ces Conseils du travail n'ont pas encore pu arriver à fonctionner. 
vrier I910 (I), décida que le projet ne devait porter que sur les ouvrières travaillant à domicile.

M. Honoré déposa, le 7 mars de la même année, un nouveau texte comme base des études de la Commission permanente : au système de la fixation de minima de salaires par les Comités de salaires (2), l'auteur substitua un tout autre système (3), dont la double base était la suivante :

D'une part, " les femmes travaillant à domicile pour la confection de la lingerie, de la broderie à la main, des vêtements, chapeaux, fleurs artificielles et tous autres travaux salariés rentrant dans l'industrie du vêtement, ne peuvent recevoir une rémunération inférieure au salaire ordinaire des ouvrières non spécialistes ou journalières dans la région;

D'autre part, c'est le Conseil des prud'hommes déjà existant et non le Comité de salaires, à la création duquel on renonce, qui est chargé d'apprécier la conformité du salaire réellement payé à l'ouvrière avec cet étalon.

C’était là une transformation profonde des projets primitifs.

L'Administration ouvrit devant la Commission permanente une enquête assez large (4) sur l'établissement éventuel d'un minimum de salaire pour les ouvrières à domi. cile.

La Commission permanente dégagea comme conclusion de cette enquête que d'une façon absolue, " ni d'avance, ni même a posteriori, des tarifs ne pouvaient ètre établis pour une partie considérable des travaux à domicile (5)").

A la suite d'une discussion assez longue (24 janvier4 júillet I9IO) (6), le texte de M. Honoré, légèrement modifié (7) sur certains points, fut adopté et soumis au Conseil supérieur du travail, dans sa session de novembre igro,

(I) Ibid. Rapport Honoré, p. Ir.

(2) Article 13 du projet de Mun et article 7 de l'avant-projet ministériel.

(3) Gf. Ia première proposition Honoré. Rapport Honoré, sup. cit., p. IIr.

(4) Gf. le texte du questionnaire de cette enquête. Rapport Honoré, sup. cit., p. Iv.

(5) Rapport Honoré. Ibid., p. vi.

(6) Rapport Honoré, pp. 4 à 105.

(7) Rapport Honoré, p. vir. 
comme base de discussion. Les principes ci-dessus énoncés du texte primitif étaient maintenus.

La discussion s'ouvrit au Conseil supérieur du travail le 15 novembre i 9 Io (I). Deux courants semblent se dégager au cours de ces nombreuses et intéressantes séances :

D'une part, un courant conservateur à la tète duquel se place M. Isaac, qui, par un contre-projet, voulait faire déclarer illicite le salaire payé à l'ouvrière à domicile dans le cas seulement où il est inférieur au salaire habituel de la profession dans la région.

D'autre part, un courant novateur et hardi, représenté surtout par MM. Raoul Jay et Keüfer, qui, tout en acceptant eomme base de discussion le système de M. Honoré, essaya de l'amender pour le rendre plus efficace et plus adapté aux réalités à réglementer.

De ces deux courants le second parvint à l'emporter, et par une série d'additions et amendements, le Conseil supérieur aboutit au vote dü texte suivant :

Article premier. - Les femmes travaillant à domicile pour la confection de la lingerie, de la broderie à la main, des vêtements, chapeaux, chaussures, fleurs artificielles et tous autres travaux salariés rentrant dans l'industrie du vêtement, ne peuvent recevoir une rémunération inférieure au salaire ordinaire, dans la région, des ouvrières occupées à des travaux analogues, mais non qualifiées et payées à la journée.

Le tarif doit permettre à une ouvrière d'habileté moyenne de gagner, en dix heures, le salaire déterminé comme il est dit cidessus.

Les Conseils de prud'hommes constatent le taux du salaire journalier visé ci-dessus. Ils publient le résultat de leurs constatations.

Pour faciliter l'appréciation des Conseils de prud'hommes prévue à l'article 3, ies Conseils du travail pourront dresser le tableau des tarifs dans les professions et les régions qu'ils représentent pour les tâches les plus usuelles.

Art. 2. - Les prix de façon des travaux fixés par tout entrepreneur de ce genre de travaux doivent être mentionnés sur un bulletin à souche ou un carnet remis à l'ouvrière. Les prix des ar-

(I) Conseil supérieur du travail. Salaire minimum pour les ouvrières à domicile. Compte rendu de la session de novembre 1910. Paris, Imp. nat., igri.

Cf. la Vingtième session du Conseil supérieur du travail. Bulletin de l'Office du travail, 1910, p. 1328. 
ticles faits en série seront afflchés en permanence dans les locaux où s'effectuent la remise des matières premières aux ouvrières et la réception des marchandises après exécution du travail.

Art. 3. - Le Conseil des prud'hommes est compétent pour juger toutes les contestations qui naîtront au sujet de la présente loi.

Art. 4. - Et à cet effet les travaux faits à domicile étant généralement tarifés à la pièce et non au temps, les prud'hommes pourront faire des enquêtes, avec ou sans expertise, en appelant les entrepreneurs et les ouvrières à déposer devant eux dans les conditions où ils siègent d'ordinaire, en vue d'établir l'équivalence entre le prix du travail à la pièce et le prix du travail au temps.

Art. 5 - La différence constatée en moins entre le salaire des ouvrières non qualifiées et le salaire payé à une ouvrière d'habileté moyenne d'après le tarif de l'entrepreneur devra être versée par celui-ci à l'ouvrière insuffisamment rétribuée, nonobstant toute convention contraire.

Art. 6. - Tout employeur contrevenant aux dispositions de l'article 2 pourra être poursuivi devant le Tribunal de simple police et passible d'une amende.

Le Conseil supérieur du travail s'en rapporte au Parlement du soin de déterminer les sanctions efficaces qui devront être prévues au cas où les salaires payés seraient inférieurs aux salaires inscrits dans les affiches et carnets visés à l'article 8 .

Les inspecteurs du travail sont chargés, concurremment avec les officiers de police judiciaire, de relever les contraventions à la présente loi.

Les associations autorisées à cet effet par décret pourront exercer toutes actions civiles résultant de la présente loi, sans avoir ì justifier d'un préjudice.

Art. 7. - Les réclamations des ouvriers ne seront recevables qu'autant qu'elles se seront produites au plus tard huit jours après le paiement de leurs salaires. Le délai ainsi fixé ne s'applique pas à l'action intentée par l'ouvrière pour obtenir l'exécution d'un jugement.

Ce texte souleva, comme on pouvait s'y attendre, dans la presse et devant l'opinion publique, des discussions passionnées.

Les uns (I) relevèrent la contradiction entre le rejet de toute fixation d'un minimum de salaire préalable et l'établissement par les Conseils du travail de tarifs constatant le taux du salaire journalier ordinaire des ouvrières non qualifiées et payées à la journée, sans voir qu’il s'agit ici

(1) Cif. Temps, 2 I décembre 1910. 
d'une détermination véritable de minima et là d'une simple constatation; ils insistèrent sur de prétendues impossibilités pratiques : rariabilité des salaires pris comme point de comparaison, difficulté de les constater et de les établir; ils critiquèrent enfin le système adopté d'action, de pénalités et de contròle ( $\mathrm{I}$ ).

D'autres regrettèrent l'abandon du système primitif des Comités de salaires et de la fixation d'un véritable minimum en rapport avec les nécessités de la vie (2).

Beaucoup insistèrent sur les répercussions éventuelles du projet, craignant une disparition partielle ou régionale du travail à domicile que l'on voulait réglementer.

La plupart des intéressés et de ceux qui les dirigent sont surtout préoccupés d'assurer d'une façon ou de l'autre le minimum vital indispensable : c'est ainsi que Mlle Rochebillard (3) estimait que le tarif minimum de salaire des femmes devrait ètre au moins, pour toute ouvrière au-dessus de 18 ans, de I franc par jour dans les campagnes et les petites villes; de I fr. 5o par jour dans les villes de I0.000 à I00.000 habitants; de 2 francs par jour dans les grandes villes de plus de Io0.000 habitants.

En même temps, les catholiques sociaux apportaient à l'idée des Comités de salaires l'appui de leur doctrine (4) et de leur action. Le cinquième Congrès diocésain de Paris (5)

(1) Cif. Temps, 3 I décembre rgio.

(2) Le Congrès de l'Aetion libérale populaire, 5-7 déc. rgog, se déclare partisan de l'application obligatoire du mininum de salaire aux travaillenr's à domicile. Monvement social, ıgro, $n^{\circ}$ I. C'est ainsi, par exemple, que le Syndicat des ouvrières de l'aiguille (38, rue Vercingétorix, Paris) consacrait une journée d'études à la question et demandait qu'un minimum vital de salaire annuel fùt fixé par régions par les Conseils de prud'hommes; des conmissions mixtes constituées par profession et dont les membres seraient désignés par le Conseil des prud'hommes adapteraient ensuile à chaque profession le minimum vital en établissant le tarif minimum horaire. C'est là un système transactionnel intermédiaire entre le projet de Mun et celui du Conseil supérieur. (Bulletin de la semaine, 20 septembre igr.)

(3) Travail ale la femme et de la jeune flle, décembre igo7, p. 889.

(4) C. art. de M. de Mun : Figaro, 16 et 21 févr. Igog. Écho de Paris, Salaire vital, 6 mars ıgog; G. Mény: le Travail à domicile. Le Matin, 3 I juillet rgog; R. Jay : protection douanière et protection ouvrière. Eveil démocratique, 6 juin Igog, etc., etc...

(5) Ve Congrès diocésain de Paris (I, 2, 3 mars rgog), Compte rendu. Paris, 5o rue de Bourgogne, rgog.

Gf. Mouvement social, Igog, $\mathrm{I}^{\mathrm{er}}$ sem., p. 647. 
consacrait sa première journée au travail de la femme à Paris et, après une intéressante discussion, aboutissait à la résolution suivante :

“ Profondément énus du sort lamentable fait aux ouvrières par le travail à domicile,

Les catholiques, réunis au Congrès diocésain de Paris, émettent unanimement le vœu qu'il soit porté remède à cette situation par l'initiative privée, par les syndicats et leurs annexes.

Ils demandent aussi en majorité que la loi intervienne, aidée par les Conseils d'arbitrage ou de salaires, afin de sauvegarder en faveur des humbles les droits de la justice (I). ")

Tout récemment le Gouvernement vient de déposer à la Chambre un nouveau projet (2).

\section{PROJET DE LOI}

\section{sur le Salaire des Ouvrières à domicile dans l'Industrie} du Vêtement.

Article premier. - Le chapitre Ier du titre III du livre Ier du Code du Travail et de"la Prévoyance sociale est modifié comme suit :

Chapitre Ier. - De la détermination du salaire. - Section I. - Du salaire des ouvrières exécutant à domicile des travaux rentrant dans l'industrie du vêtement.

Art. 32 a). - (3) Toute femme exécutant à domicile des travaux de confection de lingerie, broderie à la main, vêtements, chapeaux, chaussures, fleurs artificielles et tous autres travaux rentrant dans l'industrie du vêtement ne peut recevoir une rémunération inférieure au salaire ordinaire d'une ouvrière de la région payée à la journée ou à l'heure et non qualifiée, c'est-à-dire exécutant communément et sans spécialisation professionnelle déterminée les divers travaux courants de la profession.

Art. 32 b). - Le tarif aux pièces appliqué aux travaux à domicile ci-dessus visés doit être tel qu'il permette à une ouvrière d'habileté moyenne de gagner en dix heures un salaire égal au salaire à la journée déterminé comme il est dit à l'article $32 a$ ).

Art. $32 \mathrm{c}$ ). - Tout fabricant, commissionnaire ou intermédiaire faisant exécuter des travaux à domicile doit tenir un registre

(1) Compte rendu cité, pp. 73 et 76 .

(2) J. O., Ch. Doc. parlem., 1911, n० 1269 .

(3) Le numérotage des articles de ce projet s'explirue par son insertion éventuelle dans le Code du travail. 
indiquant le nom et l'adresse de chacune des ouvrières ainsi occupées.

Art. $32 d)$. - Les prix de façon des travaux à domicile fixés par tout entrepreneur de ce genre de travaux pour les articles faits en série sont affichés en permanence dans les locaux où s'effectuent la remise des matières premières aux ouvrières et la réception des marchandises après exécution.

Art. $32 e)$. - Les prix de façon applicables au travail à exécuter à domicile doivent être mentionnés explicitement sur un bulletin à souche ou un carnet remis à l'ouvrière.

Lors de la remise du travail achevé, une mention est portée aù bulletin ou carnet, indiquant la date de l'achèvement du travail, le montant de la rémunération acquise, ainsi que la somme nette payée ou à payer après déduction de tous frais accessoires.

Art. $32 f)$. - Pour faciliter l'appréciation des Conseils de prud'hommes dans la connaissance des différends qui peuvent s'élever au sujet de l'application de la présente section, les Conseils du travail peuvent dresser d'office ou dressent, sur la demande du Gouvernement, le tableau des salaires à la journce et à l'heure et le tableau des tarifs aux pieces correspondants pour les tâches les plus usuelles dans les professions et les régions qu'ils représentent.

A défaut de ces constatations, les Conseils de prud'hommes peuvent, sans préjudice des attributions contentieuses qui leur appartiennent en vertu de la loi, faire des enquêtes, avec ou sans expertise, en vue d'établir les mêmes données.

Les uns et les autres publient les résultats de leurs constatations.

Art. $32 g)$. - Les Conseils de prud'hommes sont compétents pour juger toutes les contestations qui naîtront de l'application de la présente section et notamment pour redresser tous les comptes de salaires inférieurs aux salaires définis à l'article $32 a$.

Toutefois, dans tous les cas oì un Conseil de prud'hommes sera appelé soit à évaluer pour la première fois le chiffre d'un salaire minimum, soit à modifier son évaluation antérieure, le bureau de jugement du Conseil devra être présidé par le juge de paix dans les conditions prévues par la loi pour les jugements en cas de partage des voix.

La différence constatée en moins entre le salaire des ouvrières non qualifićes et le salaire payé à une ouvrière d'habileté moyenne d'après le tarif de l'employeur doit être versée par celui-ci à l'ouvrière insuffisamment rétribuée, nonobstant toute convention contraire.

Tout employeur, entrepreneur ou sous-entrepreneur est civile. ment responsable lorsque c'est de son fait que le salaire minimum n'a pas pu être payé.

Art. $32 h)$. - Les réclamations des ouvrières touchant le tarif appliqué au travail par elles exécuté ne sont recevables qu'autant 
qu'elles se seront produites au plus tard huit jours après le paiement de leurs salaires.

Le délai ainsi fixé ne s'applique pas à l'action intentée par l'ouvrière pour obtenir l'exécution d'un jugement.

Art. $32 i)$. - Les associations ou syndicats autorisés à cet effet par décret rendu sur la proposition du Ministre du Travail et de la Prévoyance sociale peuvent exercer toutes les actions civiles résultant de la présente section sans avoir à justifier d'un préjudice, à charge, si le défendeur le requiert, de donner caution pour le paiement des frais et dommages auxquels ils pourraient être condamnés, à moins qu'ils ne possèdent en France des immeubles d'une valeur sufiisante pour assurer ce paiement.

La disposition qui précède ne porte point atteinte aux droits reconnus par les lois antérieures aux syndicats professionnels.

Art. $32 \mathrm{j})$. - Le Conseil de prud'hommes ou, à défaut, le juge de paix, à l'occasion de tout différend portant sur la rémunération d'une ouvrière effectuant quelqu'un des travaux visés à l'article $32 a$, rend public, par affichage à la porte du prétoire ou par tout autre mode efficace de publicité, le taux constaté du salaire journalier des ouvrières non qualifićes de la profession et de la région qui a servi de base à sa décision.

Tout intéressé et tout groupement professionnel sont autorisés à prendre sans frais, copie, au secrétariat du Conseil de prud'hommes ou au greffe de la justice de paix, des taux de salaires ainsi constatés et à les publier.

Art. 2. - La section I du chapitre Ier du titre III du livre Ier du Code du Travail et de la Prévoyance sociale portera le titre de section II.

Art. 3. - Le titre V du livre Ier du Code du Travail el de la Prévoyance sociale est modifié comme suit :

$1^{\circ}$ Après l'article 99 est inséré l'article $99 a$ suivant :

Art. $99 a)$. - Les fabricants, commissionnaires, intermédiaires ou leurs préposés qui auront contrevenu aux dispositions des articles $32 c, 32 d$ et $32 e$ du présent livre ou porté des mentions inexactes sur les registres, affiches, bulletins et carnets prévus par lesdits articles seront poursuivis devant le tribunal de simple police et punis d'une amende de 5 à 15 francs.

Dans les cas de contravention à l'article $32 \quad e$, l'amende sera appliquée autant de fois qu'il y aura de personnes à l'égard desquelles les prescriptions dudit article n'auront pas été observées, sans toutefois que le maximum puisse dépasser cinq cents francs (50o fr.).

En cas de récidive, le contrevenant sera poursuivi devant le tribunal correctionnel et puni de 16 à ıo francs.

Il y a récidive lorsque, dans les douze mois antérieurs au fait poursuivi, le contrevenant a déjà subi une condamnation pour une contravention identique.

En cas de pluralité de contraventions, entraînant des peines de 
récidive, l'amende sera appliquée autant de fois qu'il aura été relevé de nouvelles contraventions, sans que le maximum puisse dépasser trois mille francs (.3.ooo fr.)

Les tribunaux correctionnels pourront appliquer les dispositions de l'article 463 du Code pénal sur les circonstances atténuantes, sans qu'en aucun cas l'amende, pour chaque contravention, puisse être inférieure à 5 francs.

Les fabricants, commissionnaires ou intermédiaires sont civilement responsables des condamnations prononcées contre leurs préposés.

$2^{0}$ L'article 107 est modifié comme suit:

Art. I07. - Les inspecteurs du travail sont chargés, concurremment avec les officiers de police judiciaire, d'assurer l'exécution des articles $32 c, 32 d, 32 e, 75,76,77$ et, en ce qui concerne le commerce et l'industrie, des articles 43 , 44 et $45 \mathrm{du}$ présent livre. Ils ont entrée dans les locaux définis à l'article $32 d$, même lorsqu'il n'y est occupé ni ouvrier ni employé, et peuvent se faire représenter les registres prévus à l'article $32 c$ et les bulletins ou carnets prévus à l'article $32 e$.

Ce projet fut renvoyéà la Commission du travail ; le Gouvernement, en la personne de M. Léon Bourgeois, appuya très énergiquement le texte proposé (I) devant la Commission (2). Diverses tentatives furent faites devant la Commission pour étendre la sphère d'application de la loi (3); le Gouvernement semble avoir pris position en faveur d'une expérience limitée et réservée aux seules ouvrières à domicile de l'industrie du vìtement pour commencer.

En mème temps, la question était reprise à l'Association internationale pour la protection légale cles travailleurs (4): l'assemblée arlopta en principe le projet clu Gouvernement et se rallia au systeme de la fixation des minima de salaires par les Conseils de prucl'hommes; le défaut d'organisation

(I) Le projet avait été déposé par M. René Renoult, en novembre r9ix, sous le ministère Caillaux. Il a été repris par M. Léon Bourgeois, sous le ministère Poincaré, avee quelques très légères modifications.

(2) Le Parlement et l'opinion : ıo février 1912, p. 22.

(3) Notamment un amendement de M. Néron, rapporteur, pour englober dans la loi les tisseurs de la Loire et de la Haute-Loire.

(4) Séances des 7 décembre I9II, 14 décembre I9II, 11 janvier I912, 25 janvier I912. Association nationale française pour la protection légale des travailleurs : Cf. Le minimum de salaire dans l'industrie à domicile. Rapporteurs : MM. B. Raynaud, le comte A. de Mun, l'abbé Mény. Compte rendu des diseussions. Vœux adoptés. I vol., Paris, 1912, Alcan. Ce rapport sera ci-après ainsi indiqué : Rapport protection légale: Travail à domicile. 
professionnelle dans les industries à domicile, les craintes d'échec pour les Comités de salaires renforcées par l'échec récent des Conseils du travail, l'impossibilité en un mot de réaliser le contrat collectif se formant directement entre les représentants des ouvriers et les patrons (I), le désir d'aboutir le plus rapidement possible firent adopter cette solution.

Par contre, l'œuvre de la section française fut consacrée tout entière à améliorer et à amender le projet gouvernemental, " pour que l'application de ces prescriptions puisse ètre aussi rapidle, aussi complète que possible (2) $)$.

Trois questions principales retinrent l'attention de l'assemblée et furent l'objet de longues et intéressantes discussions :

a) Le domaine d'application de la loi ;

b) La définition du salaire de base;

c) Les sanctions à établir.

a) En ce qui concerne le domaine d'application de la loi, le projet du Gouvernement ne vise, on le sait, que les ouvrières exécutant à domicile des travaux existant dans l'industrie du vêtement. On envisagea successivement l'extension du projet aux travailleurs masculins de l'industrie du vêtement (3); la crainte d'évasion du travail à domicile à l'étranger, les dangers d'augmenter les résistances contre le projet en englobant tous les travailleurs à domicile sans distinction la firent écarter. Des motifs analogues firent repousser l'application immédiate aux rubanniers de la Loire et de la Haute-Loire. On se rallia à une formule transactionnelle (4) prévoyant l'extension de la loi par décret à d'autres

(I) Cf. M. Raoul Jay. Rapport protection légale. Travail à domicile. pp. 69 et suiv. " Ne pourrait-on pas, dans ces conditions, légitimement redouter que les représentants envoyés aux Comités de salaires par les travailleurs à domicile se trouvassent, en fait, incapables de défendre suffisamment les intérêts de leurs mandants, prêts peut-être à se laisser aller à consacrer la situation actuelle ou mème des situations pires?") (Op. cit., p. 73 ).

(2) M. Jay, op. cit., p. 74 .

(3) Vœu de MM. Motteau et Zamanski. Rapport protection légale. Travail à domicile, pp. 82-1 I6. C'eùt été sans éturle préalable le projet applicable à 1.200.000 Français. (M. Fagnot, op. cit., 1. 98.)

(4) Cf., plus loin, p. 39/. 
industries et en ce cas l'extension aux travailleurs des deux $\operatorname{sexes}(\mathrm{I})$.

Cette solution modérée, imitée d'ailleurs de la solution anglaise, parait à tous points de vue acceptable : elle a le réel avantage de sérier les questions et de permettre l'application de la méthode expérimentale (2) sans ajouter aux difficultés considérables que rencontre devant l'opinion la réalisation d'un minimum légal de salaire.

b) La définition du salaire de base (3) est incontestablement l'un des points les plus délicats de la législation à l'étude. On proposa plusieurs interprétations du texte du Gouvernement (4); on modifia le texte pour donner au Conseil de prud'hommes le droit de fixer le minimum de salaire en s'inspirant d'un certain nombre de considérations (gain journalier d'une ouvrière de capacité moyenne de la profession travaillant en atelier, sans spécialisation professionnelle; salaire de la journalière; tarifs au temps existants). On insista également sur la nécessité de publier le taux du salaire de base (5).

Il faut bien reconnaître que sur ce second point il paraît difficile, par une formule générale, de viser l'ensemble des cas pratiques où le Conseil de prud'hommes devra statuer. Le plus simple est peut-ètre, comme on l'a fait, de ne point trop enchaîner l'organe chargé d'établir les tarifs et de lui

(1) Vœu de M. Néron, op. cit., p. ıo8.

(2) “ On a parlé beaucoup de méthode expérimentale : on a beaucoup affirmé qu'en pareille matière il fallait procéder par la voie expérimentale, aller petit à petit, prendre une industrie, puis une autre, et, s'appuyant sur les constatations faites dans les' premières étapes, s'avancer. progressivement vers des solutions meilleures et plus complètes. " M. Jay, op. cit., p. 150 .

(3) Le texte du gouvernement est ainsi rédigé :

"Toute femme ... ne peut recevoir une rémunération inférieure au salaire ordinaire d'une ouvrière de la région payée à la journée ou à l'heure et non qualifiée, c'est-à-dire exécutant communément et sans spécialisation professionnelle déterminée les divers travaux courants de la profession. " Art. $32 a$.

(4) S’agissait-il du salaire de l'ouvrière débutante, de la petite main, c'est-ì-dire d'un salaire insuffisant pour vivre? ou au contraire était-ce le bon salaire d'atelier, ou encore celui de la femme de ménage qui n'a d'autre ressource que sa bonne volonté et ses dix doigts? Des discussions se dégage cette impression que le salaire de base du projet gouvernemental, c'est le salaire de la débutante ou de la petite main.

(5) Cf., plus loin, p. 394. 
laisser une certaine latitude dans l'accomplissement de sa délicate mission.

c) Le problème des sanctions était, en troisième lieu, un problème capital.

A cet égard, une double amélioration, à notre sens, fut apportée au projet:

D'une part, en ce qui concerne les sanctions civiles, on inscrit formellement pour l'ouvrière, au cas où un tarif aux pièces aura été établi ou homologué par le Conseil de prud'hommes, le droit de réclamer la différence entre les prix fixés par ce tarif (I) et ceux inférieurs réellement payés (2).

D'autre part, en ce qui concerne les sanctions pénales, on montra l'insuffisance des sanctions du projet gouvernemental (3) et on voulut assurer plus efficacement l'application des minima de salaires en établissant, en cas de violation de ces minima par l'employeur, le principe d'une sanction pénale.

Suivant l'exemple des législations australasienne et anglaise, " qui ont cru nécessaire et point du tout excessif qu'une sanction pénale frappât non seulement l'industriel qui ne paye pas le tarif défini, mais encore celui qui ne paye pas des salaires correspondant aux tarifs au temps fixés comme base (4) ", on se rendit compte, ce qui nous paraìt incontestable, que c'est là le seul moyen d'arriver à une réalisation pratique du minimum de salaire dans le travail à domicile.

Voici, comme conclusion de ces diverses discussions, le texte des vœux adoptés :

L'Association française pour la protection légale des tra-

(I) Sur la forme obligatoire du tarif aux pièces, cf. Rapport protection légale. Travail à domicile, plp. 194-225.

(2) On renforça aussi (cf., plus loin, p. 395) le droit d'action en justice des syndicats pour y exercer les actions eiviles et pénales naissant de la présente loi. (Op. cit., pp. 255-261.)

(3) Les sanctions prévues par les articles $99 a)$ et 107 combinés du projet n'aboutissaient qu'à faire frapper d'amende par les inspecteurs du travail les contraventions aux dispositions relatives, soit à la tenue de registres où l'on devra inserire le nom des ouvrières, soit à la remise à l'ouvrière d'un bulletin où l'on inserira les prix de façon. Rien n'existait sur la sanction du non-paiement par l'employeur du minimum de salaire.

(4) Jay', op. cit., p. 250. 
vailleurs demande au Parlement et au Gouvernement de hàter le vote du projet de loi déposé le 7 novembre igir, en tenant compte des vœux suivants :

\section{I. - Domaine d'application de la loi.}

Que le travail à domicile soit défini de façon à éviter les fraudes qui auraient pour effet de perpétuer l'exploitation des ouvrières dans de prétendus ateliers ou dans des locaux non industriels.

Que le Gouvernement soit autorisé à étendre par décret l'application de la loi à d'autres industries qu'à celle du vêtement.

Que le Gouvernement soit autorisé à étendre dans la même forme, après enquête, au cas où les conditions d'exercice de la profession le feraient apparaittre comme nécessaire, la protection du minimum de salaire aux travailleurs des deux sexes.

\section{II. - Définition du salaire de base.}

Que la définition du salaire de base prévu à l'article $32(a)$ du projet de loi gouvernemental soit ainsi modifié :

( Toute femme exécutant à domicile des travaux de confection de lingerie

(Suit l'énumération du projet de loi)

ne pourra recevoir une rémunération inférieure à un minimum déterminé par le Conseil de prud'hommes qui, pour l'établir, prendra en considération : $1^{0}$ le gain journalier d'une ouvrière de capacité moyenne de la profession, travaillant en atelier, sans spécialisation professionnelle; $2^{0}$ le salaire de la journalière dans la région. »)

\section{II. - Règles relatives à la flxation des salaires.}

Que l'article $32 b$ du projet gouvernemental soit ainsi modifié :

"Lorsque les mêmes travaux seront effectués avec le même outillage à l'atelier et à domicile, les tarifs payés à l'atelier seront. applicables au travail à domicile.

“ La preuve de l'infériorité professionnelle de l'ouvrière est à la charge du patron. »)

\section{IV. - Publicilé du taux du salaire de base.}

Qu'antérieurement à toute contestation, les Conseils de prud'hommes soient tenus de constater le taux du salaire de base et. de publier le résultat de leur constatation.

\section{V. - Force obligatoire des tarifs aux pièces établis par les Conseils de prud'hommes.}

Qu'au cas où un tarif aux pièces aura été établi ou homolo- 
gué par un Conseil de prud'hommes, l'ouvrière puise dans ce tarif même le droit de réclamer la différence entre les prix fixés par ce tarif et ceux payés par l'employeur.

\section{VI. - Sanctions pénales et constatation des infractions.}

Des sanctions pénales devront être établies contre les patrons qui ne payeraient pas habituellement le salaire minimum établi jar le Conseil de prud'hommes. Les inspecteurs du travail ont qualité pour relever ces infractions. Ils pourront dresser des procès-verbaux pour paiement de salaires inférieurs au salaire de base établi par le Conseil de prud'hommes. Dans ce cas, avant d'être porté devant le Tribunal de répression, le procès-verbal sera soumis, pour justification de l'infériorité de salaire, au Conseil de prud'hommes, ou au juge de paix dans le cas où celui-ci connaîtrait du tarif en l'absence de conseil de prud'hommes.

\section{VII. - Droit d'action des syndicats.}

Que les syndicats des professions visées à l'article $32 a$ puissent, sans autorisation et sans avoir à faire la preuve du préjudice, intenter, dans la région où ils exercent leur activité, toutes les actions naissant de la présente loi devant les juridictions répressives comme devant les juridictions civiles; que les associations autorisées par décret jouissent des mêmes droits.

Qu'il soit entendu que l'article $32 i$ ouvre à tout syndicat professionnel et aux associations autorisées une action propre en rectification de tarifs et en dommages-intérêts, sans préjudice du droit de se faire les mandataires des ouvrières lésées.

Le projet rencontre, comme on pouvait s'y attendre, une certaine résistance dans les milieux patronaux; c'est toujours l'éternel argument de la liberté qu'on lui oppose (I), la fixation d'un minimum de salaire presque irréalisable, l'utilité du travail à domicile qui fournit le salaire

(I) La Société des industriels et commerçants de France émet le vœu suivant :

" $I^{\circ}$ Que le projet relatif à la fixation du salaire minimum des ouvrières à domicile dans l'industrie du vêtement soit regardé comme attentatoire à la liberté des conventions et au principe de l'inviolabilité du domicile, contraire à la paix sociale et préjudiciable aux intérêts solidaires des employeurs et des employés, et que pour tous ces motifs il soit rejeté par le Parlement;

" $2^{n}$ Qu'il soit ouvert une enquète par les pouvoirs publics auprès de tous les groupements commerciaux et industriels et auprès de tous les intéressés pour étudier le moyen, en donnant plus d'extension au travail à domicile, de relever les salaires reconnus insuffisants. ") (Temps, 3i mars 1912 .) 
d'appoint, qui aide la femme et la mère à remplir ses charges et ses devoirs de famille...

Un contre-courant se dessine également parmi les libéraux, qui critiquent énergiquement celte nouvelle tentative de réglementation ( $\mathrm{I})$.

D'autres regrettent que pour des questions de méthode, le projet ne vise actuellement que les ouvrières à domicile dans la seule industrie du vêtement. On a proposé (2) l'extension d'un régime analogue pour les travailleurs à domicile du ruban et de la soierie (3). Le salaire minimum des travailleurs dans l'industrie du ruban et de la soie (4) serait en ce cas le salaire ordinaire d'un ouvrier non qualifié travaillant en usine, payé à l'heure ou à la journée et exécutant, sans spécialisation professionnelle, les divers travaux courants de la profession (5).

(1) Le sweating system et l'intervention de l'État dans la fixation des salaires. Discussion à la Société d'économie politique, du 5 juin igr2. Journal des Économistes, juin 1912, p. $49^{5}$.

(2) Un amendement au texte ministériel en ce même sens a été repoussé par la Conmission du travail.

(3) Proposition de loi présentée par MIM. A. Durafour, J. Godart, etc. J. O., Ch. des dép., Doc. parlem., 1912, n 1785.

(4) Leurs salaires tombent actuellement parfois au chiffre dérisoire de $1 \mathrm{fr}$. 50 à 2 francs par jour à Saint-Étienne et dans la région.

(5) Augmenté encore des frais quotidiens afférents à chaque métier. (Art. I er du projet.) 


\section{III. - L'effort des intèressès eux-mêmes.}

Encore, pour donner un aperçu complet de l'état de l'opinion en France, faut-il mentionner les réclamations des intéressés eux-mèmes et les desiderata du mouvement ouvrier.

"Bien que ce minimum légal, écrit M. Ch. Gide, n’existe encore qu'à l'état de curiosité sociale aux antipodes, nul doute qu'il ne soit le but visé par les organisations ouvrières de tous les pays (I). ")

Il est certain, en effet, que cette réforme est au fond des aspirations du prolétariat d'une manière plus ou moins consciente.

Sans dépouiller à ce sujet tous les congrès ouvriers de ces dernières années, il suffit de constater que le minimum de salaire est une de leurs plus ordinaires revendications.

On retrouve l'écho des mêmes préoccupations dans les grandes enquêtes parlementaires menées ces dernières années sur quelques-unes de nos plus importantes industries.

C'est ainsi que lors de l'enquête parlementaire (rgo2-r go3) sur l'industrie du charbon, on trouve, exprimé très nettement, le désir de la réforme. Le Syndicat d'Anzin répond au questionnaire (2):

"Nous sommes partisans d'un minimum légal de salaire, parce que nous pensons qu'il est le seul capable de faire disparaître toutes les injustices (dans l'établissement des salaires). " Le Syndicat en attend d'ailleurs les plus heureux effets : " assurer une répartition plus égale des salaires, enrayer le favoritisme et l'injustice, empècher l'entraìnement à produire exercé par certains ouvriers plus forts ou plus favorisés, faire obstacle à l'allongement de la journée et à l'accroissement de l'effort, empècher l'abaissement du salaire au-dessous du salaire de base. ")

Les Congrès miniers tenus par la Fédération nationale

(I) Cf. id. Rapport de la Section d'Économie sociale. Exposition de Igoo. Introduction, t. V, p. I 5 .

(2) Enquête parlementaire sur l'industrie du charbon, I902-1903, t. I, p. 61 . 
des mineurs, aujourd'hui (I) la Fédération nationale de l'industrie des mines, minières et carrières de France, ont maintes fois mis à l'ordre du jour de leurs discussions la réforme du minimum de salaire en l'attendant du vote d'une loi des Chambres; une résolution formelle en ce sens fut votée notamment au Congrès de Commentry, avril I9 I (2). Cependant, cette année même de I9 I2, au Congrès d'Angers (férrier) la question, par suite de la tactique syndicaliste, semble ètre passée au second plan (3). Il faut arouer d'ailleurs que les différences très grandes de salaires de bassin à bassin rendent le problème parlementaire presque insoluble.

De mème, lors de l'enquète de igo/ sur l'état de l'industrie textile et la condition des ouvriers tisseurs (4), à la question nettement posée par le questionnaire (5) la plupart des associations professionnelles ouvrières ont répondu par l'affirmative : il faut mentionner en ce sens la réponse de l'Association syndicale des ouvriers de l'industrie textile d'Armentières et d'Houplines (6), celle de l'Association syndicale ouvrière de l'industrie textile de Bailleul (7) celle du Syndicat d'Hazebrouck (8), celle du Syndicat ouvrier textile de Lille et environs (9).

Également la Chambre syndicale des ouvriers tisseurs et tisseuses de Saint-Quentin (I0), la Fédération des syndicats ouvriers des Vosges ( I I), le Syndicat des ouvriers cotonniers

(1) Depuis le congrès d'Albi, mars rgı.

(2) Cf. Temps, 20 février i912. Ch. Dulot. Chez les mineurs : le congrès d'Angers.

(3) On a préféré insister sur la question des retraites plus générale et plus accessible : elle fit l'oljet des délibérations principales du congrès. (Ibid. Temps, 20 fév. I912.)

(4) Procès-verbaux de la Commission clıargée de procéder à une enquète sur l'état de l'industrie textile et la condition des ouvriers tisseurs. 4 vol.

Ch. des dép., n ı22, 4 vol., Paris, imprimerie de la Ch. des dép., ıgo6.

(5) Minimum de salaire. Est-il possible dans votre industrie? Dans l'affirmative, comment pourrait-il être établi ? Questionnaire Enq. précitée, t. I, p. vi.

(6) Enq., t. II, p. 62.

(7) Enq., t. II, p. II 7 .

(8) Enq., t. II, p. 134 .

(9) Enq., t. II, p. 28r.

(10) Enq., t. III, p. 465.

(I I) Enri., t. III, p. 285. 
de Rouen (r), de Lillebonne (2), se prononcent dans le mème sens, en demandant la réforme sans d'ailleurs entrer dans les détails.

Enfin le Comité des chambres syndicales ouvrières pour la défense des soieries de Lyon (3), l'Union syndicale des ouvriers et ouvrières de l'industrie textile et similaires de Vienne et la région (4), la Chambre syndicale des travailleurs de l'industrie textile de Saint-Étienne (5), l'Union syndicale de l'industrie textile de Roanne (6) réclament tous, avec bien d'autres encore, la réforme du minimum de salaire, sans rien préciser sur sa réalisation éventuelle.

Il faut noter d'ailleurs une résistance nettement affirmée du côté patronal.

G'est ainsi que dans l'enquête précitée sur l'industrie du charbon les patrons objectent que " le minimum de salaire ou bien, sans minimum de production, revient à établir un salaire à la journée qui amènerait sûrement une réduction de l'effort ouvrier, ou bien, avec minimum de production corrélatif, si ce minimum est établi dans les seules conditions pratiqnes, revient au système actuel avec seulement des sources plus grandes de contestations. ")

De mème dans l'enquête précitée (7) sur l'industric textile, les réponses patronales sont toutes dans le sens de la négative: tel est l'avis de la Chambre syndicale des tissus et matières textiles de Saint-Étienne (8), du Syndicat cotonnier de l'Est (9), du Syndicat de l'industrie saint-quentinoise (Io), enfin de l'Union des syndicats patronaux des in-

(i) Enq., t. III, p. 124.

(2) Enq., t. III, p. 225.

(3) Enq., t. IV, 1. 94.

(4) Enq., t. IV, p. 197. Celle-ci déclare : "Pour établir un minimum de salaire, il faudrait, selon nous, que tout le monde soit payé à la journée. ")

(5) Enr., t. IV, p. 275.

(6) Enq., t. IV, p. 366. Assez curicuse comme symptomatique d'un état d'esprit, la réponse : "La question du ninimum de salaire est oiseuse et mal posée. Il faulrait la poser en ce sens : Si le minimum de salaire profite à l'industriel, il n'hésitera pas à le donner sous une forme qui le satisfera; si, au contraire, il lui est défavorable, il ne le subira qu'avec regret lorsque ses ouvriers sauront le lui imposer. ")

(7) Supra, p. 397 .

(8) Enq., t. III, p. 298.

(9) Enq., t. IV, p. 261 .

(10) Enq., t. IV, p. 43 I. 
dustries textiles de France (I). Cette dernière peut assez bien résumer l’opinion générale :

" Nous sommes conduits, par là même, en raison des éléments multiples qui concourent à l'établissement des' salaires, à considérer que "le minimum de salaire » est pratiquement impossible dans la plupart des industries textiles.

Ainsi que le fait remarquer la Chambre syndicale des tissus et matières textiles de Saint-Étienne, à propos des passementiers, il faudrait admettre qu'il $y$ ait égalité de matériel dans les établissements et de capacité chez l'ouvrier.

Les mèmes raisons peuvent être invoquées dans presque toutes les spécialités textiles.

En outre, l'établissement d'un minimum de salaire équivaudrait à l'élimination de tous ceux des ouvriers textiles qui ne parviendraient pas à une production équivalente à ce minimum, c'est-à-dire : les femmes, les enfants, les ouvriers âgés ou faibles.

Cette observation, présentée par le Syndicat cotonnier de l'Est et le Syndicat de l'industrie saint-quentinoise des fils et tissus, a d'autant plus de valeur que, nous l'ávons constaté, la proportion de femmes, de vieillards et d'enfants employés dans l'industrie textile est importante : $4 \mathrm{I}, \mathrm{I} 6 \%$ pour les femmes, $12,60^{\circ}$ o pour les enfants et adolescents au-dessous de 18 ans, $5 \%$ pour les vieillards au-dessus de soixantecinq ans (2). ")

Ainsi les demandes réitérées des intéressés se heurtent à la résistance patronale en général : malgré tout, on peut certainement considérer cette quasi-unanimité ouvrière sur le programme comme l'une des manifestations intéressantes. de l'opinion publique française.

(1) Enq. T. I, p. 3i .

(2) Cf. dans le même sens la réponse de l'Association générale du commerce et de l'industrie des tissus et matières textiles, rédigée par M. L. Vimont, trésorier général de l’Association. Enq. préc., t. I, p. Ir5.

Également l'opinion de M. Aftalion, prof. à la Faculté de droit de Lille. Enq., t. I, p. 88. "Quant à la question du minimum de salaire, elte me paraît très difficile. Si le mininum de salaire arrive à s'introduire en France, ce n'est pas logiquement par l'industrie tinière qu'il doit commencer.... Il y d'autres industries où le bas salaire appelle beaucoup plus l'attention du législateur. » 


\section{IV. - L'Initiative patronale.}

Cependant la chose vaut d'être notée et indique bien le caractère urgent de la réforme, un certain nombre de patrons, intelligents et avisés, ont essayé, sans succès d'ailleurs, de réaliser le minimum de salaire par l'entente des intéressés eux-mêmes et en dehors de toute contrainte légale.

Il y eut à cet égard deux expériences partielles dont l'histoire est singulièrement significative.

La première tentative est celle de M. Lefébure, le grand dentellier de la rue Castiglione (I). L'idée première du projet fut inspirée à son auteur par Mlle Rochebillard, secrétaire général des syndicats d'ouvrières lyonnaises (2).

Il s'agissait, étant admises sans discussion la nécessité d'un minimum de salaire et l'organisation de Comités de salaires, composés mi-partie d'employeurs et d'employés, seuls compétents dans la matière, de réaliser ce minimum, "ce salaire vital » (3) par le jeu libre et naturel des deux groupes professionnels intéressés (4), en opposant la solution syndicale à la solution légale. Les Comités de salaires devaient se borner à décider quel serait le minimum de salaire vital fixé à la journée pour l'année courante, sans entreprendre la fixation des prix de façon pour chaque métier et pour les milliers d'articles qui se font en chambre, ce qui serait " une besogne écrasante, inextricable, à laquelle ils ne pourraient suffire ». Ce minimum vital ainsi

(1) Lefébure : Le minimum de salaire pour les femmes. Corresponclant, 25 mars igog, p. I1 72.

Académie des Seiences morales et politi([ues. Compte rendu, rgog, I es sem., P. 814. M. Lefébure fut invité par l'Académie à défendre devant elle son projet.

C. Temps, 28 mars rgog.

Mény : Le Travail à domicile, p. 322.

(2) Communication citée. Compte rendu Académ. Sc. morales, p. 817.

(3) Ibid., p. 820.

(4) Il s'agissait, pour toute ouvrière au-dessus de 18 ans, de I frane par jour lans les campagnes et les petites villes, de I fr. 50 par jour dans les villes de 10.000 à 100.000 habitants, de 2 francs par jour dans les grandes villes de plus de 100.000 habitants. Délibération des syndicats de femmes de Lyon en date du 22 déc. Ig07 : Ibid., p. 818. 
arrêté, serait publié, affiché, afin que tous le connaissent bien; puis il serait déclaré que tout employeur, en distribuant les ouvrages, devra faire concorder ses prix de façon avec le minimum fixé (r). Si l'ouvrière, qui connaìt le minimum publié, s'aperçoit après coup qu'elle n'y arrive pas en faisant ses dix heures d'ourrage, elle sera en droit de réclamer à son employeur, et s'il résiste, elle peut le citer devant les prud'hommes (2).

Telle était la solution syndicale du minimum de salaire (3).

Pour la réaliser, M. Lefébure servit d'intermédiaire entre les syndicats indépendants de femmes de Lyon et l'Association générale des tissus et matières textiles de la rue d'Aboukir.

Le président en exercice du syndicat patronal, M. Riçois, du Bon Marché, nomma, le 10 mars i908, une Commission chargée d'étudier le projet. Cette Commission nomma rapporteur M. Kempf, président de la Chambre syndicale des batistes.

Le rapport fut déposé le 14 avril suivant (4). Le rapporteur contestait la faiblesse de la rémunération du travail à domicile et il affirmait que « de l'enquête faite par les diverses Chambres syndicales de l'Association des tissus et matières textiles, il résultait que toutes les ouvrières à domicile occupées par nos adhérents gagnent largement leur vie. Aucune d'elles, à moins d'insuffisance ou d'incapacité notoires, n'est réduite à ces salaires de famine dont nous réprourons l'existence, et il serait à souhaiter que toutes les ouvrières fussent rétribuées aussi avantageusement que chez nous. "

(r) Ibid., p. 819 .

(2) Ibid., p. 818. Au surplus, l'Inspection du travail surveillerait ce qui se fait à domicile et les patrons seraient tenus de remettre à chaque ouvrière un livret où l'employeur inscrirait le prix convenu pour le travail confié.

(3) M. Honoré, dans une communication à l'Académie des Sciences morales et politiques, en date du 27 mars 1909 , insistait dans le même sens pour la confection de séries de prix par des Comités mixtes régionaux, analogues aux séries de prix du bàtiment sans "légiférer en pareille matière, ce qui serait heurter une plaie avec un corps dur." " Ibid. Compte reńdu Acad., p. 814. Cf. Communication à la Société d'économie sociale. Réf. sociale, 16 avril ı908, p. 512.

(4) Rapport publić dans le Travail de la femme et de la jeune fille, aoùt 1908, p. 1150. 
C'était l'échec bien net de la solution patronale.

M. Lefébure lui-même avoua l'insuccès de son dessein: "Nous avons compris, en lisant ce rapport, écrit M. Lefébure à M. Riçois (I), après la publication du travail de M. Kempf, que notre question était encore prématurée et que nous ne pouvions compter sur l'Association des tissus pour adopter ce minimum et en chercher dès aujourd'hui l'application par les nombreuses (2) Chambres syndicales qui sont groupées autour d'elle. "

L'expérience de M. Lefébure avait tout au moins servi à vulgariser en France l’idée du salaire minimum.

La seconde tentative est celle de M. Lefebvre, tendant à organiser le minimum de salaire dans l'industrie de l'imprimerie (3).

M. Lefebvre est un imprimeur parisien qui, depuis de longues années déjà, soumettait à ses confrères, la question du minimum de salaire, sans obtenir qu'elle soit prise en considération.

A Marseille, en juillet r gog, au Congrès des maìtres imprimeurs, grâce à l'appui du président de l'Union des maîtres imprimeurs, M. Audibert, la question, bien que ne figurant pas à l'ordre du jour du Congrès, fut accueillie et renvoyée à une Commission pour études (4).

Le projet de M. Lefebvre était directement inspiré de

(i) Lettre publiée par le Travail de la femme et de la jeune fille, aoùt I908, p. I15 I.

(2) Dans une lettre du 3 I janvier Igog à la Vie nouvelle, M. Lefébure affirmait que l'Association générale des tissus et matières textiles comptait trente Chambres syndicales affiliées.

(3) Affches de l'Imprimerie, organe des maîtres imprimeurs, oct. Igog. (if. Mény, op. cit., p. 324.

Cf. un article de M. V. Breton sur cette tentative, Havre-Éclair, 30 oct. 1909 .

G. Lefebvre : Le tarif minimum de salaire dans ta typographie francaise. Union syndicale des maîtres imprimeurs de France, 19ro. Ce dernier ouvrage n'est pas dans le commerce : nous avons pu le consulter et l'analyser, grâce à la bienveillante communication de M. G. Lefebvre, que nous tenons ici ì remercier bien sincèrement.

(4) "Le fait même d'avoir admis la possibilité d'étudier la question démontre qu'une révolution incontestable s'est faite dans les esprits. " Courrier du Livre, igrog. 
l'exemple allemand étudić ci-dessus (I) : il consistait essentiellement en un projet de tarif minimum à élaborer entre lorganisation patronale (Union syndicale des maîtres imprimeurs de France) et l'organisation ouvrière (Fédération française des travailleurs du Livre). La réalisation de l'idée comportait plusieurs phases :

D'abord une Commission d'étude et d'organisation élue par tous les patrons et tous les ouvriers typographes syndiqués ou non, Français et âgés dle vingt-un ans (2), aurait été chargée d'élaborer le premier tarif : ce tarif, disait le projet, " devant être une loi de salaire à observer par tous les " patrons et par tous les ouvriers adhérents, devra être " égalitaire pour tous les devoirs et les droits des adhé" rents et pour obtenir une introduction rapide dans les " imprimeries typographiques françaises; ce tarif, de prin" cipe et de fait, devra ètre reconmu et accepté dans leurs " statuts par les organisations syndicales, patronale et " ouvrière (3). "Dans le projet, ce tarif comprenait un triple minimum :

Un taux de salaire uniforme à appliquer dans toutes les imprimeries typographiques du territoire français pour le travail en conscience (4);

Le salaire minimum uniforme à appliquer dans les imprimeries typographiques françaises pour le travail aux pièces à la main et à la machine à composer ou à imprimer (5);

(I) Cf., ci-dessus, pp. 21 et suiv.

(2) Pour cette élection, après un referendum préalable approuvant le principe, les organisations patronale et ouvrière auraient dû s'entendre pour diviser le territoire en dix régions typographiques numérotées de I à ro : deux délćgués, l'un patron, l'autre ouvrier, auraient été désignés dans chaque région, avec deux suppléants également l'un patron, l'autre ouvrier; l'Union syndicale des Maîtres Imprimeurs et la Fédlération Franģaise des Travailleurs du Liore assuraient cette élection chacune pour sa part.

(3) Rapport Lefebvre, p. 75 : le tarif minimum devait être en principe uniforme, pour une durée uniforme de temps de travail. On prévoyait cependant des surcharges locales basées sur des statistiques officielles, indiquant le coût de la vie dans chacun des eentres typographiques.

(4) En fait, iei, il y a de grandes différences de salaires variant de 2 fr. 50 à 8 franes, selon les villes et les lieux de travail.

(5) C'est au fond, comme l'avait bien vu M. Lefebvre, une question de concurrence entre patrons qui domine la question. C. Rapport cité p. 8 : "La concurrence, dont les conséquences sont si funestes à" notre profession, ne doit étre imputée qu'aux patrons, car les ouvriers " n'avaient et n'ont encore aucun intérêt à la susciter, à l'encourager, "bien au contraire!") 
Le taux minimum des heures supplémentaires (I).

Une fois le tarif établi, la Commission d'organisation et d'études vovait se terminer 'son mandat, et si elle le jugeait bon, pouvait se constituer définitivement en Commission de tarif pour un temps prévu égal à la durée du tarif. Celle-ci, aidée des offices régionaux et des tribunaux d'arbitrage (2), comme en Allemagne (3), était chargée de l'application dudit tarif.

C'était, en somme, une série d'institutions nouvelles à créer: Commission d'études, Comité du tarif, Offices régionaux, Tribunaux d'arbitrage; pour tout dire d'un mot, c'était l'organisation de la profession tout entière.

Les patrons imprimeurs n'accueillirent que froidement cette réforme (4): sa complication nécessaire peut-être et surtout la différence réelle dans le taux des salaires existants (5) l'empèchèrent d'aboutir.

Ce fut donc pour des raisons diverses un second échec pour la solution patronale.

D'ailleurs, celle-ci ne semble-t-elle pas en principe condamnée, puisqu'elle exige pour réussir une communauté de vues absolue et une entente complète? Comment supposer que pour remédier à des situations dues à la concurrence et dont ils profitent, les employeurs arrivent jamais à s'entendre pour limiter cette concurrence?

Le salaire minimum ne nous paraît pas, en l'état actuel des esprits et des faits, pouvoir s'établir en France par l'action patronale.

(I) Le projet comportait d'ailleurs un contrat collectif d'ensemble réglant aussi la durée du travail, l'apprentissage, le délai-congé, le travail des femmes, etc... (Cf. rapport cité, pp. 76 et 77. )

(2) Leur organisation aurait été élaborée de même par la Commission d'organisation et d'éturles.

(3) On projetait aussi des bureaux officiels de placement pour soutenir l'application du tarif.

(4) M. Lefebvre nous écrivait : “Je suis obligé de reconnaître que les patrons imprimeurs ne sont pas mûrs pour cette réforme, et cependant... la terre tourne. "

(5) C'est ainsi que le mille de lettres est payé dans certaines régions 40 à 45 centimes, ailleurs 15 à 25 centimes, en spéculant sur le travail des enfants el des femmes. Cf. art. de V. Breton, Havre-Éclair, 30 oct. r 909 . 


\section{CHAPITRE III}

\section{Les Projets et les Réformes à l'étranger.}

Le mouvement en faveur du salaire minimum est également très développé à l'étranger : il importe maintenant de l'éludier dans les différents pays, en insistant sur ses principaux aspects originaux dans chaque pays.

\section{I. - Angleterre.}

Le mouvement de réformes en faveur du minimum de salaire se présente en Angleterre sous deux aspects distincts, selon que l'on se place avant la loi du 20 octobre igog sur les Comités de salaires ou que l'on envisage la période postérieure à celte loi.

\section{1) AVANT LA LOI DU 2O OCTOBRE 1907}

L'idée de faire régler les salaires par des Comités est déjà fort ancienne en Angleterre. On la trouve mentionnée dans les "Principes d'économie politique» (I) de J. Stuart Mill, parus en 1848 . Parmi les moyens populaires contre l'abaissement des salaires, Stuart Mill indique que le moyen le plus simple est la fixation légale. "Un autre plan, qui a trouvé des avocats nombreux parmi les meneurs, consisterait à former, par la réunion des délégués des ouvriers et des patrons, des Conseils appelés en Angleterre Bureaux de métier (Trade Boards), Conseils de Prud'hommes en France, ou de tout autre nom, pour discuter à l'amiable le taux des salaires et les promulguer de manière à les rendre 
obligatoires pour les patrons et pour les ouvriers. Dans ce système, on ne se déterminerait point d'après l'état du marché, mais d'après l'équité naturelle, de manière à donner aux ouvriers un salaire raisonnable et aux capitalistes un profit raisonnable (r).

L'idée était donc dans le tréfonds de la conscience populaire anglaise.

Elle est reprise en 1876 par un publiciste australien nommé Syme, dans un ouvrage intitulé : Outlines of an inclustrial Science.

En 1877, un large débat s'engagea entre le futur premier ministre australien, M. Deakin, et sir Charles Dilke, alors président du "local Government Board ", office de l'administration locale, tendant à l'institution de Comités de salaires (2). Plus tard il la formula en une proposition directe, en 1898 , devant le Parlement : il s'agissait de donner au Ministre de l'Intérieur le pouvoir d'instituer des Comités de salaires dans les industries où il l'estimerait utile. La proposition n'aboutit pas et fut depuis lors renouvelée à chaque session parlementaire sans succès.

En mème temps, la question du travail à domicile, depuis longtemps à l'ordre du jour, fut, en ce qui concerne l'opinion publique, par la lenteur mème qu'on mit à la résoudre, un argument décisif en faveur de la réforme. A plusieurs reprises (3), des Comités furent réunis, des rapports furent déposés sans d'ailleurs aboutir pratiquement.

(1) Trad. française, $3^{\mathrm{e}}$ édit, Paris, Guillaumin, I873. Principes d'économie politique, t. I, p. $4 \mathrm{I} 7$.

St. Mill réserve, bien entendu, les difficultés pratiques que provoquerait pareille réglementation : il faudrait, dit-il, y prendre des mesures pour arrêter les progrès de la population, ce qui est impossible. Les salaires sont d'ailleurs, pour lui, fatalement déterminés par la concurrence et ce serait un vain jea d'essayer d'une réglementation légale.

(2) Sir Charles Dilke reprit ee projet en $\mathbf{1 8 8 5}$, lors de li discussion de la loi sur les fabriques et le soumit à un Congrès à Bruxelles en $189 \mathrm{I}$.

Cf. sir Charles Dilke. L'exploitation des travailleurs et le salaire minimum. Documents alu progrès, dée. Igo7, p. 65.

(3) Cf. notamment, en 1890 , une première enquète menée par un Comité de la Chambre des Lords présidé par lord Dunraven et terminée par la publication d'un premier rapport :

Reports of the Seleet Committee of the House of Lords on the Sweating System. I st., report, sess., n $36 \mathrm{r}$, I888; 2 ud., report, sess., 
C'est après i 906 que la question fait de rapides progrès. Une exposition du travail à domicile (Sweating Exhibition), organisée à Londres par le Daily News et imitée de celle de Berlin, frappa vivement l'opinion publique : elle eut pour résultat la constitution d'une Ligue nationale contre le sweating system (National Anti Sweating League) (I), qui prit en main la réforme et décida de la faire aboutir.

Par une série de publications (2) et de meetings, la Ligue s'efforça d'intéresser l'opinion à la question du travail à domicile et de préparer comme remède l'intervention légale. Le plus célèbre de ces meetings est celui qui fut tenu les 24 , 25 et 26 octobre igo6, au Guildhall, à Londres (3). Plus de deux millions de travailleurs étaient représentés : on y remarquait la présence des délégués des unions patronales australiennes et de l'Anti Sweating League de Victoria. Les plus remarquables compétences y prirent la parole, M. Sidney Webb, M. J. A. Hobson, etc., etc... Après une discussion qui dura trois jours, le Congrès aboutit au vote de l'ordre du jour suivant :

"La Conférence se félicite de la formation de la National Anti Sweating League, accueille de tout cœur la politique tendant à assurer par une action législative un minimum de salaire dans les industries sweated et s'engage à soutenir cette politique par tous les moyens en son pouvoir (4). "

$n^{\circ} 448,1888 ; 3$ rd. report, sess., $n^{\circ} 165,1889 ; 4$ th. report, sess., $n^{\circ} 33$ I, 1889 ; 5 th. report, sess., no 169 , I890.

De même, en 1908, un autre Comité parlementaire nommé par la Chambre des Communes, présidé par sir Thomas Whittaker et connu sous le nom de Comité du travial à domicile (Committee on Home Work) aboutit à la publication d'un important rapport. Report on the Home Work.

Ce dernier rapport précipita et détermina l'action parlementaire qui devait cette fois aboutir.

(I) Le siège actuel de la National Anti Sweating League est à Londres, 34, Mecklenburgh Square. Nous saisissons loceasion de remereier ici son distingué secrétaire général, M. Jas. J. Mallon, pour l'amabilité avec laquelle il a bien voulu nous fournir tous les renseignements nécessaires sur l'activité si intéressante de sa Ligue.

(2) Cf. notamment miss Constance Smith. The Case for Wages Board. Londres, I907. - Miss B. L. Hutchins. Home Work and Sweating : The Causes and the Remedies. Londres, Fabian Society, 1907.

(3) National Anti Sweating League. Report of Conference on a minimum wage. Londres, I907.

(4) Rapport eité, pp. 85 et 88. 
C'était le triomphe des Comités de salaires et du minimum légal de salaire devant l'opinion.

A la suite de cette conférence, la proposition Dilke fut complétée par une énumération des professions où devaient être tentées les premières expériences. La proposition fut aussitòt déposée à la Chambre des Communes sous le titre de projet de loi sur les industries atteintes par le sweating (Sweated Industries Bill), par M. A. Henderson, membre du parti du travail.

- Le dépôt de cette proposition de loi, soutenu par le mouvement d'opinion ainsi créé, amena le Secrétaire d'État de l'Intérieur à constituer une Commission parlementaire pour l'étude de la question du travail à domicile (Commission du Home Work) et à charger $\mathrm{M}$. E. Aves d'une enquète sur les Comités de salaires en Australie.

Pendant que la Commission poursuivait ses travaux, une proposition de loi sur les industries victimes du sweating system (I), déposée par M. G. Toulmin, fut adoptée en r 908 par la Chambre des Communes et renvoyée à la Commission d'enquète.

Celle-ci présenta vers la fin de l'année son rapport (2), qui concluait en faveur de la création de Comités de salaires pour certaines industries, mais n'ayant compétence que pour le seul travail à domicile.

Cependant le Gouvernement ne paraissait pas disposé à prendre l'initiative de la réforme.

Une nouvelle démarche de la National Anti Sweating League vint l'y contraindre : la Ligue s'adressa au premier ministre par l'organe d'une délégation composée de membres des deux Chambres du Parlement, ainsi que d'hommes et de femmes occupant un rang dans le monde officiel. M. Asquith promit à la délégation l'examen attentif des mesures à prendre.

On aboutit ainsi, en r 909 (3), au dépôt, par le président du Board of Trade, M. Winston Churchill, d'un projet de loi sur les Conseils d'industrie (Wages' Boards Bill).

(1) 2I février 1908. Parliam. Deb.

(2) Report on Home Work, 1908.

(3) 24 mars rgog, Parliam. Deb., rgor. House of Commons. Vol. II, $n^{\circ} 27$, p. 1787 . 
L'étude approfondie de la discussion parlementaire anglaise est intéressante à suivre à un double point de vue, pour marquer l'abord les progrès réels de l'opinion au cours de cette discussion, pour souligner ensuite le caractère expérimental et pratique de la nouvellé législation anglaise. 11 importe d'en relever les traits les plus saillants.

M. Churchill, en déposant son projet de loi, en soulignait l'essentiel, qui est " l'établissement de Comités de salaires dans certains milieux où prévaut le sweating system, la fixation par ces Comités d'un minimum de salaire et la force exécutoire donnée à ces tarifications de minima de salaires (1) ). Il résumait la portée de la loi, le mécanisme des Comités, leur procédure, et insistait en terminant sur le soutien que l'opinion publique devait apporter à la contrainte légale (2).

En première lecture, un seul orateur, Sir Frederic Banbury, antiinterventionniste convaincu, prit la parole : il insista sur le caractère socialiste du projet, estimant qu'il y avait déjà, en ces matières, beancoup trop d'interventions. 11 prédit que ce projet amènerait la fin de l'industrie anglaise, à cause de la concurrence étrangère. Cette dernière déclaration fut accueillie par des rires.

Sur ces entrefaites, la question revint devant le Parlement le 26 mars i 909 , à propos de la seconde lecture du Sieated Industries Bill (3).

Ce fut l'occasion de discuter toutes les questions de principe : M. Hills, unioniste, insista au début de la discussion sur la différence de son projet avec le projet gouvernemen-

(1) Ibid., Purliam. Deb., Igog. Vol. II, no 27, P. 1787. Le président du Board of Trade indiquait au surplus qu'en dehors de ce rôle essentiel, les Comités de salaires auront d'autres ròles à jouer. Ils seront un. centre d'information (instruction professionnelle, chòmage) et un foyer d'organisation : ils seront appelés à se préoccuper dans la plus large mesure possible des intérêts cles travailleurs, de leur santé et de l'état de l'industrie où ils fonctionnent.

(2) J'indique, dès le début, que l'obligation sera effective dans la mesure où il y aura pour l'appuyer un grand nombre de patrons et d'ouvriers dans les Comités ). Il insistait aussi sur la nécessité d'accor(ler pleins pouvoirs aux autorités chargées de faire appliquer la loi. (Parliam. Deb., ibia.)

(3) Parliam. Deb., igog. H. of C., vol. II, n² 29, 1. 2059 . 
tal (I), estimant que le principe n'était pas en question, mais était d'ores et déjà adopté. Sir Charles Dilike demanda qu'on fit l'expérience de la loi sur un petit nombre de métiers, parmi lesquels l'un d'entre eux serait un métier exercé dans les différentes parties du pays et ayant une large exportation sur les marchés étrangers. Il s'étendit sur le ròle nécessaire de l'Inspection du travail pour la mise en vigueur des tarifs et montra que les deux bills poursuivaient en somme le même objet. M. H. E. Carlisle écarta l'expérience australienne comme précédent impossible à invoquer, vu les conditions par trop différentes des deux pays, et fit entrevoir une hausse des prix funeste aux métiers mêmes que l'on voulait protéger, par suite de la concurrence étrangère. Il se déclara l'adversaire du projet, qualifić par lui de socialiste et contraire à la liberté lu travail. Le vicomte de Castlereagh opina dans le mème sens, critiquant l'intervention de l'État dans la fixation du salaire. M. Arthur Henderson, membre du parti du travail, constata l'unanimité des partis en faveur de la ríforme et montra comment il s'agissait seulement d'introduire dans des métiers inorganisés des Comités de salaires ayant fait leurs preuves dans la plupart des métiers. M. Churchill, président du Board of Trade, indique qu'il s'agit maintenant d'un vote de principe : l'échec de ces propositions créerait un préjugé défavorable contre le projet gouvernemental. Enfin, M. Th. Cochrane souhaita que la question fìt l'objet de conventions internationales ( 2 ). La discussion fut ajournée.

La discussion en seconde lecture d $\boldsymbol{u}$ projet gouvernemental eut lieu le 28 avril igo9 (3). M. H. J. Tennant, secrétaire du Board of Trade, sous-secrétaire d'État, ouvrit le débat en rappelant qu'il y avait exactement dix-neuf ans du dépòt

(I) Cefte proposition différait du projet rouvernemental sur deux points essentiels : les salaires minima devaient ètre fixés immédiatement par les Comités - et non plus après six mois et discussion de la tarification proposée; les Comités de salaires devaient ètre exclusivement des Comités locaux.

(2) Parlèrent encore en faveur du projet: M. John J. Clancy, nationaliste irlandais; M. Bridgemann, M. Chiozza Money, M. Hu gh Low, M. W. R. W. Peal, sir Th. Whittaker, président de la Commission. Contre ledit projet, sir Frederic Banbury.

(3) Parliam. Deb., Igog. H. of C., vol. II, no 45, pp. 340 et suiv. 
du rapport de la Commission présidée par lord Dunraven et que depuis cette époque aucun progrès n'avait été réalisé en ce qui concerne le sweating system. Il insista sur le caractère limité du projet en discussion, rappela le mouvement parallèle qui se poursuit dans les pays étrangers et formula l'espoir d'un accord international sur la question. M. Lyttleton parla en faveur du projet, invoqua Ies précédentes interventions législatives et conclut à l'établissement d'un minimum de salaire dans les métiers réglementés: dùt la nouvelle loi priver certains travailleurs de leur emploi, ce mal nécessaire est encore préférable au maintien des déplorables conditions actuelles de travail.

M. A. W. Black, M. Harry Marks, avec quelques réserves (I), M. William Bull, M. A. Q. Hooper parlèrent en faveur du projet. On constata (2) l'accord de tous les partis sur le projet en discussion (3). Sir Charles Dilke combattit une proposition de M. John Hayden voulant faire voter que la loi ne s'appliquerait pas à l'Irlande, en constatant que le sweating y sévissait comme en Angleterre. M. Churchill, président du Board of Trade, au nom du Gouvernement, se félicita de l'excellent accueil reçu par le projet et insista sur la souplesse du mécanisme : "C'est, dit-il, véritablement un mal national grave qu'une classe des sujets de Sa Majesté reçoive moins que le salaire vital en récompense de leurs plus grands efforts. " La réglementation légale est ici le seul salut (4).

D’autres membres insistèrent pour étendre la portée de la loi : M. Richards, représentant de la cordonnerie de l'East End, souhaiterait que la loi englobât l'industrie de la chaussure, où existe pareillement une grande désorganisation industrielle. M. Mannetti, nationaliste irlandais, voudrait atteindre toutes les industries sweated de l'Irlande.

L’opposition au projet fut représentée par le discours de

(x) M. Marks proposait un amendement ainsi rédigé : "Aucune législation ne sera efficace pour le relèvement des salaires si elle ne vise à empêcher l'importation des marchandises fabriquées à l'étranger par une main-d’euvre à salaire inférieur. ") Cet amendement fut retiré par son auteur au cours de la discussion.

(2) Notamment M. Richardson.

(3) M. Balfour, leader de l'opposition conservatrice, vint appuyer le projet.

(4) Cf. plus loin Conclusion, p. 460, note 1 . 
M. G. P. Gooch, qui reprit l'objection de la concurrence étrangère et de la suppression du travail à domicile, et par celui de Sir F. Banbury contre l'intervention légale et sur l'invasion des produits étrangers qu'amènera l'application du système. M. J. R. Clynes, au nom du Labour party, parla en faveur du projet, qui consacre un principe depuis longtemps appliqué et reconnu par des centaines d'établissements publics en Angleterre.

Le projet fut adopté en seconde lecture et renvoyé à la Commission permanente.

La discussion en troisième lecture et le vote des divers articles eut lieu le i6 juillet igog ( I).

On repoussa diverses propositions : l'une, des membres du parti du travail, MM. Barnes et Keir Hardie, proposant de substituer à la procédure compliquée des ordonnances provisoires pour l'extension de la loi une enquète immédiate sur les nouvelles branches d'industrie à domicile à englober dans l'expérience (2); l'autre, de M. H. H. Marks, aux termes de laquelle devait être prise en considération, pour la fixation des salaires minima, toute protestation fondée sur la concurrence faite par des articles analogues de provenance étrangère (3); on écarta également la proposition de M. G. Gooch voulant englober immédiatement dans le projet l'industrie des chemises et une autre proposition de M. Marks demandant qu'en cas d'initiative du Gouvernement il ne fùt fait état, pour les minima de salaires, que des salaires de l'industrie à domicile (4).

Quelques modifications de détail furent adoptées, notam. ment la proposition de Sir Samuel Evans prescrivant au Board of Trade de décréter la suspension de l'application des salaires fixés au cas de perturbations profondes dans les conditions de l'industrie visée; une autre, du mème auteur, substituant à la publication officielle des salaires

(1) Parliam. Deb., sess. igog. H. of C., vol. VII, no 98, p. 2/4r5.

(2) Proposition repoussée par 77 voix contre 36 . M. J. Tennant, au nom du Gouvernement, montra, en effet, avee chiffres à l'appui, que presque toujours les ordonnances provisoiles avaient été confirmées.

(3) Proposition repoussée, après longue discussion, par 151 voix contre 36 .

(4) Repoussée par 174 voix contre 40. 
fixés la notification aux districts intéressés, en vue d'éviter les doutes.

La loi fut acceptée en troisième lecture dans cette même séance.

La discussion à la Chambre des Lords fut beaucoup plus brève (I) : elle reproduit dans ses grandes lignes les allures et les traits de la discussion aux Communes que nous venons d'analyser longuement. On y retrouve la mème unanimité de tous les partis. L'opposition libérale, représentée par le marquis de Lansdowne, accepta la loi. On y relit des observations analogues sur la place à faire aux travailleurs à domicile dans les Comités de salaires, sur les conséquences possibles de la disparition de certaines branches des métiers réglementés, sur la prudence à apporter à cette expérience législative.

Le texte voté par les deux Chambres fut approuvé par le Roi et devint la loi dı 20 octobre rgog, qui devait entrer en

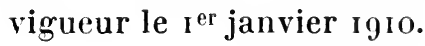

\section{B) DEPUIS LA LOI DU 20 OCTOHRE I 909}

Indépendamment du mouvement pour l'application de la loi de rgog sur les Comités de salaires (2), l’idée de minimum de salaire a fait en Angleterre, pendant ces trois dernières années, de très remarquables progrès.

Il faut insister sur deux des manifestations les plus intéressantes de ce mouvement: la proposition législative d'un minimum hebdomadaire de 30 shillings, faite aux Communes en avril I9I, et la grève des mineurs anglais de mars 1912 .

a) La proposition législative d'un minimum de salaire hebdomadaire de 30 shillings.

Le $43^{\mathrm{e}}$ congrès annuel des Trade-Unions, tenu à Sheffield

(I) $2^{\mathrm{e}}$ lecture, 30 août 1909 . Parliam. Deb., 1909, H. of L., vol. II, n 56, p. 974. - Discussion devant la Chambre entière réunie en Committee, le 13 septembre i909. Ibial., I909, vol. II, n 58, p. 1076. - 3e lecture, 20 septembre rgog. Sans aucune opposition.

Lord Hamilton de Dalzell, l'évêque de Southwart, l'évêque de Birmingham, lord Lytton, lord Amphill, le comte de Crewe, le vicomte de Milner y prirent part et contribuèrent à diverses améliorations de détail.

(2) Gf. ci-dessus, p. I 68. 


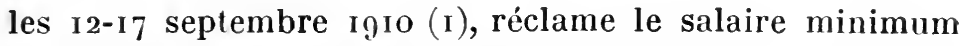
pour les ouvriers au service du Gouvernement : 30 shillings par semaine de 48 heures dans le district de Londres et application des tarifs syndicaux.

Le 26 avril i 9 I I (2), un membre des Communes, M. Crooks, déposa devant cette Assemblée un projet de résolution ainsi libellé :

"La Chambre est d'avis que le droit de chaque famille du pays à un revenu suffisant pour maintenir ses membres en état convenable et suffisant pour vivre (3) doit être reconnu; en conséquence, elle est d'avis qu'un minimum de salaire général de 3o shillings par semaine pour chaque travailleur adulte soit établi par la loi et invite le Gouvernement à donner l'exemple, en adoptant ce taux de salaire dans ses propres ateliers (4). )

L'auteur de la résolution, en un long discours (5), ne se dissimulait nullement la hardiesse de sa proposition, qu'il déclarait sans ambages " la plus importante qui ait jamais été faite à cette Chambre ". Il plaida chaleureusement les raisons d'humanité qui militent en faveur de ce salaire minimum général; il établit que ces 3 o shillings étaient, en raison du prix de la vie, le minimum indispensable.

M. William Thorne seconda la motion : il montra l'insuffisance de l'action professionnelle pour l'obtention de ce minimum vital, à cause de la concurrence qui, sans cesse, déprime les salaires et chercha à établir la nécessité de l'intervention législative. Il affirma que les diverses industries privées, notamment les chemins de fer et les houillères, ainsi que les diverses entreprises municipales, étaient en état de supporter ce minimum hebdomadaire.

M. Steel-Maitland mit la question au point, en insistant facilement sur le caractère utopique de la proposition : sur

(1) Report of Procedings. London, Cooperative Printing society, Ltd., 1910. Bulletin de l'office intern. du trav., I910, p. 556.

(2) Parliam. Deb., 26 avril igI , vol. XXIV, p. 1882.

(3) "In decency and comfort", dit le texte anglais presque intraduisible sur ce point.

(4) La proposition semble émanée du " parti du travail ». Ine résolution du 8 mars igr r votée par 150 membres de ce parti, décida de la porter devant le Parlement.

(5) A la lecture, ce long discours semble empreint de plus de bonhomie et d'humanitarisme que de véritable esprit sciẹtifique. 
le but d'un salaire vital convenable, tout le monde est d'accord (I), mais la voie choisie pour le réaliser est impossible; si le principe ancien déclarant que l'État ne peut et ne doit pas intervenir dans la fixation des salaires a été aujourd'hui abandonné, il n'en subsiste pas moins une série de difficultés pratiques; le seul moyen efficace d'aboutir serait la création d'une cour d'arbitrage : on en connait les inconvénients. De plus, les minima d'existence sont variables selon les régions: un minimum identique ne se conçoit pas à cet égard (2). Par une série de considérations pratiques, l'orateur insiste sur les difficultés bien connues d'un minimum légal directement fixé par le législateur : nécessité d'abaisser ce minimum en cas de baisse du coût de la vie, difficulté de l'appliquer également, à côté des hommes adultes, aux femmes et aux enfants, augmentation fatale corrélative du prix de tous les objets fabriqués et, par là mème insuffisance du minimum au lendemain de sa fixation, mort du travail à domicile; le progrès social ne se fait pas ainsi par des gestes épiques, mais pas à pas, au jour le jour, par une série de réformes mûries et étudiées.

M. Chiozza Money rappelle que la question du minimum de salaire a fait, pendant deux ans, l'objet de débats approfondis devant la Commission de la loi sur les comités de salaire, que celle-ci l'a proposé à la Chambre des communes et l'a fait adopter pour les industries réglementées. ll montre que les industries où l'Angleterre a une suprématie incontestée (constructions mécaniques, construction des navires, etc.), sont précisément celles ou règnent les salaires les plus élevés. Il en accepte le principe, mais condamne le moyen par lequel on veut l'obtenir : les difficultés ci-dessus énoncées ne sont pas insurmontables. La loi de rgog sur les comités de salaires a déjà fait ses preuves. Il est bon que l'attention du public et de la Chambre soit attirée sur cette très importante question: pendant les quinze dernières années, les salaires ont augmenté en moyenne de $13 \%$, tandis que le coût de la. vie

(I) Ce principe est, dit l'orateur, une sorte de nébuleuse : il faut des siècles pour qu'elle se solidifie.

(2) Les minima fixés en Nouvelle-Zélande par la Cour industrielle varient aussi bien que diffèrent ceux obtenus par les Trade-Unions. 
augmentait de $r 9^{\circ}{ }^{\circ}$. En même temps, l'inégalité des revenus a augmenté : la matière imposable de l'income tax, en quinze ans, s'est accrue de $57^{\circ} \%$, soit, en chiffres ronds, de 400.000.000 $£$ par an. Il y a là deux ou trois fois la somme nécessaire pour accorder le minimum hebdomadaire de 30 shillings à tous les travailleurs du pays! L'accroissement des salaires élargirait considérablement les débouchés de l'industrie nationale.

L'oraleur examine ensuite le coût financier de la mesure proposée : elle concerne environ les trois quarts de la population du pays et impliquerait une dépense de 90.00 .000 £ par an. La rémunération de la plus grande partie de la population resterait bien au-dessous de la moitié du revenu total du pays et plus de la moitié de ce revenu viendrait comme rémunération des onze millions de personnes restant. On voit que la proposition en discussion ne peut pas être écartée aussi légèrement. Sans trouver le moyen de l'adopter dans la présente législature, le principe du minimum de salaire aura des extensions successives dans les diverses branches d'industries, après le travail à domicile. La plupart des questions sociales se ramènent à une question de salaires. On a donc bien fait de soulever la question.

M. Moreton Frewen parla encore dans la discussion pour marquer sa sympathie à la proposition, mais pour indiquer, au nom de l'Irlande qu'il représente, combien elle paraît impraticable.

Enfin, M. Tennant, secrétaire pour le Parlement du Board of Trade, au nom du Gouvernement, repoussa la motion, comme on pouvait s'y attendre, tout en regrettant sincèrement de ne pouvoir l'approuver. Le projet est impossible à réaliser : d'après les statistiques, il y a 7.300.000 travailleurs, dont $60 \%$ gagnent moins de 30 shillings comme salaire hebdomadaire; l'accroissement de salaire à réalisel serait, pour donner à tous 30 shillings, de $\mathrm{r} .700 .000$ f par semaine, soit 88.000.000 £ par an. C'est là une charge tout à fait impossible à assumer. De plus, pareille élévation brusque des salaires amènerait un accroissement prodigieux du coût de la vie et une série de ruines industrielles: ce serait ouvrir doublement la porte à la concurrence étran- 
gère. Enfin, pareille mesure aurait pour effet d'arrêter net l'accroissement normal et naturel des salaires pour ceux qui gagnent plus de 30 shillings par semaine. En ce qui concerne les ouvriers de l'État, M. Tennant rappelle les améliorations de ces dernières années (I) et fait un tableau d'ensemble de la politique sociale, relative aux salaires des ministères. 11 conclut en indiquant que ce problème agite aujourd'hui la conscience de tous les gens de bon sens et d'esprit droit.

La résolution ne fut pas mise aux voix et le débat ajourné.

Il était nécessaire de résumer ainsi cette importante discussion : elle montre à merveille les progrès de l'idéal du minimum de salaire dans l'opinion anglaise. Il est certain que la résolution proposée était absolument chimérique et utopique : la discussion qu'elle a provoquée montre toutefois comment la question est aujourd'hui à l'ordre du jour en Angleterre et quels réels progrès le principe même de la réforme a accomplis pendant ces dernières années.

b) La grève anglaise de mars IgI2 (2).

On a vu ci-dessus (3) l'effort des mineurs anglais pour obtenir par voie de contrat collectif le minimum de salaire. On a constaté la proclamation du principe par la loi (4).

Il importe surtout ici de relever les progrès de l'opinion en faveur du minimum de salaire et de montrer comment le fameux bill d'avril ıI I fit faire un pas considérable à la question.

Pendant l'été de igıI, plus de sept cents meetings votèrent des motions en faveur du minimum de salaire (5):

(1) Cf. ci-dessus, p. 266 .

(2) Cf. Labour Gazette, mars I912, p. 82; avril I9I2, p. I26.

Yves Guyot. Le mininum de salaire des mineurs britanniques. Journal des Économistes, 15 avril 1912, p. 3.

Mantoux. La grève des mineurs en Grande-Bretagne. Revue de Paris, 15 avril 1912, p. 745.

(3) Cif. ci-dessus, pp. r 59 et suiv.

(4) C. ci-dessus, p. 326 .

(5) Mantoux. La grève des mineurs en Grande-Bretagne. Revue de Paris, 15 avril 1912 , p. 753 . 
cette revendication devint un des thèmes favoris des orateurs populaires.

Le compte rendu de tous les journaux et de toutes les revues à propos de la grève générale des mineurs multiplièrent les discussions et firent faire d'incontestables progrès à l'idée nouvelle.

La discussion parlementaire du bill consacra l'importance du nouveau principe posé : l'opposition elle-même, pour des raisons de tactique parlementaire, se contenta de proposer l'ajournement de la discussion à six mois ( $\mathrm{I}$ ).

M. Balfour soulignait très exactement " la révolution colossale que le gouvernement entendait opérer en moins d'une semaine parlementaire ") :

“ En votant le bill, vous direz à l'ouvrier : “ Vous travaillerez à tel et tel salaire ou vous ne travaillerez pas du tout." Et vous dites au patron : "Vous donnerez tel salaire ou vous liquiderez vos affaires. "

Semblable raisonnement n'est admissible que contre le sweating system. Or le salaire minimum est concédé aujourd'hui à l'industrie la plus lucrative pour les ouvriers, à celle qui leur demande le moins d'heures de travail. Le principe est donc admis sous une telle forme que logiquement il sera impossible de refuser de le donner par la loi à toutes les industries (2). ")

Sir Edward Grey, au nom du Gouvernement, répondait dans la même séance :

" J'admets que ce projet de loi, qui n'est que provisoire et nullement définitif, n'est qu'un premier essai pour régler toutes les nouvelles questions qu'aura à examiner le Parlement.

Il est bien possible que le Parlement ait à examiner des demandes analogues de la part d'autres industries; mais le cas se serait présenté, que le projet de loi ait été voté ou non, et nous aurions à examiner chacun de ces cas selon ses mérites. La porte qui a été ouverte en instituant le principe du salaire minimum ne peut pas être fermée. C'est un phéno-

(1) Motion de M. Balfour. Séance des Communes du 22 mars Igr2. Temps, 23 mars igr2.

(2) Temps, 23 mars igr 2. 
mène social inévitable. Le Parlement doit envisager froidement la situation et il est parfaitement inutile de chercher à se cacher la tête dans le sable. Si les réclamations qu'on nous soumet sont déraisonnables, nous devons les repousser avec la plus grande énergie : mais ce n'est pas rendre plus facile le règlement des luttes économiques que de refuser de regarder la situation en face sans vouloir rien faire de raisonnable.

Il est absurle de repousser une demande justifiée, sous prétexte qu'elle pourra en amener une autre injustifiée. Nous nous trouverons en bien meilleure posture si tout de suite nous faisons droit aux demandes bien fondées. C'est là résumer d'un mot la différence d'attitude entre le Gouvernement et l'opposition (I). ')

Enfin, les majorités parlementaires en faveur du Coal Mines Bill marquent le progrès des idées anglaises sur notre question :

Le passage à la seconde lecture fut voté aux Communes par 348 voix contre 225 , c'est-à-dire à une majorité de I 23 voix.

Le bill fut adopté en troisième lecture par 213 voix contre 48, soit à une majorité de i65 voix (2).

Plus récemment, à la suite du succès du Coal Mines Bill, l'idée du minimum de salaire semble avoir fait en Angleterre de rapides et réels progrès:

D’une part, dans une brochure (3) de propagande où l'idée syndicaliste et révolutionnaire est nettement visible (4), les auteurs présentent comme demande immédiate un salaire minimum de $8 \mathrm{sh}$. par jour pour tous les travailleurs des mines sans distinction.

D'autre part, cerlains meneurs comme MM. Tom Mann et

(1) Ibid., Temps, 23 mars 1912.

(2) L'opposition n'a pas voté contre la troisième lecture. Les voix contre sont fournies par le parti du travail (Labour party), à cause du rejet de la cédule des salaires portant les minima arrètés par les ouvriers, le 2 février 1912. Cf. ci-(lessus, p. 161.

(3) Miners' Next Step. Londres, 19г2.

(4) On y montre comme objet ultime du mouvement l" "élimination (le l'employeur " par le jeu de la grève irritante (the irritation strike) et enfin la reprise et le fonctionnement des mines dans l'intérêt des travailleurs eux-mènes, "taling over and worling of the mines in the interest of the workers themselves "), sec. XIII et XIV, 1) 26. 
Ben Tillet affirment que les profits de l'industrie sont aujourd'hui suffisants pour payer à tout travailleur un salaire minimum de $2 £$ (5o francs) par semaine, sans tenir compte de sa capacité ni de sa productivité (I).

On peut, sans crainte d'exagération, affirmer que l'Angleterre est aujourd'hui et de beaucoup le pays où l'idée de minimum de salaire a fait devant l'opinion les plus rapides et les plus remarquables progrès.

M. Lloyd Georges a déclaré à la Chambre des Communes, le mardi 23 juillet I912, au nom du Gouvernement, qu'il déposerait sous peu une législation générale sur l'arbitrage obligatoire (2). Le ministre est parfaitement convaincu que le moment est venu de reprendre dans son ensemble le problème du règlement des conflits industriels. C'est là un symptôme de plus de l'opinion aujourd'hui prévalente en Angleterre de l'intervention gouvernementale dans les questions de salaires.

(I) Evelyn Hubbard : The minimum IVage Past and Present. Economic Journal, juin, I912, p. 308.

(2) Daily Chronicle, 24 juillet 1912. 


\section{II. - Allemagne.}

En Allemagne, le mouvement en faveur de l'adoption d'un minimum de salaire date également déjà d'un certain nombre d'années.

Un grand nombre de Congrès professionnels ouvriers ont inscrit cette réforme à l'ordre du jour depuis longtemps déjà : on peut citer, parmi bien d'autres, l'Assemblée générale de l'Union des employés de commerce allemands ( $\mathrm{I}$ ), Munich Igog, le troisième Congrès des mineurs allemands, tenu à Eisenach (2), I6-2 I mai ıgo9; la première Conférence des ouvriers fabricants de faulx d'Allemagne (3), le Congrès des syndicats allemands (Hirsch-Dunker), tenu d̀ Berlin le 6 décembre igro (4), l'Assemblée générale de la Fédération centrale des ouvriers et ouvrières du verre (5) tenue à Ilmeneau du 22 au 27 mai rgi .

Il faut encore mentionner les très louables efforts de Nile Behm (6). Celle-ci, avec l'aide des 15 ou 20 femmes appartenant au groupe féminin de l'association dite KirchlichSozial, essaya, en 1899 , de grouper les ouvriers de la confection à domicile de Berlin : un "syndicat des travailleuses à domicile pour la confection des vètements et du linge " fut fondé en Igoo, qui parvint à réunir 5.9 I 7 (7) membres à la fin de 1908 . Dès l'une des premières réunions du Synlicat, la revendication du salaire minimum figurait au pro-

(I) Verband Deutscher Handlung-gehilfen zu Leipzig. Compte rendu. L'Assemblée demande l'institution d'un minimum de traitement pour les employés de comnierce, honnies et femmes, ayant dépassé l’àge de 18 ans.

(2) Soziale Praxis, XVIII, 9.5.7.

(3) Conferenz der Sensenarbeiter Deutschlands, Francfort, I8-i9 décembre 1909 .

(4) Soziale Praxis, $\mathrm{XX}, 340$.

(5) Korrespondenzblatt der generalkommission der gewerkschaften, Deutschlands. XXI, 36o, cité dans le Bulletin de l'offlce intern. du travail, igi1, p. 324 .

(6) Cif. Mény. Le travail à domicile. Paris, Rivière, 1910, p. 203. M"le Behm. Comment améliorer les conditions actuelles dul travail à alomicile par la réglementation légale et par l'organisation professionnelle. (Ire conférence internationale des Ligues sociales (l'acheteurs.) Genève, xgo8, pl). 392-416.

(7) Sur une dizaine de mille ouvrières environ. Rapport précité, p. 397. 
gramme : "Introduction des contrats de tarifs en vue de régler les tarifs minima pour le travail aux pièces à établir par entente au commencement de chaque saison. " La tentative réussit partiellement à Konisberg pour 160 ouvriers et à Breslau pour 250 ouvriers, où des contrats collectifs furent obtenus, mais le Syndicat ne tarda pas, en présence des difficultés de sa tàche, à faire appel à l'État (I). Ce fut d'ailleurs plutòt un patronage qu'une cuvre le défense professionnelle presque impossible à accomplir.

D'autre part, un certain mouvement d'opinion se dessine à propos de la question du travail à domicile, qui, ici comme ailleurs, aboutit à préconiser conme moyen les Comités de salaires.

Lors du premier congrès pour la réglementation du travail à domicile (7-9 mars 1904) (2), le Comité de la Fédération allemande des sociétés féministes, qui compte environ 80.000 membres, avait transmis au Congrès un projet de loi relatif à la réglementation du travail à domicile. Ce projet, sans parler d'un certain nombre de dispositions secondaires (3), demandait des tarifs obligatoires de salaires minima, établis annuellement, pour la confection et la lingerie; en voici les points principaux :

I $^{0}$ Les tarifs seront fixés par une commission relevant les tribunaux d'industrie (Geuerhegerichte). Elle se composera, pour chaque branche d'industrie, d'un nombre égal de patrons et d'ouvriers et d'un arbitre. Parmi les ouvriers, il doit y avoir des ouvriers d'atelier et à domicile. Les tarifs sont obligatoires pour l'industrie entiire. En cas de litige, le tribunal d'industrie décide.

(ı) Ibid., p. 4r3. "Ce n'est que par l'intervention légale que pourrait ètre écartée cette plaie du travail à domicile. ”

On raconte (art. J. Hébrard. Le travail à bon marché. Joumal, 5 septembre rgo7) que, lors de la visite de l'impératrice Augusta à l'exposition du Heimarbert, Mlle Behm répondit à celle-ci lui denandant comment on pourrait faire cesser cette siluation : Majesté, dites à l'Empereur ce que vous avez vu et priez-le de réglementer, de contròler te travail à domicile et d'introduire l'obligation d'un minimun de salaire. Pour remédier à ces maux, il faut que l'Empereur nous prôte sa main de fer. "Cif. Mény, op. cil., p. 206.

(2) Musée social, Ann., juin rgo4, 1) 287.

(3) Établissement de la liste des travalleur's a domicile, déclaration obligatoire de l’industriel; publicité des prix payés, etc. 
$12^{\circ}$ On fixera un tarif pour le travail à l'heure et le travail aux pièces.

I $3^{\circ}$ Le tarif berlinois servira de base pour l'Allemagne; les communes locales auront le droit de l'augmenter ou de le diminuer.

$14^{\circ}$ L'entrepreneur qui paye des salaires inférieurs au tarif encourt les peines prérues par la loi.

Le Congrès n'accepta pas l'idée des commissions de salaires spéciales (I).

Depuis, les Congrès postérieurs du travail à domicile et notamment le troisième Congrìs du Syndicat des ouvrières à domicile d'Allemagne, tenu à Berlin en avril 1909 (2), acceptèrent l'institution des Comités de salaires.

Le Congrès des travailleurs à domicile tenu à Berlin, le I2 janvier I9I, a voté une résolution qui met très exactement au point l'état actuel de la question (3) :

"Le Congrès des travailleurs à domicile, d'accord avec les résultats des enquètes scientifiques sur l'état du travail à do ricile et s'inspirant des expériences internationales qu'ont permis de faire les tentalives de réformes pratiques, déclare : dans le travail à domicile, la protection légale du travailleur doit consister, en première ligne, dans l'amélioration des salaires souvent dérisoires qui obligent les ouvriers à faire des heures supplémentaires el à s'astreindre à un régime préjudiciable à leur santé. Toutes les mesures inspirées des lois sur les fabriques, quelle que soit leur utilité pour la collectivité, retombent sur les travailleurs à domicile et les rendent personnellement responsables des conséquences des bas salaires. Or la condition primordiale de cette responsabilité, c'est une amélioration des salaires qui permette aux travailleurs à domicile de supporter les exigences de la loi. ")

Le Congrès concluait en conséquence à " la substitution de la forme de l'État à la forme ici insuffisante des organisations ouvrières »).

(i) Réforme sociale, ${ }^{\text {er }}$ déc. 1904, P. 823 .

(2) Cf. Leroy. La question du minimum de salaire dans l'industrie à domicile en Allemagne. Revue d'économie politique, igog, p. 807.

(3) Bulletin de loffce intern. du travail, igr, p. 320. 
Aussi la question est-elle bien vite entrée, comme ailleurs, dans sa phase parlementaire.

Un premier projet, déposé par les députés du centre, fut renvoyé à la Commission de législation industrielle du Reichstag, qui l'adopta, le ro mai igoj, comme complément éventuel du Code de l'industrie ( I).

I 39 y). - Le Chancelier de l'Empire, les Administrations centrales des provinces ou l'Administration supérieure peuvent créer, pour des branches d'industrie où un grand nombre d'ouvriers à domicile sont employés à des salaires inférieurs à ceux des autres ouvriers de ces industries, des bureaux de salaire (Lohnämter) composés par moitié de représentants des ouvriers et des patrons et dont le président sera désigné par l'Administration compétente.

Les règlements nécessaires à l'application de cette disposition pourront ètre pris par les mèmes autorités. Les Conseils de prud'hommes et les Chambres de commerce pourront être chargés des fonctions dévolues aux Bureaux de salaires. Ces Bureaux de salaires auront à établir, autant que possible pour les ouvriers travaillant à domicile, dans des ateliers ou dans des fabriques, de la branche d'industrie considérée, des minima de salaires au temps et aux pièces, sur la base des salaires moyens locaux et professionnels. Ces minima seront obligatoires pendant une durée déterminée, après homologation de l'autorité compétente. Toute convention contraire au prijudice des travailleurs ì domicile est nulle.

Art. 139 z). - Le Chancelier de l'Empire, les Administrations centrales des provinces ou l'Aıministration supérieure peuvent, sur la proposition d'un Conseil de prucl'hommes, d'une Chambre de commerce ou des organisations intéressées, ouvrières et patronales, décider que et dans quelle mesure les conventions collectives conclues entre ouvriers ̀̀ domicile et leurs patrons, ou entre organisations professionnelles correspondantes, ou provoquées par un arbitrage, s'appliqueront également de droit aux travailleurs à domicile de la même industrie restés en dehors de la convention ainsi qu'à leurs patrons.

(I) Cf. Soziale Praxis, 20 mai rgog. Lohnämter in der Hausindustrie Deutschlands. 
Il y avait eu deux autres projets, tous deux repoussés par la Commission.

Le premier émanait des nationaux-libéraux. Il subordonnait la création des Bureaux de salaires à deux conditions :

a) Constatation par les inspecteurs du travail que le taux des salaires des ouvriers à domicile d'une industrie est inférieur à celui des autres ouvriers de la même industrie;

b) Proposition de créer des Bureaux de salaires, faite par les travailleurs ou leurs organisations avec l'assentiment de la moitié au moins des patrons.

Le second émanait des socialistes : les fonctions des Bureaux de salaires étaient attribućes aux Conseils de prudhommes et, là où ils n'existent pas, à des Commissions mixtes présidées par un représentant de l'Inspection du travail. Ces organes, sur la proposition des travailleurs à domicile, auraient dù, dans tous les cas, fixer des minima de salaires pour une période déterminée, sans pouvoir descendre au-dessous du salaire des ouvriers de fabrique de la mème branche d'industrie.

La bonne volonté du Reichstag se heurta à la résistance du Gouvernement.

Déjà, au cours de la discussion, le représentant du Gouvernement avait manifesté des craintes contre l'intervention de l'État dans la fixation des salaires.

En mème temps, une délégation du " Comité permanent pour la défense "les intérèts des ouvrier's" se rendit auprès des pouvoirs publics.

Le conseiller supérieur du Gouvernement Koch la reçut en juin rgog: il montra les difficultés de l'établissement de minima, le manque de précision du projet de la Commission, la vexation en cas de pénalités (I).

En séance de commission, le 2 juillet igo9 (2), le Secrétaire d'État à l'Intérieur se prononça contre les Bureaux de salaires pour les deux raisons suivantes :

a) Raison pratique : difficulté d'organisation impossible à surmonter et intérêt de l'industrie nationale, qui eût été

(I) Soziale Praxis, 24 juin 1909 .

(2) Soziale Praxis, 8 juillet 1909 : Keine Lohnämter in der Hausindustrie Deutchslands. 
mise en infériorité vis-à-vis de l'étranger par mauvaises évaluations du taux des salaires;

b) Raison de principe : il faut éviter l'intervention de l'État dans la fixation des salaires. C'est le principe traditionnel : y renoncer serait entrer dans la voie socialiste.

On renonça provisoirement au projet et la Commission du Reichstag n'acheva pas la discussion avant la fin de la session.

Lors de la nouvelle session, on a repris la question en tenant compte des discussions et observations précédentes.

Le nouveau projet allemand sur le travail à domicile (I) ne parle plus des Comités de salaires : il se contente d'édicter (\$3) la publicité des salaires pour les ouvriers à domicile.

Ce projet fut discuté en première lecture le $I 6$ février I9 Io (2) et renvoyé à une commission spéciale.

Le projet paraissant insuffisant, le mouvement et la campagne d'opinion en faveur de la réforme ont continué. Un nouveau congrès du travail à domicile s'est tenu à Berlin le I 2 janvier I9I ( 3 ) : un discours étendu du professeur Wilbrandt demanda le salaire minimum. Le Congrès adopta un ordre du jour exprimant le vou suivant : "Il est à souhaiter que dans les industries à domicile où la misère est la plus grande, il soit créé, soit par le Bundesrath, soit par les autorités provinciales centrales, des organes ayant pour mission de fixer les tarifs de salaires : ces comités seraient composés de représentants des patrons et des ouvriers et présidés par une personne neutre. "

La question est revenue en discussion devant le Reichstag en décembre igı I : au sein de la Commission, la plupart des articles du projet du Gouvernement avaient été amen-

(r) Déposé au Reichstag le I I février ı9ı, n 237 .

Cf. Bulletin analytique des principaux documents parlementaires étrangers, ig10, p. 7, $\mathrm{n}^{\circ} 28$.

(2) Sten. Prot., I311, D.

(3) Prof. Dr Franke. Deutseher Heimarheitertag. Le Ciongrès allemand des travailleurs à domicile. Soziale P'r(axis, I er et iz janv. Igr I (PI). 449 à 454) et ig janv. 19 I I (pp. 484 ì 486 ). 
dés et complétés ; tous les partis, d'ailleurs, avaient prèté leur concours à ces modifications.

Le Gouvernement, cependant, s'est montré irréductible sur le principe du minimum de salaire légàl : il n’a, en commission et en séance du Reichstag, voulu accepter sur ce point aucun compromis; il estime qu'il n'appartient pas à l'État de fixer les salaires, que ceux-ci doivent rester l'objet de conventions libres entre les patrons et les ouvriers.

Devant cette attitude formelle du Gouvernement, l'attitude des partis fut diverse (I) : les socialistes refusèrent de participer à l'élaboration de la loi. Le parti du centre, au contraire, essaya de sauver, par un opportunisme diversement appréciable, ce que l'ón pouvait sauver.

A défaut des Comités de salaires (Lohnämter) refusés par le Gouvernement, le centre a proposé des Commissions professionnelles (Fachausschüsse). Celles-ci, sortes de Chambres de travail, favoriseront et proposeront des salaires convenables, mais leurs déterminations n'auront aucune valeur légale et juridique.

Le projet ainsi proposé par le centre a été voté par le Reichstag en troisième lecture en décembre I9 I.

Ce projet est levenu la loi du 20 décembre r 9 Ir (2) : les Comités de salaires (Fachausschüsse) peuvent être créés par le Conseil fédéral d'Empire dans certains métiers et certaines industries; ils ont un ròle purement consultatif; ils doivent favoriser la conclusion de contrats collectifs (art. I9).

On espère que ce n'est là qu'un premier essai de réglementation et que, dans un avenir prochain, le rôle des Comités de salaires pour fixer des minima de salaires sera légalement consacré.

(1) Le Congrès allemand des travailleurs à domicile, Berlin, $\mathbf{1} 9 \mathrm{I}$, insistait pour l'adoption intégrale du projet primitif.

(2) Le texte en a été publié dans la Dentscher Reichsanzeiger du 3o décem. г9п. Cf. Labour Gazette, 1911, janv., p. 7, Bulletin de l'offace intern. du travail, I9I2, P. 7 . 


\section{III. - Belgique.}

En Belgique, malgré quelques manifestations assez anciennes en faveur de la réforme qu'il est superflu d'étudier, la question du minimum de salaire fut mise à l'ordre du jour par le vote de la loi anglaise sur les Comités de salaires.

Dès la fin de r 909 (I), lors du douzième Congrès syndical belge (2), tenu à la Maison du Peuple, à Bruxelles, un ordre du jour très catégorique fut adopté en faveur du minimum de salaire; en voici le texte :

Considérant que le travail à domicile échappe à tout contrôle et favorise, par conséquent, l'exploitation des travailleurs;

Considérant que les enquêtes officielles ont révélé des situations abominables auxquelles il importe de mettre fin ;

Considérant que le travail à domicile se caractérise par trois tares : les salaires de famine et l'utilisation abusive de la femme et de l'enfant ;

Considérant que, à défaut de réglementation du travail domiciliaire, la loi favorise cette forme arriérée du travail, alors qu'elle devrait favoriser le travail en fabrique, forme moderne de la production,

Le Congrès décide :

D'exiger de la législature le dépôt et le vote d'un projet de loi stipulant :

$I^{0}(3)$.

$2^{\circ}(4)$

$3^{\circ}$ Que des Comités composés mi-partie d'ouvriers et mi-partie de patrons choisis par les intéressés seront chargés, d'accord avec les associations ouvrières, de déterminer, pour chaque profession à domicile, un minimum de salaire.

Le Congrès, en même temps, chargeait formellement les députés de déposer au cours de la présente session un projet de loi en ce sens.

(1) Les 25 et 26 décembre I9og.

(2) C'est le Congrès des syndicats indépendants ou socialistes. Cf. Le Mouvement social, sept. igr I, p. 799 .

(3) Que les patrons faisant exécuter du travail à domicile et les ouvricrs travaillant à domicile sont tenus de denuander une autorisation à l'Administration communale.

(4) Que les places servant à l'industrie à domicile auront un cube d'air déterminé par la loi et seront soumises à l'inspeeteur du travail. 
L'année suivante, en iq1o, le premier Congrès international du travail à domicile (I), tenu à Bruxelles, donnait un nouvel élan à l'opinion en faveur de la réforme à réaliser par le moyen des Comités de salaires.

De mème, en lécembre igro, le Congrès des Syndicats belges (2) votait aussi une résolution en faveur de la fixation légale re salaires minima.

C'est ainsi qu'actuellement deux projets sont pendants devant le Parlement belge (3) :

L'un est un projet catholique;

L'autre est le projet Huysmans, léposé au nom de la gauche avancée.

Le projet catholique est directement inspiré par la proposition de M. de Mun en France, avec, toutefois, quelques variantes :

Les Comités de salaires, qui, l'après le projet, pourraient ètre créés par le Ministre le l'Inclustrie et du Travail, ne sont pas des organismes spéciaux et nouveaux, mais bien des sections des Conseils mixtes de l'industrie et du travail qui existent, comme on le sait, chez nos voisins depuis I 887 : ces sections sont ériquées en Comités professionnels.

Ces Comités peuvent ètre saisis de demande d'établissement de salaire minimum soit par un de leurs membres, soit par l'inspecteur du travail, soit par toute personne ou tout syndicat intéressé dans la profession.

La base choisie pour déterminer le salaire minimum est le travail à l'heure, avec lequel le travail aux pièces doit être mis en concordance.

Une Commission d'appel en matière de salaire est prévue par le projet : elle est instituée par le Ministre lu Travail et composée de trois membres : un patrou, un ouvrier, un économiste.

Tout industriel ou commerçant faisant travailler à domicile devra tenir à jour un registre où seront consignés le

(I) Voir ci-dessous, p. 445

(2) Korrespondenzblatt der Generalkommission der Gewerkschaften Deutschlands. XXI, p. 147 , rapporté Bulletin intern. de l'Office du travail, ig1 I, p. 322 .

(3) Mouvement social, sept. 1911, p. 807, de Boissière : Le Travail à domicile en Belgique. 
nom et la demeure de ses ouvriers, la nature de leur travail, le taux de leurs salaires. L'employeur remettra en même temps aux travailleurs à domicile un carnet indlividuel où ces indications seront reproduites.

Des pénalités sérieuses (I) sont prévues pour les employeurs qui contreviendraient aux prescriptions de la loi et aux décisions des Comités de salaires.

Telles sont les grandes lignes de ce qu'on peut qualifier un avant-projet.

A la Société d'économie sociale, cet avant-projet subit divers amendements; notamment, on $\mathrm{y}$ introduisit la nécessité de constituer une Fédération des Comités de salaires.

Le projet Huysmans s'inspire de tout autres idées : les Comités de salaires prévus sont constitués indépendamment des Comités de l'industrie et du travail (2). De plus, le travail à domicile est entièrement supprimé dans les trois groupes d'industries suivants : alimentation, préparation de peaux pour la chapellerie, tissage et filature du jute. Enfin, la base de dílimitation du salaire minimum pour l'ouvrier à domicile de capacité moyenne est expressément indiquée : le salaire de ce dernier ne pourra jamais être inférieur au salaire de l'ouvrier le plus qualifié, de l'ouvrier de même profession et capacité travaillant dans les usines de la même circonscription (3).

Aucun de ces deux projets n'est encore venu en discussion devant la Chambre (4).

(r) Par contre, aucune pénalité ni responsabilité ne sont prévucs dans le projet, en cas d'infraction à la loi, contre les simples commerçants qui se contentent de mettre en vente les produits de la fabrication à domicile.

(2) On préconise aussi l'adoption d'un label pour les objets fabriqués à domicile.

(3) C'est ainsi que le salaire de l'ouvrier d'usine donne le niveau du salaire de l'ouvrier à Amicile.

(4) Cf. P. Verhœgen. Travail à domicile et sweating system, Bruxelles, A. Dewit, 1912 . 


\section{IV. - États-Unis.}

Le mouvement de réforme aux États-Unis (I) est tout récent. Ici comme ailleurs, l'idée des Comités de salaire et du minimum légal de salaire apparait comme le remède nécessaire aux maux du sweating system et n'entre en jeu qu'après l'échec successif de tous les autres remèdes proposés. Il est en grande partie dù jusqu'à présent aux efforts de la Ligue sociale d'acheteurs américaine (2).

Son effort est pour l'instant double :

D'une part, le Comité spécial étudie un avant-projet général basé sur la législation anglaise; l'élaboration de ce. projet est actuellement encore trop peu avancée pour qu'il soit utile d'y insister.

D'autre part, l'action a été entaméc dans divers États, particulièrement au Minnesota, dans le Wisconsin, au Massachusetts, dans l'État de Milwaokee.

Au Minnesota (3) le projet se rapproche beaucoup des types léjà éturliés basés sur l'exemple australasien et l'exemple anglais : il comporte un double organe de jury l'arbitrage et cle Comités de salaires (4) appelés à fixer le minimum de salaire.

Au Massachusetts, une Commission spéciale a été nommée; on en espère des résultats favorables.

La proposition présentée au Wisconsin (5) est plus originale et mérite une analyse plus létaillée.

(1) Holcombe. Qunterly Revielu', décembre rgrr. National Consumers' League. Twelfh Report i1910-rgril, 1. 5r. Report on the special Committee on Minimum Wage Boards, par M. Arthur N. Holcombe.

(2) Un Comité spécial a été constitué au sein de cette Ligue pour faire aboutir la question.

(3) Cf. Monvement social, avril 1911, 1). 373.

(4) Les Comités de salaire seraient institués par le Conseil d'État dans les industries employant des femmes ou des mineurs, soit sur sa propre initiative, soit à la requête de vingt-cinq personnes intéressées : il y a ici, en application du principe anglais pour la composition des Comités, dix repuésentants des patrons, dix délégués des ouvriers, dix membres officiels nommés par le Conseil d'État. Le projet prévoit enfin une dépense annuelle de 2.000 dollars pour le fonctionnement de la loi.

(5) Le texte en a été intégralement publié dans le rapport préeité de la L. S. A. antéricaine, I911, P. 5 r. 
Après une définition des termes (I) employés dans la loi, selon la mode de légiférer anglaise et américaine, le projet du Wisconsin pose (arrt. 2) l'obligation pour tout employeur, au nom de l'intérêt public, de payer au moins un salaire vital. Celui-ci (art. 3) est léterminé par l'Inspecteur du travail (commissioner of labor) qui a tous pouvoirs pour en vérifier et en assurer le paiement réel : un système de licenses assure le mécanisme nécessaire à l'application de la loi. Les sanctions sont loubles : pénale, accusation de misdemeanor et amende de ro à 50 dollars, ainsi qu'emprisonnement de dix jours à trois mois; et civile, action de l'employé en répétition du moins-payé, sans préjudice de dommages-intérèts. Ce qui caractérise en somme ce projet c'est, d'une part, l'intervention de l'Inspecteur du travail pour déterminer le minimum de salaire et, d'autre part, l'énergie de ses sanctions (2).

En dehors de ces projets législatifs, le mouvement en faveur de la réforme se poursuit surtout en ce moment comme campagne d'opinion (3); il y a une série d'efforts pour vulgariser et répanılre l'ilée des Comités de salaires; la presse quotidienne et périodique apporte sans cesse au public américain la lémonstration de la nécessité de ce remède.

(1) A relever notamment la définition du salaire vital : "La rémunération pour le travail accompli dans des conditions raisonnables qui mettra les employés à même de se procurer, pour eux-mêmes et pour ceux qui sont ou pourront être raisonnablement sous leur dépendance, le confort de vie nécessaire. "

(2) Le Mouvement social (mai r9II) signalait toujour's pour l'État du Wisconsin un projet élaboré par le sénateur Kleczka qui proposerait " d'instituer une Commission investie du pouvoir de traiter le tarif des salaires des emplois mal rémunćrés à la manière d'une Commission des services publies, chargée de (Iresser le taux des contributions ) (?)

(3) Le troisième Congrès bisannuel de la Women's Trade-Union League, tenu à Boston, le 12 juillet $191 \mathrm{I}$, vient, dans son assenıblée générale, de décréter l'urgence et l'opportunité d'élaborer un projet de loi portant établissement d'un minimum de salaire dans les sweated industries. Par les soins des Comités législatifs de la Lique, ee texte sera soumis aux décisions parlementaires des États les plus avancés de la Fédération : la Cialifornie, l'Orégon ou le Wisconsin. (Mouvement social, 1912, 1) 46.) 


\section{V. - Autres pays.}

Le mouvement en faveur du minimum légal de salaire est général; en dehors des pays précédemment étudiés, la même idée s'est encore manifestée dans quelques autres pays qu'il importe de mentionner encore:

Autriche. - Après des enquètes sur la question menées par le Conseil du travail autrichien, le Gouvernement proposa, en ${ }_{1907}$, un premier projet élaboré par le $D^{\mathrm{r}}$ Hamisch et le léputé socialiste Smitka. Ce projet fut renvoyé à un Conseil consultatif qui en approura les grandes lignes; ce fut la Chambre de commerce et de l'industrie de Vienne qui réclama l'érection des Chambres de commerce et d'industrie en Bureaux de salaires (I).

A la suite des propositions gouvernementales, de nombreuses discussions eurent lieu; le Gouvernement les utilisa dans la rédlaction d'un nouveau projet en r9r r (2), soumis de nouveau aux Chambres le commerce et aux diverses organisations intéressées pour obtenir leur avis (3).

Ce projet, qui ne comporte pas moins de quarante-huit articles (4), ne concerne que la confection, la corlonnerie et la lingerie (5).

L’organisme prévu pour la fixation du minimum de

(1) $\mathrm{D}^{\mathrm{r}}$ von Bittmann. Zur gesetzlichen Lolınregelung in der Hausindustrie. Soziale Proxis, 20 mai rgog. Le deuxième Congrès international des classes moyemnes, tenu à Vienne en rgo8, demanda également l'institution de Conilés de salaires.

(2) Texte donné par la Sozinle Rundsrleau, organe de l'Arbeitsta(istisches Amt (Office statistique du travail), mars I9II.

(3) Die Gesetzliche Regelung der Heimarbeit in Osterreich. (Soziale Praxis, 2 mars $191 \mathrm{I}$, p. 673 .)

(4) Nous ne visons au texte que les dispositions relatives au salaire minimum légal (art. II à 25) : le projet comporte tout un ensemble de dispositions réglementant le travail à domicile dans beaucoup de détails (déclaration des entrepreneurs : publicité des conditions de travail ; âge des travailleurs; arbitrage et conciliation, ete.; sur tous ces points, cf. Bo yaval. La Lutte contre te sweating system. Thèse, Nancy, igr i, pp. 522 et suiv.)

(5) « Nous avons pensé, disait le directeur de l'Arbeitstatisticher Amt de Vienne, qu'il était préférable d'établir une réglementation légale sur les terrains où celle-ci a été spécialement réclamée et là où les conditions économiques de la profession sont le mieux connues. » Boyaval, op. cit., p. 525 . 
salaire est celui des Commissions du travail à domicile; leur création est décidée facultativement par le Conseil provincial politique, autorité politique régionale.

La Commission du travail à domicile est nommée pour cinq ans. Elle est composée de six catégories le personnes (art. 13 du projet) :

I ${ }^{0}$ Les représentants des entrepreneurs propriétaires de leurs fabriques;

$2^{0}$ Les représentants des èntrepreneurs faisant le commerce;

$3^{\circ}$ Les représentants des entrepreneurs qui ont une exploitation ne répondant pas aux qualités du groupe $\mathrm{I}^{0}$;

$4^{\circ}$ Les représentants les patrons;

$5^{0}$ Les représentants des auxiliaires;

$6^{\circ}$ Les représentants des ouvriers à lomicile.

Comme en Angleterre, une assez grande latitude est laissée pour la composition de ces Commissions. La loi indique seulement (art. i5) que le nombre des membres le chacun des groupes est de trois à six (I) et est arrèté par le Conseil provincial.

L'article I4 du projet impose l'observer les prescriptions suivantes :

$I^{0}$ Les représentants du groupe I sont désignés par la Chambre de commerce et le Conseil des prud'hommes compétents, après accord des entrepreneurs appartenant au Conseil provincial politique;

$2^{\circ}$ La désignation des représentants des groupes 2 et 3 et des patrons pour l'administration des syndicats et intéressés se fait de mème;

$3^{\circ}$ Les représentants des groupes 5 et 6 sont désignés par les associations et syndicats intéressés, après entente des ouvriers appartenant au Conseil provincial. De plus, il faudra prendre en considération une représentation convenable des ouvriers ne faisant pas partie des syndicats.

Le président de la Commission du travail à domicile est désigné par le Conseil provincial politique (2).

(1) Avec des remplaçants devant supplier les titulaires au cas d'empèchement.

(2) La compétence de la Commission du travail a domicile est en principe territoriale et bornée au district ou chle opre. Elle se divise en six sections, formées par les six groupes inumérés au lexte. 
Le ròle de ces Commissions (art. 22) est, " en ce qui concerne les catégories de produits désignnés, de fixer obligatoirement des salaires minima pour les patrons auxiliaires et ouvriers, des prix minima pour les marchandises à livrer par les patrons à ceux qui les leur commandent. "

Le système d'élaboration de ces minima rappelle le système des Comités de salaires anglais. "Ces décisions ne peuvent ètre établies qu'en vertu d'arrètés unanimes pris par les sections de la Commission du travail à domicile" (art. 23); la décision d'une section ne vaudra que si au moins les trois quarts des membres de la section ou des remplaçants s'y sont ralliés. Ces tarifications doivent être approuvées par le Conseil provincial politique : elles sont ensuite proclamées et publićes par cet organe et entrent en vigueur un mois après.

Les sanctions de ces minima obligatoires sont tirées du Code commercial, c'est-à-dire des dispositions de droit commun.

Enfin, c'est un dernier tract de cette législation : elle ne s'applique qu'ì défaut de contrats collectifs dus spontanément à la collaboration des intéressés eux-mêmes (art. 42 et 43 du projet).

Tel est, lans ses grandes lignes, le projet autrichien : il est pour nous une nouvelle preuve du caractère supplétoire de cette législation du minimum légal de salaire : elle n'intervient que pour pallier au défaut d'organisation industrielle.

Hollande (1). - En Hollande, le mouvement est également commencé : la Ligue hollandaise des tailleurs et couturières (Hollandsche Kleemaliers en Naaisters Bond) a déjà fait les plus sérieux efforts pour obtenir une protection plus efficace des travailleurs à domicile. Depuis i 905 , elle a invité les organisations patronales à discuter le problème du travail à domicile. Plusieurs réunions mixtes ont été tenues (2) : l'une des dernières, en date du r3 sep-

(r) Congrès international des travailleurs à domicile, Bruxelles, I 9 Ir. Compte rendu, p. 45. Exposé de M. Kupers, délégué des syndicats hollandais.

(2) Cf. Congrès des tailleurs et coupeurs hollandais, Amsterdam, r3 décenbre 1909 . Vœu en faveur d'une commission pour la fixation du taux de salaires. 
tembre igro, a abouti à l'accord des patrons et des ouvriers pour réclamer l'intervention légale. On a alors nommé un comité chargé de remettre au Gouvernement une adresse l'invitant énergiquement à déposer un projet de loi réglementant le travail à domicile.

En Espagne, le mouvement est encore moins avancé. Le Conseil international de la Fédération des Ligues catholiques féminines, en une réunion tenue à Madrid les 2/4, 25 et 26 juin I9 I, a voté diverses résolutions demandant la réglementation du salaire féminin dans le travail à domicile et ajouté celte proposition :

"Voulant conserver entière la liberté de l'ouvrière, le Conseil déclare que ladite réglementation se bornera à fixer le salaire minimum et demande aux syndicats ouvriers de vouloir bien étudier la question et présenter les solutions les plus convenables. "

En Italie, la question est également à l'ordre du jour.

Dès r9o8, M. Ed. Guglielmetti, docteur en médecine à Rome, dans un rapport présenté au Congrès des Ligues sociales d'acheteurs, à Genève, où il étudiait la situation des travailleurs en chambre à Rome (I), concluait, après un examen approfondi de la situation :

"Comment remédier à ces maux? De deux manières : par l'intervention de l'État et par l'initiative privée (2). ")

Et parmi les mesures réclamées dans la première direction, il mentionnait comme moyen important :

"Minimum de salaire fixé par une commission spéciale nommée à cet effet par l'autorité compétente ou par des comités mixtes de marchands et d'ouvrières (3). »

Le minimum de salaire apparaissait ainsi au premier plan des réformes à obtenir.

Depuis, le mouvement s'est poursuivi :

D’un côté, le premier Congrès national des employés subalternes de l'État (Primo Congresso nazionale degli impiegati subalterni dello Stato), tenu à Florence du 8 au 10 janvier 1910 , a demandé un traitement minimum de

(1) I $^{\text {re }}$ conférence internationale des Ligues sociales dialncteurs, Genève, rgo8. Compte rendu, Fribourer, rgog, 11). 46.3-485.

(2) Rapport cite, 1). 474.

(3) Ibial., P. 476. 
I.200 francs par an. De l'autre, l'idée des Comités de salaires est également lancée (I).

Suisse. - En Suisse également, le mouvement de réforme en faveur d'un minimum de salaire commence à se dessiner : on peut signaler à cet égard le premier Congrès général suisse pour la protection des ouvriers à domicile, tenu à Zurich, qui, arec un éclectisme louable, a signalé, à côté des mesures self help à prendre par la classe ouvrière ellemème, un certain nombre de mesures légales à edicter par la Confédération ou par les cantons. Parmi ces mesures figure en première ligne “ l'institution d'offices de conciliation, chargés de fixer les minima de salaire juridiquement obligatoires (2). ") Des expositions du travail à domicile (3), les efforts de la Ligue sociale d'acheteurs suisse ont saisi le grand public de la question et le mal du sweating system est aujourd'hui nettement dévoilé (4). Il faut ajouter enfin que du còté ouvrier la réclamation d'un salaire minimum est également formulée dans l'industrie en général (5).

République Argentine. - Il n'est pas enfin jusqu'aux pays neufs, comme la République Argentine, qui n'ait eu à se préocccuper du problème - ce qui prouve que le sweating system entraine partout les mèmes maux.

Une proposition de Code puur la République Argentine (art. 31), déposée par M. Gonzalez, spécifiait assez heureusement les principes qui doivent dominer la fixation des minima de salaire (6) :

" Chaque fois que, dans des accords entre patrons et ouvriers, ou dans des tribunaux de conciliation et des cours d'arbitrage, il y aura lieu de procéder à la fixation

(i) Compte rendu de l'enquète de la Societi Lmanitaria, sur le travail à domicile à Milan, à l'assemblée générale de l'Assoeiation internationale pour la protection légale des travailleurs. Lugano, 1910.

(2) Résolution finale du premier congrès général suisse pour la protection des ouvriers à domicile (7 et 8 aoùt 19og). Bulletin de la Ligue sociale a'acheteurs, 1909 , $4^{\mathrm{C}}$ trim., p. 219.

(3) Zurich, en juillet 1909 ; Bàle, septembre 1909 .

(4) Les industries à domicile en Suisse, publication du Bureau de statistique du département fédéral de l'intérieur. Berne, rgog.

(5) Cf. conférence internationale des brodeurs, Saint-Gall, i9 et 20 novembre rg10. On y a formellement réclamé l'institution de tarifs de salaires minima.

(6) Cité par G. Renard. Le minimum légal de salaire. Idées modernes, 1905 , p. 248 . 
d'un type minimum, moyen ou générique, de salaire, on derra tenir compte des considérations suivantes :

$\mathrm{I}^{0}$ Suffisance de salaire pour assurer la subsistance de l'ouvrier et celle de sa famille;

$2^{0}$ Valeur du travail fourni par un ouvrier de force et d'aptitudes moyennes, à moins qu'il ne soit question d'aptitudes techniques spéciales et que le contrat ne se base sur cette spécialité;

$3^{0}$ Les coutumes locales et les prix des vivres et des matières de première nécessité dans la région ou la localité où doit fonctionner l'industrie;

$4^{\circ}$ Les conditions dans lesquelles l'ouvrier a été admis dans l'établissement et toutes les prescriptions en sa faveur fixées par le contrat;

$5^{\circ}$ La nature du travail.

Dans les contrats de l'État ou de ses dépendances, l'Administration respective fixera toujours et rendra public un type minimum de salaire d'accord avec les présentes bases. 0

Ainsi dans presque tous les pays se développe, avec des chances de réussite plus ou moins prochaines, avec un inégal succès auprès de l'opinion publique, un mouvement très net en faveur de notre réforme, le minimum de salaire. 


\section{. VI. - Le mouvement international.}

Enfin notre étude serait incomplète si nous ne signalions en terminant ce qu'on peut appeler le mouvement international en faveur de la réforme.

Ce n'est guère qu'au vingtième siècle, depuis rgoo, que le mouvement s'est précisé. Il serait intéressant cependant d'en rechercher les toutes premières origines.

Il faut, à cet égard, signaler le Congrès international pour la protection légale des travailleurs, tenu à Zurich en 1893 ( 1 ).

Parmi les nombreuses questions soumises à l'Assemblée figurait la journée de huit heures. La délégation française(2) aurait voulu joindre la fixation légale du salaire minimum.

"A quoi sert de travailler moins, disait M. Chausse, délégué français, si le salaire devient insuffisant? "Le délégué italien, M. Codla, acceptait ce point de vue en déclarant que réclamer la journée de huit heures sans fixation d'un minimum de salaire serait une absurdité. La motion fut vivement combattue par les délégués allemands et anglais (3) qui demandèrent la disjonction des deux questions. L'amendement Chausse fut écarté par la majorité du Congrès, comprenant douze nationalités, soutenu par six: l'Espagne, l'Italie, la France, la Roumanie, la Serbie et la Norvège. La Belgique s'abstint.

La question du minimum de salaire n'était pas encore mûre.

L'Association internationale pour la protection légale des travailleurs qui exerce, comme chacun sait, une action si puissante et si féconde pour développer tout à la fois la législation nationale protectrice des travailleurs dans chaque pays et pour faire progresser la législation inter-

(1) Cf. de Seilhac. Les Congrès ouvriers en France (1896-1898). I vol. Paris, Colin, I 899 .

(2) Elle comprenait au Congrès 38 délégués.

(3) M. Kleims, délégué anglais, affirmait que les ouvriers anglais, qui ne sont pas unanimes à demander la journée de huit heures, le seraient bien moins encore à exiger la fixation du salaire minimum. 
nationale, a mis plusieurs fois à l'ordre du jour de ses délibérations la question du travail à domicile et envisagé de ce biais le problème du minimum de salaire. Il est inutile d'insister ici sur l'intérêt par trop évident que présentent ces efforts: le problème est intéressant au premier chef, et les délicates questions de concurrence de pays à pays se répercutent ici comme ailleurs.

Dès sa réunion de Bàle (en r 904)( I), l'Association internationale pour la protection légale des travailleurs invitait les sections nationales à ouvrir une enquête sur le travail à domicile, les invitant surtout à étudier l'influence de la législation protectrice du travail sur le développement du travail à domicile et les principaux abus résultant de l'absence ou de l'insuffisance de la réglementation de ce mode de travail.

Deux ans plus tard, à Genève en igo6 (2), l'Assemblée, estimant que les abus et les inconvénients déjà constatés auxquels donne lieu le travail à domicile rendaient nécessaire l'action des pouroirs publics, invitait les sections nationales à réclamer de leurs gouvernements respectifs des mesures légales et en traçait le cadre général : obligation de dresser et de tenir à jour les listes d'ouvriers travaillant à domicile, publicité des salaires, extension de l'inspection, des assurances sociales et des règles d'hygiène, encouragement aux organisations professionnelles, ligues sociales d'acheteurs, etc., etc.

Plus tard, en Igo8, à l'assemblée de Lucerne(3) apparaissait très nettement l’idée et le remède des Comités de salaires.

L'Assemblée votait la résolution suivante, qui a grandement contribué à constituer ce que l'on pourrait appeler la doctrine de l'intervention en matière de minimum légal de salaire :

(I) Troisième assemblée des délégućs de l'Association internationale pour la protection légale des travailleurs. Bàle, 25-28 septembre 1904 . Compte rendu.

(2) Quatrième assemblée générale de l'Association internationale pour la protection légale des travailleurs. Genève, 27-29 septembre igo6. Compte rendu.

(3) Cinquième assemblée de l'Association internationale pour la proteetion légale des travailleurs. Lucerne, 20-30 septembre igo8. Compte rendu, p. 210. 
"L’Assemblée des délégués estime que la mauvaise situation des travailleurs à domicile provient principalement de l'insuffisance des salaires, et que, par conséquent, il faut d'abord chercher les moyens de les relever.

A cette fin :

a) L'Assemblée des délégués recommande vivement l'organisation corporative des professions exercées à domicile, l'établissement de contrats collectifs et leur reconnaissance par la loi dans les pays où cette reconnaissance ne résulte pas du droit actuel ;

b) L'Assemblíe des délégués prie les sections d'examiner dans quelle mesure serait efficace et pratique dans leurs pays respectifs une loi civile et pénale permettant aux juges d'annuler et de réprimer les contrats stipulant des salaires insuffisants et usuraires ;

c) L’Assemblée des délégués prie les sections :

I ${ }^{\circ}$ I'étudier la question de l'organisation des Comités de salaires ;

$2^{0}$ Dans les cas où l'action professionnelle s'est montrée inefficace et où les circonstances le permettent, d'inviter leurs gouvernements à faire, en s'inspirant des propositions des lois britanniques, l'essai de l'application d'un minimum Iu salaire établi sous forme de séries de prix par des Comités mixtes. Il y aurait lieu de commencer ces expériences par les industries où les applications paraissent les plus aisées et où le travail visé est pour le grand nombre des ouvriers la ressource principale;

$3^{0}$ D'informer l'Association des résultats réali-és. En particulier la section britannique est priée de tenir l'Association au courant des expériences éventuelles qui pourraient être faites à ce sujet dans le Royaume-Uni. »"

Enfin, en 1910, à l'assemblée de Lugano( (1), la même thèse était confirmée et reprise par des résolutions analogues.

Tout dernièrement ( IO-I 2 septembre I912), une Assemblée de l'Association internationale pour la protection légale des travailleurs vient de se tenir à Zurich; elle a confirmé plei-

(1) Compte rendu de l'Assemblée de l'Association internationale pour la protection légale des travailleurs. Lugano, i910. Paris, BergerLevrault, p. 184. 
nement les vœux précéllents; voici le texte non encore officiellement publié des résolutions adoptées :

L'Assemblée des délégués déclare avec une énergie nouvelle, que justifient les expériences et les études des dernières années, que la situation lamentable d'un très grand nombre de travailleurs à domicile provient, avant tout, de l'insuffisance extrême des salaires et que rien d'efficace n'aura été fait tant qu'on n'aura pas trouvé les moyens de les relever.

\section{A cette fin :}

I. - L'Assemblée recommande à nouveau l'organisation corporative des travailleurs à domicile et l'établissement de contrats collectifs. La liberté de coalition et d'association lui apparaît comme la condition nécessaire du développement de ces contrats. Elle demande la reconnaissance légale du contrat collectif dans les pays où cette reconnaissance ne résulte pas du droit actuel, de façon à assurer leur efficacité juridique et même éventuellement leur extension à d'autres travailleurs à domicile de la même catégorie professionnelle qui n'étaient pas partie au contrat. L'Assemblée invite les sections nationales à entrer en contact avec les organisations des travailleurs it domicile actuellement existantes, dans le but d'encourager la conclusion de contrats collectifs;

II. - L'Assemblée recommande l'affirmation dans la législation de chaque pays du principe permettant d'annuler et de réprimer les contrats stipulant des salaires insuffisants et usuraires. Elle considère ce principe comme essentiel, tout en reconnaissant que les difficultés de son application judiciaire en limitent trop l'efficacité pour que l'adoption de ce principe suffise à résoudre pratiquement, même en partie, le problème;

III. - L'Assemblée est d'avis qu'actuellement toute législation visant à protéger les travailleurs à domicile serait inefficace si elle n'avait pour base l'institution d'un minimum de salaire fixé par des comités constitués d'après les règles suivantes :

In Les Comités de salaires contiennent une représentation paritaire des ouvriers et des patrons. En règle générale, cette représentation doit être élue par les intéressés. Si cette élection ne peut avoir lieu, la désignation doit être faite par les organismes ayant la confiance des intéressés, à défaut, par le Gouvernement.

Le président est pris en dehor's des catégories intéressées. Il est nommé par le Comité ou, à défaut d'entente sur ce choix par le Gouvernement. Il a voix délibérative;

$2^{\circ}$ Le salaire minimum doit être déterminé de façon à permettre aux travailleurs à domicile de capacité moyenne de gagner par heure de travail un salaire équivalent, autant que possible, à ceux des ateliers similaires de la localité ou de la réggion qui assurent à leur personnel des salaires convenables (fair wagles);

D’une manière générale, il faut que le salaire minimum assure 
aux travailleurs des conditions normales d'existence et, notamment, une nourriture saine et un logement hygiénique;

3o Le Comité de salaires détermine d'office et publie immédiatement le salaire ainsi cléfini;

$4^{\circ}$ Le Comité doit, toutes les fois que la chose est possible, établir des séries de prix minima pour les diverses opérations qui comporte la profession ;

5o Le sulaire devra être augmenté des charges telles que fournitures, pertes de temps, etc., imposées aux ouvriers;

6o Le salaire minimum doit être payé intégralement à l'ouvrier, sans aucune déduction pour la rétribution des entrepreneurs ou sous-entrepreneurs ;

$7^{\circ}$ Lorsque, dans une profession relevant d'une commission de salaires, il existe des contrats collectifs de travail, la commission appelće à établir les salaires minima visera en premier lieu à étendre le bénéfice du contrat collectif à tous les ouvriers à domicile;

$8^{0}$ Pour les opérations non visées aux séries de prix dont question au $4^{\circ}$, l'employeur doit prouver, en cas de contestation, que les conditions faites aux ouvriers sont telles qu'elles permettent aux travailleurs de capacité moyenne d'obtenir le salaire de base fixé au temps.

Les contestations sont tranchíes par les Comités de salaires;

$9^{\circ}$ Le Comité fixe aussi des íchelles re salaires et, si possible, de prix minima, pour les apprentis de la profession, même si l'apprentissage a lieu en atelier;

$10^{\circ}$ Toute violation d'une des dispositions de la loi constitue, pour chaque fait, vis-à-vis de chaque ouvrier, un délit et donne lieu à une peine distincte;

$11^{\circ}$ Toute organisation professionnelle, toute personne intéressée dans la profession et toute association autorisée à cet effet peut signaler au Comité que le salaire payé est inférieur au salaire minimum fixé pour la profession.

Ces personnes et organisations peuvent igalement exercer toutes actions en justice prérues par la loi :

$12^{\circ}$ Les salaires fixés par les Comités locaux sont soumis au contrôle d'une Commission centrale de revision opérant d'office, à bref délai. Cette Commission pourra modifier et coordonner les décisions locales. Elle sera instituće par le ministre et composée, sur la base paritaire, de délégués choisis parmi les membres des Comités du salaire.

IV. - L'Assemblée invite les parlementaires membres de l'Association internationale à faire ou à provoquer le dépôt de propositions de loi conçues dans les vues des résolutions votées.

Elle demande instamment aux sections nationales d'entrcprenclre une campagne énergique en vue de convaincre l'opinion publique de la nécessité de l'iustitution du minimum légal de salaire dans les industries à domiciie. 
Ainsi se trouvaient coordonnés et reliés les efforts tentés dans chaque pays en faveur de la solution du problème des maux du sweating system.

Une deuxième manifestation, également intéressante, du mouvement international en faveur de la réforme est due aux congrès internationaux spéciaux du travail à domicile.

Le premier de ces congrès a été tenu à Bruxelles, les I5-i6 septembre I9Io (I). Il s'agissait de réunir, à l’occasion de l'exposition, les publicistes, les savants et professeurs qui s'occupaient de ce problème. Le Congrès s'est prononcé à l'unanimité en faveur d'un minimum légal de salaire établi par des Comités de salaires.

Voici, d'ailleurs, le texte in extenso dle ce vœu; on y retrouvera acceptée la mème solution que ci-rlessus :

" Le Congrès, estimant que l'intervention du législateur s'impose pour remédier aux abus flagrants dont souffrent la plupart des travailleurs à lomicile et sans préjudice d'une extension aussi large que possible des lois de protection ouvrière, se rallie aux propositions suivantes :

$1^{0}$ Enregistrement des employeurs et des ouvriers.

$2^{\circ}$ Des Comités mixtes obligatoires fixeront, pour un laps de temps restreint, un minimum de salaire applicable $\grave{a}$ tout ouvrier normal. Les décisions le ces Comités seront sanctionnées par des pénalités. Il pourra en ètre appelé à un conseil supérieur.

$3^{\circ}$ Hygiène et suppression éventuelle de certaines industries. ")

A plusieurs reprises également, dans les divers Parlements, l'idée d'un salaire minimum, établi par voie de convention internationale, a été formulée; c'est ainsi, notam-

(1) Cf. Compte rendu du premier congrès international du travail a domicilc. Bruxelles, Misch et Tron, IgII.

(2) Ibid., p. 60. 
ment, qu'au Parlement anglais, le 26 avril ig i ( I) M. Tennant, secrétaire parlementaire du Board of Trade, a exprimé l'espoir l'arriver à un minimum de salaire par entente internationale : sans entrevoir le règle uniforme, le représentant du Gouvernement anglais compte sur l'exemple de l'Angleterre pour inviter les Gouvernements étrangers à prendre eux-mèmes des mesures contre le sweating: le parallélisme de ces actions nationales simplifierait la solution du problème.

Enfin le mouvement ouvrier international a eu, lui aussi, l'occasion de faire plusieurs manifestations en faveur du minimum de salaire.

La question a été discutée à plusieurs reprises par les Congrès internationaux lle mineurs.

Le sujet fut discuté pour la première fois au congrès international des mineurs à Berlin, en $\mathrm{I} 894$; reprise aux congrès d'Aix-la-Chapelle en 1896 (2), de Londres en 1897 (3), de Londres en rgor (4) et de Bruxelles en 1903 . On y relève deux courants distincts : en dehors de la question de principe sur laquelle l'accorıl est réalisé, les délégués du continent préconisent le minimum obligatoire par une loi, les délégués anglais le veulent par l'initiative ouvrière et par des procédés de conciliation, en un mot, par le contrat collectif libre (5). Les motions, vu le nombre des délégués

(i) Parliam. Det., vol. XXIV. House of Commons, p. i922. Sur la résolution qui a donné lieu à cette déclaration, ef. ci-dessus, p. 415.

(2) Musée social, série A, 1896 , circul. $n^{\circ} 6.7^{\mathrm{e}}$ congrès international des mineurs, p. ror. Une certaine confusion régna dans la discussion; quant au but visć et aux modalités propres à l'ohtenir.

(3) Musée social, série A, 1896 . Cireul. n 16, p. 357.

(4) Musce social, 1901, P. 267.

(5) M. Ralph Young disait très nettement en 1897 : "Ce n'est pas que les mineur's de l'Union nationale (anglaise) soient opposés au principe du minimum de salaire, nous croyons seulement que vous préeonisez des méthodes fàcheuses. Pour une chimère vous allez tuer cette œuvre des Comités de conciliation qui est une réalité; puis infailliblement vous roulerez sur la pente : après la journće de travail imposée par l'État, ce sera l'obligation pour les Comités de recon naître un minimum, ensuite la fixation (le ce salaire par l'État lui-mème, ensuite les prix, etc.» Musée social. Cireulaire, $1896, \mathrm{n}^{\circ} \mathrm{16}, \mathrm{p} .359$. 
anglais, ont été longtemps repoussées du fait de cette division (I). On eut bien vite cependant le sentiment que la question restait au premier chef une question internationale.

La même question a été encore reprise par le vingt et unième Congrès international des mineurs, tenu à Bruxelles les 9-12 aoùt I9ro (2). Sur la question des salaires, les Allemands ont parlé en faveur du contrat collectif, les Français et les Belges en faveur d'une loi réglementant le salaire minimum et en faveur de l'échelle mobile; les Anglais se sont déclarés partisans de la combinaison des deux méthodes.

Le mème problème a été aborlé par les ouvriers boulangers et pàtissiers qui réclament " un minimum de salaire raisonnable (3) ", par les ouvriers gantiers (4), etc., etc.

La revendication d'un salaire minimum est au fond le la conscience de la classe ouvrière et elle a le sentiment, exact l'ailleurs, que le problème implique certaines répercussions d'ordre international.

Au terme de cette revue du mouvement contemporain en faveur du salaire minimum, lont on roudra bien excuser la longueur en raison de son importance et de sa nouveauté, on a le sentiment très net que la question est aujourd'hui posée devant l'opinion et qu'un premier pas, encore timidle et hésitant, a déjà été fait vers le minimum de salaire.

(1) Ce minimum fut cependant voté au congrès de Londres, en Igor. Ibid., Musée social, 19or, p. 274.

(2) Cf. Mouvement social, 1910, p. 297.

(3) $1^{\text {er }}$ congrès international des ouvriers houlanger's et pàtissiers. Stuttgrart, 25 août 1907. Cf. Bulletin de l'office intern. du tranail, sgo7, p. 5 go.

(4) Congrès international des ouvriers gantiers. Bruxelles, 10-14 septembre igio, rapporté par Boyaval, op. cit., p. 558 . 



\section{CONCLUSION}

\section{Le Problème du îlinimum de salaire.}

Ainsi, rien de plus simple au premier abord, rien, en réalité de plus complexe et de plus difficile que le problème du minimum de salaire ( $\mathrm{I}$ ).

A en prendre tout d'abord les éléments concrets obtenus par l'observation, on constate, depuis de nombreuses années déjà, ce que l'on pourrait appeler, avec un de nos philosophes contemporains, une idée force dans la classe ouvrière, parmi les travailleurs. Ceux-ci ont confusément l'idée que le travail doit nourrir son homme, qu'il est injuste et inexplicable que des salaires de famine, dérisoires, insuffisants ne mettent pas l'ouvrier à même de vivre et d'entretenir sa famille : cette idée est enregistrée dans les congrès et les réclamations ouvrières sous le nom de minimum de salaire.

Mais encore que faut-il entendre par là et quel est au juste l'objet de cette revendication?

Les théoriciens arrivent alors, essayant de préciser ce que l'on pourrait appeler, d'après une formule chère à Sorel, le mythe du minimum de salaire.

S'agit-il, à véritablement parler, d'un minimum, c'est-àdire du salaire le plus bas qui puisse être effectivement payé, d'une limite au-dessous de laquelle le patron ne puisse, en aucun cas, descendre? C'est assurément l'une des conceptions les plus répandues du minimum de salaire, l'une des idées surtout de ceux qui le combattent.

Scientifiquement, cette première interprétation du pro-

(I) C. la communication de M. Asquith, à la Conference on a minimum wage. Anti sweating League. Report, 1907, 1· $9 \cdot$ 
blème se heurte à une double difficulté, pour ne pas dire, à une double impossibilité.

Tout d'abord, comment déterminer et apprécier ce minimum? Il est évident qu'il ne peut être unique et uniforme, et devrait varier avec les régions, les villes et les individus, les besoins étant élastiques et surtout le coût de la vie infiment divers et varié. Il faut vraiment renoncer à un minimum de salaire numérique, déclarant que partout et toujours, par exemple, l'ouvrier doit toucher 5 francs par jour.

De plus - et cette seconde impossibilité va plus loin que la première - mème en substituant à l'idée et au programme d'un minimum fixe, unique et invariable, la notion plus pratique de minima différents et adaptés, cette première conception d'un minimum de salaire signifiant " le salaire le plus bas qui puisse ètre effectivement payé " paraît également utopique et irréalisable du point de vue patronal. Il est incontestable que le salaire est la contre-partie du travail fourni et qu'on ne peut admettre en théorie qu'un salaire donné soit payé, quel que soit le travail fourni : il est certain que le patron, l'employeur, dans ce cas, ne s'y retrouverait pas, qu'il préférerait fermer l'usine ou l'atelier et que, pour avoir voulu établir un minimum de salaire de ce genre, on supprimerait le salaire lui-même. Comme le dit avec l'humour anglais M. Asquith, le patron répliquerait : “ Je ne vois pas le moyen d'employer des hommes qui ne me donnent pas en retour un travail suffisant contre mon argent, et même si je le voulais, comment le pourrais-je dans une industrie qui ne saurait en porter la charge et se survivre sur la base de la charité. Je ne suis pas là pour montrer des chiens savants. ")

Cette double critique, par laquelle nous venons de résumer l'opinion courante, paraìt la condamnation décisive et irrévocable de tout minimum de salaire envisagé comme l'octroi d'un salaire fixé sans contre-partie assurée pour le patron : l'idée de minimum de salaire, poussée à bout et reposant sur la seule base d'un salaire préfixe forcément payé, présente, on le voit, d'inextricables difficultés.

Mais alors est-ce nécessairement une utopie et, avec ce point de vue strictement individuel, faut-il déclarer le problème insoluble, comme la quadrature du cercle? 
Nullement : dans sa richesse ordinaire, le minimum de salaire est heureusement susceptible d'une seconde interprétation plus large, plus extensive et aussi, disons-le de suite, autrement pratique.

Un minimum de salaire, c'est d'abord le juste salaire : $a$ fair wage for work done, un bon salaire pour le travail effectué; c'est ensuite cette assertion qu'au-dessous d'une certaine limite le paiement du travail est si bas qu'il devient injuste et que l'on tombe dans le domaine de l'exploitation et du sweating (I).

Le minimum de salaire c'est donc the lowest fair wage that should be paid, le salaire le plus bas encore convenable qui puisse être payé (2). Avec cet autre élément, l'équivalence entre le salaire payé et le travail effectué, tombent les difficultés précédentes, mais aussi surgissent toutes les délicates questions et les subtiles répercussions de notre problème.

\section{Le salaire le plus bas encore convenable qui puisse être}

(x) Par là, notre conception du minimum de salaire s'oppose à l'idée plus large et plus compréhensive du juste salaire : le juste salaire est celui qui réalise l'équivalence objective entre le travail exécuté et l'argent reçu.

Les deux idées ne sont pas coextensives : d'une part, l'idée de juste salaire dépasse l'idée de minimum de salaire. Dans l'immense majorité des cas, les exigences du minimum seront dépassées en fait, étant données la productivité du travail de l'ouvrier, son habileté technique, etc., et, d'autre part, on peut concevoir certains cas où le juste salaire pour des ouvriers incapables ou inférieurs serait au-dessous du minimum d'existence.

En d'autres termes, dans une théorie complète du salaire, celui-ci est soumis à deux régulateurs: l'un éloigné, le minimum de salaire, l'autre immédiat et prochain, le juste salaire.

Les deux normes sont d'ailleurs subordonnées, non sur le même plan : il faut d'abord que le salaire respecte le mininum, ensuite qu'il soit juste.

(2) C'est d'ailleurs la conception qui paraît avoir prévalu dans la discussion de la loi anglaise de 1908. Cif. Parliamentary Debates passim et plus particulièrement la discussion à la Chambre des Lords du 30 août 1909. (P. D., vol. 2, $\mathrm{n}^{\circ} 56$, p. 995), dans laquelle le comte de Lytton se trouve employer les termes mêmes de notre texte : "Le véritable objet du bill est d'élargir la fixation des salaires en la transposant de l'individu à la profession tout entière et l'assurer par un mécanisme artificiel qu'une fois un taux de salaire accepté comme convenable (fair) par les travailleurs et les employeurs, ce taux sera le minimum qui prévaudra dans tout le métier." (That shall be the minimum which shall prevail in the whole trade).

C'est aussi la conception qui parait avoir prévalu en Belgique. Cf. Le minimum de salaire et les administrations publiques en Belgique. offlce clu travail belge, Ig⿵, pp. 24 et suiv. 
payé! La formule est grosse de contingences et d'éléments soumis à discussion et à appréciation.

Nous pourrions, en la grossissant un peu et en la vulgarisant, l'interpréter : "Pas d'exploitation! Pas d'utilisation abusive par l'employeur du travail de l'employé, c'est-à-dire sans rémunération juste et équitable. "

Telle est l'idée complexe, délicate, difficile surtout dans sa réalisation concrète, qu'implique le minimum de salaire.

Elle comporte trois éléments bien distincts qu'il est nécessaire de dégager à la fin de cette étude :

D'abord un élément relatif au plus haut degré, l'idée de convenance, la relation équitable entre le travail fourni et le salaire payé : quelques piastres en Indo-Chine ou en Chine, quelques kopecks en Russie pourront être des minima de salaire équitables pour le pays.

Quelques livres sous l'ancien régime, quelques francs de nos jours pourront être des minima équitables pour l'époque et pour le temps.

Ensuite une exigence de la justice qui veut un bon salaire pour le travail effectué, qui proscrit l'exploitation et l'abus de situation d'une partie envers l'autre.

Enfin un accord et une convention de ne jamais descendre au-dessous de ce minimum de rémunération, un élément de sécurité pour l'avenir, une assurance contre des variations exagérées et erratiques dans le taux des salaires (I).

Ainsi relativité, justice, sécurité, telles sont les trois idées générales dont est faite la notion du minimum de salaire.

On voit, par cette analyse mème, la profonde complexité du problème.

Le problème du minimum de salaire nous apparaît ainsi en premier lieu comme un problème de garantie pour le travailleur et non comme une question brutale de réglementation ou de détermination quantitative : il ne s'agit pas dès lors d'un chiffre à déterminer une fois pour

(I) Cet élément de sécurité différencie encore sous un autre aspect notre minimum de salaire du juste salaire, qui ne fait pas l'objet de notre étude.

Sur le juste salaire, cf. : Polier, L'Idée de juste prix. Thèse, Paris, I9o3, Giard et Brière ;

De Tarde, L'Idée de juste prix. Thèse, I907, Paris, Alcan. 
toutes, mais bien d'un système de relations à établir entre employeurs et employés, impliquant pour ceux-ci la sécurité dans le salaire, englobant pour ceux-là un certain travail convenable fourni en retour du salaire convenu. C'est, dirions-nous volontiers, une question de bonne foi et de confiance, bien plus qu'une simple question d'arithmétique.

C'est, en second lieu, un problème posant une question d'accord, d'entente, de contrat entre les deux parties, bien plus qu'une question de contrainte, d'autorité ou de pression d'une des parties imposant sa décision à l'autre. Il s'agit, par des mécanismes complexes que nous avons étudiés, d'amener le patronat à cette politique du salaire convenable le plus bas qui puisse être payé pour un travail convenu : par là des Comités de salaires, des contráts collectifs, des organismes en un mot à créer et à faire vivre, bien plutòt que la brutale contrainte d'un minimum quantitatif qui ne devrait janıais être dépassé.

Enfin, en troisième et dernier lieu, le problème lu minimum de salaire apparaît encore comme un problème collectif, de masse et de groupements, au lieu d'un problème individuel, de personne à personne, de patron isolé à ouvrier isolé. Il y a une certaine conscience variable d'ailleurs, un état de l'opinion tant patronale qu'ouvrière, chargée d'apprécier la relation désirée entre le juste salaire et le travail fourni.

Sous ces trois aspects, garantie nécessaire, accord et contrat, rôle de la collectivité dlans la fixation du salaire minimum, notre question apparaît avec toute sa richesse réelle et sa fuyante complication.

On aperçoit aussitòt pourquoi, tant au point le vue théorique qu'au point de vue pratique, les opinions et les solutions sont nombreuses, divergentes, opposées. On voit mieux comment il s'agit vraiment d'un mouvement vers le minimum de salaire. 


\section{Nécessité d'une intervention législative.}

Au terme de cette longue étude, il importe de poser franchement le problème actuel : Le minimum de salaire deviendra-t-il jamais une réalité et le mouvement vers le minimum de salaire parviendra-t-il un jour à la généralisation de l'illéal entrevu?

Un point semble incontestable, c'est le progrès, la diffusion de l'idée, aujourd'hui de plus en plus vulgarisée et admise dans des milieux, des pays, voire mème par quelques patrons, qui lui étaient jusqu'alors réfractaires.

Aussi certains esprits optimistes ont-ils conclu à l'avènement de ce minimum, que l'on a pu qualifier de " loi d'or " (les salaires! Une nouvelle théorie vient en effet d'être tout récemment (1) formulée : au fur et à mesure que les masses populaires prendront plus énergiquement conscience du minimum de salaire qui leur est nécessaire, celui-ci aurait de plus en plus de chance de se réaliser. "Dans chaque profession, écrit M. P. Bureau (2), la rémunération du travailleur manuel doit ètre équivalente aux frais de subsistance de la moyenne des ouvriers laborieux et capables de cette profession. Par frais de subsistance, il faut entendre non pas ce qui correspond strictement aux besoins physiologiques de la famille ouvrière pour s'entretenir, mais ce qui correspond aux besoins très divers de nourriture, de vêtement, d'habitation, de distraction, de vie morale et intellectuelle, effectivement et profondément ressentis (3)

(1) Tarde. Psychologie économique, 2 vol., Paris. - De Tarde. L'idée ale juste prix, thèse, Paris, Ig07. - P. Bureau. La théorie sur le taux des salaires et l'idée de justice. Revue hebdomadaire, 17 décembre 1910 , p. 334. - C. P. Hans. A propos de la théorie des salaires. Réforme sociale, $\mathrm{I}^{\mathrm{er}}$ février IgI $\mathrm{1}$, I 86.

(2) M. P. Bureau est arrivé à cette théorie par une affirmation nouvelle de la loi d'airain, transformee et rajeunie. Cf. P. Bureau. Le contrat de travail. Le róle des syndicats professionnels, I vol., Paris, Giard, Igo2. Peu importe ici d'ailleurs l'origine historique de la doctrine, que nous examinons seulement en sa consistance aetuelle.

(3) C'est nous qui soulignons. 
dans le milieu social qui entoure ces ouvriers ou dans lequel ils se recrutent. Cette supputation des besoins effectivement et profondément ressentis a déjà, lans une large mesure et dans un certain nombre de professions, réussi à fixer le taux des salaires; la conscience contemporaine lemande que ce succès se développe parce que la justice le requiert. ) Et ainsi, par la liberté, par la liberté seule, avec les progrès de la conscience ouvrière, le minimum de salaire serait appelé bientôt à se réaliser.

Deux considérations obligent, à notre sens, à écarter cette nouvelle conception :

D'une part, le facteur psychologique a une influence incontestable sur le taux des salaires, mais à côté de ce facteur prépondérant si l'on veut, combien d'autres facteurs que l'on néglige : la relation entre l'offre et la demande, les conditions du marché économique, les forces d'organisation patronale et ouvrière, etc., etc... Comment affirmer a priori que ceux-ci ne l'emporteront pas sur celui-là et qui ne sait que parmi ces facteurs, la plupart ou ignorent le minimum de salaire, ou mieux luttent contre lui par le jeu d'une concurrence au rabais?

D'autre part, il paraît à tout le moins prématuré, en l'état actuel de nos connaissances, de qualifier de loi économique cette loi d'or des salaires. Que de milieux encore où la supputation des besoins effectivement et profondlément ressentis n'a pu triompher! Tout le monde du sweating system qui souffre si cruellement de l'insuffisance des salaires n'en est-il pas la réfutation vivante et louloureuse?

Donc, c'est un premier point qui semble acquis, il ne faut pas compter, comme on l'affirmait, sur une réalisation généralisée du minimum de salaire qui aurait lieu spontanément!

C'est donc seulement par une série d'efforts nouveaux et continus que. le minimum de salaire sera appelé à réaliser de nouvelles conquètes.

Ces efforts et ces conquêtes seront l'œuvre, principalement de l'Association professionnelle, accessoirement de la loi.

C'est par le contrat collectif, par les accords syndicaux, 
que s'introduira normalement dans un nombre chaque jour croissant de professions la pratique du minimum de salaire. Et ici tout dépendra, sans doute, de la sagesse des syndicats ouvriers, de la perspicacité des associations patronales. Le minimum de salaire, à supposer qu'on le trouve juste et raisonnable, ne peut être, en raison des nécessités impérieuses de la concurrence, qu'une mesure collective, une clause de la réglementation contractuelle de la profession. Sur ce point encore l'opinion contemporaine semble à peu près unanime. On l'a fort nettement affirmé lors de la discussion de la loi anglaise de rgog (r).

"Le véritable principe dans tous les cas est certainement celui-ci : les industries elles-mèmes doivent s'organiser et arrêter par leurs propres efforts ce que doit être le taux de rémunération pour chaque genre de travail. C'est là, j'ose le dire, le seul vrai et réel principe; les métiers ont tous ce droit. ")

M. Jay faisait également consacrer la mème doctrine par l'Assemblée internationale de l'Association pour la protection légale des travailleurs, réunie à Lugano en septembre г9го : "Comment relever les salaires des travailleurs à domicile? Je ne crois pas me tromper en disant que la Commission III est unanime à voir dans le contrat collectif de travail le véritable noyen, le moyen normal de défendre le salaire contre les concurrences qui tendent à le rabaisser, unanime à penser que c'est vers la généralisation suffisante de ce contrat collectif qu'il nous faut tendre en aidlant de toutes nos forces à son développement le plus large possible parmi les travailleurs à domicile (2). »

Mais, pour la vulgarisation lu système, se posent trois formidables points d'interrogation :

Les syndicats ouvriers comprendront-ils la sagesse et l'utilité de cette méthode réformiste et ne préféreront-ils pas, avec les progrès croissants du syndicalisme, les voies soi-disant plus rapides de la méthode révolutionnaire et de l'action directe?

(1) Le marquis de Lansdowne. Parliam. Deb. Lords, Igog, vol. II, n॰ 56, 30 aoùt r 909 , p. rorr.

(2) Compte rendu, rgro. Paris, Berger-Levrault, p. 43. Cf. plus loin la suite du texte. 
Les associations professionnelles patronales auront-elles dans les divers pays, et plus spécialement en France, la sagesse de comprendre que le minimum de salaire, au fond des choses, est aussi bien dans leur intérèt et l'intérêt général de l'industrie que dans celui, plus immédiat et plus direct, des ouvriers?

Enfin, quelle conception du minimum de salaire fera-t-on prévaloir? un minimum absolu, limite inférieure basée localement sur les seuls besoins des travailleurs, ou un minimum de rémunération soudé à un minimum de travail, avec garanties pour le patron?

L'examen détaillé des deux premiers points d'interrogation nous entraînerait trop loin : ce seraient de nouvelles études, pour la France notamment, et ce serait sortir de notre sujet.

Il suffira d'insister brièvement sur le troisième problème : quelle est la conception du minimum de salaire qui a chance de triompher dans les faits?

On l'a vu plus haut, le minimum de salaire peut s'entendre de deux façons bien différentes:

Pour les uns c'est le salaire le plus bas qui puisse être effectivement payé, sans aucun équivalent corrélatif en travail;

Pour les autres, c'est le salaire le plus bas encore convenable qui puissse ètre effectivement payé eu égard au travail effectué.

Dans la première alternative les besoins de l'ouvrier seuls seront la base du salaire; dans la seconde, à côté de ces besoins, est pris en consilération le travail effectué.

L'étude des faits que nous avons précédemment passés en revue montre, semble-t-il, que partout où la seconde conception a pu prévaloir et être mise en pratique le salaire minimum est aujourd'hui une réalité.

L'œuvre de l'organisation professionnelle a été surtout féconde là, où, par un ingénieux mécanisme, le salaire hebdomarlaire minimum garanti l'était dans de telles conditions, par l'application d'un tarif aux pièces le plus souvent, que l'employeur était du même eoup assuré d'avoir un certain minimum de travail ;

L'œurre de la puissance publique paraît, quoique moins 
nettement, imposer une conclusion semblable : ici, il est vrai, le minimum est bien un peu salaire au temps dans l'immense majorité des cas, mais la situation particulière des ouvriers de l'État, des départements et des communes permet à l'employeur qui jouit d'un monopole de remercier pratiquement ceux qui ne fourniraient pas la quantité le travail normal, tacitement sous-entendue ( 1 ).

Enfin, l'œuvre ile la loi, tant en Australasie qu'en Angleterre, a abouti pratiquement (2) à des tarifs minima aux pièces : les minima au temps sont le plus ordinairement soudés pratiquement à dles minima aux pièces, ou bien le taux des premiers est si bas que de toute façon l'employé fournira un équivalent corrélatif au travail (3).

Jusqu'à présent donc, l'expérience semble indiquer qu'un minimum de salaire ne peut pratiquement fonctionner qu'avec la garantie expresse ou tacite par l'employeur d'un certain travail corrélatif.

Tout récemment, lors de la grève des mineurs anglais (mars I912), ceux (les patrons anglais qui, pendant les négociations, étaient disposés à accepter les revendications ouvrières demandlaient (4) comme garanties les trois clauses suivantes :

$I^{0}$ Quand pendlant deux payes successives un mineur, sans donner d'explication valable, n'aura fourni qu'une

(I) On a constaté pour les ouvriers des établissements de la marine en France que cette sorte de contre-partie tacite du minimum ayant fait défaut, l'expérience a partiellement échoué et que l'on songe aujourd'hui à combiner le mininum hebdomadiare avec le tarif aux pièces, c'est-à-dire une certaine équivalence en travail.

(2) On s'est souvent contenté d'assimiler le salaire des ouvriers sweated à celui dlautres ouvriers qualifiés : c'est là un moyen pratique d'aboutir à unc élévation dans le taux des salaires; ce n'est pas toujours - et provisoirement - la fixation d'un véritable salaire vital.

(3) Cf. P. Boyaval. La lutte contre le sweating system. Thèse, Nancy, Igr I. "Le salaire base quotidien est appliqué à la somme de travail qu'un ouvrier d'habileté moyenue pourra effectuer en une journée d'une durée normale, et comme le travail se fait d'ordinaire aux pièces, la tarification minimum de celle-ci s'obtiendra tout simplement en divisant l'étaton fixé par le nombre d'objets confectionnés quotidiennement dans ces conditions.

Si, par exemple, dans une région où l'étalon vital a été fixé à 3 franes, une ouvrière d'habileté moyenne peut confectionner dix objets déterminés en une journée de dix heures, le salaire minimum fixé pour chaque objet sera de o fr. 30 centimes. ")

(4) Temps, 28 février ı 912. 
quantité de charbon inférieure à la production moyenne, il pourra ètre renvoyé ;

$2^{0}$ Le salaire minimum sera inférieur de I sh. au salaire moyen des places anormales (pour le travail à la tâche);

$3^{\circ}$ Les infirmes, les ouvriers àgés, les ouvriers qui ne travaillent pas régulièrement n'auront pas droit aux salaires minima.

C'est donc bien le problème de la garantie de production qui les préoccupe. C'est le point central, le nœuil même de la question.

Mais alors, et pour l'avenir, le problème se pose très nettement : comment ce minimum pourra-t-il se généraliser?

Théoriquement, en effet, on peut formuler le dilemme suivant :

Ou bien le salaire est le juste salaire, fixé d'après la quantité de travail fourni par l'ouvrier, et ce travail, étant tarifé aux conditions économiques présentes, pourra n'ètre pas suffisant pour faire vivre le travailleur;

Ou bien le salaire est, à proprement parler, un minimum basé sur les besoins physiologiques, intellectuels, moraux (le l'ouvrier, et alors l'équivalence en travail disparaìt.

Pratiquement, cependant, la conciliation les deux normes du salaire est possible, grâce à l'association professionnelle.

C'est précisément la souveraineté économique de l'association professionnelle par le contrat collectif qui est assez puissante pour réaliser l'accọrd de ces deux mesures du salaire en apparence contradictoires. Ce fut toute la politique du Trade-Unionisme anglais que d'affirmer et de faire triompher cette maxime que les prix des produits doivent être suffisants pour permettre aux travailleurs dle vivre. Grâce au syndicat, la concurrence, dans son action déprimante, est ici limitée, et il s'établit un certain niveau dans les salaires par un mécanisme délicat; ceux-ci sont en même temps suffisants pour assurer un certain minimum vital, en même temps que ce minimum vital est obtenu par l'application d'un tarif aux pièces pour garantir pratiquement à l'employeur un certain équivalent en travail. La souveraineté économique de l'association professionnelle opère ce prodigieux tour de force. 
Le minimum de salaire - on ne saurait l'oublier pour le passé, ni assez l'affirmer pour l'avenir - est avant tout une réforme professionnelle, nous voulons dire subordonnée directement à la puissance économique et sociale de l'association professionnelle.

Donc c'est par l'association professionnelle, avec les réserves ci-dessus indiquées, que le minimum de salaire aura chance de se réaliser.

Mais, à côté de ce chemin norınal et ordinaire, il paraît indispensable d'envisager comme moyen extraordinaire et supplétoire l'action de la loi par l'institution des Comités de salaires.

Toutes les fois que l'organisation professionnelle sera inexistante ou impossible, c'est au législateur seul qu'il faudra faire appel pour y suppléer.

C'est également l'opinion (I) qui tend de plus en plus à triompher aujourd'hui.

(I) Mais ici, disait le narquis de Lansdowne (Parliam. Deb., 3o août 1909 , loc. cit.), nous sommes en présence de métiers pratiqués par des individus si désarmés et si misérables dans l'état actuel des choses qu'il leur est impossible de s'associer, de s'organiser et de se protégrer eux-mèmes comme le font ceux qui sont occupés dans des métiers et industries pleinement organisés. Là est la raison - et la seule - d'accepter le principe d'intervention de la loi.

M. Churchill avait exposé très nettement la même idée dans la même discussion (28 avril 1909, H. of C. Parliam. Deb., vol. II, n 45, p. 39o) aux Communes :

"On supposait autrefois que l'action de la loi de l'offre et de la demande viendrait naturellement régulariser ou supprimer ce mal (des salaires insuffisants). La division la plus claire que l'on puisse faire à ce sujet aujourd'luui est celle des conditions normales ou anormales du contrat. C"est dans la première alternative que la loi de l'offre et de la demande produit à la longue un prix convenable: quand dans la plupart des métiers on rencontre une organisation puissante des deux còtés, des meneurs responsables capables d'amener leurs mandants à leur avis, quand cette organisation est jointe à une échelle mobile de salaires automatiques ou à des arrangements pour éviter le refus de travail par l'arbitrage, vous avez un contrat normal qui augmente la puissance de l'industrie, établit un niveau de vie qui s'améliore avec la productivité industrielle et enchaine sans cesse plus étroitement le capital et le travail. Mais, dans les métiers que nous appelons sweated, il n'y a aucune organisation, aucune égalité dans le contrat : le bon patron est concurrencé par le mauvais et le mauvais par le pire; le travailleur, dont toute la vie dépend de son travail, est concurrencé au rabais par le travailleur qui prend seulement le métier comme une 
M. Jay (I) l'indiquait très nettement à l'Assemblée précitée de Lugano :

" Si nous ne voulons pas renvoyer à une époque indéterminée et à coup sûr lointaine une réforme particulièrement urgente, il faut faire appel à d'autres moyens de relever les salaires, moyens peut-être moins parfaits, moins sympathiques à beaucoup de ceux-là mème qui les réclament, mais moyens pouvant nous donner des résultats immédiats ou du moins prochains. C'est pourquoi la Commission de Lugano, comme la Commission de Lucerne, estime qu'il est nécessaire de faire appel au législateur. ")

L’Assemblée de Lugano votait, en conséquence, les vœux suivants, qui formulent ce que l'on pourrait appeler la théorie de l'intervention :

I. L'Assemblée recommande à nouveau l'organisation corporative des travailleurs à domicile et l'établissement de contrats collectifs.

II. L'Assemblée est d'avis qu'actuellement le remède le plus efficace aux abus du travail à domicile consiste dans l’institution de Comités de salaires analogues à ceux que vient d'établir la loi anglaise.

a) Ces Comités auront pour mission :

I $^{0}$ La fixation de minima de salaires pour les travailleurs à domicile de régions et de professions déterminées;

$2^{\circ}$ L'extension éventuelle des tarifs établis par contrats collectifs à d'autres travailleurs à domicile de la même catégorie professionnelle que ceux qui furent portés au contrat et à d'autres régions que celles visées au contrat;

b) Le gain journalier des travailleurs en atelier faisant les mêmes articles ne pourra être inférieur à celui des tra-

seconde corde à son arc; sa faiblesse et son i grnorance font généralement du travailleur une proie toute prête pour la tyrannie des maîtres et contremaîtres. Vous n'avez alors aucun progrès, mais une constante et progressive déchéance.

De mème que dans le premier cas le progrès est constant si personne ni aucune loi ne vient l'arrêter, de même ici la déchéance continuera; il u'y a pas de raison pour qu'elle ne continue pas comme dans un gouffre visqueux pour une périorle qui, par rapport à notre vie, est indéfinie. ")

Cf. en général toute la discussion de la loi anglaise, où la doctrine indiquée au texte a été maintes lois exprimée et finalement admise.

(I) Loc. cit., compte rendu, p. 43. 
vailleurs à domicile dont les salaires ont été déterminés dans les conditions indiquées ci-dessus ;

c) L'Assemblée estime que toute législation établissant des minima de salaires pour les travailleurs à domicile resterait inefficace si des sanctions pénales sérieuses ne réprimaient la violation des tarifs;

d) L'Assemblée estime que des inspecteurs devront être chargés d'assurer le respect des tarifs ;

e) Les syndicats professionnels pourront exercer toutes les actions naissant de la législation prévue ci-dessus (I).

Cette doctrine s'applique évidemment à tous les cas de sweating system pour lesquels elle est née (2).

On peut aussi l'étendre aux travailleurs de l'État, des communes et des départements, pour lesquels le droit de coalition et la grève, instruments nécessaires du contrat collectif, seraient difficiles à accorder.

Ainsi, par l'association professionnelle et, subsidiairement, par la loi, le salaire minimum est appelé à de nouvelles réalisations pratiques.

En attendant, beaucoup de préjugés, bien des malentendus, bon nombre de positions a priori pour ou contre la réforme en retarderont vraisemblablement l'application.

Puisse ce modeste travail contribuer à les faire disparaître! L'esprit d'observation scientifique qui a constamment orienté nos recherches et lirigé nos efforts est, semble-t-il, la meilleure manière de servir un idéal qui nous est cher. De moins en moins, dans notre vingtième siècle positif, le temps est aux rèveries vaines, si généreuses soient-elles. L'heure est toute à l'action précise et documentée : la marche vers l'Idéal se poursuit, les pieds ancrés dans le sol rude des réalités contemporaines, les yeux toujours fixés vers le ciel bleu, lointain, mais pas inaccessible.

Aix-en-Provence, juin 1912.

(1) Compte rendu, op. cit., p. 184 .

(2) Elle apparaît, en ce cas, comme un provisoire nécessairc : " De la pratique du contrat collectif imposé et réglementé, que ces Comités ont pour but de réaliser, se dégagera, comme de lui-même, le contrat collectif libre, spontané et autonome. ") R. Jay. Compte rendu, Lugano, 1910. Ibid., p. 57 . 


\section{ANNEXES}

\section{A. - Législations australiennes.}

\section{I. - Victoria.}

Toute la législation antérieure ayant été refondue dans la loi de igo5, il suffira, à titre documentaire et historique, de mentionner les lois et leurs dates avec leurs références :

Loi du 28 juillet $\mathrm{i} 896$. (6o, Vict., no 1445 . The Factories and Shops Act 1896 .)

Loi du 24 décembre 1896 . (6o, Vict., no 1476 . The Factories and Shops Amendement Act $189^{6}$.)

Loi du 27 septembre 1897 . (6I, Vict., no 1518 . The Factories and Shops Act 1897 .)

Loi du 20 février igoo. (63, Vict., no 1654 . The Factories and Shops Act igoo.)

Loi du 5 décembre ig02. (2, Edward VII, no 1804 . The Factories and Shops Continuance Act.)

Bulletin de l'Offce intern. du travail, I902, t. I, p. 646, no 3 .

Loi du 30 octobre 1903 (3, Edward VII, no 1857 . The Factories and Shops Act igo3.)

Bulletin de l'Office intern. du travail, igo/, t. III, p. 384.

Loi du 3o novembre igo4. (4, Edward VII, no ig55. The Factories and Shops Act igo4.)

Bulletin de l'Offlce intern. du travail, igo5, t. IV, p. 407.

Loi du 6 octobre igo5. (5, Edward VII, no i 975 . The Factories and Shops Act ig05.)

Bulletin de l'Offce intern. du travail, igo7, t. VI, p. I64.

Loi du 12 décembre igo5. (5, Edward VII, no 2008. The Factories and Shops Act $1905, \mathrm{n}^{0}$ 2.)

Bulletin de l'Offce intern. du travail, Igo7, t. VI, p. I64, note 2.

Loi du 23 décembre ig07. (An Act to Amend the Factories and Shops Act 1907 , Edward VII, no 2137.)

Bulletin de l'Offlee intern. du travail, I909, t. VIII, p. I45. 
Loi du 2 mars 1909. (An Act to Amend the Factories and Shops Act rgog, Edward VII, no 2194.)

Bulletin de l'Office intern. du travail, 1909, t. VIII, p. 321.

4. Nonobstant toute disposition des lois sur les fabriques et magasins, le Comité spécial qui a été constitué le I 7 décembre I go I, sous le nom de Comité des mouleurs en fer (Iron Moulders Board), est, par la présente loi, autorisé à fixer des prix et tarifs de salaires minimum qui doivent être payés à une ou plusieurs personnes ou catégories de personnes occupées à des travaux, manipulations ou opérations se rattachant à la fonderie d'acier et a qualité pour exercer, en ce qui concerne les travaux, manipulations et opérations de la fonderie d'acier, toutes les attributions conférées aux comités spéciaux par la neuvième partie de la loi principale.

5. Le pouvoir conféré par les lois sur les fabriques et magasins au Gouverneur, assisté du Conseil, de constituer un Comité spécial pour la fixation des prix et tarifs de salaires minimum qui doivent être payés à une ou plusieurs personnes ou catégories de personnes occupées à l'intérieur ou au dehors d'une fabrique ou d'un atelier ou en un lieu quelconque, implique le pouvoir d'instituer un Comité spécial pour la fixation des prix et tarifs de salaires minimum qui doivent être payés à raison d'un ou plusieurs travaux, manipulations ou opérations nommément désignés, par voie d'arrêté, par le Gouverneur assisté du Conseil. Les lois susvisées doivent être interprétées en tenant compte des modifications qui sont nécessaires pour l'application des dispositions de la présente. 
I. - Loi no I975, du 6 octobre igo5, consolidant la loi sur la surveillance et la réglementation des fabriques, ateliers et maga$\operatorname{sins}(\mathrm{I})$.

II. - Loi no 2008, du I2 décembre I9o5 (2), modifiant la loi de I 905 sur les fabriques et magasins.

III. - Loi no 2 I 37 , du 23 décembre 1907 , modifiant la loi de I905 sur les fabriques et magasins (3).

IV. - Loi no 224I, du 4 janvier I910 (4).

Les quatre lois sont réunies ici pour donner le texte actuellement en vigueur; les textes abrogés sont en italique.

ixe PARTie. - Comités SPÉciaux

\section{Objets des Comités spéciaux.}

75. - I. Pour fixer les prix et tarifs de salaires minimum qui doivent être payés à un ou plusieurs ouvriers ou à des catégories d'ouvriers employés n'importe où (5), soit à la préparation ou à la fabrication, en tout ou en partie, d'articles de confection, d'effets d'habillement ou de meubles, soit à la cuisson du pain ou à toute autre cuisson, soit à tout travail, métier ou profession généralement ou fréquemment exercés dans des fabriques ou ateliers, soit à un travail, métier, profession se rattachant à la boucherie ou à la charcuterie, ou chez un fabricant ou marchand d'articles de charcuterie,

$\mathrm{Ou}(6)$ dans des affaires quelconques qui se font d'habitude ou fréquemment dans un magasin,

Ou dans toute entreprise de camionnage ou de transport ou en concourant au camionnage ou au transport d'une manière générale ou dans des travaux déterminés,

Ou dans certains travaux, industries ou affaires se rapportant à la construction de bâtiments ou à l'exploitation de carrières, sauf dans l'agriculture,

Ou dans toutes affaires ou occupations se rapportant à la préparation du bois à brûler destinć au commerce, ou se rapportant à la vente, à la distribution du bois, du coke ou du charbon (7),

(1) Bulletin de l'Offlce intern. du travail, 1907, t. VI, p. 164.

(2) Ibld., 1907, t. VI, p. 164, note 2.

(3) Ibld., I909, t. VIII, p. 145.

(4) Annuaire de la législatlon du travall, 1910, p. 345.

(5) Le texte de la loi de 1905 était : " d'ouvriers occupés dans une fabrique ou un atelier ou hors de ces élablissements ". Le nouveau texte résulte de l'article 7 de la loi du 23 décembre 1907 .

(6) Le reste de l'énumération ajouté par l'article 6 b) de la loi du 23 décembre 1907.

(7) Également dans les mines (de houille, métaux et minerais), l'horlogerie, l'électricité, etc. Cr. art. 6 de la loi du 4 janvier ıgro, qui n'a pas été incorporé au texte principal. 
Le gouverneur, par décision prise en conseil, peut, à tout moment, s'il le juge utile, constituer un Comité spécial qui comptera au minimum quatre membres et un président, et dont les membres pourront être, à tout moment, révoqués.

2. Pour la fixation des prix ou tarifs de salaires minimum, le Comité spécial tiendra compte de la nature, du genre et de la catégorie du travail, ainsi que des conditions dans lesquelles le travail s'exécute, de l'âge et du sexe des ouvriers et de toutes circonstances dont il lui sera prescrit de tenir compte, ainsi (I) que a) de l'endroit ou de la localité où le travail sera exécuté ; $b$ ) de l'heure du jour ou de la nuit à laquelle le travail sera exécuté; $c$ ) si on travaille plus de six jours consécutivement ; $d$ ) du commencement et de la fin de chaque journée de travail et de la fixation d'un salaire plus élevé à payer pour toute heure ou partie d'heure de travail en sus des heures de la journée normale; $e$ ) si le travail est occasionnel, c'est-à-dire s'il doit durer un jour ou moins d'un jour. Le Comité spécial peut, en ce qui concerne le travail à exécuter le dimanche ou un jour férié, fixer des prix ou taux spéciaux de salaires.

3. Sauf en ce qui concerne les métiers et industries qui étaient déjà visés, au I $^{\text {er }}$ octobre 1896 , par les dispositions de la loi sur les fabriques et ateliers concernant les comités spéciaux, il ne peut être constitué de Comité spécial que sur résolution, votée par les deux Chambres du Parlement, jugeant utile la création de ce Comité spécial.

\section{Mode ale recrutement lles membres et alurée des fonctions.}

76. - I. Les comités spéciaux seront composés moitié de représentants des patrons et moitié de représentants des ouvriers.

2. Les représentants des patrons devront être ou avoir été, en fait et réellement, patrons dans l'industrie visée, pendant les trois ans qui auront précédé leur nomination (2), et les ouvriers devront être ou avoir été, en fait et réellement, ouvriers de l'industrie, pendant les trois ans qui auront précédé leur nomination (3). Toutefois, cette disposition ne s'applique pas aux nominations faites par le ministre.

3. a) Les membres des comités spéciaux sont nommés pour trois ans; mais à l'expiration de ce terme leur mandat peut être renouvelé.

b) Le président d'un comité spécial est considéré comme membre de ce comité.

(1) A partir de ce mot et jusqu'à la fin de l'alinéa, le texte a été ajouté par l'article 5 de la loi du 4 janvier igio.

(2) Les neuf mots précédents sont ajoutés par l'article 9 de la loi du 23 décembre 1907 .

(3) Les neuf mots précédents sont ajoutés par l'article 9 de la loi du 23 décembre 1907. 
77. - I. Avant la nomination des membres d'un comité, le ministre peut, par voie de notification publiée dans la Government Gazette, désigner des personnes comme représentants des patrons et représentants des ouvriers, ayant qualité pour être nommés membres dudit comité.

2. Si un cinquième des patrons ou ouvriers d'une profession, industrie ou entreprise exercent ladite profession, industrie ou entreprise hors du district urbain, tel qu'il est défini dans la présente loi, une au moins des personnes désignées comme représentants des patrons et une au moins des personnes désignées comme représentants des ouvriers devront résider et exercer ou avoir exercé la profession, l’industrie ou l'entreprise hors du district urbain.

3. Si, dans un délai de vingt et un jours, à dater de la publication des noms des personnes ainsi désignées, un cinquième au moins des patrons ou un cinquième au moins des ouvriers adultes appartenant à la profession, l'industrie ou l'entreprise relevant du Comité spécial visé n'ont pas adressé au ministre une protestation écrite contre la nomination éventuelle des personnes désignées comme représentants de leur catégorie respective, le gouverneur peut, par décision prise en conseil, nommer les personnes ainsi désignées membres du Comité spécial, comme représentants des patrons ou des ouvriers.

4. S'il est établi, de façon jugée satisfaisante par le ministre, que le quart au moins des patrons ou des ouvriers adultes ont, dans le délai prescrit, protesté contre la désignations desdites personnes comme leurs représentants respectifs, les représentants de ces patrons et les représentants de ces ouvriers seront élus d'après le mode qui aura eté adopté en vertu des dispositions de la présente loi.

5. Il appartient au ministre de juger, à l'aide des données fournies par le dernier rapport annuel de l'inspecteur en chef, si le nombre des personnes qui ont protesté contre la désignation de leurs représentants éventuels correspond bien au quart au moins des patrons ou des ouvriers adultes de la profession visée.

6 (1). a) Lorsqu'un Comité spécial a été nommé par le gouverneur en conseil, en vertu des pouvoirs additionnels conférés par la section 7 de la loi de 1907 sur les fabriques et ateliers, tous les employeurs susceptibles d'être soumis au régime de l'arrêté dudit Comité spécial, enverront à l'inspecteur en chef, lorsqu'une élection sera nécessaire, leurs noms et adresses, ainsî que les noms et adresses de tous les employés de dix-huit ans au moins, dans la forme ou dans le sens de l'annexe à ladite loi; chaque patron et chaque employé dispose d'une voix ; 
b) Tout patron qui négligera de faire parvenir son nom et son adresse n'aura pas le droit de prendre part à l'élection des représentants des employeurs au Comité spécial;

c) Tout employé, de dix-huit ans au moins, qui prouvera, à la satisfaction de l'inspecteur principal, que sa besogne ordinaire consiste à être employé à des travaux ou des affaires pour lesquels un minimum de salaire doit être fixé par un Comité spécial sera inscrit comme électeur des représentants ouvriers au Comité spécial, quoique son patron n'ait pas fait connaître son nom et son adresse.

78. - Nonobstant toutes dispositions contraires de la présente loi, les membres d'un comité spécial chargé d'arbitrer ou de fixer les salaires et tarifs minimum à payer à une personne pour fabrication ou préparation, totale ou partielle, de meubles, ne seront pas élus, mais seront nommés par décision prise par le gouverneur en conseil.

79. - S'il s'agit d'un comité spécial pour l'industrie du vêtement pour hommes et jeunes gens, les représentants des patrons comprendront trois représentants des patrons tailleurs-confectionneurs et deux représentants des patrons tailleurs sur mesure. Il sera procédé à l'établissement des listes électorales et au vote pour la désignation de ces représentants, conformément à la procédure qui aura été fixée à cet effet.

80. - Si le nombre des personnes désignées comme représentants des patrons ou comme représentants des ouvriers n'excède pas le nombre des personnes à élire, les personnes ainsi désignées seront considérées comme élues et seront en conséquence nommées, par le gouverneur assisté du Conseil, membres du comité spécial.

81. - S'il se produit, pour une cause quelconque, une vacance au sein d'un comité spécial, le gouverneur peut, sans désignation ou élection préalable, par décision prise en conseil, nommer une personne représentant des patrous ou représentant des ouvriers. La personne ainsi nommée a la mème qualité que si elle avait été élue par les patrons ou par les ouvriers et elle est appelée à remplir ses fonctions pour la période qui reste à courir du mandat $d u$ membre décédé, démissionnaire ou exclu.

\section{Désignation du président.}

82. - I. Les membres d'un Comité spécial devront, dans un délai de quatorze jours à dater de leur nomination, désigner, par écrit, une personne (autre qu'un d'entre eux) qu'ils proposeront comme président du Comité. Cette personne sera nommée à ce poste par décision prise par le gouverneur en conseil.

2. Si, dans le délai de quatorze jours à dater de la nomination des membres du Comité, le ministre n'a pas reçu la proposition pour la désignation du président, le gouverneur pourra, sur l'ordre 
du ministre, procéder à cette désignation par déćlsion prise en conseil.

\section{Attributions des Comités spéciaux.}

83 (1). - Tout Comité spécial nommé postérieurement au 3o octobre igo3 devra, chaque fois qu'il aura à fixer des prix ou tarifs de salaires, observer les règles suivantes :

a) Le Comité s'attachera à déterminer les prix et tarifs de salaires moyens (pour le travail aux pièces ou pour le travail au temps) qui ont été effectivement payés par les patrons honorablement connus (reputable employers) à des ouvriers de capacité moyenne.

b) Les prix on larifs de salaires minimum qui seront fixés par la décision du Comité ne devront en aucun cas être supérieurs aux prix ou tarifs de salaires moyens ainsi déterminés.

c) Si le Conseil spécial estime que les prix ou tarifs de salaires moyens ainsi déterminés ne sont pas suffisants pour pouvoir servir de limite en vue de la faxation de prix et tarifs de salaires minimum à payer, il adressera, ì ce sujet, un rapport au ministre, qui, en ce cas, confiera à la Cour d'appel en matière industrielle le soin de fixer ces prix ou tarifs de salaires, que la Cour pourra fixer sans tenir compte de la disposition de l'alinéa b) cle la présente section.

d) Si la chose paraît juste et opportune, il pourra être fixé des salaires, prix ou tarifs spéciaux en ce qui concerne les ouvriers âgés, infirmes ou lents.

84. - Tous les pouvoirs d'un Comité spécial peuvent être exercés par la majorité des membres dudit Comité.

85. - S'il se produit une vacance au sein d'un Comité spécial (sauf s'il s'agit du siège du président), les membres restant en fonctions peuvent continuer à remplir leur mandat, comme s'il n'existait aucune vacance, si aucun d'entre eux ne s'y oppose.

86. - Le président d'un Comité spécial peut exiger de toute personne (même s'il s'agit d'un membre du Comité) appelée à témoigner devant ce Comité qu'elle dépose sous la foi du serment. A cet effet, il est autorisé à recevoir le serment prêté par le témoin.

87. - I. En tant qu'il s'agit de marchandises, professions, entreprises, relevant de la compétence d'un Comité spécial, ce Comité fixe les prix et tarifs de salaires minimum qui doivent être payés à une ou à plusieurs personnes ou à des catégories de personnes occupées dans une de ces professions, industries ou entreprises et concourant à la fabrication ou à la préparation de marchandises spécifiées par ledit Comité. 
2. Ces prix ou tarifs de salaires peuvent être fixés, au gré du Comité spécial, comme prix ou tarifs de salaires aux pièces ou comme prix ou tarifs de salaires au temps, ou à la fois aux pièces et au temps. Toutefois, pour la préparation ou la fabrication; totale ou partielle, de vêtements ou d'effets d'habillement hors de l'usine ou de l'atelier, il ne pourra être fixé que des prix et tarifs de salaires aux pièces. D'autre part, à la demande du patron d'une fabrique, d'un atelier, d'un magasin ou d'un local, le Comité établira des salaires ou tarifs au temps pour le personnel occupé à la conduite des machines fonctionnant dans l'établissement.

88. - Nonobstant toute disposition contraire de la présente loi, tous prix ou tarifs de salaires fixés par un Comité spécial pour la préparation ou la fabrication, totale ou partielle, d'un meuble devront, chaque fois que cela sera possible, être à la fois des prix ou tarifs de salaires aux pièces et des prix ou tarifs de salaires au temps, les prix ou tarifs de salaires aux pièces ayant pour base les prix ou tarifs de salaires au temps fixés par le Comité.

89. - Si, en vertu de la présente loi, une décision du Comité spécial fixe, pour un travail, à la fois des prix ou tarifs de salaires aux pièces et des prix ou tarifs de salaires au temps, les prix ou tarifs de salaires aux pièces devront toujours avoir pour base les prix ou tarifs de salaires au temps. Toutefois, une décision ne sera pas attaquable ou sans valeur du fait qu'un prix ou tarif de salaires aux pièces représente un gain supérieur ou inférieur à celui que donnerait un calcul basé sur les prix ou tarifs de salaires au temps.

90. - Tout Comité spécial, en fixant les prix on tarifs de salaires au temps minimum qui doivent ètre payés à une ou plusieurs personnes ou à des catégories de personnes, fixera également le maximum hebdomadaire des heures de travail auxquelles correspondent, d'après la nature ou les conditions de travail, les salaires au temps ainsi déterminés. Les prix ou tarifs de salaires au temps qui seront appliqués à une plus courte durée du travail ne devront pas être inférieurs au chiffre correspondant proportionnellement aux prix ou tarifs de salaires fixés ou au prix ou tarifs de salaires fixés pour le travail occasionnel (r). En outre, pour tout ouvrier du sexe masculin, àyé de moins de seize ans (2), travaillant un nombre d'heures supérieur au maximum fixé, le Comité déterminera des prix ou tarifs de salaires au temps supérieurs à ceux qui ont été fixés par la décision dudit Comité visant les prix ou tarifs de salaires applicables au maximum hebdomadaire des heures de travail.

(1) Ces douze mots ont été ajoutés par l'article 9 de la loi du 4 jan vier 1910.

(2) Abrogé par l'article 9 de la loi du 4 janvier 19 gro. 


\section{Apprentis, volontaires et jeunes ouvriers.}

91. - 1. En fixant les salaires et tarifs, en vertu des présentes dispositions, tout Comité spécial fixera également le nombre ou la proportion de volontaires qu'il est permis d'occuper dans une fabrique, un atelier, magasin ou local ou dans tous travaux, industries ou affaires ( $\mathrm{I}$ ), ainsi que les prix ou tarifs de salaires minimum qui devront être payés aux apprentis et volontaires concourant à la préparation ou à la fabrication, totale ou partielle, de marchandises visées par une décision du Comité spécial, ou travaillant dans une industrie, profession ou entreprise visée par une décision du Comité spécial.

2. En fixant ces salaires, le Comité pourra tenir compte de l'âge, du sexe et de l'expérience des apprentis ou volontaires visés, établir une échelle de salaires et tarifs à payer suivant l'âge, le sexe et l'expérience desdits apprentis et volontaires, et fixer une proportion différente de volontaires de l'un ou l'autre sexe.

92. - En fixant les salaires à payer à des personnes âgées de moins de vingt et un ans (autres que des apprentis ou volontaires) pour des catégories déterminées de travaux, le Comité spécial, peut, eu égard à la longue expérience acquise par les personnes appartenant à ces catégories déterminées, fixer, en faveur de ces personnes, des tarifs différents.

93. - Tous apprentis qui ne sont pas liés par un contrat d'apprentissage obligeant le patron à enseigner à l'apprenti, pendant une période de trois années, l'exercice de l'industrie ou de la profession, seront, pour l'application des présentes dispositions, considérés comme des volontaires.

17 (2). - Nonobstant toutes dispositions contraires de la loi principale, $a$ ) il est permis, avec l'autorisation écrite du ministre, de s'engager comme apprenti pour une durée inférieure à trois ans, si, en raison de l'expérience déjà acquise par l'intéressé ou de la durée de ses services dans la profession, il est impossible de l'engager comme apprenti pour une durée de trois années; b) quiconque s'est engagé, avec l'autorisation du ministre, dans les conditions prévues par la présente section, ne devra pas être considéré comme « volontaire ».

94. - Lorsque, par application d'une décision du Comité spécial, les salaires d'un apprenti ou d'un volontaire devront varier selon l'expérience acquise ou la durée des services rendus, il devra être tenu compte, dans le calcul de la durée des services rendus, pour la fixation du salaire que cet apprenti ou volontaire a le droit de réclamer, de tout laps de temps pendant lequel ledit apprenti ou volontaire a exercé la profession.

(1) Ces sept derniers mots ont été ajoutés par l'article 12 de la loi du 23 décembre 1907 .

(2) Disposition de la loỉ du 12 décembre 1905. 
95. - Si un apprenti âgé de moins de vingt et un ans s'est engagé, par contrat écrit, pour une durée de deux ans au minimum, aucune disposition d'une décision rendue par un Comité spécial ne peut, en quoi que ce soit, annuler ou modifier le contrat d'apprentissage, si ledit contrat a été signé par toutes les parties intéressées antérieurement au dépôt, sur le bureau d'une des Chambres du Parlement, du projet de résolution tendant à la création dudit Comité spécial.

96. - En vertu des présentes dispositions, le ministre est autorisé à accorder à toute personne âgée de plus de vingt et un ans qui aura prouvé d'une façon suffisante qu'elle n'a pas acquis entièrement l'expérience exigée des volontaires par un Comité spécial l'autorisation de travailler en qualité de volontaire, pour une durée qui sera déterminée par l'autorisation, moyennant le salaire fixé par le Comité pour les volontaires ayant acquis la même expérience.

97. - A moins que le contexte n'exige une interprétation différente, les mots ( apprenti ) (apprentice) et ( volontaire ) (improver) auront, dans toute décision d'un Comité spécial, le sens qui leur est attribué dans la présente loi.

\section{Conditions d'établissement du salaire aux pièces flxé par l'employeur.}

98. - I. Tout Comité spécial peut, au lieu de fixer lui-même les prix ou tarifs de salaires minimum aux pièces à attribuer à la préparation ou à la fabrication totale ou partielle de certaines marchandises, décider que ces prix ou tarifs de salaires aux pièces seront établis et payés, dans les conditions fixées par la sous-section suivante, sur la base des salaires au temps par le Comité luimême.

2. Tout employeur qui; par application d'une décision ainsi prise par un Comité spécial, établit et paye des prix ou tarifs de salaires aux pièces doit baser ces prix ou tarifs sur le gain d'un ouvrier moyen, travaillant dans les mêmes conditions que les ouvriers auxquels devront être appliqués lesdits prix ou tarifs aux pièces, qui serait payé d'après les tarifs de salaires au temps établis par le Comité spécial. Tout employeur faisant application de ces dispositions devra, à toute réquisition, fournir à l'inspecteur en chef un releré des salaires et tarifs ainsi fixés.

3. Quiconque, ayant établi un prix ou tarif de salaires aux pièces conformément aux dispositions de la présente section, paye ou offre, fait offrir ou essaye de payer, soit directement, soit indirectement, sous un prétexte quelconque ou par un détour quelconque, un prix ou tarif de salaires aux pièces inférieur au prix ou tarif de salaires ainsi établi, ou contrevient de façon quelconque aux dispositions de la sous-section précédente, est coupable d'infraction aux dispositions du présent titre. 
4. En cas de poursuites judiciaires contre une personne prévenue d'infraction aux dispositions des deux dernières sous-sections de la présente section, la preuve que cette personne a établi ou payé un prix ou tarif de salaires aux pièces répondant aux dispositions desdites sous-sections incombera, dans tous les cas, au défendeur.

\section{Ouvriers âgés, lents et infirmes.}

99. - I. S'il est établi, de façon jugée satisfaisante par l'inspecteur en chef, qu'une personne, en raison de son âge, de sa lenteur ou de ses infirmités, n'est plus en état de trouver du travail au salaire minimum fixé par un Comité spécial, l'inspecteur en chef pourra, en pareil cas, accorder à cet ouvrier âgé, infirme ou lent, pour une durée de douze mois, l'autorisation de travailler moyennant un salaire (dont le taux sera fixé par l'autorisation) inférieur audit salaire minimum. Cette autorisation pourra être indéfiniment renouvelée.

2. Le nombre des personnes munies de l'autorisation à titre d'ouvriers lents, occupés dans une fabrique, ne pourra, à moins de permission du ministre, excéder le cinquième du nombre total de personnes occupées dans l'établissement soit au temps, soit aux pièces, aux salaires minimum des adultes. Toutefois, dans une fabrique enregistrée, il ne peut être occupé qu'un seul ouvrier muni de l'autorisation à titre d'ouvrier lent. Quiconque, sans permission du ministre, occupe un nombre d'ouvriers lents supérieur à la proportion ci-dessus fixée, est coupable d'infraction aux présentes dispositions.

3. Quiconque, directement ou indirectement, sous un prétexte quelconque ou par un détour quelconque, paye ou offre ou fait offrir ou payer à un ouvrier âgé, infirme ou lent un salaire inférieur au salaire fixé par l'autorisation de l'inspecteur en chef, est coupable d'infraction aux dispositions du présent titre.

4. En cas de refus de l'inspecteur en chef de délivrer une autorisation dans les conditions ci-dessus, l'ouvrier en cause peut en appeler au ministre, qui a qualité pour délivrer l'autorisation aux lieu et place de l'inspecteur.

\section{Durée, publication et application des décisions des Comités spéciaux et de la Cour d'appel en matière industrielle.}

100. - Les prix ou tarifs de salaires fixés par un Comité spécial entrent en vigueur à la date fixée par le Comité (au plus tôt trente jours après la date de la décision) et restent en vigueur jusqu'à modification par une nouvelle décision du Comité spécial. Toutefois cette décision peut, à tout moment, être modifiée ou cassée par la Cour d'appel en matière industrielle.

101. I. Toute décision d'un Comité spécial sera signée par le président de ce comité et publiće dans la Government Gazette. 
Elle sera applicable à toute ville (city or town) et à toute commune urbaine à laquelle elle aura été expressément déclarée applicable par ordonnance prise par le gouverneur en conseil et publiée dans la Government Gazette.

2. Exceptions faites de toutes décisions d'un Comité spécial qui auraient été rendues applicables à un comté ou à une partie de comté antérieurement à l'entrée en vigueur de la loi complémentaire de 1902 sur les fabriques et magasins (Factories and Shops Continuance Act, 1902), les décisions de Comités spéciaux ne sont applicables à aucun comté et à aucune partie de comté, sauf application des dispositions ci-après.

3. a) Toute décision d'un Comité spécial peut, par voie d'arrêté pris par le gouverneur en conseil, être étendue à toute partie d'un comté située dans le rayon d'une ville (city or town) à une distance de moins de 10 milles;

b) Toute décision d'un Comité spécial peut, par voie d'arrêté pris par le gouverneur en conseil, être étendue à toute partie d'un comté situce dans le rayon d'une ville (city or town), à une distance de ro milles et au delà, si le Conseil de Comté sollicite cette extension de la décision;

c) Tout arrêté pris par le gouverneur en conseil, par application de la présente section, sera publié dans la Government Gazette et toute décision ainsi étendue à une partie de comté sortira son plein effet dans ladite partie de comté.

4. Quand une décision d'un Comité spécial aura été ainsi étendue expressément à une commune urbaine, à un comté ou à une partie de comté par décision prise par le gouverneur en conseil, toutes modifications apportées, à un moment quelconque, à cette décision par le Comité spécial lui-mème ou par la Cour d'appel en matière industrielle, sont applicables à ladite commune urbaine, audit comté ou à ladite partie de comté.

102. - Aucune décision d'un Comité spécial n'est applicable aux enfants d'un employeur.

\section{Dispositions visant les Comités du meuble, cle la boulangerie- et de la pàtisserie.}

103. - I. Un Comité spécial peut être constitué pour fixer les prix ou tarifs de salaires minimum à payer à une ou plusieurs personnes ou à des catégories de personnes pour la préparation ou la fabrication totale ou partielle d'une catégorie déterminée de meubles, à une ou plusieurs personnes ou à des catégories de personnes occupées à la fabrication de panneaux de cheminées (dessus de cheminées) ou de dessus de cheminées en bois (exception faite des panneaux de cheminées en bois à peindre, communément fabriqués dans les scieries mécaniques), et à une ou plusieurs personnes ou à des catégories de personnes occupées à la fabrication de matelas et objets de literie. 
2. Un Comité spécial peut être constitué pour fixer les prix ou tarifs de salaires minimum à payer à une ou à des catégories de personnes pour un travail de boulangerie ou de cuisson au four en général et à une ou plusieurs personnes ou à des catégories de personnes occupées au travail de fabrication d'articles de pâtisserie.

\section{La compétence des Comités peut être étendue par voie de décision prise par le Gouverneur en conseil.}

104. - Lorsqu'une ou plusieurs personnes ou des catégories de personnes sont employées par un employeur à la préparation ou à la fabrication d'objets pour la préparation ou la fabrication desquels des prix ou tarifs de salaires minimum ont été fixés par un Comité spécial, tout Ćomité spécial devra, sur ordonnance prise en conseil par le Gouverneur, fixer également, dans la forme prescrite par la présente loi, les prix ou tarifs des salaires minimum que tout employeur devra payer à ladite personne ou auxdites personnes ou auxdites catégories de personnes pour la préparation ou la fabrication totale ou partielle d'objets quelconques, soit à l'intérieur, soit en dehors de la fabrique ou de l'atelier.

19 (I). - I. Par voie d'arrêté pris en conseil et publié dans la Government Gazette par le Gouverneur lorsqu'il a reçu pouvoir à cet effet en vertu d'une résolution adoptée par les deux Chambres du Parlement, la compétence d'un Comité spécial, par application des lois sur les fabriques et magasins, peut être étendue de telle sorte que le Comité ait qualité pour fixer les prix ou tarifs de salaires minimum applicables à tous objets fabriqués, industries, professions ou entreprises, ou à partie des objets fabriqués, industries, professions ou entreprises qui, de l'avis du Gouverneur, sont de la même catégorie ou du même genre que ceux pour lesquels ledit Comité spécial a été institué; le Comité spécial est revêtu, en ce qui concerne les objets fabriqués, industries, professions ou entreprises dénommés dans l'arrêté, de tous les pouvoirs conférés aux Comités spéciaux par les lois sur les fabriques et magasins.

2. Un exemplaire de la Government Gazette contenant le texte d'un arrêté étendant la compétence d'un Comité spécial constitue une preuve suffisante de l'existence dudit arrêté, et cet arrêté ne peut être annulé ou contesté par aucun tribunal.

\section{Suspension des décisions.}

105. - Nonobstant toute disposition de la présente loi, le Gouverneur peut, à tout moment, par voie d'arrêté pris en conseil et publié dans la Government Gazette, suspendre, pour toute période qui lui paraîtra convenable, sans que la durée totale de la suspen-

(1) Disposition de la loi du 12 décembre 1905. 
sion puisse dépasser six mois, l'application d'une décision émanant d'un Comité spécial. Quand l'application d'une décision a été ainsi suspendue (que cette décision ait été ou non publiée dans la Government Gazette), le Comité spécial visé doit immédiatement interroger, citer et entretenir au sujet de la décision suspendue tous témoins utiles; après quoi, il pourra soit maintenir sa décision première, soit faire subir à cette décision toutes modifications jugées nécessaires.

2. Si le Comité spécial modifie sa décision, la décision modifiée devra être immédiatement publiée dans la Government Gazette et elle sera applicable à tous égards comme décision émanant dudit Comité spécial ; elle sera applicable, à partir de l'époque qu'elle aura fixie, à toute ville (cily and town) et à toute commune urbaine ou à tout comté ou partie de comté auxquels elle aura été rendue expressément applicable par une ordonnance prise en conseil par le Gouverneur et publice dans la Government Gazette. La décision suspendue devient alors nulle et de nul effet.

3. Si le Comité spécial visé fait connaître au Ministre qu'il maintient sa décision sans modification, la suspension de l'application de cette décision sera, par voie d'arrêté pris en conseil par le Gouverneur et publié dans la Government Gazette, révoquée à partir de l'époque qui aura été fixće par ledit arrêté, au plus tard dans un délai de quatorze jours.

\section{Dispositions générales.}

106. - Dans le prísent titre, le terme " vêtements et effets d'habillement « (clothing and wearing apparel) comprend également les chaussures et souliers.

107. - Lorsqu'un ouvrier est occupé à exícuter deux ou plusieurs genres de travail pour lesquels des salaires ont été fixés par un Comité spécial, il doit recevoir, proportionnellement au temps consacré par lui à chaque genre de travail, le salaire fixé par le Comité pour ce genre de travail.

15 (1). - Lor'squ'un ouvrier est, au cours d'une journée, occupé pour le compte d'un employeur à un travail pour lequel un Comité spécial a fixé des prix ou des tarifs de salaires au temps, tout travail auquel peut être appelé cet ouvrier durant cette même journée, pour le compte du même employeur, à l'intérieur ou en dehors d'une fabrique ou d'un atelier, doit être payé aux mêmes prix ou tarifs de salaires au temps.

108. - Si une décision rendue par un Comité spécial est modifiée et révoquée, cette modification ou cette révocation ne porte directement ou indirectement aucun préjudice aux actions judiciaires qui ont pu être engagées antérieurement, en vertu de la présente loi, à raison d'une contravention à cette décision, non plus qu'aux

(1) Disposition de la loi du i2 décembre 1905. 
droits existant en vertu des dispositions du présent titre, au moment de cette modification ou de cette révocation.

109. - Dénomination abrégée des conseils.

110. - Une copie certifiée conforme de toute décision d'un Comité spécial concernant les prix et tarifs de salaires minimum tels qu'ils ont été fixés par ledit Comité sera imprimée, peinte ou affichée, en caractères romains et lisibles, en un endroit apparent, de façon que tout le personnel occupé puisse le lire facilement, à l'entrée ou près de l'entrée de tout établissement (fabrique ou atelier) situé dans tout pays ou lieu auquel est applicable la décision dudit Comité spécial.

111. - Lorsqu'un Comité spécial a, par une décision, fixé des prix ou tarifs de salaires aux pièces pour la préparation ou la fabrication totale ou partielle de certains objets, si le Comité, dans l'énumération des travaux auxquels doivent être attribués lesdits prix ou tarifs de salaires aux pièces, a énuméré diverses opérations et si une ou plusieurs de ces opérations ont été omises sur l'ordre ou avec le consentement exprès ou tacite des contre maîtres, chefs de service ou représentants de celui-ci, le prix ou salaire qui devait être payé pour le travail visé n'est pas modifié de ce fait, mais demeure, sauf dispositions contraires insérées dans la décision, tel qu'il a été fixé pour l'ensemble du travail visé.

112. - Lorsqu'un Comité spécial, pour la préparation ou la fabrication totale ou partielle de certains objets dans un établissement (fabrique ou atelier) ou en dehors de l'établissement ou pour l'exécution d'un travail quelconque, n'a fixé qu'un salaire au temps, il est interdit de payer ou de faire payer pour ce travail des salaires aux pièces, et la réception de salaires aux pièces ne constitue pas, dans ces conditions, payement, intégral ou partiel, dudit salaire au temps.

113. - Lorsqu'un Comité spécial, pour la préparation ou la fabrication totale ou partielle de certains objets dans un établissement (fabrique ou atelier) ou en dehors de l'établissement ou pour l'exécution d'un travail quelconque, a fixé des prix ou tarifs de salaires aux pièces ou des prix ou tarifs de salaires au temps, il est interdit d'engager ou contraindre, directement ou indirectement, une personne visée par la décision du Comité à accepter, au lieu de monnaie ou comme payement ou acompte pour un travail effectué ou comme sal'aire gagné, des denrées de n'importe quelle espéce, et la réceptión ou l'acceptation de denrées ne constitue pas payement, intégral ou partiel, du prix du travail ou des salaires prévus.

33. - I. Il est interdit aux patrons de fabriques, ateliers et magasins (à l'exception des magasins dénommés dans la quatrième cédule de la loi principale) ainsi qu’à leurs femmes et 
enfants d'accepter ou d'avoir, directement ou indirectement, comme pensionnaires ou logeurs, moyennant une indemnité quelconque, des ouvriers adultes, ou d'avoir une part quelconque dans l'exploitation d'un établissement où leurs ouvriers sont en pension ou sont logés. Toutefois, l'inspecteur en chef peut, s'il le juge utile, autoriser, sous certaines conditions qu'il fixera, un patron de fabrique, atelier ou magasin, ou la femme ou l'enfant de ce patron, à recevoir de l'argent d'un ouvrier en échange de la pension ou du logement.

2. En dehors du cas prévu dans la présente section, il est interdit à tout ouvrier de payer ou de s'engager à payer une somme d'argent quelconque à un patron de fabrique, atelier ou magasin, ou à la femme ou à l'enfant de ce patron, en échange de la pension ou du logement.

114. - Lorsqu'un employeur occupe une personne exécutant pour lui un travail pour lequel un Comité spécial a fixé des prix ou tarifs de salaires minimum, l'employeur est tenu de payer à ladite personne le prix ou salaire fixé intégralement en espèces et sans retenue d'aucun genre et devra agir en conséquence. La personne visée peut, dans un délai de douze mois à dater du moment où cette somme lui est due, engager devant le tribunal compétent une action en vue d'obtenir de l'employeur le salaire intégral qui lui est dû ou ce qui lui reste dù sur le salaire fixé par la décision du Comité, nonobstant tout paiement d'un salaire moindre déjà effectué ou toute entente ou toute convention contraire, soit expresse, soit tacite.

115. - Les Comités spéciaux qui, antérieurement à l'entrée en vigueur de la présente loi, ont été constitués pour l'industrie, la profession ou l'entreprise de construction de voitures et charrettes ou de fabrication d'autres véhicules (exception faite des voitures d'enfants ou de malades [perambulators]) ainsi que pour les ouvriers qui sont occupés à la fabrication d'une partie quelconque desdites voitures, charrettes et autres véhicules (exception faite des voitures d'enfants ou de malades [perambulators]) ne seront ni maintenus ni prorogés. Aucune décision prise par ces Comités spéciaux ne sera applicable ou valable à l'avenir.

116 (1). - Les décisions prises antérieurement au 9 septembre Igoz par des Comités spéciaux institués pour l'industrie et la profession de ferblantier (tinsmith), ainsi que toutes décisions prises ultérieurement par ces Comités spéciaux, ne sont ni applicables ni valables dans la mesure où elles visent les salaires à payer aux personnes occupées à la fabrication de boîtes ou récipients pour confitures ou conserves de fruits, de légumes ou d'autres produits alimentaires.

(1) Abrogé par l'article i3 de la loi du 23 décembre 1907. 


\section{II. - Queensland.}

Loi du 28 décembre ı 900 modifiant la législation sur les fabriques et magasins. (64, Vict., $\mathrm{n}^{\circ} 28$.)

Bulletin de l'Office intern. du travail, I909, t. VIII, p. 254, no $\mathrm{I}$.

Loi no 8 du i5 avril i 908 sur les Comités de salaires.

Bulletin de l'Office intern. du travail, t. VII, igo8, p. I80.

Le texte reproduit pour la plus grande partie textuellement les dispositions de la loi de Victoria.

\section{III. - Australie du Sud.}

Loi du 2 I décembre 1907.

Bulletin de l'Office intern. dlu travail, I908, t. VIII, no 1 , p. I94. Art. 78 à i 6 .

Loi du 23 décembre 1908.

Bulletin de l'Office intern. du travail, I909, t. IX, p. 394, no 5 . Art. 3.

\section{IV. - Nouvelle-Zélande.}

The industrial conciliation and arbitration Act.

Loi du 3 I août I 894 sur la conciliation et l'arbitrage obligatoire.

Loi du 18 octobre $189^{5}$. Amendment Act no 30 .

Loi du 12 octobre 1896 . Amendment Act no 57 .

Loi de 1898 . Amendment Act $\mathrm{n}^{\circ} 40$.

Loi du 2 I octobre 1899-I900. (Compilation Act no $5 \mathrm{r}$.)

Loi du 7 novembre rgor. Amendment Act no 37 .

Bulletin de l'Office intern. du travail, t. I, I902, p. 278.

Lois du 4 septembre igo3 et du 27 septembre 1903 . Amendment Act.

Bulletin de l'Office intern. du travail, I904, t. III, p. 305. Loi du 20 novembre igo3.

Bulletin de l'Office intern. du travail, rgo3, t. II, p. 410.

Loi du 8 novembre igo3. Amendment Act no 53.

Bulletin de l'Office intern. du travail, i 905 , t. IV, p. $4 \mathrm{ro.}$

Loi du 27 octobre igo5. Compilation Act no 32 .

Loi du 3i octobre igo5. Amendment Act no 56.

Loi du 29 octobre igo6. Amendment Act no 40.

An Act to consolidate certain enactements of the general Assembly relating to the settlement of industrial disputes by conciliation and arbitration. $1908, \mathrm{n}^{\circ} 82$.

Loi no 82 de 1908 , consolidant certaines dispositions légales 
prises par l'assemblée générale, concernant le règlement des conflits industriels par voie de conciliation ou d'arbitrage.

Bulletin de l'Office intern. du travail, 1908, t. VII, p. 35o.

Industrial conciliation and arbitration amendment.

i 6 octobre igo8, no 239 .

An Act to amend the conciliation and arbitration. Act 1908 .

3 décembre i910, I Géo. V, I910, no 68.

Bulletin de l'office intern. du travail, I91, p. 68.

\section{V. - Nouvelle-Galles du Sud.}

\section{I. - Système DE L'ARBitrage OBLIGATOIRE}

Loi du ro décembre i 90 . (Industrial arbitration. Act no $5_{9}$.) Bulletin de l'office intern. du travail, I902, t. I, p. 124.

Loi du 30 juin i 905 .

Bulletin de l'Office intern. clu travail, ıgo8, t. VII, p. $9^{3 .}$

\section{II. - SYSTÈME DES COMITÉS DE SALAIRES}

Loi du 24 avril i 908 .

An Act to provide for the constitution of boards to determine the conditions of employment in industries : to define the powers, jurisdiction and procedure of such boards, and to give effect to these awards and appoint a court; to prohibit lock-outs and strikes, and to regulate employment in industries; to preserve certain awards, orders, direction and industrial agreements; and for purposes consequent thereon or incidental thereto. Assented to $24^{\text {th }}$ april. (Act $n^{\circ} 3$, I908.)

Loi ayant pour objets : d'instituer des conseils spéciaux pour la fixation des conditions du travail dans l'industrie; de déterminer les pouvoirs, la juridiction et le fonctionnement de ces conseils; de rendre exécutoires leurs décisions et d'instituer une Cour industrielle; de prohiber le lock-out et la grève et de réglementer le travail dans l'industrie; d'assurer l'exécution de diverses décisions, prescriptions, instructions et accords industriels, avec toutes ses conséquences et connexités. Approuvée le 24 avril 1908 .

Bulletin de l'office intern. du travail, $\mathbf{1 9 0 8 , ~ t . ~ V I I , ~ p . ~} 328$.

\section{VI. - Australie occidentale.}

The Industrial and Conciliation Act (no 13 ).

Loi du 19 février 1902.

Annuaire de la législation du travail belge, r9o2, p. 204.

Bulletin de l'Office intern. du travail, I902, t. I, p. 524.

Loi du 2 i décembre rgo9, no 47.

Bulletin de l'office intern. du travail, 1910, p. 295. 


\section{VII. - Australie (Confédération).}

Loi du r5 décembre i904. Commonwealth conciliation and arbitration Act.

Art. 40. - Dans sa sentence ou par ordonnance rendue ì la requête d'une partie, la Cour pourra, aussi longtemps que la sentence est en vigueur :

a) Fixer un minimum de salaire ou de rémunération et, en pareil cas, prendre, à la requête d'une partie ou de toute organisation, des mesures pour permettre au tribunal à désigner de fixer, suivant tel mode et sous telles conditions qui seront déterminés dans l'ordonnance ou la sentence, un taux moins élevé pour les ouvriers incapables de gagner le minimum ainsi établi. Bulletin de l'office intern. dlu travail, 1905, t. IV, p. $52 \mathrm{I}$.

Loi du r3 décembre r 909 , no 28.

Annuaire de l'Office du travail belge, igo9, p. 407.

Loi du 29 août 1910, no $^{7}$.

Annuaire de l'Office du travail belge, ig1o, p. 273. 


\section{B. - Grande-Bretagne}

\section{Loi du 20 octobre 1909, instituant des Conseils (I) d'industrie dans certaines industries.}

An Act to provide for the establishment of Trade Boards for certain trades (20 oct. Igo!) [9. Edw. 7. ch. 22].

\section{Institution ale Conseils a'malustrie aluns les industries soumises iı la présente loi.}

1. - I. La présente loi est applicable aux industries désignées dans la cédule annexée ci-après, ainsi qu’à toute autre industrie à laquelle elle est étendue par une ordonnance provisoire (provisional orler) du Boarl of Trale (Ministère du Commerce), rendue en vertu de la présente section.

2. Le Borral of Tralle peut, par une ordonnance provisoire, rendre la présente loi applicable à toute industrie désignée non encore soumise à la loi s'il considire que le taux des salaires courants dans une branche quelconque de ladite industrie est exceptionnellement bas en comparaison avec celui pratiqué dans d'autres professions et s'il estime que, vu la situation de cette industrie, il convient de la soumettre ì la présente loi.

3. Si, à un moment quelconque, le Board of Trade estime que, dans une quelconque des inclustries soumises à la présente loi, les conditions du travail se sont modifiées au point de rendre inutile l'application de la présente loi, il peut, par nue ordonnance provisoire, soustraire ladite industrie à l'application de la loi.

4. Le Board of Tralle peut faire confirmer par le Parlement toute ordonnance provisoire rendue en application de la présente section ; ladite ordonnance n'est valable, toutefois, qu'après avoir été confirmée par le Parlement.

5 . Si, pendant qu'un projet de loi confirmant une ordonnance provisoire de cet ordre est soumis à l'une ou l'autre Chambre du Parlement, une protestation est formulée contre l'une quelconque des ordonnances contenues dans ledit projet de loi, ce dernier peut, pour ce qui a trait à l'ordonnance visée, être renvoyé à une commission d'enquête ou, si les deux Chambres du Parlement en ordonnent ainsi, à une commission mixte composée de membres des deux Chambres ; l'auteur de la protestation doit être autorisé à comparaître en personne et à faire valoir ses observations, comme s'il s'agissait d'un projet de loi d'intérêt privé.

6. Toute loi confirmant une ordonnance provisoire rendue en vertu de la présente section peut être abrogée, modifiée ou amen- 
dée par une autre ordonnance provisoire ultérieure du Board of Tracle confirmée par le Parlement.

2. - I. Le Board of Trade doit, quand la chose est possible, instituer, conformément aux règlements rendus en vertu de la présente loi, un ou plusieurs Conseils d'industrie (Trade Boards) pour toute industrie ou pour une branche d'industrie quelconque soumise à la présente loi.

Si, en vertu de la présente loi, il a été institué un Conseil dans une industrie ou branche d'industrie ayant une certaine importance en Irlande, il doit être institué un Conseil spécial à l'Irlande pour ladite industrie ou branche d'industrie.

2. Lorsqu'un Conseil a été institué pour une branche quelconque d'industrie, toute allusion faite dans la présente loi à l'industrie pour laquelle le Conseil a été institué doit être considérée comme s'appliquant à la branche d'industrie pour laquelle il a été institué.

3. - Le Conseil institué pour une industrie a pour mission d'examiner, selon les besoins de l'espèce, toutes les questions intéressant les conditions industrielles qui lui sont soumises par un secrétaire d'État, par le Board of Tracle ou par tout autre département ministériel; il doit adresser un rapport au département qui lui a soumis la question.

\section{Tarif minimnm.}

4. - I. Les Conseils d'industrie doivent, conformément aux dispositions de la présente section, fixer, dans'leurs industries, le taux minimum du salaire au temps (désigné dans la présente loi sous le nom de (tarif minimum au temps »); ils peuvent en outre fixer le taux minimum général des salaires pour travail aux pièces dans leurs industries (désigné dans la présente loi sous le nom de "tarif minimum général aux pièces »). Ces taux de salaire (au temps ou aux pièces) peuvent être établis en vue d'être appliqués soit à l'industrie tout entière, soit à un procédé spécial de travail, ou à une catégorie spéciale d'ouvriers de l'industrie, soit à une circonscription particulière.

Si un Conseil déclare au Boarcl of Tracle qu'il lui est, dans un cas donné, impossible de fixer un tarif minimum au temps conformément à la présente section, le Board of Trade peut, pour ce cas particulier, relever le conseil de ses obligations.

2. Avant de fixer un tarif minimum au temps ou un tarif minimum général aux pièces, le Conseil doit faire connaître le taux qu'il se propose de fixer et examiner toutes les objections qui peuvent lui être présentées dans un délai de trois mois.

3. Le Conseil publie tout tarif minimum général aux pièces établi par lui.

4. Un Conseil peut, s'il le juge convenable, annuler ou modifier tout tarif minimum au temps ou tout tarif ninimum général aux 
pièces fixé en vertu de la présente loi; sur la requête du Board of Tracle, qu'une demande ait été ou non formulée en ce sens, il doit examiner à nouveau tout minimum fixé par lui.

Il reste entendu que les dispositions de la présente section relatives à la publicité $d u$ minimum sont applicables en cas d'annulation ou de modification du minimum fixé en vertu des dispositions ci-dessus, de la même facon qu'elles le sont en cas de fixation du minimum.

5. Sur la demande d'un patron, un Conseil doit fixer un tarif minimum spécial aux pièces, applicable aux personnes au service du patron, dans les cas où il y a lieu d'appliquer un tarif minimum général aux pièces; il peut, s’il le juge convenable, annuler ou modifier tont tarif de cet ordre, soit sur la demande du patron, soit après en avoir avisé ce dernier ; cet avis devra être donné au moins un mois avant toute annulation ou modification du tarif.

5. - I. Tant que le Boaral of Tracle n'a pas, par voie d'ordonnance, rendu obligatoire un tarif minimum au temps ou un tarif général aux pièces, fixé par un Conseil, le tarif fixé parce dernier est applicable dans les limites preserites par la présente loi.

2. A l'expiration d'un délai de six mois après qu'un Conseil aura publié un tarif minimum au temps ou un tarif minimum général aux pièces qu'il a fixé, le Boarl of Trale rend une ordonnance (désignée dans la présente loi sous le nom d' “ ordonnance obligatoire ") rendant ce tarif minimum obligatoire, dans les cas où il est applicable, a toutes les personnes employant de la maind'œuvre ainsi qu'à toutes les personnes employées, à moins qu'il ne considère que, dans les circonstances présentes, il est prématuré ou peu convenable d'en ordonner ainsi. En pareil cas, le Board of Trade rend une ordonnance suspendant l'application obligatoire du-taux fixé (désignée dans la présente loi sous le nom d' (" ordonnance suspensive )).

3. Lorsqu'une ordonnance suspensive a été rendue à l'égard d'un tarif quelconque, le Conseil peut, à n'importe quel moment après l'expiration d'un délai de six mois à compter de la date de l'ordonnance, demander au Board of Troule de rendre une ordonnance obligatoire en ce qui concerne ledit tarif. Au reç d'une requête de ce genre, le Boarl of Trarle rend une ordonnance déclarant ce taux obligatoire, à moins qu'il ne considère qu'il y a lieu de rendre une nouvelle ordonnance suspensive : en pareil cas, il rend une nouvelle ordonnance en ce sens et les dispositions de la présente section, applicables à la première ordonnance suspensive, s'appliquent à toute ordonnance ultérieure de même nature.

Toute ordonnance suspensive relative à un tarif reste applicable tant que le Board of Trade n'a pas rendu une ordonnance obligatoire conformément à la présente section.

4. Le Boarl of Trade peut, s'il le juge convenable, rendre une ordonnance s'appliquant, d'une façon générale, à tous les tarifs 
fixés par un Conseil institué, ou sur le point d'ètre institué, dans une industrie soumise à la présente loi. Tant que l'ordonnance reste applicable, tout tarif minimum au temps ou tout tarif minimum général aux pièces, à l'expiration d'un délai de six mois à compter du jour où il a été publié par le Conseil d'industrie, devient obligatoire tout comme si le Board of Trade avait rendu, en vertu de la présente section, une ordonnance le déclarant obligatoire, à moins que, dans un cas particulier, à la requête d'une personne intéréssée, le Board of Trade ne décide le contraire.

Le Board of Trade peut, en tout temps, abroger une ordonnance générale de ce genre, pourvu qu’il en informe le Conseil trois mois d'avance.

6. - I. Lorsque le Board of Trade, conformément à la présente loi et par voie d'ordonnance, a rendu obligatoire un tarif minimum fixé par un Conseil, le patron doit, dans les cas où ledit tarif est applicable, payer à toute personne à son service un salaire net au moins égal, toutes retenues déduites, au salaire minimum; en cas contraire, il est passible, sur condamnation sommaire, d'une amende de 500 francs au plus, par contravention, et d'une amende de 125 francs au plus par jour, après cette condamnation, tant qu'il n'est pas en règle.

2. - En condamnant un patron aux termes de la présente section pour n'avoir pas payé à une personne à son service un salaire au moins égal au tarif minimum fixé, le Tribunal peut, par son jugement, obliger le patron condamné à payer, en plus de l'amende, les sommes qu'il considère comme dues en salaires aux personnes employées, en calculant ces salaires sur la base du tarif minimum : cette faculté d'ordonner un payement de salaires en vertu de la présente section n'enlève nullement à la personne employée le droit de poursuivre par d'autres voies le recouvrement de salaires dus.

3. Si un Conseil d'industrie reconnaît qu'un ouvrier travaillant ou désirant travailler au temps dans une quelconque des branches d'une industrie soumise au tarif minimum au temps qu'il a fixé est atteint d'une infirmité ou d'une incapacité physique le rendant incapable de gagner ce salaire minimum au temps, et s'il estime qu'il est impossible de résoudre la difficulté en faisant travailler l'ouvrier aux pièces, ledit Conseil peut, s'il le juge convenable, délivrer à l'ouvrier, aux conditions qu'il croit devoir éventuellement fixer, une autorisation spéciale (permit) l'exemptant des dispositions de la présente loi déclarant obligatoire le tarif minimum au temps. Tant que l'autorisation reste valable, le patron ne peut être puni pour ce motif qu'il paye à l'ouvrier un salaire inférieur au tarif minimum au temps, pourvu qu'il se conforme aux conditions imposées par le Conseil en accordant ladite autorisation.

4. Tout patron poursuivi en vertu de la présente section doit prouver, soit en présentant ses feuilles de paie mêmes ou d'autres 
documents relatifs aux salaires, soit autrement, qu'il n'a pas payé ou accepté de payer des salaires inférieurs au tarif minimum.

5 . Est nulle et sans valeur toute convention relative au payement de salaires contraire aux présentes dispositions.

7. - I. Tout tarif minimum fixé par un Conseil d'industrie, mais qu'une ordonnance rendue par le Board of Trade, en application de la présente loi, n'a pas encore déclaré obligatoire, est applicable dans les limites déterminées ci-après, sauf avis contraire du Board of Tracle dans les cas où il a invité le Conseil à l'examiner à nouveau :

a) Dans tous les cas ou le tarif minimum est applicable, le patron doit, en l'absence d'une convention écrite stipulant le contraire, payer aux personnes à son service un salaire au moins égal au tarif minimum; en pareil cas, la personne employée peut se faire rembourser la différence par son patron.

b) Le patron pent informer par écrit le Conseil d’industrie qui a fixé le tarif minimum qu'il accepte de se voir appliquer obligatoirement le tarif; en pareil cas, il est tenu de payer aux personnes qu'il emploie un salaire au moins égal au tarif minimum et il est passible, au cas contraire, des amendes qui pourraient lui être infligées si le Borrd of Trade avait rendu une ordonnance rendant le tarif obligatoire et si cette ordonnance était en vigueur; et

c) Aucun département ministériel, non plus qu'aucune autorité locale ne peut passer un contrat impliquant l'emploi de maind'ceuvre soumise à un tarif minimum avec un patron qui n'aurait pas fait au Conseil d'industrie une déclaration conforme à la disposition ci-dessus.

Il reste entendu que, lorsqu'il s’agit de l'intérêt général, le Board of Tralle peut. par voie d'ordonnance, et dans les limites et pour la période y stipulées, suspendre l'application de cette disposition aux contrats de travaux exécutés ou à exécuter pour le compte de la Couronne, ainsi que le détermine l'ordonnance.

2. Le Conseil d'industrie doit inscrire sur un registre toutes les déclarations faites conformément à la présente section.

Ce registre est communiqué gratuitement au public et fait foi des mentions qui y sont portées.

Toute copie d'une mention inscrite au registre et certifiée conforme par le secrétaire du Conseil ou par tout autre agent du Conseil autorisé à ce faire peut ètre admise en témoignage sans autre preuve.

8. - Le patron qui fait travailler aux pièces doit, lorsqu'il existe un tarif minimum au temps, mais quand il n'existe pas de tarif minimum général aux pièces, être considéré comme payant des salaires inférieurs au tarif minimum aux pièces spécial :

a) Dans le cas où un tarif minimum aux pièces spécial a été fixé, conformément à la loi, pour les personnes au service du 
patron, si les salaires payés par lui sont inférieurs à ce tarif minimum aux pièces spécial, et

b) Dans le cas où il n’a pas été fixé de tarif minimum aux pièces spécial, s’il ne peut établir que le salaire aux pièces effectivement payé représenterait en l'espèce, pour un ouvrier ordinaire, au moins la somme d'argent que lui rapporterait le tarif minimum au temps.

9. - Tout boutiquier, marchand ou commerçant qui, pour l'expédition de ses affaires, conclut expressément ou implicitement avec un ourrier un contrat impliquant l'exécution d'un travail pour lequel un tarif minimum a été fixé en vertu de la présente loi, est considéré, pour l'application de la présente loi, comme le patron de l'ouvrier; la rémunération nette due à l'ouvrier pour son travail est considérée comme son salaire.

10. - I. Tout ouvrier ou toute personne autorisée par lui peut se plaindre au Conseil d’industrie de ce que les salaires à lui payés par son patron, dans un cas où il y a lieu d'appliquer un tarif minimum fixé par le Couseil, sont inférieurs au tarif minimum : le Conseil examine la plainte et, s'il le juge convenable, peut commencer, en application de la présente loi, des poursuites au nom de l'ouvrier.

2. Avant de commencer des poursuites au nom de l'ouvrier, en vertu de la présente loi, le Conseil peut et - si c'est la première fois qu'il est appelé à poursuivre son patron - doit faire de son mieux pour que ledit patron en soit informé, et ce en vue d'arriver à un règlement amiable.

\section{Constitution, fonctionnement, etc., des Conseils d'industrie.}

11. - I. Le Board of Trade peut rendre des riglements relatifs a la constitution des Conseils d'industrie. Ces Conseils doivent comprendre un nombre égal de représentants des patrons et de représentants des ouviers (désignés dans la présente loi sous le nom de ( représentants )) et des membres nommés. Tous les règlements de ce genre peuvent être appliqués à la constitution de tous les Conseils d'industrie, en général, ou tout particulièrement à celle d'un Conseil spécial ou d'une catégorie spéciale de conseils.

2. Les femmes sont, tout comme les hommes, éligibles aux Conseils d'industrie.

3. Les représentants sont élus ou présentés, ou en partie élus et en partie présentés, selon que le prescrivent les riglements; les règlements doivent prévoir la représentation des ouvriers à domicile dans tous les conseils institués dans les industries où ces ouvriers se rencontrent en proportion notable.

4. Dans chäque conseil le Board of Trale désigne un président choisi parmi les membres et nomme un secrétaire.

5. Les délibérations d'un Conseil ne peuvent ètre annulées 
parce qu'une vacance s'est produite dans son sein, ou pour cause de vice dans la nomination, l'élection ou la présentation d'un membre.

6. Le quorum nécessaire est atteint quand au moins un tiers des représentants et au moins un des membres nommés sont présents à une séance du Conseil.

7. Le Boarl of Trade peut prévoir, par voie de règlement, le mode de fonctionnement et de réunion des conseils, y compris le mode de votation; toutefois, les Conseils peuvent, sous réserve des dispositions de la présente loi et des règlements ainsi rendus, régler comme ils l'entendent leur mode de fonctionnement.

12. - I. Un Conseil d'industrie peut instituer des Comités industriels de district comprenant à la fois des membres du conseil et des personnes étrangères, mais représentant des patrons ou des ouvriers de l'industrie; res Comités sont constitués conformément aux réglements spćciaux rendus par le Board of Trade et fonctionnent pour la circonscription fixće par le Conseil.

2. Les règlements doivent prescrire que chaque Comité de district comprendra au moins un des membres nommés, un nombre ígal de représentants des patrons et des ouvriers de la localité, des représentants des ouvriers à domicile pour les industries comptant dans le district une proportion considérable d'ouvriers de cette catégorie; ils prévoient la nomination de Sous-Comités permanents chargés d'examiner les demandes de tarif minimum aux pièces spécial et les plaintes adressées au Conseil en vertu de la présente loi, ainsi que le renvoi des demandes ou plaintes audit Sous-Comité.

3. Un Conseil peut sounetlre à un Comité industriel de district toutes les questions qu'il croit devoir lui soumettre, en lui demandant de faire un rapport et des propositions; il peut également, s’il le juge convenable, déléguer à un Comité industriel de district les pouvoirs et obligations que lui. confére la présente loi, sauf le pouvoir et l'obligation de fixer un tarif minimum au temps ou un tarif minimum général aux pièces.

4. Tout Comité industriel de district institué dans une circonscription est tenu de proposer au Conseil un tarif minimum au temps et, s’il le juge utile, un tarif minimum général aux pièces, applicable à l'industrie dans sa circouscription : aucun tarif minimum fixé en vertu de la présente loi, non plus qu'aucune modification ou annulation dudit tarif, ne peut être mis en vigueur dans cette circonscription, sans que le Comité de district ne l'ait proposé ou, le cas échéant, n'ait recommandé sa modification ou son annulation, ou sans que ledit Comité n'ait été mis à même d'adresser un rapport à ce sujet au Conseil et que ce dernier n'ait étudié le rapport qui lui aura été ainsi éventuellement adressé.

13. - 1. Le Boarl of Trade peut nommer comme membres des conseils d'industrie autant de personnes (y compris les femmes) qu'il le juge nécessaire. 
2. Les membres des conseils d'industrie ainsi nommés doivent siéger au conseil ou au comité industriel de district pour lequel ils sont désignés par le Board of Tracle; dans les conseils institués pour des industries occupant $11 n$ grand nombre de femmes, l'un au moins des membres nommés doit être du sexe féminin.

Il reste entendu que le nombre des membres nommés siégreant en même temps dans un même conseil on dans un même comité industriel de district, doit être inférieur à la moitié du nombre total des représentants des ouvriers.

Nomination ales fonctionnaires ef asposilions averses pour lapplication ale la loi.

14. - I. Le Board of Trarle pent nommer les fonctionnaires dont il a besoin pour examiner les plaintes et assurer à tous égards une bonne application de la loi ; les agents ainsi nommés sont placés sous les ordres du Board of Trade ou, si ce dernier en décide ainsi, sous les ordres de l'un ou l'autre des conseils d'industrie.

2. Au lieu de nommer des fonctionnaires ou d'en augmenter le nombre en vertu de la présente section, le Borarl of Trade peut également, s’il le juge convenable, s'entendre avec tout autre département ministériel pour que les fonctionnaires de ce département ayant, de par leurs attributions, à s'occuper d'une industrie soumise à la présente loi, contribuent, soit d'une façon génćrale, soit dans des cas particuliers, à assurer l'application de cette même loi.

15. - I. Tout fonctionnaire nommi par le Board of Trade, en vertu de la présente loi, et tout fonctionuaire d'un autre département ministériel, pendant le temps qu'il contribuera à assurer l'application de cette même loi, jouit, dans l'exercice de ses fonctions, des attributions ci-après. Il peut:

a) Exiger du patron la production des fenilles de paye on d'autres documents relatifs aux salaires, exiger des personnes faisant travailler à domicile les états des paiement effectués à des ouvriers à domicile, examiner et vérifier ces documents et en prendre copie:

b) Demander à toute personne faisant travailler à domicile ou travaillant à domicile les renseignements qu'elle posscide en ce qui concerne les noms et adresses des personnes acceptant ou dounant, selon le cas, du travail à domicile, et en ce qui concerne les salaires payés pour ce travail;

c) Pénétrer à toute heure raisonnable daus les fabriques ou ateliers et dans tout endroit ou se fait la distribution du travail a domicile;

a) Examiner et recopier toute liste d'ouvriers à domicile tenue par un patron ou une personne donnant du travail au dehors. 
2. Quiconque néglige de fournir à un fonctionnaire qui lui en fait la demande les moyens de pénétrer dans un lieu, ou de faire une inspection, ou de remplir les fonctions que lui confère la présente section, ou le moleste, ou refuse de produire un document, ou de domner un renseignement qu'un fonctionnaire lui demande de produire ou de donner en vertu des attributions à lui conférées par la présente section, est passible, sur condamnation sommaire, d'une amende de 5 livres (125 francs) au plus pour chaque contravention. Quiconque présente à un fonctionnaire agissant en vertu des pouvoirs que lui confère la présente section une feuille de paye ou un état des salaires, ou des états de paiement, ou des listes d'ouviliers a domicile, qu'il sait pertinemment être faux, ou qui ournit à un fonctionnaire des renseignements qu'il sait être inexacts, est passible, sur condamnation sommaire, d'une amende de 20 livres (50o francs) au plus ou d'un emprisonnement de trois mois au plus avec ou sans hard labour.

16. Chaque fonctionnaire nommé par le Board of Trade en vertu de la présente loi et chaque fonctionnaire d'un département ministériel prêtant son concours pour lapplication de la loi, reçoit du Boaral of Tralle ou de son département un certificat de nomination qu'il est tenu de produire pendant qu'il remplit ses fonctions ou agit en vertu des pouvoirs à lui conférés par la présente loi, à toute personne intéressée qui lui en fait la demande.

17. - 1. Tout fonctionnaire nommé par le Boarl of Trade en vertu de la présente loi et tout fonctionnaire d'un département ministériel prètant présentement son concours pour assurer l'application de la présente loi a, en exécution des instructions spéciales ou générales du Board of' Tradle, tout pouvoir pour engager des poursuites en vertu de la présente loi; un Conseil d'industrie peut également engager des poursuites de ce genre, soit au nom d'un fonctionnaire nommé par le Boarl of Trade et agissant présentement selon les instructions du Conseil d'industrie, en exécution de la présente loi, soit au nom de son secrétaire ou de l'un quelconque des agents qu'il a autorisés à ce faire.

2. Tout fonctionnaire nommé par le Board of Trade en vertu de la présente loi ou totit fonctionnaire d'un département ministériel prêtant présentement son concours pour assurer l'application de la présente loi, et le secrétaire d'un Conseil d'industrie ou tout agent d'un Conseil ayant qualité pour ce faire peut, bien que n'étant ni avocat, ni solicitor, ni homme de loi, engager ou continuer, devant un tribunal de juridiction sommaire, toutes les poursuites auxquelles peut donner lieu l'application de la présente loi.

\section{Dispositions complémentaires.}

18. - i. Le Board of Trade rend les règlements nécessaires pour que les intéressés soient informés de la meilleure façon pos- 
sible de tout ce qui, aux termes de la présente loi, doit être porté à leur connaissance.

2. Toute personne exploitant une fabrique ou un atelier ou occupant un lieu où l'on distribue du travail à des ouvriers à domicile doit, selon le mode établi par les règlements rendus en vertu de la présente section, afficher dans sa fabrique, son atelier ou le lieu où se distribue le travail à des ouvriers à domicile, les avis que les règlements peuvent prescrire : elle doit également porter à la connaissance de son personnel tout ce que les règlements lui enjoignent de faire connaître, en adoptant tout autre mode d'information qui peut être prescrit.

Toute personne exploitant une fabrique ou un atelier ou occupant un lieu où se distribue du travail à des ouvriers à domicile qui néglige de se conformer à cette disposition est passible, sur condamnation sommaire, d'une amende de 2 livres (5o francs) au plus par contravention.

19. - Les règlements rendus en exécution de la présente loi doivent être, aussitôt que possible, soumis aux deux Chambres du Parlement; si l'une ou l'autre des Chambres, dans les quarante jours qui suivent le dépôt, décide qu'il y a lieu de les annuler, tous ou certains d'entre eux, les règlements cessent d'être valables du jour de cette résolution, sans préjudice pour la validité de l'application qui a pu en ètre faite entre temps, ni pour la confection de nouveaux règlements. Si un ou plusieur's règlements d'une même série ont été annulés, le Board of Trade peut abroger la série tout entière.

20. - I. Sa Majesté peut, par ordonnance rendue en Conseil, décider que toutes les attributions reconnues on les obligations imposées au Board of Trade en exícution de la présente loi doivent être exercées ou remplies, soit en général, soit dans certains cas ou certaines catégories de cas, par un Secrétaire d'État et que, tant que cette ordonnance reste en vigueur, la présente loi est applicable, comme si, dans la mesure nécessaire à assurer l'application de ladite ordonnance, un Secrétaire d'État était substitué au Board of Trade.

2. Toute ordonnance rendue en Conseil en vertu de la présente section peut être modifiée ou annulće par une autre ordonnance ultérieure rendue en Conseil.

21. - Sont acquittés sur les crédits votés par le Parlement :

Io Tous les frais supportés par les Conseils d'industrie ou leurs Comités pour l'application de la présente loi, sous le contrôle et avec l'autorisation du Board of Trade, jusqu'ì concurrence du montant approuvé par le Trésor ;

$2^{\circ}$ Les émoluments et frais des membres nommés et des secrétaires des Conseils d'industrie et ceux des fonctionnaires nommés par le Board of Trade en exécution de la présente loi, tels qu'approuvés par le Trésor;

$3^{\circ}$ Les frais (y compris l'indemnité pour perte de temps) sup- 
portés, pendant l'éxercice de leurs fonctions, par les représentants patronaux et ouvriers des Conseils et par les membres (autres que les membres nommés) des Comités de district, jusqu’à concurrence du montant approuvé par le Trésor;

$4^{0}$ Tous les frais supportés par le Board of Trade, soit pour des enquetes, soit pour recueillir des renseignements, soit pour des études préliminaires en vue d'appliquer la présente loi à une industrie qui ne lui est pas encore soumise, jusqu'à concurrence du montant approuvé par le Trésor, y compris les frais encourus pour obtenir une ordonnance provisoire ou faire aboutir un projet de loi sanctionnant une ordonnance provisoire rendue conformément ou en vue de l'application de la présente loi.

22. - I. La présente loi peut être citée sous le nom de « loi de igog sur les Conseils d'industrie ».

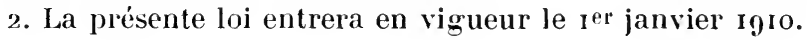

\section{Céclule.}

Industries soumises à la loi sans ordonnance provisoire :

$1^{0}$ Confection de vêtements tout faits et sur mesure, en gros, et toutes autres branches du vêtement dans lesquelles le Ministre du Commerce estime que le systeme de confection est, en général, semblable au systime le plus usiti dans le gros;

$2^{0}$ Fabrication des boîtes ou parties de boîtes manufacturées en tout ou en partie, avec du papier, du carton, des copeaux ou matières similaires ;

3 Finissage de la dentelle et des filets à la mécanique; travaux de raccommodage ou de reprisage dans le finissage des rideaux de dentelle;

$4^{0}$ Fabrication des chaînes martelées et rivées à la main ou au marteau à pédale. 


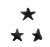

Règlement du 27 avril 1910, pris par te Board of Trade en application de la section is de la loi de 1909 sur les Conseils d'industrie, sur le mode de publicité des tarifs (r).

En vertu des pouvoirs à lui conférés par la section 18 de la loi de 1909 sur les Conseils d'industrie, le Board of Trade édicte, conformément audit article, les dispositions suivantes :

$1^{\circ}$ Dans le présent règlement, les expressions suivantes :

"Gazette " (The Gazette) désigne la gazette le Londres, d'Édimbourg ou de Dublin, ou l'une ou plusieurs d'entre elles, selon les cas;

"Personne » (person) désigne tout groupement de personnes constituées ou non en corporation;

"Patron » (employer) comprend des personnes telles que définies ci-dessus ;

$2^{\circ}$ Lorsqu'un Conseil d'industrie se propose de fixer, d'annuler ou de modifier un tarif minimum au temps ou un tarif minimum général aux pièces dans une industrie particulière, il doit :

a) Faire connaître par écrit à tous les employeurs de maind'œuvre dans l'industrie intéressée dont il connaît les noms et adresses le tarif qu'il se propose de fixer, en les invitant à lui communiquer leurs observations dans un délai de trois mois;

6) Publier dans la Gazette un avis faisant connaître son intention de fixer ledit tarif, en déclarant qu'il fournira ì toute personne lui en faisant la demande (pourvu que ladite personne lui semble susceptible d'être touchée par le tarif) des renseignements sur le tarif qu'il se propose de fixer et en annonçant qu'il recevra toutes les observations qui lui seront adressées dans le délai prévu par l'avis susdit;

30 Tout patron d'une fabrique ou d'un atelier ou d'un local utilisé pour distribuer du travail à domicile doit, au reçu de l'avis prévu à la lettre $a$ de la section ci-dessus, afficher en bonne place un nombre suffisant de copies conformes dudit avis dans chaque fabrique, atelier ou local servant à distribuer du travail à domicile; il doit faire en sorte que le contenu en soit toujours porté it la connaissance de tous ceux de ses ouvriers qui sont intéressés en la matière;

$4^{\circ}$ Une fois le tarif établi, le Conseil en fait connaître la teneur à tout patron désigné ci-dessus dont il connaît le nom et l'adresse;

$5^{\circ}$ Tout patron désigné ci-dessus doit, au reçu de l'avis prévu à la section précédente, afficher en bonne place un nombre suffisant d'exemplaires conformes dudit avis dans chaque fabrique,

(1) Bulletin de l'ofлce intern. du travall, 1910, p. 382. 
atelier ou local servant à distribuer du travail à domicile et faire en sorte que le contenu en soit toujours porté à la connaissance de tous ceux de ses ouvriers qui sont intéressis en la matière.

Règlement du 25 novembre 1909 (I), publié par le Board of Trade par application de la section iI de la loi de 1909 sur les Conseils d'industrie portant création d'un Conseil d'industrie pour la fabrication des chaînes martelées et rivées à la main ou all marteau à pérlale.

Règlement du 27 avril 1910 (2), pris par le Board of Trade en application de la section it de la loi de rgog sur les Conseils d'inclustrie instituant un Conseil pour la fabrication des boites ou parties de boîtes confectionnées, en tolalité ou en partie, en papier, carton, copeanx on matières similaires.

Règlement du 25 juillet 1910 (3), pris par le Board of Trade en application de la section iI de la loi de 1909 sur les Conseils d'industrie instituant un Conseil pour la confection des vêtements tout faits et en gros pour hommes.

\section{Règlement du 4 mai 1910, instituant un Conseil dans l'Industrie dentellière (4).}

I. 11 sera institué un Conseil d'industrie pour cette branche de l'industrie dentellière où l'on finit les dentelles et filets confectionnés à la machine, non compris le finissage des filets unis fabriqués à la machine.

2. Le Conseil ne comprendra pas moins de ig personnes et pas plus de 23, savoir : 3 membres nommés (par le Ministre) et un nombre égal de représentants des patrons et de représentants des ouvriers.

Le Boarl of Trade désignera le président et le vice-président parmi les membres.

3. Le Board of Trade choisira 6 représentants patronaux parmi les candidats présentés par les patrons de l'industrie désignée ci-dessus possédant des entrepôts, et 2 autres parmi les candidats présentés par d'autres patrons. Il sera pourvu, selon le même mode, à toute vacance survenue parmi les membres patrons.

4. Le Board of Trade choisira 8 représentants ouvriers parmi les candidats présentés par les ouvriers de l'industrie désignée ci-dessus, en se préoccupant d'assurer une représentation convenable aux travailleurs à domicile. Il sera pourvu, selon le même mode, à toute vacance survenue parmi les membres ouvriers.

(1) Bulletin de l'Offlce Intern. du travail, 1910, t. IX, p. 133.

(2) Ibid., 1910, t. IX, p. 383.

(3) Ibid., 1910, t. IX, p. 4 亿0.

(4) Bulletln de l'Offlce intern. du travail, 1910, t. IX, p. 385. 
5. Le Board of Trade peut, s’il le juge nécessaire en vue d'assurer une représentation convenable à toutes les catégories de patrons ou d'ouvriers, et après avis du Conseil d'industrie, nommer des membres suppléants soit pour toute la duríe du mandat dudit Conseil, soit pour une partie de ce mandat. Le nombre de ces suppléants ne peut, à aucun moment, ètre supérieur à 4, soit à 2 pour chaque catégorie.

6. Le premier Conseil est nommé pour une période d'une année, avec faculté pour le Board of Trade de prolonger ce mandat pour deux autres périodes d'une année chacune; sauf stipulations contraires, tout Conseil d'industrie nommé par la suite siégera dans les mêmes conditions.

7. Tout représentant des patrons qui cesse d'ètre patron et devient ouvrier dans l'industrie doit résigner son mandat. Tout représentant ouvrier qui devient patron dans l'industrie doit également résigner son mandat. Le président établit, dans chaque cas, la réalité des faits.

8. Chaque membre du Conseil a droit à une voix. Il reste entendu que, dans toute question de minimum de salaire, le président ou, en son absence. le vice-président, peut, s’il le juge convenable, et doit, à la demande de la majorité absolue des membres patrons ou ouvriers, faire voter les membres par catígorie; en pareil cas, le vote de la majorité des membres présents de l'une ou de l'autre catégorie, prenant part au scrutin, constitue le vote de cette catigorie. Dans un vote de ce genre, les membres nommés (par le Ministre) ne prennent pas part au scrutin; si le vote accuse une divergence d'opinion, la question est tranchée par le vote, à la majorité, des membres nommés (par le Ministre).

9. Si, dans une séance de Conseil, des membres patrons et des membres ouvriers présents ne sont pas en nombre égal, la catégorie de représentants qui est en majorité peut décider que, en vue de rétablir l'équilibre, un ou plusieurs de ses membres s'abstiendront de prendre part au vote. En l'absence d'une décision de ce genre, le président ou, à son défaut, le vice-président peut, s’il le juge utile, remettre à une autre sćance du Conseil le vote sur n'importe quelle question.

ro. Tout représentant des patrons ou des ouvriers qui, sans motif plausible, néglige d'assister à la moitić du total des séances tenues dans une année doit résigner son mandat; il peut toutefois être réélu ou renommé, selon le cas.

II. Toute contestation relative au sens ou à l'interprétation du présent règlement sera examinće et tranchée par le Bortrl of Trade. 
Loi du 29 mars 1912 rela:ive au salaire minimum des ouvriers employés aux travaux souterrains dans les houillères (y compris les mines de minerai de fer stratifié) et à diverses questions connexes. Ch. 2, 2 Geo V (I).

An Act to provide a minimum wage in the case of workmen employed underground in coal mines (including mines of stratified ironstone) and fur purposes thereto (Ch. 2. 2 Geo V) 29 mars 1912.

The Coal Mines (minimum wage) Act rg12.

1. - I. Tout contrat de travail d'un ouvrier occupé aux travaux souterraius dans une houlliere sera considéré comme stipulant implicitement l'obligation pour l'employeur de payer à cet ouvrier un salaire au moins égal au salaire calculé d'après le tarif minimum fixé conformément à la présente loi et applicable audit ouvrier, à moins qu'il ne soit élabli, dans les formes prévues par le reglement de district, que l'ouvrier fait partie du personnel exclu, aux termes dudit règlement,.du bénéfice de la présente section, ou qu'il est déchu de son droit au salaire calculé d'après le tarif minimum comme n'ayant pas satisfait aux conditions de régularité dans le travail et de productivité (effciency) exigées des ouvriers, aux termes dudit riglement. Totıte convention relative aux salaires contraire aux dispositions de la présente section sera nulle et non avenue.

Pour l'application de la présente loi, l'expression " règlement de district " (district ruless) désigne tout règlement établi par un Comité mixte de district (joint district boarl) en vertu des pouvoirs qui lui sont conférés par la présente loi.

2. Tout rìglement de district devra - pour le district auquel il s'applique - comporter des dispositions excluant du droit au salaire calculé d'après le tarif minimum les ouvriers âgés et infirmes, $y$ compris les ouvriers atteints d'incapacité partielle de travail par suite de maladie ou d'accident, ainsi que des dispositions concernant les conditions de régularité dans le travail et de productivité exigées des ouvriers et le temps pendant lequel l'ouvrier devra être payé en cas d'interruption du travail pour cause de force majeure (emeryency); il prévoira la déchéance du droit au salaire calculé d'après le tarif minimum pour tout ouvrier qui ne remplirait pas les conditions ci-dessus, à moins que le manquement auxdites conditions ne soit dû à une cause indépendante de la volonté de l'ouvrier.

Le rìglement de district devra également stipuler par quelles

(1) Bulletin de l'office intern. du travail, 1912, p. 129. 
personnes et suivant quelle procédure seront tranchées toutes difficultés sur le point de savoir si un ouvrier du district est de ceux auxquels s'applique le tarif minimum des salaires, ou si un ouvrier s'est conformé aux conditions fixíes par le règlement, ou si un ouvrier qui ne s'est pas conformé auxdites conditions est déchu de son droit au salaire calculé d'après le tarif minimum; il prévoira la délivrance d'un certificat constatant toute décision prise en exćcution de la présente section.

3. Les dispositions de la présente section relatives au paiement de salaires calculés d'après le tarif minimum entreront en vigueur à dater de la promulgation de la présente loi, quand bien même un tarif minimum des salaires n'aurait pas encore été fixé. Toute somme qui, en vertu de la présente section, aurait été due à un ouvrier à titre de salaire si un tarif minimum avait été établi, pourra être recouvrće par l'ouvrier sur l'employeur à toute époque après la fixation de ce tarif.

2. - I. Les tarifs minima de salaires et le règlement de district prévus par la présente loi seront établis séparément pour chacun des districts désignés dans la cédule annexće à la présente loi, par un groupement de personnes reconnu par le Board of Trade comme constituant, pour ce district, le Comité mixte du district.

Les dispositions de la présente loi ne portent pas préjudice à la validité de toute convention (agreement) conclue ou de toute coutume existant antérieurement à sa promulgation, concernant le paiement de salaires calculés d'après des tarifs supérieurs aux tarifs minima établis conformément à la présente loi; pour la fixation d'un tarif minimum de salaires, le Comité mixte de district tiendra compte du salaire moyen des ouvriers de la catégorie pour laquelle le tarif minimum doit être fixé.

2. Le Board of Trade pourra reconnaître comme Comité mixte de district, pour un district quelconque, tout groupement de personnes existant antérieurement à la promulgation de la présente loi ou constitué en vue de l'exécution de la présente loi qui, de l'avis du Board of Trade, représenterait exactement et équitablement tant les ouvriers employés dans les houillères du district que leurs employeurs et dont le président serait une personne n'ayant aucun intérêt en jeu (independant) nommée après accord entre les personnes représentant respectivement les ouvriers et les patrons dans le groupement ou, à défaut d'un tel accord, par le Board of Tracle.

Comme condition à la reconnaissance de la qualité du Comité mixte à un groupement, si le règlement de ce groupement ne prévoit ni l'égalité du droit de vote des représentants ouvriers et des représentants patronaux, ni l'attribution au président d'une voix prépondérante en cas de partage égal des voix, le Board of Trade pourra imposer à ce groupement une règle approuvée par lui, visant ces points. Toute règle ainsi adoptée sera considérée comme incorporée au règlement régissant la procédure du Comité. 
3. Tout Comité mixte de district déterminera, pour son district, des tarifs généraux minima de salaires et un règlement général de district appelés dans la présente loi « tarifs généraux minima de district » et " règlement général de district ».

Les tarifs généraux minima et le règlement général de district seront les tarifs et le règlement applicables, dans toute l'étendue du district, à toutes les houillères situées dans le district et à tous les ouvriers ou catégories d'ouvriers employés à des travaux souterrains dans ces houillères, exception faite des houillères et des ouvriers auxquels s'appliquent un tarif minimum spécial ou un règlement spécial de district établis conformément à la présente loi, ainsi que des houillères et des ouvriers pour lesquels le Comité mixte déclarera que l'application des tarifs généraux et du règlement général de district doit être suspendue jusqu'à ce qu'il soit décidé s'il y a lieu d'arrêter, en ce qui les concerne, un tarif spécial ou un règlement spécial de district.

4. S'il est établi qu'en raison de circonstances particulières à un groupe ou à une catégorie de houillères, le tarif général minimum de district ou le règlement général de district ne leur sont pas pratiquement applicables, le Comité pourra fixer pour ce groupe ou cette catégorie de houillères un tarif minimum spécial (supérieur ou inférieur au tarif général de district), ou un règlement spécial de district (plus ou moins rigoureux que le règlement général de district). Ce tarif spécial ou ce règlement spécial deviendront applicables au groupe ou à la catégorie de houillères aux lieu et place du tarif général de district ou du règlement général de district.

5. Pour la détermination des tarifs minima de salaires, le Comité mixte de district pourra subdiviser son district en deux parties ou, si les membres du Comité mixte représentant les ouvriers et patrons y consentent, en plus de deux parties; en ce cas, chaque partie du district ainsi subdivisé sera considérée comme constituant un district.

6. Pour l'établissement de règlements de district, plusieurs Comités mixtes pourront décider que leurs districts respectifs seront considérés comme formant un seul district; ces districts seront alors considérés, à cet égard, comme un district «combiné » (as one combined district), doté d'un Comité mixte "combiné " nommé selon la procédure qui aura été adoptée par les Comités mixtes des districts ainsi agglomérés. Le Comité mixte du district "combiné » sera présidé par celui des présidents des districts agglomérés qui aura été désigné par les Comités mixtes de ces districts ou, à défaut d'accord entre les Comités, par le Board of Trade.

3. - ı. Tout tarif minimum de salaire ou tout règlement de district établis en vertu de la présente loi demeureront valables jusqu'à ce qu'ils aient été modifiés conformément aux dispositions de la présente loi. 
2. Le Comité mixte d'un district pourra morlifier tout tarif minimum de salaire ou tout règlement de district en vigueur dans son district :

a) A toute époque, par accord entre les membres ouvriers et patrons du Comité mixte de district;

b) Un an après la dernière fixation ou modification du tarif ou du règlement, sur une demande formulíe (avec trois mois de préavis après expiration de l'année) par tous ouvriers ou patrons qui, de lavis du Comité mixte de district, paraîtront représenter l'opinion d'une fraction importante soit des ouvriers, soit des patrons intéressés.

Les dispositions de la présente loi concernant l'établissement de tarifs minima de salaires ou de règlement de district s'appliqueront, dans la mesure oì elles seront applicables, à la morlification desdits tarifs ou règlements.

4. - I. Si, dans un délai de deux semaines après la promulgation de la présente loi, un Comité mixte de district n'a pas été reconnu par le Board of Trade dans un district déterminé, on si, à un moment quelconque, postérieurement à la promulgation de la présente loi, les circonstances nécessitent, dans un district où il n'existe pas de Comité mixte de district, l'exercice l'un des pouvoirs ou l'accomplissement d'une des missions que la présente loi a conférés aux Comités mixtes de district, le Boarll of Trarle pourra, immédiatement ou dans le délai qu’il aura jugé nécessaire ou utile, désigner une personne compétente pour agir aux lieu et place du Comité mixte de district. Pendant la durée des fonctions de cette personne, les dispositions de la présente loi s'appliqueront, en ce qui concerne le district visé, comme si la personne désignée était substituće au Comité mixte de district. Dans le cas où les employeurs ne nommeraient pas les membres chargés de les représenter au Comité mixte de district, alors que les ouvriers seraient disposés à nommer leurs représentants, ou dans le cas ou les ouvriers ne nommeraient pas les membres chargés de les représenter au Comité mixte de district, alors que les employeurs seraient disposés à nommer leurs représentants, si le Board of Trade estime devoir user des pouvoirs que lui confere la présente section, il pourra désigner, au lieu d'une seule personne chargée de remplir l'office de Comité mixte de district, plusieurs personnes jugées capables de représenter, suivant le cas, celle des deux parties, employeurs ou onviers, qui u'a pas nommé ses représentants. Les personnes ainsi désignées par le Borral of Tracle seront considérées comme membres du Comité mixte de district représentant les employeurs ou les ouvriers, suivant le cas.

2. Si, dans un délai de trois semaines aprés sa reconnaissance en vertu de la présente loi, un Comitó mixte de district n'a pas fixé les premiers tarifs minima de salaires et le premier righlement de district pour son district, on si, dans un délai de trois 
semaines après expiration du préavis fixé pour l'examen d'une demande formulée en vertu de la présente loi en vue de la modification d'un tarif minimum de salaires ou d'un règlement de district, le Comité mixte n'a pas examiné ladite demande, le président du Comité mixte devra, aux lieu et place du Comité, établir les tarifs ou le règlement. ou examiner la demande, selon le cas. Tout tarif minimum de salaires ou tout règlement de district établis par lui auront le mème effet pour l'application de la présente loi que s'ils avaient été établis par le Comité mixte de district.

Toutefois. si les membres patrons et ouvriers du Comité mixte de district sont d'accord pour juger qu'un délai déterminé, excédant trois semaines, doit être substitué au délai de trois semaines prévu par la présente sous-section, ou si le président du Comité mixte de district ordonne qu'il en soit ainsi, les dispositions de la présente sous-section s'appliqueront comme si le délai ainsi fixé était substitué au délai de trois semaines.

5. - I. Dans la présente loi, l'expression "houillères" (coal mines) comprend les mines contenant du minerai de fer stratifié (stratifieal ironstone).

Le terme "ouvrier " (worliman) désigne tout ouvrier occupé aux travaux souterrains dans une houillère, à l'exception :

a) Des ourriers qui n'y sont occupés qu'occasionnellement ou accidentellement;

b) Du personnel occupé exclusivement aux travaux de topographie ou de mesurage;

c) Des personnes employées comme mécaniciens (mechanics);

(l) Des directeurs des mines ou de leurs adjoints;

e) De tous autres employés de la mine dont l'emploi aura été reconnu par le Comité mixte de district comme étant différent de celui d'un ourrier.

2. Si les personnes procédant à l'élection d'un président en vertu de la présente loi ou si le Bonrd of Trade désignant un président le jugent bon, les fonctions de président pourront être confiées à trois personnes; dans ce cas, ces trois personnes, agissant à la majorité, seront considérées comme président pour l'appliçation de la présente loi.

6. - I. La présente loi pourra être citée sous le titre de loi de Igr2 sur les houilleres (salaire minimum) : Coal Mines (Minimum Wage, Act I912).

2. La présente loi restera en vigueur pendant trois ans à dater du jour de sa promulgation, et non au delà, à moins de décision contraire du Parlement. 


\section{CÉDULE}

Districts.

Northumberland.

Durham.

Cumberland.

Lancashire et Cheshire.

South Yorkshire.

West Yorkshire.

Cleveland.

Derbyshire (sauf le South Derbyshire).

South Derbyshire.

Nottinghamshire.

Leicestershire.

Shropshire.
North Staffordshire.

South Stafford (sauf Cannock Chase) et East Worcestershire. Cannock Chase.

Warwickshire.

Forest of Dean.

Bristol.

Somerset.

North Wales.

South Wales (y compris Monmouth).

L'Écosse continentale.

Si une mine, bien que situce dans un de ces districts, est habituellement considérée, au point de vue industriel, comme ayant son siège dans un district voisin, elle sera considérće, pour l'application de la présente loi, comme situce dans ce dernier district, à la condition que les comités mixtes des deux districts $\mathrm{y}$ consentent. 


\section{C. - Roumanie.}

\section{Loi sur les contrats agricoles (Lege pentru invoeli agricole).}

Loi des 23 décembre I907-5 janvier i 908 sur les conventions dans l'agriculture (I).

Article premier. - Les conventions agricoles suivantes, passées entre des propriétaires fermiers ou fermiers et des paysans cultivant le sol sont soumises aux dispositions de la présente loi :

a) Les conventions, en argent ou en dìme, aux termes desquelles il est donné au paysan une pièce de terre arable, prairie ou pâturage d'une superficie inférieure à vingt hectares par chef de famille. Sont exceptées les conventions relatives à la culture des légumes, du tabac et des melons.

b) Les conventions relatives au pacage des bestiaux, jusqu'à six têtes de gros bétail et dix têtes de menu bétail, par chef de famille, en cousidérant cinq têtes de menu bétail (moutons, chèvres) comme équivalent à une tête de gros bétail.

c) Les conventions par lesquelles les paysans s'engagent à exécuter, à la journće ou à la tâche, les travaux agricoles suivants : labour, ensemencement, hersage, cylindrage, bêchottage, bêchage, serrage des récoltes, fauchage, sarclage, engrangeage, mise en tas, battage du grain, confection des meules de foin, mise en aire et en magasin, transport des céréales aux lieux d'entrepôt et aux gares, travail dans les vignes, ainsi que tout autre travail nécessaire à la culture du sol.

Art. 36. - Les dispositions de la présente loi, relatives aux conventions agricoles prévues à l'articles $1^{\mathrm{er}}$, lettre $\left.r\right)$, ne sont applicables qu'aux paysans engagés sur place au moins trente jours avant le commencement des travaux prévus. Elles ne s'appliquent pas aux ouvriers ćtrangers. non plus qu'aux ouvriers roumains engagés pendant la saison des travaux.

Les ouvriers agricoles engagés par les propriétaires et les fermiers au mois ou à l'année sont soumis aux dispositions de la loi sur les domestiques.

Art. 39. - Tout paysan qui s'engage pour les travaux des champs chez un propriétaire ou un fermier doit posséder un livret d'ouvrier agricole établi selon le modìle fixé par le Ministre de l'Agriculture. Ce livret est établi par le secrétaire de la commune du domicile du paysan et il constitue, pour le paysan, une pièce d'identité vis-à-vis de tout propriétaire ou fermier qui désire l'engager.

(1) Builetin de l'Office intern. du travail, t. IX, 1910, p. I62. 
Chaque livret doit mentionner le nom, le signalement et l'âge du paysan, la commune de sa résidence, le nombre et l'âge des membres de sa famille mineurs et ne possédant pas leur livret propre, ainsi que l'importance de sa propriété foncière et le nombre des tètes de bétail dont il dispose.

Mention est faite au livret, dans l'ordre ci-après, des indications suivantes qui doivent être légalisées : d'une part, le travail de l'année écoulée restant à exécuter, l'étendue du terrain cédé moyennant un paiement en dìme ou en argent par le propriétaire, la nature des travaux convenus, la durée approximative de ces travaux, le lieu où ils doivent être exécutés et les sommes dues au paysan; d'autre part, les travaux exécutés et les paiements reçus.

Ces mentions doivent être inscrites à l'encre sur le livret et ce, au plus tard, le dimanche le plus proche; il n'est tenu compte des ratures et additions que lorsqu'elles sont approuvées par la personne qui les a faites, par exemple par le comptable du propriétaire ou le secrétaire de la commune.

Art. 40. - Est passible d'une amende de ro lei, au profit de la commune, quiconque néglige de porter les mentions prévues aux alinéas 3 et 4 de l'article précédent.

Le secrétaire de la commune doit tenir un registre annuel spécial dans lequel sont inscrits immédiatement les travaux convenus dans la localité et d'autre part les noms des paysans résidant dans la commune.

Le livret doit porter le numéro correspondant de la page où est inscrit chaque paysan engagé et reproduire fidèlement les mentions du registre.

En cas de perte du livret, l'autorité de la commune de résidence du paysan en délivre à ce dernier un duplicata, établi d'après la teneur du registre et portant cette inscription : (Duplicata. )

Le livret est valable pour une année. Il est remplacé par le secrétaire de la commune à la fin de l'année agricole. Le prix du livret est de 20 bani.

Art. 4i. - Seul le ma:re de la commune de résidence du paysan qui s'engage a qualité pour approuver et enregistrer les contrats agricoles.

Si le maire est lui-même partie au contrat, son adjoint donne l'approbation.

Le paysan peut passer des conventions agricoles dans une autre commune, à la condition de présenter son livret en entreprenant les travaux agricoles convenus.

Le secrétaire de la commune qui a approuvé le contrat d'un paysan d'une autre commune doit, dans les trois jours, transmettre au secrétaire de la commune de résidence du paysan une copie légalisée du contrat conclu. Il mentionne également sur le livret du paysan les conditions de la convention. 
En cas d'infraction à ces dispositions, le secrétaire est passible d'une amende de ro lei au profit de la commune.

Art. 42. - Le maire qui a approuvé la convention passée par un paysan d'une autre commune sans vérifier le livret, conformćment aux dispositions de l'article 4i, est passible d'une amende de 20 lei.

Le paysan qui s'est engagé au delà de ses forces, vis-à-vis de plusieurs proprićtaires ou fermiers et qui ne peut exécuter les travaux dont il est chargé, est responsable du dommage causé.

Les contrats par lesquels un paysan s'est engagé, en pareil cas, vis-à-vis de plusieurs propriétaires ou fermiers, doivent être exécutés dans l'ordre dans lequel ils ont été approuvés.

Art. 43. - Le propriétaire ou fermier qui a renvoyé des paysans embauchés ailleurs est passible d'une amende de 200 à 500 lei, sauf dédommagement du préjudice causé à l'intéressé.

Art. 44. - Le juge du cercle détermine et juge les infractions aux dispositions des articles 42 et 43 .

Art. 45. - Le propriétaire ou fermier qui, lors de l'engagement, s'est chargé de nourrir le paysan est tenu de mentionner au contrat la ration qu'il accorde (ration de pain ou de gâteau de maïs, légumes, poisson, viande, etc.). En cas de nourriture à la journée, mention doit ètre faite du nombre des repas.

La valeur de la nourriture doit toujours être indiquée en argent au contrat.

La quantité de nourriture fournie ne doit pas être inférieure au minimum nécessaire déterminé par le Conseil supérieur d'hygiène. La nourriture doit être de bonne qualité, saine et donnée en quantité suffisante. Dans le cas contraire, le paysan peut faire constater par le maire que la nourriture ne répond pas aux conditions présentes. Si le maire reconnaît le bien-fondé de la plainte, il prescrit, dans une décision sans appel significe au propriétaire ou au fermier, que la valeur de la nourriture doit être payée en argent au paysan.

Art. 65. - Il est institué, dans chaque district, une commission de cinq membres comprenant l'inspecteur de l'agriculture, deux délégués des propriétaires fermiers et deux délégués des paysans.

Cette commission détermine pour le district :

a) Les limites extrêmes atteintes par les salaires au moment des travaux au cours des trois dernières années : elle fixe, sur les bases, le minimum de salaire au-dessous duquel les contrats agricoles ne pourront être conclus ;

b) La quantité des différents travaux pouvant être exécutée par jour par un homme, une femme ou un mineur.

Etc...

Art. 66. - Les prix fixés par la Commission de district sont, une fois approuvés par le Conseil supérieur de l'agriculture, 
publiés dans le.Journal offciel et portés à la connaissance du public, par le secrétaire communal, à l'aide de tableaux imprimés fournis par le Ministre des domaines.

Les secrétaires communaux sont tenus d'afficher ces tableaux dans les bureaux des mairies, où les propriétaires fermiers, les fermiers et les paysans peuvent en prendre connaissance.

Les tableaux demeurent affichés dans les bureaux des mairies pendant tout le temps qu'ils sont valables.

Les secrétaires communaux coupables d'infraction au présent article sont passibles d'une amende de 50 lei au profit de la commune.

Art. 67. - Les contrats ne peuvent être approuvés que s'ils contiennent des prix conformes à ceux fixés par la Commission de district.

Les prix fixés par la Commission pour les travaux désignés à l'article $\mathrm{I}$, lettres $a$ ), $b$ ) et $c$ ), sont valables pour cinq ans. Ils sont toujours revisés dans l'année qui suit l'établissement de l'assiette de l'impôt. 



\section{TABLE DES MATIÈRES}

Pages

Préface . . . . . . . . . . . . . . . . I I

Ixtroduction. - L'Histoire doctrinale du Minimum de salaire . . . . . . . . . . . . . . . 111

Première partie. - L’Idéal du Minimum de salaire . . . . 1

Chapitie I. - La Doctrine du Catholicisme social . . . 2

Chapitre II. - La Doctrine socialiste . . . . . . . . 25

Chapitre III. - La Doctrine utilitaire. . . . . . . . . . 32

Deuxième partie. - Les Faits : le mouvement contemporain vers le Minimum de salaire . . . . . . . . . . . . . 41

Chapitre I. - L'Histoire. . . . . . . . . . . 52

Section A. - Réalisation indirecte. . . . . . . . . 53

Chapitre II. - Vers le Minimum de salaire par les clauses relatives au travail dans les adjudications de travaux publics. . . . . . . . . . . 54

I. Les Conditions du travail dans les adjudications de travaux publics en France. . . . . . . . . 56

A) Salaire minimum. Salaire courant . . . . . . 57

B) L'application de la clause du Salaire normal ou courant. . . . . . . . . . . 72

ro Dans les travaux de l'État. . . . . . . . 73

$2^{\circ}$ Dans les travaux du Département. . . . . . 77

$3^{\circ}$ Dans les travaux des Communes et Établissements publics. . . . . . . . . . . 88

C) Les Réformes . . . . . . . . . . . . . . 91

I0 L'œuvre de la Commission interministérielle. 91

$2^{\circ}$ L’œuvre du Conseil supérieur du travail. . . 92

30 L'action de l'Administration . . . . . . . 95

II. Les Conditions du travail dans les adjudications de travaux publics à l'étranger. . . . . . . . . . . 98

I. Angleterre . . . . . . . . . . . . . 98

a) Historique . . . . . . . . . . . . . . . . 9 98

b) Situation présente . . . . . . . . 102

A. Les traváux de l'État. . . . . . . . 102

B. Les travaux des Municipalités. . . . 106 
Pages

II. Belgique. . . . . . . . . . . . . . . . . 110

a) Historique . . . . . . . . . . . . . . 110

b) Résultats actuels . . . . . . . . . . 112

c) L'application . . . . . . . . . . . . . 114

III. Allemagne . . . . . . . . . . . . . . 118

Travaux de l'État. . . . . . . . . . 118

Travaux des Municipalités. . . . . . . . 118

Iv. Autres pays . . . . . . . . . . . . . 123

Chapitre III. - Vers le Minimum de salaire par l'introduction de la lésion dans le contrat de travail . • : 124

La Législation allemande. . . . . . . . . . . 124

La Législation suisse . . . . . . . . . . . 127

Les Projets francais . . . . . . . . . . . . . . 129

Chapitre IV. - Vers le Minimum de salaire par la diffusion des Assurances sociales en tout ou partie à la charge de l'employeur. . . . . . . . . . . . 136

Insuffisance du salaire en cas de crise individuelle . . 136

Diffusion des Assurances sociales. . . . . . . . . 141

Section B. - Réalisation directe. . . . . . . . . 150

Chapitre V. - L'ueure de l'Association professionnelle. 151

I. Angleterre . . . . . . . . . . . . . . 152

a) IIistoire . . . . . . . . . . . . . . 152

b) Principes. . . . . . . . . . . . . . . 153

c) Résultats . . . . . . . . . . . . . 154

Bàtiment . . . . . . . . . . . 155

Mines. . . . . . . . . . . . . . 157

Industries métallurgiques. . . . . . . . 176

Constructions navales. . . . . . . . . . 178

Industries textiles. . . . . . . . . . . . 179

Industries dı Vêtement . . . . . . . . 184

Industries du Livre . . . . . . . . . . . 193

Chemins de fer . . . . . . . . . . . 194

Autres industries. . . . . . . . . . . 194

Coopération. . . . . . . . . . . . . 197

II. France . . . . . . . . . . . . . . 202

III. Autres pays. . . . . . . . . . . . . . 211

Allemagne . . . . . . . . . . . . 211

Autriche . . . . . . . . . . . . . . 219

Chapitre Vl. - L'œuvre de la Puissance publique. . . . 223

A. En France. . . . . . . . . . . . . . . 224 
I. Action de l'État. . . . . . . . . . . . . . . 225

a) Ouvriers soumis au régime du Monopole. . 225

Ouvriers et Employés des Tabacs. . . . . 225

Ouvriers et Employés des Allumettes. . . 227

Ouvriers et Employés des Poudres . . . . 227

Ouvriers et Employés des Postes, Télégraphes et Téléphones. . . . . . . . . 229

Ouvriers et Employés des Monnaies et Médailles . . . . . . . . . . . 237

b) Ouvriers soumis au régime de la Concurrence. . . . . . . . . . . . . 239

Ouvriers et Employés des Chemins de fer. 239

Ouvriers et Employés de la Guerre. . . . 241

Ouvriers el Employés des Arsenaux de la Marine . . . . . . . . . . . . . 242

Ouvriers et Employés des Gobelins. . . . 249

Ouvriers et Eimployés de Beauvais . . . . 249

Ouvriers et Employés de Sèvres . . . . . 250

Ouvriers et Employés de l'Imprimerie nationale... . . . . . . . . 250

II. Action des Départements. . . . . . . . . . 254

III. Action des Municipalités. . . . . . . . . . 255

Paris. . . . . . . . . . . . . . . 258

Travailleurs municipaux . . . . . . 258

Personnel du Métropolitain . . . . . . . 259

Lyon . . . . . . . . . . . . . 264

B. A l'étranger . . . . . . . . . . . . . . 265

Angleterre . . . . . . . . . . . . . . 266

Personnel de l'État . . . . . . . . . . . . 266

Personnel des Municipalités . . . . . . . . . 267

Allemagne . . . . . . . . . . . . . . . . . 269

Personnel de l'État . . . . . . . . . . . 269

Personnel des Municipalités . . . . . . . . 269

Belgique . . . . . . . . . . . . . . 272

Italie. . . . . . . . . . . . . . . . 275

Suisse .. . . . . . . . . . . 275

Chapitre VII. - L'œeuvre de la Loi. . . . . . . . . . . 276

I. Législations confiant à des Comités de salaires le soin d'établir des minima. . . . . . . . . . 278

Section A. - L'Australie. . . . . . . . . . . . 278

Antécédents. . . . . . . . . . . . 278

Principales dispositions. . . . . . . . . . 283

Résultats. . . . . . . . . . . . . . 289 
Section B - L'Angleterre. $\quad 300$

Antécédents. . . . . . . . . . . . . 300

Principales dispositions. . . . . . . . . . 303

Résultats . . . . . . . . . . . 314

II. Législations confiant à une Cour industrielle d'ar-

bitrage le soin d'établir des minima . . . . . 330

Nouvelle-Zélande . . . . . . . . . . . . 330

Australie occidentale . . . . . . . . . . 336

Nouvelle-Galles du Sud . . . . . . . . . . . 338

Commonwealth australienne. . . . . . . . . 341

Troisiène partie. - Les chances de réalisation du Minimum de salaire. Projets et Réformes. . . . . . . . . . . . 351

Chapitre I. - Les objections actuelles contre le Minimum de salaire. . . . . . . . . . . . 352

$\S$ I. Le Minimum de salaire est-il impossible ?. . . . 353

$§$ II. Le Minimum de salaire est-il irréalisable ? . . . 355

III. Le Minimum de salaire est-il nuisible et contraire à l'intérêt général ? . . . . . . . . . . 359

Chapitre II. - Projets et Réformes en France. . . . . . 367

§. Les propositions socialistes. . . . . . . . . . 367

$\S$ II. Les propositions de Comités de salaires pour le travail à domicile. . . . . . . . . . . 378

క. III. L'effort des intéressés eux-mêmes. . . . . . . . 397

§IV. L'initiative patronale. . . . . . . . . . . . . . 400

Chapitre III. - Projets et Réformes à l’étranger . . . . 406

§. Angleterre. . . . . . . . . . . . . . 406

Avant la loi du 20 octobre igo9 . . . . . . 406

Depuis la loi du 20 octobre igo9..... . 414

\$I. Allemagne . . . . . . . . . . . . . . . 422

§II. Belgique . . . . . . . . . . . . . . . . 429

IV. États-Unis. . . . . . . . . . . . . . 432

$\$$ V. Autres pays : Autriche, Hollande, Espagne, Italie, Suisse, République Argentine . . . . . 43'

§ VI. Le mouvement international. . . . . . . . . . 440

Conclusion . . . . . . . . . . . . . . 448

Le problème du Minimum de salaire. . . . . . . . . 448

Nécessité d'une intervention législative. . . . . . . . . 454

Arrexes. - Textes législatifs . . . . . . . . . . . . 463

Législation australasienne. . . . . . . . . . 463

Victoria . . . . . . . . . . . . . . 463

Queensland. . . . . . . . . . . . . 479

Australie du Sud . . . . . . . . . . . . . 479 
Nouvelle-Zélande .0479

Nouvelle-Galles du Sud . . . . . . . . . . . . . . . . 480

Australie occidentale . . . . . . . . . . . . . . . . . . . 480

Confédération australienne . . . . . . . . . . . 481

Angleterre . . . . . . . . . . . . . . . . . 482

Loi du 20 octobre rgo9 sur les Conseils d'industrie . 483

Loi du 29 mars I9I2 sur le Minimum de salaire dans les mines. . . . . . . . . . . . . 496

Roumanie . . . . . . . . . . . 502

Loi du 23 décembre 1907 sur les conventions dans l'agriculture (extraits). . . . . . . . . 502 



\section{TABLE ANALYTIQUE}

(Les chiffres en caractères gras renvoient aux pages où la question a été princtpalement traitée.)

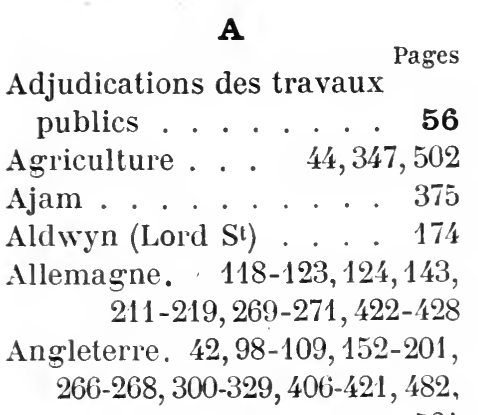
501

Allumettes. . . . . . 227 Amalgamated Union of

Cooperative Employees. 197 Antoine (Abbé Ch.). 15, n. 2 ; 18, n. 2

Antonin (Saint)

Apprentis. vir, 287, 295, 317, 320, 323

Argeliès . . . . . . . 262 Argentine (Rép.). . . . 438 Asquith . . 164, 451,314, n. 4 Assistance. . . . . . 26

Association internationale pour la protection légale des travailleurs . . . 440 Id. Section française . 390 Assurances sociales . . 136 Aubriot . . . . . . . 252 Autriche. . . . 219, 434-436 Australasie . 278-299,345, 463 Australie (Confédération). 341, 346,480

Australie occidentale. 336,346 , 480

Australie du Sud. 282, 287, 297, 346,479

Aves. 279, n. $1 ; 280$, n. 1 et 2 ; 283 , n. 1; 293, 336, 362, 363, 409
B

Pages

Balfour . . 412, n. 3; 419 Banbury. . . 411, n. 2; 413 Basly . . . . . . 372 Bàtiment . . . 59, 155,203 Baudin . . . 56, n. 1;70 Beauregard . . . . . 70 $\operatorname{Behm}\left(\mathrm{MH}^{\mathrm{He}}\right)$. . . . . . 422 Belcredi . . . . 8, n. 3 Belgique. . 110-117,272-274, 429-431

Berthélemy . . . . . 134 Berthelot . . . . . 260 Black . . . . . . 412 Blome. . . . . 8, n. 3 Bohringer. . . . 289, n. 1 Boissard . . 16, 18, n. 3, 140 Boîtes . . . . 301,317-321 Bolton List . . . . . . 181 Bonacina . . . . . . viII Bonneterie. . . . . 192 Boulangerie . . . 195, 447 Bourgeois (Léon). 39, 67,376, 390, n. 1 Boyaval. 277, n. $2 ; 364$, n. 2 ; 458, n. 3

Bozérian. . . . . . . 67 Brants. . . . . . . . III Brentano . . . x, 136, n. 1 Broda . . 289, n. $1 ; 321$, n. 6 Brooklands agreement . . 179 Brouckere (De) . . . . . 110 Bruxelles . . . . 110,115 Bruyn (De). . . . . . 111 Bull (V.) . . . . . . 412 Bureau (Paul) . . . . . $45 \cdot$ Buxton (Sydney). 100, 105, 327, n. 1

C

Aynard 
$\begin{array}{lr}\text { Catholicisme social. . . } & \mathbf{2}, 386\end{array}$

Cercles catholiques ou-

vriers (CEuvre des) . . . 7

Cernesson . . . . . . 197

Chaînes . . . 301,315-317

Chaussure. . . . . . 184

Chauvière . . . . . . 368

Chemins de fer. 194, 239, 272,

Chiozza Money ..... 415

Churchill . $357,409,410,411$, 412,460, n. 1

Clynes. . . . . . . 413

Coal Mines Bill. 168, 326, 496,

501

Cochrane ...... 411

Colonies . . . . 277, n. 1

Commission interministérielle ........ 91

Commission du travail (de l'Association nat.de 18.48)

Commission du travail (de la Ch. des députés). . . 368

Concurrence . . . . 36,362

Concurrence internationale ...... . 360 Confection . . 191, 290, 298,

Congrès catholique international de Liége

Congrès diocésain de $\mathrm{Pa}-$ ris

386

Congrès des maires . . . 256

Congrès international des mineurs . . . . . .

Congrès international dı travail à domicile . . . 445

Congrès de Zurich . . . . 440

Conseil d'État . . . 60,63, 261

Conseil municipal de Paris. $\quad 58$

Conseil municipal des villes de province.

66

Conseil de prud'hommes . 383

Conseil supérieur du travail . . . . . . 92,384

Conventions d'Arras . . . 207

Coopératives (Personnel des).
Cornelissen

Pages

Cour industrielle d'arbi-

trage . . 330,332, 338, 341

Coutant . . . . . 369,374

Crooks. . . . . . 415

Cruppi. . . . . . . 370

Cuny ....... . 374

D

Dansette. . . . . . 68

Dausset . . . . . 258

Deakin . . . . . 300, 407

Decurtins . 8, n. $3 ; 18$, n. 3

Denis (II.) . . . . 54, n. 2

Dentelle. 183, 301, 321-323, 401

Départements (Ouvriers et

employés des) . . . . 254

Deschars . . . . . 291

Dilke . . . 300, 407, 411, 412

Disparition des industries

parasites . . . . 36

Dockers . . . . . 194, 208

Doctrine du juste prix . . III

Dreyfus (Camille) . . . 67

Droit à l'existence . . 11, 30

Droit au produit intégral

du travail . . . . . 30

Droit d'action des Syndicats . . . . . . . 395

Dumont (Louis) . . . . 369

\section{E}

Échelle mobile. . . . . 152

Élisabeth (Reine). . . . . 42

Employés de mairie . . . 255

Encyclique «Rerum Novarum »....... 11

Engels . . 136, n. $1 ; 367$, n. 1

Engerand . . . 382, n. 1

Enoch (Edwards). . 169, n. 1

Enquête industrie du char-

bon . . . . . . 397

Enquête industrie textile. 398

Enquête travail à domicile . . . . . 378, n. 4

Espagne. . . . . 437 
État (ouvriers et employés

d') . 224, 266, 269, 272, 275 Evans (Samuel) . . . . 413

\section{F}

Fair wages clause $100,106,266$ Fédération nationale des travailleurs de l'industrie du bâtiment. . . . 203 Fédération du Livre . . . 204 France 45, 56-98, 129, 141, 202210, 224-264, 367-405

Fondeurs en fer ... 49 Fonds des salaires (Loi du) 353 Fontaine . . . . 360 Fristot . . . . . 19

\section{G}

Garantie professionnelle 25-27 Gide (Charles) . 353, n. 2; 397 Godts . . . . . 18, n. 3 Gonzalez. . . . . . 438 Gooch. . . . . 413 Goosens . . . . . 14 Gough . . . 3555, n. 1 Goyau (Georges) . . 8, n. 3; 20 Gregoresco . . . 34그, n. 1 et 3 Grève des mineurs anglais ..... 167, 418 Grey (Sir Edward) . . . . 419 Guerre (Établissements de la) ........ 241 Guesde (Jules) . . . 367, n. 1 Guyot (Yves). . 139, 327, n. 1; 418, n. 2

H

Hamilton (Lord) . . . . 414 Hamisch .... 434 Hans ..... 454, n. 1 Hayden . . . . . 412 Hellepulle . . . 8, n. 3 Henderson. . 302, 409, 411 Hills 410

Histoire doctrinale du minimum de salaire...
Histoire des clauses relatives au minimum de salaire dans les adjudications de travaux publics ... . 58, 98, 110 Histoire de la législation sur le minimum légal de salaire . . . 283, 300 Histoire du minimum de salaire ...... 42 Hoatson . . 289, n. 1 : 355, n. 1 Hobson . . . . 408 Hodge. . . . . . . 104 Holcombe . . . . . . 68 Hollande . . . . 436 Holtz . . . 432, n. 1 Hongrie. . . . 128, n. 2 Honoré 92 , n. 3 ; 93, 382, n. 3 ; 383,401, n. 2

Hooper . . . . . 412 Hubert Valleroux . 352, n. 1; 363, n. 5 Hugues (Clovis) . . . 368 Hutchins ... 408, n. 2

\section{I}

Imprimerie . . 193, 204, 403 Imprimerie nationale. . . 250 Initiative patronale. . . 401 International (Mouvement) $\mathbf{4 4 0}$ International (Salaire minimum) . . . . . 350

Italie . . . . 128, 275, 437 Intervention de l'État. $6,13,20$, 163, $223,348,396$, n. 1, 454-462

\section{J}

Jay (Raoul) . . 22, 94, 131, 138, 384,386, n. $4 ; 391$ n. 1 et $2 ; 456$, 461, 462, n. 2 Joint district Boards . . 326 Juges de paix . . . 42-13 Juste salaire . . . III, VI, viII Justice commutative . . 15 
$\mathbf{K}$

Pages

Keir Hardie . . . . . 413

Ketteler. . . . 3, n. 1; 4

Keüfer.

$92,94,384$

Kleczka 433, n. 2

Kuefstein (De)

8. n. $3 ; 9$

$\mathbf{L}$

Label 145

Lafargue. 367, n. 2

Lagasse de Locht. 355, n. 2 Laine . 182

Langenstein (De). . . . . IV Lansdowne (Marquis de) . 414, 456, n. $1 ; 460$, n. 1

La Tour du Pin . . 8, n. 3 Laubœuf. . . . . . . . 248 Lefébure. . . . . . . 401 Lefebvre . . 211, n. 3; 403 Législation expérimentale 280 Législation in extremis . 278 Le Marchand . . . . . . 259 Lemkmuhl. 8,18, n. $3 ; 21$, n. 2 Léon XIII. 11 Leroy-Beaulieu (Paul). 328 , n. $1 ; 355$, n. $2 ; 361$, n. $1 ; 365$, n. 4

Leroy (J.) . . . 4 424, n. 2 Lésion. . . . . . . 124

Levasseur . . . . 353, n. 2 Liberatore (P.). . . 7, 18, n. 3 Lichtenstein (Prince de). 8, n.3 Liége (Congrès de) . . . . 9 Ligues sociales d'acheteurs 145 Livre. . . . . 193, 204, 212 Lloyd (Georges) . . . . 421 Lois naturelles. . . . . 353 London County Council . 98, 108,267 Londres . . . . . . 98, 107 Lorin (Henri) . . . . . 22 Lugo . . . . . . . . VI Lyon . . . . . . . 264 Lyon-Caen. . . . . . 134 Lytton (Lord) . . 414,551, n. 2

\section{M}

Pages

Magasin de gros . . . . 199

Mairie (Employés de). . . 255

Mallon . 314, n.1;317, n. 2; 318

Mannetti. . . . . . 412

Manning . . . $3, \mathrm{n} .1 ; 6$

Mantoux. . . . . 418, n. 2

Marine. . . . . . . . 242

Marks (Harry) . . . . . 412

Marroussem (Du). . . 365, n. 7

Martin St-Léon. . . 42, n.1

Marx (Karl) . . . 367, n.1

Médolago (Comte) . . 8, n.3

Menger (Anton) . . . . 30

Mény . 365, n. 4;378, n. 1;386,

n. 4

Mermillod . . . . 8, n.3

Métallurgie . . . . 176

Métin . . 292,330,n.1;333

Métropolitain (Personnel

du) . . . . . . . 259

Meuble . . . . . . 194

Milcent ..... $8 \mathrm{n} .3$

Mill (Stuart) . . . . 300, 406

Millerand. . . 70,132, n. 2

Mines . . . . 157, 207, 397

Modistes. . . . . . 298

Molina. . . . . . . . v

Monnaies et médailles . . 237

Morel (Jean) . . . . . 371

Moreton Frewen . . . . . 417

Mortimer . . . . . . $\mathbf{x}$

Mulhouse . . . . . 120

Mun (De) . 8, n. 3; 17, 18, n. 3; 277, n. $2 ; 378,386$, n. $4 ; 390$, n. 4

Municipalités (Ouvriers et

employés des). $\quad 255,267,269$,

274

\section{$\mathbf{N}$}

Naudet (Abbé) . . . . .

National Anti Sweating

League . . 300,316, n.4; 4 C8

Navarre . . . . . . 65

Néron . . . . . 390, n. 3

New Protection .... 344

Nogaro . . . . 330, n.1 
Nouvelle-Galles du Sud. . 330, 346,479

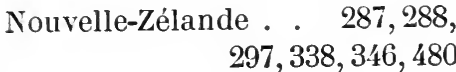

\section{0}

Objections au minimum de salaire . . . . 352 O'Connor (Arthur) . . . 172 O'Connor, juge australien. 342,

Offre et demande. . . 49,353 Oldham list . . . . . 179 Ouvriers âgés . . . 310,363 Ouvriers moins productifs . . . . . 310,363

\section{$\mathbf{P}$}

Pascal (P. de) 3, n. 1; 20, n. 5 Paris . . . . . 58, 88 Pastre. . . . . . 369 Peacock. ... 279, n. 5 Pêche ....... 195 Périn (Ch.) . . 15, 21, n. 3 Postes, télégraphes, téléphones . . . 229, 266 Pottier . 3, n. $1 ; 18$, n. 1 et 3 ; 20, n. 6

Poudres . . . . . 227

Problème du minimum de salaire ...... 449

Productivité du travail (Loi de la) ...... 353

Programme socialiste 367, n. 1 Projets de lois :

L. Bourgeois. . 390, n. 1

R. Renoult ... 387

Viviani . . . . 382

Propositions de lois :

Basly . . . . . 372

Chauvière . . . 368

Clovis Hugues . . . 368

Constant . . 369, 374

Durafour . . 396, n. 3

De Mun . . . . 378

Vaillant... 368, 370
Provisional orders . . . . 301

Python . . . . 8, n. 6

Q

Queensland. 287, 297, 346, 479

\section{$\mathbf{R}$}

Rambaud(Joseph). . 21, n. 3; $22, \mathrm{n} .1$

Ramsay (Macdonald) 164, n. 1 Reewes . . 292, 295, n. 3;330 Révision douanière. . . 370 Richards ...... 412 Richardson . . 412, n. 2 Riçois. . . . . . 402 Risque professionnel . . . 138 Risser. . . . . . . 137 Rochebillard (Mlle). . . 401 Roumanie . . 129, 347, 502, 505 Rubanniers . . . 50, 396 Ryan . . . 18, n. 1; 18, n. 3

\section{$\mathbf{S}$}

Salaire de base . . . 392

Salaire courant . . . IX, 57 Salaire familial . . . 12, 18 Salaire nécessaire (Loi du) 353 Salaire vital . . . . 3 Saleilles. . . . . . 125

Sanctions de l'application des clauses relatives au salaire dans les adjudications $73,85,107,116,123$ Sanction du minimum légal de salaire . 285, 310, 395 Say (Léon). . . . . 139 Schwalm (P.) . . . . 16 Secrétariat typographique international . . . 219 Seine . . . . $\quad \mathbf{5 8 , 8 8}$ Sismondi ..... 25 Smith (Miss Constance) 31., n. 1; 32 \%, 408, n. 2. Smitka ...... 434 Soie. . . . $45,183,369$ 


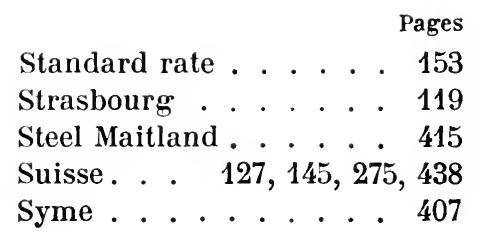

\section{$\mathbf{T}$}

Tabacs ....... 225

Tapisseries . . . . 249

Tarde . . . . . 454, n. 1

Tarde (De). . 452, n. 1; 454, n. 1

Tasmanie .... 345, n. 1

Tennant. 266, 411, 413, n. 2;417,

446

Textiles (Industries). 179, 398 Théologiens .... III, $\mathrm{IV}, \mathrm{x}$ Théorie de l'intervention. 461

Thomas (Albert) . . . . 376

Thomas (Saint) . . . . III

Thorne (William) . . . 415

Trade Boards Act . . . 303

Travail marchandise. . 4

Travaux publics de l'État. 68 , $70,73,97,102,112,118$

Travaux publics des départements . 68, 70, 77, 113

Travaux publics des communes et établissements publics. $58,67,68,70,88,106$, 113,118

Toniolo . . . . . . . 483

Tonnellerie . . . . . 194

Toulmin. . . . . . . 409
$\mathbf{U}$

Pages

Union de Fribourg. . . 8

Utilitarisme social . . . . 32

\section{V}

Vaillant . . 65, 68, 368, 370, 373

Vandervelde . . . . . 360

Verhægen . . 18, n. 1;431, n.4

Vermeersch . . . 18, n. 2

Verre . . . . . 195

Vêtement . . 291, 296, 298, 387

Vêtements tout faits et sur

mesure . . . 301,323-325

Victoria. 278-282, 2@3-286, 289$296,463-478$

Villeneuve-Bargemont . . $\quad 3$

Viviani . . . . . 382

Vogelsang. . . 3, n.1;8, n.3

Vol des serviteurs . . . vil, $x$

\section{W}

Wambodt (Baron). . . 8, n.3 Webb (B. et S.). $\quad 32,152,300$, $360,361,408$

Whitbread ..... 44

Willis clause .... 331

Wolf ....... $x$

\section{$\mathbf{Y}$}

Young (Ralph). . . 4 446, n.5

\section{Z}

Zigliara (Cardinal) . . 14,19 




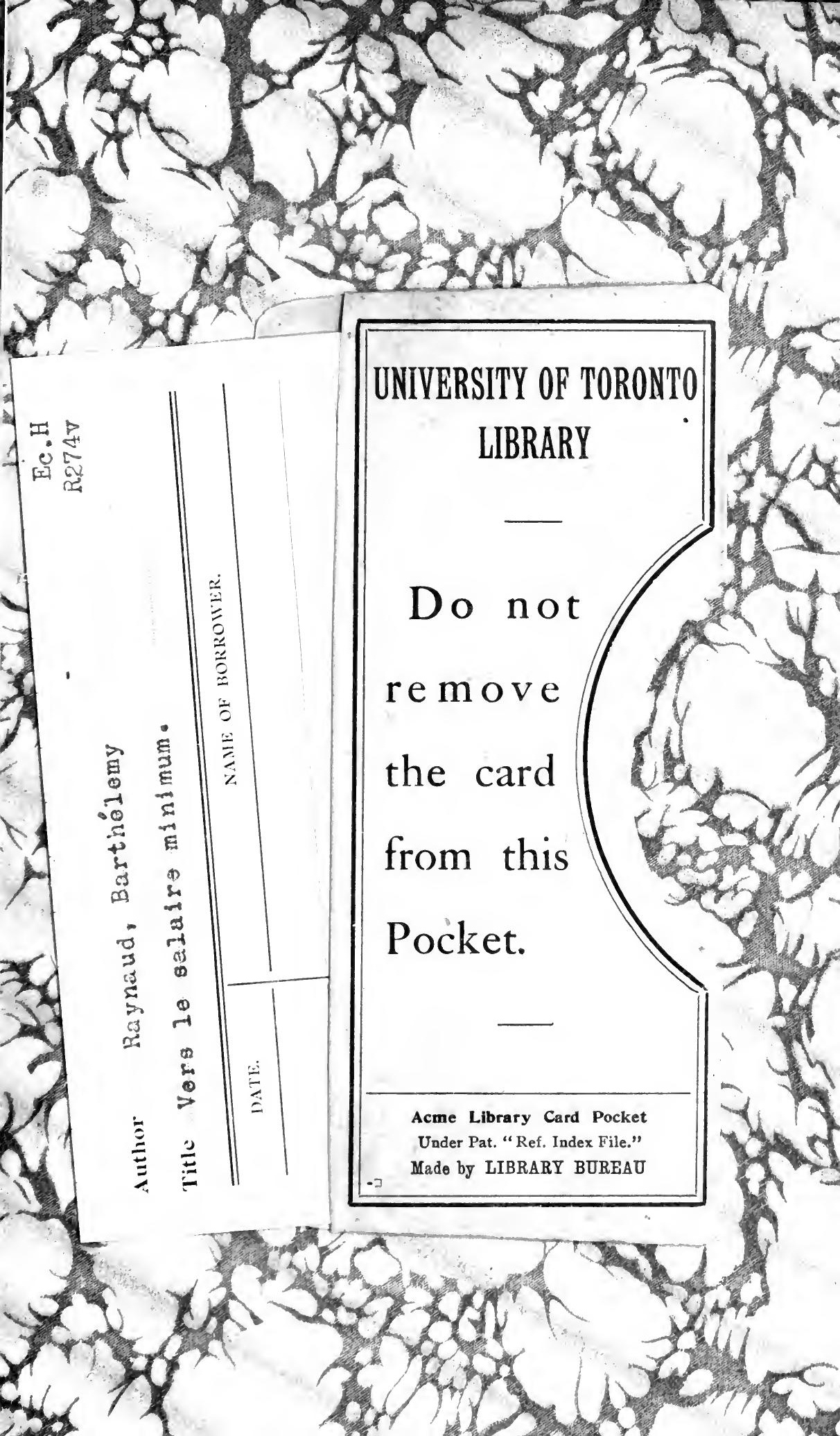


$P=1, b x+2$ y $y^{2}+x^{2}+x^{2}+3^{2}$

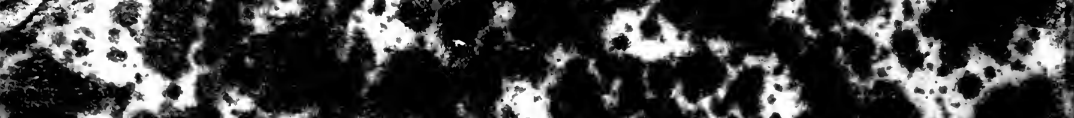

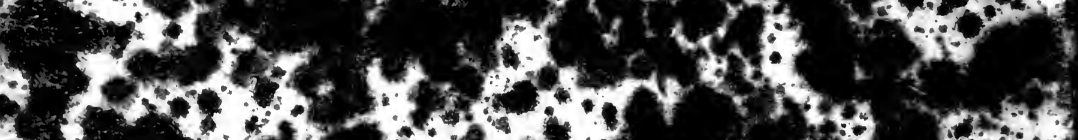

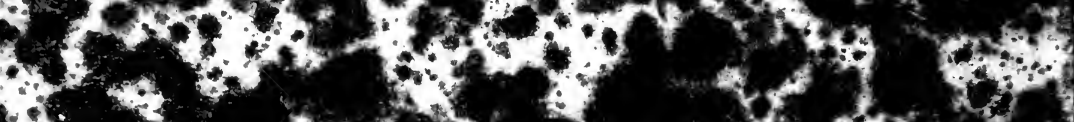

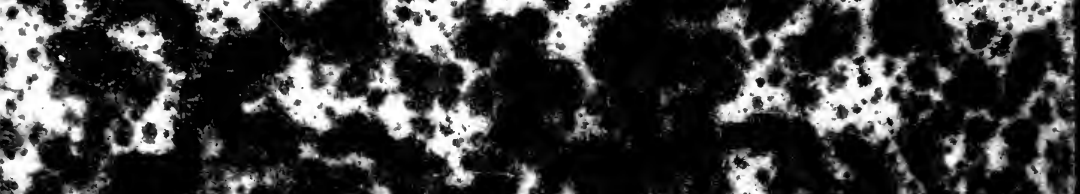

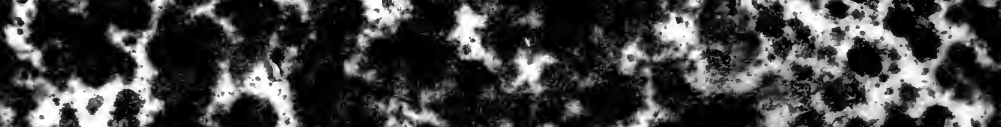

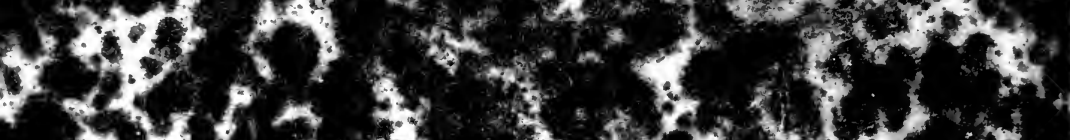

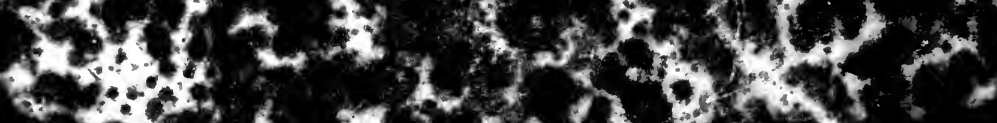

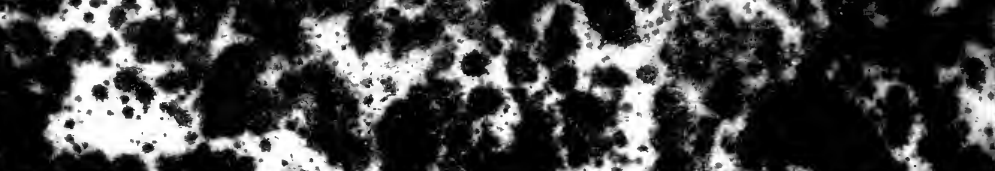

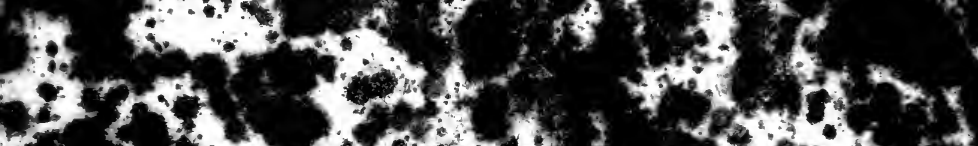

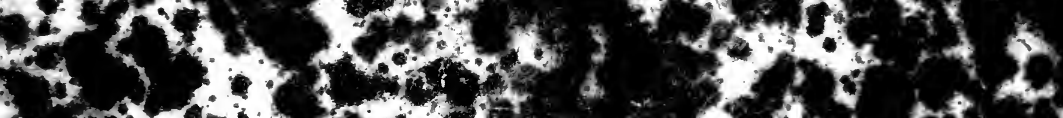

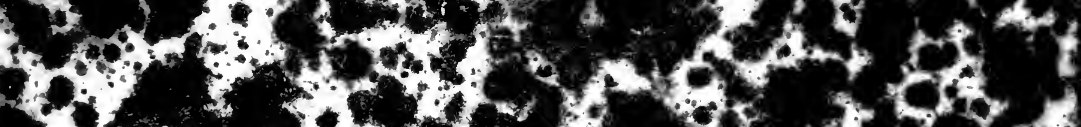
$30+9,4,94,5 \%$ 1. $+4+4+1$

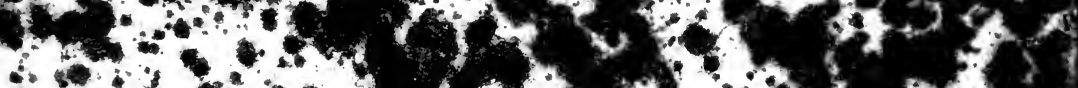

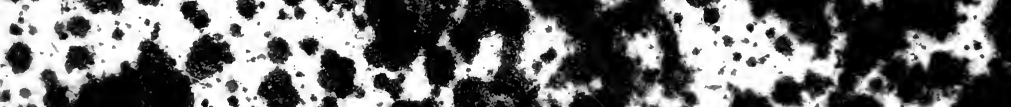

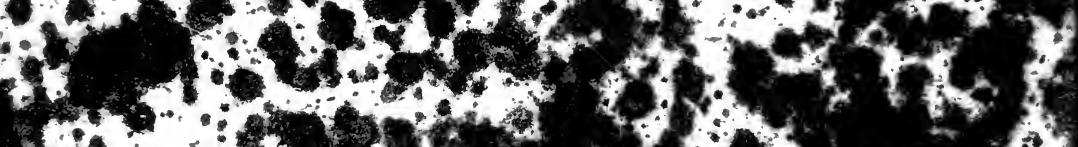

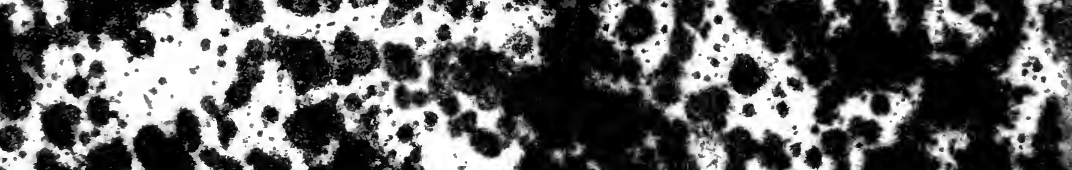

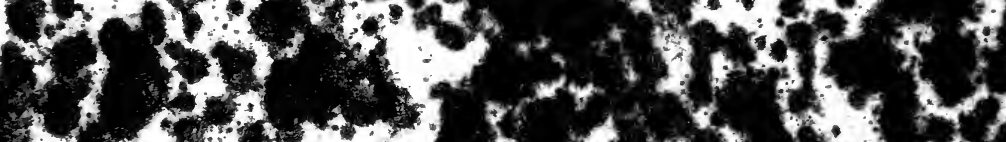

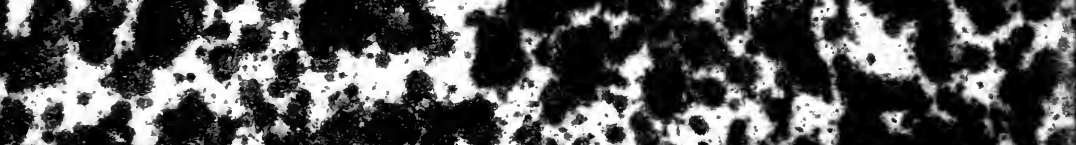

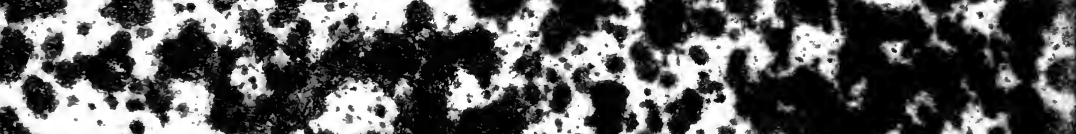

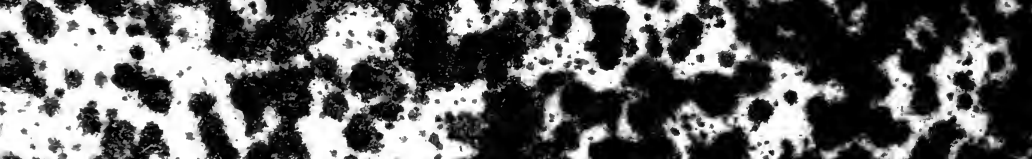

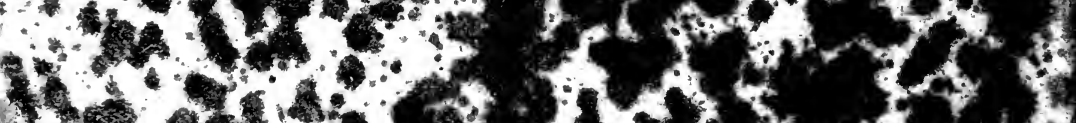

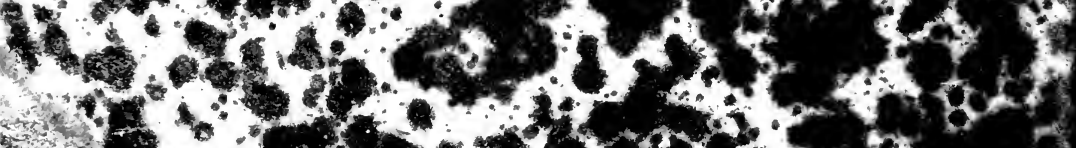

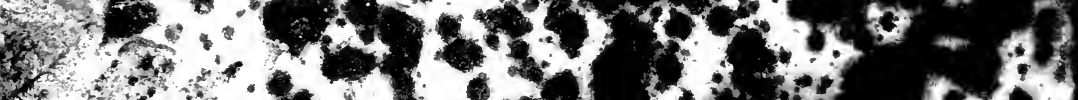

